\title{
MULTIPLE CRITERIA \\ ANALYSIS OF \\ THE LIFE CYCLE \\ OF THE BUILT ENVIRONMENT
}

Editors A. Kaklauskas, E. K. Zavadskas

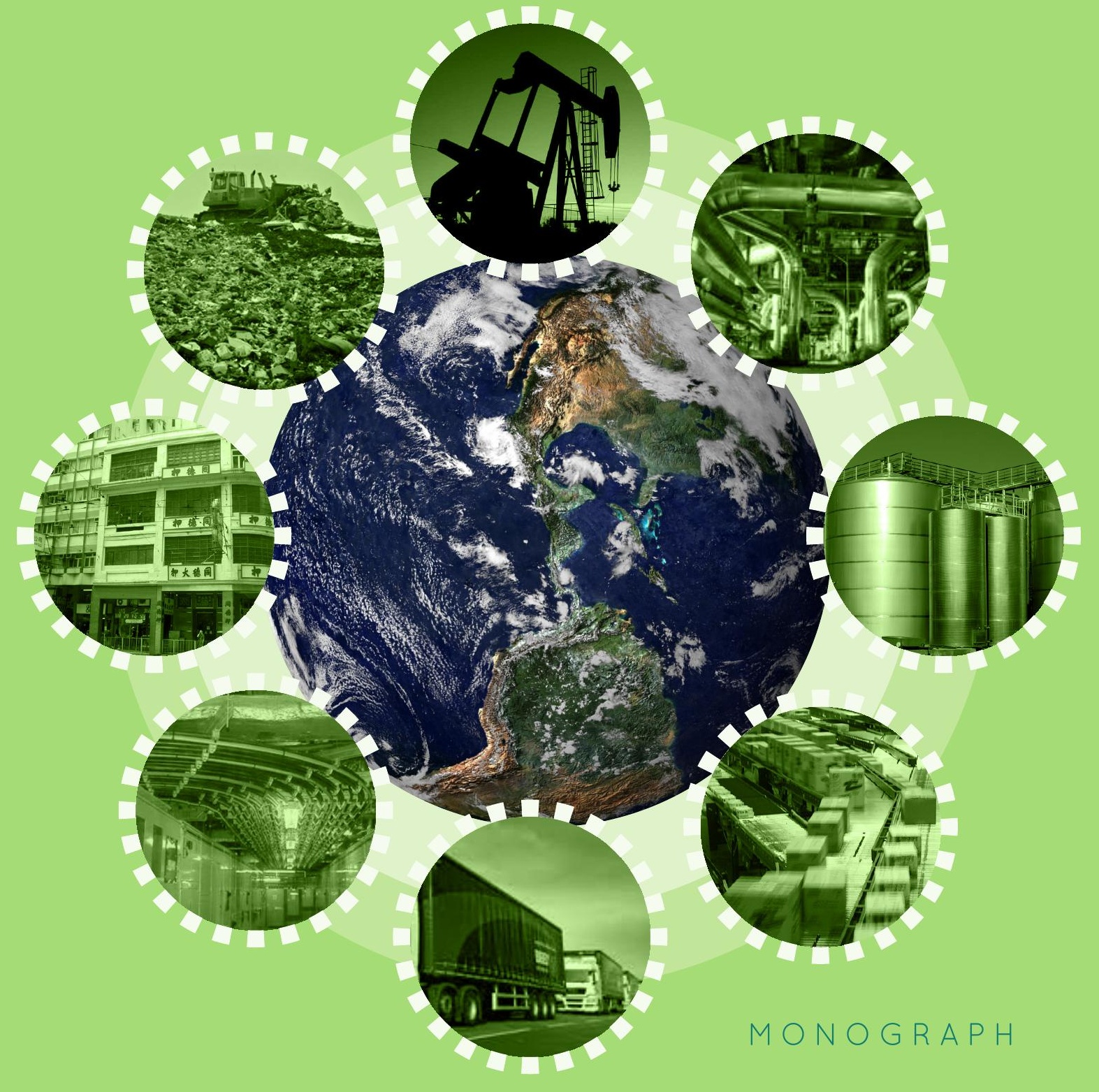


MULTIPLE CRITERIA

ANALYSIS OF
THE LIFE CYCLE
OF THE BUILT
ENVIRONMENT 



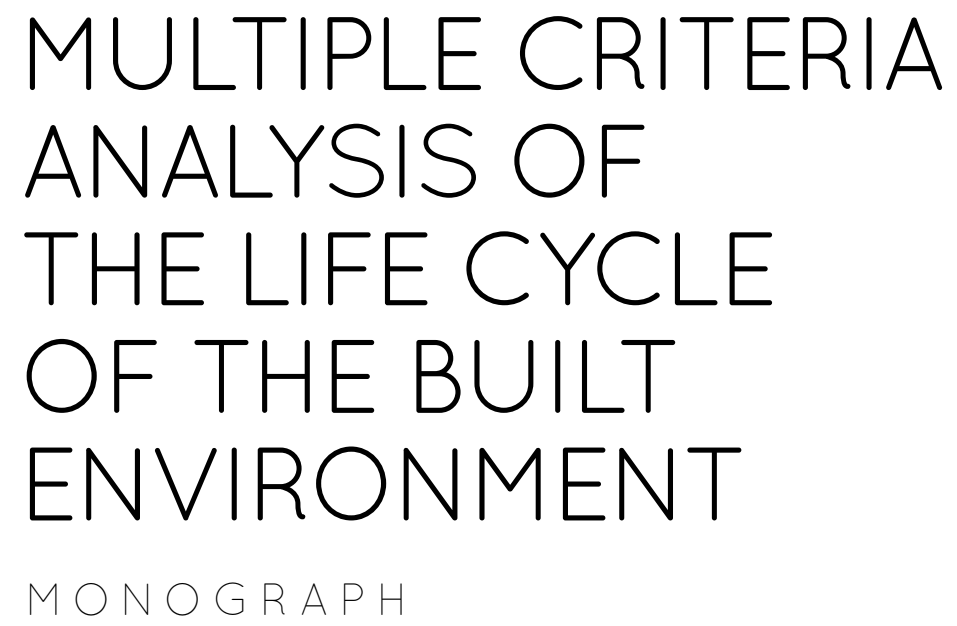

EDITORS

A. Kaklauskas, E. K. Zavadskas 
Multiple Criteria Analysis of the Life Cycle of the Built Environment: monograph. Editors: A. Kaklauskas, E. K. Zavadskas. Vilnius: Technika, 2015. 448 p.

To design and achieve effective the life cycle of the built environment a complex analysis of its stages as well as stakeholders, their aims and potentialities is needed. The effect of micro, meso and macro environmental factors should also be taken into account. A thorough built environment's life cycle (brief; design; raw material extraction, transport and processing; construction materials production and distribution; construction; use, repair and maintenance; demolition; disposal, reuse, or recycling) analysis is quite difficult to undertake, because a buildings and its environment are a complex system (technical, technological, economical, social, cultural, ecological, etc.), where all sub-systems influence the total efficiency performance and where the interdependence between sub-systems play a significant role. Various stakeholders (clients, users, architects, designers, utilities engineers, economists, contractors, maintenance engineers, built environment material manufacturers, suppliers, contractors, finansing institutions, local government, state and state institutions) are involved in the life cycle of the built environment, trying to satisfy their needs and affecting its efficiency. The level of the efficiency of the life cycle of the built environment depends on a number of variables, at three levels: micro, meso and macro level. The problem is how to define an efficient built environment life cycle when a lot of various parties are involved, the alternative project versions come to hundreds thousand and the efficiency changes with the alterations in the environment conditions and the constituent parts of the process in question. Moreover, the realization of some objectives seems more rational from the economic perspective thought from the other perspectives they have various significance. Therefore, it is considered that the efficiency of a built environment life cycle depends on the rationality of its stages as well as on the ability to satisfy the needs of the stakeholders and the rational character of environment conditions. Formalized presentation of the research shows how changes in the environment and the extent to which the goals pursued by various stakeholders are satisfied cause corresponding changes in the value and utility degree of a built environment life cycle. With this in mind, it is possible to solve the problem of optimization concerning satisfaction of the needs at reasonable expenditures. This requires the analysis of the built environment life cycle versions allowing to find an optimal combination of goals pursued and finances available.

References to the most modern world scientific literature sources are presented in the monograph. The monograph is prepared for the researchers, MSc and PhD students of civil engineering, construction management and real estate development. The book may be useful for other researchers, MSc and $\mathrm{PhD}$ students of economics, management and other specialities. The edition was recommended by the Committe of Studies of VGTU Faculty of Civil Engineering.

Reviewers: prof. dr. I. Lill, Faculty of Civil Engineering, Tallinn University of Technology prof. dr. A. Banaitis, Faculty of Civil Engineering,

Vilnius Gediminas Technical University

The publication of monograph was funded by European Social Fund according to project No. VP1-2.2-ŠMM-07-K-02-060 Development and Implementation of Joint Master's Study Programme "Sustainable Development of the Built Environment".

VGTU Press TECHNIKA id 2335-M

http://leidykla.vgtu.lt

ISBN 978-609-457-840-3

eISBN 978-609-457-839-7

doi:10.3846/2335-M

(C) Artūras Kaklauskas, 2015

(C) Edmundas Kazimieras Zavadskas, 2015

(C) Vilnius Gediminas Technical University (VGTU) Press TECHNIKA, 2015 


\section{CONTENTS}

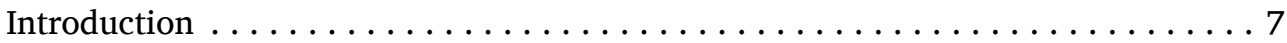

Chapter 1. Multiple criteria analysis of the life cycle of the built environment.

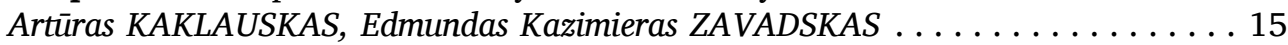

1.1. Periodic life cycles of various systems across the universe . . . . . . 15

1.2. Introduction to the life cycle of the built environment. . . . . . . . 24

1.3. Areas of practice of energy-efficient built environment .......... 31

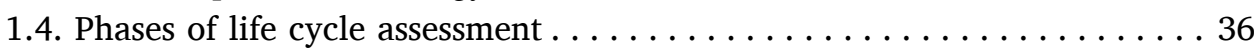

1.5. Stakeholders . .............................. 39

1.6. Compiling a criteria system to comprehensively describe the life cycle of the built environment $\ldots \ldots \ldots \ldots \ldots \ldots \ldots \ldots \ldots 47$

1.7. Methods, models and rating systems of the building life-cycle.

Multiple-criteria decision-making. . . . . . . . . . . . . . . 62

1.8. Model for a complex analysis of the life cycle of the built environment ..........................69

1.9. Practical realization of a model for a complex analysis of

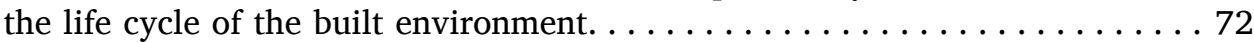

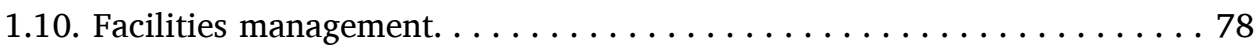

1.11. Quality of life in a built environment $\ldots \ldots \ldots \ldots \ldots \ldots \ldots \ldots$

1.12. LCA tools and databases. Vision of information and communications

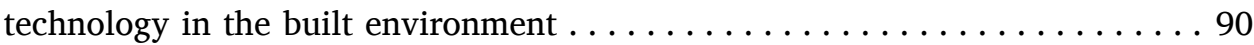

Chapter 2. Facilities and Property Management. Natalija LEPKOVA . . . . . 117

2.1. The review of the scientific researches on the Facilities Management performed in the world ............................ 118

2.2. Facilities Management quality and price management......... 130

2.3. Application of nominal group technique for Facilities Management in

Lithuania . . . . . . . . . . . . . . . . . . . . . . . 152

2.4. Suggested Facilities Management complex analysis model......... 161

2.5. Model of Facilities Management consulting knowledge system . . . . . 165

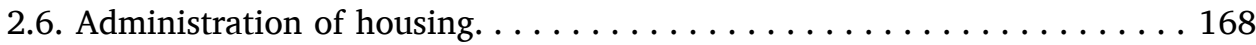

Chapter 3. Retrofit of buildings in urban neighborhoods. Saulius RASLANAS, Arturas KAKLAUSKAS, Edmundas Kazimieras ZAVADSKAS . . . . . . . . . . 182

3.1. The issues with retrofit planning in urban residential areas/blocks $\ldots 185$

3.2. Strategies for modernisation of areas with apartment houses and

the related scenarios . . . . . . . . . . . . . . . . . . . 187

3.3. The selection of effective retrofit scenarios for panel houses $\ldots \ldots \ldots 194$

3.4 Retrofit of public buildings . . . . . . . . . . . . . . . . . 229 
Chapter 4. Sustainable development of energy sector with emphasis

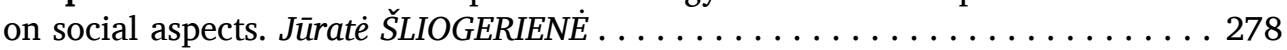

4.1. Sustainable development of the energy sector $\ldots \ldots \ldots \ldots \ldots \ldots 278$

4.2. Infrastructure of the energy industry and its economic significance $\ldots 280$

4.3. Objectives of the sustainable development of the energy industry . . . 2 283

4.4. Energy sector and the environment ................. 293

4.5. Social considerations and values in sustainable energy development. . . 296

4.6. The role of the Social/value aspect in energy sector value creation. . . . 310

4.7. Use of multiple criteria decision support tools to validate energy sector development decisions..................... 313

Chapter 5. Knowledge management in the built environment.

Artüras KAKLAUSKAS, Lina BARTKIENĖ . . . . . . . . . . . . . . . . . 345

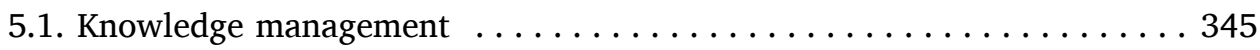

5.2. Air pollution \& noise, illnesses they cause and real estate prices . . . . 363

Chapter 6. Built environment life cycle process and climate change.

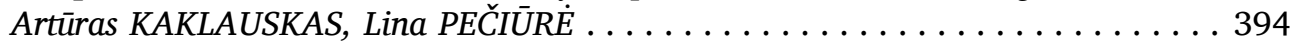

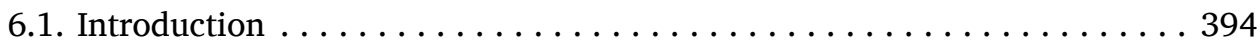

6.2. Climate change mitigation and adaptation in built environment

quantitative and qualitative analyses aspects. . . . . . . . . . 396

Chapter 7. Distance learning experience in construction and real estate at VGTU. Natalija LEPKOVA, Silva RIMKUVIENE . . . . . . . . . . . 419

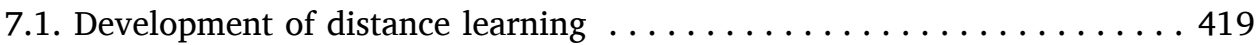

7.2. Analysis of questionnaire-based survey results $\ldots \ldots \ldots \ldots \ldots \ldots 434$

APPENDIX 7.1. Questionnaire ..................... 443 


\section{INTRODUCTION}

The monograph analyses the life cycle of the built environment. This, however, is only one of many periodic life cycles characteristic to various systems across the universe (time and calendar cycles, planetary cycles (astronomical cycles, climate and weather cycles, geological cycles), organic cycles (agricultural cycles, biological and medical cycles, brain waves and cycles), physics cycles (mathematics of waves and cycles, electromagnetic spectrum, sound waves), miscellaneous cycles (economic and business cycles), music and rhythm cycles, religious, mythological, and spiritual cycles, social and cultural cycles, military and war)).

The building life cycle assessment (LCA) methodology dates back to 1960s, when concerns over the limited availability of raw materials and energy resources led to new ways to account for energy use and the consequences of these uses (SAIC 2006). First developed in the 1960s, Life Cycle Assessment (LCA) is the most widely used and highly regarded tool for quantifying the environmental impacts of products and services (SteelConstruction). The oil price increases of the 1970s spurred significant research and activity to improve energy efficiency and find renewable energy sources. This, combined with the environmental movement of the 1960s and 1970s, led to the earliest experiments with contemporary green building (Barrows and Iannucci 2009).

In the 1980s, the product life cycle was used by Weber (1976), Doyle (1976) and Wasson (1978) for external purposes, such as marketing. Its application broadened in the present decade into building materials, construction, chemicals, automobiles, and electronics. This was primarily because of the formalization of LCA standards in the ISO 14000 series (1997 through 2002) and the launch of the Life Cycle Initiative, a combined effort by United Nations Environment Programme (UNEP) and the Society of Environmental Toxicology and Chemistry (SETAC), in 2002 (SAIC 2006). In the 1990s and later, the building life cycle analysis was used by Preiser (1983), Fereig and Younis (1985), Gustafsson and Karlsson (1989), Zavadskas, Kaklauskas and Bejder (1992a, 1992b), Zavadskas, Peldschus and Kaklauskas (1994), and other researchers. Later, Kaklauskas (1996, 1999) applied the concept of the building life cycle analysis in the construction industry life cycle analysis.

To design and achieve effective life cycle of the built environment a complex analysis of its stages as well as stakeholders, their aims and potentialities is needed. The effect of micro, meso and macro environmental factors should also be taken into account.

A built environment life cycle consists of closely interrelated stages: brief; design; raw material extraction, transport and processing; construction materials production and distribution; construction; use, repair and maintenance; 
demolition; disposal, reuse, or recycling. A built environment life cycle may have a lot of alternative versions. These variants are based on the alternative brief, design, construction, facilities management, refurbishment, demolition, utilization and recycling processes and their constituent parts. Millions of the built environment life cycle alternative versions can be obtained. The diversity of solutions available contributes to more accurate evaluation of climatic and energetic conditions, risk exposure, maintenance services, as well as making the project cheaper and better satisfying a client's architectural, comfortability, technological and other requirements. This also leads to better satisfaction of the needs of all parties involved in the project design and realization.

Various stakeholders (clients, users, facilities and property managers, architects, designers, utilities engineers, economists, contractors, maintenance engineers, built environment material manufacturers, suppliers, contractors, finansing institutions, local government, state and state institutions) are involved in the life cycle of the built environment, trying to satisfy their needs and affecting its efficiency. The level of the efficiency of the life cycle of the built environment depends on a number of variables, at three levels: micro, meso and macro level.

The problem is how to define an efficient built environment life cycle when a lot of various parties are involved, the alternative project versions come to millions and the efficiency changes with the alterations in the environment conditions and the constituent parts of the process in question. Moreover, the realization of some objectives seems more rational from the economic perspective thought from the other perspectives they have various significance. Therefore, it is considered that the efficiency of a built environment life cycle depends on the rationality of its stages as well as on the ability to satisfy the needs of the stakeholders and the rational character of environment conditions.

Formalized presentation of the research shows how changes in the environment and the extent to which the goals pursued by various stakeholders are satisfied cause corresponding changes in the value and utility degree of a built environment life cycle. With this in mind, it is possible to solve the problem of optimization concerning satisfaction of the needs at reasonable expenditures. This requires the analysis of the built environment life cycle versions allowing to find an optimal combination of goals pursued and finances available.

This monograph consists of seven chapters.

In recent years, many theories, methods, models and systems for the analysis of the life cycle of the built environment have been developed worldwide and described in Chapter 1. For a broader application of the life cycle of the built environment in the practice of various countries, more attention needs to be paid not only on the selected most rational processes and solutions, the interest level of the stakeholders, but also on the micro, meso and macro level 
factors. The authors of Chapter 1 developed the Life Cycle of the Built Environment Model over the course of two international projects (IDES-EDU and LEAN CC). Based on this Model, professionals involved in design and realization of the life cycle of the built environment can develop a lot of the alternatives as well as assessing them and making the final choice of the most efficient variant. Designing and realising an efficient life cycle of the built environment requires an exhaustive investigation of all solutions that form it. The efficiency of a specific built environment depends on a great number of factors such as energetic, technical, technological, economic, legal/regulatory, infrastructure, innovative and microclimatic, social, cultural, ethical, psychological, emotional, religious, ethnic, etc. Solutions based on alternatives allow a more rational and realistic assessment of traditions and of energy-related, economic, ecological, legislative, climatic, social and political conditions. They also help meet customer requirements better. Multi-variant design and multiple criteria analysis of the built environment came to mean processing and evaluation of loads of data. The number of feasible alternatives could be in the range of millions. With such enormous amounts of information, multi-variant design and multiple criteria analysis of alternative options has become problematic. To address these issues, the authors have developed the Life Cycle Model of the Built Environment. It can be noticed that researchers from various countries engaged in the analysis of the life cycle of the built environment and its stages did not consider the research's object as was analyzed by the authors of the present investigation. Authors of the Monograph analyse a life cycle of the built environment as follows: the built environment, the stakeholders involved in its life cycle as well as the micro, meso and macro environments, having a particular impact on it and making an integral whole.

Chapter 2 "Facilities Management" presents following aspects: the origin and the analysis of the definition of the Facilities management; Facilities Management goals and tasks; Facilities Management process and other. Special attention paid on Facilities management services quality assurance. The quality criteria system for facilities management services in Lithuania is presented. The fulfilled survey in 2010 year on customer satisfaction with facilities management services in Lithuania is described. For decision making it is possible to apply different decision-making methods. The application of Nominal Group Technique for facilities management in Lithuania is analysed in the chapter. The two completed surveys are described. The complex Facilities Management Process analysis model is suggested. The Consulting Knowledge System for Facilities Management Sector in Lithuania is suggested and described. At the end the administration of housing in Lithuania, Estonia and USA is analysed. Conclusions presented as well. 
Chapter 3 "Retrofit of buildings in urban neighborhoods" analyse modernisation and retrofit of buildings as one of the forms of urban development. Modernisation of apartment houses is a particularly relevant issue both in Lithuania and many other countries. To make it more efficient, the modernisation of apartment houses must be integrated an entire block or residential area must be renovated and the principles of sustainable development must be followed. It dwells on the issues related to retrofit planning in residential blocks/ areas and analyses the condition of apartment houses and their environment and the strategies for retrofit of residential areas with apartment houses. The strategies aim to improve the living standards and the quality of environment, to cut energy consumption and $\mathrm{CO}_{2}$ emissions, to maintain mixed social structure, to integrate new buildings into the existing environment in a sustainable manner, to develop an urban centre of a residential area as a functioning part of the city, to develop democratic planning and to seek close cooperation of modernisation partners. The scenarios based on relevant strategies must define the measures of retrofit, their priority and their potential effect. Some of the problems associated with assessing the retrofit effectiveness of apartment buildings in urban areas are considered. The retrofit of houses should be followed by the amelioration of their surroundings. The priority order of districts to be renovated depends on the condition of the buildings in a district and on strategic urban development programmes. In order to determine the profitability of investments in housing retrofit, a number of retrofit scenarios should be developed. The authors of this section offer a new approach to determining the retrofit effectiveness of houses based both on expected energy savings and the increase in market value of renovated buildings. In line with the proposed approach, retrofit scenarios for apartment buildings in Vilnius were developed, i.e. retrofit investment packages for various districts were prepared and arranged in the priority order for their application according to the method of geographical analysis suggested by the authors. Calculations of building retrofit effectiveness have shown that the replacement of original windows with new ones is not as effective in terms of heat energy saving as are the insulation of a roof, walls and other improvements because the investments are large and take a long time to be repaid. However, in addition to energy saving, window replacement improves the indoor climate of the building, its interior and architectural appearance as well as its market value. The sequence of building operations determines when the replacement of windows should be done. When financial resources are limited, managers of public buildings often begin the renovation of a building's envelope with the replacement of windows. The client faces some problems in choosing among the great variety of windows to satisfy his/her needs, especially with respect to the cost-quality relationship. The method of multiple criteria complex proportional assessment (COPRAS) 
developed by the authors aims at solving the above- mentioned problems. The solutions based on multicriteria analysis allow for a more rational and realistic assessment of customer's needs as well as cutting down window renewal costs.

Chapter 4 reviews academic research papers which discuss the role of values in the energy sector and then presents a set of criteria and automated decision support system for the assessment of the environment of energy generation technologies with emphasis on the dimension of social issues and values. Comprehension of the effect of energy generation technologies on the natural environment, human health and safety leads to a new and responsible approach to the choice and development of technologies. Although the issues predominant in the concept of sustainable energy development are economic and environmental ones, the changing environment necessitates a new approach towards the impact of social systems on the industry and demands for a more profound assessment of the role this aspect plays. Social development obeys the laws of sociology, thus energy policies must be established and solutions of technological development that meet societal needs must be found always making sure that the impact on social processes has been considered and public attitudes, values, sentiments towards development decisions, and the right of selfdetermination have been respected. Values-culture, cultural identity, ethics, beliefs, religion, education, weight of social institutes and other - can make an important impact on decisions related to the development of energy generation technologies, or even be the determining factor. Growing significance of public attitudes demands consideration of the dimension of values in environmental studies; when problems concern technologies they must also consider the values which are important and significant to the public or its separate groups. One way to make quantitative and qualitative assessment of the effect of technologies on the environment is through a thorough integrated analysis, which, in addition to economic and technical solutions, also considers other aspects of concern to the public. End parts of chapter examines how the dimension of values affects the analysis of the impact of environmental factors on the value of energy generation technologies. It presents a set of criteria for the assessment of energy generation technologies; the set, in addition to technological, economic and environmental criteria, includes criteria which reflect the values. The case study also introduces the automated decision support system EGTAV-SPS, which helped assess the effect of environment on energy production technologies.

Chapter 5 analyses definitions, resources and methods of information management; capital and information; expert and information systems; strengths and weaknesses of information systems and possibilities for their implementation in an organization and the best experience along with its information bases. The description of the life process of the built environment, the interest groups acting within it and the micro, meso and macro environment acting on 
project effectiveness regards them as one entity. This description contains various aspects of explicit and implicit knowledge regarding the life process of the built environment. A major portion of knowledge on the built environment is implicit: abilities, competence, experience, an organization's culture, informal and unrecorded procedures, skills, informal networks of organizational contacts, an intelligent organization's capital, ideals, values, customs, traditions and emotions. The development of the complex data and information base on a built environment's life cycle process and the informational model for the life cycle of the built environment's renovation appear next. Also, Chapter 5 presents a write-up of the team and its team work employing Web-based technologies and discusses the computer-based work accomplished collectively.

In order to design and realize an efficient built environment life cycle with focus on climate change mitigation and adaptation, it is necessary to carry out exhaustive investigations of all the decision and processes that form it. The efficiency level of the considered built environment life cycle depends on a great many micro, meso and macro factors. The authors of Chapter 6 participated in the different EU projects related with built environment and climate change (LEAN CC (Linking European, Africa, and Asian Academic Networks on Climate Change), etc.). One of the LEAN CC project's goals was to develop a Model and Intelligent System of the built environment Life Cycle Process for Climate Change Mitigation and Adaptation. The presented Model and Intelligent System enables one to form up to 100 million alternative versions. In order to demonstrate the micro, meso and macro factors that influence the efficiency of the built environment in climate change mitigation and adaptation processes, the Model will be considered as an example. In the past there has been no intelligent approach to learning from climate change mitigation and adaptation in built environment projects once they are completed. Now, however, the built environment is adapting concepts of tacit and explicit knowledge management to improve the situation. Top managers generally assume that professionals in enterprises already possess tacit and explicit knowledge and experience for specific types of projects. Such knowledge is extremely important to organisations because, once a project is completed, professionals tend to forget it and start something new. Therefore, knowledge multifold utilisation is a key factor in productively executing a climate change mitigation and adaptation in built environment project. The main purpose of the Chapter 6 is to present the Model of the built environment Life Cycle Process for Climate Change Mitigation and Adaptation which the authors of this Chapter have developed.

Chapter 7 "Distance Learning Experience in Construction and Real Estate at VGTU" contains the general information about distance learning development in the World, Lithuania and Vilnius Gediminas Technical University (VGTU). The main attention paid on infrastructure and new technologies used 
in distance learning at VGTU. The Chapter analyses the possible ways of advertising and management of distance education. The possible ways of marketing and management at the Department of Construction Economics and Property Management are described. Joint second-cycle distance-learning programmes at the Department of Construction Economics and Property management are presented. In order to clarify a number of issues related to the study process (first and foremost the student motivation, efficiency of advertising, issues related to the quality of study materials, reaction of social environment, etc.) the 4 survey researches were conducted during the period of 2003-2013 years and the results are analysed and the conclusions presented in the Chapter 7. 



\title{
CHAPTER 1
}

\section{MULTIPLE CRITERIA ANALYSIS OF THE LIFE CYCLE OF THE BUILT ENVIRONMENT}

\author{
Artūras KAKLAUSKAS, Edmundas Kazimieras ZAVADSKAS
}

\subsection{Periodic life cycles of various systems across the universe}

The monograph analyses the life cycle of the built environment. This, however, is only one of many periodic life cycles characteristic to various systems across the universe (time and calendar cycles, planetary cycles (astronomical cycles, climate and weather cycles, geological cycles), organic cycles (agricultural cycles, biological and medical cycles, brain waves and cycles), physics cycles (mathematics of waves and cycles, electromagnetic spectrum, sound waves), miscellaneous cycles (economic and business cycles (see Figure 1.1), music and rhythm cycles, religious, mythological, and spiritual cycles, social and cultural cycles, military and war)).

Various astronomical (full moon cycle, Galactic year, Great year, Lunar phase, Mesoamerican calendars, Milankovitch cycles, Moon phases, Orbital period, etc.) and climate and weather (animal migration, carbon cycle, climate change, global cooling, global warming, 1500-year climate cycle, etc.) cycles exist. A few examples are presented here. Life affects climate through its role in the carbon and water cycles and through such mechanisms as albedo, evapotranspiration, cloud formation, and weathering (Spracklen et al. 2008). The Earth's axis completes one full cycle of precession approximately every 26000 years. At the same time, the elliptical orbit rotates more slowly. The combined effect of the two precessions leads to a 21000 -year period between the astronomical seasons and the orbit. In addition, the angle between Earth's rotational axis and the normal to the plane of its orbit (obliquity) oscillates between 22.1 and 24.5 degrees on a 41 000-year cycle (Milankovitch 1998). According to (Willson and Hudson 1991), solar output also varies on shorter time scales, including the 11-year solar cycle.

A more detailed overview of the theory of the life process and cycles and specific cycles follows.

Theories of cycles are concepts that define the development of the society or its individual subsystems (economy, social policy, culture, etc.) as a sequence of repeating cycles; a cycle means an aggregate of processes and phenomena that make up a full turn over a defined period of time and bring the social system back to its initial state or a state similar to it. The theories date back to 

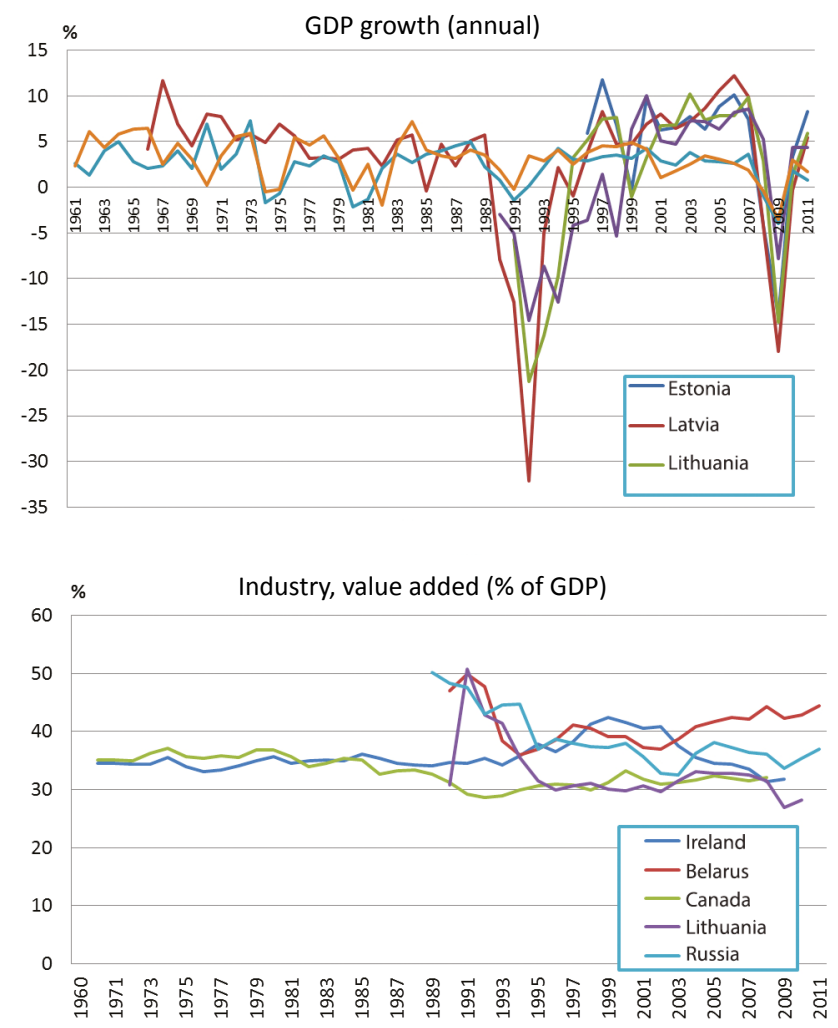

Figure 1.1. GDP growth (annual \%) and industry (value added, \% of GDP) cycles (the World Bank 2013)

ancient times. Notions of a cyclical development of the society and the cosmos as a whole are characteristic to the philosophy of Heraclitus, Empedocles, Plato, Aristotle and Marcus Aurelius; they pervade the Indian philosophy. According to Plato, the cosmos exists as an eternal alternation of disasters and births; any society has its own cycles of development, for example, the Hellenic history (Новая философская энциклопедия 2010).

In nature, all cyclical processes can be classified into the following main groups (Экономический справочник):

- Simple cycles. This group comprises the majority of cyclical processes that happen in the cosmos and the microworld. These cycles define the movement of celestial bodies along a closed curve which brings them back to the initial state.

- Complex cycles. This group includes processes with an ascending phase and a descending phase in their development. They are particularly abundant in 
the world of living things, but they can also be found in the world of nonliving things, in the space and on Earth. An example of such cycles is the development cycle of any organism that goes through the phases of birth, youth, maturity, ageing and death. An example in the world of non-living things could be stars that move through the same cycle.

- Multiple cycles. They are mostly found in the world of living things; their defining attribute is that organisms in one cycle launch a new cycle of another organism that co-exists with the old organism for a while.

- Single and repeating cycles. An absolute majority of cycles are repeating cycles. An example of a single cycle in the world of living things is catching an infectious disease. In the world of non-living things an example of a single cycle could be a one-off volcanic eruption.

Climate, for instance, is a complex cycle (see Chapter 6). Different concepts of the cycles of climate change and their link with social, economic and other cycles exist. These concepts also exist in attempt to make a direct link between natural (first of all cosmic) cycles and historical cycles and fluctuations; this way William Jevons linked the cycles of solar activity with economic cycles, while Alexander Chizhevsky linked them to the rise and fall of mass social movements, revolutions and so on. The ideas of Russian "cosmists" (Vladimir Vernadsky, Nikolai Morozov, Konstantin Tsiolkovsky, etc.) served, to some extent, as a methodological foundation for similar concepts (Новая философская энциклопедия).

A multiple cycle is, for instance, the solar cycle. Currently 11-year, 22-year and 80-90 year solar cycles are known. The cycle of sunspot activity has a direct link to the Earth's climate. The ring width of some trees shows an 11-year cycle.

Next, an example is briefly provided simple cycles.

Dreams and daily emotional spin cycle are simple cycles. Normal sleep is a cyclical phenomenon that happens approximately every 24 hours. These cycles are known as circadian rhythms. According to Edgar et al. (2012), a circadian rhythm is any biological process that displays an endogenous, entrainable oscillation of about 24 hours. These 24-hour rhythms are driven by a circadian clock, and they have been widely observed in plants, animals, fungi, and cyanobacteria. The rhythm is linked to the light-dark cycle. Animals, including humans, kept in total darkness for extended periods eventually function with a free-running rhythm. Their sleep cycle is pushed back or forward each "day", depending on whether their "day", their endogenous period, is shorter or longer than 24 hours (Shneerson et al. 2007).

Humans have a well-defined internal clock that shapes their energy levels throughout the day: the circadian process is often referred to as Circadian rhythm because it tends to be very regular. This natural - and hardwired - ebb and flow in our ability to feel alert or sleepy has important implications for 
people-on-the-job. Although managers expect their employees to be at their best at all hours of the workday, it's an unrealistic expectation. Employees may want to be their best at all hours, but their natural Circadian rhythms will not always align with this desire (Barnes 2015). In the opinions of Hufford et al. (2014), cognition is affected by Circadian rhythms over the course of a day. Students face an analogical situation. Esteki and Sadeghi (2010) compare students' short term memory (visual and audio) by Circadian rhythm at the different hours of the day. This data shows that biological rhythms are highly important for distributing and planning mental activity.

Students are unable to learn effectively all day long. Learning effectiveness is greater at one time and less at another, when the organism requires rest. Any time a person has been sitting or concentrating longer than 90-120 minutes (depending on his/her personal rhythm), he/she will begin to experience signals sent by the body telling him/her that it's time to take a break (Bentley 1999). In the last decade a growing number of researches that investigate the relationship between Circadian rhythm and academic performance have been conducted. These researches have indicated that there is an asynchrony problem between Circadian rhythm of individuals and face-to-face course times. Online learning can be seen as a potential solution (Horzum et al. 2014).

The 12 settings are arranged in a circle from negative red, to negative blue, to positive blue, to positive red. How well do you know your own daily emotional spin cycle? There are two methods psychologists use to answer this question. One approach is to ask you to respond to various questions (or "personality scale items") and then comparing your answers to other people's answers or to some standards already established. This method raises reliability issues since the data depend on how accurate your responses are, or how well they represent what you really do. A second approach is to have you monitor your feelings, thoughts, and actions as they occur and make some sort of record of it for later analysis. This approach offers a better promise of being valid and comprehensive and is the method we will use for this report. The idea in a nutshell is for you to monitor your threefold-self at certain designated times during the day and recording which of the 4 zones you are in at the time of the self-observation. By doing this several times a day over a few days, you will be able to have the data on your emotional spin cycle (James, Nahl 2003).

This might seem obvious, but previous studies have arrived at conflicting results about our mood cycles. For example, psychologists have variously said that positive feelings peak: just once, 8 to 10 hours after waking; once at noon and once in the evening; and once in the afternoon and again in the evening. Different studies have also claimed that negative feelings are most common in the morning, afternoon or evening... or don't have any daily cycles all! The mood cycles suggest that sleep gives us a chance to reboot our moods from the 
stress of a working day, and weekends are doubly refreshing for our emotions. And people show the same emotional cycles around the world even though they might come from different cultures and countries (including the UK, USA, Canada, India, Australia, New Zealand and various African nations) (Golder, Macy 2011).

By their duration, cycles are classified as follows. The longest cycles exist in the space, such as the main cycle of the Universe, the galactic cycle, and the development cycle of our solar system.

Besides very long "life cycles" (that can take between several hundred and several thousand years), a number of theories of cyclic development use cycles of "generational shifts" spanning periods between several decades (usually 25-35 years) and a century. The majority of these approaches mean "social" generations with their shift, first of all, related to changing cultural and political conditions, rather than pure biological generations. The issues of social generations and their shift as a mechanism that pushes social development are presented in works by such thinkers as Niccolò Machiavelli, Jean Bodin, Tommaso Campanella, Blaise Pascal, David Hume, Jean-Jacques Rousseau, Adam Ferguson, Henri de Saint-Simon, Charles Fourier, Auguste Comte, John Stuart Mill, Herbert Spencer, Wilhelm Dilthey, Leopold von Ranke, Vilfredo Pareto, Karl Mannheim, and José Ortega y Gasset. Among modern authors, the idea of shifting social generations as a foundation for historical cycles is present, for instance, in works by Arthur Schlesinger, an American historian and political philosopher (Новая философская энциклопедия 2010). Also, economic cycles have been classified depending in their periodicity. The most common are (Business cycles):

- Very short cycles, with duration of 30-40 months; also known as Kitchin cycles, whose studies saw in stock rotation the origin of these cycles.

- Short cycles, with duration of 7-11 years; also known as Juglar cycles, which origin is based on subsequent inventions.

- Long cycles with duration of 15-25 years; commonly known as Kuznets cycles, whose analysis placed the origin of cycles in demographic factors such as birth rates or migrations.

- Very long or Kondratiev cycle with duration of 50-60 years. This cycles originate with breakthroughs in capital goods, such as the steam engine or the Internet.

Cycles of related areas interact; together they create a higher-level aggregate and their dynamics reflects the influence of three types of cycles: their own cycle, cycles of directly related processes, and cycles that characterise the dynamics of the whole aggregate. This can be illustrated by an example of productive forces: their dynamics reflects the cyclic irregularity of changes in productive forces as a whole of their constituent elements (humans with their educational background and qualifications, science, technology and forces of nature engaged 
in production, the structure and organisation of production, economic management) has its own patterns and trends of cyclic development; at the same time each process (e.g. the process of science, the process of technology and the educational process) is exposed to irregular dynamics of related, closely integrated processes (Экономический справочник).

Fedulov and Astafieva (2008) give several examples of interaction between cycles of related domains. The shift of Earth's geographic poles is caused by seasonal movement of air and water masses and is also influenced by the elastic and viscous properties of the lithosphere. A detailed analysis of interactions between the atmosphere and the ocean, based on the observations of the phenomenon known as El Niño Southern Oscillation, leads to a conclusion that Earth, ocean and atmosphere go through concerted oscillations and affect each other. In addition to the Southern Oscillation and quasi-biennial oscillations in the atmosphere and ocean, another visible manifestation of such oscillations is the shifts of Earth's poles (Федулов, Астафьева 2008).

The interaction between remote cyclic oscillations related to other domains, which may disrupt and deform the normal flow of a process's cyclic development, must also be considered. Nature's cycles (global changes of the Earth's climate, movements of the Earth's crust that cause regular large earthquakes, solar cycles of various duration), for instance, may greatly affect the dynamics of ecological, economic and social processes, temporarily disrupt the intrinsic rhythm of their movement, and change the flow of cyclic time (Экономический справочник).

\subsubsection{Social cycle theories}

Various principles and theories are applied in the analysis of social, economic and other cycles. In the context of wave and cycle mathematics, they are, for instance, the chaos theory and the catastrophe theory.

Nefedov $(2003,2004)$ developed his mathematical model of preindustrial sociodemographic cycles. The basic logic of these models looks as follows: after the population reaches the ceiling of the carrying capacity of land its growth rate declines toward zero values and the system experiences significant stress with decline of the living standards of common population, increasing severity of famines, growing rebellions etc. Most complex agrarian systems had considerable reserves for stability, however, within 50-150 years these reserves usually got exhausted and the system experienced a demographic collapse, when increasingly severe famines, epidemics, increasing internal warfare and other disasters led to a considerable decline of population. As a result of this collapse, free resources became available, per capita production and consumption considerably increased, the population growth resumed and a new demographic cycle started (Nefedov 2003, 2004). 
Tarrow (1998) tries to explain the cyclical history of social movements in the form of the protest cycles. Tarrow (1998) defines protest cycles as a phase of heightened conflict across the social system, with intensified interactions between challengers and authorities which can end in reform, repression and sometimes revolution.

Dynastic cycle is an important political theory in Chinese history. According to this theory, each dynasty rises to a political, cultural, and economic peak and then, because of moral corruption, declines, loses the mandate of heaven (the Emperor was favored by heaven to rule over China), and falls, only to be replaced by a new dynasty. The cycle then repeats under a surface pattern of repetitive motifs (Reischauer 1965). This theory sees a continuity in Chinese history from early times to the present by looking at the succession of empires or dynasties, implying that there is little basic development or change in social or economic structures (Dillon 1998). The cycle appears as follows (Fairbank 1979; Ching 1974): a new ruler unites China, founds a new dynasty, and gains the mandate of heaven; China, under the new dynasty, achieves prosperity; the population increases; corruption becomes rampant in the imperial court, and the empire begins to enter decline and instability; a natural disaster wipes out farm land (the disaster normally would not have been a problem; however, together with the corruption and overpopulation, it causes famine; the famine causes the population to rebel and a civil war ensues; the ruler loses the mandate of heaven; the population decreases because of the violence; China goes through a warring states period; one state emerges victorious; the state starts a new empire; the empire gains the mandate of heaven; the cycle repeats itself.

Turchin (2003) connects population dynamics, state resources and internal warfare in the population dynamics models. In this model the elites controlling the state are not assumed to be selfish. It is rather assumed that the state has a positive effect on population dynamics. There are many mechanisms by which the state can increase the carrying capacity: the strong state protects the productive population from external and internal (banditry, civil war) threats, and thus allows the whole cultivable area to be put into production; states often invest in increasing agricultural productivity by constructing irrigation canals and roads, by implementing flood control measures, by clearing land from forests, etc. Again, the end result of these measures is an increase in the number of people that can be gainfully employed growing food, i.e., the carrying capacity. When the population size becomes large, food sup-plies are exhausted and the elite multiplies out of control - then state collapse is observed, followed by a significant decrease in the number of peasants. A large number of elite cannot be supported by a shrunken population, so eventually the elite decreases, and the cycle of growth starts over (Turchin 2003). 
Notions that historical development displays cyclical nature and consistent repeating patterns were the basis of philosophical and historical concepts of social development on which, at different times, worked Giambattista Vico, Heinrich Rükkert, Nikolay Danilevsky, Oswald Spengler, Arnold Toynbee, Carroll Quigley, Lev Gumilyov, etc. In these concepts, the cycles of social development are usually seen as the "life cycles" of specific social systems with their own birth, growth and death (Vico's "age of barbarians", "age of heroes", "age of cities, laws and reason"; Spengler's "spring", "summer", "autumn" and "winter" of cultures; Toynbee's "genesis", "growth", "time of troubles" and "disintegration" of civilisations; Gumilyov's phases of the ethnogenesis and development of ethnic groups). These concepts do not negate the fact that a given social system can go through periods of progressive, ascending movement, but they see the periods as distinct development phases of limited duration, inevitably replaced by phases of stagnation and decline. A unifying feature of these theories is that "life cycles" are seen as more or less universal schemes that, in line with their authors' intent, define the development of any culture, civilisation or ethnic group. At the same time such theories, though they capture some general development patterns of different ethnic, national or civilisation formations, often fail to take into account the unique features and qualities characteristic to each specific social system (Новая философская энциклопедия 2010).

On a related matter, studies of long-term cycles by the famous Russian economist Kondratieff and others have shown that both the frequency and amplitude of military conflicts tend to increase after commodity prices have hit major (secular) lows and turned higher. Further to the above, in his interesting and controversial book "War Cycles Peace Cycles" Richard Kelly Hoskins correlates secular commodity price trends, war, peace, and the practice of borrowing money into existence. He produced the following chart representing the secular trends in commodity prices over the past 340 years and explained that most of the important conflicts occurred during the "up phases" on the chart. The secular up-trends for commodity prices were hence termed "war cycles" and the downtrends termed "peace cycles". Hoskins' book was written in 1985, so there is no date shown for the bottom of the "peace cycle" that began in 1980. However, if the 1999 low for commodity prices turns out to be THE major bottom then we are presently in the fourth year of a "war cycle" that is likely to last at least 20 years (Saville 2003).

Job-Loss Cycle outlines the stages and emotions that people typically experience during job loss and transition. It is important to keep these stages in mind as you experience work transition and make decisions about what you will do next. Knowing where you are at in the cycle will help you to understand your emotions and will help you in the transition process. It should be noted that this process can't be rushed by ignoring your emotions - our experience tells us 
that negative experiences can often lead to feelings of anger, depression, and despair, and these emotions inevitably come across to potential employers. Your success will rely on you taking the time to move through the negative emotions stemming from a job transition towards positive feelings to hope and opportunity. Notice that the cycle has two parts - job loss and job search. The cycle appears to be like a roller-coaster through both sections - and it is. Both will present emotional stresses. Seek out support - from family, friends, an employment counsellor or a counsellor. These connections will be important to your successful transition. With the job loss comes both shock and anger followed by worry and anxiety. When the initial emotional jolt subsides it is time to start to anticipate the upcoming job search. The job search is rightly called a "yoyo" period, with moments of hope and excitement countered with moments of fear and rejection. The yo-yo period of the Job Loss Cycle can be an important time to ally with an employment counsellor - it helps to have someone outside of your regular network who can help you keep things in perspective and keep actively job searching (Job-Loss Cycle).

The transition cycle provides a valuable model for organisations, managers and employees to understand the different phases of transition that all employees and groups will go through during a period of change. Understanding this process helps managers to support employees through this natural human process. The transition cycle highlights the pattern of feelings and behaviours that employees typically go through when they experience change, whether the change is personal or organisational. Management style must adapt to different phases of the change process. Launching a change may require a firm, directive style, whereas the transition will require a more supportive and consultative approach. Trust is a key component for all employees going through the transition cycle. Employees need to trust their senior management team's competence, credibility and motives for launching any change. If the transition process is not effectively managed then an organisation is likely to experience some or all of the following (Managing the transition):

- Increased sickness absence.

- Reduced/poor performance.

- Scapegoating.

- Loss of creativity and initiative.

- Increased grievances.

- Resignations.

\subsubsection{Philosophy}

Analysis of cycles is a fairly popular topic in philosophy as well.

In philosophy, the notion of cyclicity can be traced back to the Ancient Greece. Bible wrote: "What has been is what will be, and what has been done 
is what will be done, and there is nothing new under the sun." The notes of Herodotus (5th c. BC) introduce the first full scheme of a cycle applied to political regimes: kingship, tyranny, oligarchy, democracy, and ochlocracy. Works by Polybius (200-118 BC) dwell on a similar idea that all political units (polities) pass through an inexorable cycle of growth, zenith and decay. In the Middle Ages, Ibn Khaldūn (1332-1406), a careful observer of social life, had similar ideas and was also convinced that "there is nothing new under the sun". He likened the cycles of civilisation to life cycles of living organisms: growth, maturity and senility (Штомпка 2011).

\subsubsection{Industry cycles}

In many industries, market dynamics such as sales, price, capacity, and investment are highly cyclical, observed in the form of successive expansions and contractions that affect all firms. These industry-level cycles may have different patterns from the general business cycles at the country level; and they are also distinct from fluctuations due to seasonal effects and those due to random shocks in the industry. The generation of industry cycles is considered from the Schumpeterian perspective to be endogenous, while from the neoclassical perspective they are created by exogenous shocks. Different mechanisms may be seen to account for them, depending on the industry, ranging from effects of macrobusiness cycles, to mismatch and delay between different market dynamics, and to dynamics of innovations, among others. These cyclical industrial dynamics have profound implications for firms' strategizing (Tan 2015).

\subsection{Introduction to the life cycle of the built environment}

The building sector contributes about a third of all energy-related emissions worldwide. Taking into account the emissions caused by land-use change impacts caused by urbanization, the manufacturing of building elements and the production of building materials, the share becomes even larger. According to the World Watch Institute, if the current trend continues the entire global community will run out of raw building materials by approximately 2030. Moreover, the building sector consumes water - a scarce resource in many parts of the world - for domestic use, landscapes and cooling towers. The building sector also generates a large variety of waste in construction, operation, renovation and, finally, demolition. Consequently, finding an effective way to transform the way we plan, design, build, operate, renovate and demolish buildings in the direction of sustainable practices has been the goal of many environmental assessment tools. In addition, there are co-benefits from this effort such as decreasing air and environmental pollution, improving health and productivity, and enabling sustainable economic development by promoting new sustainable technologies and behavior (Airaksinen et al. 2011). 
In recent years, many theories, methods, models and systems for the analysis of the life cycle of the built environment have been developed worldwide (Ali et al. 2015, Almeida et al. 2015, Antipova et al. 2014, Ayoub et al. 2015, Azari 2014, Ba-baizadeh et al. 2015, Chau et al. 2015, Chiang et al. 2014, Cobut et al. 2015, Cui et al. 2015, Desideri et al. 2014, Dong and Ng 2015, Edgar 2010, Islam et al. 2015a, 2015b, Kim et al. 2015, Kovacic and Zoller 2015, Kaklauskas et al. 1999, 2005, 2006, 2007, 2012, 2013, 2015, Amnatou et al. 2015, Lamnatou et al. 2014, Lamnatou et al. 2015, Love et al. 2015, Miller et al. 2015, Mosteiro-Romero et al. 2014, Nadoushani and Akbarnezhad 2015, Nicolae and George-Vlad 2015, Pajchrowski et al. 2014a, Pajchrowski et al. 2014b, Pargana et al. 2014, Pheng 1996, Rain-ville et al. 2015, Rashid and Yusoff 2015, Rauf and Crawford 2015, Russell-Smith et al. 2015a, 2015b, Safaei et al. 2015, Srinivasan et al. 2014, Takano et al. 2014, Takano et al. 2015, Teravainen et al. 2011, Tsai et al. 2014, Wen et al. 2015, Wong and Zhou 2015, Zabalza et al. 2011, Zhang et al. 2015, Ooteghem and Xu 2012, Ramesh et al. 2010, 2012a, 2012b, Verbeeck and Hens 2010a, 2010b, Mora et al. 2011, Li et al. 2013, Kofoworola et al. 2009, Gustavsson et al. 2010, Wallhagen et al. 2011, Hernandez and Kenny 2010, Asdrubali et al. 2013, Li 2006, Hu et al. 2013, Utama and Gheewala 2009, Dodoo et al. 2011, Huberman and Pearlmutter 2008, Baek et al. 2013, Stephan et al. 2012, You et al. 2011, Kneifel 2010, Dodoo et al. 2010, Zhang et al. 2013, Hernandez and Kenny, 2011, Taborianski and Prado 2012, Ramesh et al. 2012, Raniga and Wong 2012, Yung et al. 2013, Dodoo et al. 2012, Mitropoulou et al. 2011, Tianyan and Min 2012, Peuportier et al. 2013, Ma and 2013, Blengini and Carlo 2010, Marszal and Heiselberg, 2011, Kua and Wong 2012, Marszal et al. 2012, Rossi et al. 2012, Sartori and Hestnes 2007, Chel et al. 2009, Rossi et al. 2012).

Built environment can be defined in several ways:

- All the structures people have built when considered as separate from the natural environment (the British English definition).

- Artificial or man-made surroundings built to serve for a particular purpose, e.g. human activities ranging from the large-scale civic surroundings to the personal places (Biology-Online.org).

- All the structures people have built when considered as separate from the natural environment (the American English definition).

- The term built environment refers to the human-made surroundings that provide the setting for human activity, ranging in scale from buildings and parks or green space to neighborhoods and cities that can often include their supporting infrastructure, such as water supply, or energy networks. The built environment is a material, spatial and cultural product of human labor that combines physical elements and energy in forms for living, working and playing. It has been defined as "the human-made space in which people live, work, and recreate on a day-to-day basis" (Linked in). 
- The "built environment encompasses places and spaces created or modified by people including buildings, parks, and transportation systems". In recent years, public health research has expanded the definition of "built environment" to include healthy food access, community gardens, "walkabilty", and "bikability" (http://www.ieltsinternational.com/).

The built environment is at the origin of most of the mass and energy flows for which man is responsible. It absorbs large economic resources and embodies considerable cultural capital. Its form and composition may vary from place to place, but the built environment invariably constitutes a principal societal resource in the modern world. Sustainable development of the built environment is concerned with trying to enhance this resource - as an economic asset - while simultaneously achieving many related ecological, social and cultural objectives. However, given the scale of resource flows and corresponding impacts, sustainable development is ultimately about transforming the built environment in ways. And the focus of research is increasingly expanding from individual buildings to management of the built environment (defined as the construction, operation, renovation and final elimination of buildings, infrastructure and exterior surfaces) (Kohler, Moffatt 2003).

Life-cycle thinking also encourages using less materials and more efficient use of materials. In addition to awarding credits for reuse of all or part of an existing building, LEED v4 now allows project teams to use a whole building LCA to optimize decisions on structure and envelope. It provides the most points for reuse to account for the large environmental and, in many cases, economic and social benefits associated with reuse strategies. When reuse is not possible, projects are rewarded for using less material while maintaining building function, durability and reducing environmental impact. Life-cycle assessment and various forms of Environmental Product Declarations do not address all environmental and human health impacts adequately. Therefore, LEED v4 includes credits that are intended to better address human and ecological health impacts of material extraction and the human health effects of constituents used in the product life cycle. Specifying better materials is impossible without an understanding of what goes into the products themselves. The life-cycle approach to MR credits provides incentives for project teams to specify products from manufacturers that provide a product's full backstory (Todd 2013).

It is estimated that about 20 per cent of the US population suffers from asthma, emphysema, bronchitis, diabetes or cardiovascular diseases and are thus especially susceptible to external air pollution (American Lung Association 2005). Outdoor air quality plays an important role in maintaining good human health. Air pollution causes large increases in medical expenses and morbidity and is estimated to cause about 800000 annual premature deaths globally (Cohen et al. 2005). Much research, digital maps and standards on the 
health effects (respiratory and cardiovascular effects, cancer, infection etc.) of outdoor air pollution, a premise's microclimate and property valuation, have been published in the last decade. These and other problems, are related to a built environment's air pollution, a premise's microclimate, health effects, and real estate market value.

A built environment is developed in order to satisfy residents' requirements. Human needs can be physiological or social and are related to security, respect and self-expression. People want their built environment to be aesthetically attractive and to be in an accessible place with a well-developed infrastructure, convenient communication access and good roads, and the dwelling should also be comparatively cheap, comfortable, with low maintenance costs and have sound and thermal insulation of walls. People are also interested in ecologically clean and almost noiseless environments, with sufficient options for relaxation, shopping, fast access to work or other destinations and good relationships with neighbours.

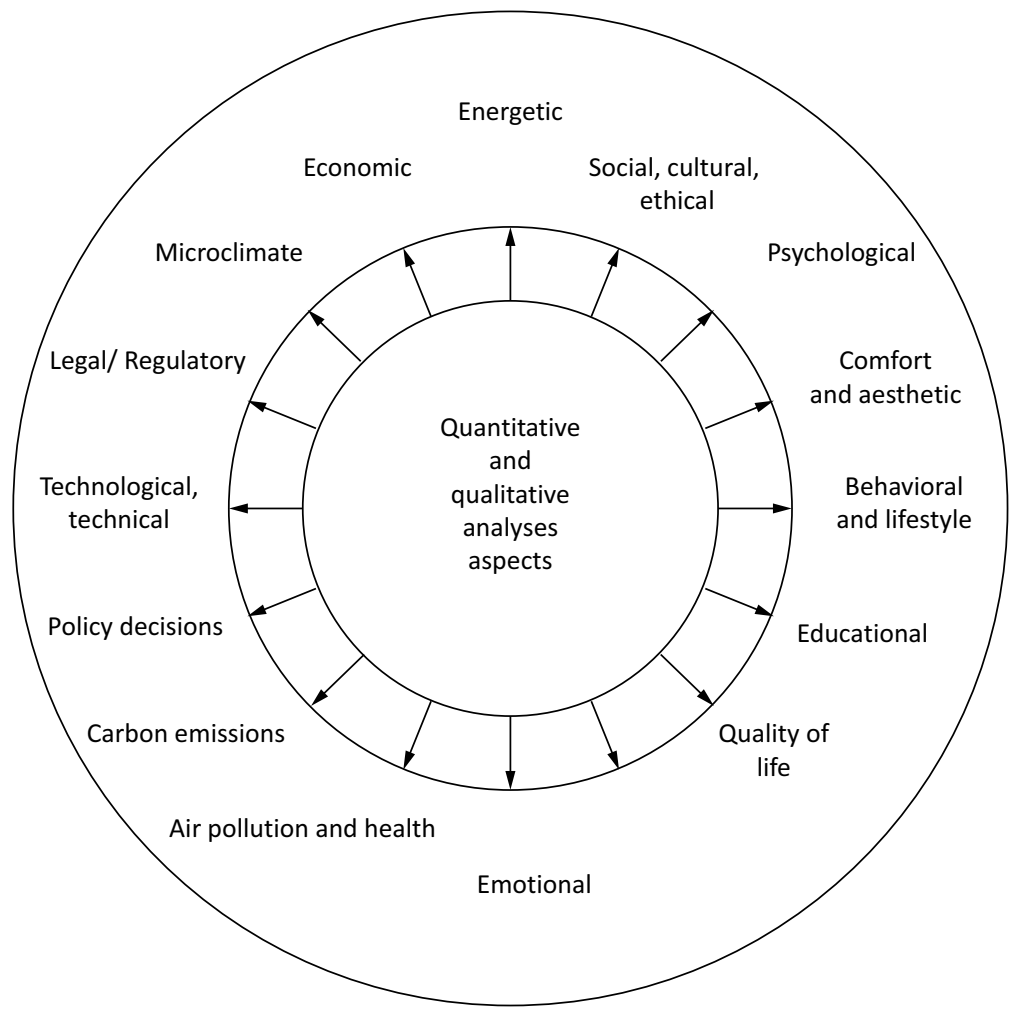

Figure 1.2. Life cycle of the built environment quantitative and qualitative analyses aspects 
Both project teams and manufacturers benefit from the availability of good information in the marketplace. Project teams can improve their product choices to minimize negative impacts and encourage manufacturers to strive toward improving their production practices or highlighting their best-in-class innovations. Product manufacturers that report on the environmental, human and ecological health impacts of their products demonstrate market leadership. With time, markets are expected to function more effectively and freely through the open sharing of this information (Todd 2013).

It must be admitted that the most serious problems of built environments, e.g. unemployment, vandalism, lack of education, robberies, are not always related to the direct physical structure of housing. Increasing investment into the development of social and recreational centres, such as athletic clubs, physical fitness centres, and family entertainment centres, the infrastructure, a good neighbourhood and better education of young people, can solve such problems. Investment, purchase and sale of a property, and its registration have related legal issues. The legal system of a country aims to reflect its existing social, economic, political and technical state and the requirements of the market economy. As illustrated, the life cycle of the built environment can be assessed taking into account many quantitative and qualitative criteria. Life cycle of the built environment quantitative and qualitative analyses aspects are presented in Figure 1.2. The aspects listed in Figure 1.2 are detailed in further sections (Quality of Life in a Built Environment, etc.).

On the contrary, EN 15978 standards have also classified the building lifecycle into four phases and named as material manufacturing, construction, maintaining the integrity of the specifications and maintaining the integrity of the specifications as elaborated below (Guinee et al. 2001; Arena, Rosa 2003; Elkaseh et al. 2013):

- Material Manufacturing. This stage includes removal of raw material from the earth, transportation of these materials to the manufacturing location, manufacture of finished or intermediate materials, building product fabrication, and packaging and distribution of building products.

- Construction. This phase accounts for activities relating to actual construction of a building project. Typically, the following activities are included in this stage: transportation of materials and products to the project site, use of power tools and equipment during construction of the building, on-site fabrication, and energy used for site work. Permanent impacts to the building site also fall into this stage, though these impacts are fully considered in current LCA methods.

- Maintaining the Integrity of the Specifications. This stage refers to build an operation, which includes energy consumption, water use, and environmental waste generation. It also takes into account the repair and 
replacement of building assemblies and systems.

- Maintaining the Integrity of the Specifications. This includes energy consumed, and environmental waste produced due to building demolition and disposal of materials to landfills. The transport of waste building material is also included in this stage. Recycling and reuse activities related to demolition waste can also be included in this stage, depending on the availability of data. It should be noted here that the description of building life-cycle stages presented above is based on review of previous LCA studies. Each life-cycle stage may or may not include all the activities described above, depending on the scope of the project.

Building life cycle refers to the view of a building over the course of its entire life - in other words, viewing it not just as an operational building, but also taking into account the design, construction, operation, demolition and waste treatment (Kotaji 2003).

The built environment is not constructed in an empty space. During the built environment life cycle - brief, designing, construction, maintenance, facility management, renovation, demolition and utilization - built environment are affected by various micro, meso and macro level factors.

The construction sector, as compared to all other sectors of industry, is notable for its low labor productivity and high fragmentation. Theoreticians, practitioners and politicians alike from different countries contribute a great deal of attention, efforts and time to eliminate such shortcomings. Scientists from different countries have sought to resolve problems in their works regarding project planning issues by complexly analyzing the life cycle of the built environment or of its component parts. Research of the life cycle of the built environment aimed to increase its efficiency that is being conducted globally may be classified in various ways, including:

- As investigations aimed at solving actual problems appearing at a particular stage of a built environment life cycle (i.e., brief, design, construction, maintenance, facilities management).

- As investigations handling a certain problem through the entire life cycle of the built environment.

- As investigations aimed at increasing overall efficiency of the life cycle of the built environment.

- As investigations aimed at increasing the efficiency of the life cycle of the built environment or its particular stage by applying recent IT achievements.

A thorough built environment's life cycle (brief; design; raw material extraction, transport and processing; construction materials production and distribution; construction; use, repair and maintenance; demolition; disposal, reuse, or recycling (see Figure 1.3) analysis is quite difficult to undertake, because a buildings and its environment are a complex system (technical, technological, 
economical, social, cultural, ecological, etc.), where all sub-systems influence the total efficiency performance and where the interdependence between subsystems play a significant role. It can be noticed that researchers from various countries engaged in the analysis of the life cycle of the built environment but its stages did not consider the research's object as was analyzed by the authors of the present investigation. Authors of the Monograph analyse a life cycle of the built environment as follows: the stakeholders involved in its life cycle as well as the micro, meso and macro environments, having a particular impact on it and making an integral whole. Various stakeholders (clients, users, architects, designers, utilities engineers, economists, contractors, maintenance engineers, built environment material manufacturers, suppliers, contractors, financing institutions, local government, state and state institutions) are involved in the life cycle of energy-efficient built environment, trying to satisfy their needs and affecting its efficiency.

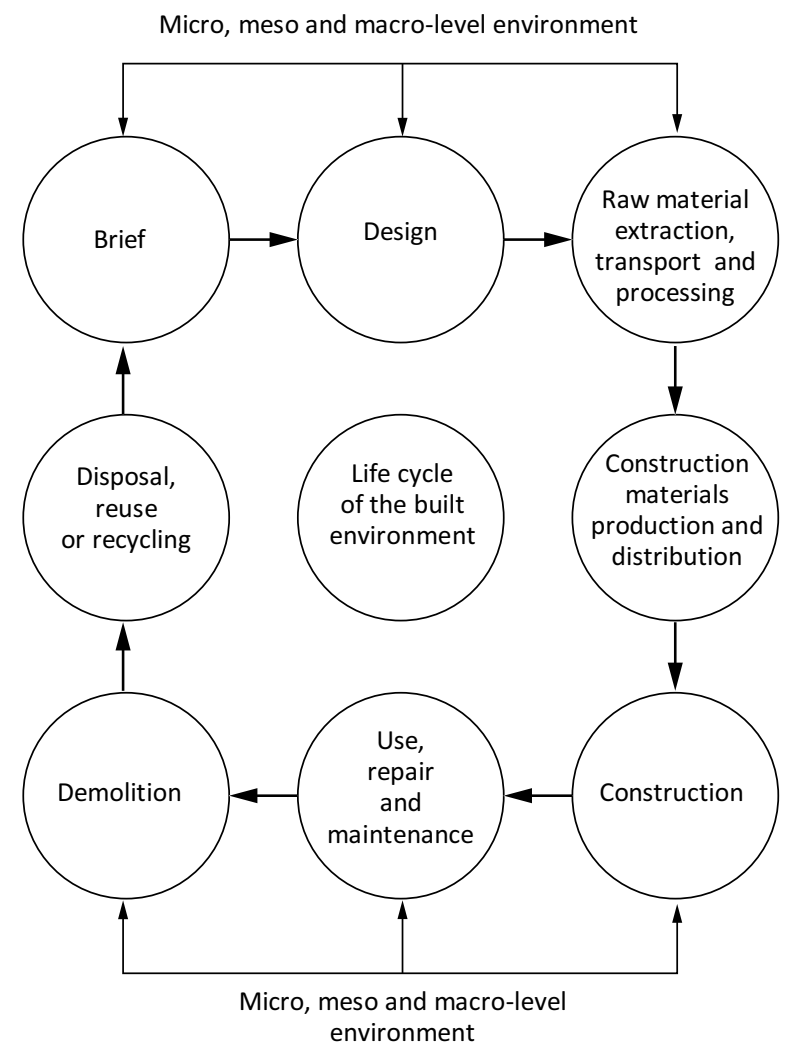

Figure 1.3. Life cycle of the built environment

The problem is how to define a life cycle of the built environment when a lot of various parties are involved, the alternatives come to hundreds thousand 
and the efficiency changes with the alterations in the environment conditions and the constituent parts of the process in question. Moreover, the realization of some objectives seems more rational from the economic perspective thought from the other perspectives they have various significance. Therefore, it is considered that the rationality of life cycle of the built environment depends on the rationality of its composite parts as well as on the ability to satisfy the needs of the interested parties and the rational character of environment conditions. Our research object is life cycle of the built environment, interested parties striving to attain their goals and micro, meso and macro environment making an integral whole.

In view of the global practice, any analysis of various aspects characteristic to the life cycle of the built environment focuses on the analysis of energy. The next two sections analyse this aspect.

\subsection{Areas of practice of energy-efficient built environment}

It is well known that buildings consume between $35 \%$ and $40 \%$ of the overall energy produced. Therefore, the EU has launched energy legislation (Renewable Energy Directive, Energy Efficiency Directive, etc.) and multiple initiatives (e.g. Public Private Partnerships in Energy-Efficient Buildings (PPP EeB), 2030 framework for climate and energy policies, Energy Efficiency Plan, etc.) to make built environment more energy efficient.

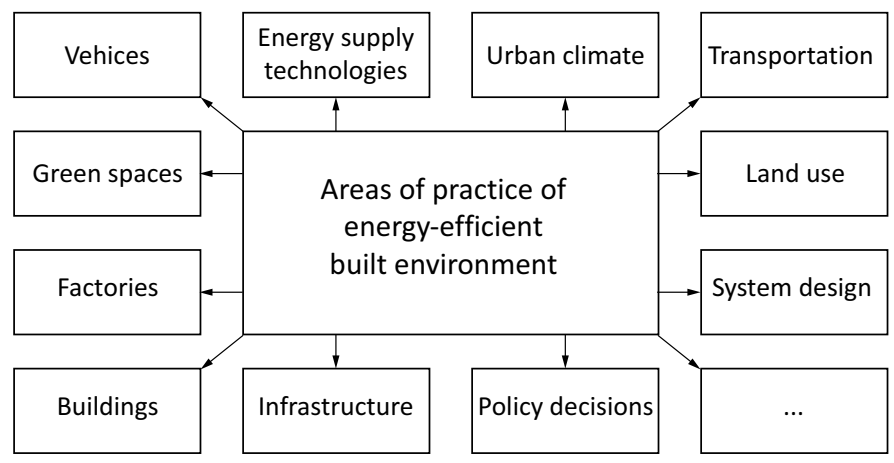

Figure 1.4. Areas of practice of energy-efficient built environment

The imperative to reduce atmospheric carbon is well documented and one significant area of production is from the built form which is responsible for up to $40 \%$ of global energy consumption and $30 \%$ of the world's carbon emissions. Over the full life cycle of buildings, which includes construction and demolition, $80-90 \%$ of this energy is used during the operational phase to heat, cool, 
ventilate, light and run appliances. The balance of $10-20 \%$ represents the embodied energy and is consumed during the building process of construction and production of the raw materials themselves. The need for the transport of goods and services, delivery of water and waste services to and from buildings adds further to account of emissions that the built form is responsible for and the total can be described as the carbon footprint (Goodfield et al. 2011).

Life cycle of the built environment application areas are presented in Figure 1.4.

Passive systems are the last technical components in each energy chain. Examples of passive systems include a car (excluding the engine) which delivers transport, or a house (without the boiler or lighting device) which provides thermal comfort and illumination (Cullen, Allwood 2010). Cullen and Allwood (2010) describe passive energy systems within three broad categories (vehicles, factories, and building):

- Vehicle: car (light-duty vehicle: car, mini-van, suv, pick-up), truck (heavy duty vehicle: urban delivery, long-haul, bus), plane (aircraft: jet engine, propeller), ship (ocean, lake and river craft: ship, barge, ferry), train (rail vehicle: diesel, diesel-electric, electric, steam).

- Factory: driven system (system refrigerator, air compressor, conveyor, pump), steam system (medium temperature application: petrochemical cracker, reaction vessel, cleaning facility).

- Furnace (high temperature application: blast furnace, arc furnace, smelter, oven).

- Building: hot water system (fuel and electric immersion boilers), heated/ cooled space (residential/commercial indoor space), appliance (refrigerator, cooker, washer, dryer, dishwasher, electronic devices), illuminated space (residential/commercial indoor space, outdoor space).

Demand-side energy-conservation measures include improving the energyout/energy- in efficiency of end uses (e.g., with more efficient vehicles, more efficient lighting, better insulation in homes, and the use of heat- exchange and filtration systems), directing demand to low-energy- use modes (e.g., using public transit or telecommuting instead of driving), large-scale planning to reduce energy demand without compromising economic activity or comfort (e.g., designing cities to facilitate greater use of non-motorized transport and to have better matching of origins and destinations, thereby reducing the need for travel), and designing buildings to use solar energy directly (e.g., with more daylighting, solar hot water heating, and improved passive solar heating in winter and cooling in summer) (Jacobson, Delucchi 2011).

Keirstead et al. (2012) first presented a definition of urban energy systems, as the combined processes of acquiring and using energy to satisfy the energy service demands of a given urban area. This set the context and scope for a review of 219 papers, covering five distinct areas of practice (Keirstead et al. 2012): 
- Technology design. The studies focused on energy supply technologies including the design and performance of urban wind turbines; solar energy systems including PV, hot water, and cooling; other heating or cooling technologies, including fuel cells; vehicle performance under urban load cycles; waste-to-energy systems, etc.

- Building design. Broadly speaking the studies might be classified as dealing with building design and renovation, energy demand estimation in the built environment, urban climate as it directly affects buildings, urban planning and policy, and transport. They represent a range of spatial scales, from single buildings to groups of buildings in a street or district or the whole city, and the behaviour of individuals.

- Urban climate. The studies operated at two main spatial scales. The first group looked at the effect of urban climate and heat island effects on buildings and the second looked at a larger district scale, including street cross-sections or raster grid of several hundred metres.

- System design. These studies are characterized primarily by their use of optimization techniques. The typical problem definition in these studies is, for an exogenously specified pattern of energy service demands, to determine the combinations of capital equipment and operating patterns to meet some objective subject to constraints (e.g. what is the lowest cost system that satisfies heat and power demands subject to a carbon emissions reduction target?).

- Policy assessment. This cluster representing studies of the whole city and how its energy performance might be shaped by policy decisions.

- Transportation and land use. Within this field of transportation and land use research, integrated land-use-transport models are most relevant. These are large complex, generally econometric, model systems which seek to capture the major dynamics of urban processes such as land use change and transportation use.

Almost one-third of energy is attributed to the production of materials and goods in industry (Cullen and Allwood 2010). Allwood et al. (2009) analyzed options for reducing energy use in material production (improving material efficiency through substituting less energy intensive materials, light-weighting products, designing for reuse and recycling, etc.).

Nakicenovic et al. (1993) introduce the term 'service efficiency', defined as 'the provision of a given task with less useful energy (the output from conversion devices) without loss of 'service' quality'. The effect is to separate out efficiency measures, for example using a more fuel-efficient car, from conservation measures, such as improving the flow of traffic (Nakicenovic et al. 1993).

Next, we present a few examples of components that comprise energy-efficient built environment (energy carrier networks, pedestrian pavements in cities, 
trees and the open green spaces, environmental impacts of building structures, the importance of ergonomics to sustainability throughout a building's life cyclea-nd city-level greenhouse gas management).

Employing different energy carrier networks in connection with distributed renewable energy generation is an attractive way to improve energy sustainability in urban areas. An effective option to increase local renewable energy production is to convert surplus electricity into e.g. thermal energy (Niemi et al. 2012).

Mendoza et al. (2012) examine the relevance of incorporating comprehensive life-cycle environmental data into the design and management of pedestrian pavements to minimize the impact on the built environment. The overall primary energy demand and global warming potential of concrete, asphalt and granite sidewalks are assessed. A design with a long functional lifetime reduces its overall primary energy demand and global warming potential due to lower maintenance and repair requirements. However, long-lived construction solutions do not ensure a lower life-cycle primary energy demand and global warming potential than for shorter-lived designs; these values depend on the environmental suitability of the materials chosen for paving. Asphalt sidewalks reduce long-term global warming potential under exposure conditions where the functional lifetime of the pavements is less than 15 years. In places where it is known that a concrete sidewalk can have a life of at least 40 years, a concrete sidewalk is the best for minimizing both long-term primary energy demand and global warming potential. Granite sidewalks are the largest energy consumers and greenhouse gas contributors (Mendoza et al. 2012).

The trees and the open green spaces have multiple uses and their presence in the outdoors makes a major contribution to the saving of energy inside the buildings as well as to the improvement of the microclimate in the urban spaces adjacent to buildings and in urban subareas. The amount of energy needed for heating and cooling is decreased considerably by the suitable placement of trees around buildings, so that there is much shading from the sun during the summer and as little as possible during the winter (Georgi, Dimitriou 2010).

The term green building encompasses the design, construction, operation, and deconstruction phases of a building's life. In general, green buildings conserve resources by using energy, water, and materials more efficiently during the entire life of the building, including the initial construction phase. Currently, the green building and sustainable building philosophies are merging in what may best be described as a movement based upon "creating a healthy built environment based on ecologically sound principles" while considering the entire life cycle of the built environment: planning, design, construction, operation, renovation, and retrofit. Architects began to ignore environmental, health, and social effects of buildings and their occupants, and the increasing complexity of 
building technologies brought about specialization in professionals who, unlike the generalists, were not inclined to whole systems thinking. Selecting sites in close proximity to existing services and infrastructure also minimizes disruption of the natural environment (Shurtz 2012).

Environmental quality has become increasingly influenced by the built environment and buildings play an important role in energy consumption and $\mathrm{CO}_{2}$ emissions through phases of life cycle. Li and Altan (2011) evaluate environmental impacts of reinforced concrete structure, steel structure and wood structure in terms of embodied energy and $\mathrm{CO}_{2}$ emissions of building materials in Taiwan. Environmental burdens of materials from cradle to gate including long transportation factor are taken into analysis since a great amount of wood is imported from the North America and ore of steel is imported from the West of Australia to Taiwan. The results show that wood structure has great benefits for the built environment in Taiwan (Li, Altan 2011).

Protecting and conserving environmental resources is a global concern. Over the past decade, a number of certification processes have emerged to help designers and operators of buildings assess the potential impact of a building on the environment. Certifications such as the Leadership in Energy and Environmental Design (LEED) consider the environmental impact through the lifecycle of a building, but may not be considering the people that construct and utilize it. It is important to remember the human factor. Considering the human factor throughout the lifecycle is crucial to ensure individuals are protected during construction and in operation in the built environment. Miller et al. (2012) highlights how ergonomics can be integrated into the life cycle of a building to promote sustainability goals for both the human factor and the environment. A case study approach was used to illustrate how ergonomics was integrated into a LEED renovation and expanded into its daily operations on a large university campus Miller et al. (2012).

Built environment carbon reduction strategies materialize predominantly in city-level greenhouse gas (GHG) management, where new residential development appears as one of the key instruments. However, city-level assessments are often incapable of producing data at a community or neighborhood level and thus they may heavily underestimate the emissions from new construction (Heinonen et al. 2012). Heinonen et al. (2012) explore the implications of low-energy residential construction as an instrument of climate change mitigation in the built environment and demonstrates why city-level approaches easily fail to identify the significance of the emissions from construction. Heinonen et al. (2012) employ a hybrid life cycle assessment (LCA) approach to demonstrate that, when the temporal allocation of emissions from the construction and use phases is taken into account, construction phase emissions come to have a central role in finding effective 
GHG mitigation strategies-even when the emissions from all consumption activities during the use phase are included in the assessment. In fact, their role would seem to be so central that new residential construction cannot be utilized as an instrument of city carbon management, even over a relatively long period (Heinonen et al. 2012).

\subsection{Phases of life cycle assessment}

The imperative to reduce atmospheric carbon is well documented and one significant area of production is from the built form which is responsible for up to $40 \%$ of global energy consumption and $30 \%$ of the world's carbon emissions (UNEP, 2009). Over the full life cycle of buildings, which includes construction and demolition, $80-90 \%$ of this energy is used during the operational phase to heat, cool, ventilate, light and run appliances. The balance of $10-20 \%$ represents the embodied energy and is consumed during the building process of construction and production of the raw materials themselves (Goodfield et al. 2011).

The output from an energy model, such as $\mathrm{DOE}_{2}$ or BLAST, is the projected energy use within a building as it operates over a typical meteorological year. This energy is considered the "operational energy" and is one component of the input needed to complete a building life cycle assessment (LCA). The second major component of energy consumed by a building is the "embodied energy," which comes from the materials manufacturing and construction phases of the building project. The need to understand embodied energy becomes more important as measures to reduce operational energy are taken. For "net-zero buildings," the majority of the energy impacts will be embodied, as operational energy needs are increasingly met by on-site power generation. An LCA that includes the materials manufacturing and construction phase of the project is the primary means of computing the embodied energy in a building (Bayer et al. 2010). In manufacturing, the LCA process is governed under ISO 14000, the series of international standards addressing environmental management (Jones 2008).

The building phases commonly evaluated by a LCA begin with material sourcing and manufacturing (raw material mining, transportation to manufacturing plants, manufacturing processes, packaging, distribution and transportation), construction (construction of building, including all aspects such as design, planning, electrical work, plumbing; manual labor, consultations, and so on), operation and maintenance (move-in of tenants; general building operation; energy use, water use, waste generation, etc.; replacements needed for repair, transport of replacement parts and labor; general maintenance activities), and lastly decommissioning or recycling (demolition and salvaging of the building at the end-of-life stage; transport of materials either to landfill or recycling center; 
recycling process; reuse activities) if appropriate (Bayer et al. 2010; Assefa et al. 2007; Bribian et al. 2009).

Life cycle assessment shall include definition of goal and scope, inventory analysis, impact assessment and interpretation of results (applications of LCA (product development and improvement, strategic planning, public policy making, marketing, other) are outside the scope of this International Standard):

- The goal and scope of an LCA study shall be clearly defined and consistent with the intended application. The goal of an LCA study shall unambiguously state the intended application, the reasons for carrying out the study and the intended audience, i.e. to whom the results of the study are intended to be communicated. In defining the scope of an LCA study, the following items shall be considered and clearly described: the functions of the product system, or, in the case of comparative studies, the systems; the functional unit; the product system to be studied; the product system boundaries; allocation procedures; types of impact and methodology of impact assessment, and subsequent interpretation to be used; data requirements; assumptions; limitations; initial data quality requirements; type of critical review, if any; type and format of the report required for the study. LCA is an iterative technique. Therefore, the scope of the study may need to be modified while the study is being conducted as additional information is collected. The primary purpose of a functional unit is to provide a reference to which the inputs and outputs are related. This reference is necessary to ensure comparability of LCA results. Comparability of LCA results is particularly critical when different systems are being assessed to ensure that such comparisons are made on a common basis. The system boundaries determine which unit processes shall be included within the LCA. The selection of inputs and outputs, the level of aggregation within a data category, and the modelling of the system shall be consistent with the goal of the study. The system should be modelled in such a manner that inputs and outputs at its boundaries are elementary flows. The data quality requirements should address timerelated, geographical and technology coverage; precision, completeness and representativeness of the data; consistency and reproducibility of the methods used throughout the LCA; sources of the data and their representativeness; uncertainty of the information) (ISO 14040). Impacts from the built environment are plentiful and can range from measuring air pollutants to noise levels, to habitat destruction, etc. (Hossain 2013). Buildings are always described as complex products, complexity which lays in the process of production. Due to the complexity of construction industry and the long life span of buildings (the life span was assumed to be 50 years as in many LCA studies applied to buildings), and because 
the scenarios within a building life span are not very clear, all subsequent phases of LCA will affect and modify the goal and scope definition phase in some way or another, so it will need review and modification within and after each phase (Khasreen et al. 2009).

- Inventory analysis involves data collection and calculation procedures to quantify relevant inputs and outputs of a product system. These inputs and outputs may include the use of resources and releases to air, water and land associated with the system. Interpretations may be drawn from these data, depending on the goals and scope of the LCA. These data also constitute the input to the life cycle impact assessment. The process of conducting an inventory analysis is iterative. As data are collected and more is learned about the system, new data requirements or limitations may be identified that require a change in the data collection procedures so that the goals of the study will still be met. Sometimes, issues may be identified that require revisions to the goal or scope of the study. The qualitative and quantitative data for inclusion in the inventory shall be collected for each unit process that is included within the system boundaries. The procedures used for data collection may vary depending on the scope, unit process or intended application of the study. Data collection can be a resource-intensive process. Practical constraints on data collection should be considered in the scope and documented in the study report (ISO 14040). The indicator datasets can include energy, raw material, physical inputs, products, waste, releases to air, water and soil, and any other environmental aspects. Choosing the indicators can be a subjective, value-laden activity if established industry benchmarks and standards are not followed (Dammann and Elle 2006).

- The impact assessment phase of LCA is aimed at evaluating the significance of potential environmental impacts using the results of the life cycle inventory analysis. In general, this process involves associating inventory data with specific environmental impacts and attempting to understand those impacts. The level of detail, choice of impacts evaluated and methodologies used depends on the goal and scope of the study. This assessment may include the iterative process of reviewing the goal and scope of the LCA study to determine when the objectives of the study have been met, or to modify the goal and scope if the assessment indicates that they cannot be achieved. The impact assessment phase may include elements such as, among others: assigning of inventory data to impact categories (classification); modelling of the inventory data within impact categories (characterization); possibly aggregating the results in very specific cases and only when meaningful (weighting) (ISO 14040). The second optional part of the impact assessment phase is weighting. During this process, the data from all of the impact categories are aggregated by applying weights to each category. The 
numerical weights are based on value choices and as such are often a point of criticism. However, by utilizing this optional step and having one single score as the final outcome, the LCA tool provides a qualitative aspect to the quantitative calculations, allowing for a value-based outcome that is tailored to the specific needs of the decision-maker (Gloria et al. 2007). Each LCA tool applies a different scale of weights for their impact categories and as such cannot be compared across tools (Hossain 2013).

- Interpretation is the phase of LCA in which the findings from the inventory analysis and the impact assessment are combined together, or, in the case of life cycle inventory studies, the findings of the inventory analysis only, consistent with the defined goal and scope in order to reach conclusions and recommendations. The findings of this interpretation may take the form of conclusions and recommendations to decision-makers, consistent with the goal and scope of the study. The interpretation phase may involve the iterative process of reviewing and revising the scope of the LCA, as well as the nature and quality of the data collected consistent with the defined goal. The findings of the interpretation phase should reflect the results of any sensitivity analysis that is performed. Though subsequent decisions and actions may incorporate environmental implications identified in the findings of the interpretation, they lie beyond the scope of the LCA study, since other factors such as technical performance, economic and social aspects are also considered (ISO 14040).

It is notable that researchers from various countries who engaged in analyzing a built environment life cycle and its stages did not consider the research object under analysis by the authors of this present investigation. The latter may be described as follows: a life cycle of the built environment, the parties involved in its design and realization as well as the micro-, meso and macroenvironments having a particular impact on it constituting an integral entity. A complex analysis of the formulated research object was conducted with the help of new methods, multiple criteria project analysis especially developed for this purpose.

\subsection{Stakeholders}

\subsubsection{General information about stakeholders}

The concept of sustainable community combines the principles of architecture, ecology and sociology, reflects the harmonious relationship between human and nature, and follows the tenets of sustainable development. Constructing sustainable communities needs the cooperation of different stakeholders of planner, real estate developer, governor, inhabitant, and manager of department of property. Sustainable community indicators are normally under an indicators framework, 
applying quantitative or qualitative indicators to assess the sustainable development level of communities (Zhou et al. 2011).

Building projects have a great impact on stakeholder values such as economy, safety, sustainability, urban aesthetics, etc. However, there is neither a formal model for assessing values (what is of worth, merit, utility, or importance to project stakeholders) nor an automated system for measuring how values are impacted by our planning and design decisions. As such, there is a need for a semantic model for values and value measurement. This entails: (1) discovering the values that are significantly impacted by building projects, (2) identifying how to measure the value of buildings to its stakeholders based on those values, (3) integrating such value data with the Building Information Model (BIM) so it becomes part of a dynamic building data/information model throughout the building's life cycle. Jahani and El-Gohary (2012) discusses value discovery and provides a brief overview of a proposed formal, axiological value assessment model and its integration with BIM (Jahani, El-Gohary 2012).

Establishment of rational stakeholders is one of the more important assignments regarding upgrading quality in a built environment's process of life cycle. Every interest group understands the degree of quality of any project as the relationship between the degree of its own contribution and the goals achieved due to it (amount of a received salary, risk and the like). In other words, a project's increased effectiveness due to the efforts of each interest group must be directly proportional to the achievement of their own goals and needs satisfaction. The understanding that generally predominates is like that, as stakeholders consider their "slice of pie" (final benefit of a joint project, compensation for a job done) to be a set size.

Stakeholders attempt to increase a project's effectiveness, wanting to increase the size of their "slice of pie". Thereby the slicing of the "pie" (including its increase) can be considered a positive problem. It means, this is a way to generate a more effective system for organizing stakeholders.

Everyone who is related to the project, i.e., everyone who makes a contribution and receives a benefit is interested. The efforts and the received "pie" can be either tangible or intangible. An interest group can be described from different perspectives:

- Temporary (design and construction process) or permanent (exploitation process).

- Main sphere of an interest group's activities.

- Suitable time when an interest group must enter into an ongoing process.

- The contribution and received "pie" of an interest group is monetary (yes/no).

- Degree of influence stakeholders have on a project.

- Dependency of stakeholders on a project (Zavadskas et al. 1992). 
Stakeholders are rarely established at once while a project is being compiled. It is additionally characteristic for them to join a project during its implementation process. Despite this, it is very important to establish the stakeholders that greatly influence a project or greatly depend on it as soon as possible.

"Brain storming" (a specific means of problem solving, where everyone participates in a free-for-all discussion) is a suitable method to foresee and select rational stakeholders. One means to apply this method is "snow cards", which is a small card for a person under questioning to write down only one interest group and the reasons why, in that person's opinion, this is a rational interest group. The person under questioning can fill out as many cards as he/she deems necessary. The "snow card" method can be applied at large meetings (with hundreds of participants), where groups consisting of 3-6 people work together filling out these cards. Afterward, project management can process, distribute and select rational stakeholders according to the functions they perform by utilizing a criteria system of their meanings and significances (Zavadskas et al. 1992).

Next, an example is briefly provided regarding the establishment of stakeholders. A bridge must be constructed to cross the river. It is easy to establish that the stakeholders are the owner, consumers, project designer, contractors, neighbors and those who sail under the bridge. So, what about the fish swimming in that water? It could be their spawning zone. Construction materials (sand and stones) are in a different place, where other fish spawn or where the best fishing areas are found. How can an interest group be established in an early stage of the project, while it is still possible to control and correct this process (Zavadskas et al. 1992)?

There are quite a few areas requiring coordination of interest group interests:

- Selection of a construction site.

- Organizational and pubic interests.

- The construction lot environment (before and after construction, internal and external).

- Aesthetics.

- Functionality.

- Longevity.

- Reliability.

- Risk (technical/financial/political).

- Applicability.

- Duration of construction.

- Construction methods.

- Project price.

- Exploitation expenses and the like. 
Each one of the mentioned project areas can be deliberated by various aspects, e.g., selection of the construction site determines numerous factors (Zavadskas et al. 1992):

- Price of a lot.

- The boundaries of the "geographical" market of the owner's company.

- Financing possibilities.

- Economic, political and other conditions for organizational activities.

- Amount of designated taxes.

- Living expenses.

- School, health protection, social and other administrative offices.

- Ability to shop.

- Conditions for spending free time.

- Workplaces of suppliers.

- Energy supply.

- Other types of supplies.

- Postal, telegraph, port, railroad, roads, airport.

- Life cycle (distance to them).

- Suitability of a construction site for construction.

- Price of the labor force.

- Means for digging a foundation pit and so forth.

Whether life cycle assessment (LCA) is applied to individual buildings or the entire built environment, the knowledge gained cannot easily be used without significant changes to the traditional planning and design process. In simple terms, what is required is an integrated design process (IDP) that reflects the trans-disciplinary nature of the built environment and encourages functional integration of long-term environmental performance with the many other sustainable development objectives. IDP involves creating a design or planning team with a wider range of technical experts, local stakeholders and partners than is normal - including individuals with knowledge of and responsibility for operations, maintenance, refurbishment and community relations. A facilitator may be needed to ensure successful communications, and to help experts and stakeholders negotiate the inevitable trade-offs (Kohler, Moffatt 2003).

The needs of stakeholders expand and change over the long term, and new stakeholders join as a project is being implemented. A project that is large and complicated and has many stakeholders participating becomes difficult or impossible to handle without the assistance of computers and different methods to operatively and rationally formulate, coordinate and manage its own requirements.

\subsubsection{Analysis of stakeholders}

One of the major assignments when aiming for effective design planning and implementation of a project involves having an alternative design and quality 
analysis over the entire process of the project's life cycle, when an objective is to satisfy maximally all the goals of stakeholders participating over the entire process.

The previously described process of the life cycle of a project cannot be implemented effectively without the maximal satisfaction of all the goals of all stakeholders (clients, buyers, construction and design organizations, suppliers, lawmakers, governmental bodies, consumers and others). A brief discussion on certain stakeholders follows.

The concept of a buyer encompasses all persons or companies, both external and internal, using the production of the organizations under discussion. "External buyers" (client, owner, media, local residents, local government and such) do not belong to an organization under discussion but they are associated with its production in one way or another. All these "external buyers" want something specific from the organization under discussion: the client wants good quality, low-priced production; the owner - income, stability; the media - advertising orders, valuable information or news, local residents - jobs and taxes and the local government - upholding the laws. Analogically the organization under discussion is also attempting to get something from the "external buyers": from the client - income and respect, from the owner - broad-based support, from the media - a good reputation and advertising dissemination, from local residents - employees and from the local government - protection, peace and quiet, legal guarantees and various services. The concept, "average buyers", denotes persons or companies that are part of the organization under discussion. There are numerous "average buyers" (suppliers) in a large organization. Here a spiral takes shape, where some subsidiaries are the "average buyers" of different subsidiaries of the same organization.

Construction organizations implement a project for all practical purposes by using different materials, equipment, energy, financial resources, labor force and the like. A good deal of responsibility of assuring an effective construction process falls on suppliers. The dependency between a construction organization and suppliers is one of the most obvious examples of how an environment directly impacts an organization. Gaining construction resources from other parties can be beneficial to a construction organization and future consumers from the perspective of prices, quality or quantity. However, the State may not be interested in such supply, since it may cause an increase in the number of unemployed and currency fluctuations, which could cause political instability. At times all the construction organizations in a region negotiate with one or practically with one supplier and all depend on that one supplier equally. For example, all organizations receive electricity at a price set by the State, and an alternative supplier rarely appears, even if an organization believes that the price of electricity in this case is too high. Therefore, in certain cases, the effectiveness level of an 
organization (e.g., when selling production in a foreign market) could depend on the overly centralized pricing policies of the State.

The outlook of a State on some specific activity (by various laws and resolutions, the work of governmental institutions and the like) also greatly impacts the operations of organizations. The mutual contact between a client and contractor winds up in the regulatory sphere of legal relationships in many cases. Every construction organization has a certain legal status, which establishes the kinds of activities in which an organization engages and its taxes. However, some laws are very complicated and not particularly expedient.

The most important goal of every organization is to satisfy consumer needs maximally and, by that, to implement its own objectives. To put it another way, the capability of an organization to survive and develop effectively depends on its ability to find a consumer within the sphere of its own interests and abilities who satisfies its demands maximally. Consumers determine the most effective direction for development among competing organizations in consideration of the results of their activities as they decide the kinds of goods and services they need according to a desirable price. In this instance, consumer needs are being satisfied and this has a determining influence on the relationships between contractors, suppliers and other stakeholders. It is expedient for an organization to orient its production to the large-scale consumer groups, and it primarily depends on these groups.

Competitors constitute an extremely important external factor. They greatly influence one another. The management of every company understands that, if the consumer demands are not met as effectively as competitors do, the company will not survive for long. Many times it is not the consumers who establish what production can be sold at what price but specifically the level of competition that does this. Consumers are not the only targets of an organization's competition. A competitive battle can break out over work resources, materials, capital and the right to exploit innovations. Most internal factors of an organization also depend on the level of competition: work conditions, salaries, the relationship between a boss and subordinate and other matters.

Certain stakeholders, such as project design and construction organizations and suppliers, are selected on the basis of competitive bids. The hiring person leads the negotiations with them. The stakeholders must identify the areas where their goals are suitable or unsuitable during the negotiations. Afterwards the reason for any mismatch of interests must be discovered. Disagreements that arise are usually resolved in three ways: 1 ) dominating; 2) compromising; 3 ) constructively.

\subsubsection{A multicriteria analysis of interest group goals and strategies}

The previous discussion was about the effectiveness of the process of the life cycle of the built environment and how it depends on various decisions, processes 
and stakeholders. A multicriteria analysis of all operable factors endeavoring to achieve the best, comprehensive result is necessary when aiming to better design and implement the life cycle process of a built environment. Performance of a multicriteria analysis of alternatives under discussion permits establishing the rational goals and effective strategies of stakeholders. These issues are further discussed as organizational examples. The principles that are laid out are also partly applicable for other stakeholders, as well.

Every organization (design, construction, suppliers and such), the same as every one of its employees, is seeking numerous, economic, social, moral, legal and other kinds of goals at the same time.). Some are easier to achieve than others are and, besides that, they are not all equally important. Thus, even if stakeholders do not achieve all the goals they might desire, they can still be satisfied having their most important goals satisfied. In such a case, it is highly beneficial to apply the interdependent principle of substitutability and total needs satisfaction.

It is very difficult to formulate the goals an organization is seeking to achieve, because nearly every one of its employees has his/her own opinion. This process can be accomplished more objectively by applying experimental and multicriteria evaluation methods. Organizational goals can only be implemented effectively, if they are correctly, unambiguously and clearly formulated. Meanwhile the employees must be informed about the goals, thereby raising their interest in them. The rationality level of company goals depend on how much they, along with the means for their implementation, correspond with the surrounding environment, as well as the desire of the stakeholders to participate in the process.

The effort to increase organizational effectiveness must include improvements in the mental systems of the employees. It is also possible to learn from past mistakes. Experience provides and organization with an opportunity to correctly adjust the direction of its activities, work more professionally and forecast the future effectively. The surrounding environment and the dynamic nature of the organization must be considered when selecting the different elements of a company's activities, as well as the company as a comprehensive entity, for analysis. This makes the analysis of this complex process much more difficult.

The general goals of a company are formulated and, step by step, they become entrenched based on the foundation of the organization's value orientations. The pursued goals must be described on the basis of numerous quantitative and qualitative characteristics. Descriptions of some of them appear below.

Above all else, goals must be specific. They should be expressed in numbers. One of the most important goals for some organizations is the satisfaction of their employee needs. Goals might be expressed as, for example, increase employee on-the-job satisfaction by 10 percent in a year, promote 15 percent of 
the employees on a career track and decrease employee turnover by 10 percent. Such specific numbers illustrate rather accurately what awaits employees in the future. The organization generates a terrific foundation of mutual interestedness and accountability by expressing its rules with specific indicators. In this sort of case, middle management gains a decent orientation on different issues requiring resolution (including upcoming concentrations required for employee education and training, or where, and other issues). Additionally it will be easier to determine, to what degree the organization has implemented its goals and, consequently, how much the company's effectiveness increases. A company's executive policies can change, once the final results become known.

It is necessary to define exactly, what the organization wants to implement, along with exactly, when it must be begun, when it should be achieved and what its intermediate and final results should be. Goals are usually defined in the short term and in the long term. The long term time for planning is approximately five years, sometimes more. Short term goals usually have to be implemented within a year. The average goal planning time lasts from one to five years. Long term goals tend to be quite abstract. An organization formulates these first. The average term and short term goals are defined next. Generally the sooner is the time of implementation, the more specific the goal is. For example, long term goals can be formulated such as, "Increase overall work capacity by 25 percent over the next 5 years." Then, accordingly, an organization can establish that work capacity must increase by 10 percent over the first two years. Furthermore short term goals are defined for specific areas, such as the price of material resources, upgrading employee qualifications, company modernization, more effective utilization of manufacturing resources and such. This group of goals is meant to help implement the long term goals, which are directly related to the group, as well as other organizational goals of construction. Essentially all the goals orient to increasing organizational effectiveness.

The pursuit of unrealistic goals can cause undesirable consequences. Such goals might include an effort to implement a project that either is greater than the capabilities of the organization or the surrounding environment does not form the conditions for it (due to imperfect laws, overly powerful competitors, poor demand to supply ratio for the offered production and such). Additionally an organization's level of goal achievement destines its employee interrelationships, because the future goals of the employees often closely relate to the organization's goals. When goals of an organization remain unachieved, certain employee goals remain correspondingly unachieved. Thereby the future perspectives of the employees shrink, and work motivation. A person tries to shoot as many rabbits as possible with one shot in everyday life. For example, it is a pleasure to comprehensively relate to receiving a good salary, holding 
an interesting and creative job and being promoted on-the-job. Unachieved employee goals can actually harm an organization. An organization's level of competitiveness can decrease, as employee motivation weakens.

\subsection{Compiling a criteria system to comprehensively describe the life cycle of the built environment}

The thoughts of other authors served as basis for compiling a criteria system describing the life cycle of the built environment. This relates to the considerable subjectivity, in a certain sense, of a criteria system that would actually define the goals of interest groups. Therefore the ideas of experts in this field based the compilation of a criteria system to define built environment aiming to increase the objectivity level of this analysis. The criteria system or its subsystems describing the life cycle of the built environment has been published in publications.

For example, the criteria system can be conditionally subdivided into five Level 1 subsystems:

1. Criteria subsystem describing the impact of macro-level factors on built environment effectiveness.

2. Criteria subsystem describing the impact of meso-level factors on built environment effectiveness.

3. Criteria subsystem describing the impact of micro-level factors on built environment effectiveness.

4. Criteria subsystem describing the impact of interest groups on built environment effectiveness.

5. Criteria subsystem describing the impact of different building life cycle process stages on built environment effectiveness.

Each one of these Level 1 criteria subsystems based on the principle of a tree diagram can be discussed in much greater detail. To illustrate, the life cycle of the built environment described according to an example of the $i^{\text {th }}$ level criteria subsystem could be a construction resources supply criteria subsystem.

For the sake of clarity, the impact of the micro-, meso- and macro-level factors that describe the Level 1 criteria subsystem on built environment effectiveness will be briefly discussed next along with the $i^{\text {th }}$ level criteria subsystem describing the supply of resources for construction.

\subsubsection{Level 1 criteria subsystems}

This subsection contains a brief discussion of Level 1 criteria subsystems, which describe the impact of the micro-, meso- and macro-level factors on built environment effectiveness. 
The macro-level is the highest level on which the effectiveness of the built environment depends. The following macro-level factors impact the effectiveness of the built environment:

- The level of a country's economic, political, legal and institutional and cultural development.

- Social, ethnic and religious environment.

- Technological and technical level.

- Government's policies including regional support programs, regulation of competitiveness, governmental orders, grants, subsidies, social policies and taxation system.

- Legal documents and standards relevant to the built environment.

- Interest rates.

- Inflation.

- The market.

- Insurance systems.

- Fluctuations of currency rates.

- Customs duties.

- Unemployment level.

- Labor force qualifications.

- Level of work compensations.

- Labor laws.

- Environmental protection.

- Customs and traditions.

- Life cycle of local resources and so forth.

A complex analysis of a built environment on the macro-level scope (city, country) is recommended basing it of the following system of criteria (Masure 2003; Raipa 2007; Sinkienè 2008; McAvoy 2002; Cheshire, Hay 1989; Webster, Muller 2000):

- Political, legal and institutional factors such as work cooperation between municipalities, effectiveness of city administration, the image of a city, the programs of different political parties, the governmental position with respect to certain areas of city operations (taxes, means for regulating the labor market and the like), effectiveness of the legal base of a built environment and the application of electronic democracy and electronic municipal governing. National and EU policies also require analysis, because it is essential for city heads and interest groups to understand the intentions of national governance (along with supranational governance, such as the European Commission) in the context of city evolvement and the means the government uses to implement its policies. Legal factors are distinguished on the basis of an analysis of the laws and standardized acts. These assist in establishing the limits of allowable operations and 
applicable methods to represent the interests of one's own city at different levels. Political factors are notable for their dynamism, whereas the legal ones, by stability, and these assure the continuity of the main rules for city development independently of changes in the dominating political forces occurring in the city.

- Analysis of economic factors in the external environment that include international competitiveness for capital, labor force, institutions, arranged events and the like; unemployment levels, growth in the number of jobs and attracted investments; the business environment; productiveness of companies; capability of exploiting macro-level conditions better than the capabilities of other cities with similar natural, human, technological and other resources; governmental policies (taxes and their benefits, grants, subsidies), interest rates, inflation, currency exchange rates and documents regulating a built environment; national tax policies; tariffs and macroeconomic and industrial initiatives; structure of the country's economic operations; level of innovations and application of electronic business. These factors assist in understanding the macro-economic indicators of the country or the broader region, growth trends of the external economy, fiscal and monetary policies and the specifics of corporate management as well as in evaluating the existing conditions of transportation, communications and other parts of the infrastructure with possible changes in the near future.

- Analysis of social, cultural, ethnic and religious factors that include memberships in networks, quality and knowledge of human resources, changes with respect to the rational expectations of the public regarding the city and the services it provides, rational city development that does not cause huge conflicts between interest groups for resources (land, money and others), political influence, development of human resources, educational level of the work force, capabilities and generation of innovations by joint work and expansion of networks, demographic changes in the country and region, the dominant family and community relationships, the situation in the area of equal opportunity and discrimination, features of the society's life style and their changes along with aspects of health and education, work and income and the criminological situation. An analysis of cultural factors concentrates on changes in the mobility of the country's or region's residents, the outlook on the major issues regarding city operations and development (forthrightness, insularity, rationality, cosmopolitism and the like).

- Analysis of technological and technical factors permits a timely determination of the operations opportunities and threats for that city, which outcrop due to new technologies and the conditional methods for their operations. They also condition the formation of rules regarding the directions of strategic 
technological breakthroughs for a certain city or the social and economic backwardness of a city due to a technological lag. In the case of a city analysis, it is also appropriate to analyze the development of informational and communications technologies operating beyond city borders, consolidation of new industrial branches, advancement in manufacturing technologies, the international and national policies for technological development and the like.

- Review of the state and tendencies of natural and ecological environments and structures as well as their possible consequences. Essential analyses involve indicators of the broader region (country, continent, world) for air quality, emissions, water quality of drinking water and open reservoirs, refuse handling, the condition of living nature, risk of natural disasters, physical expansion of city boundaries as well as the goals and means of national and international policies for regulating these areas.

The impact of the aforementioned macro-level factors on the effectiveness of the built environment must be expressed by the Level 2 and other level criteria subsystems that thoroughly describe such factors to achieve a comprehensive evaluation of them. The market is used as an example to illustrate this.

Market research is one of the most important issues that organizations must resolve, because their level of effectiveness depends on it. Numerous criteria can provide the basis for evaluating the market:

- Demand level (more information about this indicator can be gained by answering questions such as what kinds of users and why, how much, when and how they purchase the production offered by the organization under discussion and other similar sorts of production).

- Supply level (more information about this indicator can be gained by the availability of data about direct and indirect competitors and their strategies).

- Price levels of the production manufactured by the organization under discussion and its competitors.

- Market size (what share of the market belongs to the organization under discussion).

- Trends in market changes (What are the growth opportunities? How will the market share of the organization under discussion change, if the market should expand?).

- The strengths and weaknesses of the organization under discussion and its competitors.

- Analysis of the production buyers by their different personalities (age, sex, nationality or ethnicity, favored pursuits, education, life style, social status, standard of living, profession, marital status and the like). 
- Production buyers (of various organizations) analysis (involving the buyer's sphere of activity, job, structure, production sales level, distribution channels, number of employees).

- The individual who makes the final decision regarding purchases of the production.

- Opportunities for disseminating information and advertising about the manufactured production.

These criteria describing the market can be analyzed in even greater detail. Here the supply and demand of construction production will serve as an example. Demand for construction production depends on the following factors:

- Prices.

- Interest rates.

- Prices of other products/services.

- Income.

- Population numbers.

- Interests.

- Governmental policies.

- Future perspectives.

Prices change, whenever the aforementioned factors of demand change.

The supply of production from the construction sector depends on numerous factors:

- Expenses (construction costs).

- Technology improvements causing lower production prices and higher quality.

- Interrelated product prices that can replace or supplement each other while under production (for example, cheaper window alternatives lower the price of a building's revitalization).

- Other factors on which supply and demand depend: political shakeups, wars, strikes, policies on interest rates and such.

Criteria subsystems can be compiled analogically to the aforementioned macro-level factors describing them to achieve comprehensive definitions of those factors.

Factors, which impact the effectiveness of the built environment, also can be categorized at the micro and meso-level. These factors depend on the macro-level factors (various laws regulating construction sector operations, normative documents and the like). For example, it might be noted that, if the tax level becomes sufficiently high, then national companies could bankrupt due to the huge tax load or their effectiveness could drop (the number of international companies that want to enter the local market and competition will drop as taxes increase). Contrariwise, as taxes decrease, the international companies entering the local market can either push national companies out of their respective market share, 
or the national companies that face such competition will be forced to increase their effectiveness. Various areas could feel the consequences from such a process, including the unemployment rate, changed level of tax collection and such).

The effectiveness of the micro- (house, project) and meso-levels (region, organization) of a built environment can be evaluated according to the following system of criteria (Jacobs 1970, 2000; Castells 1989; Storper 1997; Sinkienè 2008; Hall 1998; Storper, Scott 2003; Petrakos, Economou 2000; Florida 2002):

- Physical factors referencing the supply and demand of land and facilities, prices of land and facilities, selection of an area of operations, quality of the residential environment including its pollution (hard particles, noise and so forth), infrastructure of the construction site, quality of life, geographical situation of the city and its accessibility, resources of the city's natural environment, territorial assets, advantages of the physical location, the dwelling and its location and image, size of the city or its status as capital and the city's geographical situation: Is it centrally located or in the peripheries of a country? In reference to the city's geographical situation in Europe - is it northerly, southerly or otherwise?

- Human resources referencing effective interest groups (residents, media, clients, consumers, project designers, construction materials manufacturers, suppliers, contractors, building utilization organizations) and an active and conscientious local community that is integrated, not splintered by social conflicts; a city like the locales distinguished for the greatest competitiveness, where companies and people want to invest and to reside; strong personal contacts of the leaders and direct contacts; a capability for attracting good employees; the qualification levels of the work force along with its innovativeness and exceptional knowledge and abilities; application of advanced techniques and technology and organizational management; opportunities for life-long learning and studying; the demographic situation along with the national and religious composition of the residents as well as the creativity, talent, tolerance, culture, traditions and the like of the residents.

- National and EU institutions, societies and social and political organizations referencing effective public organizations, political parties, financial institutions, municipalities and State; the numbers of national and EU institutions and the effectiveness of their operations; joint work between cities; development of public, social and strategic networks; public and private partnerships; the vision and strategy for development of the area and so forth.

- Economic factors referencing application of advanced economic propagation methods, services provided by the city, ability to exploit the micro- and meso-level conditions better than other municipalities or regions can, 
structure of the economy, operations generating high added value, local tax system, city's levels of economic compensations, accessibility of capital in the city, the city's institutions for education and research and for experimental development, the city's industrial clusters and the like.

Different micro and meso-level factors affect project effectiveness:

- Prices of land lots and buildings.

- Infrastructure of the construction site.

- Informational systems for construction.

- Organizational mergers in the construction sector.

- Selection of the type of operations.

- Project planning integrated with the life cycle process of a built environment.

- Effectiveness increases in process of supplying construction materials and products by using Internet.

- Lifelong learning.

- Financing for organizations.

- Type of contract.

- Goal determination process.

- Project planning process.

- Construction process.

- Exploitation process.

- Facilities management and so forth.

The impact of the aforementioned micro and meso-level factors on built environment and construction effectiveness is next illustrated in brief by the examples of indicators for evaluating sustainable communities, technologies, selecting the type of commercial credit and contract.

First, concepts, contents and research history of sustainable communities were summarized, and current evaluating indicator systems such as Leadership in Energy and Environmental Design (LEED), Building Research Establishment Environmental Assessment Method (BREEAM), Comprehensive Assessment System for Building Environment Efficiency (CASBEE), China Evaluating Standard for Green buildings (ESGB), China Evaluating Indicators \& Evaluating Standards for Green Communities (EIASGC) and other relative literatures of sustainable community indicators were reviewed by Zhou et al. (2011). The main findings were: (1) different evaluating systems of sustainable communities focused on different stakeholders, such as planner, real estate developer, governor, inhabitants, and manager of department of property; (2) methods such as theory analysis, frequency statistics, experts consultation and public participation could be applied in the processes of establishment indicator framework and selection of indicators; (3) sixty-nine indicators were found from twenty relative literatures, and the cited frequency of each indicator was counted; among these sixty-nine indicators, twelve indicators cited frequency were more than $50 \%$, while five 
indicators cited frequency were less than 5\%; (4) weights, standard values and results express methods were important parts of evaluating indicator systems, both average weight and weight determined by method of analytic hierarchy process (AHP) were applied in current evaluating systems. CASBEE proposed another useful way of expression the evaluating results; the ratio of building quality (Q) and environmental load reduction (LR) were adopted to express the concept of efficiency. The review also found some deficiencies in the current researches. Firstly, most of the researches focused on the community themselves and neglected the materials and energy interaction between the community and the natural environment. Secondly, dynamic developing progress of constructing sustainable communities was not paid enough attention in reviewed literatures, which was important for evaluating the built urban communities. Thirdly, designing process of indicator system lacks of public participation. Inhabitants were the most important stakeholders of constructing sustainable communities, thus their requirements should be considered at the starting point. Lastly, there were still arguments on the indicators weight and the standard values because the basic natural economic and social conditions are different among communities. In response, some new areas should be rising in the field of sustainable community research: (1) complexity theory and distributing intelligence should be introduced to analyze the demands of different stakeholders and dynamic developing progresses; (2) life cycle analysis and ecological footprint analysis could be applied to analyze the dynamic interaction between community and the outside environment; (3) the executive methods to integrate consulting experts knowledge and the demands of communities inhabitants in the process of designing the evaluating indicator systems should be developed. However, an objective and systematic evaluating indicator system framework with public participation were needed for sustainable communities (Zhou et al. 2011).

Technologies, such as Building Information Modeling (BIM) and Cloud Computing are disruptive technologies converging to significantly change traditional construction and facility management practices. The two technologies also embed associated business process rules and components that will enable enhanced life-cycle management of the built environment alignment of structures with organizational mission, and better consideration of general community impacts. Leading organizations are investing in the formalized definition and creation of robust business process frameworks, cultures, workflows and capabilities to support collaboration, continuous improvement and lean practices needed to achieve higher productivity within the architecture, engineering, construction, owner and operator (AECOO) sector. BIM and Cloud provide the digital foundation to support the cost effective, scalable development and deployment of adaptive and efficient facility life-cycle management practices (Cholakis 2012). 
Companies use commercial credit that will enable them to receive needed resources or services at once while postponing payments to a later date (usually for two to three months). Companies try to use more commercial credit as interest rates rise conditionally. Thus money is saved by not paying interest. However, suppliers can provide long-term credits, when the time period between the purchasing resources and selling the final production is quite lengthy (as is often the case in construction). The suppliers who provide commercial credits often offer discounts encouraging early repayments. Nonetheless, an assessment of all the expenses and discounts relevant to the commercial credit could lead to conclude that short-term financing is not cheap and that it is better to use alternative financing sources. Despite this, many small construction firms have a difficult time finding better alternative sources of short-term financing. Thus commercial credit remains one of the most important sources of financing for them. The construction industry makes broad use of commercial credits between suppliers and subcontractors, between subcontractors and contractors and between contractors and a client.

Numerous factors, which impact a project's effectiveness, determine how a type of contract will be selected:

- Overall policy of the owner on contracts.

- Qualification level of the local construction personnel.

- Time needed for project planning and construction.

- Owner's desire to control certain parts of the project.

- Importance of price to the owner.

- Degree of risk involved in drawing the contract.

- Exiting number of contractors and their suitability.

- Climate at the construction site.

- Level of trust of the contractor.

- Experience of the contractor.

- Pre-contractual period (long or short).

- Consultants (selection by the contractor or by the client).

- Subcontractors (local or assigned).

- Assessment of changes (expensive, cheap or the same price).

The effectiveness of every micro and meso-level factor can be assessed by basing it on the adequately described Level 2 or lower criteria subsystems.

\subsubsection{The $i$-th level criteria subsystems and a compilation fragment of their descriptive, conceptual information}

This subsection discusses in brief the $i$-th level criteria subsystem describing the supply of resources for construction.

A company must consider how to organize its operations effectively after it has selected a specific market and nomenclature of offered production. This 
depends on the decisions made regarding construction materials and goods, personnel and construction machinery. A company's level of competitiveness depends on the decisions made in these regards. These issues will be next analyzed briefly.

The effectiveness of construction machinery can be evaluated on the basis of the following $n$-th level criteria subsystem:

- Price.

- Exploitation expenses.

- Repair (ongoing and capital) expenses.

- Productivity.

- Number of performed operations.

- Reliability.

- Comfortableness.

- Physical and moral longevity.

- Weight.

Making huge investments into construction machinery is risky, because losses can be suffered when work capacity lessens. Profits could be down to a minimum, if the need for construction machinery and its manner of acquisition (rental, buyout lease or purchase) turn out to be wrong.

The larger companies and those that make greater profits can get a bank loan to purchase their construction machinery, which is more advantageous than renting or leasing with a buyout clause. Even though considerable money is invested for purchasing construction machinery, the buyout period is just a few years. Such an investment is unjustified, if the construction machinery will be used insufficiently intensely. Owners of construction machinery in Western Europe gain many benefits by purchasing, like tax advantages, which they do not receive by renting construction machinery or leasing it with a buyout option. Additionally, once the value of the construction machinery reaches zero due to amortization deductions, the machinery will still have scrap value or it can be resold.

The rationality of renting, leasing and purchasing construction machinery can be evaluated on the basis of the following indicator subsystem:

- Price of renting, leasing or purchasing construction machinery.

- Duration of time the construction machinery is to be used and intensity of its use.

- Physical and moral durability of the construction machinery.

- Financial situation of the organization.

- Tax advantages.

- Inflation level.

The effectiveness of construction materials and goods can be evaluated on the basis of the following $n$-th level criteria subsystem: 
- Price.

- Technical characteristics.

- Physical and moral longevity.

- Heat conductivity.

- Sound conductivity.

- Harmfulness to health.

- Assessment of the aesthetic view (assuming the construction materials and goods will be seen in the building to be constructed).

- Weight.

The prices of construction materials and goods constitute a good portion of the price of the building. Therefore all constructions that are trying to increase their profits also try to minimize the prices they pay for construction materials and goods while assuring the necessary level of quality at the same time. The larger construction organizations that seek to minimize the prices they pay for construction materials and goods usually hire experts on a full-time basis. Such experts analyze all the alternative sources for supplying construction materials and goods and their conditions for acquisition and then they select the most effective alternatives. The supply of construction materials and goods involves attempting to deliver the required amount and nomenclature of resources at the desired level of quality at the right time to the right place. Contractors generally request delivery of the needed amount of resources at the time they are needed in construction (avoiding shortages on one end and surpluses on the other). Construction materials and goods that are delivered before they are needed must be safeguarded from spoilage and thefts. Warehousing requires a special place and increased expenses for storage and insurance, so turnover capital is frozen. If resources are delivered too late, the construction may be stalled (laborers have no work to do) and its completion time, causing all the related consequences (paying fines to the client and greater interest fees to the bank on borrowed capital). Sometimes the delivered resources could be defective or at the wrong nomenclature and quantity. That is why construction materials and goods must be delivered to the construction site somewhat in advance of the work.

The prices of construction materials and goods depend on quality. Contractors often try to use cheaper materials during the construction, and the quality of the project suffers as a result. However, there is a sufficiently large choice of resources at the same level of quality. Additionally, over time, many alternative construction materials and goods are developed that have the same features as the traditional ones albeit at a lower per unit price.

Most large-scale contractors try to acquire construction materials and goods directly from their manufacturers: they get a lower per unit price when purchasing large quantities at a time. The prices for construction materials and goods can fluctuate depending on various offered discounts (for stability of purchases, 
timely payments and other conditions). Other conditions relevant to deliveries of construction materials and goods also interest buyers, such as credit availabilities (maximally saving turnover capital), reliability (upholding contractual terms defined in a contract maximally accurately), on-time deliveries, competitiveness of the supplied resources, quality of the delivered materials, good service, a level of joint work and mutual trust that would result in needed changes in the supply process whenever changes appear in the project and other similar circumstances. Sometimes clients are prepared to pay a slightly higher price for the same construction materials and goods, so long as the supplier satisfies the named conditions.

Supplier selection can be made on the basis of the following $n$-th level criteria subsystem:

- Price and quality of the supplied materials and goods (considering technical characteristics, physical and moral durability, heat and sound conductivity and harmfulness to health).

- Guality of supplied materials and goods (considering technical characteristics, physical and moral durability, heat and sound conductivity and harmfulness to health).

- Provided discounts.

- Reliability.

- Repayment and payment procedures.

- Credit opportunities.

- On-time deliveries.

- Good service.

The goals employees and employers have do not always coincide. Employees want as high a salary as possible, whereas employers are trying to save that money to increase the competitiveness and profits of the organization. Nonetheless, there are quite a few interests in common as well. Construction is becoming more and more mechanized and technically complicated, demanding more highly qualified personnel. Thus organizations find themselves needing to hire more qualified and trustworthy employees who are versed in the latest technologies and able to work effectively with the most modern equipment. Employee compensations and opportunity for a stable job highly depend on the effectiveness of an organization's operations. Therefore most employees are interested in working constructive with their employers.

Insufficiently qualified personnel can negatively affect the effectiveness of the construction process. Money is spent for staff training, and employees must designate their spare time to it. However, once employees advance, they will work more effectively and earn more themselves. Meanwhile the organization will be earning more and more profits. A lack of mastery increases the prices of performed jobs and the difficulties of introducing new technologies. It lowers 
the quality of the construction. Firms encourage their employees to improve their mastery by offering them higher salaries. However, the increased salaries raise prices leading to a drop in demand for the work the organization performs. Meanwhile the supply of a qualified labor force increases as compensations increase. Conversely, lowering salaries will cause the best employees to leave the company, and the competitiveness of the company drops. Therefore the hiring of personnel with differing levels of qualification along with opportunities for advancing qualifications need to be considered.

\subsubsection{Compiling a criteria system to comprehensively describe the life cycle of the built environment at level 1 and 2}

Porkka et al. (2010) propose a criteria system to comprehensively describe the life cycle of the built environment at level 1 and 2:

\section{Cost, price and life cycle economy}

1.1. Capital, investment, construction, commissioning and decommissioning cost

1.1.1. Site costs

1.1.2. Programming and planning costs

1.1.3. Design and engineering costs

1.1.4. Construction of ground and plot

1.1.5. Construction of building

1.1.6. Administration costs and commissioning fees

1.1.7. Decommissioning cost

1.2. Building services related to operation, maintenance and development

1.2.1. Administration

1.2.2. Operation

1.2.3. Maintenance and repair

1.2.4. Development

1.2.5. Consumption

1.2.6. Cleaning

1.3. Business services related the activities in the building (not building related)

1.3.1. Security and safety

1.3.2. Reception and switchboard

1.3.3. Mail

1.3.4. IT service

1.3.5. Moving

1.3.6. Catering

1.3.7. Accessories and copying

1.3.8. Administrative support 
1.3.9. Furniture and inventories

2. Location, site. plot, region and country

2.1. Location and address

2.1.1. Country and region

2.1.2. Address, postal code and city

2.1.3. Land, villages, town, city or city centre

2.2. Plot opportunities

2.2.1. Size of the plot

2.2.2. Site characteristic (e.g. bearing capacity, topography, sea level)

2.2.3. Outdoor environment and climate

2.2.4. Diversity of activities and mixed use in blocks

2.2.5. Building efficiency and density

2.3. Spatial solution and property aesthetics

2.3.1. Adaptability and compliance with needs

2.3.2. Spatial quality of the outdoor spaces

2.4. Surrounding services

2.4.1. Distance to growing neighbourhood

2.4.2. Distance to public transport

2.4.3. Pedestrian and bicycle access

2.4.4. Access to services

2.4.5. Access to green and open spaces

2.5. Social value

2.5.1. Cultural heritage

2.5.2. Community acceptance

2.5.3. Social cohesion

3. Building performance and indoor environment

3.1. Category of building, quantity, size and areas

3.1.1. Application and function of building

3.1.2. Shape and volume of building

3.1.3. Number of storeys

3.1.4. Build-up area

3.1.5. Gross floor area

3.1.6. Net floor area

3.2. Safety and security of burglary

3.2.1. Construction safety

3.2.2. Fire safety

3.2.3. Security of burglary

3.3. Usability and adjustability

3.3.1. Adaptability and compliance with needs

3.3.2. Accessibility for different users 
3.3.3. Spatial organisation and workplace quality

3.3.4. Adjustability over time

3.4. Thermal comfort

3.5. Air quality and health

3.6. Visual climate

3.7. Acoustic climate

3.8. Aesthetics of building and indoor spaces

3.8.1. Physical form and spatial solutions

3.8.2. Surfaces and colours

3.8.3. Details

3.9. Feelings and sensations

4. Building part and product performance

4.1. Category of building parts, quantity, size and area

4.2. Safety

4.3. Durability

4.4. Thermal quality

4.5. Impact on air quality

4.6. Lighting quality

4.7. Acoustic quality

4.8. Aesthetic quality as form, surface, colour and details

4.9. Feelings and sensations

5. Facility performance in operation and use

5.1. Category of tenant and operation and size and area of space

5.2. Applicability of the facility

5.2.1. Branding and certification

5.2.2. Meeting owner's strategy

5.2.3. Meeting users' strategies

5.3. Operation

5.3.1. Defects in use

5.3.2. Maintenance

5.4. Services

5.4.1. Facility services

5.4.2. Range of user services

5.4.3. Parking

5.5. Social performance

5.5.1. Employment

5.5.2. Social diversity

6. Process performance in design and construction

6.1. Category of process, supplier and organisation

6.2. Resource control and project management

6.2.1. Control of economy 
6.2.2. Working plan and time consumption

6.2.3. Logistic of materials and equipment

6.2.4. Internal cooperation

6.2.5. External cooperation

6.3. Health and safety and work environment

6.3.1. Health and safety control and documentation

6.3.2. Accidents

6.3.3. Physical work environment

6.3.4. Mental work environment

6.4. Quality management

6.4.1. Quality control and documentation

6.4.2. Operation and maintenance instruction

6.4.3. Handover defects and repairing

6.4.4. Guarantee period defects and repairing

6.5. User involvement and cooperation

6.5.1. User involvement in briefing

6.5.2. User evaluation of cooperation and process

\section{Environmental impact}

7.1. Resource use

7.1.1. Land use

7.1.2. Material use

7.1.3. Recycling

7.1.4. Water consumption

7.1.5. Energy consumption

7.2. Emissions

7.2.1. Carbon footprint

7.3. Biodiversity

\subsection{Methods, models and rating systems of the building life-cycle. Multiple-criteria decision-making}

While LCA is the most common method of evaluating environmental impacts for buildings, there are a number of related methods that assess complementary facts of the built environment, such as the economic and social costs. Each method has specific goals, which means they do not have to be used exclusive of each other. In some instances, it may be useful to the professional to apply a number of methods to glean the most comprehensive assessment possible, or combine tools for a hybrid variation. Hybrid assessments are commonly undertaken by combining LCA and EIO-LCA to get a sense of how the environmental and economic impacts relate (Hossain 2013). For example, Jørgensen et al. (2008) by using Social Life-Cycle Analysis evaluates social and socioeconomic 
effects of products and companies, i.e. worker health, human rights, labor practices, consumer safety, etc.

The construction and property sector has seen the development of a number of methods for evaluating the 'greenness' of buildings in the 1990s - both for new designs and existing buildings. These range from very detailed life cycle assessment methods, which account for all the embodied and operational environmental impacts of building materials, to higher level environmental impact assessment methods, which evaluate the broader implications of the building's impact on the environment. In between these two are environmental assessment methods such as BREEAM, BEPAC, LEED, and GBA (Crawley, Aho 1999). Crawley and Aho (1999) discuss the potential market applications of these systems and compare and contrast several of the major environmental assessment methods.

Currently in the U.S., the building assessment frameworks/rating systems that include LCA are (ATHENA Sustainable Buildings Institute 2012; Bayer et al. 2010; Hossain 2013):

- Leadership in Energy and Environmental Design (LEED) - the recent LEED update includes points for conducting a LCA.

- Green Globes - directly awards points for the educational experience of conducting a LCA and the first in the U.S. to incorporate LCA in the rating system.

- International Code Council (ICC) 700 National Green Building Standard, National Association of Home Builders' residential green standard - awards points for conducting a LCA.

- ASHRAE 189.1 Standard for the Design of High-Performance Green Buildings Except Low-Rise Residential Buildings - recommends conducting a LCA to assess the building's impact on natural resources, minerals, and the atmosphere.

- CalGreen - California's Green Building Standards Code offers LCA as an alternative to comply with material requirements on the whole-building level.

- International Green Construction Code (IGCC) - the ICC's standard offers LCA as an alternative to comply with material requirements on the whole building and assembly level.

A few previous studies are briefly discussed below as an example.

Under LEED v4, project teams will find credits that support a life-cycle approach in their designs and building material choices, deliver improved performance, and provide for the most resource-efficient building overall and over time. Life-cycle thinking means that the entire life cycle of a product should be examined, the processes and constituents identified, and the impacts of those processes and constituents assessed both upstream, from the point 
of manufacturing or use toward raw materials extraction, and downstream, from that point toward end of life. This type of thinking is sometimes called "cradle to grave" to illustrate the inclusion of the whole life cycle, or "cradle to cradle" to emphasize recycling and reuse at the end of life rather than disposal. Life-cycle assessment (LCA) is a methodology for implementing lifecycle thinking. LCA methods have been developed by international standardsetting organizations and include rigorous requirements to ensure data quality, comparability and objectivity. LCA is data-intensive and generally requires a trained professional (Todd 2013).

Cicas et al. (2007) developed a model to calculate the regional environmental impacts of an industry entire supply chain or sector. Cicas et al. (2007) utilized regional economic and environmental data to assess the impact of petroleum refineries. The regional results showed pollution discharges $8 \%$ above the national models. Cicas et al. (2007) emphasize the importance of calculating impacts by region rather than across the nation, as there are marked differences between states in the U.S.

One of the ongoing challenges in the quest to make the built environment more sustainable is to identify and mitigate environmental impacts in all phases of buildings, from design to construction to use and maintenance and finally end of life phases (Ndungu et al. 2012). Ndungu et al. (2012) compare the life cycle environmental burdens of constructing Composite Metal Deck and Hollow Core floor systems for commercial buildings by using a Hybrid Life Cycle Assessment (LCA) approach. The study covers material extraction (cradle-to-gate) and construction (gate-to-gate) phases and includes a detailed assessment of both direct and supply chain impacts. A comprehensive set of results is obtained from the study. These results are presented in several categories for comparative assessment - energy use, Carbon Dioxide $\left(\mathrm{CO}_{2}\right)$, Carbon Monoxide (CO), Nitrogen Dioxide $\left(\mathrm{NO}_{2}\right)$, Sulphur Dioxide $\left(\mathrm{SO}_{2}\right)$, PM10 and VOC emissions. Other categories include solid waste and liquid emissions (Ndungu et al. 2012).

Srdić and Šelih (2011) systematically builds an integrated model that includes quality as well as sustainable performance of the built environment and accompanying construction processes. This model for the "Integrated Quality and Sustainability Performance Assessment in Construction" presents a three-level arrangement, namely: the structure, process/project, and construction product. Srdić and Šelih (2011) propose a holistic sustainability assessment methodology based on the authors' previous research work for structures. The strict implementation of quality and environmental management systems in the participating organisations and in the whole construction project guarantees quality and environmental performance at project/process level. On the construction product level, Srdić and Šelih (2011) complement the existing requirement of providing a statement of conformity for each product of the structure with the 
Environmental Product Declaration (EPD) for all construction products. Srdić and Šelih (2011) use the Life Cycle Assessment methodology to obtain the EPDs for specific construction products; in this way, Srdić and Šelih (2011) can evaluate their environmental impacts throughout the life cycle of a product or structure. Integration of all three levels by Srdić and Šelih (2011) ensures that the desired plateau of quality and sustainability performance is achieved for structures, processes and products.

A thorough energy-efficient built environment multiple criteria analysis is quite difficult to undertake, because a building and its environment are complex systems (technical, technological, environment, ecological, social, economical, comfort, esthetical, etc.), where all sub-systems influence the total efficiency performance and where the interdependence between sub-systems play a significant role. Many multiple-criteria decision-making (MCDM) or multiple-criteria decision analysis (MCDA) methods have been developed in the world for solving the above-mentioned and other problems as follows: AHP method (Kablan 2004; Nigim et al. 2004; Jaber et al. 2008; Alanne et al. 2007), COPRAS (Kaklauskas et al. 2005, 2006), Data envelopment analysis, Decision EXpert, Disaggregation approach (Diakoulaki et al. 1999), Displaced Ideal (Mirasgedis and Diakoulaki 1997), Dominance-based rough set approach, ELECTRE (Georgopoulou et al. 1997; Beccali et al. 1998, 2003; Thiel and Mroz 2001), Evidential reasoning approach, Fuzzy sets (Beccali et al. 1998; Cavallaro and Ciraolo 2005; Gamboa and Munda 2007; Jaber et al. 2008; Alanne et al. 2007), Genetic algorithm (Juan et al. 2009; Wright et al. 2002), Goal programming, Grey relational analysis, Information deficiency method (Afgan and Carvalho 2002), Inner product of vectors, MACBETH, Multi-attribute-utility analysis (Renn 2003), PAPRIKA, PROMETHEE (Georgopoulou et al. 1998; Goumas et al. 1999; Haralambopoulos and Polatidis 2003; Cavallaro 2005), SIR method, TOPSIS, Value analysis, Value engineering, Value tree method (Renn 2003), VIKOR, Weighted product model, Weighted sum model, PAIRS (Salo, Hämäläinen 1992).

The aforesaid methods were used to solve various problems of energy-efficient built environment:

- ELECTRE (Georgopoulou et al. 1997; Beccali et al. 1998, 2003; Thiel and Mroz 2001): regional energy planning, evaluation of renewable energy options, renewable energy diffusion strategies, renewable energy technologies, selecting a heating system for a historical building.

- Disaggregation Approach (UTADIS: Diakoulaki et al. 1999): energy analysis and policy making.

- Value tree method (Renn 2003): evaluation of energy scenarios, waste energy utilization.

- Multi-attribute utility analysis (Renn 2003): selection of energy scenarios, waste energy utilization. 
- PROMETHEE (Georgopoulou et al. 1998; Goumas et al. 1999; Haralambopoulos, Polatidis 2003; Cavallaro 2005): promotion, planning and assessment of renewable energy sources; geothermal and renewable energy projects; 'scenarios' for geothermal resources; renewable energy plants.

- Fuzzy sets (Zadeh 1965) (Beccali et al. 1998; Cavallaro, Ciraolo 2005; Gamboa, Munda 2007; Jaber et al. 2008; Alanne et al. 2007): technologies of energy conversion and heating distribution, renewable energy diffusion strategies, wind energy plants, locating wind turbines.

- PAIRS (Salo, Hämäläinen 1992): residential heating systems and the handlinge of uncertainties related to the actual preferences of decision makers for type heating systems.

- Displaced Ideal (Mirasgedis, Diakoulaki 1997): electricity generation systems.

- Information deficiency method (Afgan, Carvalho 2002): new and renewable energy technologies (power plants).

- AHP (Saaty 2001) method (Kablan 2004, Nigim et al. 2004; Jaber et al. 2008; Alanne et al. 2007): evaluation of conventional and renewable energy sources for household heating, prioritisation of policy instruments, prefeasibility ranking of alternative renewable energy sources.

Multiple-criteria decision-making (MCDM) is the most well-known branch of decision making. It is a branch of a general class of Operations Research (or OR) models which deal with decision problems under the presence of a number of decision criteria. According to many authors MCDM is divided into MultiObjective Decision Making (or MODM) and Multi-Attribute Decision Making (or MADM) (Triantaphyllou et al. 1998). Different authors have different names for the concept of Multi-Objective Decision Making (MODM) such as multiplecriteria design, multiple objective mathematical programming, or multi-objective optimization. MODM methods (Diakaki et al. 2010; Asadi et al. 2012a 2012b; Diakaki et al. 2008; Wright et al. 2002) and MADM methods (Gero et al. 1983; Jaggs, Palmar 2000; Flourentzou, Roulet 2002; Rey 2004; Kaklauskas et al. 2006; Allane 2004; Kim et al. 2009; Diakaki et al. 2010) are widely used in analyses of energy-efficient built environment.

MODM studies decision problems in which the decision space is continuous. A typical example is mathematical programming problems with multiple objective functions. The first reference to this problem, also known as the "vectormaximum" problem. (Triantaphyllou et al. 1998). The alternatives in this class of problems are not explicitly known, they are either infinite and not countable or typically very large if countable. MODM methods sometimes using interactive computer methods to involve the analyst explicitly in the process also, directly seek to specify what the definition of the best option should be. The question is essentially one of identifying an optimal design for the option, guided by MODM 
methods. Almost always, the optimisation is subject to specific constraints, for example on cost or technical specification (Multi-criteria analysis... 2009).

The problem faced by the decision maker is in fact a multi-objective optimization problem, characterized by the life cycle of multiple and competing objectives, the decision space consisting in a set of feasible solutions that are not predefined but are implicitly defined by a set of parameters and constraints that should be taken into account. Therefore, it is not necessary to enumerate the set of actions to be considered (Diakaki et al. 2010).

A number of MODM methods has been used to analyse different areas of energy-efficient built environment such as design of building envelopes (Diakaki et al. 2008), selection of heating systems (Wright et al. 2002), optimal thickness of insulation (Malckzewski 1999), retrofit actions aimed at minimizing energy use in a cost-effective manner (Asadi et al. 2012), and improving energy efficiency in buildings (Diakaki et al. 2010).

Multi-Attribute Decision Making (MADM) methods often have alternative names, too (e.g. multiple-criteria evaluation).

There are many ways one can classify MADM methods. One way is to classify them according to the type of the data they use. That is, we have deterministic, stochastic, or fuzzy MADM methods (for an overview of fuzzy MADM methods (Chen, Hwang 1992). However, there may be situations which involve combinations of all the above (such as stochastic and fuzzy data) data types. Another way of classifying MADM methods is according to the number of decision makers involved in the decision process. Hence, we have decision maker MADM methods and group decision making MADM (Triantaphyllou et al. 1998).

MADM concentrates on problems with discrete decision spaces. In these problems the set of decision alternatives has been predetermined (Triantaphyllou et al. 1998). In MADM problems with a finite number of options, each of which is assessed in terms of a given number of criteria. For each option, with respect to each criterion, this performance information needs to be collected. Most decisions concern choices between a finite number of options, the details of which have already been predetermined before they are subject to MADM. It is concerned simply to assess the strengths and weaknesses of options as they stand and find the best alternative (a set of good alternatives) for a decision maker (Multi-criteria analysis 2009). In a number of countries, scientists used MADM methods to solve miscellaneous problems of energy-efficient built environment:

- Local energy systems involving several energy resources (Løken 2007).

- Selection process (Malckzewski 1999).

- Selecting a heating system for a historical building (Thiel and Mroz 2001).

- Design of building envelope and refurbishment problems; selecting contractors for public buildings (Kaklauskas et al. 2005; Kaklauskas et al. 2006). 
- Evaluation of conventional and renewable energy sources for household heating (Jaber et al. 2008; Alanne et al. 2007).

- Energy conversion and heating distribution technologies (Nagesha, Balachandra 2006).

- Residential heating systems and the handlinge of uncertainties related to the actual preferences of decision makers for type heating systems (Salo, Hämäläinen 1992).

- Building design (Gero et al. 1983).

- Evaluation of retrofitting scenarios (Jaggs, Palmar 2000; Flourentzou, Roulet 2002; Rey 2004).

- Multivariate design and multiple criteria analysis for building retrofitting (Kaklauskas et al. 2005, 2006).

- Selection of the most feasible retrofit actions in the conceptual phase of a retrofit project (Allane 2004).

- Housing condition assessment to suggest optimal retrofit actions considering the trade-off between cost and quality (Juan et al. 2009).

A few brief examples follow, as a quick illustration of the aforementioned MCDM methods applied in some areas of energy-efficient built environment.

Diakaki et al. (2010) investigated the feasibility of applying multi-objective optimization techniques to the problem of improving energy efficiency in buildings, considering a simplified model for building thermal simulation

Due to growing limitations on land use and awareness of sustainability concerns, the building retrofit market has faced increasing opportunities worldwide. Several technological/constructive options are available to improve energy efficiency and indoor environmental quality in buildings. The identification of the most appropriate retrofitting options is a topic of outstanding importance given the potential costs and impacts involved (Asadi et al. 2012). Asadi et al. (2012) present a multi-objective optimization model and method to assist stakeholders in the definition of intervention measures aimed at minimizing the energy use in the building in a cost effective manner, while satisfying the occupant needs and requirements. An existing house needing refurbishment is taken as a case study to demonstrate the feasibility of the proposed multi-objective model in a real-world situation. The results corroborate the practicability of this approach and highlight potential problems that may arise (Asadi et al. 2012).

Coherent and efficient retrofit scenarios are commonly built on the basis of the knowledge of the degradation state of the building and its obsolescence. The architect or building engineer prepares a list of refurbishment works required on the basis of the building audit, his experience and the available budget (Flourentzou, Roulet 2002). Flourentzou and Roulet (2002) describe a systematic method, based on multicriteria analysis and a constructivist approach, which helps an expert in designing retrofit scenarios. This approach includes several 
steps and follows an iterative process. The associated computer tool takes charge of tedious tasks such as calculating the associated costs, performing an energy balance, and checking for coherence between actions; and presents various viewpoints to the expert. It also helps the user in quickly creating various scenarios. The expert can then interact with this information and makes the decision for selecting the final scenario. This interactive approach brings together expert intuition and rational systematic verification (Flourentzou, Roulet 2002).

As one can see, the above-mentioned research has enabled the authors to solve a majority of problems in a complex way as far as energy-efficient built environment's multiple-criteria decision-making is concerned. However, one of the weakest aspects of the above research was the formation and multiple criteria analysis of alternative variants of the whole energy-efficient built environment. The authors of this chapter have developed methods of multivariant design and multiple criteria analysis of energy-efficient built environment to tackle these problems.

\subsection{Model for a complex analysis of the life cycle of the built environment}

A thorough built environment's life cycle (brief; design; raw material extraction, transport and processing; construction materials production and distribution; construction; use, repair and maintenance; demolition; disposal, reuse, or recycling) analysis is quite difficult to undertake, because a buildings and its environment are a complex system (technical, technological, economical, social, cultural, ecological, etc.), where all sub-systems influence the total efficiency performance and where the interdependence between sub-systems play a significant role.

In order to develop a high-quality built environment, it is necessary to take care of its efficiency from the brief to the end of service life, demolition; disposal, reuse, or recycling. The entire process must be planned and executed with consideration of goals aspired by participating stakeholders and micro, meso and macro level environment. In order to realize the above purposes an original Model of a Complex Analysis of the life cycle of the built environment (see Figure 1.5) was developed enabling to analyze life cycle of the built environment, the parties involved as well as its micro, meso and macro environment as one complete entity.

A Model was being developed step by step as follows (see Figure 1.5): a comprehensive quantitative and conceptual description of a research object; multivariant design of life cycle of the built environment; multple criteria analysis of the life cycle of the built environment; selection of the most rational version of life cycle of the built environment; development of rational micro, 
meso and macro level environment. The above Model will be now described in more detail.

For more comprehensive study of a research object and methods and ways of its assessment major constituent parts of the above object will be briefly analyzed. They are as follows: life cycle of the built environment, the parties involved and micro, meso and macro environment having a particular impact on it.

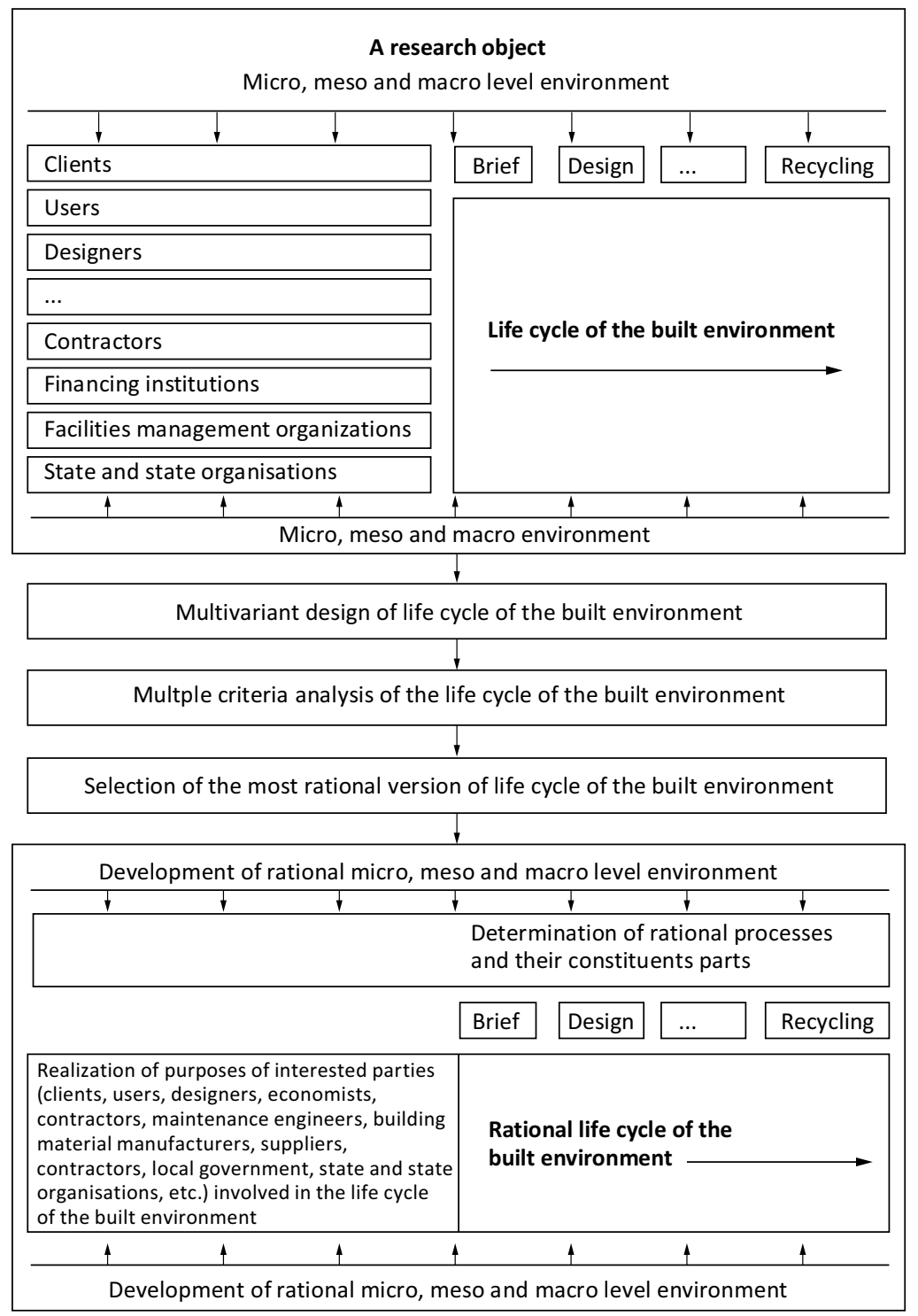

Figure 1.5. Model for a Complex Analysis of the Life Cycle of the Built Environment 


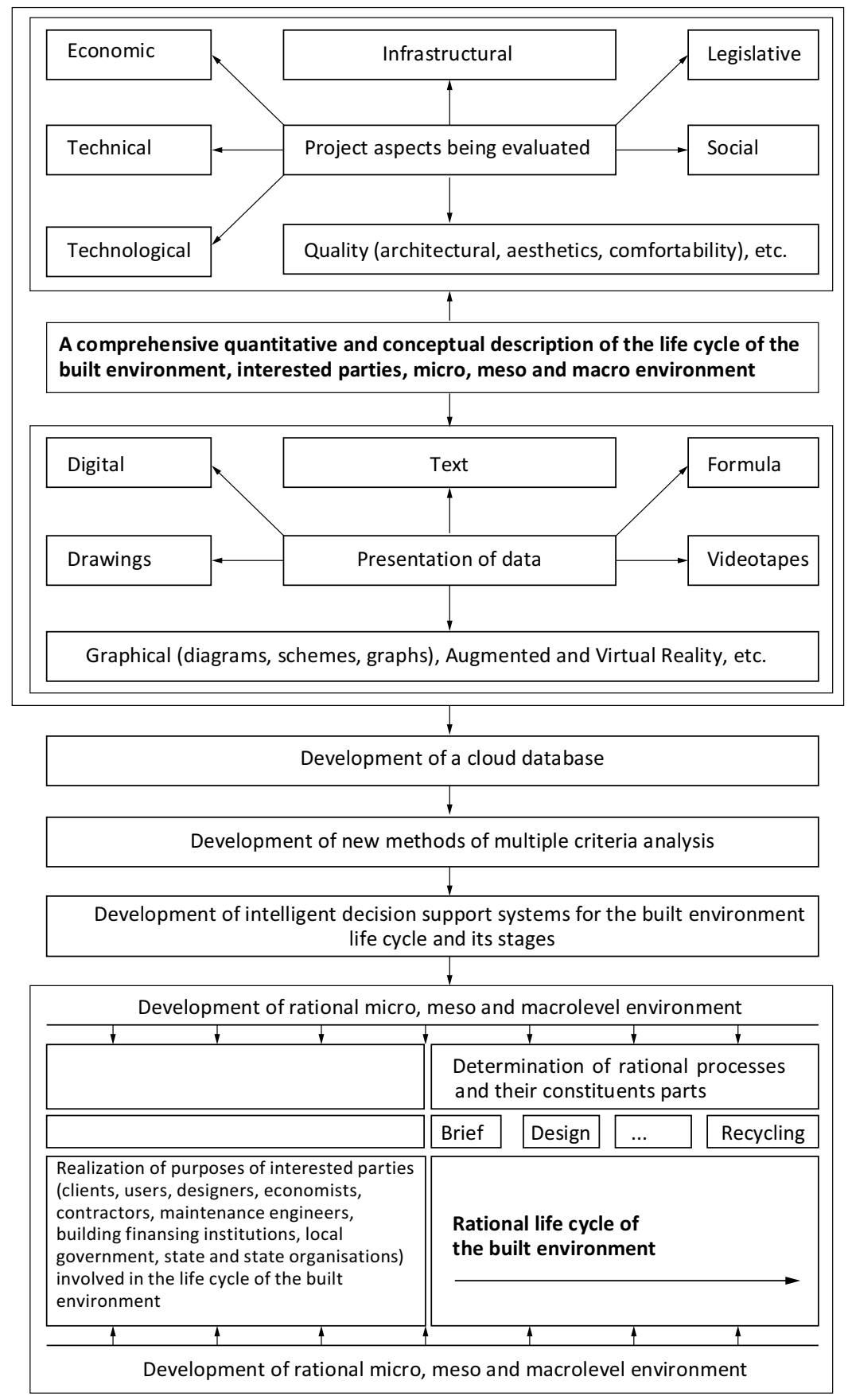

Figure 1.6. Practical realization of Model for a Complex Analysis of the Life Cycle of the Built Environment 
Life cycle of the built environment in turn consists of eight closely interrelated stages, such as brief; design; raw material extraction, transport and processing; construction materials production and distribution; construction; use, repair and maintenance; demolition; disposal, reuse, or recycling.

At the stage of brief the stakeholders state major requirements and limitations regarding the built environment in question.

Built environment is being designed with account of the stakeholders' needs as well as the possibilities of designers, constructors, suppliers, facilities managers, etc. At the design stage life cycle of the built environment multivariant design and multiple criteria analysis should be carried out taking into account the experience gained in realizing similar projects and seeking to harmonize the activities of various stakeholders. At a design stage, the strategy and means of its realization related to maintenance, facilities management, demolition, disposal, reuse, or recycling should be defined. These should ensure that maintenance, facilities management, demolition, disposal, reuse, or recycling problems are continually dealt with, starting from the brief stage. Since the rationality of various aspects of project often depends on a particular interested party only complex design of a life cycle process of built environment involving close collaboration of major stakeholders can lead to good results. Various parties are involved in the brief; design; raw material extraction, transport and processing; construction materials production and distribution; construction; use, repair and maintenance; demolition; disposal, reuse, or recycling of built environment, their cooperation taking rather long period of time.

Life cycle efficiency of built environment depend to a very great extent not only on the selected most rational processes and solutions, the interest level of the concerned parties involved in the project, expressed as the effectiveness of their participation in the process, but also on the micro, meso and macro level factors. As can be seen from Figure 1.5 the object of investigation is rather complicated involving not only life cycle of the built environment and its stages but also including stakeholders and micro, meso and macro environment factors having impact on the former. To select a rational alternative a new Model of a Complex Analysis of the life cycle of the built environment was developed. Based on this Model, professionals involved in design and realization of life cycle of the built environment can develop a lot of the alternative versions as well as assessing them and making the final choice of the most efficient variant. A practical realization of a Model is presented in Figure 1.6.

\subsection{Practical realization of a model for a complex analysis of the life cycle of the built environment}

By modelling and forecasting future perspectives and trends of life cycle of the built environment, it is possible to get ready to respond to the variation of micro, 
meso and macro-level variables. Model for a Complex Analysis of the Life Cycle of the Built Environment suggested by this research is based on presumption that the built environment depends on many micro, meso and macro-level variables. The presence of specific micro, meso and macro-level variable factors right away imposes objective limitations for efficient life cycle of the built environment.

Therefore, basing oneself on main worldwide development trends and best practices, it is possible to issue recommendations on the increase of efficiency of life cycle of the built environment in specific country. When rational variable micro, meso and macro-level factors determine for specific country have been realized, they should create better and more favourable conditions for efficient realization of life cycle of the built environment would be created.

The research aim was to produce a Model for a Complex Analysis of the Life Cycle of the Built Environment in specific country by undertaking a complex analysis of micro, meso and macro-environment factors affecting it and to give recommendations on the increase of its competitive ability.

The research was performed by studying the main worldwide development trends and best practice, taking into consideration specific countries' history, development level, needs and traditions. Simulation was undertaken to provide insight into creating an effective environment for the life cycle of the built environment by choosing rational micro, meso and macrofactors. The most of stakeholders cannot correct or alter the micro, meso and macro-level variables, but they can go into the essence of their effect and take them into consideration when realizing various activities. Stakeholders, knowing the micro, meso and macro-level factors affecting the activities being realized, can organize their present and future activities more successfully.

To design and achieve effective built environment life cycle a complex analysis of its stages as well as stakeholders, their aims and potentialities is needed. The effect of micro, meso and macro environmental factors should also be taken into account.

Dozens of millions of built environment life cycle alternatives can be obtained. The diversity of solutions available contributes to more accurate evaluation of economical, technological, social, cultural, climatic and other conditions, risk exposure, as well as making the project cheaper and better satisfying different stakeholders requirements. This also leads to better satisfaction of the needs of all parties involved in the project design and realization.

Various stakeholders are involved in the life cycle of the built environment, trying to satisfy their needs and affecting its efficiency. The level of the efficiency of life cycle of the built environment depends on a number of variables, at three levels: micro, meso and macro level.

The problem is how to define an efficient built environment life cycle when a lot of various stakeholders are involved, the alternative project versions come 
to hundreds million and the efficiency changes with the alterations in the environment conditions and the constituent parts of the process in question. Moreover, the realization of some objectives seems more rational from the economic perspective thought from the other qualitative perspectives they have various significance. Therefore, it is considered that the efficiency of a sustainable built environment life cycle depends on the rationality of its stages as well as on the ability to satisfy the needs of the stakeholders and the rational character of micro, meso and macro environment conditions.

Formalized presentation of the research shows how changes in the micro, meso and macro environment and the extent to which the goals pursued by various stakeholders are satisfied cause corresponding changes in the value and utility degree of a sustainable built environment life cycle. With this in mind, it is possible to solve the problem of optimization concerning satisfaction of the needs at reasonable expenditures. This requires the analysis of built environment life cycle versions allowing to find an optimal combination of goals pursued and finances available.

The research object is a built environment life cycle, stakeholders striving to attain their goals and micro, meso and macro environment making an integral whole.

Model for a Complex Analysis of the Life Cycle of the Built Environment was developed with the goal of integrating different quantative and qualitative aspects of the process over the life of the built environment. This six-stage model is presented in brief heretofore:

Stage I. Comparative description of the life cycle of the built environment basing oneself on main worldwide development trends and best practices:

- Determining a system of criteria characterizing the efficiency of a life cycle of the built environment by employing relevant literature and expert methods.

- Describing, per this system of criteria, the present state of the life cycle of the built environment in countries under consideration in conceptual (textual, graphical, numerical, virtual and augmented reality and such) and quantitative forms.

Stage II. Comparison and contrast of the life cycle of the built environment in countries under consideration:

- Identifying the global development trends (general regularities) of the life cycle of the built environment.

- Identifying the differences in life cycle of the built environments in countries under consideration.

- Determining the pluses and minuses of these differences.

- Determining the best practice for the life cycle of the built environment in countries under consideration as per actual conditions. 
- Estimating the deviation between the knowledge stakeholders have of worldwide best practices and their practice-in-use.

Stage III. Development of certain general recommendations on how to improve the knowledge levels of stakeholders.

Stage IV. Submission of certain recommendations to stakeholders including several particular alternatives for each general recommendation proposed.

Stage V. A multiple criteria analysis of the composite parts of a life cycle of the built environment and selection of the most efficient versions - henceforth interlinking the received compatible and rational composite parts into a full life cycle of the built environment process.

In order to assure the efficiency of a project, it should be executed within certain bounds which are determined by the built environment. The fact is that these factors are different in each country, so also the possibilities for efficient realisation of projects (see Figure 1.7) will also vary.

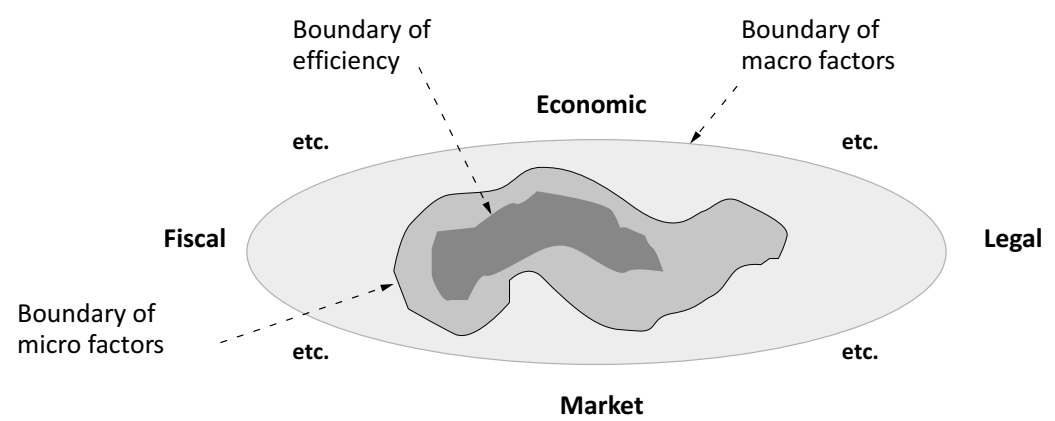

Figure 1.7. Micro, meso and macro factors that influence the efficiency of the life cycle of the built environment

Figure 1.7 indicates diagrammatically the factors at micro, meso and macro level which may impinge upon the efficiency of the built environment. This means that to be efficient the built environment must operate within certain boundaries imposed by the micro, meso and macro factors. Recognising that in each country the factors will be different, this diagram will vary accordingly. It is necessary to utilise knowledge and experience about the micro, meso and macro level factors, so as to increase the efficiency level in each country under consideration. This will be done by analysing the worldwide experience, knowledge and best practices and applying this to specific country.

Using carbon tax as an example of this, it can be appreciated that if the level of carbon tax is high, national firms could either go bankrupt because of increased tax liabilities, or they could decrease efficiency in the face of a lack of competition from international companies who will not attempt to enter the local market. Similarly, if the carbon tax level is lowered, this may cause national 
firms to lose market share to international companies entering the local market, or to force them to increase efficiency in the face of such competition.

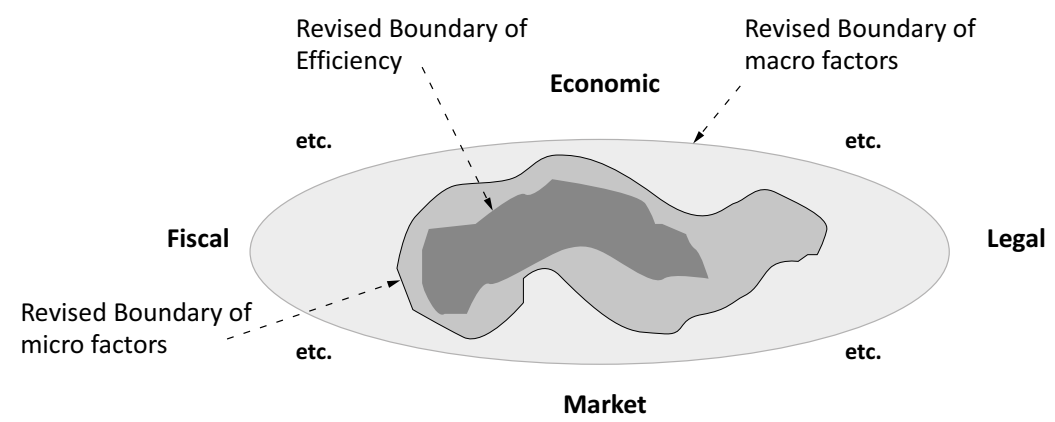

Figure 1.8. Fluctuation of efficient boundary of micro, meso and macro environment

Such changes in taxation will alter the boundary of efficiency of the built environment. Similar built environment changes can shift this boundary (the area within boundary of efficiency expresses the total satisfaction level of needs of all stakeholders). For example, the specific country government (in order to solve the most important problems for specific country society) may abolish VAT on new passive houses in order to promote investment in passive housing. Thus the boundary of efficiency is extended to include this new development from the former situation. After development of the specific country built environment the boundary will alter again (Figure 1.9 illustrates a revised level of efficiency as an example of how to take account of these alterations).

Figure 1.9 graphically illustrates interrelationships between macro-level factors and the built environment. The area inside the ellipse represents the positive action of specific macro-level factors on the efficiency of the built environment. The area outside the ellipse represents the negative effect of the macro-level factors on the efficiency of the built environment. Where the macro-level factors overlap a better environment for the built environment is created. In this case the optimum environment for the built environment is when all four ellipse areas are overlapping (i.e. economic, fiscal, legal and market). The greater the common overlapping area (taking into account the significance of the factors), the greater will be the efficiency level of the built environment. Having investigated the effects of the micro, meso and macro variables affecting built environment by using best practices, differences have been identified between these and specific country. On the basis of these differences, the main implications for specific country can be identified. Studying only some worldwide experience, knowledge and best practices could lead to any inferences being purely subjective. However, by studying a number of countries any bias can be diminished. In other words, the presence of specific micro, meso and macro-level variable 
factors immediately imposes objective limitations on the efficient activities of stakeholders. The stakeholders, in the presence of these objective limitations, try to perform their activities in a more rational way.

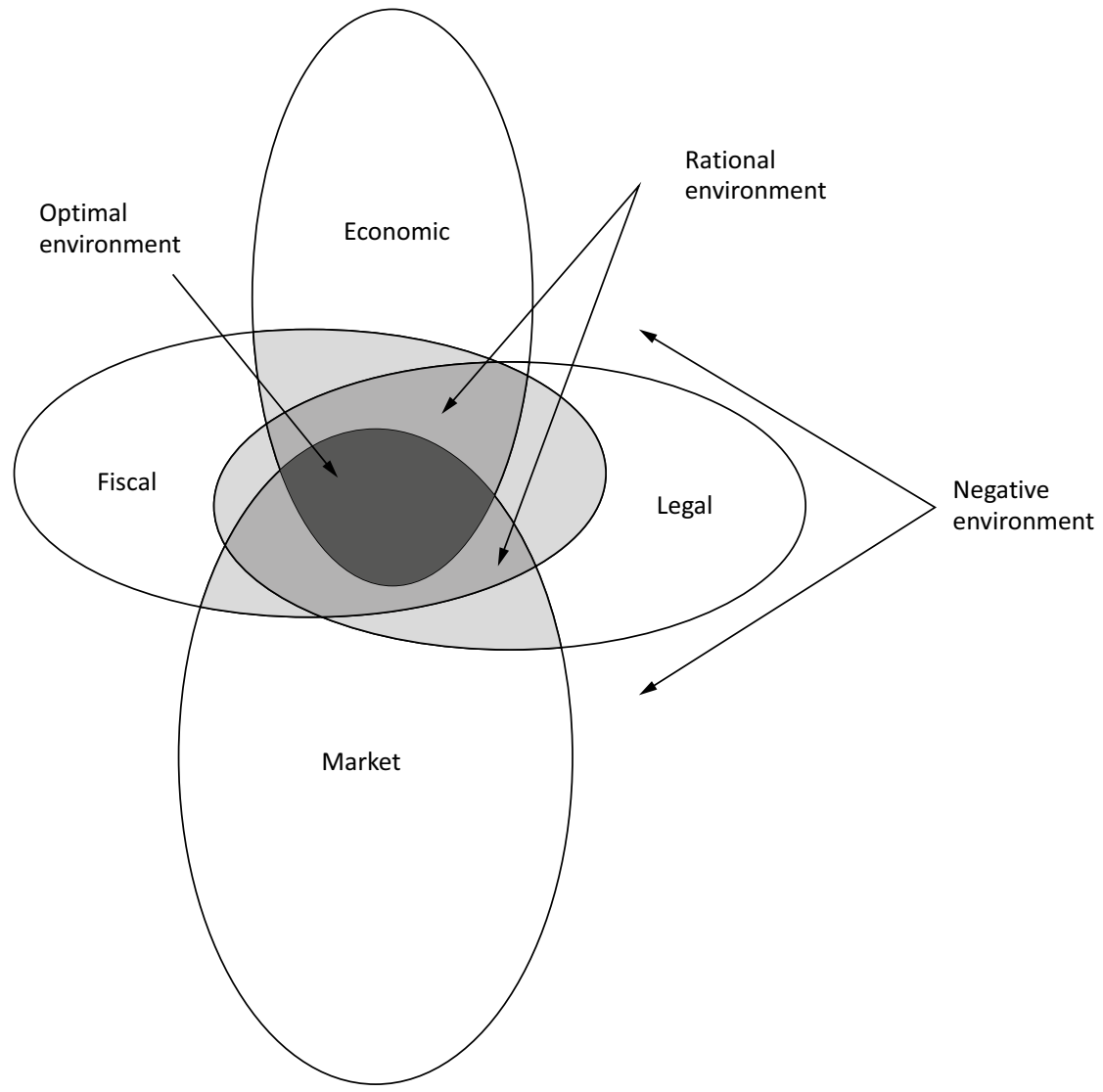

Figure 1.9. Determination of optimal, rational and negative environment for the built environment

Based on the above considerations, it is possible to propose a Model for a Complex Analysis of the Life Cycle of the Built Environment on the basis of the performed search for a rational variable environment for specific country (i.e. seek to explore ways of harmonising the relationship between the specific country built environment and its micro, meso and macro environment). Upon completion of such a model, the stakeholders by taking into consideration existing limitations of micro, meso and macro-level environment and existing possibilities, will be able to use their resources in a more rational manner.

One of the major tasks of an organization is to carry out its activities under the most favourable micro, meso and macro-level conditions. Efforts are made to ensure that the structure, goals, output, efficiency and quality of production 
of the organization would be in maximum conformity with the existing environmental conditions. The pursuit of impracticable goals, for instance, trying to realize projects which surpass the organization's capabilities or the environment (economical, social, legal, political, competitive and technological conditions) is adverse, may cause undesirable consequences.

In order to assure the efficiency of a project, it should be executed within certain bounds which are determined by micro, meso and macro-level factors.

Model for a Complex Analysis of the Life Cycle of the Built Environment was developed with the goal of integrating the environmental, energetic, political, economical, legal/regulatory, infrastructural, technical, technological, pollution, health, quality of life, social, cultural, ethical, psychological, emotional, religious, ethnic and other aspects of the process over the life cycle of the built environment.

It can be noticed that researchers from various countries engaged in the analysis of the life cycle of the built environment but its stages did not consider the research's object as was analyzed by the authors of the present investigation. A life cycle of the built environment may be described as follows: the stakeholders involved in its life cycle as well as the micro, meso and macro environments, having a particular impact on it and making an integral whole.

\subsection{Facilities management}

Facilities management is a stage of the lifecycle of the built environment. It is briefly discussed below.

\subsubsection{Composite parts of facilities management}

Scholars from different countries understand facilities management as an object differently quite frequently. For example, German scientists hold the opinion that the environment, infrastructure, buildings and the equipment, installations and furnishings within comprise the facilities management object. The main objective of facilities management is the supply of a set of services that a client needs encompassing rational planning and implementing operations in the buildings, adapting to ever-changing needs and pursuing formation of good conditions for the development of effective organizational operations. This way the value of the real estate also increases. Such a perspective does not establish any strict boundaries between the objects and their functions of facilities management and of real estate management. There is a belief in the Netherlands that the main purpose of a facilities manager for assuring the effective operations of an organization is to determine the needed set of services and quality and capacity considerations and to provide them by the agreed time for the agreed price. Meanwhile a real estate manager endeavors to gain profits from the building under exploitation. An analogical opinion has taken hold in Great Britain as well. 
Facilities management consists of four composite parts: the supervision of space (of the facilities), administration, technical and other services. A deliberation of these composite parts follows.

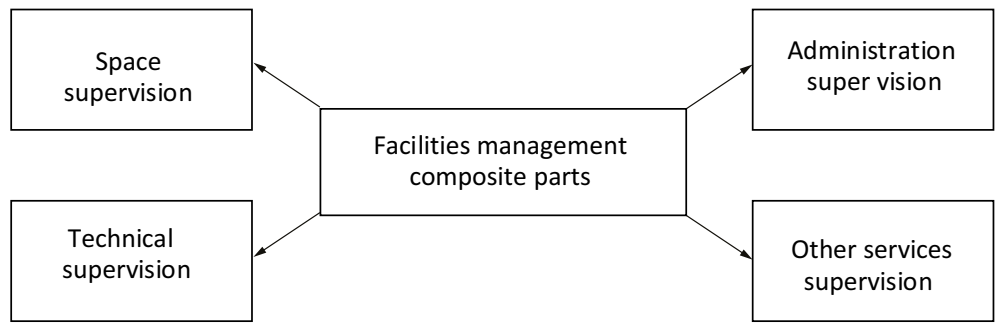

Figure 1.10. Facilities management composite parts

Space supervision is understood as the supply of services attempting to form effective organizational work condition. Space supervision encompasses:

- Space planning and adaptation to ever-changing needs.

- Equipment (cleaning, loading, warehousing), installations (machine tools, software), furnishings, analysis of inventory requirements and supply.

- Services supply provided for the building, facilities, property security, reception area duty, telephone links, mail, central archives, couriers, reproduction services (copying machines, scanners), cleaning (floors, windows, rooftop), snow removal, supervision of the environment, care of building plants, environmental protection, business travel handling, organization and maintenance of parking spaces, public food provisions organization (breakfast, lunch, number of coffee vending machines including the determination and layout of sites), trash removal and other sorts of services.

Administration supervision encompasses:

- Building use control: budget handling and optimization, coordination of provided services, contract obligations monitoring, building transferring and receiving, supervision of the building and parking spaces, documents handling, announcements handling, image improvements.

- Accounting of leases, supplemental income, taxes and the like.

- Transactions supervision: transactions drafting, insurance agreements drafting.

- Personnel acceptance and subcontractor control.

- Supervision of leases and leases with options to purchase (developing a concept and its practical implementation).

Technical supervision (control) encompasses:

- Systems and installations exploitation, inspectorate, maintenance; emergency services involving gas, water supply, sewage, heating, water heating, 
ventilation, electricity, lightening protection, elevators, transporters and warehouses, automated doors and gates; building and facilities security; measurements and control; cable and network communications; laundry and dry cleaning; medical and laboratory equipment and other equipment and systems.

- Building constructions and exploitation of elements, inspectorate and maintenance.

- Energy supervision.

Other services supervision encompasses special services according to client requests: computers and their networks, Internet connection, introduction and supervision of information technologies, building modeling, consultations on energy savings and such.

Space, administration, technical and other services can be supervised in the following stages: consulting, planning, supplying, implementing, supervising and controlling.

The variety of facilities management will be illustrated next applying the example of workplaces supervision in Europe.

\subsubsection{Workplaces supervision in Europe}

The understanding of a workplace has been changing as information technologies and communications develop. Some of the personnel spend time in several places for various reasons. An effective workplace is frequently not at the traditional site of an employer. It can also be found at a client's place, at home, while traveling and other places. For example, a good deal of work can be performed while traveling by train by using a laptop computer containing an Internet link. The work that can be done includes calculations, estimates, report writing, order placement and transmitting information by Internet to a client or to one's colleagues. A workplace has been named in exotic ways: satellite, nonterritorial, virtual, "hotel-type" workplace and the like. Facilities management faces numerous new assignments requiring resolution as understandings about job sits change.

The features of a workplace largely depend on the type of work the organization does. Nonetheless, the comfortableness and effectiveness of workplaces at organizations engaged in similar areas in various European countries differ. These differences depend on more than merely the economic situation of an organization. In the opinion of Van Meel (2000), factors other than simply the operations of an organization influence the differences in the workplace in Europe: market differences, the organizational view regarding real estate, the architectural view regarding design, laws and culture. Broader analyses of these factors follow. 
Economical buildings with strong exploitation features enjoy demand in the real estate market in the United Kingdom. There is less attention paid to consumer needs in such cases. Therefore economically rational buildings with average work conditions are built frequently. An analogical albeit often inferior situation is found in Eastern Europe. Meanwhile buildings are built at a higher standard with well-equipped workplaces in markets, where consumers predominate, such as in the Netherlands and Germany.

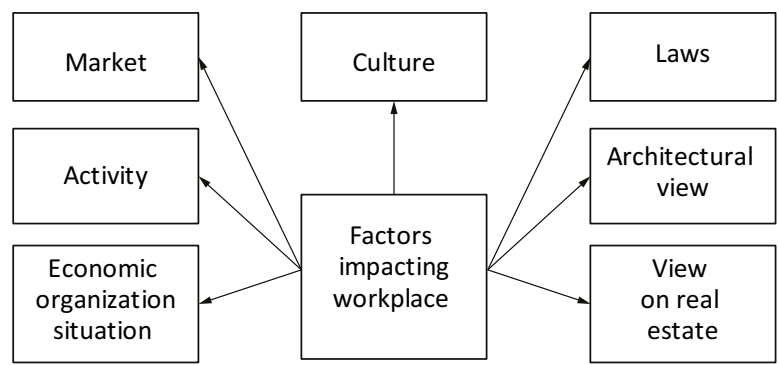

Figure 1.11. Factors impacting a workplace

Organizational viewpoints on real estate as a means to increase the effectiveness of the company's operations differ in different countries. Attention in Eastern and Central Europe is primarily directed towards the fundamental operations of an organization, not towards rationalizing facilities management. Consequently business faces additional problems. Numerous Western European organizations assess real estate not only by price but also from the perspective of increasing the effectiveness of their organizations.

Whether the architectural view of a building is as a piece of art or as a discussion on the utilization of the designated unit depends on the effectiveness of the workplace. A variety of architectural traditions predominates in Europe; thus these and other architectural views differ. In France, for one example, architecture closely relates with art. Meanwhile Scandinavian architects traditionally pay more attention to the practical needs of consumers and try to create an environment that is comfortable and encourages effective work. Often it happens that more of the implemented ideas come from the architects while they are designing a building, not from the organization that is about to inhabit the building.

Although the European Union seeks harmonized workplaces by its laws, such implementation has not been fully successful to its finality. The differing climatic, economic, social security and other conditions preclude that. The valid laws of the Netherlands and Germany, as example, raise high demands on space, convenience and comfortableness. However, in the United Kingdom, it is economically unsound to have such laws, because they would require tremendous 
investments to reorganize workplaces. This is partly due to the relationships between employers and employees. To illustrate, labor unions are very influential in Scandinavian countries, where it took lengthy negotiations to achieve compliance of their workplaces with European standards. However, in the United Kingdom and Southern Europe, labor unions are less influential, because here company managements make the primary decisions. This causes workplaces to be of a rather poor quality. Still, in this case, the positive feature is that workplace innovations can be implemented quickly, without long-lasting negotiations.

Every organization retains certain values, which are upheld in daily activities. Such an influence on the effectiveness of workplaces will be briefly illustrated next by employing examples of employee selection, planning and layout of workplaces.

As mentioned previously, a workplace does not have to be at the job site. All that's needed is a powerful laptop computer and a link into Internet, and one can work while travelling to see clients. There are many more such "virtual" employees in Northern Europe than there are in Southern Europe. The explanation for this is the common culture and the level of trust in one another. These "virtual" employees can only appear where there is a sufficient level of trust. Therefore, to provide an example, there are many less "virtual" employees in France and Italy than there are in Germany and the Netherlands.

The planning of workplaces is also not the same throughout Europe. In the United Kingdom, they are installed in huge, common work areas, whereas, in Northern Europe, they are in separate rooms. The employees of Northern European organizations actively participate in reaching decisions that affect them. Thus the workplaces in these countries are of a higher standard, generally consisting of separate rooms. Separate rooms provide employees with greater personal freedom and control over their environments. Meanwhile the employees in the United Kingdom usually work in cramped facilities without any windows or natural ventilation.

The size and quality of a workplace often depends on the position its employee holds in the organization. A person at a higher position has a more spacious workplace with a better view of the environment and greater privacy. The lower level workers are found either in smaller rooms in one, large common area with poorer conditions of comfort. This is the custom in France, Italy, Germany, Sweden and Denmark, whereas, in the Netherlands, the workplace depends more on the kinds of activities being executed, rather than by the position held.

\subsubsection{Complexity and dynamism}

The assortment of services provided by facilities management expands as time passes. Meanwhile clients raise greater demands for the building and its environment as a singular system, and laws raise greater demands for health and 
environmental protection. Generating more effective conditions for a company's operations and improving the quality of work conditions are important factors, increasing the competitiveness of a company, which is vitally important for battling in an area with ever-growing competition.

The effort to resolve issues stemming from the building industry requires information and experience in management, economics, technology and psychology. Only a "hybrid" manager who is a qualified manager, economist, technologist and psychologist can fully understand the unfolding problems and find effective decisions for resolving them. The ability to interact and gain needed information is one of the most important qualities of a manager. Effective feedback assures an organization of always knowing consumer needs and the levels of their satisfaction, along with new wants that arise consequently. This assists in guaranteeing the supply of the required quality and prices at full capacity on a timely basis at the desired site of delivery.

Many organizations understand that their human resources are among the most important factors for effective organizational activities. The effort to attract highly qualified specialists requires not only paying them suitably high salaries but also providing them with comfortable work condition.

The effectiveness of organizations providing facilities management services can be evaluated from different perspectives. Various stakeholders assess organizational objectives, duties, operations and their final results from their own reference points. Such groups include clients, the personnel, stockholders, creditors, suppliers, the media and other means for mass information, municipalities and the like. The evaluations of such stakeholders do not always coincide. This is entirely understandable, because different stakeholders assess the effectiveness of the organization's operations by factors of greatest concern to themselves, resulting in different criteria systems for the evaluation. Organizational effectiveness can be described as having good relationships internally as well as with other stakeholders. An organization must have the ability to improve quality and increase capacity, expand the assortment of supplied services, augment the relationship between benefit and price, lower risk and adapt to its external, ever-changing environments involving the economy, laws, politics and the society. The most advanced organizations consider facilities management a composite part of the process of seeking increased competitiveness as they restructure their companies.

All the stages of a building's life cycle are interrelated. Therefore facilities management specialists must interact with stakeholders over the entire life cycle of a building.

Facilities management is pushed by all the aforementioned reasons and other trends to become a more complex and dynamic organism. Therefore its complexity and expenses rise. On the other hand, the indicators of such an 
organization's operations, such as the income to expense ratio, for one, tend to improve, along with the effectiveness of the workplaces and the production process and the like.

\subsubsection{Determination of a rational assortment, capacity and quality of provided services}

Obviously every specific organization does not require all the aforementioned services. The requirements for assortment, capacity and quality can be established by questioning clients based on the experience of other organizations providing similar services. The assortment, capacity and quality of services depend on the needs of the organization, its financial capabilities and most importantly - on its prices and abilities to increase the effectiveness of its organizational operations. Such a case can be resolved as a multicriteria assignment: the variations of possible alternative services are compiled, and the most rational is selected according to a certain system of criteria.

It is not always clear who can supply various services more rationally: the organization internally or one or several external organizations working jointly. An assessment of the effectiveness of alternative provided services by organizations is accomplished by a price comparison of their provided services either per square meter or price per year. A rational variation can be selected by calculating these indicators as well as assessing other factors. Several questions should be answered before coming to a final decision regarding the services that the organization should provide internally. Does the organization internally have all the required technology, economic conditions, managerial knowledge, equipment and documents, which will be essential for providing services effectively? Will the internal organization care about the continual training of the personnel and about taking over its best practices? Will it exploit the latest technologies effectively? Generally organizations do not have required expertise internally. One of the advantages of external organizations is their ability to offer an enlargement or a reduction in assortment and capacity in consideration of existing needs.

\subsection{Quality of life in a built environment}

The life cycle of the built environment can be assessed taking into account many quantitative and qualitative criteria (see Figure 1.3). One of them is "Quality of Life in a Built environment" discussed further as a Vision for Lithuania.

Vision entitled "Quality of Life in a Built environment" seeks radical reductions in the negative effects of a built environment's lifecycle on the environment. Furthermore this vision pursues preservation of resources and a guarantee of a good quality of life by broadly applying technical, technological, 
social, cultural, ICT, organizational, managerial, economic, business, work safety and other innovations. It bases significant economic prosperity on a social agreement between all levels of society. This vision is broken up further into five subtopics.

One subtopic of this vision is titled "Indoor Microclimate, Morbidity, Quality of Place for Work and Studies". The goal here is to develop a lifecycle of healthy, comfortable and aesthetic premises for people using innovative solutions.

Another subtopic is "Work Safety and Creation of Attractive Work Conditions". Here the desired goal is to make a construction site a safe, attractive workplace based on modern innovations (technical, technological, ICT, organizational, managerial, economic, business, social, work safety and such).

"Reduction of the Effect on the Environment" is a subtopic of the vision endeavoring to implement a radical reduction in the negative effects of a built environment's lifecycle on the environment by an effective use of resources and wasteless and other innovative technologies and restoration of a desolated environment and ecosystem.

The subtopic "Reduction of Natural and Technogenic Dangers" is the part of the vision pursuing an evaluation at the EU level about the effects of natural and technogenic dangers on a built environment and preparation of normative documents on a built environment's lifecycle to reduce natural and technogenic dangers in various areas (resistance of buildings and the infrastructure to earthquakes, excessive rainfall, storms, floods and erosion of river and coastal systems, whirlwinds, landslides, explosions, fires, climatic and geologic changes and others).

"Transformation of the Construction and Real Estate Branch" is the subtopic aiming for transformations in the construction and real estate branch (including all its stakeholder groups) in order to make it more creative, flexible, innovative, knowledge-based, open to new business opportunities and a source of attractive jobs. The process will help:

- To achieve more transparency and justice in the branch and a more comfortable and safe built environment, better health and increased mobility.

- To achieve increasing value and importance of the branch to the urban and regional economy locally and to remain an important employer to urban and rural people.

A certain strategic research program must be implemented to bring life to this vision. An analysis must be made on how this program can be effectively implemented in practice, i.e. to include these measures in practical business solutions.

Implementation of this vision's goals - guarantee of an indoor microclimate, reduction of morbidity and improvement of the place for work and studies requires the following accomplishments: 
- Making an integrated analysis of life quality by applying various sciences such as environmental protection, economics, management, organizational behavior, architecture, law, engineering, ethics, aesthetics, psychology, sociology, professional medicine and ergonomics.

- Paying special attention to satisfying consumer needs, i.e., implementing consumer oriented knowledge and device-based transformation of a built environment's lifecycle.

- Expressing requirements and needs of stakeholder groups, including persons with various disabilities, and requirements of the indoor environment by quantitative and qualitative indicators.

- Developing relevant knowledge and a device-based intelligent decision support system for accumulating, processing and analyzing the aforementioned types of information.

- Making decisions and offering recommendations on requirements and needs.

- Creating a healthy, comfortable and safe environment by using innovative construction materials and products that do not emit pollutants indoors, sensors, intelligent systems, engineering systems and facility management methods.

- Constructing more social housing units.

- Creating new technologies for minimizing negative effects of construction sites, such as dust and noise, on the health, safety and life quality of neighborhood residents.

- Minimizing use of harmful construction materials and products in construction.

- Adapting a built environment for disabled and elderly people.

- Increasing the safety of a built environment (including home, work, recreational and other facilities as well as the travel between such sites) with non-skid stairs and floors and the like

- Providing rational thermal comfort, lighting, humidity and noise reductions.

- Reducing effects of the sick building syndrome and incidences of respiratory diseases and allergies as well as improving environmental conditions for work and studies.

- Optimizing a healthy and comfortable indoor environment in an integrated manner and a sustainable low energy built environment.

- Reducing social problems in a built environment.

- Applying intelligent e-democracy systems for resolving issues relevant to quality of life.

Implementation of this vision's goals - work safety and creation of attractive work conditions - requires the following accomplishments:

- Installing automated production lines for construction materials and products by moving more and more construction processes to factories, 
thus minimizing construction processes at a construction site.

- Adapting construction materials and products to producing semimanufactures in factories along with a larger variety of modular products for productivity and work safety improvements.

- Intellectualizing machinery and equipment to industrialize and mechanize construction processes.

- Reducing the number of accidents in construction using the newest technologies including 3D and 4D modeling, intelligent devices, equipment and clothing.

- Minimizing the number of accidents and professional diseases.

- Integrating the latest knowledge in all construction processes.

- Using the latest knowledge and device-based intelligent systems in all construction processes.

- Improving the image of the construction branch to attract the maximum number of qualified employees, women among them, thereby minimizing the unqualified work force.

- Increasing the responsibility of each employee and encouraging effective teamwork.

- Creating conditions for employees to advance their qualifications while actively working.

- Improving work relations along a vertical management hierarchy, thereby improving career opportunities.

The following accomplishments are required to implement a reduction of effects on the environment for this vision:

- Rationalizing the planning of various city functions by geographic locations (residential, work, recreation, industrial areas, highways, green zones).

- Urban planning and management from the lifecycle theory perspective of a city, block, district or building to reduce the negative effects of the lifecycle of a city's block, district or building on the environment and restoring the desolated environment of green areas and such.

- Organizing construction for reductions of negative effects on the environment and energy consumption to a minimum during a building's lifecycle (i.e., setting goals and designing; manufacturing construction products including recycling and recycled materials and products; construction; commissioning; facility management and demolition).

- Designing and constructing a building for reducing noise to residents and preventing harm to their health, thereby allowing decent conditions for work and rest.

- Improving protection of people, animals, plants and the ecosystem from the effects of pollution on the surrounding environment (prevention of air, soil and water pollution).

- Regenerating polluted soil. 
- Developing soil and water quality monitoring systems (chemical sensors providing real time information about ground water quality and integrated technologies for protection of soil and water from critical situations or drastic changes, etc.).

- Conducting studies and implementing innovative solutions to reduce energy consumption and its negative effects on the environment (e.g., $\mathrm{CO}_{2}$ emissions) by:

- installation of low energy and renewable energy technologies;

- development of new technologies for production of efficient and clean energy;

- development of technologies for efficient energy management in a built environment;

- development of construction products that drastically reduce the heating needs of new and renovated buildings;

- construction of new buildings able to generate energy without $\mathrm{CO}_{2}$ emissions.

- Conducting studies and implementing innovative solutions to improve the system of public transport by developing:

- personalized public transport accessible to all, including the disabled;

- a logistic system with centers at the edges of urban areas integrated with main highways, thereby avoiding heavy vehicles in a city's centre;

- innovative and more efficient public transport.

- Utilizing waste from various construction organizations.

- Manufacturing construction products and increasing waste recycling to save resources and energy for improving manufacturing processes of construction materials and products.

- Planning in the early designing stages for building construction, demolition/ disassembling, utilization and reuse of construction materials and products that will aid more efficient use of waste produced by building construction, demolition/disassembly and utilization and exploitation of unused resources (while designing a construction site, working at it and such).

- Integrating systems to analyze the effect of a building's lifecycle on the environment (traffic noise, vibrations and air, soil and water pollution, etc.), thereby enabling such systems to model and forecast the negative effects of a built environment on the environment.

- Developing intelligent teamwork systems involving all stakeholder groups. Implementation of a reduction of natural and technogenic dangers to realize the vision requires the following actions:

- Harmonizing EU scientific research on new construction products, sensor technologies, mathematical models, computer modeling methods and natural research with normative documents from various fields relevant to 
reducing natural and technogenic dangers, such as resistance of buildings and the infrastructure to earthquakes, excessive rainfall, storms, floods and erosion of river and coastal systems, whirlwinds, landslides, explosions, fires, climatic and geologic changes and the like.

- Analyzing the effect of climatic changes on a built environment to evaluate any increasing effect of floods, excessive rainfall, storms, coastal erosion, etc.

- Developing advanced integrated methods, models and systems to monitor, evaluate, forecast, determine and notify early, manage, prevent and analyze risk and reduce natural and technogenic dangers by employing methods, models and systems that must include information to the society on preparation for unforeseen cases, analysis of the effects on business processes, distribution of roles and responsibilities during crises, training and competence, quality and performance management.

- Reducing natural and technogenic dangers with stakeholder group participation (end users, policy makers, practitioners) by applying interdisciplinary knowledge.

- Informing the society about existing and forecasted situations by developing a system for lifelong e-education and training of the society.

This vision also requires implementation of the transformation of the construction and real estate branch by accomplishing the following:

- Reforming branch management by applying more efficient and simpler management systems, thereby reducing the time and resources required for management.

- Determining how the state should regulate the construction business (from maximum state involvement to unlimited market forces) and how regulations should change over time.

- Aiming for legal acts and normative documents that regulate the construction business to create good conditions for innovative organizational development in construction by applying innovative activities more broadly.

- Creating a legal environment that facilitates and encourages development of innovative practices and stimulates interest among employees and companies to improve the quality of the work force.

- Reviewing documents on construction related regulations issued by ministries, counties and municipalities for creating a uniform system of national, technical and building safety requirements that is free of duplicated, unimportant or ambiguous documents.

- Improving employer-employee relations in the entire sector.

- Developing a consumer-oriented, innovative lifecycle of a built environment.

- Transforming the construction and real estate branch into a knowledgeable and device-based sector covering the entire value chain, from a client to a rank and file worker. 
- Developing an integrated knowledge system of a built environment's lifecycle.

- Applying knowledge, information, communication, satellite technologies and electronics during the entire lifecycle of a built environment.

- Developing "intelligent products" (identification devices, sensors, diagnostic tools) that are able to disseminate information about a construction process condition involving deviations from the work schedule, supply of construction materials and such, the microclimate, conditions supporting constructions and other aspects.

- Constantly evaluating and monitoring the quality of a built environment in a transparent process reflecting a new image of innovations, creating new business opportunities and offering good work conditions for all.

\subsection{LCA tools and databases. Vision of information and communications technology in the built environment}

\subsubsection{LCA tools}

Due to rising environmental concerns many local and global assessment tools (BREEAM, LEED, PromisE, etc.) have been developed. Because of the varying perspectives of the assessment tools the weighting factors applied to the various issues differ to some extent (Airaksinen et al. 2011).

Any attempt by North or South to clearly define objectives for sustainable development, or to evaluate progress in meaningful terms, must be rooted in formal methods and tools for quantifying and comparing performance of the built environment. Otherwise, the concepts will have little effect in the real world. Among the choice of assessment methods, life-cycle analysis (LCA) is particularly interesting. LCA provides crucial insight into the nature of the problem, yet it is almost impossible to operationalize within the traditional design or policymaking process (Kohler, Moffatt 2003).

Athena Institute's simple tool classification system suggests three main levels of tools, describing the spectrum from individual product assessments through to whole building assessment and rating systems (Trusty, Horst 2005):

- Level 1 tools (SimaPro, GaBi, Umberto, TEAM, BEES, LCAiT, TAKE-LCA) focus on individual products or simple assemblies (e.g., floor coverings or window assemblies) and are used to make comparisons in terms of environmental or economic criteria (or both), especially at the specification stage of project delivery.

- Level 2 tools (Athena Environmental Impact Estimator, BRI LCA, EcoQuantum, Envest, Green Guide to Specifications, LISA, LCA design) focus on the whole building, or on complete building assemblies or elements, with each tool typically providing decision support with regard to specific areas of 
concern, such as operating energy, lighting, life cycle costing, and life cycle environmental effects. These tools tend to be data-oriented and objective, and apply from the early conceptual through detailed design stages.

- Level 3 tools (BREEAM, GBTool, Green Globes) are the more familiar whole building assessment frameworks or systems that encompass a broader range of environmental, economic, and social concerns relevant to sustainability. They use a mix of objective and subjective inputs, leaning on Level 2 tools for much of the objective data-energy simulation results, for example. All use subjective scoring or weighting systems to distill the information and provide overall measures, and all can be used to inform or guide the design process.

Different LCA tools specific to the built environment are available on the Web: ECO-QUANTUM (www.ecoquantum.nl), LEGEP (www.legep.de), EQUER (www.izuba.fr), ATHENA (www.athenaSMI.ca), OGIP (www.ogip.ch), ECO-SOFT (www.ibo.at/de/ecosoft.htm), ENVEST 2.0 (www.envestv2.bre.co.uk), BECOST (www.vtt.fi/rte/esitteet/ymparisto/lcahouse.html), BEES (www.bfrl.nist.gov/ oae/software/bees.html), GREENCALC (www.greencalc.com), ECOEFFECT (www.ecoeffect.se), ECO-QUANTUM (www.ecoquantum.nl), LEGEP (www.legep. de), EQUER (www.izuba.fr). Free-of-charge LCA tools include (Hossain 2013):

- Building for Environmental and Economic Sustainability (BEES), developed by the U.S. Environmental Protection Agency (EPA) and the National Institute of Standards and Technology, is marketed as a tool for selecting cost-effective and environmentally preferable building products.

- ATHENA EcoCalculator provides users with a quick snapshot of a building environmental footprint.

- CMLCA, developed and hosted by the University of Leiden, is a free software tool to calculate LCA, SLCA, EIO-LCA, LCC, hybrid versions and others.

- OpenLCA is a free open source software tool providing the basic LCA framework, currently being pilot tested in the US.

- Economic Input-Output Life-Cycle Assessment (EIO-LCA), developed and hosted by Carnegie Mellon University, calculates the energy, material resources and emissions output from activities in the US economy.

When practising professionals are able to apply LCA easily to the built environment, this will likely be as a result of improvements to LCA tools. One promising solution in industrialized building economies would be to combine tools for LCA with those used for quantity surveying, so as to construct a common basis for LCA, cost estimation and tender operations. Through sharing basic data and tools, the supplementary effort required for LCA analysis and interpretation may become acceptable (Kohler, Moffatt 2003).

Next, we present a few environmental assessment tools implemented in practice; they are applicable to transportation projects, climate change adaptation, 
context-aware virtual prototyping, the Green Building Information Management System, the new LEED rating system and the integrated modelling system for bridge asset management.

In line with current trends of measuring the sustainability in built environments, there has been an increasing interest in the environmental assessments of green transportation projects. As a result, a number of environmental assessment tools are used, or are being developed to evaluate the sustainability level of a transportation project. Thus, the use of quantitative environmental assessment tools for transportation projects is expected to increase, making it relevant to ascertain their status of development process (Curaz et al. 2012). Curaz et al. (2012) apply a unified thematic framework to compare the sustainability rating systems for transportation projects. In an effort to do so, Curaz et al. (2012) describe and compare various different tools used for the quantitative environmental assessment of transportation projects.

There have been a number of developments in adaptation models and strategic planning technologies in the context of climate change adaptation for the built environment. These adaptation models are developed to assist governments and decision makers make appropriate decisions regarding the adaptation of the built environment to anticipated climate conditions in the future. However, there is no tool at present that can assist planning and design professionals estimate the optimal environmental decision from a range of adaptation interventions and design strategies. Developing such a tool will require incorporating a comprehensive life-cycle component into the assessment process (Iyer-Raniga et al. 2012). Iyer-Raniga et al. (2012) present the development of a comprehensive life-cycle focussed design support tool, called BELCADS (Built environment Life Cycle Assessment Decision Support) tool. The aim of this tool is to provide a quick assessment of the carbon emission implications of new or existing buildings incorporating climate change adaptation measures into their design and construction. The tool will aid planners and developers in assessing the possible impacts of building and development options, therefore providing optimal solutions under climate change scenarios (Iyer-Raniga et al. 2012).

Recent advances in the use of virtual building prototypes as a tool to support various site-based production processes coupled with improvements in contextaware mobile computing offer significant potential of improving decision making during construction phase of a building by providing relevant and timely access to design and process information (Aziz 2012). Aziz (2012) investigates the scope and potential for integrating intelligent context-aware interfaces with sophisticated virtual building prototypes, to provide highly relevant and contextspecific building information to concerned stakeholders throughout the building life cycle. Architecture to integrate context awareness with virtual building prototype is presented to allow for integration of context at various levels, and timely retrieval of building model data is presented (Aziz 2012). 
Likhitruangsilp et al. (2012) developed the Green building Information Management System (GBIMS). GBIMS is a web-based client-server system designed to assist all project participants in accessing and retrieving information necessary for the planning and control of green building projects. Its schema includes two main components: project life cycle and information. The life cycle of a green building project was broken down into the three hierarchical levels of stages, processes, and activities using an adaptation of the OmniClass Construction Classification System. Important information concerning green building project management was compiled from the LEED rating system, including credits, project participants and their roles, certification documents, design and construction standards, and green materials (Likhitruangsilp et al. 2012).

The new LEED rating system will encourage product manufacturers to begin with disclosing information about a variety of product attributes, which will influence the industry's material selections and lead to more sustainable products in the marketplace. And, it will give project teams the tools and information to enable them to make product selections that are optimized across a broad range of impacts. Use of life-cycle thinking and the expanded approach proposed in LEED v4 requires reporting or disclosure of information, as well as tools for comparative evaluation of materials and products. Reporting allows for evaluation and comparison, which enables preferential selection, which drives further innovation to create more competitive products with improved profiles (Todd 2013).

Integrated modeling system for bridge asset management to store and analyze bridge data collected during field inspections is presented. The management of an existing bridge asset is a multistep process that involves bridge inspectors, owner/agency for the overall management and maintenance, structural engineers for rating and design of repairs, fabricators and detailers for execution of repairs. The described approach is based on the integration of existing commercial bridge software and Building Information Modeling (BIM) techniques and other applications to the life cycle management of existing bridge assets. A case study is presented with an application to a medium span steel truss bridge. The model used for the truss bridge contains easy-to-reference databases built from record plans and field inspections data and is integrated with rating and analysis software. The use of the model allows the stakeholders to evaluate at various times different aspects that affect the structural safety of the asset (Dibernardo 2012).

\subsubsection{LCA databases}

Life-cycle approaches to assessment of materials have been available since the 1990s. Life-cycle thinking addresses major environmental impacts throughout the complete life cycle of a product, from extraction of raw materials, the processing of those materials, manufacturing of the product, transportation, use and final disposal, reuse or recycling. In Europe and a few other parts of the world, 
manufacturers, regulators, specifiers and consumers in many fields have used lifecycle information to improve their product selections and product environmental profiles. Just like nutrition labels in the grocery store, project teams want to know what's in the building products they are using. By providing this information, innovative manufacturers will gain a competitive advantage in the market, as they will be differentiated from 'business as usual' manufacturers (Todd 2013).

Life cycle assessment (LCA) provides a holistic, science-based analysis method for decision-makers in all sectors concerning policies, product purchases, process performance, and education systems. The use of LCA for product and service analysis is increasing and the demand for life cycle inventory (LCI) data is growing. The U.S. LCI Database was created and has been publicly available at www. nrel.gov/lci since 2003. The advantages of such a data source include (U.S. Life Cycle Inventory Database 2012):

- It provides comprehensive information for policy makers to make consistent comparisons between policy options regarding environmental decisions.

- It enables better evaluation of environmental opportunities and trade-offs of alternative product systems.

- Indirect sources of environmental impacts can be addressed in the redesign of products for better overall environmental performance.

- Legitimate, verifiable environmental market claims can be better substantiated based on quality LCI data.

- Environmental hotspots can be identified and targeted for improvement.

- It provides input to measure and monetize environmental externalities through, for example, a cap-and-trade system.

Also, other different built environment life-cycle inventory analysis databases can be found on the Web (Hossain 2013): EPA TRACI (http://www.epa. gov/nrmrl/std/traci/traci.html), Green Footsteps (http://greenfootstep.org), NREL LCI Database (https://www.lcacommons.gov/nrel/search), Pharos Framework (http://www.pharosproject.net/framework/index), ecoScorecard (http:// ecoscorecard.com), CORRIM (http://www.corrim.org), University of Bath, Inventory of Carbon \& Energy (http://perigordvacance.typepad.com/files/inventoryofcarbonandenergy.pdf).

Next, we present a few projects implemented in practice; they are applicable to life cycle energy consumption and carbon dioxide emission of residential building, green and non-green school buildings.

Rapp B. (2012) research is based on the three types of residential buildings with framework structures in Beijing: concrete framework construction (CFC), light-gauge steel framework construction (SFC), and wood framework construction (WFC). The analysis of the environmental load across the life cycle of the three types of buildings is conducted using life cycle assessment (LCA) according to the protocols of the International Organization for Standardization (ISO) 
14040/44. The functional unit is the three material building designs, which possess the same function and design plan, and are built in concrete, light-gauge steel, and light frame wood, inclusive of their respective envelope materials. Throughout the investigation, the calculations of the environmental load data of materials, energy consumption, and carbon dioxide $\left(\mathrm{CO}_{2}\right)$ emissions are comprehensively assessed and compared. The study shows that over the life cycle, the energy consumption of CFC is almost the same as that of SFC, and each of them is approximately $30 \%$ higher than that of WFC. Building use, steel material production, cement production, gypsum board production, and material transport are the main construction activities related to the energy consumption; the net $\mathrm{CO}_{2}$ emission of $\mathrm{CFC}$ is $44 \%$ higher than that of SFC and $49 \%$ higher than that of WFC. The main source of $\mathrm{CO}_{2}$ emission is the use of electricity; its contributions to the net $\mathrm{CO}_{2}$ emissions of WFC, SFC, and CFC are $67 \%, 64 \%$, and $44 \%$, respectively. The net $\mathrm{CO}_{2}$ emissions in the transport category cannot be ignored, with proportions amounting to $8 \%, 12 \%$, and $11 \%$ for WFC, SFC, and CFC, respectively (Rapp et al. 2012).

The main goal of U.S. Green building Council (USGBC) is to create prosperous and sustainable future through cost-efficient and energy saving green buildings. Several initiatives and steps have been taken by the USGBC and the construction industry to promote sustainable, cost-efficient construction practices. To stop further depletion of fuel energy sources, sustainability has been implemented on a large scale in such institutional buildings as schools, colleges, universities. Green buildings are designed to reduce operating costs by reducing energy consumption, but literature has shown that green buildings can cost more than non-green buildings. In this study, data were collected on construction cost and schedule for 30 Green School Buildings (GSB) and 30 Non-Green School Buildings (NGSBs) of the Clark County School District (CCSD) in Nevada. Statistical tests were performed to determine whether there was a significant difference in construction cost and time of completion between a GSB and an NGSB project. The results showed that the construction cost per square feet of a GSB is significantly higher than that of NGSB. In addition, the construction duration in building a GSB is significantly greater than that of an NGSB. The findings of this study will benefit further research on life-cycle cost analysis of green and non-green buildings (Shrestha, Pushpala 2012).

\subsubsection{Vision of Information and Communications technologies in built environment}

The vision in the built environment of information and communications technologies (underground construction, cities and buildings, materials, networks and infrastructure, cultural heritage, quality of life, Eurocodes and compilation of national annexes) - this involves radically reducing the negative effects of the 
lifecycle period of a built environment, saving resources, assuring the quality of life and widely introducing information, intelligent and telecommunications technologies that maximally satisfy the needs of all interest groups. Further the main benchmarks, such as information and communications technologies, are drawn for an integrated introduction at the built environment level (underground constructions, cities and buildings, materials, networks and infrastructure, cultural heritage, quality of life, Eurocodes and compilation of national annexes) for the purpose of increasing its effectiveness.

Five major directions for implementing the vision of information and communications technologies in built environment are deliberated next, as follows:

- Lithuanian built environment transformation.

- Construction materials, equipment and machinery.

- Construction process.

- Built environment and its management.

- Training, education and experience transference.

The following major objectives are sought for executing the transformation of a Lithuanian built environment:

- Wider use of information technology opportunities at three levels (national, organizational and projects levels).

- Development of the analysis, modeling and forecasting of the construction and real estate branch based on an intelligent decision support system.

- Development and practical application of new business and joint cooperation models in the ICT area among interest groups.

- Transformation of the construction and real estate branch into a sector that is based on know-how and instruments in which the entire chain of values rests on knowledgeability (from a client to a run-of-the-mill employee).

- Development of a base of tacit and explicit information held by Lithuania's construction and real estate experts and an information system.

- Expressed demands by interest groups and the needs and demands of information and communications technologies as quantitative and qualitative indicators along with the development of an intelligent decision support system grounded on the applicable storing, processing and analyzing of such information by the information and instruments for decision-making and for providing recommendations.

- Retention of closer contacts with residents via electronic discussion forums, electronic forms and direct access to files by eventually going over to new, democratic expressions by developing means for interacting with politicians who represent users and by organizing electronic discussion forums in which residents and politicians can discuss specific matters, for example, like forming plans for building up micro-regions and allocating financing for alternative municipal projects. 
- Development of construction and real estate intelligent decision support systems grounded on knowledge and instruments.

- Development of auctions grounded on electronic information.

- Development of a catalogue of Lithuania's construction and real estate directives containing the information of interest to the organizations in the entire construction and real estate branch.

- Integration of an information system for Lithuania's construction and real estate industry such as electronic sales of construction products, exports of construction products and services, public purchases and other activities of interest.

- Development of work systems involving intelligent groups consisting of all interest groups.

- Development of advanced and integrated methods, models and systems for the observation, evaluation, forecasting, early establishment and warning, management, prevention and risk analysis that encompass public information and readiness relevant to unexpected events, analysis of their impact on business processes, allocation of their roles and responsibilities in the event of a crisis, relevant training and competence upgrades and the management of quality and results.

- Utilization of knowledge, information, telecommunications and satellite technologies and electronics over the entire lifecycle process of a built environment.

- Integration of a virtual environment of construction and facilities management (3D and 4D models) with developed information and instruments grounded on systems like a digital home or city model containing a virtual walk through a house or city, modeling levels of street pollution, virtual design of a building, means for analyzing various technological processes by their suitability for a specific project in virtual reality, virtual exploitation of buildings and facilities modeling and analysis as well as on other types of virtual modeling (indoor climate of a building, features of a fire, energy use, sound insulation as well as a management system for work safety).

- Integration of planning a virtual lifecycle for a building (involving integrated virtual systems for determining the purposes of a building, project planning, construction, exploitation and facilities management), preparing applications for competitive bidding and construction management (compiling estimates during the time of virtual planning, calculating expenses for the exploitation of a building, applying for a competitive bid and correlating planned expenses and those actually incurred during construction and others).

The following recommendations reference advanced construction materials, equipment and machinery incorporated during the time of construction:

- Incorporate automated production lines of construction materials and 
goods in an effort to transfer more construction processes into plants, thus minimizing the construction processes at construction sites. Semimanufacturing of construction materials and goods can be produced at plants. The variety of modular types of products can be increased by applying industrialized construction processes. Thereby productivity and safety at work will increase. Application of such innovations permits revitalizing buildings faster. Work safety will increase at the construction site, and the number of accidents will decrease.

- Develop new construction materials using nanotechnologies that reduce defects in constructions to a minimum by adapting to the climate (climate control) and lengthening the duration of use to the time when capital renovation is required.

- Develop a subsystem of intelligent, electronic construction materials and goods for export involving market research, searches for transactions and business partners, financial information, legal and technical information, information about commercial events, special tips and factors operating in the construction and real estate environment.

- Industrialize and mechanize construction processes maximally.

- Develop intelligent, robotized construction equipment, machinery and systems of a new class grounded on interactive information and sensors (cranes, excavators, pipe fitting equipment, automated welding aggregates and the like).

- Develop "intelligent products" such as identification instruments, sensors, and diagnostic tools, which can transmit information about the state of the construction process (including deviations from the work completion schedule or supplies of construction materials and similar situations), the microclimate, condition of retentive constructions and the like.

There can be a goal to support exports of construction products and services from an information and analytical perspective. Then the recommendation is to develop a subsystem of export products and services stemming from the system of information on Lithuania's construction. This would assist in generating conditions needed for construction to compete more effectively in world markets, thereby creating new jobs. A construction products and services export subsystem would assist in accomplishing the following:

- Registering and organizing the documents relevant to exporting construction products and services.

- Performing different calculations.

- Conducting an analysis of various export stages and composite parts (goods and services, sectors, markets, investments, suppliers, disseminators and so forth) and establishing effective alternatives. 
- Searching for alternative credit loans, performing their analysis and establishing the most effective ones.

- Drawing up orders, selecting the means for payments, transferring orders, paying for orders and double-checking payments.

- Finding needed information.

- Finding new and expanding existing markets for Lithuania's goods and services.

- Attracting more investments to Lithuania.

- Reducing business expenses by increasing its effectiveness and quality.

- Entering global markets for goods and services and for credit provisions.

The rational actions to take in the effort to increase the effectiveness of the construction process would be the following:

- Assure applications in common of construction standards, norms and rules by exchanging electronic information and their legal validities.

- Develop an information system on Lithuania's construction.

- Form an intelligent, electronic subsystem on public purchasing.

- Form an intelligent system for modeling Lithuania's construction exports and penetrating foreign markets.

- Form an information system on construction permits intended to supply public services using a computer and other IT networks (application admissions, issuance of construction permits, issuance of permits to continue suspended construction, issuance of approval acts for suitable use of a structure, issuance of incomplete construction certificates and others). Then gather, accumulate, process, systematize, store, use data on the state of construction and state administration of construction in the country from the signing of the code on designing conditions for preparing the structure project up to the point when the structure is approved for use. It is also possible to supply data to governmental institutions and offices as well as to legal entities and physical persons. Formation of the following basic, functional and information subsystems are expected: organization of data on construction permits, compilation and storage of projects for legal acts, organization of documents and their data, accounting, data provisions to users, systems administration, regulation of classifiers and data exchanges.

- Implement the accumulating of electronic data at the construction site along with their analysis, processing, monitoring and control as well as recommendation provisions.

- Establish real-time monitoring systems of the construction process based on sensors that generate the conditions to know, analyze and monitor the actual construction situation and deviations from the work schedule and that provide reports and recommendations in real time in order to complete the construction on time. 
- Generate virtual construction environments. Use the latest technologies (3D and 4D modeling, intelligent instruments, equipment and clothing) to reduce the number of accidents during construction.

- Install the use of satellites and other communications technologies as quickly as possible at the construction site.

- Utilize robotic technologies.

- Integrate the latest information into all construction processes.

- Use intelligent systems based on the latest information and tools in all construction processes.

- Increase the responsibility of every employee and encourage effective team work.

The following primary goals are sought while executing a transformation in a built environment and its management:

- Special attention must be paid to satisfying user needs, i.e., execution of a transformation of a built environment's lifecycle process must be oriented towards users and grounded on information and instruments.

- The production and incorporation of intelligent sensors for all built environment elements generate the conditions needed always to have full historical information covering all needs.

- An intelligent decision support system must be formed that is grounded on information and instruments in an effort to model the effects of pollution on public health and on the built environment.

- A system must be formed to observe the quality of the soil and waterways (chemical sensors providing real time information about the quality of the groundwater, the integrated protection of the ground and water from any critical situation or technologies for drastic changes and so forth).

- An integrated system of analysis must be formed regarding the lifecycle effects of structures on the environment (noise and vibration pollution caused by traffic on the air, soil and water and the like). Such analyses should be able to model and forecast the negative effects of a built environment on the overall environment.

- Systems grounded on information and instruments are constructed in the effort to improve the lifecycle of a built environment. These utilize the experiences of numerous experts and the information gained by a full array of sensors. Consultants on information will assist in implementing a process of a built environment lifecycle more effectively.

- An open digital administration is installed when the residents consuming its services have an opportunity to send official documents electronically. They are able to watch their own movements through the necessary institutions, learn post-haste about problems arising and the chances for resolving them and repeatedly utilize the personal information gained from various 
databases (by using a digital signature) and repeatedly use the most reliable information.

- Participation by members of the society in decision-making processes relevant to land use, territorial planning and project designing and land regeneration and development must be implemented.

- An intelligent subsystem must be formed for issuing electronic land lot zoning permits, changing land designation permits and electronic construction permits.

- A multi-functional, computerized, information search system - a Multiple Listing Service [MLS] - must be installed that encompasses the entire real estate market for sale or for lease within some specific area (a city, region or country).

- Real estate transactions can be formed for full or partial implementation in virtual space using an electronic signature and virtual documentation arranging technologies.

- A "smart" (or intelligent) home idea for people with serious physical disabilities must be implemented at the scope of the entire country of Lithuania. This would provide such people with an opportunity to have greater independence, thereby bettering their quality of life.

- Mounted implants or small micro chips should be used in the constructions and elements of structures, which receive and transmit digital information about the status of some certain element of the building, into the network of the main computer of the home. Such a system of a structure's self-control would permit noticing malfunctions in time for appropriately eliminating them.

- A system of integrated knowledge about the lifecycle process of a built environment must be developed.

Societal agreement is needed for implementing an intelligent built environment transformation. The rational, preparatory work that needs to be done to realize this purpose is to educate the public-at-large and the experts in this field. Then the following tasks must be executed:

- Learning and demonstration centers must be established, where employees of small and average-sized companies can become familiar on a practical level with the capabilities of the latest information and Internet technologies.

- An intelligent system for lifelong learning must be developed providing employees in the construction and real estate sector with opportunities to better their qualifications.

- An intelligent system for lifelong learning must be developed providing employees in the construction and real estate sector with opportunities to better their their qualifications by using diverse tools: electronic books, audio and visual materials, computerized teaching systems, software for a 
specialized field, electronic assignments and jobs, a testing system and the like. Numerous alternative study programs can be compiled for learners by selecting the most rational teaching materials.

\section{Reference}

Afgan, N. H.; Carvalho, M. G. 2002. Multi-criteria assessment of new and renewable energy power plants, Energy 27: 739-755.

Airaksinen, M.; Huovila, P.; Nummelin; J., Tuominen, P. 2011. Sustainability assessment of facilities - A comparative analysis of rating schemes: Case VTT Digitalo. VTT Symposium (Valtion Teknillinen Tutkimuskeskus) (262), pp. 95-105.

Alanne, K.; Salo, A.; Saari, A.; Gustafsson, S. I. 2007. Multicriteria evaluation of residential energy supply systems, Energy and Buildings 39 (12): 1218-1226.

Ali, A. A. M. M.; Negm, A. M.; Bady, M. F.; Ibrahim, M. G. E. 2015. Environmental life cycle assessment of a residential building in Egypt: a case study, Procedia Technology 19: 349-356.

Allwood, J. M.; Cullen, J. M.; Milford, R. L. 2009. Options for achieving a 50\% cut in industrial carbon emissions by 2050, Environmental Science and Technology (under review).

Almeida, R. M. S. F.; Ramos, N. M. M.; Manuel, S. 2015. Towards a methodology to include building energy simulation uncertainty in the Life Cycle Cost analysis of rehabilitation alternatives, Journal of Building Engineering 2: 44-51.

American Lung Association. 2005. State of the Air.

Antipova, E.; Boer, D.; Guillén-Gosálbez, G.; Cabeza, L. F.; Jiménez, L. 2014. Multiobjective optimization coupled with life cycle assessment for retrofitting buildings, Energy and Buildings 82: 92-99.

Arena, A. P.; Rosa, C. D. 2003. Life cycle assessment of energy and environmental implications of the implementation of conservation technologies in school buildings in Mendoza-argentina, Building and Environment 38(2): 359-368.

Asadi, E.; Silva, M. G.; Antunes, C. H.; Dias, L. 2012a. A multi-objective optimization model for building retrofit strategies using TRNSYS simulations, GenOpt and MATLAB, Building and Environment 56: 370-378.

Asadi, E.; Silva, M. G.; Antunes, C. H.; Dias, L. 2012b. Multi-objective optimization for building retrofit strategies: a model and an application, Energy Buildings 44: 81-87.

Asdrubali, F.; Baldassarri, C.; Fthenakis, V. 2013. Life cycle analysis in the construction sector: guiding the optimization of conventional Italian buildings, Energy and Buildings 64: 73-89.

Assefa, G.; Glaumann, M.; Malmqvist, T.; Kindembe, B.; Hult, M.; Myhr, U.; Eriksson, O. 2007. Environmental assessment of building properties - where natural and social sciences meet: the case of ecoeffect, Building and Environment 42: 1458-1464.

ATHENA Sustainable Materials Institute. LCA in Construction Practice. Available from internet: http://www.athenasmi.org/resources/about-lca/lca-in-construction-practice 
Ayoub, N.; Musharavati, F.; Pokharel, S.; Gabbar, H. A. 2015. Risk based life cycle assessment conceptual framework for energy supply systems in large buildings, Journal of Cleaner Production, In Press, Accepted Manuscript, Available online 30 April 2015.

Azari, R. 2014. Integrated energy and environmental life cycle assessment of office building envelopes, Energy and Buildings 82: 156-162.

Aziz, Z. 2012. Supporting site-based processes using context-aware virtual prototyping, Journal of Architectural Engineering 18 (2) , pp. 79-83

Ba-baizadeh, H.; Haghighi, N.; Asadi, S.; Broun, R.; Riley, D. 2015. Life cycle assessment of exterior window shadings in residential buildings in different climate zones, Building and Environment 90: 168-177.

Baek, C.; Park, S.-H.; Suzuki, M.; Lee, S.-Ho. 2013. Life cycle carbon dioxide assessment tool for buildings in the schematic design phase, Energy and Buildings 61: 275-287.

Barnes, C. M. 2015. The ideal work schedule, as determined by circadian rhythms. Harvard Business Review. Available from internet: https://hbr.org/2015/01/theideal-work-schedule-as-determined-by-circadian-rhythms. Accessed 12 February 2015

Barrows, J.; Iannucci L. The Complete Idiot's Guide to Green Building and Remodeling. ALPHA books. 2009.

Bayer, Ch.; Gamble, M.; Gentry, R.; Joshi, S. 2010. AIA guide to building life cycle assessment in practice. Washington, DC: The American Institute of Architects. 190, 194 p.

Beccali, M.; Cellura, M.; Ardente, D. 1998. Decision making in energy planning: the ELECTRE multicriteria decision analysis approach compared to a fuzzy-sets methodology, Energy Conversion Management 39(16-18): 1869-1881.

Beccali, M.; Cellura, M.; Mistretta, M. 2003. Decision-making in energy planning. Application of the Electre method at regional level for the diffusion of renewable energy technology, Renewable Energy 28: 2063-2087.

Bentley, E. 1999. Awareness: biorhythms, sleep, and dreaming. London: Routledge.

Blengini, G. A.; Di Carlo, T. 2010. The changing role of life cycle phases, subsystems and materials in the LCA of low energy buildings, Energy and Buildings 42 (6): 869-880.

Bribian, I. Z.; Uson, A. A.; Scarpellini, S. 2009. Life cycle assessment in buildings: stateof-the-art and simplified LCA methodology as a complement for building certification, Building and Environment 44(12): 2510-2520.

Business cycles. Policonomics. Available from internet: http://www.policonomics.com/ economic-cycles.

Castells, M. 1989. The Informational City: Information Technology, Economic Restructuring and the Urban-Regional Process. Oxford/Malden, MA: Blackwell.

Cavallaro, F. 2005. An integrated multi-criteria system to assess sustainable energy options: an application of the PROMETHEE method. The Fondazione Eni Enrico Mattei Note di Lavoro Series Index. Available from internet: http://www.feem.it/ Feem/Pub/Publications/WPapers/default.htm 
Cavallaro, F.; Ciraolo, L. 2005. A multicriteria approach to evaluate wind energy plants on an Italian island, Energy Policy 33: 235-244.

Chau, C. K.; Leung, T.M.; Ng, W.Y. 2015. A review on life cycle assessment, life cycle energy assessment and life cycle carbon emissions assessment on buildings, Applied Energy 143: 395-413.

Chel, A.; Tiwari, G.N.; Chandra, A. 2009. Simplified method of sizing and life cycle cost assessment of building integrated photovoltaic system, Energy and Buildings 41 (11): 1172-1180.

Chen, S. J.; Hwang, C. L. 1992. Fuzzy multiple attribute decision making: methods and applications. Lecture Notes in Economics and Mathematical Systems No. 375, SringerVerlag, Berlin, Germany.

Cheshire, P.; Hay, D. G. 1989. Urban problems in Western Europe: an economic analysis. London: Unwin Hyman.

Chiang, Y. H.; Li, J.; Zhou, L.; Wong, F. K. W.; Lam, P. T. I. 2014. The nexus among employment opportunities, life-cycle costs, and carbon emissions: a case study of sustainable building maintenance in Hong Kong, Journal of Cleaner Production, In Press, Corrected Proof, Available online 14 August 2014.

Ching, F. 1974. Ancestors: 900 years in the life of a Chinese family. New York: William Morrow and Company, p 78.

Cholakis, P. 2012. Cloud computing and BIM, Military Engineer 104 (675): 59-60.

Cicas, G.; Hendrickson, Ch. T.; Horvath, A.; Matthews, H. S. 2007. A regional version of a us economic input-output life-cycle assessment model, International Journal of Life Cycle Assessment 12 (6): 365-372.

Cobut, A.; Blanchet, P.; Beauregard, R. 2015. The environmental footprint of interior wood doors in non-residential buildings - part 1: life cycle assessment, Journal of Cleaner Production, In Press, Corrected Proof, Available online 30 April 2015.

Cohen, A. J.; Ross, A. H.; Ostro, B.; Pandey, K. D.; Krzyzanowski, M.; Künzli, N.; Gutschmidt, K.; Pope, A.; Romieu, I.; Samet, J. M.; Smith, K. 2005 The global burden of disease due to outdoor air pollution, Journal of Toxicology and Environmental Health 68: $1-7$.

Crawley, D.; Aho, I. 1999. Building environmental assessment methods: Applications and development trends, Building Research and Information 27 (4-5). pp. 300-308.

Cui, B.; Gao, D.; Wang, S.; Xue, X. 2015. Effectiveness and life-cycle cost-benefit analysis of active cold storages for building demand management for smart grid applications, Applied Energy 147: 523-535.

Cullen, J. M.; Allwood, J. M. 2010. The efficient use of energy: tracing the global flow of energy from fuel to service, Energy Policy 38(1): 75-81.

Curaz, R.; Kim, J.-L.; Cha, H.S. 2012. Using a thematic framework to compare sustainability rating systems applicable to transportation projects. Construction Research Congress 2012: Construction Challenges in a Flat World, in Proceedings of the 2012 Construction Research Congress, pp. 1991-2000.

Dammann, S.; Elle, M. 2006. Environmental indicators: establishing a common language for green building, Building Research \& Information 34(4): 387-404. 
Desideri, U.; Arcioni, L.; Leonardi, D.; Cesaretti, L.; Perugini, P.; Agabitini, E.; Evangelisti, N. 2014. Design of a multipurpose "zero energy consumption" building according to European Directive 2010/31/EU: Life cycle assessment, Energy and Buildings 80: 585-597.

Diakaki, C.; Grigoroudis, E.; Kabelis, N.; Kololotsa, D.; Kalaitzakis, K. 2010. A multiobjective decision model for the improvement of energy efficiency in buildings. Energy 35: 5483-5496.

Diakaki, C.; Grigoroudis, E.; Kolokotsa, D. 2008. Towards a multi-objective optimization approach for improving energy efficiency in buildings, Energy and Buildings 40 (9): 1747-1754.

Diakoulaki, D.; Zopounidis, C.; Mavrotas, G.; Doumpos, M. 1999. The use of a preference disaggregation method in energy analysis and policy making, Energy 24: 157-166.

Dibernardo, S. 2012. Integrated modeling systems for bridge asset management - case study, Structures Congress 2012: 483-493.

Dillon, M. 1998. Dynastic cycle. China: a historical and cultural dictionary. Richmond, Surrey: Curzon, p. 87

Dodoo, A.; Gustavsson, L.; Sathre, R. 2010. Life cycle primary energy implication of retrofitting a wood-framed apartment building to passive house standard. Resources, Conservation and Recycling 54(12): 1152-1160.

Dodoo, A.; Gustavsson, L.; Sathre, R. 2011. Building energy-efficiency standards in a life cycle primary energy perspective, Energy and Buildings 43(7): 1589-1597.

Dodoo, A.; Gustavsson, L.; Sathre, R. 2012. Effect of thermal mass on life cycle primary energy balances of a concrete- and a wood-frame building, Applied Energy 92: 462472.

Dong, Y. H.; Ng, S. T. 2015. A life cycle assessment model for evaluating the environmental impacts of building construction in Hong Kong, Building and Environment 89: 183-191.

Doyle, P. 1976. The realities of the product life cycle. Quarterly Review of Marketing. Summer.

Easterlin R. A. 2010. Happiness, growth, and the life cycle. Oxford Univ Press, New York.

Edgar, R. S.; Green, E. W.; Zhao, Y.; van Ooijen, G.; Olmedo, M.; Qin, X.; Xu, Y.; Pan, M.; Valekunja, U. K.; Feeney,K. A.; Maywood, E. S.; Hastings, M. H.; Baliga, N. S.; Merrow, M.; Millar,A. J.; Johnson, C. H.; Kyriacou, Ch. P.; O’Neill, J. S.; Reddy, A. B. 2012. Peroxiredoxins are conserved markers of circadian rhythms, Nature 485 (7399): 459-464.

Elcock, D. 2007. Life-Cycle Thinking for the Oil \& Gas Exploration \& Production Industry. Argonne National Laboratory. p. 160.

Elkaseh, T. A. A.; Rahman, I. A.; Memon, A. H. 2013. Implementation of LCA tools during construction phase in context of libyan building projects, International Journal of Zero Waste Generation 1(2): 13-17.

Esteki, M.; Sadeghi, D. 2010. Comparison of short term memory efficiency (visual and audio) at circadian rhythm (chronopsychology), Procedia - Social and Behavioral Sciences 5: 2002-2005. 
Fairbank, J. K. 1979. The United States and China. Cambridge, Mass: Harvard University Press, pp. 80-104. ISBN 0674924355,

Fereig, S. M.; Younis, M. A. 1985. Effects of energy conversation measures the life cycle cost of Kuwaiti residential buildings, Energy and Buildings 8(1): 71-78.

Florida, R. 2002. The Rise of the Creative Class: And HowIt's Transforming Work, Leisure, Community and Everyday Life. 1st ed. Perseus Books Group.

Flourentzou, F.; Roulet, C.-A. 2002. Elaboration of retrofit scenarios. Energy Buildings 34: 185-192.

Gamboa, G.; Mund, G. 2007. The problem of windfarm location: a social multicriteria evaluation framework, Energy Policy 35: 1564-1583.

Georgi, J. N.; Dimitriou, D. 2010. The contribution of urban green spaces to the improvement of environment in cities: case study of Chania, Greece, Building and Environment 45(6): 1401-1414.

Georgopoulou, E.; Lalas, D.; Papagiannakis, L. 1997. A multicriteria decision aid approach for energy planning problems: the case of renewable energy option, European Journal of Operational Research 103: 38-54.

Gero, J. S.; Neville, D. C.; Radford, A. D. 1983. Energy in context: a multi-criteria model for building design, Building and Environment 18(3): 99-107.

Gloria, T. P.; Lippiatt, B. C.; Cooper, J. 2007. Life cycle impact assessment weights to support environmentally preferable purchasing in the United States, Environmental Science \& Technology 41(21): 7551-7557.

Golder, S. A.; Macy, M. W.2011. Diurnal and seasonal mood vary with work, sleep, and daylength across diverse cultures, Science 333(6051): 1878-1881.

Goodfield, D.; Anda, M., Ho, G. 2011. Carbon neutral mine site accommodation village: developing the model, in MODSIM 2011 - 19th International Congress on Modelling and Simulation - Sustaining Our Future: Understanding and Living with Uncertainty 2011: 3038-3044.

Goumas, M. G.; Lygerou, V. A.; Papayannakis, L. E. 1999. Computational methods for planning and evaluation geothermal energy projects, Energy Policy 27: 147-154.

Guinee, J. B.; Gorree, M.; Heijungs, R.; Huppes, G.; Kleijn, R.; Koning, A. D.; Oers, L. V.; Sleeswijk, A. W.; Suh, S.; Haes, H. A. U.; Brujin, H. D.; Duin, R. V.; Huijbregts, M. A. J. 2001. Life cycle assessment - an operational guide to the ISO standards, Final Report, May 2001.

Gustafsson, S.; Karlsson, B. G. 1989. Insulation and bivalent heating system optimization: Residential housing retrofits and time-of-use tariffs for electricity, Applied Energy 34(4): 303-315

Gustavsson, L.; Joelsson, A.; Sathre, R. 2010. Life cycle primary energy use and carbon emission of an eight-storey wood-framed apartment building, Energy and Buildings 42(2): $230-242$.

Hall, P. 1998. Cities in civilization: culture, innovation, and urban order. London: Weidenfeld \& Nicolson. 
Haralambopoulos, D. A.; Polatidis, H. 2003. Renewable energy projects: structuring a multi-criteria group decision-making framework, Renewable Energy 28: 961-973.

Heinonen, J., Säynäjoki, A-J., Kuronen, M., Junnila, S. 2012. Are the greenhouse gas implications of new residential developments understood wrongly? Energies 5(8): 2874-2893.

Hernandez, P.; Kenny, P. 2010. From net energy to zero energy buildings: defining life cycle zero energy buildings (LC-ZEB), Energy and Buildings 42(6): 815-821.

Hernandez, P.; Kenny, P. 2011. Development of a methodology for life cycle building energy ratings, Energy Policy 39(6): 3779-3788.

Horzum, M. B.; Önder, İ.; Beşoluk, Ş. 2014. Chronotype and academic achievement among online learning students, Learning and Individual Differences 30: 106-111.

Hossain, Y. 2013. Life-cycle assessment for the built environment: methods, limitations and case study. Cold Climate Housing Research Center. $41 \mathrm{p}$.

Hu, Sh.-Ch.; Shiue, A.; Chuang, H.-Ch., Xu, T. Life cycle assessment of high-technology buildings: Energy consumption and associated environmental impacts of wafer fabrication plants, Energy and Buildings 56: 126-133.

Huberman, N.; Pearlmutter, D. 2008. A life-cycle energy analysis of building materials in the Negev desert, Energy and Buildings 40 (5): 837-848.

Hufford, M. R.; Davis, V. G.; Hilt, D.; Dgetluck, N.; Geffen, Y.; Loebel, A.; Haig, G.; Santarelli, L.; Keefe, R. S. E. 2014. Circadian rhythms in cognitive functioning among patients with schizophrenia: impact on signal detection in clinical trials of potential pro-cognitive therapies, Schizophrenia Research 159(1): 205-210.

Islam, H.; Jollands, M.; Setunge, S. 2015a. Life cycle assessment and life cycle cost implication of residential buildings-a review, Renewable and sustainable energy reviews 42: 129-140.

Islam, H.; Jollands, M.; Setunge, S.; Bhuiyan, M. A. 2015b. Optimization approach of balancing life cycle cost and environmental impacts on residential building design, Energy and Buildings 87: 282-292.

ISO 14040 environmental management life cycle assessment principles and framework. International Standards Organization: Brussels, Belgium, 2006.

Iyer-Raniga, U.; Wong, J. P. C. 2012. Evaluation of whole life cycle assessment for heritage buildings in Australia, Building and Environment 47: 138-149.

Jaber, J. O.; Jaber, Q. M.; Sawalha, S. A.; Mohsen, M. S. 2008. Evaluation of conventional and renewable energy sources for space heating in the household sector, Renewable and Sustainable Energy Reviews 12(1): 278-289.

Jacobs, J. 1970. The economy of cities. New York: Vintage Books.

Jacobs, J. 2000. The death and life of great american cities. London: Pimlico.

Jacobson, M. Z.; Delucchi, M. A. 2011. Providing all global energy with wind, water, and solar power, Part I: Technologies, energy resources, quantities and areas of infrastructure, and materials, Energy Policy 39 (3): 1154-1169. 
Jaggs, M.; Palmar, J. 2000. Energy performance indoor environmental quality retrofit a European diagnosis and decision making method for building refurbishment, Energy and Buildings 31: 97-101.

Jahani, H.; El-Gohary, N. 2012. Value-sensitive construction: Value discovery in building projects. Construction Research Congress 2012: Construction Challenges in a Flat World, in Proceedings of the 2012 Construction Research Congress 797-807.

James, L.; Nahl, D. 2003. Customizing your emotional lifestyle. Available from internet: http://www.soc.hawaii.edu/leonj/leonj/leonpsy15/g15reports-instructions.html

Job-Loss Cycle. The Working Centre. Available from internet: http://www. theworkingcentre.org/job-loss-cycle/428

Jones, L. 2008. Environmentally responsible design: green and sustainable design for interior designers. John Wiley and Sons. 432 p.

Jørgensen, A.; Le Bocq, A.; Nazarkina, L.; Hauschild, M. 2008. Methodologies for social life cycle assessment, International Journal of Life Cycle Assessment 13(2): 96-103.

Juan, Y.-K.; Kim, J. H.; Roper, K.; Lacouture, D. C. 2009. GA-based intelligent decision support system for housing condition assessment and refurbishment strategies, Automation in Construction 18: 394-401.

Kablan, M. M. 2004. Decision support for energy conservation promotion: an analytic hierarchy process approach, Energy Policy 32: 1151-1158.

Kaklauskas A. 2015. Biometric and Intelligent Decision Making Support. Series: Intelligent Systems Reference Library 81(XII). Springer-Verlag, Berlin, 228 p.

Kaklauskas, A. EC Phare-ACE Programme 1996. Contract Number: P96-6708-F. Total Life Analysis, Modelling and Forecasting of Construction in Lithuania. Team leader.

Kaklauskas, A. 1999. Multiple criteria decision support of building life cycle: research report presented for habilitation: technological sciences, Civil Engineering (02T), 119 p.

Kaklauskas, A. 1999. Multiple Criteria Decision Support of Building Life Cycle. Research Report presented for Habilitation. Vilnius: VGTU Press Technika, 60 p.

Kaklauskas, A.; Rutè, J.; Zavadskas, E. K.; Daniūnas, A.; Pruskus, V.; Bivainis, J.; Gudauskas, R.; Plakys, V. 2012. Passive house model for quantitative and qualitative analyses and its intelligent system, Energy and Buildings 50: 7-18.

Kaklauskas, A.; Zavadskas, E. K.; Lapinskiene, V.; Sliogeriene, J.; Gudauskas, R.; Raistenskis, J.; Cerkauskiene, R.; Jackute, I.; Kumzaite, S. 2013. Multiple-Criteria Analysis of Life Cycle of Energy-Efficient Built Environment, in Nearly Zero Energy Building Refurbishment: A Multidisciplinary Approach (Editors: F. P. Torgal, M. Mistretta, A. Kaklauskas, C. G. Granqvist, L. F. Cabeza). London: Springer-Verlag, 299-325 pp.

Kaklauskas, A.; Zavadskas, E. K. 2007. Intelligent decision support system for innovation with a special emphasis on pollution, International Journal of Environment and Pollution 30(3-4): 518-528.

Kaklauskas, A.; Zavadskas, E. K.; Raslanas, S. 2005. Multivariant design and multiple criteria analysis of building refurbishments, Energy and Buildings 37 (4): 361-372.

Kaklauskas, A.; Zavadskas, E. K.; Raslanas, S.; Ginevicius, R.; Komka, A.; Malinauskas, P. 2006. Selection of low-e windows in retrofit of public buildings by applying multiple criteria method COPRAS: a Lithuanian case, Energy and Buildings 38 (5): 454-462. 
Keirstead, J.; Jennings, M.; Sivakumar, A. 2012. A review of urban energy system models: approaches, challenges and opportunities, Renewable and Sustainable Energy Reviews 16(6): 3847-3866.

Khasreen, M. M.; Banfill, P. F. G.; Menzies, G. F. 2009. Life-Cycle Assessment and the environmental impact of buildings: a review, Sustainability 1: 674-701.

Kim, C.-J.; Kim, J.; Hong, T.; Koo, C.; Jeong, K.; Park, H. S. 2015. A program-level management system for the life cycle environmental and economic assessment of complex building projects, Environmental Impact Assessment Review 54: 9-21.

Kneifel, J. 2010. Life-cycle carbon and cost analysis of energy efficiency measures in new commercial buildings, Energy and Buildings 42(3): 333-340.

Kofoworola, O. F.; Gheewala, S. H. 2009. Life cycle energy assessment of a typical office building in Thailand, Energy and Buildings 41(10): 1076-1083.

Kohler, N.; Moffatt, S. 2003. Life-cycle analysis of the built environment, Sustainable building and construction 26(2-3):17-21.

Kotaji, S. 2003. Life-cycle assessment in building and construction: a state-of-the-art report. Pensacola, FL: Society of Environmental Toxicology and Chemistry 2003(19). Print.

Kovacic, I.; Zoller, V. 2015. Building life cycle optimization tools for early design phases, Energy (In Press), Corrected Proof, Available online 4 April 2015.

Kua, H. W.; Wong, Ch. L. 2012. Analysing the life cycle greenhouse gas emission and energy consumption of a multi-storied commercial building in Singapore from an extended system boundary perspective, Energy and Buildings 51: 6-14.

Likhitruangsilp, V.; Putthividhya, W.; Ioannou, P. G. 2012. Conceptual framework of the Green building Information Management System. Construction Research Congress 2012: Construction Challenges in a Flat World, in Proceedings of the 2012 Construction Research Congress 658-667.

Lamnatou, Chr.; Chemisana, D.; Mateus, R.; Almeida, M. G.; Silva, S. M. 2015. Review and perspectives on life cycle analysis of solar technologies with emphasis on buildingintegrated solar thermal systems, Renewable Energy 75: 833-846.

Lamnatou, Chr.; Notton, G.; Chemisana, D.; Cristofari, C. 2014. Life cycle analysis of a building-integrated solar thermal collector, based on embodied energy and embodied carbon methodologies, Energy and Buildings 84: 378-387.

Lamnatou, Chr.; Notton, G.; Chemisana, D.; Cristofari, C. 2015. The environmental performance of a building-integrated solar thermal collector, based on multiple approaches and life-cycle impact assessment methodologies, Building and Environment 87: 45-58.

Li, D. Z.; Chen, H. X.; Hui, E. C. M.; Zhang, J. B.; Li, Q. M. 2013. A methodology for estimating the life-cycle carbon efficiency of a residential building, Building and Environment 59: 448-455.

Li, Z. 2006. A new life cycle impact assessment approach for buildings, Building and Environment 41(10): 1414-1422.

Løken, E. 2007. Use of multicriteria decision analysis methods for energy planning problems, Renewable and Sustainable Energy Reviews 11(7): 1584-1595. 
Love, P. E. D.; Liu, J.; Matthews, J.; Sing, C.-P.; Smith, J. 2015. Future proofing PPPs: life-cycle performance measurement and building information modelling, Automation in Construction 56: 26-35.

Malczewski, J. 1999. GIS and multicriteria decision analysis. Wiley, New York. 1999.

Managing the transition. Available from internet: http://knowhownonprofit.org/ leadership/change/tools/transition

Marszal, A. J.; Heiselberg, P. 2011. Life cycle cost analysis of a multi-storey residential Net Zero energy building in Denmark, Energy 36 (9): 5600-5609.

Marszal, A. J.; Heiselberg, P.; Jensen, R. L.; Nørgaard, J. 2012. On-site or off-site renewable energy supply options? Life cycle cost analysis of a Net Zero Energy Building in Denmark, Renewable Energy 44: 154-165.

Masure, Ph. 2003. Variables and indicators of vulnerability and disaster risk for land-use and urban or territorial planning. Information and indicators program for disaster risk management. Inter-American Development Bank. Manizales - Colombia.

McAvoy, M.; Cohen, N. 2002. Time to give space to regeneration. Financial Times, September 13.

Mendoza, J. M. F.; Oliver-Solà, J.; Gabarrell, X.; Rieradevall, J.; Josa, A. 2012. Planning strategies for promoting environmentally suitable pedestrian pavements in cities, Transport and Environment 17(6): 442-450.

Milankovitch, Mi. 1998 [1941]. Canon of insolation and the ice age problem. Belgrade: Zavod za Udžbenike i Nastavna Sredstva. ISBN 86-17-06619-9.

Miller, D.; Doh, J.-H.; Panuwatwanich, K.; van Oers, N. 2015. The contribution of structural design to green building rating systems: an industry perspective and comparison of life cycle energy considerations, Sustainable Cities and Society 16: 39-48.

Mirasgedis, S.; Diakoulaki, D. 1997. Multicriteria analysis vs. externalities assessment for the comparative evaluation of electricity generation systems, European Journal of Operational Research 102: 364-379.

Mitropoulou, Ch. Ch.; Lagaros, N. D.; Papadrakakis, M. 2011. Life-cycle cost assessment of optimally designed reinforced concrete buildings under seismic actions. Reliability Engineering \& System Safety 96(10): 1311-1331.

Mora, M.; Bitsuamlak, G.; Horvat, M. 2011. Integrated life-cycle design of building enclosures, Building and Environment 46(7): 1469-1479.

Mosteiro-Romero, M.; Krogmann, U.; Wallbaum, H.; Ostermeyer, Y.; Senick, J. S.; Andrews, C. J. 2014. Relative importance of electricity sources and construction practices in residential buildings: A Swiss-US comparison of energy related life-cycle impacts, Energy and Buildings 68(Part A): 620-631.

Multi-criteria analysis: a manual. 2009. Department for Communities and Local Government: London. 2009. Available from: https://www.gov.uk/government/ uploads/system/uploads/attachment_data/file/7612/1132618.pdf

Nadoushani, Z. S. M.; Akbarnezhad, A. 2015. Effects of structural system on the life cycle carbon footprint of buildings, Energy and Buildings 102: 337-346. 
Nagesha, N.; Balachandra, P. 2006. Barriers to energy efficiency in small industry clusters: multi-criteria-based prioritization using the analytic hierarchy process, Energy 31(12): 1969-1983.

Nakicenovic, N.; Grubler, A.; Inaba, A.; Messner, S.; Nilsson, S.; Nishimura, Y.; Rogner, H.- H.; Schafer, A.; Schrattenholzer, L.; Strubegger, M.; Swisher, J.; Victor, D.; Wilson, D. 1993. Long-term strategies for mitigating global warming, Energy 18(5): 401-609.

Nefedov, S. A. 2003. A theory of demographic cycles and the social evolution of ancient and medieval oriental societies, Oriens 3: 5-22.

Nefedov, S. A. 2004. A model of demographic cycles in traditional societies: the case of Ancient China, Social Evolution \& History 3(1): 69-80.

Nicolae, B.; George-Vlad, B. 2015. Life cycle analysis in refurbishment of the buildings as intervention practices in energy saving, Energy and Buildings 86: 74-85.

Niemi, R.; Mikkola, J.; Lund, P. D. 2012. Urban energy systems with smart multi-carrier energy networks and renewable energy generation, Renewable Energy 48: 524-536.

Nigim, K.; Munier, N.; Green, J. 2004. Pre-feasibility MCDM tools to aid communities in prioritizing local viable renewable energy sources, Renewable Energy 29: 1775-1791.

Ndungu, P.; Tsao, C.; Molavi, J. M. 2012. Sustainable construction: Comparison of environmental effects of two construction methods. ICSDC 2011: Integrating Sustainability Practices in the Construction Industry - Proceedings of the International Conference on Sustainable Design and Construction 2011, pp. 398-405.

Ooteghem, K., V.; Xu, L. 2012. The life-cycle assessment of a single-storey retail building in Canada, Building and Environment 49: 212-226.

Pajchrowski, G.; Noskowiak, A.; Lewandowska, A.; Strykowski, W. 2014a. Wood as a building material in the light of environmental assessment of full life cycle of four buildings, Construction and Building Materials 52: 428-436.

Pajchrowski, G.; Noskowiak, A.; Lewandowska, A.; Strykowski, W. 2014b. Materials composition or energy characteristic - What is more important in environmental life cycle of buildings? Building and Environment 72: 15-27

Pargana, N. Pinheiro, M. D.; Silvestre, J. D.; de Brito, J. 2014. Comparative environmental life cycle assessment of thermal insulation materials of buildings, Energy and Buildings 82: 466-481.

Petrakos, G.; Economou, D. 2000. Internationalism and structural changes in European system of urban centers, in H. Adricopoulou, G. Kafkalas (Eds.). The New European Space. Atsens.

Peuportier, B.; Thiers, S.; Guiavarch, A. 2013. Eco-design of buildings using thermal simulation and life cycle assessment, Journal of Cleaner Production 39: 73-78.

Pheng, L. S. 1996. Total quality facilities management: a framework for implementation. Facilities 14(5/6): 5-13.

Porkka, J.; Huovila, P.; Bertelsen, N. H.; Hansson, B.; Haugbølle, K.; Hietanen, P.; Karud, O. J.; Widén, K. 2010. Nordic and Baltic case studies and assessments in enterprises. 
CREDIT Report 2 (SBi 2010:15). Hørsholm: Danish Building Research Institute, Aalborg University.

Preiser, W. F. E. 1983. The habitability framework: a conceptual approach towards linking human behaviour and physical environment, Design Studies 4(2): 84-91.

Rain-ville, A.; Hawkins, R.; Bergerson, J. 2015. Building consensus in life cycle assessment: the potential for a Canadian product category rules standard to enhance credibility in greenhouse gas emissions estimates for Alberta's oil sands, Journal of Cleaner Production 103: 525-533.

Raipa, A. 2007. Naujoji viešoji vadyba. Kaunas: Technologija.

Ramesh, T.; Prakash, R.; Shukla, K. K. 2010. Life cycle energy analysis of buildings: An overview, Energy and Buildings 42(10): 1592-1600.

Ramesh, T.; Prakash, R.; Shukla, K. K. 2012a. Life cycle approach in evaluating energy performance of residential buildings in Indian context, Energy and Buildings 54: 259265.

Ramesh, T.; Prakash, R.; Shukla, K. K. 2012b. Life cycle energy analysis of a residential building with different envelopes and climates in Indian context, Applied Energy 89(1): 193-202.

Rapp, B.; Vornberger, J.; Renatus, F.; Gösling, H. 2012. Life cycle energy consumption and carbon dioxide emission of residential building designs in Beijing: A comparative study, Journal of Industrial Ecology 16(4): 576-587.

Rashid, A. F. A.; Yusoff, S. 2015. A review of life cycle assessment method for building industry, Renewable and Sustainable Energy Reviews 45: 244-248.

Rauf, A.; Crawford, R. H. 2015. Building service life and its effect on the life cycle embodied energy of buildings, Energy 79: 140-148.

Reischauer, E. O. 1965. The Dynastic Cycle, in The Pattern of Chinese History (John Meskill), Heath and Company 31-33. Boston: D.C.

Renn, O. 2003. Social assessment of waste energy utilization scenarios, Energy 28: 13451357.

Rey, E. 2004. Office building retrofitting strategies: multicriteria approach of an architectural and technical issue, Energy and Buildings 36: 367-372.

Rossi, B. Marique, A.-F.; Reiter, S. 2012. Life-cycle assessment of residential buildings in three different European locations, case study, Building and Environment 51: 402-407.

Rossi, B.; Marique, A.-F.; Glaumann, M.; Reiter, S. 2012. Life-cycle assessment of residential buildings in three different European locations, basic tool, Building and Environment 51: 395-401.

Russell-Smith, S. V.; Lepech, M. D. 2015a. Cradle-to-gate sustainable target value design: integrating life cycle assessment and construction management for buildings, Journal of Cleaner Production 100: 107-115.

Russell-Smith, S. V.; Lepech, M. D.; Fruchter, R.; Meyer, Y. B. 2015b. Sustainable target value design: integrating life cycle assessment and target value design to improve building energy and environmental performance, Journal of Cleaner Production 88: 43-51. 
Saaty, T. L. 2001. Fundamentals of decision making and priority theory with the Analytic Hierarchy Process. Pittsburgh: RWS Publications.

Safaei, A.; Freire, F.; Antunes, C. H. 2015. A life cycle multi-objective economic and environmental assessment of distributed generation in buildings, Energy Conversion and Management 97: 420-427.

SAIC. Life Cycle Assessment: Principles \& Practice. 2006, EPA. p. 88.

Salo, A. A.; Hämäläinen, R. P. 1992. Preference assessment by imprecise ratio statements, Operations Research 40(6): 1053-1061.

Sartori, I.; Hestnes, A. G. 2007. Energy use in the life cycle of conventional and lowenergy buildings: a review article, Energy and Buildings 39(3): 249-257.

Saville, S. 2003. War cycles and peace cycles. Available from internet: http://www. safehaven.com/article/690/war-cycles-and-peace-cycles

Shneerson, J. M.; Ohayon, M. M.; Carskadon, M. A. 2007. Circadian rhythms. Rapid eye movement (REM) sleep. Armenian Medical Network. Retrieved 2007-09-19.

Shrestha, P. P.; Pushpala, N. 2012. Green and Non-Green school buildings: an empirical comparison of construction cost and schedule. Construction Research Congress 2012: Construction Challenges in A Flat World, Proceedings of the 2012 Construction Research Congress 2012: 1820-1829.

Shurtz, N. E. 2012. Journal of Environmental Law \& Litigation 27(1): 237. Springer.

Sinkienė, J. 2008. Miesto konkurencingumo veiksniai, Viešoji politika ir administravimas 25: $67-82$.

Spracklen, D. V; Bonn, B.; Carslaw, K. S. 2008. Boreal forests, aerosols and the impacts on clouds and climate, Philosophical Transactions of the Royal Society A: Mathematical, Physical and Engineering Sciences 366(1885): 4613-26.

Srdić, A.; Šelih, J. 2011. Integrated quality and sustainability assessment in construction: A conceptual model, Technological and Economic Development of Economy 17(4): 611626.

Srinivasan, R. S.; Ingwersen, W.; Trucco, C.; Ries, R.; Campbell, D. 2014. Comparison of energy-based indicators used in life cycle assessment tools for buildings, Building and Environment 79: 138-151.

Stephan, A.; Crawford, R. H.; de Myttenaere, K. 2012. Towards a comprehensive life cycle energy analysis framework for residential buildings, Energy and Buildings 55: 592-600.

SteelConstruction.info. The free encyclopedia for UK steel construction information. http://www.steelconstruction.info/Life_cycle_assessment_and_embodied_carbon

Storper, M. 1997. The regional world; territorial development in a global economy. New York/London: The Guilford Press.

Storper, M.; Scott, A. J. 2003. Regions, globalization, development, Regional Studies 37(6-7): 579-593.

Taborianski, V. M.; Prado, R. T. A. 2012. Methodology of $\mathrm{CO}_{2}$ emission evaluation in the life cycle of office building façades, Environmental Impact Assessment Review 33(1): 41-47. 
Takano, A.; Pal, S. K.; Kuittinen, M.; Alanne, K.; Hughes, M.; Winter, S. 2015. The effect of material selection on life cycle energy balance: A case study on a hypothetical building model in Finland, Building and Environment 89: 192-202.

Takano, A.; Winter, S.; Hughes, M.; Linkosalmi, L. 2014. Comparison of life cycle assessment databases: a case study on building assessment, Building and Environment 79: 20-30.

Tan, H. 2015. Cyclical Industrial Dynamics. International Encyclopedia of the Social \& Behavioral Sciences (2nd ed.), pp. 651-654.

Tarrow, S. 1998. Power in movement: collective action, social movements and politics. Cambridge University Press.

Teravainen, T., Lehtonen, M., Martiskainen, M. 2011. Climate change, energy security, and risk: debating nuclear new build in Finland, France and the UK, Energy Policy 39: 3434-3442.

The World Bank. 2013. World Development Indicators, World Bank national accounts data, and OECD National Accounts data files. [cited 13 June 2013]. Available from: http://data.worldbank.org/indicator?display = default

Thiel, T.; Mroz, T. 2001. Application of multi-criterion decision aid method in designing heating systems for museum buildings, Informatica 12(1): 133-146.

Tian-yan, W.; Min, Ch. 2012. Research on Low-carbon building development based on whole life cycle analysis, Procedia Environmental Sciences 12: 305-309.

Todd, J. A. 2013. Life Cycle \& LEED. January issue of EDC (official magazine for the LEED Professional). Available from internet: http://www.usgbc.org/articles/life-cycleleed-out-now-edcs-january-issue

Triantaphyllou, E.; Shu, B.; Sanchez, S. N.; Ray, T. 1998. Multi-criteria decision making: an operations research approach, Encyclopedia of Electrical and Electronics Engineering 15: $175-186$.

Trusty, W.; Horst, S. 2005. LCA tools around the world. life cycle assessment and sustainability. Third in a Series of Annual Reports on the Green Building Movement. A supplement to building design \& construction.

Tsai, W.-H.; Yang, C.-H.; Chang, J.-C.; Lee. H.-L. 2014. An activity-based costing decision model for life cycle assessment in green building projects, European Journal of Operational Research 238(2): 607-619.

Turchin, P. 2003. Historical dynamics: why states rise and fall. Princeton, NJ: Princeton University Press.

U.S. life cycle inventory database. 2012. National Renewable Energy Laboratory. Accessed November 19, 2012. Available from internet: https://www.lcacommons. gov/nrel/search

UNEP. 2009. Common carbon metric: for measuring energy use \& reporting greenhouse gas emissions from building operations, a United Nations Environment Program Sustainable Building Climate Initiative. Available from Internet: http://www.unep. org/sbci/pdfs/UNEPSBCICarbonMetric.pdf

Utama, A.; Gheewala, Sh. H. 2009. Indonesian residential high rise buildings: a life cycle energy assessment, Energy and Buildings 41(11): 1263-1268. 
Van Meel, J. 2000. The European office: Office design and national context. Publishers, 128 p.

Verbeeck, G.; Hens, H. 2010a. Life cycle inventory of buildings: a contribution analysis, Building and Environment 45(4): 964-967.

Verbeeck, G.; Hens, H. 2010b. Life cycle inventory of buildings: a calculation method, Building and Environment 45(4): 1037-1041.

Wallhagen, M.; Glaumann, M.; Malmqvist, T. 2011. Basic building life cycle calculations to decrease contribution to climate change - case study on an office building in Sweden, Building and Environment 46(10): 1863-1871.

Wasson, C. R. 1978. Dynamic Competitive Strategy and Product Life Cycles. Austin Press.

Weber, J. A. 1976. Planning corporate growth with inverted product life cycles, Long Range Planning 9(5): 12-29

Webster, D.; Muller, L. 2000. Urban competitiveness assessment in developing country urban regions: the road forward. Paper prepared for Urban Group, INFUD, The World Bank, Washington, July 17.

Wen, T. J.; Siong, H. C.; Noor, Z. Z. 2015. Assessment of embodied energy and global warming potential of building construction using life cycle analysis approach: case studies of residential buildings in Iskandar Malaysia, Energy and Buildings 93: 295-302.

Willson, R. C.; Hudson, H. S. 1991. The Sun's luminosity over a complete solar cycle, Nature 351(6321): 42-44.

Wong, J. K. W.; Zhou, J. 2015. Enhancing environmental sustainability over building life cycles through green BIM: A review, Automation in Construction 57: 156-165.

Wright, J. A.; Loosemore, H. A.; Farmani, R. 2002. Optimization of building thermal design and control by multi-criterion genetic algorithm, Energy and Buildings 34(9): 959-972.

You, F.; Hu, D.; Zhang, H.; Guo, Z.; Zhao, Y.; Wang, B.; Yuan, Y. 2011. Carbon emissions in the life cycle of urban building system in China - a case study of residential buildings, Ecological Complexity 8(2): 201-212.

Yung, P.; Lam, K. C.; Yu, C. 2013. An audit of life cycle energy analyses of buildings, Habitat International 39: 43-54.

Zabalza Bribián, I.; Valero Capilla, A.; Usón, A. A. 2011. Life cycle assessment of building materials: comparative analysis of energy and environmental impacts and evaluation of the eco-efficiency improvement potential, Building and Environment 46(5): 11331140. doi:10.1016/j.buildenv.2010.12.002

Zadeh, L. A. 1965. Fuzzy sets, Information and Control 8: 338-353.

Zavadskas, E. K.; Kaklauskas, A.; Bejder, E.; Motekūnas, T. 1992. Pastato statybos ir eksploatacijos daugiatikslè selektonovacija. Vilniaus technikos universitetas, Aalborgo universitetas. Vilnius: Techika, 82 p.

Zavadskas, E. K.; Peldschus, F.; Kaklauskas, A. 1994. Multiple criteria evaluation of projects in construction. Vilnius Technical University. Vilnius: Technika, 226 p.

Zavadskas, E. K.; Kaklauskas, A.; Bejder, E. 1992. Multiple criteria analysis of projects. Aalborg University. Aalborg: Aalborg Universitetscenter, 93 p. ISBN 87-89867-00-9 
Zhang, X.; Shen, L.; Zhang, L. 2013. Life cycle assessment of the air emissions during building construction process: A case study in Hong Kong, Renewable and Sustainable Energy Reviews 17: 160-169.

Zhang, Y.; He, C.-Q.; Tang, B.-J.; Wei, Y.-M.. 2015. China's energy consumption in the building sector: a life cycle approach, Energy and Buildings 94: 240-251.

Zhou, C.; Dai, X.; Wang, R.; Huang, J. 2011. Indicators for evaluating sustainable communities: a review, Acta Ecologica Sinica 31(16): 4749-4759.

Новая философская энциклопедия. 2010. Институт философии Российской академии наук. [Электронный ресурс]. Доступ по интернету: http://iph.ras.ru/ elib/3359.html

Федулов К. В.; Астафьева Н. М. 2008. Структура климатических изменений. Институт космических исследований Российской академии наук (ИКИ РАН), 62 с.

Штомпка, П. 2011. Социология социальных изменений. Библиотека «Полка букиниста». [Электронный ресурс]. Доступ по интернету: http://polbu.ru/sztompka_ sociology/

Экономический справочник. [Электронный ресурс]. Доступ по интернету: http:// econtool.com/vidyi-tsiklicheskih-protsessov-v-prirode.html 


\title{
CHAPTER 2
}

\section{FACILITIES AND PROPERTY MANAGEMENT}

\author{
Natalija LEPKOVA
}

Property management is the operation of commercial, industrial or residential real estate. This is much akin to the role of management in any business.

Property management is also the management of personal property, equipment, tooling and physical capital assets that are acquired and used to build, repair and maintain end item deliverables. Property management involves the processes, systems and manpower required to manage the life cycle of all acquired property as defined above including acquisition, control, accountability, responsibility, maintenance, utilization, and disposition.

Technical and social progress in the world, the growth of the human needs, cause higher requirements on the supervision of the buildings.

At this time in Lithuania there are a lot of buildings: dwelling houses, industrial and public buildings and etc. All this above mentioned property needs to be supervised, repaired, renovated and modernized and this must be carried out by the high quality specialists.

Building owners, seeking (trying) to sustain and increase the value of their buildings are trying to stop the physical and functional depreciation process of the buildings.

The object of the real estate by its constructive decisions, engineering system and the equipment are that much difficult that need professional care and investments. That are the basic factors that prompted the origin of the Facilities Management, the separate activity ensuring the satisfaction of the requirements of the interested parties in this field.

The objects of the management - land, facilities, buildings of various use (dwelling houses, non-residential houses, industrial and other ones), within the equipment, furniture and other necessary things.

Facilities Management (FM) is a wide field of the activity, covering the whole building's life cycle - the idea of creation, design, construction, exploitation and demolition and the accomplishment of all other systems related to the real estate - investments, solicitation in buying or selling, mortgaging and etc.

All buildings are related to many companies and institutions responsible for: administrating and supervision of the building, heat, cold and hot water supply, telecommunication facilities, disposal of the domestic garbage, watch in for plants, the covering of the yards and carriageways, sanitary cleaning and other ones. That is why there is such a great demand of the specialized companies 
and institutions that could professionally carry out miscellaneous supervision of the building.

The scientists from foreign countries pay the greatest part of their attention towards the exploitation of the building, which covers $75 \%$ of the expenses coming to the building and they perceive the real necessity in this field.

The subjects of the management are all the parties related to the real estate: owners, consumers, tenants, investors, professional negotiators, institutions authorized by the government and the other ones.

Facilities Management like any other field of activity, can not do without clearly defined tasks which is the base line of any factor of the activity.

The system of Facilities Management in Lithuania is only being established now, meanwhile some developed countries have settled down and are still improving the model of this kind of activity. These countries are looking for the best ways of the development of Facilities Management and are creating favorable infrastructure of the real estate accordant to the states economical and social requirements.

\subsection{The review of the scientific researches on the Facilities Management performed in the world}

\subsubsection{The origin and the analysis of the definition of the Facilities Management}

Facility Management came into existence as a particular activity in the second part of the 20th century. Facility Management originally entered Europe in mid 1980s from the USA (Tuomela, Puhto 2001). From its first landing into the UK and the Western Europe, it has slowly entered Scandinavia through the Netherlands and then to the Eastern Europe. It may propose an idea that the practises of the USA and the UK predominantly establish attainments in facility management. Their established standard, specification and programmes have become benchmarks for other countries which accept the importance of FM and the importance to research, standardise and develop the FM function (Maliene et al. 2008).

Is not clear when the profession of FM came into existence. Previously FM was understood as the maintenance of buildings with engineers systems applying to all the cycle of life of a building. The 1950s and 1960s were significant periods for facilities expansion. The post-World War II boom had fuel the need for FMs and engineers. It is difficult to comprehend the explosive growth in all areas of FM's Professional responsibilities (Maliene et al. 2008).

The development of FM formed two different schools: American and British. In the USA the FM is focused on workplace efficiency and management of the facilities. Comparing to the British approach, the American FM pays more attention to the technical issues and installations. The main target is the physical 
workplace (Tuomela, Puhto 2001). The British FM focuses on the integrated services, health and productivity, improvement of the work environment and employees. The British employee based approach pays relatively less attention to the technology. The most attention is paid to the core business and employee support. FM and maintenance services considering healthy environment were described by Liias and other researches (Liias 2007).

Facility Management is a new field that is why we have to pay special attention towards the definition of the term "Facilities management".

"Facilities management" (FM) - there is no direct equivalent nor in Lithuanian nor in German language. But time passing by, German scientists and experts after many intensive researches identify this term with "Die Gebaudemanagement".

The Federation of Russia perceive "Facilities Management" as "upravlenije nedvizimostju" (the management of real estate), in that way justifying the possibility of the wider specter of the management.

"Facilities management" originated in the middle of the XX century in the USA.

The word "Facilities" covers: plots, buildings, gears, the technical servicing means and infrastructure (Facility Management... 1999).

With the growth of the states economy and establishments, the requirements of the interested parties became higher too. Especially the necessity of the modernization of the office equipment and supervising was the basis for this idea of the management to be found. International Association of Facilities Management was found in 1980 in Michigan. Sudden rate of development in 1982 was the ground for the establishment of The International Facilities Management Association (IFMA). Nowadays it has over 14000 members and one of the bestknown organizations in the world.

In Europe the way of the development of Facilities Management was slow and difficult. The conception of FM was first mentioned by the architecture Francis Duffy in 1980 in England. And in 1985 Association of Facility Managers and Institute of Administrative Management/Facilities Management Group (IFM/ FMG) were founded (Zechel 1997).

Later on, the developing of FM was started in Holland, Germany and other European countries.

Scientists from different foreign countries perceive the object of FM differently. That is why we need help in orientating in the variety of conceptions, by creating constructive system of the conceptions, which could help to solve the practical tasks arising to the manager and other parties involved in FM process. The necessity of help comprises the conceptions describing interrelations among various parties one or other way belonging to the field of real estate and to which the need of the management is directed (Schneider 1996). 
FM in the USA, combined creative, planned, servicing, dynamic functions of the building and the management supervision fields of activity (Zechel 1997).

In Holland (Tempelmans Plat 1995) the experts of the management describe FM as the management of the property of the organization (the vitally essence property). The main goal of the manager is to make the efficient activity of the organization, to set the complex of all the necessary services, quality and the size and to render it at the appointed time for the contracted price. Still, there is no solid opinion on the content of this relative and new field of activity in Holland.

In Germany, which got interested in the achievements in the USA, in the end of 1980, FM became the public subject of the researches. Many German scientists and experts such as Gerhard Palisek ("The object of Facilities Management" 1988), Walter Moslener ("The Management of the Resources" 1988), Haus Kahlen ("Building's life cycle management" 1989), Martin Ott ("The management of the real estate objects" 1991), Daniel Frutik and Dietrich Reiblich ("Facilities Management" 1995) working in this field (Schneider 1996).

The German Facilities Management Association (GEFMA) describes FM ("Die Gebaudemanagement") as the conception of complex and strategic planning of the building's lifecycle stages. According to this organization, the main goal of FM is to render the customer all the necessary complex of services, comprising rational planning of the activity in the buildings, adjusting to the changing needs aspiring to set favorable conditions for the future development of the efficient activity of the organization (Schneider 1996).

Wes McGregor ir Danny Shiem-Shim Then define facilities as "The infrastructure that supports the people in the organization in their endeavours to achieve business goals" (McGregor, Shiem-Shin 2001). In other words, facilities are the tools which people in the business have at their disposal to carry out their tasks.

The United States of America Library of Congress provides an initial definition that is often quoted to explain the breadth of the field of facilities management: the practice of coordinating the physical workplace with people and work of the organization; integrates the principles of business administration, architecture and the behavioral and engineering sciences (Then 1994).

The definition of the International Facility Management Association (IFMA) (International Facility Management Association 2004), clearly implies that a major part of facilities management activities is inextricably tied to the provision and ongoing management of an organization's real estate assets and its facilities-related support services, as a productive working environment: Facility Management is a distinct management function and, as such, involves a well defined and consistent set of responsibilities. Simply stated, it is management of a vital asset - the organization's facilities.

The British Institute of Facilities Management (BIFM) adopts a definition that emphasizes the multidisciplinary nature of the role of facilities managers, which 
includes extensive responsibilities for providing, maintaining and developing services ranging from property strategy, space management and communication infrastructure, to building maintenance, administration and contract management: Facilities Management is the integration of multi-disciplinary activities within the built environment and the management of their impact upon people and the workplace. Effective Facilities Management is a vital to the success of an organization by contributing to the delivery of its strategic and operational objectives (British Institute of Facilities Management 1996a; British Institute of Facilities Management 1996b).

According to Hinks (Hinks 1998, 1999) building manager must treat FM as profitableness of the property while seeking the effectiveness of the activity.

One of the most exact definitions of Facility Management (FM) which used by Becker (1990) is: "Facility Management is a term, which encompass the activities in planning, designing and managing complex facilities such as offices, hospitals and schools, differ from architecture and interior design".

According to Barrett (1998), Facility Management refers to buildings in use, to the planning, design, management of occupied buildings and their associated building systems, equipment and furniture to enable and (one hopes) to enhance the organisation's ability to meet its business objectives. Facility management thus refers to organisational effectiveness (Barrett 1998). Facility management is the process by which an organization ensures that its buildings, systems and services support core operations and processes as well as contribute to achieving its strategic objectives in changing conditions (Barrett 1993).

In Jone's (1996) opinion, Facility management - the process by which an organization delivers and sustains support services in a quality environment to meet strategic needs (Jones 1996).

According to Alexander (1997), FM is exploitation and supervision, support services, furniture, equipment and other things lay out inside of the building. The scope of the discipline covers all aspects of property, space, environmental control, health and safety, and support services, and requires that appropriate control points are established in the organization (Alexander 1997).

In Elastman's (1993) opinion, FM is a management of space - layout of furniture, equipment, all communications, management of capital investments (Elastmas 1993).

Each definition (only in different words) defines these indications of FM (Smith et al. 2000):

- organizational structure - entity, systematization, coordination, integration;

- process - dynamism, adaptation in changing requirements, flexibility, longterm advantage, solidity, continuous changes;

- goals - planning of profit and expenses, clearness, the protection of value, accounting of the significant processes, successful management, potential usage, preservation of the resources; 
- the activity of managers - strategic, tactical, normative, flexible, orientated to a particular client.

Summarizing all the above mentioned information, we may assert that FM (Facilities Management, Das Gebäudemanagement):

- is mostly applied by the organizations and institutions of the construction;

- is not looking for new priorities of the conception because the already existing ones are widely applied in the principal fields of activity (for example: by planning);

- combines not only the realization of the particular process but also preparation and improvement of it, taking into account the requirements set by the client;

- does not recognize theoretical description of plans in the context of the new definition (Kahlen 1999).

\subsubsection{Facilities Management goals and tasks}

The eminent thinker and philosopher Aristotel once said, "Clear goal is the way to success".

The goals of FM are real estate planning, construction, supervision and reconstruction. All these above-mentioned factors are unseparatable from the increasing benefit of the building benefit and the reduction of the expenses on keeping of it.

The benefit of the building is the ensuring of the medical care, wealth and proper working conditions to the people living in the building.

Expenses the building requires time (for planning, construction, protection and for renovation), time for the workers and for the natural resources (plot, construction material, energy and etc.).

The basic goals of FM are (Balabanov 2000):

- Putting into reality the constitutional rights of the citizens to real estate and the carrying out of the obligations related to the management of it;

- To define specific order and working conditions to the all market participants;

- Protection from dishonesty and criminal performed by the organizations or people;

- To set free level of the prices for the real estate objects taking into account demand and supply;

- To create favorable investment conditions which would stimulate the activity in the production field;

- Supervision of the ecological environment, stimulation of the economical growth, reduction of unemployment, solving of problems concerning dwelling or other similar problems;

- To tax properly real estate and the participants of this market; 
- To create favorable conditions for soling problems concerning dwelling in the country and in the region.

The basic goal is to reduce expenses on supervision of the building, to extend the duration of the usage and to preserve the value of the building.

The success of the management can be decided by the exhaustive analysis on the real estate market together with the needs set by the client. The goal of FM must be coherent and open to every physical or juridical person involved in this field of activity (McGregor, Shiem-Shin 2001).

The FM and the services provided consist of these component parts (Swistock 2001):

1. The prophylactic supervision of electricity installation, mechanical, communal and of other systems of the building and its current repair.

2. The supervision of the building (for example: of household, parcel delivery and other services).

3. Public utilities, such as electricity, cold and hot water supply, ventilation, gas and the supervision of all the systems, characteristic to the building, also cleaning of territory and of the parking places.

The search for value for money has had one important implication for the whole spectrum of businesses selling products and services of all kinds - the need to describe (specify), to measure (assess performance) and to quantify (price) the output (end product). In terms of operational real estate management, the response for more effective utilization of built assets has been in three main areas (McGregor, Shiem-Shin 2001):

1. Strategic evaluation of the real estate portfolio, which has led to the development of strategic facilities planning in many large organizations.

2. Space management and post-occupancy evaluations, which have been driven by the need to maximize utilization of the workplace.

3. Premises audits and condition assessments, which have raised the awareness and need for cost effective, long-term asset management.

These three developments have prompted a number of writers (McGregor, Shiem-Shin 2001) to stress the need for corporate management to consider their operational real estate assets as business resources, and to integrate their consideration within the strategic planning process of the business (McGregor, Shiem-Shin 2001).

Two aspects that have seen rapid development through the 1990s are (McGregor, Shiem-Shin 2001):

- Asset management and maintenance.

- Space planning and management.

Facilities management systems must be connected with processes and base of organization strategic plans. 


\subsubsection{The interrelation of Facilities Management goals and the possible changes}

Each kind of activity seeks for concrete goals that must have general base in this way to ensure efficiency of the above-mentioned activity.

Agreeably, FM goal is twofold: financial, economical and immaterial - barren in monetary sense (sociable, public, on the consideration of charity and etc.) (Balabanov 2000).

The variations of the management goals are possible in those cases:

- Realization of tasks at the current time after when they completely justified itself or when seeking of them is beside the purpose.

- Changes in the political, social and economical market-led conditions and setting of other external factors concerning the establishment of law.

- Change of the owner's interests and priorities as well as other factors in various stages of the real estate object lifecycle (Kahlen 1999).

Properly defined Facilities Management goals have to meet these requirements:

- Measurability - the qualitative and quantitative evaluation of achieved tasks degree and goals (considerable and inconsiderable measurement);

- Reality - stage attainability, including present restrains;

- Precision and concreteness - proper and clear formulation of the content, size and time (Atkin, Brooks 2009).

\subsubsection{Facilities Management process}

The structure of facilities management process is shown in Figure 2.1.

FM is the management of space - equipment, furniture and all communicational facilities layout, etc. as well as the management of capital investments (Elastman 1993).

That is the optimization of the units, such as workplace, equipment and other ones present in the building. The management of space is very relevant in largescale organizations, such like hospitals, universities and other similar ones. The process of organization activity must be fixed so, that it would be productive, with less interference and other factors. In order to achieve it the following information needed:

- Plans of the building for planning and managing;

- Electricity and telecommunications diagrams to foresee possible changes;

- Information presented in tables, showing the exposition of the equipment.

Planning and constant supervision must be performed in order building and the equipment within to meet the requirements, set by the occupants and by standards. Building's supervision is the whole complex of means, which are used to ensure that the building and its parts would define the fixed mission 
and conditions during the economical or otherwise based period of use (STR 1.12.05:2010). The goal of the supervision to guarantee:

1) the usage of the building and its elements answering to its purpose;

2) the mechanical resistance and stability of the constructions of a building;

3) prevention from fire in the building;

4) save conditions of the use;

5) environmental protection;

6) prevention from noise, vibration;

7) economical usage of energy and preservation of heat within the building;

8) Esthetical interior, exterior and the whole surrounding.

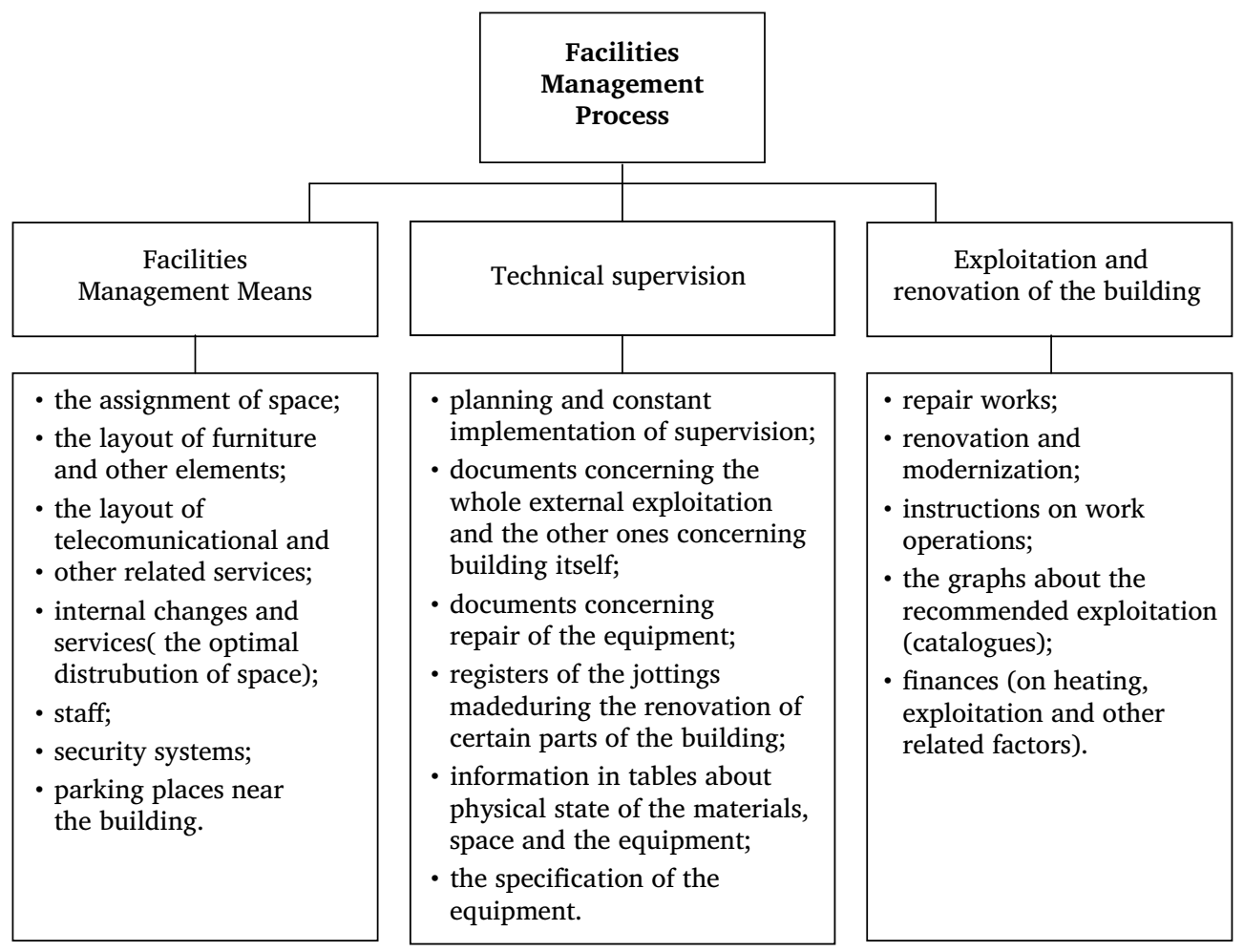

Figure 2.1. The composite parts of Facilities Management process (Smith et al. 2000)

Supervision works contain:

1) Cleaning of the premises and the whole surrounding;

2) Observation of the building and its elements;

3) Filling in of the journals concerning the supervision of the building and its elements;

4) Intended time for the usage of the equipment, gear, and elements and etc.; 
5) The prophylactics of engineering systems, coordination of the equipment, preparation for the heating period and etc. (STR 1.12.05:2010).

The depreciation of the building has a great influence on the process of exploitation. The depreciation of the building is the deterioration of the building together with its constructions as well as the deterioration of the designed features of the equipment (STR 1.12.05:2010). The resources to eliminate the defects of the elements within the building needed. In order to achieve this, the documents and journals of observation needed and of course necessary information. The preservation of the information concerning the process of Facilities Management and its functions is very complex and the way this information is structured, collected, processed and presented is appointed according to how informative (how much of the information is presented) or proper for various decisions to make the information is. In turn, it is as a mean, which can be managed and is an instrument using which the Facilities Management can be applied. In other words - the proper use of information and the decisions made with the help of it assure the qualitative control of Facilities Management.

Properly developed Information Managing System (IMS) ensures qualitative sequence of the process of decision making. Informative reports must have friendly interface, the equipment of the report must also reflect the needs of the consumer.

That above-mentioned kind of Information Managing System (IMS) can be used while managing such types of information:

- Physical resources - place, infrastructure (utility systems), buildings, resources and the property within the building;

- Supporting services - administration, technical supervision of the property, security, health, provision, management of parking places, cleaning and other services;

- Human resources - supervision of the staff, contracts, training and etc.;

- Information about working activity - documents concerning the process as well as the ones of financial, contract and of the kind of information (Alexander 1997).

Software eases the solutions to the problems. Space management software are based on simple graphics and on the database. Space (planning) management systems usually cover the decision support systems, which select the best ways of the space usage, combined with the communications, the distribution of material and etc. In that way multi-criteria analysis is being made.

Talking from the wider point of view, Facilities Management is made of 4 basic parts: real estate, reconstruction, basic works and space (see Table 2.1) (Barrett 1993). 
Table 2.1. The basic parts of Facilities Management (Barrett 1993).

\begin{tabular}{|c|c|c|c|}
\hline Real estate & Reconstruction & Basic works & Space \\
\hline - the management & - building and its mate- & - planning; & - planning of \\
of property as- & rial reconstruction; & - architectural design; & the capac- \\
sets; & - reconstruction services; & - design of the build- & ity; \\
- choosing of con- & - the reconstruction of & ing; & - furniture \\
struction side; & decoration; & - design of machinery & layout; \\
- layout; & - outer reconstruction; & and of the electricity; & - use of \\
- rent; & - energy management; & - interior design; & space; \\
- management & - IT infrastructure; & - project management; & \\
utility; & - telecommunications & - basic works in the & \\
- disposition & infrastructure; & building & \\
\multicolumn{2}{|l}{} & & \\
\hline
\end{tabular}

Real estate management comprises many fields of business and the fields of property management can be divided into 5 categories: rent, rent charge, property supervision, insurance, drawing of the budget and preservation of documents (Kyle 2000).

Rent is divided into these categories (Kyle 2000):

1. Common rent is the type of rent when a tenant pays the fixed payment and the lessor pays the rest of expenses.

2. Pure rent is the type of rent when a tenant pays the fixed payment and the appointed maintenance and property taxes.

3. Partial (percentage) rent - the type of rent when rent payment is usually expressed by the percentage part of the general incomes of the tenant. This type of rent is widely used in retailed rent.

Some other conditions like the term for rent, the conditions of the extension of the contract, insurance, insurance requirements, deposit, keeping of a car, property maintenance(current repairs) and the other ones related conditions must be determined.

The fine for the delayed payment for the tenant must also be defined. This is the way of self-insurance will be comprehensively useful for both sides-the tenant and the lessor as well. In that way the tenant will be interested to pay the rent on time in order not to get a fine.

Even if the building is not in use it depreciates: the paint cracks, peels off and fades, meanwhile the roof is affected by the direct rays of the sun, cold, rain and snow. When the building is occupied, the usage of it calls out natural depreciation of some of its elements. Some of the repairs are simply regular and quite usual and useful, so that the building would be able to carry out its defined functions. For instance, cleaning of the carpet (cover) makes it not only cleaner but also more esthetical to look and also extends the period of its usage, because it is obvious that dirty carpet wears out faster. This kind of supervision is called 
the regular one. Together with the regular supervision, some parts of the building attract special attention towards itself. For example, air-conditioning system filters and ventilation hoods need to be cleaned out and changed, and some parts need to be replaced or smirked. All the above-mentioned proceedings are the examples of the prophylactic repair (Kyle 2000).

Insurance is one of those kinds of services that are salable and are expected never to be used. Insurance does not ensure from the idea whether the concrete event would take place or not, it only guarantees that if this accident would take place all the suffered losses (taking into account conditions of the insurance contract) will be compensated. Factors that make to insure one are called the risk.

Preparation of the budget is very essential for the owner, because it turns the purposes into the amount of money and foresees the way of management and the instruments using which the property owner will be able to evaluate the success (Kyle 2000). Budget preparation is a common work of the owner and of the property manager. They have to decide how exhaustive the budget will be and what period of time it will cover. The detail's of the budget depends on the condition of how it will be used. The budget has to be the real estimation of the expected management results.

Real estate management - is the complex system of the concrete type of real estate, which meets the requirements of the customer. The main problem that has to be solved while preparing real estate management system is the formulation of the goals of the above-mentioned systems. For example, the goal of the builder is taking into account market requirements to build an object that could be profitably sold or rented.

The customer while obtaining the object of real estate defines for the object and the deal these requirements:

- Object must as much as possible satisfy the motivated requirements of the customer;

- In comparison with the other similar objects the comparative price of the marketable object must be the lowest (the proportion with the utility of the basic object or the complex index);

- Supposed specific expenses for the technical maintenance and repair of the object during the period of exploitation comparing to similar ones must be minimal;

- Documents concerning right of ownership as well as the subsidiary ones have to be thoroughly examined and evaluated legally (Krutik, Gorenburgov 2000).

\subsubsection{Suggested conception of Facilities Management}

According to the analysis (Facility Management... 1999; Zechel 1997; Schneider, 1996; Tempelmans Plat 1995; McGregor, Shiem-Shin 2001; Then 1994; 
International Facility Management Association 2004; British Institute of Facilities Management 1996a; British Institute of Facilities Management 1996b; Hinks 1998; Hinks 1999; Becker 1990; Barrett 1993; Barrett 1998; Jones 1996; Alexander 1997; Elastman 1993; Smith et al. 2000; Kahlen 1999; Balabanov 2000; Swistock 2001) of the completed works it is suggested to look at the Facilities Management as at 4 constituent parts: space management, technical management, administrative management and management of other services (see Figure 2.2) (Kaklauskas, Zavadskas 2002).

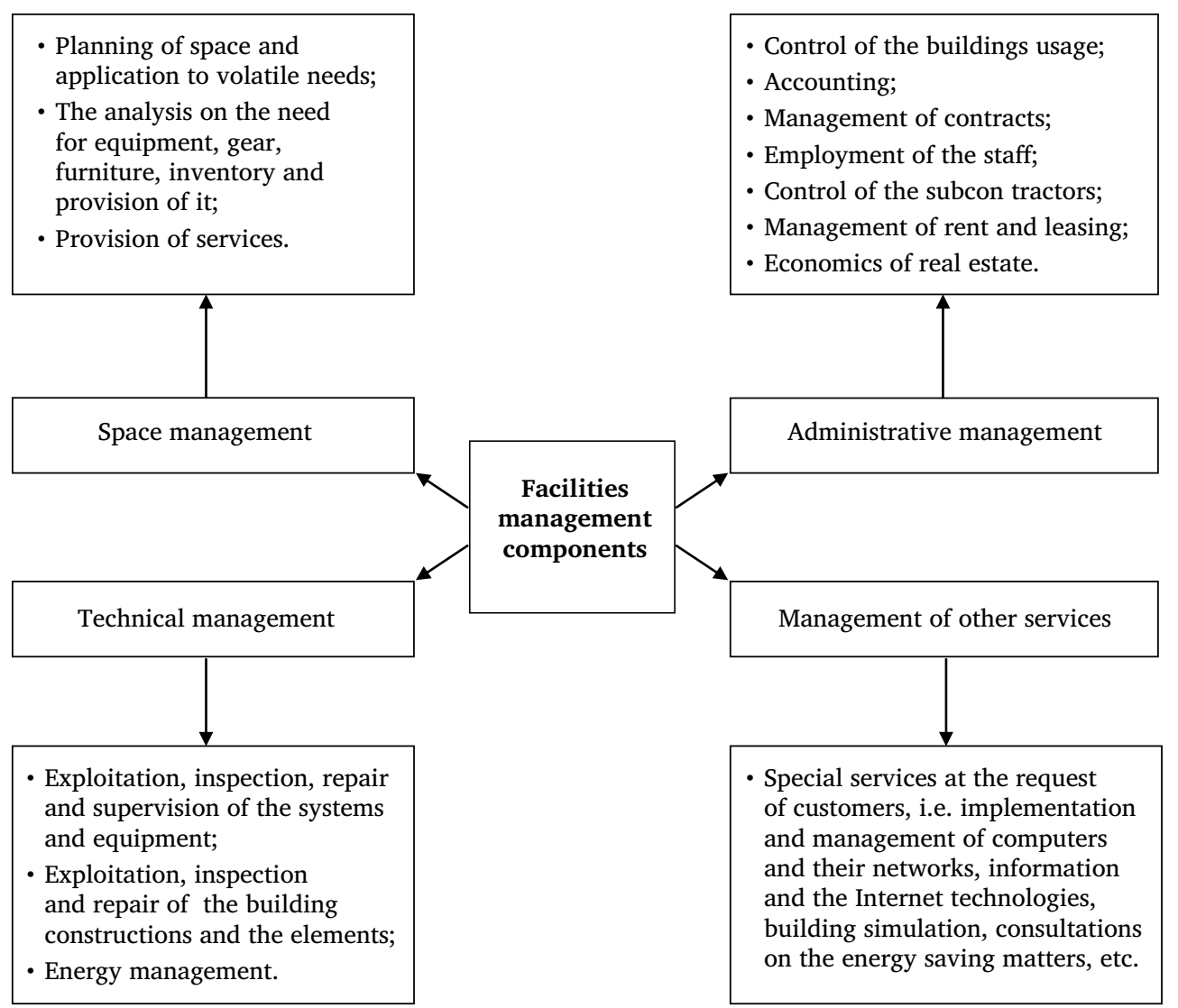

Figure 2.2 Facilities management components (Kaklauskas, Zavadskas, 2002)

\section{Space management}

Space management is conceived as the rendering of services and making efficient operating conditions in the organization.

Space management includes (Kaklauskas, Zavadskas 2002):

- space planning, workplace analysis, removals;

- inventory compilation/updating; 
- main services (e.g. building security, reception, telephone switchboard, cleaning, snow-clearing service, upkeep of outdoor facilities, gardening services, plant care in the building, post room, travel office, office service, central secretarial services, canteen management, removals service, central archives, courier services, office supplies and safety specialist).

\section{Administrative management}

Administrative management includes (Kaklauskas, Zavadskas 2002):

- Control of the buildings usage (drafting and optimization of the budget, coordination of rendering of services, monitoring of contractual commitnens, transfer and acceptation of thebuilding, supervision of the building and the parking place, regulation of the documents, repot preparation, improvement of the image);

- Accounting (rent, extra incomes, taxes, etc.);

- Management of contracts (drafting of contracts and insurance contracts);

- Employment of the staff and control of the subconractors;

- Management of rent and leasing (preparation of the concept and its practical implementation).

The technical management

The technical management includes (Kaklauskas, Zavadskas 2002):

- technical operation's management, maintenance, inspection and repair of equipment and systems e.g. gas, water, wastewater, heating, ventilation, cooling, electrical systems, lifts, warehousing systems, automatic doors and gates, communication, cable and network, security, laundry and drycleaning systems;

- exploitation, inspection and repair of the building constructions and the elements;

- energy management.

Management of other services includes (Kaklauskas, Zavadskas 2002):

Special services at the request of customers, i.e. implementation and management of computers and their networks, information and the internet technologies, etc.

\subsection{Facilities Management quality and price management}

\subsubsection{Importance of quality management}

While exploiting the building the most essential thing is qualitative supervision of it. Rendered services must be properly organized and managed. According to 
the representatives of Great Britain Service Management Centre (British Institute of Facilities Management... 1996a, 1996b) service management is general point of view toward the maintenance of the surrounding area and auxiliary rendering of the services. Quality Managed Service structure developed by Great Britain's Service Management Centre can be defined as the basis of quality for customer, services, and property management in strategic, tactical and process level. It defines and suggests service the service activity. Quality Managed Services can assure that services meet the organization requirements, increase value, associate oneself with seeking for goals and decreases business risk. The above-mentioned services enquire into the processes and link servicing results with the common quality and customer servicing. Quality management is affected by these factors:

- Management (political, planned, organizational);

- People (motivation, training, usage);

- Information (collection, preservation, dissemination and usage).

General quality management follows these principles (Barczyk 1999; Sakalas et al. 2000):

- Quality price;

- Standards;

- Constant improvement

- Management support.

We can look at quality price from different point of view. Short-term point of view is the one, let's say decrease of outside window frame painting is the way of saving. But long-term damage is this that window frames need to be changed earlier because they were not properly maintained. Another example work done wrong at first will need to be repaired later. In those cases customers complain about services. If work was done properly at once there won't be extra costs for the elimination of defects. While looking for ways of work improvement we can decrease high expenditure. We call these quality expenses. In order to find out how much the bad quality of organization activity cost, to define which establishment or organization have bad quality expenses formed in their links, it is necessary to make bad quality expenses accounting as well as it is important to analyse these factors. This kind of analysis is important while implementing quality management projects in order to measure the activity quality development level in money.

Analysis of bad quality expenses is impossible without preliminary classification of that kind of quality.

Quality expenses comprise two partly different groups: quality management and failure expenses (Sakalas et al. 2000). Quality management expenses are: preventive and evaluation. Failure expenses are: Inner loss and outer loss.

Preventive expenses - are the expenses for actions, whose destination is to bar the way to defects and inadequacy that way to decrease failure and control 
expenses to minimum. There are also typical preventative expenses for: quality engineering, practical training, quality management systems, prepared according to international quality management standards, also the ones for implementation of business perfection model and others (Sakalas et al. 2000).

Evaluation expenses are the ones arising while evaluating the condition of products and processes, trying to establish whether they satisfy the requirements or not. The examples of evaluation expenses: project supervision expenses; quality audit expenses; control, experiments and measurements also acquiring of the equipment in order to carry out the operations; for quality management systems and product certifications. We will not suffer failure if the product is made properly at once (Sakalas et al. 2000).

Examples for inner loss expenses: damaged products and waste; lost time; repairing and reconstruction expenses.

Examples for outer loss expenses: consumer complaint and investigation of them, compensations, buyer losses, price reduction expenses. In some newest literature harm done to the environment and losses of resources in the process of production are attributed to quality expenses as well.

A.Feigenbaum, after carrying out steady researches, affirms that from 65 to $70 \%$ of the quality expenses make inner and outer loss expenses, from 20 to $25 \%$ - evaluation expenses and only $5-10 \%$ are the preventive expenses. It is a very bad proportion (Sakalas et al. 2000).

These data shows, that the money spent not productive. If the biggest part of the money spent on prevention, quality expenses would be reduced to minimum.

Standard - is good from the first time and all service organizations should reach for it. Not doing from the first time is only a waste o time (of customers and service providers as well), unnecessary stress, money expenditure and dissatisfaction. We should also reach for the keeping to the set standards, such as ISO and alike, which valid in Lithuania, are fundamental aspects for the establishments providing services.

Common quality management never ends. Not to mention, how much the service organization will improve its services, there will always be competitors whose will also do their best to render services as good and professional as they can. Constant improvements are the review of the provided services always basing on some facts. It is also related to the responsibility for the quality of work. Constant improvement is the main and the most complex part of common quality management that is why good management support is required here.

Many organizations are already occupied with common quality management, so service manager's job is to render help and support while accomplishing it. Almost all-common quality management principles are just good management methods. The problem is the application of the above-mentioned methods, whether service providing organization has many works, has a small budget or 
the need to attract clients. That are the situations, that make common quality management essential for the nowadays manager.

Organizations operating buildings have to understand that building supervision and proper exploitation are the indispensable conditions for keeping the facilities in good form.

\subsubsection{Quality criteria system for Facilities Management services in Lithuania}

Facilities management services quality is expressed by client satisfaction indicators (Atkin, Brooks 2009; EN 15221-3:2008). However, there is a wide gap between the residential building owners' perception of facilities management services and the actual need for them (EN 15221-3:2008). This gap was caused by the difficulty for the people to see the use of long-term planning as well as economic motives. In the absence of clear service quality criteria and highquality provision of building maintenance services, the consequences remain obscure for a long time. Real estate owners often insist on saving resources at the expense of long-term sustainable life-cycle of a building. Nevertheless, due to its hardly measurable nature, facilities management is often characterized by a large number of real estate owners as inevitable evil. In the current situation, valuing the quality of services in terms of client satisfaction would mean dooming the real estate stock to uncontrollable depreciation and the problems that would occur would in the long run amount to a social catastrophe. The drastically depreciated and unfit for use residential area would reduce the living standards of the residents and would have strong influence on the state economy. Self-government as well as non-governmental organizations should shape and raise consumers' awareness; however, good practice is still scarce. So are actually applicable methods of evaluating and presenting the service quality reasonably to the owners of residential buildings.

In this chapter Natalija Lepkova together with Robertas Uselis (practitioner from Lithuanian Facilities management company) provide the concept of facilities management services and their delivery in different countries, analyze the perception of customer satisfaction with facilities management services, examine consumer assessment of the facilities management service quality, propose a quality criteria framework for facilities management services, present quality levels of facilities management services.

\subsubsection{Facilities Management services in different countries}

The FM has widely developed in the last ten years. FM has become more miscellaneous, flexible; more polarized towards wishes and requirements of purchasers. Therefore, today, FM covers old "traditional" ranges and absolute new ranges, which sometimes could be strongly related to FM (Maliene et al. 2008). 
FM is a typology of contract for services provision, which covers an extremely wide field of activities. FM encompasses workplace, facility, support services, property, corporate real estate, and infrastructure. In general, support services concerning FM range from building operational services, to construction management, and real-estate activities (Ancarani, Capaldo 2005; Chotipanich 2004).

FM uses different approaches and has distinctive priorities in every particular country. It is not surprising that there are widely divergent views and interpretations (Lepkova et al. 2003; Lehtonen, Salonen 2006; Lavy, Shohet 2007; Straub, Mossel 2007; Kaklauskas, Lepkova 2001; Zavadskas et al. 2001; Zavadskas et al. 2002; Zavadskas et al. 2004; Vilutiene, Zavadskas 2003; Zavadskas, Vilutiene 2004; Jarvan, Liias 2003; Then 2005; Ventovuori 2006; Wang, Xie 2002; Paadam, Liias 2008) of the concept that is used in various countries. Among those FM is understood in a similar way, but at the same time it may use different strategies. Consequently, there is yet no consistent definition of the scope of FM activities (Maliene et al. 2008). EN 15221-1 provides the facilities management definition as following: integration of processes within an organisation to maintain and develop the agreed services which support and improve the effectiveness of its primary activities (EN 15221-1:2006).

FM services were first provided in the 1950s and 1960s in the USA and they were fully developed in the 1970s. But it was only in the1980s that such an FM market developed in Europe (Ancarani, Capaldo 2005; Salaris 2002).

The UK is the most important FM market in Europe. The most frequently outsourced services are catering, cleaning, waste and recycling, security and hospitality, whilst the services most frequently retained in-house are procurement, human resources, finance, estate management and business strategy. Facility managers are consolidating the choice toward performance quality and flexibility with respect to core business needs, and regard quality of services from suppliers as the most important current issue (Ancarani, Capaldo 2005; BIFM 2004).

Germany and France are also relevant markets. In particular, the German market is rapidly changing both on the supply and demand sides (Ancarani, Capaldo 2005).

In Italy, the FM sector developed considerably later, compared to other countries. The causes for such delay can be found in the peculiarities of the Italian economic structure, which is strongly biased towards small and medium enterprises (SMEs). In particular, such peculiarities do not fit either with a total FM approach or traditional models based on in-house management of even non-core services. Nonetheless, during the last 10 years there has been a rapid growth in the Italian market, due to a diffused trend to outsource non-core activities and to a process of reorganization of the supply market (Ancarani, Capaldo 2005).

Very important point in Facilities Management field is customer satisfaction with provided services. 
Companies win or lose based on what percentage of their customers they can keep. Success is largely about the retention of customers, which again depends on the customer satisfaction level. It would be a great help to be able to comprehensively measure the quality of products and services by relating the measures of quality to real customer behaviour. Some companies get feedback about customer satisfaction through the percentage of complaints and some through non-systematic surveys, but some do not measure customer satisfaction at all, because "the system would not add anything useful and is very time-consuming" (Chotipanich 2004).

In the growing service sector there is still the most problematic challenge of how to deal with service quality. Quality is one of the most expected aspects by customers of almost all service products (Urban 2009).

For quality regulation the following standards exist in Europe: the IS0 9000 Quality standards (ISO 9001:2008); EN 15221-3: 2008 Facility Management Part 3: Guidance how to achieve/ensure quality in Facility Management (EN 15221-3:2008).

Alexander (1996) broadened the concept of facilities management quality and described it as balancing the surrounding environment and assisting organisations meet their strategic needs. Quality determines the usefulness of a service to the user as well as commercial success to the service provider. Due to low quality, organisations do not only experience moral damage (dissatisfied consumers and staff) but also material loss. According to scientific estimations, over a third of costs in service organisations are allocated to error corrections (Bagdoniené, Hopenienè 2009). Quality assurance has a cost; therefore, it is worthwhile to increase quality only up to the required level rather than aiming at perfection. It is necessary to know what level of quality ensures stable condition of a building, is sufficient to sustain owner satisfaction and the facilities manager competitive advantage. Measuring the quality of building maintenance services is necessary not only due to above-mentioned reasons but also in order to break out of a vicious circle of mistrust (between owners, customer and facility management service providers).

Different from manufacturing, measurement of quality of complex municipal services, as of other services, is not intuitive and depends on changing composite qualitative indicators (Parasuraman et al. 1985). The delivery model of such services differs greatly from the single buyer and single seller model described in ISO 9000 standards. Here, in most cases, no tangible product is created (Pheng 1996). As a result, measurement indicators must contain adaptive functions that would change the indicators in the constantly changing situation. In other words, it is necessary to implement feedback interpretation. It is just as important for quality indicators to have minimal values, independent of the owner satisfaction level, which are necessary in order to ensure stable technical 
condition of a building. Moreover, in many cases clients do not wish to participate in the evaluation of service quality since they are not professionals in the field. Part of the investment should be assigned to client awareness-raising. A client's feedback on the quality of a service is the most important and crucial aspect of quality (Aatsalo-Sallinen 2006).

While carrying out further research, adaptive artificial neural network systems should be applied for quality measurement. Both the client satisfaction index and the changes in the pricing of building's lifecycle can serve as a response to artificial neural networks.

Although global practice indicate client satisfaction as a principal measure of quality, it is important to introduce an additional dimension of quality that would be least influenced by consumers in the current Lithuanian market. For the evaluation of facilities management services a multi-criteria model of the pricing of a building life-cycle (from construction to demolition) designed by taking into consideration not only economic but also social factors should be applied (Zavadskas et al. 2001). Thus it is possible to reduce the importance of resident satisfaction criterion and to obtain an important qualitative indicator required in order to preserve the stable condition of a building. The Quality management system must also encompass operation efficiency measurement.

\subsubsection{Quality levels of Facilities Management services}

Facilities management services can be divided into 4 levels: preventive, correctional, improving and top quality (ISO 9001:2008; Construction Technical Regulation STR 1.12.05:2010). Services of the first level are aimed at ensuring the stable condition of a building and they do not depend on the owners' desires or their perceived quality. Most owners of residential buildings in Lithuania do not wish to receive even the minimal level of services and due to insufficient state (or private) control and constant inability to meet financial obligations; the condition of these buildings is constantly deteriorating.

Exemplary quality levels identified by Natalija Lepkova together with Robertas Uselis (practitioner from Lithuanian Facilities management company) (based on Maslow 2009) are presented in Figure 2.3.

All further quality levels are based on the needs and expectations of the owners. In general the aim of the owners of every building should be to ensure good quality of facilities management services or, in other words, the increase of real estate value. Households and tenants would like their buildings to become more attractive, comfortable, safe and harmonious as well as cost efficient. These intensified requirements, to some extent, have increased the relative importance of customer satisfaction in the success of FM. These demands also require the FM companies to monitor the effect and progress of their service (Hui, Zheng 2010). 
Although such attitude has an obvious economic justification, in reality it is not only economic criteria that determine the owners' behaviour. In many cases uncertainty about the future, mistrust as well as lack of savings prevent people from deciding to invest into the value of their real estate.

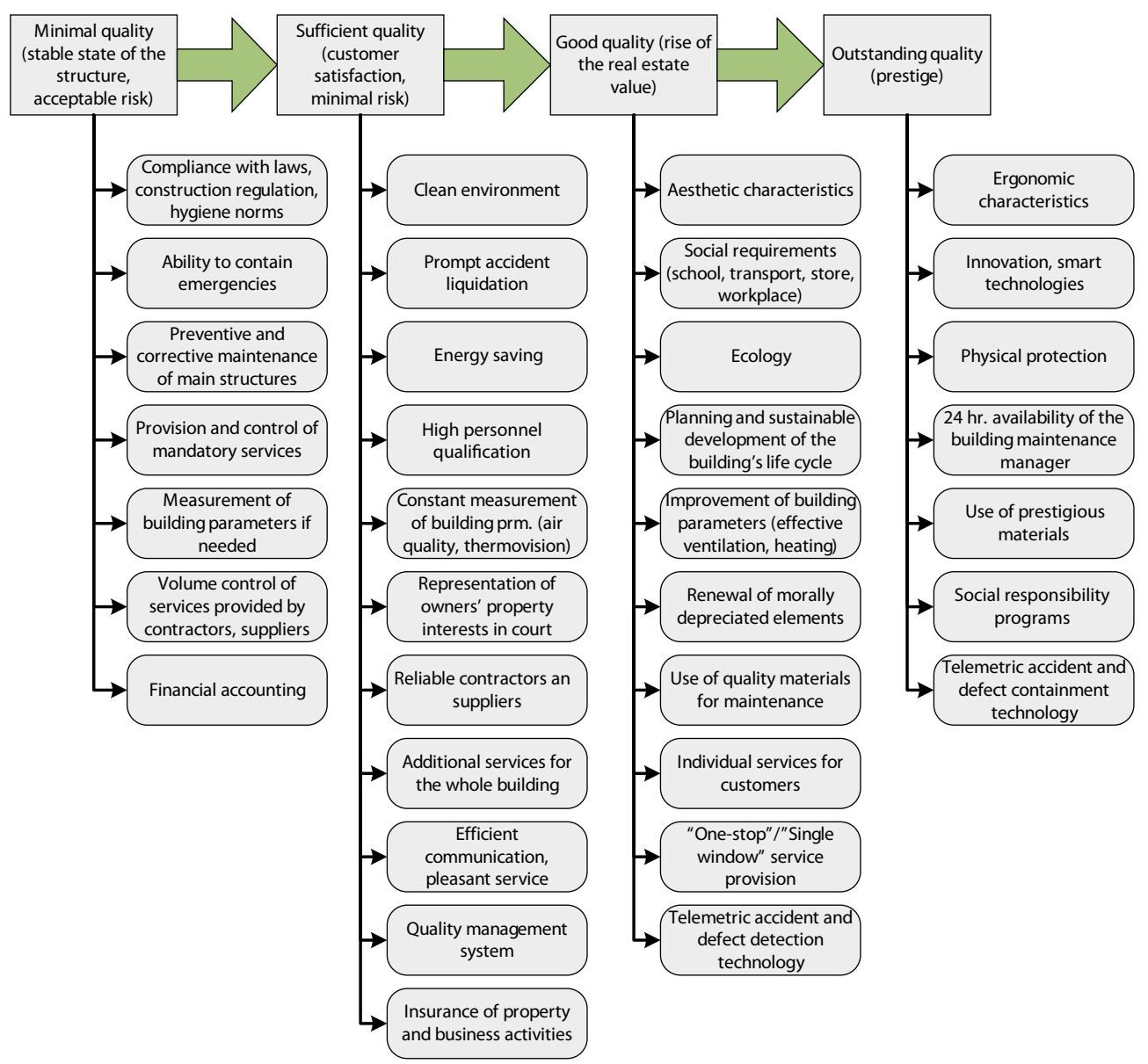

Figure 2.3. Exemplary quality levels of facilities management services, identified by Natalija Lepkova and Robertas Uselis based on Maslow 2009 (Lepkova, Uselis 2013)

\section{Minimal Building Maintenance Quality}

Due to the situation in the Lithuanian market, the greatest focus will be put on, namely, measuring minimal building maintenance quality. In the current situation, minimal quality criteria are left to the competence of employees stating that an engineer shall know what is to be done, a cleaner shall certainly know how it must be cleaned etc. (APO - Asian Productivity Organization 2008). This tacit knowledge is one of the most frequent reasons of poor quality and conflicts with clients. On the other hand, no strict building maintenance 
Table 2.2. Facilities management services: influencing factors, constraints, measured indexes (recommended by Natalija Lepkova and Robertas Uselis), (Lepkova, Uselis 2013)

\begin{tabular}{|c|c|c|c|}
\hline Service & $\begin{array}{l}\text { Influencing } \\
\text { factors }\end{array}$ & Constraints & Quality indexes \\
\hline Administration & $\begin{array}{l}\text { Internal regula- } \\
\text { tions of a build- } \\
\text { ing, fiscal and } \\
\text { monetary policy }\end{array}$ & $\begin{array}{l}\text { Laws, } \\
\text { standards }\end{array}$ & $\begin{array}{l}\text { 1. Compliance with obligatory frequency } \\
\text { and efficiency } \\
\text { 2. Orderly documentation and finance } \\
\text { 3. Positive customer recommendations } \\
\text { 4. Bureaucracy (document flow) } \\
\text { characteristics } \\
\text { 5. Communication skills }\end{array}$ \\
\hline Cleaning & $\begin{array}{l}\text { Seasons, habits } \\
\text { of residents and } \\
\text { visitors }\end{array}$ & $\begin{array}{l}\text { Hygiene require- } \\
\text { ments, surface } \\
\text { cleaning stand- } \\
\text { ards. }\end{array}$ & $\begin{array}{l}\text { 1. Compliance with obligatory frequency } \\
\text { 2. Prompt handling of hazardous pollution } \\
\text { 3. Compliance with surface cleaning } \\
\text { standards } \\
\text { 4. Compliance with the cleaning standards }\end{array}$ \\
\hline Exploitation & $\begin{array}{l}\text { Depreciation, } \\
\text { defects, damage, } \\
\text { threat of natural } \\
\text { disaster, third- } \\
\text { party activity }\end{array}$ & $\begin{array}{l}\text { Regulations, } \\
\text { manufacturers } \\
\text { recommendations } \\
\text { for maintenance, } \\
\text { potentially dan- } \\
\text { gerous equipment } \\
\text { operating rules }\end{array}$ & $\begin{array}{l}\text { 1. Service provision based on } \\
\text { recommendation of manufacturers } \\
2 \text {. Timely preventive and corrective main- } \\
\text { tenance } \\
\text { 3. Evaluation of the state of the building } \\
\text { by experts } \\
\text { 4. Correct assessment of defects } \\
5 \text {. Employee qualification }\end{array}$ \\
\hline $\begin{array}{l}\text { Electrical sys- } \\
\text { tems mainte- } \\
\text { nance }\end{array}$ & Crime level & $\begin{array}{l}\text { Potentially dan- } \\
\text { gerous equipment } \\
\text { operating rules }\end{array}$ & $\begin{array}{l}\text { 1. Timeliness } \\
\text { 2. Timely measurements, testing }\end{array}$ \\
\hline $\begin{array}{l}\text { Cold water and } \\
\text { wastewater } \\
\text { systems main- } \\
\text { tenance }\end{array}$ & $\begin{array}{l}\text { Habits of } \\
\text { residents and } \\
\text { visitors }\end{array}$ & & $\begin{array}{l}\text { 1. Timely measurements, testing } \\
2 \text {. Correct assessment of defects }\end{array}$ \\
\hline $\begin{array}{l}\text { Heating and } \\
\text { hot water sys- } \\
\text { tems mainte- } \\
\text { nance }\end{array}$ & Seasons & $\begin{array}{l}\text { Laws, heat } \\
\text { consumption and } \\
\text { supply rules }\end{array}$ & $\begin{array}{l}1 \text { Timely measurements, testing, mainte- } \\
\text { nance checks } \\
\text { 2. Expert consumption assessment } \\
\text { 3. Correct assessment of defects } \\
\text { 4. Zero accidents during the cold season }\end{array}$ \\
\hline $\begin{array}{l}\text { Automated and } \\
\text { fire protection } \\
\text { systems main- } \\
\text { tenance }\end{array}$ & $\begin{array}{l}\text { Threat of } \\
\text { natural disaster, } \\
\text { humidity, tem- } \\
\text { perature }\end{array}$ & $\begin{array}{l}\text { Laws, regulations, } \\
\text { standards, quality } \\
\text { manual }\end{array}$ & $\begin{array}{l}\text { 1. Timely measurements, testing } \\
\text { 2. Correct assessment of defects }\end{array}$ \\
\hline $\begin{array}{l}\text { Maintenance of } \\
\text { elevators and } \\
\text { hoists }\end{array}$ & $\begin{array}{l}\text { Crime level, } \\
\text { habits of } \\
\text { residents and } \\
\text { visitors }\end{array}$ & $\begin{array}{l}\text { Potentially dan- } \\
\text { gerous equipment } \\
\text { operating rules }\end{array}$ & $\begin{array}{l}\text { 1. Timeliness } \\
\text { 2. Timely measurements, testing }\end{array}$ \\
\hline $\begin{array}{l}\text { Waste } \\
\text { collection }\end{array}$ & $\begin{array}{l}\text { Habits of } \\
\text { residents and } \\
\text { visitors, beliefs, } \\
\text { architectural } \\
\text { layout }\end{array}$ & $\begin{array}{l}\text { Waste handling } \\
\text { rules }\end{array}$ & $\begin{array}{l}\text { 1. Amount of waste } \\
\text { 2. Timely collection } \\
\text { 3. Sanitary state of equipment }\end{array}$ \\
\hline
\end{tabular}


instructions are present and constructor and manufacturer recommendations in most cases are considered a commercial secret available exclusively to authorised representatives.

In case of bad economic situation, it is useful to minimaze the scale of maintenance as much as possible but avoid crossing the limit below which the building condition deteriorates faster and the economically viable term of use shortens. Nevertheless, defining absolutely minimum criteria will not be possible since while reducing the volumes of individual works, the quality of other services decreases too; therefore, criteria of particular significance shall remain above the minimum level (Zavadskas et al. 2001). For instance, laying a mud rug in the staircase might seem a needless waste of money; however, if refused, it increases the cost for cleaning significantly. In many cases, owners of residential buildings, in order to save even more, refuse certain services and start organizing maintenance activity themselves (Law on Apartment Block Owners Associations, 2012). In the long term, such decision often brings great losses. It is often the case with cleaning services and surfaces are spoilt due to incorrectly selected detergents. In the recent years, similar trends occur in terms of heating system maintenance. The residents lack relevant knowledge of how to ensure stable condition of a building and a cheap contractor hired does not prepare long term plans of building exploitation. In order to simplify the information relevant to the residents of a residential building on minimal building maintenance before hiring a facilities management services company, the Natalija Lepkova and Robertas Uselis recommend a control questionnaire. Later, when evaluating the quality of services of the organization, Natalija Lepkova and Robertas Uselis recommend applying the assessment criteria presented in Table 2.2.

In order to achieve minimal quality, all the following questions must be answered positively:

1. Does the organization have a collection of legal acts regulating building management and maintenance?

2. Does the organization have an emergency (accidents, natural disasters) management plan?

3. Does the organization have sufficient technical and material basis for solving emergencies?

4. Does the organization have a technical passport (descriptor) of the building? Are the required construction and equipment monitoring, preventive and correctional works listed according to the passport?

5. Does the organization have a continual building monitoring plan?

6. Does the organization have a list of critical areas in the building or those with expired exploitation date and does it carry our continual monitoring of those? 
7. Does the organization properly fill in the technical maintenance logbooks of the building? Does the person filling them have proper qualification? It is important to analyze the thoroughness and documents and photo material here.

8. Does the organization have the recommendations of the designers, manufacturers or other organizations with regard to the exploitation and renovation of the buildings or its parts? Are the employees familiar with the recommendations?

9. Does the qualification of the employees of the organization meet minimal requirements?

10. Is the company's activity insured?

11. Are the company's liquidity criteria good?

12. Does the company have set standards for maintenance and cleaning works?

13. Does the company know the external factors and is capable of managing internal ones that may have negative influence on quality indicators?

14. Is the hydroinsulative state of partitions continually monitored?

15. Do the building maintenance staff constantly build their qualification?

16. Does the organization have and fill in a logbook of incompliance with minimal quality requirements?

\section{Conclusions}

The authors of this chapter (Natalija Lepkova and Robertas Uselis) identified the exemplary quality levels of facilities management services, starting from minimal quality level up to outstanding quality. This level system allows to evaluate the quality of facility management services.

Authors recommended and described facilities management services influencing factors, constraints, measurement indexes. These factors have great impact for facilities management service provision and customer satisfaction with provided services.

The authors believe that the dossier of every building, which consisting of technical documentation, energy audits, maintenance logs and plans must also include assessment of minimum volume and quality of facilities management services as well criteria used in the process of assessment. The description of these criteria would increase the transparency of the service and trust towards companies providing facilities management services.

\subsubsection{Study on customer satisfaction with Facilities Management services in Lithuania}

Quality dimensions of FM services have been discussed in section 2.2.2. In this Chapter the Customer satisfaction measurement and research on customer satisfaction with facilities management services in Lithuania will be presented. 


\section{Customer satisfaction measurement}

Customer satisfaction is the key factor determining how successful an organisation will be in customer relationships; therefore, it is very important to measure it (Fečikova 2004).

It is also important to note that (Zairi 2000):

- Satisfied customers are more likely to share their experiences with other people, even up to five or six people. In the same vein, dissatisfied customers are more likely to tell ten other people of their unfortunate experience.

- Furthermore, it is important to realise that many customers do not complain, and this will differ from one industry sector to another.

- Lastly, if people believe that dealing with customer satisfaction/complaints is costly, they need to realise that it costs as much as 25 per cent more to recruit new customers.

Satisfied customers are more likely to return to those who have helped them, and dissatisfied customers are more likely to go elsewhere next time. The key to organisational survival is the retention of satisfied customers. Loyalty of customers is a function of satisfaction, and loyal customers spend more on your products and services, encourage others to buy from you and believe that what they buy from you is worth what they pay for it (Fečikova 2004).

\section{Satisfaction measurement approach}

If companies want to achieve customer satisfaction, they must measure it, because "you cannot manage what you cannot measure" (Fečikova 2004).

A customer satisfaction survey is a useful performance measurement format that should help an organization and its staff to understand a customer's viewpoint of a firm's performance on a completed project (Rondeau et al. 2006).

The starting points for effectively measuring a customer satisfaction are the following steps (Fečikova 2004):

1. customer identification;

2. understanding what customer satisfaction includes and what it means;

3. defining what needs to be measured;

4. choosing the measurement method.

These steps will be discussed further.

1. Customers. Customers are the purpose of organizations activities, instead of their depending on a firm, organizations very much depend on them. Accurate information about customers enables companies to provide products or services which match their needs. There are two kinds of customers for processes within an organisation: external and internal. External customers are the customers in a marketplace, whereas internal customers are the customers within the corporation, the employees of the corporation. 
The satisfaction of internal customers (below, the term "employee" is used) and external customers is seen as a cause-and-effect relationship. Employee satisfaction is the source of excellent quality, because if the organisation satisfies the needs of its internal customers, it is also enabling its internal customers to perform their tasks, and the network of organisational units are more adept at working effectively together to achieve customer satisfaction.

Problems with employee satisfaction (turnover of employees, etc.) lead to problems with customer satisfaction (Figure 2.4) (Fečikova 2004; Zairi 2000).

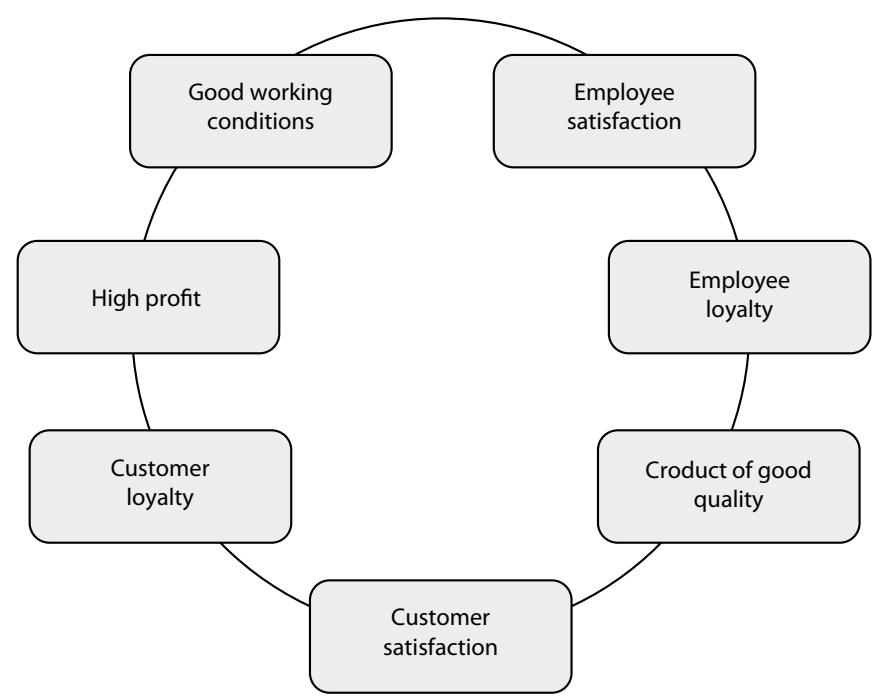

Figure 2.4. The circle of satisfaction (Fečikova 2004)

Firms can apply their employee management practice to customers. They can enhance the clarity of customer's role (customers knowing what is expected of them), motivation (being motivated to engage in desired behaviours), and ability (to fulfil their responsibilities).

Managers should carefully select, train and socialize customers, just the same as the firm would do with respect to its employees. Managers should also provide customers with empowerment and resources to serve employees or other customers successfully. Furthermore, firms need to develop and establish effective mechanisms for controlling customer behaviours. Communication with customers might be helpful in this respect. Indeed, effective communication between customers and employees can yield successful customer behaviour management, because managers can recognize customer needs and expectations better (Yi et al. 2011).

2. Satisfaction. Organisations have to know how satisfied customers feel. The word "satisfaction" is central to many definitions and in a marketing context it has many meanings (Fečikova 2004): 
- satisfaction is merely the result of "things not going wrong";

- satisfying the needs and desires of the consumer;

- satisfaction-as-pleasure;

- satisfaction-as-delight;

- customer evaluations of the quality of goods and services.

The most common interpretations reflect the notion that satisfaction is a feeling which results from a process of evaluating what was received against that expected, the purchase decision itself and/or the fulfilment of needs/want.

The perception of the word "satisfaction" influences the activities which we conduct to achieve it.

3. Things to measure. Many organisations identify the level of customer satisfaction through:

- the number of product support problem calls;

- the number of direct complaints by phone, e-mail, etc.;

- the number of returned products and the reason for their return, etc.

This is a measurement of customer dissatisfaction (no satisfaction) and offers a possibility for the elimination of mistakes, not a possibility for product development and product innovation.

Organisations can collect and analyze appropriate data, which will provide relevant information relating to real customer satisfaction. It is important to measure the right things, i.e., what is really important to customers. There is the possibility of wrong specifications or misinterpretations of what a customer actually wants (the gap between what companies think customers probably want and what customers really want). The criteria for the measurement of customer satisfaction must be defined by the customer (Fečikova 2004).

4. Method for measurement. Any method that gathers customer feedback is good, but for effective measurement, appropriate methodology (description processes and measurement scales) needs to be found. The alternative methods to use include questionnaires (by post, by e-mail), direct interviews, telephone interviews, marketing research, comparison with competitors (benchmarking) and so on. The validity and relevance of the data gathered through these methods also varies.

\subsubsection{Survey on Facilities Management companies customers satisfaction with FM services}

To learn the opinions about FM services in Lithuania, a questionnaire was distributed to customers of one FM company, but, for the sake of confidentiality, neither the company nor its customers will be disclosed. Nineteen organisations of different size and from different industries were surveyed during face-to-face meetings and by e-mail. The results will be discussed below. The survey was fulfilled by Giedrè 
Žūkaitè-Jefimovienè (was working in Facilities management company) and Natalija Lepkova in 2010 (Lepkova, Žūkaitè-Jefimovienè 2012).

The first thing to determine was the way customers of the FM company inform the latter about failures, emergencies and required services. The customers have several options: a general phone number, faxing or e-mailing, or direct communication with the company's contact person. The frequency distribution of each method is shown in Figure 2.5 (the respondents were allowed to choose several options).

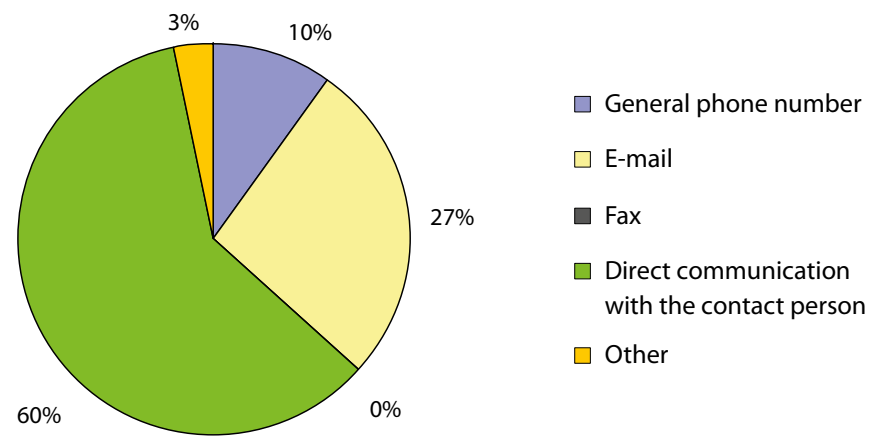

Figure 2.5. How do you inform the company about the required services (additional services, failures, emergencies)?

The majority of respondents prefer direct communication with the contact person and e-mails, only three respondents use the general phone and none reports about the required services or failures by fax. A company's representative works in one of the surveyed organisations; the representative is responsible for the quality of services and current operations.

Since the majority of customers most often communicate with the contact person directly, they were asked to assess on a five-point scale ( 1 the lowest, worst, and 5 the highest, best, score) their possibilities to get through to their contact person. The scores are shown in Figure 2.6.

The results in Figure 2.6 show that the majority of respondents (13) scored the possibilities as the best - these customers assured their contact person was always available when needed. Four customers sometimes had troubles to reach that person (on holidays or when he/she was occupied); and only one customer gave 3 points. None gave the lowest scores ( 1 and 2$)$, so they are not in the diagram.

The customers were then asked to assess (on a five-point scale) accessibility to information about the services, as well as about the current repairs, the response to accidents and other work underway in the building. Figure 2.7 shows customer opinions. 


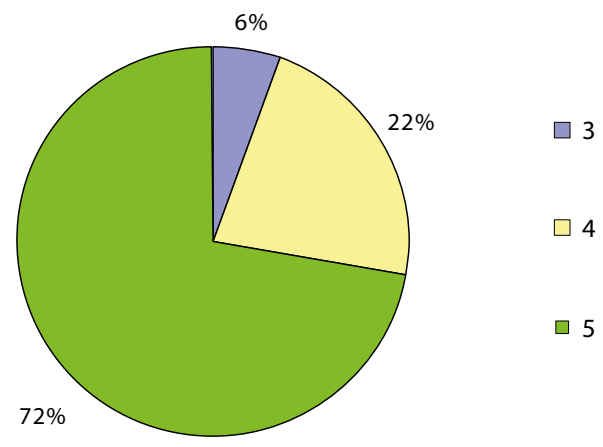

Figure 2.6. Score the possibilities to get through to your contact person when needed

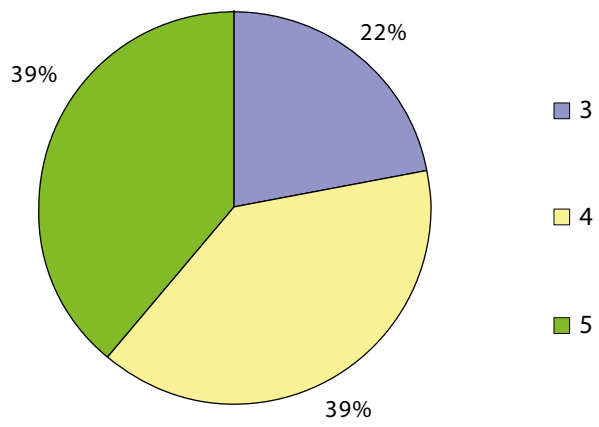

Figure 2.7. Assess the accessibility to information about the services, as well as about the current repairs, the response to accidents and other work underway in the building

Equal portions of customers (seven in each) gave 4 and 5 points to information accessibility and four gave 3 points; the lowest scores ( 1 and 2 ) were given by none. Some customers noted they needed at times to inquire additionally and missed more detailed descriptions of problems, while one customer desired better adjustment to its needs because the arrivals to the site or operations happened without a prior warning and arrangement.

The customers were also asked to assess the comprehensiveness and clarity of reports about the completed work (also on a five-point scale; Figure 2.8).

Figure 2.8 shows that many customers (7) find the information sufficient, but others have some remarks: five gave 4 points for the comprehensiveness of reports, four scored the comprehensiveness with 3 and four with 2 points; the lowest score was given by none. Customers comment that they often receive the certificates of additional work which simply state the fact but lack conclusions as to the reasons of failures, possible solutions, warnings and post-inspection 
tips, more detailed comments and explanations, suggestions of action on different occasions and ways to improve the quality and performance of equipment.

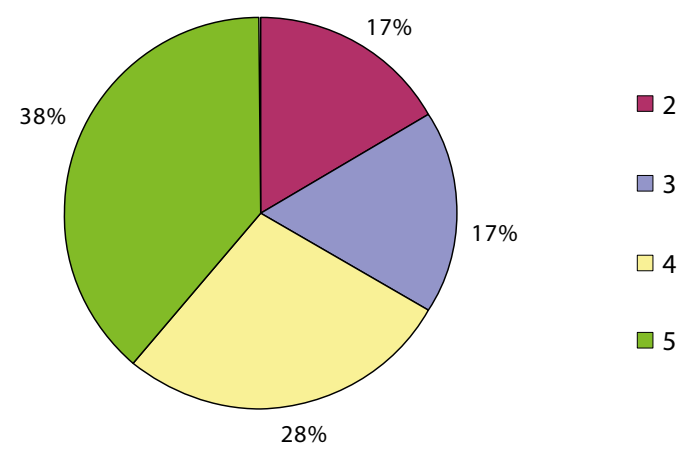

Figure 2.8. Assess the comprehensiveness and clarity of reports about the completed work

The fifth question attempted to ascertain whether or not the customers would like to meet their contact person more frequently (Figure 2.9).

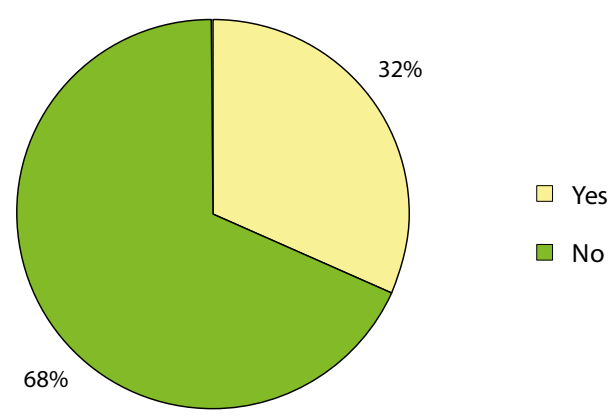

Figure 2.9. Would you like to have regular meetings with your contact person (to discuss scheduled and completed work, the results, etc.)?

The majority of respondents (13) were satisfied with meeting their contact person if needed and did not want regular meetings; six customers, however, noted they saw the need in such meetings. One customer, which answered this question with "no", already had regular meetings and each meeting had been recorded, thus improved satisfaction with the quality of services and done operations, as well as with the cooperation with the company, was observable at once.

Customers were also asked to assess the service culture, expertise and knowledge of employees of the FM company. They were asked to score (on a five-point scale) the administration, the contact person and the technical staff separately. The scoring of the service culture is shown in Figure 2.10, while that of the expertise and knowledge in Figure 2.11. 


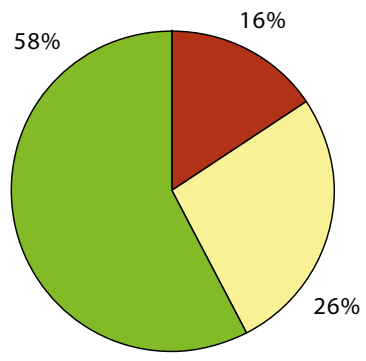

a) Administration

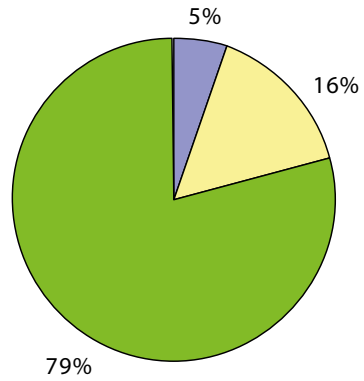

b) Contact person

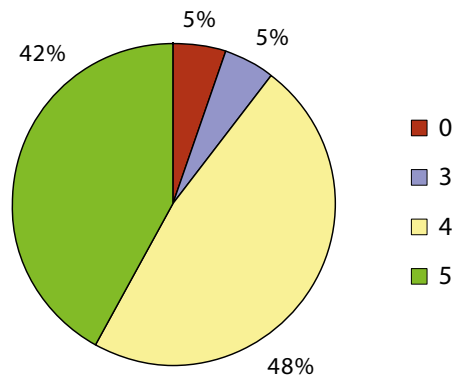

c) Technical staff

Figure 2.10. Assess the service culture of employees

Figure 2.10 shows that the majority of the respondents (11) gave the highest points to the service culture of the administration, four customers gave 4 points and three customers did not assess claiming their rare communication with the administration bared them from assessing (their opinion in the diagrams is shown as 0 points). The lowest points (1, 2 and 3) were given by none.

Fifteen customers scored the contact person's service culture with the maximum points, three scored with 4 points and only one gave 3 points; the lowest points were given by none.

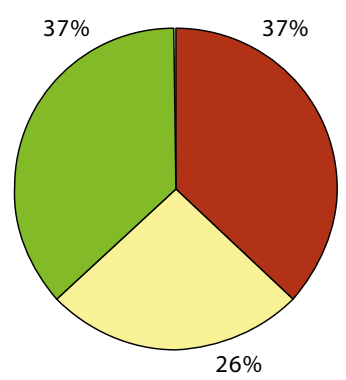

a) Administration

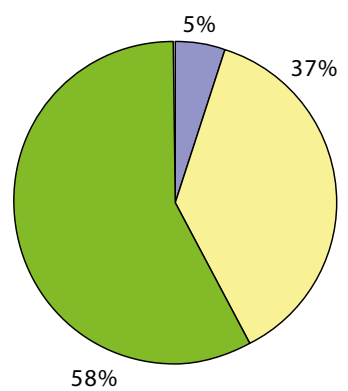

b) Contact person

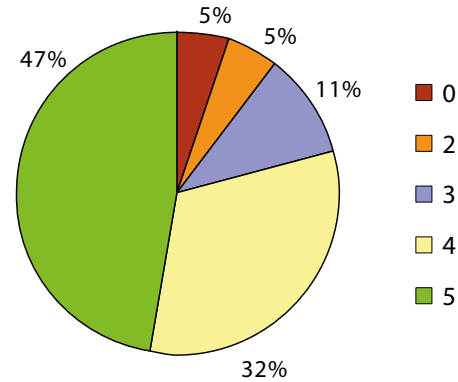

c) Technical staff

Figure 2.11. Assess the expertise and knowledge of the employees

The biggest portion of remarks from the customers came for the technical staff (some complained about unnecessary comments from workers or were dissatisfied with their behaviour), the overall opinion about the service culture, however, was positive: eight customers gave 5 points, nine customers gave 4 points, only one gave 3 points and one customer declined assessing on the grounds it had no personal contacts with the technical staff.

Twelve customers assessed the administration's expertise positively: seven with 5 points and five with 4 points. Seven customers stated they could not assess because of rare meetings (their opinion is shown as 0 points in the diagrams). 
Eleven customers were fully satisfied with the knowledge of their contact person, seven respondents gave 4 points and only one gave 3 points. The lowest scores ( 1 and 2) were given by none.

The scores given to the knowledge of the technical staff vary more: nine customers gave the highest score, six gave 4 points, two gave 3 points, one gave 2 points and one customer did not assess. The customer who gave 2 points to the expertise of the technical staff expressed a wish the staff would try to find out the specific requirements applicable to operations in its organisation because often the work failed to meet certain norms and needed redoing.

The survey also attempted to ascertain the customer opinions about the quality of services (Question 8). All services offered by the company were listed and the customers were asked to assess on a five-point scale the specific services they receive. The results are summarised in Table 2.3.

Table 2.3. The assessment of the quality of services

\begin{tabular}{|l|c|c|c|c|c|}
\hline & 1 & 2 & 3 & 4 & 5 \\
\hline Facilities management & & & 1 & 2 & 3 \\
\hline PVS (remote facilities management system) & 1 & & 1 & & 2 \\
\hline Microclimate laboratory & & & & 1 & 6 \\
\hline Energy-saving & 2 & 1 & 1 & 1 & 1 \\
\hline Technical support for engineering facilities & & & 4 & 6 & 9 \\
\hline Maintenance of oil and fat traps & & 2 & 1 & 2 & 1 \\
\hline Maintenance of lifts & & & & & 1 \\
\hline Maintenance of car parks & & & & 2 & \\
\hline Cleaning of grounds & & & & 1 & \\
\hline Cleaning of indoor premises & & & & 1 & \\
\hline Waste disposal & & & & 2 & \\
\hline Replacement of entrance mats & & & & 2 & \\
\hline Woodworks & & & & 3 & 2 \\
\hline Other: maintenance of electric facilities & & & & 1 & \\
\hline Other: minor repairs & & & & 1 \\
\hline
\end{tabular}

Table 2.3 shows that the customers are not dissatisfied with the rendered services: most gave the best scores ( 4 or 5 points), with exceptional praises to the microclimate laboratory. Six respondents gave the lowest scores ( 1 and 2 points) to the PVS, energy-saving services and the maintenance of oil and fat traps without giving any particular reasons of such assessment, thus it is difficult to gather whether the services are indeed of poor quality or just at variance with 
the customer's needs and expectations (all the more so when the other respondents scored the same services higher).

Asked to name specific services the quality of which, in their opinion, most needed improving, customers often noted their expectations to see the company as the initiator of energy-saving and to get more tips hereof; they also expected general suggestions about the ways to improve the weaknesses of their buildings and to optimise the performance of the equipment - instead of asking for services and solutions, customers wanted the company to be proactive and offer them. Some also criticised the services rendered through subcontractors - customers wanted better control of them to ensure the fulfilment of all contractual obligations.

In order to consider customer needs they were also asked whether they wanted any new services. Only a few respondents replied positively and named very specific services:

- maintenance of low voltages;

- configuration of the HVAC control and monitoring system, controllers and frequency transducers; inspection and calibration of HVAC sensors;

- maintenance of the tenants' cars (insurance, repair-shops).

In terms of future perspectives, each company needs to know what to expect from its customers, thus the survey ended with several questions that might help to assess possible actions of the customers and the perspectives of further cooperation.

First, they were asked to assess the cooperation with the company on a fivepoint scale (Figure 2.12).

Figure 2.12 shows that the majority of the customers were fully satisfied: eight gave 5 points, nine gave 4 points and only a couple scored the cooperation with 3 points (none scored with 1 and 2 points, thus they are not in the diagram). The lower scores were given for the aforesaid lack of the company's pro-activeness.

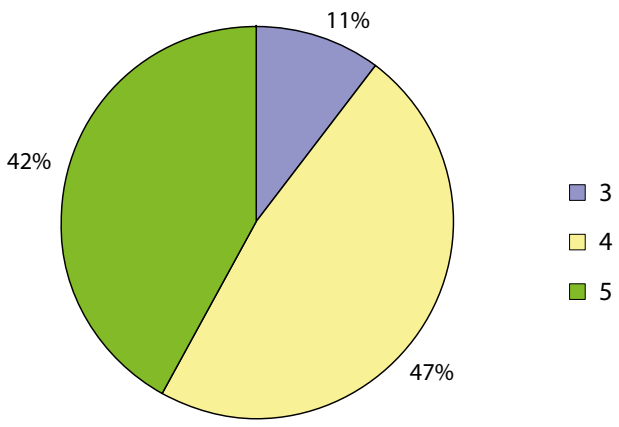

Figure 2.12. Please assess the cooperation with the company 
The customers were then asked whether they were willing to recommend this company to others (Figure 2.13). Eight respondents were absolutely sure they would ( 5 points for the likelihood), six gave 4 points, three gave 3 points and two gave 1 point. One of the customers who scored the likelihood with the lowest score was not sure whether it would recommend this particular company, and the other thought it more sensible at the moment (when quite a few organisations are short of money) to employ a person in charge of the facilities management rather than to hire a company. One of the customers which gave 3 points noted its inclination to recommend the company depended on the services important to the inquiring party.

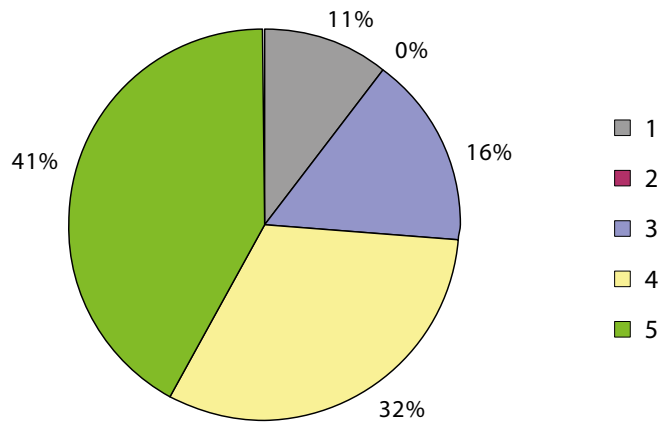

Figure 2.13. Would you recommend the company to others?

Question 10 asked the customers to state the degree, they believe, facilities management services contribute to their success (Figure 2.14).

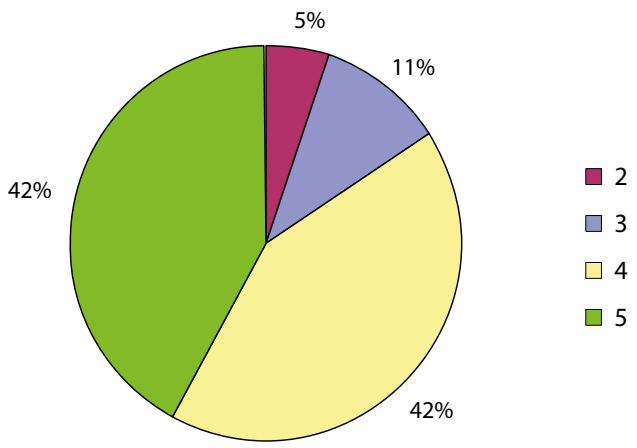

Figure 2.14. How much, in your opinion, facilities management services are important to your company (activities)?

The majority of the respondents realise that the facilities management is an important contributor to their operating success and is part and parcel of their activities: the same number of respondents ( 8 in each case) gave the highest points 
(5 and 4). Two customers gave 3 points and one gave 2 points. None claimed that such services did not have anything in common with daily activities.

Finally, the customers were asked whether or not they intend to decline any of the services in the nearest future. Only two respondents admitted such intentions and said they were keen to decline the full set of services in favour of a more alluring offer from another company (none of the customers said they constantly received offers from other facilities management companies) and in desire to save up; several other customers, speculating on things that could force them to terminate their cooperation with the company, also gave the same possible reasons to decline the services.

The results of this survey suggest that the customers of this particular company are satisfied with the services and their quality - the best scores (4 and 5 points) dominate. Those customers who give lower scores also state their reasons. Notably, customer satisfaction improves with regular meetings, also with chances to provide feedback, get answers and explanations - it can be employed for serving the customers better and improving their loyalty. The company's response and follow-up actions are also very important: it ought to consider customer feedback and requests and to take steps eliminating the causes of poor quality. It is equally important to make sure this survey is not a one-off event and to survey customer opinions on a regular basis in order to monitor company's progress and adjust to changing customer needs better.

\section{Conclusions}

The survey of service providers suggests that Lithuanian companies realise the importance of customer satisfaction as a key to successful operation, too. They ask customer opinions and do not ignore the complaints, because they believe customer satisfaction surveys are an important tool that helps to determine possible improvements and the potential of services to analyse the performance and to assess corporate activities from the customer's perspective - all leading to achievement of the main operating goals of the company. Notably, a customer survey is not enough: a broader dissemination of the survey data is required, because more often than not only the top managers discuss the results while each employee must be in the know of customer opinions and seek to achieve their satisfaction.

The surveyed customers of facilities management services stated their satisfaction with the services and although they might have a few remarks on the quality of some work, they have an overall positive opinion about their cooperation with the company. The main suggestion to the company is to consider the customer remarks and carry out regular surveys of their opinions in order to accommodate customer needs, to determine customer expectations and thus to improve their loyalty. 


\subsection{Application of nominal group technique for Facilities Management in Lithuania}

Nowadays decisions are no more taken by one decision maker, but by a group of people, called the stakeholders.

The term Decision-making is used in various disciplines. First of all we should talk about economics, where users and producers study deliberate and rational usage of resources problems. It is considered that people have inside themselves "the inner scales", using which the attractiveness (utility) of various objects can be balanced. Economics set rational rules of mans behaviour while solving problems concerning option (Nejman D. Fon, Morgenshtern 1970; Larichev 2000).

The term Decision-making is also applied in cognitive psychology (Solso 1995). Psychologists research the peculiarities of information handling system of a man. Hypotheses about how human memory affects processes concerning decisionmaking are also widely researched. With the help of many experiments psychologists try to test the possibility of human confines while solving problems of choice.

One of the fundamental objects of research in political sciences is the decision-making mechanism of political leader (Naylor 1984).

Decision-making - is one of the fundamental terms used in operation research science directions (Ventcel 1980).

This term can also be found in other branches of science: applied mathematics, zoology and other ones. The admissions of solution in many science disciplines are well founded. The basic emphasis of these problems is man's decision to select one solution from several possible ones. The fundamental object of decision-making theory is the research of the process of ones choice. This branch of science analyses how a man makes decisions and how the help has to be rendered while establishing special methods or computer systems (Larichev 2000).

So decision-making is an applied scientific discipline and while developing it the main part goes to the partitions that help people to solve problems related with choice.

By solving problems concerning facilities management and the decision-making by the group of specialists, the Nominal Group Technique will be presented (Brauers, Lepkova 2003).

\subsubsection{Nominal methods}

Questionnaires, Referenda, Delphi and Nominal Group Technique are Nominal Methods, i.e. the face-to-face dialogue is absent in order to decrease subjective influence.

Questionnaires fail, if broad issues are involved. Indeed the Steering Group may influence the opinions through its phrasing of the questions. Opinions can 
also be too divergent for a consensus to be reached. The steering group may well make too subjective a summary when analyzing the questionnaires.

Referenda, as a direct vote of people, may fail also, if broad issues are involved.

Delphi method. In broad problems the range of expertise required is not likely to be provided by one individual.

Round-table discussions show:

- failure to make assumptions and reasoning explicit;

- "bandwagon" effects;

- unwillingness to publicly expressed opinions;

- passionate debating.

Questionnaires fail when broad issues are posed. The opinions are too divergent to reach a consensus.

Delphi tries to improve either the committee or the questionnaire approach.

The Delphi method is a method for obtaining and processing judgmental data. It consists of a sequenced program of interrogation (in session or by mail) interspersed with feedback of persons interested in the issue while everything is conducted through a steering group.

This method is better because it eliminates the other disadvantages because of:

- Quantitative treatment;

- Expert knowledge;

- Anonymity;

- Convergence.

Delphi in its present form was first used by Dalkey and Helmer at RAND Corporation around 1953 (Dalkey, Helmer 1963; Brauers, Lepkova 2003).

The essential features of Delphi method are:

- A group of especially knowledgeable individuals (experts).

- Inputs with a singular meaning and quantitative as much as possible.

- The opinions about the inputs are evaluated with statistical indexes.

- Feedback of the statistical indexes with request for re-estimation also after consideration of reasons for extreme positions.

- The sources of each input are treated anonymously.

- Two developments: meetings and questionnaires. The organization of a meeting produced quicker results; the meeting however has to be organized in such a way that communication between the panel members is impossible (on-line computer with desk terminals and television screen, computer controlled feedback).

Disadvantages of Delphi method:

- Too long certainty with the questionnaire approach.

- Costly. 
Nominal Group Technique. A. L. Delbecq, A. H. Van De Ven, D. H. Gustafson initiated this technique (Delbecq et al. 1975; Gill et al. 1981; Delbecq 1983, Delbecq et al. 1986).

Similar to the Delphi method, the Nominal Group Technique is a method for obtaining and processing judgmental data. A group of especially knowledgeable individuals (experts), representing all stakeholders, is formed which comes together in a closed meeting at least during half a day. Out of experience the group is composed of at least eighteen individuals. This group is conducted through a steering group or a panel leader. The nominal group technique consists of a sequence of steps each of which has been designed to achieve a specific purpose (Brauers 1987):

1. The problem to be researched is carefully phrased by the steering group or by the panel leader as a question, which will stimulate creative thinking. Much of the success of the technique hinges around a well-phrased question. Otherwise, the exercise can easily yield a collection of truisms and obvious statements. A successful question is quite specific and refers to real problems. The question has to have a singular meaning and a quantitative form as much as possible.

2. The panel leader explains the technique to the assembled group of participants and they are asked to generate and write down ideas about the problem under examination. These ideas have to have also a singular meaning and a quantitative form as much as possible. Participants are not speaking to each other.

These conditions last for twenty minutes.

3. Each person in a "round-robin fashion" produces one idea of his own list and eventually gives further details. Other rounds are organized until all ideas are recorded.

4. The steering group or the panel leader will discuss with the participants about the overlapping of the ideas and the final wording of the ideas.

5. The nominal voting consists of the selection of priorities rating by each participant separately, while the outcome is the totality of the individual votes. A usual procedure consists of the choice by each participant of the $\mathrm{n}$ best ideas from his point of view with the best idea receiving $\mathrm{n}$ points and the lowest one point. All the points of the group are added up and a ranking is the democratic result for the whole group.

6. Out of experience one may say that there is still much wishful thinking, even between experts. Therefore, the group is also questioned about the probability of occurrence of the event. In this way, they become more critical even about their own ideas. The probability of the group is found as the median of the individual probabilities. 
7. Finally, the group rating $(\mathrm{R})$ is multiplied with the group probability $(\mathrm{P})$ in order to obtain the effectiveness rate of the event $(\mathrm{E}): \mathrm{R} \times \mathrm{P}=\mathrm{E}$.

Once again, the effectiveness rates of the group are ordered by ranking.

Advantages and disadvantages of the Nominal Group Technique:

1. Faster and less costly then Delphi.

2. No convergence, but final voting.

3. In this way Nominal Group Technique can be used:

- For a quick result

- As a preliminary version of Delphi (Brauers, Lepkova 2003).

\subsubsection{Application of Nominal Group Technique for the solutions to problems concerning Facilities Management}

In order to show how the Nominal Group technique is applied, the experiment was made at Vilnius Gediminas Technical University (October 15, 2002).

The main purpose was to show how this technique is applied for the concrete problem and also to show its working principles.

As the experts the specialists of Facilities management and representatives from Ministries and scientists took part in the experiment (see Table 2.4) (Brauers, Lepkova 2003).

Table 2.4. The composition of the group of experts took part in the seminar

"Application of Nominal Group Technique to Facilities Management"

(October 15, 2002, at Vilnius Gediminas Technical University) (Brauers, Lepkova 2003)

\begin{tabular}{|l|c|}
\hline \multicolumn{1}{|c|}{ Name of the represented company } & Number of members \\
\hline JSC „Valymo sistemos” & 4 \\
\hline JSC „Rubrikon apskaitos sistemos” & 2 \\
\hline JSC „Ogmios centras” & 2 \\
\hline JSC „Deltima” & 1 \\
\hline Vilnius Gediminas Technical University & 3 \\
\hline The Ministry of Defence & 2 \\
\hline The Ministry of Environment of the Republic of Lithuania & 1 \\
\hline
\end{tabular}

The steering group was composed of Prof. Dr. W. K. Brauers (University of Antwerp, Belgium) and on that time PhD student N.Lepkova (now Associate Prof. Dr., Vilnius Gediminas Technical University). Panel leader, directing the exercise, was Prof. Dr. W. K. Brauers.

During the experiment the following question was asked:

"Which events will the most influence the business outlook of the facilities sector of Lithuania in the following ten years"? 
Table 2.5. Important Events influencing the Business Outlook of the Facilities Sector of Lithuania over the period 2003-2012 (ranked after importance) (Brauers, Lepkova 2003)

\begin{tabular}{|c|c|c|c|c|c|c|}
\hline Rank & Name of event & \begin{tabular}{|c|} 
Given points \\
$\mathrm{R}$
\end{tabular} & Rank & $\begin{array}{c}\text { Media } \\
\text { probabilities } P\end{array}$ & $\begin{array}{c}E=R \\
\times P\end{array}$ & $\begin{array}{l}\text { Final } \\
\text { rank }\end{array}$ \\
\hline 1 & Member of European Union & 37 & 1 & 0,75 & 27,75 & 1 \\
\hline 2 & Large increase in foreign capital & 20 & 2 & 0,75 & 15 & 2 \\
\hline 3 & $\begin{array}{l}\text { More competition between facilities } \\
\text { management companies }\end{array}$ & 16 & 3 & 0,88 & 14,08 & 3 \\
\hline 4 & Large increase in GDP & 16 & 3 & 0,75 & 12 & 4 \\
\hline 5 & New materials and technologies & 12 & 6 & 0,75 & 9 & 5 \\
\hline 6 & Stability in international security & 14 & 5 & 0,50 & 7 & 6 \\
\hline 7 & $\begin{array}{l}\text { Higher quality in building } \\
\text { construction }\end{array}$ & 8 & 11 & 0,75 & 6 & 7 \\
\hline 8 & $\begin{array}{l}\text { Application of new information } \\
\text { technologies to facilities manage- } \\
\text { ment }\end{array}$ & 9 & 9 & 0,63 & 5,67 & 8 \\
\hline 8 & $\begin{array}{l}\text { More relations with foreign com- } \\
\text { panies having more experience in } \\
\text { facilities management }\end{array}$ & 9 & 9 & 0,63 & 5,67 & 8 \\
\hline 10 & $\begin{array}{l}\text { Better legislation in supervision } \\
\text { sector }\end{array}$ & 11 & 7 & 0,5 & 5,5 & 10 \\
\hline 11 & $\begin{array}{l}\text { Optimal quality-price relation for } \\
\text { services }\end{array}$ & 7 & 13 & 0,75 & 5,25 & 11 \\
\hline 12 & $\begin{array}{l}\text { Better public estimation for facilities } \\
\text { management }\end{array}$ & 8 & 11 & 0,63 & 5,04 & 12 \\
\hline 13 & Increase of the cost of living & 10 & 8 & 0,50 & 5 & 13 \\
\hline 14 & $\begin{array}{l}\text { Positive influence of the laws in } \\
\text { favour of facilities management }\end{array}$ & 6 & 16 & 0,75 & 4,5 & 14 \\
\hline 15 & $\begin{array}{l}\text { Higher qualification of the staff in } \\
\text { facilities management }\end{array}$ & 5 & 20 & 0,75 & 3,75 & 15 \\
\hline 16 & $\begin{array}{l}\text { Change taxation for buying and sell- } \\
\text { ing property }\end{array}$ & 7 & 13 & 0,50 & 3,5 & 16 \\
\hline 17 & Higher demand for construction & 6 & 16 & 0,5 & 3 & 17 \\
\hline 17 & Higher level of education & 6 & 16 & 0,50 & 3 & 17 \\
\hline 19 & $\begin{array}{l}\text { International exchanges between } \\
\text { students of facilities management }\end{array}$ & 7 & 13 & 0,25 & 1,75 & 19 \\
\hline 20 & $\begin{array}{l}\text { Increase of industrial sector and } \\
\text { decrease of agricultural sector }\end{array}$ & 6 & 16 & 0,25 & 1,5 & 20 \\
\hline 21 & Improvement of sanitary services & 4 & 21 & 0,25 & 1 & 21 \\
\hline 22 & $\begin{array}{l}\text { Increase of individual property of } \\
\text { housing }\end{array}$ & 1 & 22 & 0,25 & 0,25 & 22 \\
\hline
\end{tabular}

Each participant made the list of events to his mind, which could affect Facilities Management in Lithuania in the following ten years. Each event was named 
and discussed with the experiment leaders. Later each participant has chosen the most important five events from his point of view, with the most important event receiving five points and the less important event one point.

Events, named during the experiment ( 22 on the whole) are shown in Table 2.5 , also the intermediate data of the experiment is presented (Brauers, Lepkova 2003).

The results of the Nominal Group Technique by a group of especially knowledgeable persons around the Facilities Sector are extremely interesting.

Nineteen $\%$ of all the voting points go to the event called "Membership of the European Union", which indeed will not only influence the Business Outlook of the Facilities Sector, but the Economic Outlook of Lithuania itself.

Concerning international trade, perhaps not so much will change for the ten new members of the European Union. Indeed, they were already part of a European Free Trade Zone with a large possibility for European international trade. Lithuania may form an exception as being, until now from the ten new members, the less dependent from trade with the European Union, see Table 2.6 (Brauers, Lepkova 2003).

Table 2.6. Comparison of indicators concerning Lithuania for the year $2001^{\text {a) }}$ (Commission of the European Union 2001)

\begin{tabular}{|c|c|c|c|c|}
\hline Attributes & E.U. & Lithuania & Last Country & \\
\hline G.D.P/Capita (in Euro) & 23,200 & 8,700 & Latvia & 7,700 \\
\hline$\Delta$ G.D.P. $\%$ & 1.7 & 5.9 & Malta & -0.8 \\
\hline Unemployment \% & 7.6 & 16.5 & Slovakia & 19.4 \\
\hline Inflation $\%$ & $2(2.3)$ & 3.3 & Hungary & 12.4 \\
\hline Exports to E.U. (\%) & - & 47.8 & Malta & 41.3 \\
\hline Imports from E.U. (\%) & - & 44.0 & Lithuania & \\
\hline Agriculture (\% of G.D.P) $)^{\mathrm{b})}$ & & 7.0 & Lithuania & \\
\hline Agriculture (\% of Employment) $)^{\mathrm{b})}$ & & 16.5 & Poland & 19.2 \\
\hline
\end{tabular}

a) Source: Commission of the European Union. Report about the ten countries, candidate members of the European Union. The figures are standardised after the E.U. norms.

b) High figures in agriculture mark a country as being less developed, certainly when the \% of employment in agriculture is high.

A low productivity in agriculture occurs if the percentage of agriculture in GDP is smaller than the percentage of employment.

In Poland productivity in agriculture is extremely low. With $19,2 \%$ of the population only $3,4 \%$ of GDP is realized in agriculture.

More important for the ten new member countries will be that in the long run more and more interest will be shown for investment in these countries. 
Therefore, the experts of the Nominal Group Technique could be right to rank second a large increase in foreign capital. A positive consequence could be a large increase in Gross Domestic Product (rank 4), together with a negative one: an increase in the cost of living (rank 13). This last consequence could look strange. It is interesting to develop this point a bit further.

Furthermore, the facilities sector is aware of its other problems in the future:

- new materials and technologies

- higher quality in building construction

- application of new information technologies

- more relations with foreign companies having more experience in facilities management (does this mean possible mergers?)

- better legislation in supervision sector

- optimal quality-price relation for services

- better public estimation for facilities management

- positive influence of the laws in favour of facilities management

- higher qualification of the staff

- a change in taxation for buying and selling property

- higher demand for new construction

- international exchange of students in facilities management, etc.

The Nominal Group Technique for the Facilities Sector gave inspiration for going a step further, namely for writing down scenarios for the medium and the long term (Brauers, Lepkova 2003).

\subsubsection{Scenarios about the future of the Facilities Sector}

Three scenarios are foreseen for the period 2003-2012: the Fifth Resource Scenario, the Scenario of the Status Quo and the Cut Throat Competition Scenario (a World or a European war are assumed not to happen) (Brauers 1987; Brauers 1976).

\section{The Fifth Resource Scenario}

Foreign direct investments will come to Lithuania. They may find industrial zones with ready premises. However, they want more and they like to decide themselves on location. This is the moment that the fifth resource beside the resources of people, technology, information and capital, comes fully alive, namely the management of the Corporate Real Estate Assets. New companies will respond to this demand. These new companies of real estate assets management will look after space (location), design of the buildings, construction, reparations, maintenance, waste management and eventually demolition. They will look after the direct investments so to say "from the cradle until the grave". This has to happen in the most effective way, i.e. with an Optimal Multiple Objective Utility. In this way the foreign firms can look for an optimal Multiple Objective 
Utility for their People, Technology, Information and Capital, but also for their Corporate Real Assets.

2. The Status Quo Scenario

In this scenario, the situation in the facilities sector does not change. A set of small firms will remain operative in the facilities sector of Lithuania. By competition, aging, disagreement, etc. some small firms will disappear, but new ones will take their place.

\section{The Cut Throat Competitive Scenario}

In the Cut Throat Competitive Scenario the consequences of the "Balassa Samuelson Effect" will fully play. The productivity in the new member countries of the European Union will rise in the internationally traded sectors. The result is an increase in wages. The more national services have to raise their wages too, without an increase in productivity of the same size. This increase in wages will have an inflation effect in the country.

The Facilities Sector in Lithuania will fully undergo that influence. If it increases its prices, together with the other not internationally traded services, inflation will go up in Lithuania and ipso facto the cost of living will rise.

Instead of increase in prices, diminution of quality of its services forms another alternative for the facilities sector. At that moment cut throat competition between the facilities management companies will occur. In this struggle for life, only the fittest will survive. It is also the moment that mala fide companies will appear, which will exploit the customers as much as possible (Brauers, Lepkova 2003).

The same experiment was conducted with the group of master level students at VGTU in 2015 April. During the experiment the following question was asked:

"Which events will the most influence the business outlook of the facilities sector of Lithuania in the following ten years"?

The students were all working persons in Construction and Real Estate industry.

The differences from previous research were following:

1. Lithuanian already joined EU in 2004 and introduced euro as national currency in 2015 January 1.

2. A lot of legal acts of EU were adopted to Lithuania.

3. The competition between facilities management companies became more strong.

4. Few international facilities management companies came into the Lithuanian market.

5. The home owners' associations federation of Republic of Lithuania was established.

6. Apartment House Owners' Association of Vilnius city was established.

The results are shown in Table 2.7. 


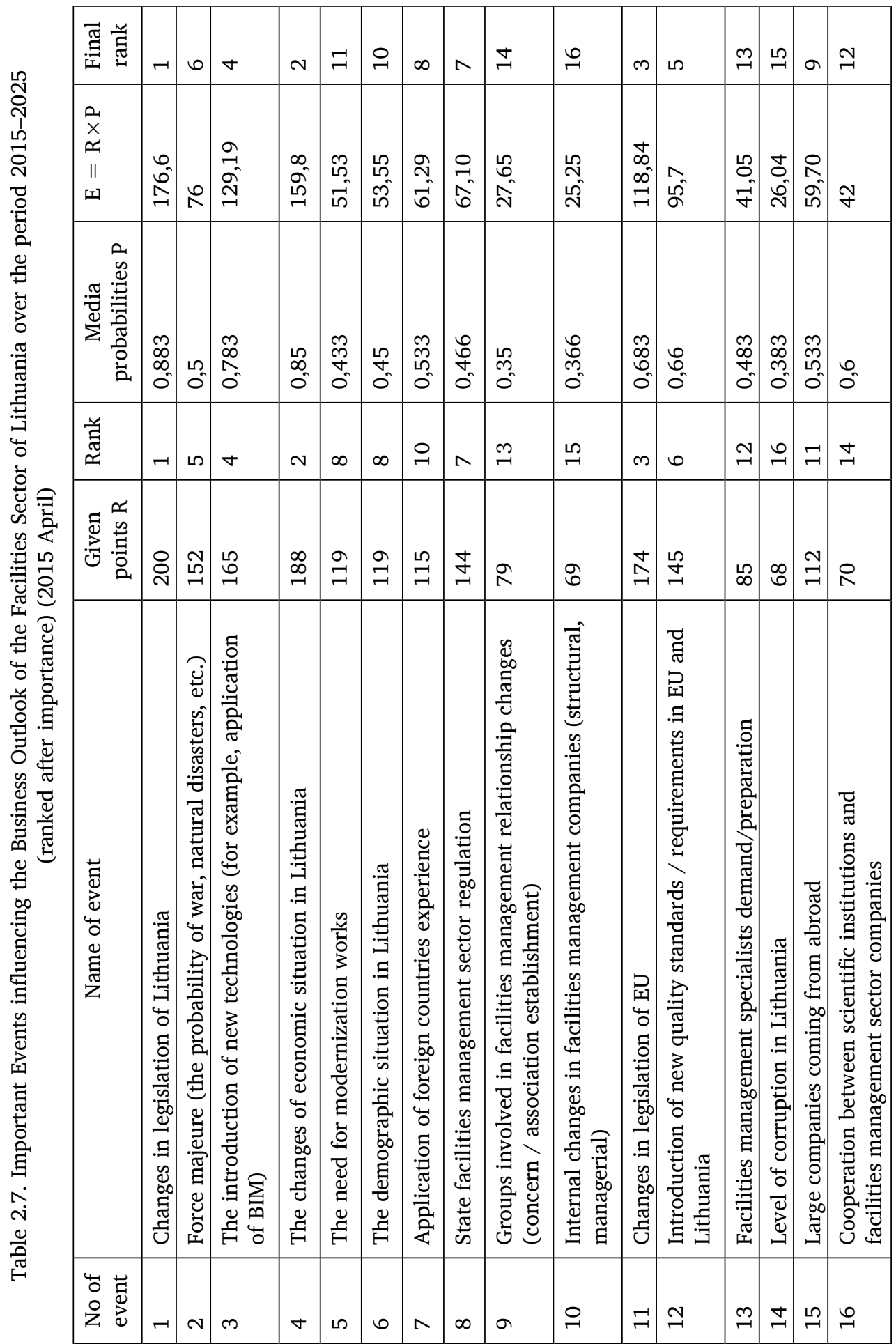


As can be seen from Table 2.7, the first place took possible changes in legislation of Lithuania, and this is influenced by a lot of factors, also becoming a member of EU.

\subsection{Suggested Facilities Management complex analysis model}

\subsubsection{Facilities Management Process complex analysis model}

In order to design and realize efficient Facilities Management process it is necessary to concern of its rationality starting with the determination of goals ending with their end of realization. Facilities Management process must be designed and implemented taking into account goals of the interested parties involved in this process, also possibilities and external micro- and macro-level environment that affects Facilities Management efficiency (Lepkova 2003).

Seeking to implement those tasks Facilities Management process complex analysis model was established (following the ideas of many authors), that comprises Facilities Management and the interested groups (involved in this sector) operating and trying to implement their goals also external environment, as a whole variant design, multiple-criteria analysis and determination of the effective variants, options (see Figure 2.15). This model is described in short.

Facilities management process consists of those between related stages: goal establishment, information collection, activity planning as well as its assurance, implementation and supervision.

While defining goals users or other interested groups together with building owners define main goals and their ways of implementation. While defining goals problems concerning buildings and management of them, supervision funding and other ones of similar manner are formulated.

The second stage is the collection of the exhaustive information necessary for the desirable problem to be solved.

Taking into account the user or other interested groups made requirements and influence of micro and macro environment, some alternatives are set. In the process of version examinations (researches) variant planning and Facilities Management multiple-criteria analysis, taking into account earlier accomplished analogical version experience and seeking for the interest groups to coordinate between themselves their actions. In the process of defining of goals and implementation of them, politics of the building supervision, usage, renovation and also the ways to implement the above-mentioned factors that could assure the problems concerning building usage will be solved attentively from the beginning of goal setting, are also the matters that have to be formed. 


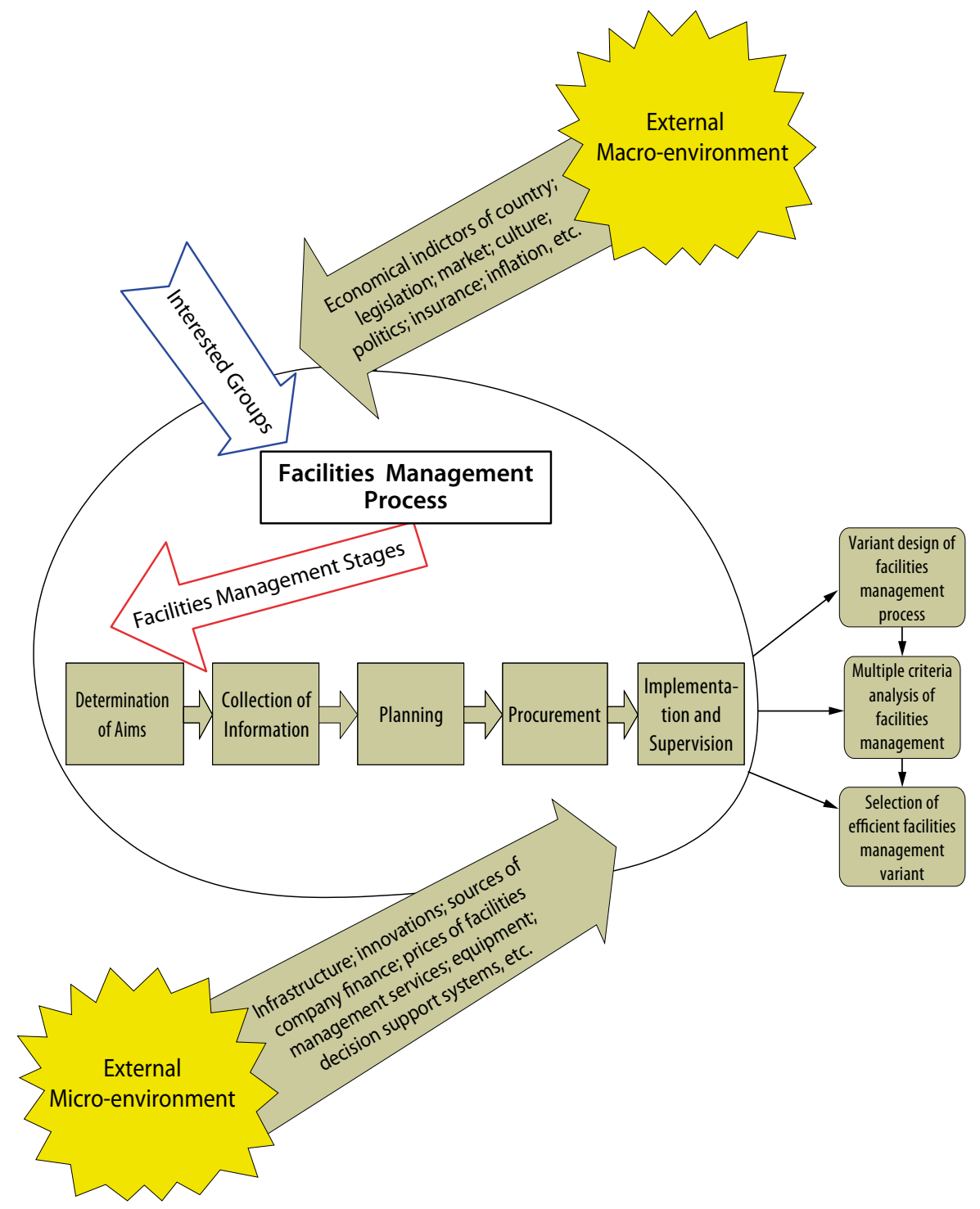

Figure 2.15. Complex analysis model of Facilities Management process

(Lepkova 2003)

Facilities Management process can be made of many other alternative variations. They are made of the alternative goal definition, information collection, processes of activity planning and supervision and of their composite parts, etc. These solutions and processes can be examined in more detail.

Interested groups (see Figure 2.16) acting reciprocally between themselves for a log time also take part in all the above - mentioned processes. 
In daily routine, FM managers, suppliers, building usage and supervision specialists form and analyze alternative decisions differently affecting decisions made by other specialists and general Facilities Management efficiency (Lepkova 2003).

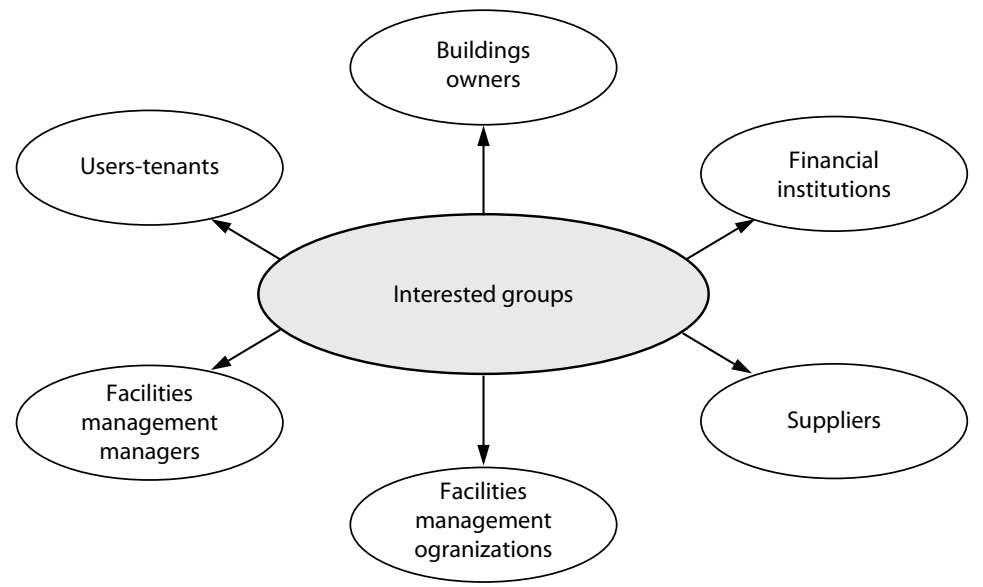

Figure 2.16. Interested groups involved in Facilities Management process (Lepkova 2003)

FM managers are interested in architectural, aesthetical, volumetric-planned building solutions, assurance of building strength and stability, prevention from noise, assurance of comfort conditions (temperature, relative moisture, natural light, protection from noise) rational engineering systems (heating, ventilation, water supply, sewerage, relations, automatics) regulation and maintenance; hygiene specialists are interested in pollution, structural decisions harm made to health, establishment; economists are interested in building price, usage expenses, taxes, insurance, loan interest norm, price change tendencies, quality level (social, technical, economical indexes); building supervision organizations are interested in efficient technology, organization and management methods and their application; exploitation specialist - in effective building use, supervision and renovation. In the process of Facilities Management alternative choice, different specialist present different information about the same examined version and makes the whole, comprehensively describing Facilities Management Process efficiency.

One of the fundamental tasks trying to increase FM process efficiency is the carrying out of the exact requirements set by the interested groups.

Interested groups always achieve many goals, and sometimes goals of one group are incompatible with the ones of the other. In order to avoid arguments of no meaning it is important to coordinate aspired goals of all interested groups, so that Facilities Management process would be efficient. 
Interested groups take part in the main FM process stages, that's why they have close interaction, and as only the whole (FM process stages and interested groups) reach the efficiency of the process it is necessary to establish variant planning and complex analysis.

Facilities management process efficiency depends on separate stages and the degree of solution rationality, external micro- and macro-environment and the level of the implementation of the defined goals, set by the interest groups. As you can see, the object of research made of few composite parts is rather difficult. For the establishment of rational alternative for Facilities Management process the complex analysis model of FM was created (see Figure 2.15). Taking into account this model it is possible to compose a lot of alternative variants, as well as to evaluate them and choose the most efficient one. Variety of solution helps rationally and more really to evaluate the risk, supervision conditions and to meet the requirements of the interested groups involved in this process (Lepkova 2003)

\subsubsection{Creation of criteria systems comprehensively describing facilities management process}

When creating criteria system of FM process reference was made to authors and their ideas. It is related with this that interested groups goals and the criteria system describing FM alternatives, in some way is rather subjective, so in order to increase the degree of objectivity of that system, we had to refer to the ideas of specialists involved in that field.

For example, criteria system relatively speaking, can be divided into four first level subsystems:

- criteria subsystem describing macro level factors influence made on the efficiency of FM process;

- criteria subsystem describing micro level factors influence made on the efficiency of FM process;

- criteria subsystem describing interested groups influence made on the efficiency of FM process;

- criteria subsystem describing separate FM process stages influence made on the whole FM process efficiency.

Each of these first level criteria subsystems, referring to Tree principle can be analysed in details.

Criteria affecting FM process are divided into quantitative and qualitative ones. Quantitative criteria are space and height of premises; furniture and equipment layout; exploitation expenses (see Figure 2.17). Quantitative criteria: rational planning and use of the premises, building supervision, repair and renovation, depreciation establishment (see Figure 2.18). 
When the building is built and is presented for exploitation, new requirements related with the proper object exploitation are risen. In order to assure building quality people occupying the building have to keep to the appointed requirements concerning exploitation. Building has to be supervised properly during the whole exploitation period in order to answer all the requirements set by people or appointed standards. When the building depreciates there's a need for evaluation of the degree of depreciation to foresee the further possibilities of existence: whether the building will be renovated, or demolished (Lepkova 2003).

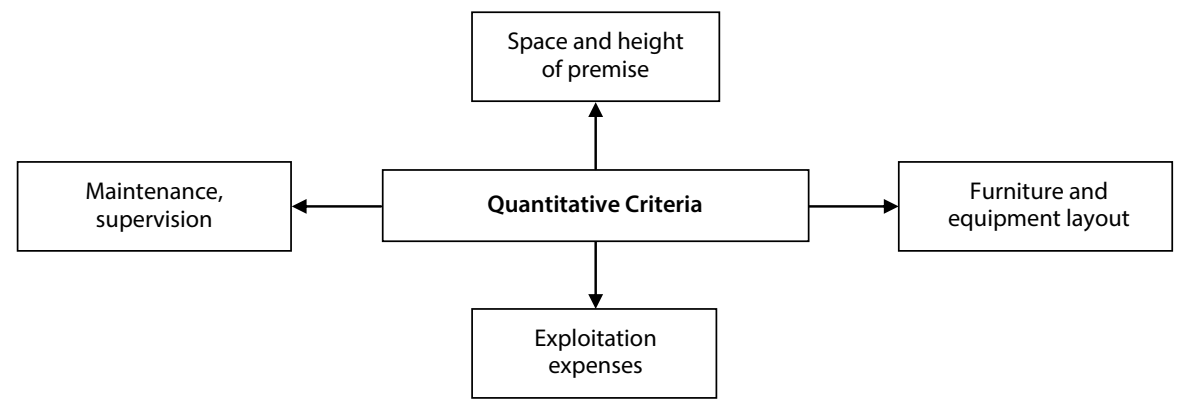

Figure 2.17. Quantitative criteria influencing facilities management (Lepkova 2003)

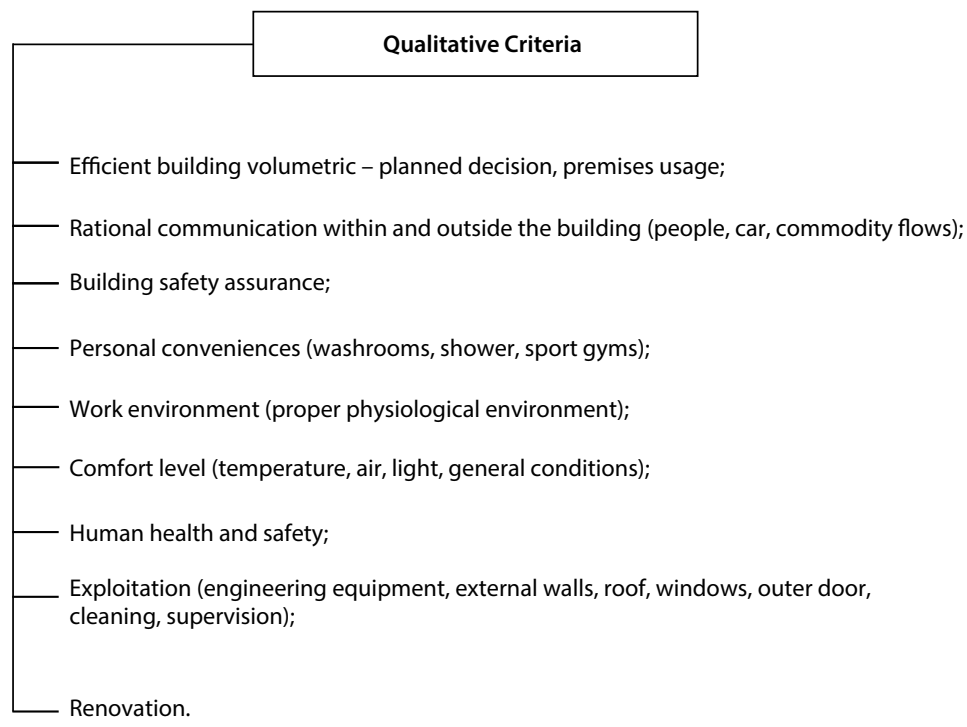

Figure 2.18. Qualitative criteria influencing facilities management (Lepkova 2003)

\subsection{Model of Facilities Management consulting knowledge system}

In any organization, there is a certain component of the work carried out that can be termed "knowledge work". Many researches (Gurteen 1998; Martin 2003; 
Kamara et al. 2002; Kululanga, McCaffer 2003; Koch 2003) have provided discussions and definitions of the terms "knowledge", "knowledge work", and "knowledge management". In an engineering consultancy domain "knowledge work" refers to work that relies on the accumulated knowledge, experience, and judgment of the individuals both as persons or members of a team, rather than the ability to be trained to learn and execute simple procedures. Garvin (1998) provides distinctions between tangible assets and intangible (knowledge) assets. The knowledge that is required to carry out those work elements can be considered to be an asset of the company - its "intellectual capital" (Garvin 1998).

In consulting engineering, knowledge work makes up the major component of a firm's effort, output, efficiency and profitability. The primary product is an intellectual capital the firm's specialists knowledge rather than physical. Any physical output, such as design drawings, documents, etc., are simply a representation of the knowledge that is being sold. This is not only the technical or professional knowledge acquired by the firm's staff members during, and subsequent to, tertiary education, but also their accumulated knowledge of clients, business sectors, organizational procedures, other industry personnel, and so forth (Kazi 2005).

When knowledge is considered as an asset in consulting engineering, a loss of company knowledge, or its inefficient use, will have an impact on the company economic performance (Kamara et al. 2002). Company knowledge can be lost either through staff turnover or simply a loss of organizational memory of what once was known. Martin (2003) reports on the problems of inefficient knowledge management for a company and how this can impact on its operation and profitability (Lepkova, Bigelis 2007).

\subsubsection{Consulting knowledge system for Facilities Management sector in Lithuania}

The main objective is to create a Web-based consulting knowledge system that will enable different users to get relevant information on the facilities management subject.

The users of the system are:

- facilities management professionals;

- facilities management managers, services suppliers;

- universities lecturers and students;

- other interested parties.

Consultations should be provided in different ways such as:

- searching website using domain ontology;

- email;

- or by using decision support systems. 
The consulting knowledge system will be developed by a few stages: short specification - development of standalone prototype - prototype enhancement after entering information and knowledge - development of detail specification - development of an online system - implementation - enhancement using every day experience.

Standalone prototype can be developed as an off-line software application (without Internet access). Later, the part of main information and knowledge will be stored in the system. The interface, reports (their content and forms), searching tools, questions and answers and additional metadata (semantics) is to be analyzed and enhanced on the next stages.

The main parts of the systems are: content-information snippets-ontologyqueries on the internet-questions/answers.

The main parts of the system are shown in the Figure 2.19.

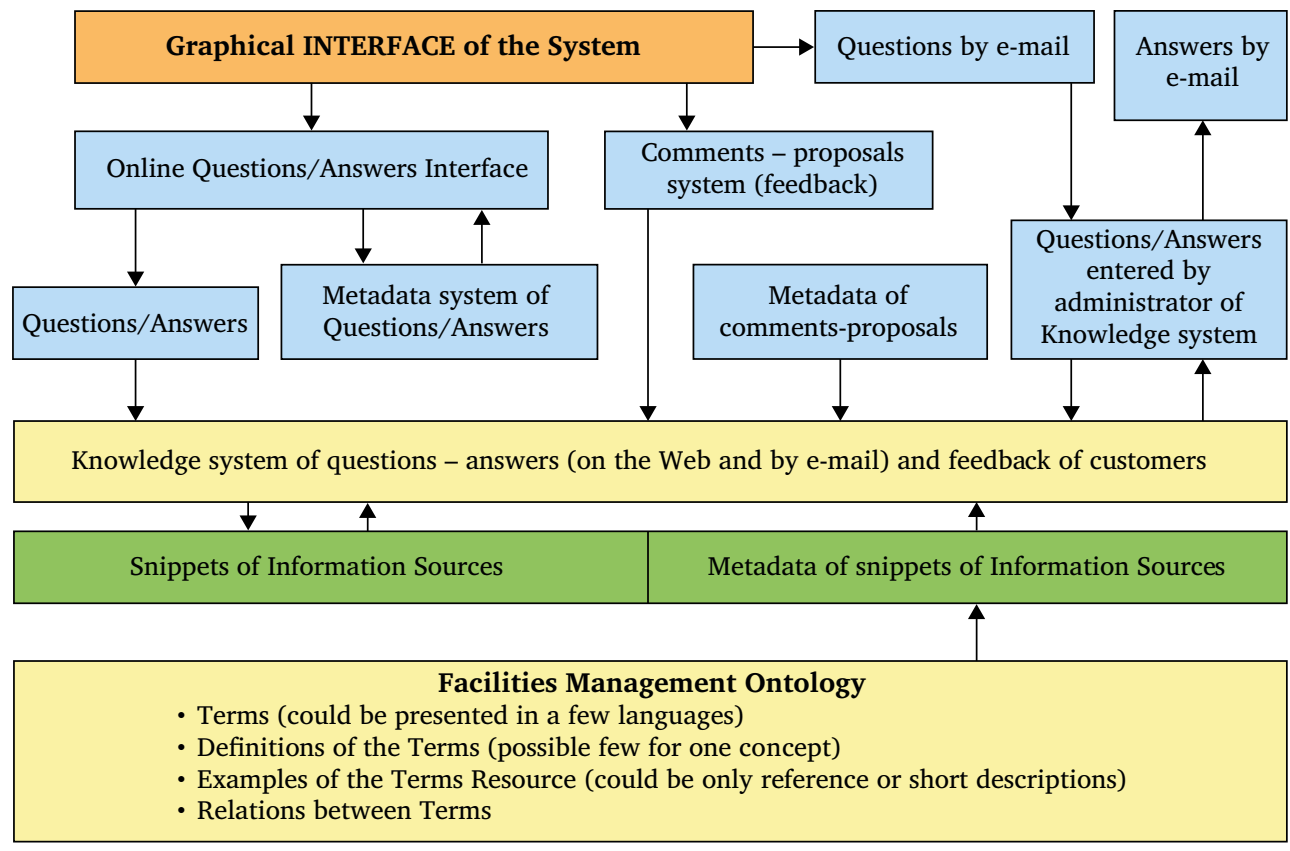

Application of Multiple-Criteria analysis Methods for Facilities Management Alternatives (System Integration with Existing Facilities Management Decision Support System)

Figure 2.19. The main parts of Facilities Management Consulting Knowledge System (created by Lepkova and Bigelis 2007)

The main functions of the system are:

1. Consultation of different interested parties in different ways (questions online, questions by email and comments (proposal) of customers). 
2. Continual development of the system (interface, ontology development, new information complement to the system, continual development of learning software applications).

3. Arrangement of analytical reports.

4. Development of methods.

5. System integration with other systems (Lepkova, Bigelis 2007).

Main features of the facilities management consulting knowledge system are:

- the system is a people and technology integrated system;

- the system will evolve by using it each day;

- the system will be used by different interested parties;

- feedback will be collected, analyzed and stored;

- the system will store information and knowledge on facilities management during all building life cycle;

- Questions-answers, feedback and snippets of information sources (e.g. documents) will be enriched by metadata that will be created manually or selected from facilities management ontology.

Different information is entered mainly as snippets. Therefore search results are short and contain only relevant information. User can browse domain ontology before entering question (query). It provides better quality both of queries and search results. The term "question-answer" is used instead of terms "search" and/or "query" as it is planned to use natural language queries (Lepkova, Bigelis 2007).

\section{Conclusions}

The proposed facilities management consulting knowledge system should be created in a few languages (Lithuanian, English, using of other languages depends on the market where the system will be applied).

Collaboration with specialists from other countries is needed.

The appropriate EU legal information (full documents or snippets) will be entered when the requirements of customers will be specified.

The proposed system will facilitate interaction between facilities management services users and providers.

\subsection{Administration of housing}

\subsubsection{Administration forms of housing (multi-family apartment houses) in Lithuania}

The Civil Code provides that the part of communal-use objects of a multi-family apartment house which belongs to the flat or other premises owner equals to the ratio of the useful area of owned premises and the useful area of an apartment house. The obligation of owners to pay expenses for maintaining and preserving 
the house, taxes, levies and other payments, to make regular settlements in order to accumulate funds which will be allocated for the house refurbishment proportionally to their part arises from the size of share in the common partial ownership of every owner defined in the Civil Code (2005).

Three administration forms of common partial ownership of flats and other premises owners are provided for in the Civil Code (2005):

- a multi-family apartment house owners association,

- joint activity contract concluded by flat owners;

- or an administrator of communal use objects appointed by the municipality.

Multi-family apartment house owners association. The Lithuanian practice has shown that communal-use objects are administered the most effectively and economically when the function is carried out by multi-family apartment house owners associations created by owners themselves. A multi-family apartment house owners association is a non-profit legal person of limited liability which may have all rights and duties of legal persons. However, the association may not become the founder of other enterprises and engage in other activity which is not related with the management of the multi-family apartment house, usage, maintenance and management of communal-use objects as well as land plot attributed to the house. An association is responsible for the management, maintenance and other administration of communal-use objects. Decisions regarding the funds related with the implementation of mandatory requirements for the maintenance and usage of communal-use objects, their accumulation or borrowing are legal if more than $S$ of all members of the association vote for them during the association members' meeting. It should be noted that the membership in the association is not mandatory in Lithuania. It was established in the legal acts valid earlier that a person who has acquired a flat or other premise where a multi-family apartment house owners association has been established shall become a member of the association and obtain all the rights and obligations of the association member automatically. However, the Constitutional Court of the Republic of Lithuania accepted a decision by which it stated that such regulations of legal acts contradicted the Constitution and that no one might make a person become a member of any organisation against his/her will. The decision of the Constitutional Court determined frequent disputes in multi-family apartment houses where associations were established. Should people who are not members of the association obey to the association decisions? A recourse was found after the regulation was established in the Civil Code that decisions of the association should be mandatory to people who are not members of the association only in cases when such decisions are related with mandatory requirements of the building maintenance.

Joint activity contract concluded by flat owners. Another method of managing communal-use objects of a multi-family apartment house is a joint activity 
contract concluded by owners of flats and other premises in a multifamily apartment house. This is a civil deal by which owners do not create a separate legal person but directly implement the rights of owners related with the communaluse objects maintenance and other management established in legal acts. Owners of flats and other premises agree among each other by the joint activity contract regarding the procedure of communal-use objects maintenance, distribution of expenses and acceptance of decisions regarding the maintenance of communaluse objects. The parties of the joint activity contract shall assume solidary responsibility according to the joint non-contractual obligations.

Administrator of communaluse objects appointed by the municipality. The legislator provided for an alternative method for maintaining and managing communal-use objects in order a multi-family apartment house would not be left without the proper maintenance when owners of the house flats and other premises do not establish an association and do not conclude a joint activity contract - an administrator of communal-use objects appointed by executive municipal institutions. A private or public legal or natural person who has the right to provide real property administration services may be appointed as an administrator. An administrator shall be responsible for the proper maintenance of communal-use objects of the house: he/she shall make the description of communal-use objects, shall perform and organise constant supervision works of the communal-use objects and shall carry out liquidation of accidents, announce tenders and conclude contracts with natural or legal persons performing repairs, he/she shall summon meetings of premises owners regarding the acceptance of decisions related with the communal-use objects, shall collect contributions from flats and other premises owners for the performed or planned maintenance or repair work of the communal-use objects. The meeting of flats and other premises owners may demand that the executive municipal institution which has appointed the administrator should change him/her if he/she does not carry out the functions properly. Also, more than $1 / 2$ of the premises owners may demand for changing the administrator by expressing their distrust in writing.

Facilities Management Service providers in Lithuania

The activities of the facilities management service companies are regulated by laws of Republic of Lithuania. Companies that shoulder the responsibilities for a building's supervision have to operate within the confines of the Law on Joint Stock Companies.

These companies carrying out the following exploitation and repair works:

- Repair and exploitation of the building and its engineering infrastructure;

- Supervision and repair of heating systems and gears;

- Supervision and repair of hot and cold water supply and canalization systems; 
- Electric power supply, supervision of general housing electrical systems and responsible for mentioned services quality (Lepkova, Bigelis 2007).

These companies also manages the accounting of the provided services: calculations of charges by estimated rates for premises heating, hot and cold water usage, electric power usage in electrical system, general buildings exploitation, supervision and repair. These companies are responsible for all the above mentioned calculations and ensure that they are correct.

The owners of the buildings and occupants pay all the charges through the banks, online or through other specified financial institutions.

The companies can also have other activities, close to the main functions. For instance, the production of construction materials, exploitation of parking places etc.

Majority of such companies are joint stock companies, but mostly all or part of the share capital belongs to municipality.

As earlier mentioned, the occupants of buildings and also owners pay for the supervision of premises and also utilities and services provided by facilities management companies. This is the main activity of the facilities management companies and main source of incomes.

Municipalities are obligated to ensure that facilities management companies provide fixed quality services to the occupants. The companies must inform the occupants and buildings owners about technical conditions and quality of gears and communications. Unfortunately, sometimes buildings owners and occupants are dissatisfied with the provided services, quality and charge rates.

The main works carried out by facilities management companies are as follows (Lepkova, Bigelis 2007):

1. Supervision of construction of the buildings: of foundations, walls, floor, roof, balconies and etc.;

2. Supervision of facades, out doors, windows of premises of general usage;

3. Supervision of engineering systems of dwelling houses: hot and cold water, heating, gas, electrical systems supervision and repair;

4. Supervision and cleaning of general usage premises, foundations and stairway.

5. Supervision of lifts and communication systems.

6. Supervision and cleaning of yard territory.

7. Facilities management companies have signed exploitation and payment for services agreements with dwellings houses owners or multi-flat story buildings owners associations, by which the companies obligated to exploitation, repair, supervision of buildings and engineering systems, also to prepare the buildings for the heating season. The above mentioned companies could organize technical inspections of buildings and evaluate their condition. 
The main problem of all the above mentioned relationship between occupants and facilities management companies is that in Lithuania the common system, which could provide all the needed information to the occupants, is non-existent (Lepkova, Bigelis 2007).

\subsubsection{Administration forms in Estonia}

By the present day there are 2 basic management forms in Estonia: flat owners associations (FOA) - this is the prevailing form and communities of flat owners, which had been taken on a national level as an additional measure for blocks where residents could not found flat owners association. Both forms dominantly function on a block basis.

What is characteristic for both forms is that they actually out-source services from management and maintenance companies, which are as is known private companies in Estonia. There are no any longer municipal management divisions. So, all are at the market competing for clients and clients have free choice to choose between the companies offering services.

This is a crucial qualitative step forward already from the second half of the 1990s onwards as flat owners have every opportunity to control their resources and which is significant to make the decisions about maintenance and renovation which the hired company realises. More and more often not only maintenance service is being out-sourced but the whole package of management, which means that the company makes all the work but has to report to the flat owners, discuss with tem before taking a decision and then act only upon FOAs decision.

There could exist still on a very small scale and in small blocks of flats some self-management and self-maintenance practice. However, there are particular services which have to be out-sourced and done by professionals.

The general tendency is that the whole field of housing property management and maintenance is becoming professionalised and more cooperation occurs between clients and service providers particularly within the context of knowledge exchange along this experience.

Contract-based form was a dominating type before the maintenance divisions at city districts were privatised in Estonia. Then indeed all individual flat owners had to use this opportunity to keep their blocks in shape. However, this form has practically disappeared. On the other hand, it does exist for single family house owners who buy their services on an individual basis - determined by their type of housing - from companies.

There are no municipal-public services in Estonia any longer - yes, there is social housing and municipal housing, but the owner of that housing usually buy also the maintenance services from the companies active at the service market. 


\subsubsection{Administration forms (types of ownership) in USA}

Housing ownership is of three primary types: fee simple, condominium, and cooperative. A fourth type, "interval ownership", describes a variety of options for ownership that allow the owner's use of real property on an occasional basis (Schmitz 2004).

Free Simple. Most housing sold in USA is free simple; that is, the owner is invested with the right to dispose of the property in any way he or she wishes. The owner can use the property so far as it will not interfere with the rights of others as typically controlled by zoning ordinances. The purchase of the property can be financed outright or, more commonly, through a mortgage arrangement. Free simple ownership is used for most single-family detached projects; the property owner owns the house in its entirely, the land the house sits on, and generally the property around the periphery of the house-the front and rear yards and two side yards. The design of the lot and the house is largely a function of the sale price the developer hopes to receive as determined by the market analysis. As a rule, the larger the lot, the more expensive the house, although luxury homes on small lots or expensively finished attached houses are becoming more prevalent as available land becomes more scarce. And with aging population and today's lifestyles, homeowners may actually prefer smaller lots to reduce maintenance chores and costs (Schmitz 2004).

Condominium. A condominium is a form of ownership, not a housing type. Each dwelling unit is owned outright by its occupant, not in common with other tenants like a cooperative. Each condominium may carry an individual mortgage, while a cooperative has a common mortgage. A mortgage for a condominium might be reduced as the individual's financial position permits, while the owners of a co-op are bound by a set schedule of payments on the cooperative corporation's mortgage. The condominium form of ownership first acquired legal status in the United States and its possessions in 1951 with the passage of a law in Puerto Rico. It was followed by another Puerto Rican law in 1958, the Horizontal Property Act, which governed the ownership of property categorized as condominium. Congress amended the National Housing Act in 1961 to extend government insurance of mortgages to condominiums, and by 1968, all 50 states had enacted their own enabling legislation for condominiums. Condominiums may be structured so that a unit is defined as an airspace or as a portion of real property, such as walls and land. All parts of the condominium development not specifically owned by an individual are owned in common by all the development's owners. Ownership of common elements is typically defined as a percentage proportionate to the square footage of each unit; the percentage interest in common elements is granted to owners by deed. Owners of condominiums have a choice of owning their units and clear of any mortgages or financing them through regular mortgage channels. Typically, a condominium id 
financed in two phases: the developer finances the entire project through a blanket mortgage, and owners finance individual units through individual mortgage or government-insured loans. Owners may sell, will, or give away the property. Each deed is recorded separately, and taxes are levied individually. These advantages of actual ownership appeal to many-especially those who may not be able to afford a free simple lot and those who may not want the responsibilities of maintenance associated with more conventional homeownership. Because the condominium form of ownership is not tied to a particular design, it may appear in mid-rise or high-rise buildings, garden-density units, attached town-houses, or even single-family detached houses. It might also exist as a combination of two or more of these types of houses as part of a single condominium association. The condominium form of ownership is so versatile that it exists in commercial and industrial buildings as well as in residential housing; condominium associations can also include combinations of residential and commercial uses.

Management of condominium is controlled by a condominium association. The developer who has constructed the units and established the condominium association usually assumes responsibility for managing the association initially, before passing it on to home-owners. Common responsibilities typically shared by the association may include maintenance of the building(s), landscaping, private streets and parking areas, recreational facilities like swimming pools and tennis courts, and any common interior elements like lobbies, elevators, heating and air-conditioning equipment, and hallways.

The association is also responsible for acquiring insurance coverage for the building; owners of individual units carry separate coverage for their personal belongings. Owners are charged a monthly free to cover costs of maintenance, insurance, and a reserve account according to the value of their units. Often, fees are based on square footage so that those with larger units pay a proportionately greater share of the costs. Without agreement of the owners in accordance with the condominium's legal documents, neither the assessment nor the maintenance liability can change (Schmitz 2004).

Cooperative. In the cooperative form of ownership, a single property is divided into units, or use portions, with each user or "buyer" owning shares of stock in the corporation that owns the building. Typically, cooperative ownership is employed in a multiunit building-garden density, mid-rise, or high rise-where all the customary services are offered but where ownership and cost of operation are shared by the occupants in proportion to the value of the space they occupy. Co-op buyers are entitled to a proprietary lease of their space.

The predetermined rental rate for each unit is reached by prorating the costs of operation among tenants. The lease requires the co-op owner to make a monthly maintenance payment to the corporation to cover its operating expenses, mortgage interest, and real property taxes. Because interest and property 
taxes are obligations of the corporation, deductible only for calculating its taxable income, the proprietary tenant must be individual, who is under strict requirements by the Internal Revenue Service to receive tax deductions.

The cooperative form of ownership has existed for some time, notably in major urban markets like New York City. The form of ownership appeals to confirmed city dwellers and those who seek the tax advantages of a corporation. The cooperative has not caught on in this country as a popular form of ownership, although it is suitable for many suburban locations and offers advantages to investors who might otherwise be merely tenants. A primary disadvantage lies in the prorating of the building's operating costs among owners. Further, responsibility for mortgage payments is shared with other owners, each according to its own portion of ownership. Only that amount of the mortgage interest for which an individual owner is responsible can be deducted from his or her income tax.

Perhaps the most significant reason that cooperative housing has not been more popular is that ownership rests with the corporation, not in the individual units. Thus, owners cannot pass their shares in the corporation on through their estates or by any other means. The shares instead are sold back to the cooperative's board of trustees, which has ultimate authority over their disposition. Further, the co-op can incur liabilities, and stockholders may find themselves obligated for the liabilities of other stockholders (Schmitz 2004).

Interval Ownership. The most commonly known form of interval ownership is vacation timesharing. Most timeshare units are located in popular resort settings; owners of the units are guaranteed a period each year (usually a week) when they can use the unit. Ownership in vacation timeshare units is usually in free simple title, with each owner holding a deed. Alternatively, owners may purchase a "right to use" the unit for some period (usually 30 years) without a deed. Most vacation timesharing developments are structured as condominiums, with all owners belonging to the condominium association and paying fees.

Another form of interval ownership is "fractional ownership". Rather than purchasing one week, owners purchase up to 13 weeks, or a quarter year. Thirteen-week purchases are often called "quarter shares". Fractional ownership is most often purchased with a deed that gives the owners the right to use the unit in a solid block of time or in "floating" blocks that may be reserved in advance.

Vacation timeshare and fractional ownership programs have historically been most popular with active retirees, but as baby boomers age, there may be wider market opportunities for this type of homeownership (Schmitz 2004). 


\section{References}

Aatsalo-Sallinen, J. 2006. A need to measure quality. EuropeanFM insight 2006. Issue 1, pp. 13-14.

Alexander, K. 1997. Facilities Management. Theory and Practice. London. 173 p.

Alexander, K. 1995. Facilities risk management, Facilities 10(4), April.

Alexander, K., 1996. Facilities Management: Theory and practice. Taylor\&Francis. p. 174.

Ancarani, A.; Capaldo G. 2005. Supporting decision-making process in facilities management services procurement: A methodological approach, Journal of Purchasing \& Supply Management 11: 232-241.

APO (Asian Productivity Organization), 2008. Knowledge Management. P-Glossary, [accessed 10 July 2012]. Available from Internet: http://www.apo-tokyo.org/cgi/ apo_p-glossary.pl?record $=56$

Atkin, B.; Brooks, A. 2009. Total facilities management (3d ed.), Wiley-Blackwell, p. 304.

Bagdonienè, L., Hopenienè, R., 2009. Service Marketing and Management (textbook in Lithuanian). Kaunas: Technologija, 465 p.

Balabanov, I. T. 2000. Real Estate Economics. Sankt-Petersburg. 208 p.

Barrett, P. 1993. Facilities Management. Research Directions. London, RICS Books. 250 p.

Barrett, P. 1998. Facilities Management: towards best practice. Blackwell Science. 256 p.

Becker, F. 1990The Total Wokrplace: Facilities Management and the Elastic Organization. New York, Van Nostrand Reinhold.

BIFM, 2004. Rethinking facilities management: accelerating change through best practice, Survey Report, [viewed 201212 10]. Available from Internet: http://www.bifm.org. uk/docs

Brauers, W. K. 1976. Systems Analysis, Planning and Decision Models, Elsevier Scientific Publishing Company, Amsterdam-New York, 42-44 inspired this text on the open discussion methods.

Brauers, W.; Lepkova, N. 2003. The application of the Nominal Group Technique to the business outlook of the facilities sector of Lithuania over the period 2003-2012, International Journal of Strategic Property Management 7(1): 1-9.

Brauers, W. K. 1987. Nominal Methods in Group Multiple Decision Making. Research Paper $\mathrm{N}^{\circ}$, Institute for Developing Countries, University of Antwerp, RUCA, Antwerpen.

British Institute of Facilities Management. Best Practice Guide: Space Planning and Management. London, BIFM, 1996a.

British Institute of Facilities Management. Best Practice Guide: Business Continuity Planning. London, BIFM, 1996b (updated Nov 2010).

Casimir C. Barczyk. 1999. General Quality Management (in Lithuanian). Vilnius: Piligrimas. $256 \mathrm{p}$.

Chotipanich, S. 2004. Positioning facility management, Facilities 22(13/14): 364-372. 
Civil Code of Republic of Lithuania. 2005. 447 p. ISBN 9955-517-07-7.

Commission of the European Union. Report about the ten countries, candidate members of the European Union. The figures are standardised after the E.U. norms. 2001.

Construction Law of the Republic of Lithuania. Actual since 200212 10. Internet access: http://www.lrs.lt

Construction Technical Regulation STR 1.12.05: 2010 Required building (residential) operation and maintenance requirements (in Lithuanian). Vilnius, 2010.

Construction Technical Regulation STR 1.12.05:2010 Mandatory buildings (residential) use and maintenance requirements (in Lithuanian). Approved by the Minister of Environment of the Republic of Lithuania in 2002. 1 July. Order No. 351.

Dalkey, N.; Helmer, O. 1963. An Experimental Application of the Delphi Method to the use of Experts, Management Science April 1963, 458-487.

Delbecq, A. L. 1983. The Nominal Group as a Technique for Understanding the Qualitative Dimension of Client Needs, in Assessing Health and Human Service Needs, R. A. Bell, editor, N. Y., Human Services Press, pp. 210-218.

Delbecq, A. L.; Van de Ven, A. H. and Gustafson, D. 1986. Group Techniques for Program Planning (2nd ed.). Greenbriar Press, Madison, Wisconsin.

Delbecq, A. L.; Van De Ven, A. H.; Gustafson, D. H. 1975. Group Techniques for Program Planning: A Guide to Nominal Group and Delphi Processes, Scott, Foresman and Co, Glenview (III).

Eddie C.M. Hui, Zheng, X., 2010. Measuring customer satisfaction of FM service in housing sector: A structural equation model approach, Facilities 28(5): 306-320.

Elastman, C. M. 1993. Life Cycle Requirements for Building Product Models, 672 p.

EN 15221-1:2006. Facility Management-Part 1: Terms and Definitions. 2006 CEN, p.15.

EN 15221-3:2008. Facility Management-Part 3: Guidance how to achieve/ensure quality in facility management, 2008 CEN, p. 41.

Facility Management: Grundlagen - Methoden Anwendungen. (1999). Berlin: VDI Geselschaft Technische Gebäudeausrüstung, 219 s.

Fečikova, I. 2004. An index method for measurement of customer satisfaction. The TQM Magazine 16(1): 57-66.

Finch, E. 1995. Risk and the facilities manager. Facilities 10(4) April, 1995.

Flanagan, R. and Norman, G. 1995. Risk Management and Construction, Blackwell, Oxford.

Garvin, D. A. 1998. Building a learning organization. Harvard Business Review on Knowledge Management. Boston: Harvard Business School Press. 1998. Jul-Aug 71(4):78-91.

Gill, S. L.; Delbecq, A. L. and Snodgrass, T. J. 1981. Three chapters on Program Planning, Nominal Group Technique and Value Engineering, in Shirley Jones (ed.), Group Process Planning and Problem Solving Methods, N.Y., John Wiley and Sons.

Gurteen, D. 1998. Knowledge management and creativity. Journal of Knowledge Management 2(1): 25-37. 
Hinks, J. All FM is Non-Core, But Some FM is Less Non-Core Than Others? A Discussion on Realising The Strategic Potential of FM. Research Workshop of the 1998 BIFM Annual Conference "Facilities Management-The New Agenda". Queen's College, Cambridge, 21-23 September 1998.

Hinks, J. 1999. FM in the future - a speculation on key performance issues. Proceedings of the International Conference on Futures in Property and FM: Creating the Platform for Innovation. University College, London.

International Facility Management Association. 2004. What is FM? Available from Internet: http://www.ifma.org/

ISO 9001:2008 Quality management systems - Requirements. TC 176/SC 2 p. 27.

Jarvan, A.; Liias, R. 2003. Developing the database for facilities management: a case study for an University, International Journal of Strategic Property Management 7: 44-52.

Jones, O. 1996. The future is Global Facilities Management. Construction Manager magazine. CIOB Magazine Dec./Jan. 2(11).

Kahlen, H. 1999. Integrales Facility Management: Management des ganzheitlichen Bauens. Mit fünf Exkursen von Christian Aichner. Düsseldorf: Werner, 332 s. ISBN 3-8041-4946-4.

Kaklauskas, A.; Lepkova, N. 2001. Facilities management object and multiple criteria analysis, in Proceedings of the 7th International Conference "Modern Building Materials, Structures and Techniques", held on 16-18 May, Vilnius, Lithuania (CD-ROM), VGTU, Vilnius, pp. 170-171.

Kaklauskas, A.; Zavadskas, E. K. 2002. Web-based decision support (in Lithuanian). Vilnius. Technika, p. 291.

Kamara, J. M.; Anumba, C. J.; Carrillo, P. 2002. A Clever approach to selecting a knowledge management strategy, International Journal of Project Management 20(3): 205-211.

Kazi, A. S. 2005. Knowledge Management in the Construction Industry: A Socio-Technical Perspective. Idea Group Publishing. 385 p.

Koch, C. 2003. Knowledge management in consulting engineering-joining IT and human resources to support the production of knowledge. Engineering, Construction and Architectural Management 10(6): 391-401.

Kotler, Ph. 1997. Marketing management, analysis, planning. Implementation and control, in 9th Engelewood Clifts, Prentice Hall Inc, 718 p.

Kululanga, G. K.; Mccaffer, R. 2003. Measuring knowledge management for construction organisations, Engineering, Construction and Architectural Management 8(5/6): 346-354.

Kyle, R. C. 2000. Property management (6th ed.). Real Estate Education Company, 480 p.

Larichev, O. I. 2000. Theory and methods of decision making (in Russian). Moscow: Logos, p. 295.

Lavy, S.; Shohet, I. M., 2007. A strategic integrated healthcare facility management model, International Journal of Strategic Property Management 11(3): 125-142.

Law on Apartment Block Owners Associations, 2012 (in Lithuanian). Available from Internet: http://www.lsta.lt/lt/acts/related/190, accessed 10 October 2012 
Lehtonen, T.; Salonen, A. 2006. An empirical investigation of procurement trends and partnership management in FM services - a Finnish survey, International Journal of Strategic Property Management 10(2): 65-78.

Lepkova, N. 2003. Facilities management multiple criteria analysis of public buildings (Visuomeninès paskirties pastatų ūkio valdymo daugiakriterinè analizè). Doctoral dissertation in Lithuanian language, p. 150.

Lepkova, N.; Bigelis, Z. 2007. Model of facilities management consulting knowledge system, in The 9th international conference "Modern building materials, structures and techniques": selected papers, May 16-18, 2007 Vilnius, Lithuania 1: 300-304. Vilnius: Technika, ISBN 9789955281986.

Lepkova, N.; Žūkaitè-Jefimovienè. 2012. Study on customer satisfaction with facilities management services in Lithuania, Slovak Journal of Civil Engineering Bratislava 20(4): 1-16. Versita. ISSN 1210-3896.

Lepkova, N.; Zavadskas, E. K.; Kaklauskas, A. 2003. Modelling of facilities management process, in International Conference of Modelling and Simulation of Business Systems, held in Vilnius, May 13-14, 2003, Kaunas University of Technology. Kaunas: Technologija, pp. 132-136.

Lepkova, N.; Uselis, R. 2013. Development of a quality criteria system for facilities management services in Lithuania, in Procedia Engineering, 11th international conference on modern building materials, structures and techniques (MBMST), May 16-17, 2013, Vilnius, Lithuania 57: 697-706. Amsterdam: Elsevier Science Ltd. ISSN 1877-7058.

Liias, R. 2007. Housing maintenance management: the key-factor when creating healthy environment, International Journal of Environment and Pollution 30(3-4): 457-470.

Liias, R. et al. 2001. Real Estate Supervision-owner's manual. (In Russian). Tallinn, EKHHL, p. 95.

Maliene, V.; Alexander, K.; Lepkova, N. 2008. Facilities Management Development in Europe, International Journal of Environment and Pollution 35(2/3/4): 171-184.

Martin, B. Knowledge-based organizations: Emerging trends in local government in Australia, Journal of Knowledge Management Practice 2: 2000-2001. Retrieved November 2003 from www.tlainc.com.

Maslow, A. H. 2009. Motivation and personality (in Lithuanian). Apostrofa, p. 405.

Maslow, A. A theory of human motivation, Psychological Review 50.

McGregor, W.; Shiem-Shin, D. 2001. Facilities management and the business of space. Great Britain, St Edmundsbury Press. 248 p.

Naylor, S. S. 1984. Public Policy: Goals, Means and Methods. Lanham: University Press of America.

Nejman D. Fon; Morgenshtern, O. 1970. Games theory and economical behaviour (in Russian). M.: Nauka.

Paadam, K.; Liias, R. 2008. Knowledgeability and capacity of the owners: assuring professionalism when providing housing services, International Journal of Environment and Pollution 35(2/3/4): 205-218. 
Parasuraman, A.; Zeithaml, V.; Berry, L. 1985. A conceptual model of service quality and its implications for future research, Journal of Marketing 49(4): 41-50.

Pheng, Low Sui. 1996. Total quality facilities management: a framework for implementation, Facilities 14(5/6): 5-13.

Rondeau, E. P.; Brown, R. K.; Lapides, P. D. 2006. Facility management (2nd ed.). Hoboken: Wiley, 589 p. ISBN 0471-70059-2.

Sakalas, A.; Vanagas, P.; Martinkus, B. et al. 2000. Management of Industrial Enterprises (in Lithuanian). Kaunas: Technologija, $491 \mathrm{p}$.

Salaris, A. 2002. Facilities management opportunities, in I Quaderni EDILforma, 2 Facilities management and global service, AFMANCE, Rome (in Italian).

Schmitz, A. et al. 2004. Residential Development Handbook (3rd ed.). Washington, D.C.: ULI-the Urban Land Institute, 376 p.

Schneider, H. 1996. Outsourcing von Gebäude- und Verwaltungsdiensten : Unternehmenspolitik - Projektmanagement - Vertragsarbeit. [BME, Bundesverband Materialwirtschaft, Einkauf und Logisitk e.V.]. Stuttgart: Schäffer-Poeschel, X, 218 s. ISBN 3-7910-1015-8.

Smith, P.; Seth, A.; Wessel, R.; Stiemiest, L. 2000. Facilities Engineering and management Handbook. Comersial, Industrial and Institutional Buildings. New York, San Francisko, Aucland, Bogota, London, 968 p.

Solso, R. L. 1995. Cognitive Psychology (in Russian). Moscow: Trivola.

Straub, A.; Mossel, H.-J. 2007. Contractor selection for performance-based maintenance partnerships, International Journal of Strategic Property Management 11(2): 65-76.

Swistock, J. R. Facilities management systems. McGraw-Hill. Facilities engineering and management handbook: commercial, industrial, and institutional buildings. 2001 . USA Library of Congress Cataloging-in-Publication Data, 3.14-3.31.

Tempelmans Plat, H. 1995. A Housing Cost Allocation Schemes for Facilities Management, International Bulding Economics, Hong Kong.

Then, D. S. S. 1994. Facilities management - the relationship between business and property, in Proceedings of EuroFM/OFMA Conference on Facility Management European Opportunities, Brussels. p. 259.

Then, D.S.-S. 2005. A proactive property management model that integrates real estate provision and facilities service management, International Journal of Strategic Property Management 9(1): 33-42.

Tuomela, A.; Puhto, J. 2001. Service Provision Trends of Facility Management in Northern Europe, Helsinki University of Technology Construction Economics and Management publications 1999, Espoo.

Urban, W. 2009. Service quality gaps and their role in service enterprises development, Technological and Economic Development of Economy 15(4): 631-645.

Ventcel, E. S. 1980. Investigation of operations: aims, principles, methodology (in Russian). Moscow: Nauka.

Ventovuori, T. 2006. Elements of sourcing strategies in FM services - a multiple case study, International Journal of Strategic Property Management 10(4): 249-267. 
Vilutiene, T.; Zavadskas, E. K. 2003. The application of multi-criteria analysis to decision support for the facility management of a residential district, Journal of Civil Engineering and Management 9(4): 241-252.

Vischer, J. C. 1995. Environmental Quality in Offices. New York: Van Nostrand Reinhold.

Wang, S.; Xie, J. 2002. Integrating building management system and facilities management on the internet, Automation in Construction 11(6): 707-715.

Wineman, J. D. 1993. Behavioral Issues in Office Design. New York: Van Nostrand Reinhold.

Yi, Y.; Nataraajan, R.; Gong, T. 2011. Customer participation and citizenship behavioural influences on employee performance, satisfaction, commitment, and turnover intention, Journal of Business Research 64: 87-95.

Zairi, M. 2000. Managing customer satisfaction: a best practice perspective, The TQM Magazine 12(6): 398-394.

Zavadskas, E. K.; Kaklauskas, A.; Banaitiene, N. 2001. Multiple criteria analysis of building life cycle (in Lithuanian). Vilnius: Technika, p. 380.

Zavadskas, E. K.; Vilutiene, T. 2004. Multi-criteria analysis of the multi-family apartment blocks maintenance service packages, Journal of Civil Engineering Management 10(Suppl. 2): 143-152.

Zavadskas, E. K.; Kaklauskas, A.; Lepkova, N. 2002. Multiple criteria analysis of facilities management alternatives, Int. J. Strategic Property Management (Property Management) 6(1): 31-39.

Zavadskas, E. K.; Kaklauskas, A.; Gikys, M.; Lepkova, N. 2004. A multiple criteria decision support web-based system for facilities management, International Journal of Internet and Enterprise Management 2(1): 30-44.

Zavadskas, E. K.; Kaklauskas, A.; Lepkova, N.; Zalatorius, J. 2001. Multiple criteria analysis of facilities management, Journal of Civil Engineering Management 7(6): 476484.

Zechel, P. 1997. Facility-Management in der Praxis: Herausforderung in Gegenwart und Zukunft; mit 15 Tabellen. Renningen-Malmsheim. Wien: expert-Verl., $167 \mathrm{~s}$.

Krutik, A. B.; Gorenburgov, M. A. 2000. Real Estate Economics. Sankt-Petersburg, p. 478. 


\title{
CHAPTER 3
}

\section{RETROFIT OF BUILDINGS IN URBAN NEIGHBORHOODS}

\author{
Saulius RASLANAS, Arturas KAKLAUSKAS, \\ Edmundas Kazimieras ZAVADSKAS
}

Modernisation and retrofit of buildings is one of the forms of urban development. Both in Lithuania and in other countries, it should help to solve energy and environmental issues and to improve the quality of life (Mitkus, Šostak 2009; Kaklauskas et al. 2009; Ginevičius, Podvezko 2008). Therefore, modernisation should comply with the sustainable development requirements (Šeduikytė and Jurelionis, 2009) based on three components with equal importance: environmentalism, economic development and social development. Sustainable development aims to reconcile economic growth, social progress and frugal use of natural resources, to maintain ecological balance and to ensure favourable living conditions for current and future generations (Burinskienè, Rudzkienè 2009; Medineckiene et al. 2010). The concept of sustainable development is interpreted as a process for development of healthy environment, viable economics, social welfare and active community (Juškevičius 2005). The UK Government introduced the Sustainable Community Plan in 2003, describing a vision of how our communities are to be developed over the next 20 years economically, socially and environmentally, while respecting the needs of future generations (McDonald et al. 2009). Sustainable development in construction is interpreted as construction of buildings that better satisfy the needs of people and environment. Fundamental retrofit of buildings constructed in earlier decades and their environment is an increasingly important objective for private, public and non-profit owners or investors. Of course, technical requirements applicable to the building must be considered, but economic and ecological expedience of thorough wide scale modernisation must also be compared with an alternative to demolish the building and to construct a new one or to change the building's purpose.

Retrofit of apartment houses and their environment aims:

- to cut energy consumption;

- to cut building maintenance costs;

- to reduce the effect of polluting factors thus boosting the value of the environment;

- to improve the condition of buildings and to extend their service (30-40 years);

- to improve the indoor comfort; 
- to improve the quality of buildings and to make urban areas more attractive;

- to increase the market value of buildings;

- to attract and retain middle classes.

One of the goals set in the Strategic Plan of the City Vilnius for 2002-2011 is to promote residential construction, retrofit and development of urban residential areas and apartment houses with dwindling attractiveness, investment and new construction in such areas, preparation of template retrofit projects for apartment buildings and setting up of programmes for energy saving measures (Vilniaus miesto... 2002). Strategic plans of Vilnius and the condition of houses and their environment in the neighbourhoods in question determine the priority order for retrofit of apartment houses in Vilnius neighbourhoods. Separate neighbourhoods of Vilnius have different priority because the condition of their houses and environments differs. Retrofit of houses should not be separated from landscaping. Zoning of the environment is important and the retrofit must be based on territorial considerations, which means that the priority order for retrofit of Vilnius neighbourhoods must be set and the retrofit must be integrated to encompass retrofit of buildings plus arrangement and modernisation of their environment. Thus attractiveness of the territories would improve and the market value of the land would increase along with increasing private investment in the territories to be renovated (Zavadskas et al. 2008a).

Retrofit of residential houses usually covers diverse measures aimed at cutting energy and maintenance bills, improving safety, comfort and aesthetic properties, as well as boosting market value (Martinaitis et al. 2007; Užšilaitytė, Martinaitis 2010). Energy saving measures in buildings considerably reduce energy consumption and thus the GHG emissions. Plenty of scientists, Galvin (2010), Sartori et al. (2009), Jurelionis and Isevičius (2008), Zavadskas et al. (2008 b, c), Naimavičienè and Mickaitytė (2007), Mickaitytė et al. (2008), Swan and Ugursal (2009), Filippin and Larsen (2009), Lloyd et al. (2008), Johansson (2007), Balaras et al. (2005, 2007), Saidur et al. (2007), Kazakevičius et al. (2002), Bell and Lowe (2000) among them, analyse and suggest solutions how to cut high energy consumption through retrofit in the residential sector. The Copenhagen Climate Change Conference, which took place between 7 and 18 of December 2009 and attracted representatives from 194 countries, shows international understanding and huge economic potential to cut global GHG emissions in the nearest decades. Countries wanted to sign a joint agreement covering three main issues: financial aid of rich to poor countries, reduction of pollution emissions in developing and developed countries, and setting the upper limit for average global temperature. Active retrofit of residential blocks/areas would have a considerable impact on reduction of energy consumption and $\mathrm{CO}_{2}$ emissions. However, modernisation must follow the urban structure which reflects the principles of sustainable development and corresponds to the quality of life: compactness, multifunctional 
use of territories, sustainable transport, ensured public interests and visually attractive (unpolluted) environment. Decisions on retrofit of residential spaces must avoid being too narrow, when retrofit projects for separate houses are considered (Tupenaite et al. 2010).

The key imperatives for efficient modernisation are listed below.

- To sort the legal basis for territorial planning, which (LR Aplinkos Ministerija... 2008):

- would ensure uncompetitive integration of various laws and would help to set up a single system for sustainable development;

- would set the underlying quantitative and qualitative requirements for territorial development and use;

- would establish universal and informative concepts intelligible to anyone;

- would establish clear criteria for the quality of life in line with the principles of sustainable development.

- To ensure transition from individual plot planning to block planning; to regulate accessibility of social infrastructure and to handle the issues related to transport and monofunctional areas.

- To foresee integrated development of business and social infrastructure.

- To promote public and engine free transport; to actively integrate such transport into the urban transport structure and to enhance the network of walkways; to enhance and reconstruct the street network and to improve traffic planning.

- To ensure sufficient quantity and quality in the development of social and engineering infrastructure.

- To renovate old houses, thus contributing to energy efficiency policies.

- To reclaim abandoned territories.

A significant amount of energy, materials and finances are consumed when using and demolishing the buildings. Proper planning, design, construction, management and marketing allow to reduce the environmental impact and expenses as well as to improve the quality of buildings and to raise their market value. Renovation of blocks of multi-apartment houses is nowadays one of the most important problems in residential districts which have been built in Lithuania before 1993. Sustainable development of blocks of multi-apartment houses requires to analyze various renovation strategies, prepare scenarios and select the most rational alternative. Based on the definition of sustainability, technical, economical, social and ecological requirements, not only alternatives for buildings, but also for their environment should be analyzed. It is important to improve the quality of the living environment, to reduce pollution and energy consumption, maintain mixed social structure and make a sustainable integration of new buildings into the existing environment. A successful renovation 
project can be prepared only by conducting a thorough research and properly evaluating buildings and their surrounding environment.

\subsection{The issues with retrofit planning in urban residential areas/blocks}

The future of Lithuanian cities and towns depends on the territorial planning system, which is improving due to ever-freer market and ever more democratic society (Bardauskienè et al. 2007). Implementation of the sustainable development policies is one of the most complicated tasks and challenges facing a community (Burinskienè, Rudzkienè 2009). Territorial-spatial planning of residential areas/blocks is important in development of sustainable and attractive cities and areas. Therefore, any part of the city must also comply with the sustainable development requirements, which include environmental, social, construction and transport aspects (Viteikienè, Zavadskas 2007). Modernisation of apartment houses is a particularly relevant problem in terms of planning. To make it more efficient, modernisation of apartment houses should be integrated and encompass an entire block instead of a single house (Zavadskas et al. 2008d). Such move calls for the development of clear territorial planning regulations for residential areas/blocks.

Currently Lithuania lacks a single normative basis for territorial-spatial planning of residential areas/blocks. Concepts and their definitions are regulated by different legal acts and are often interpreted differently. Ongoing amendment of normative acts is another problem. It is particularly important in development of sustainable and attractive environment in cities and their areas. "Norms for Separate Recreational Green Spaces" of the Republic of Lithuania set the following concepts of a residential area and block: urban residential areas are territories delimited by arterial or intensive traffic streets, while a group of blocks is delimited by supporting streets (LR Aplinkos Ministerija... 2007). The "Regulations on State Support for Modernisation of Apartment Buildings and Determination of Energy Efficiency in Investment Projects" approved by the Government state that "a residential area/block is an urbanised territory of Lithuania dominated by residential buildings and surrounded by transport roads and engineering networks or natural elements" (LR Vyriausybė... 2008a). The project of the Ministry of Environment "Norms for Planning of Cities, Towns and Villages (settlements)" defines a residential area as "a residential space delimited by physical phenomena (streets, green spaces, natural barriers) together with transport and engineering infrastructure corridors and green spaces inside such area" (LR Aplinkos Ministerija... 2009).

On 1 January 2010, a new version of the Law on Territorial Planning (LRS... 2010) came into force, however the law still lacks the definitions of both "block" 
and "area", although the concepts are used throughout the law. The current legal basis of Lithuania lacks a universal definition to interpret the concept of "residential area/block": current norms do not define the size of residential areas or subdivisions/blocks; also the distances to the most important companies and agencies are not regulated. No mechanism is in place to balance the solutions set in residential planning documents. Plans of territories do not foresee green spaces and areas for social infrastructure; detailed plans often fail to reflect the principles of territorial management and use. Thus the planning environment becomes complicated (inefficient and non-transparent).

In the times of planned economy, a residential area and a block had specific descriptions and their parameters were expressed in numerical values. Therefore, planners of those times hardly encountered any problems to mark functional zones in a single parcel or in the entire territory set for construction. Undefined concept of a residential area/block means that there are no clear measures to determine the density and intensity of buildings, as well as the demand for public spaces and public territories (transport and engineering infrastructure objects).

The current legal basis of Lithuania leads to expansion of monofunctional residential areas/blocks and to ongoing disintegration of social and functional purposes (LR Vyriausybė... 2008b). Such trends contradict sustainable development of cities and urban areas.

The current normative documents of Lithuania regulate the minimum size of the plot for a residential building, as well as the maximum space occupied by buildings and the maximum density of buildings in such plot; however, they fail to regulate the density of population in a residential area/block. Legal acts, which regulate territorial development, even fail to set the recommended values. The current norms of Lithuania stipulate the allowed height of buildings (in meters) in the plot; however, there are no norms or techniques for height calculation. The said issues hinder the planning procedures and leave ample space for interpretations.

Construction regulations set the requirement for green spaces in the plot to take up at least $25 \%$ of the unbilt area; such areas intended for green spaces can host playgrounds, simple sports fields for teenagers or recreational zones for elderly residents (STR 2.02.09:2005; STR 2.02.01:2004). Before the order (LR Aplinkos Ministerija, 2007) passed on 21 December 2007, not a single document regulated the interdependence between green spaces and the number of residents, the maximum heights in the spaces and the catchment area of such green spaces. The rules regulating preparation of detailed plans do not make green spaces a mandatory requirement in landscaping and land use. Territorial planning documents (here, detailed plans) often fail to consider non-mandatory regulations for territorial planning and land use. Territories are usually planned without any space left for green areas and social infrastructure. The definition 
of social infrastructure appeared in the Law on Territorial Planning only in 2010 (LRS... 2010). Yet sustainable social environment is a very important aspect in the quality of life, which is essential to attract and retain people. It helps to satisfy educational, training, cultural, healthcare, social care and other essential needs of people, but it is possible only if we handle the following issues: depopulation and aging populations in some residential areas; increasing disparities between the quality of environment in certain residential areas; uneven distribution of social infrastructure and social objects; and lack of services (LR Aplinkos Ministerija... 2008). The current legal acts of Lithuania scarcely regulate social infrastructure issues - they consider development of only a small portion of social infrastructure objects. Thus distribution of social infrastructure objects becomes a problem; the catchment area for such services remains undefined. A subdivision of a residential area must have the essential social services such as kindergartens, schools and shops, while the entire residential area must have such social services as a special school, a supermarket, a library, a cinema, a sports club and an outpatient clinic. Lithuanian legal and normative acts do not regulate reservation of spaces for social infrastructure (educational, cultural, healthcare and other) in residential areas, the catchment area of such infrastructure, etc.

Newly designed residential areas suffer from land related problems. Urban land increasingly becomes private property, and this fact brings about a conflict of interests between the municipality and the private landowner. Moreover, the municipality sometimes lacks the capacity to control and to regulate land use properly. Thus no space is left for streets and engineering networks, for green spaces and social infrastructure. The definition of public interest is unclear in territorial planning. Representatives from public organisations believe that public interest must be clearly defined in the Law on Territorial Planning and in normative acts, and must be clearly marked in territorial planning documents (Darni urbanistine pletra Lietuvoje... 2008). The priority of public interest (common streets, corridors of engineering networks, social infrastructure, parks, etc.) must be legitimised, because the quality of life is impossible without development of public infrastructure.

\subsection{Strategies for modernisation of areas with apartment houses and the related scenarios}

The main provisions of the strategy of the long-term sustainable development on a global scale were formulated in "Agenda 21" of the United Nations, in the Earth Summit, held in Rio de Janeiro, Brazil. The basis of the conception of the sustainable development consists of 3 equivalent components: environmental protection, economic and social development (LR Vyriausybė... 2009). 
Sustainable development is described as the development of the society, providing the possibility to achieve the universal well-being for the present and future generations, by harmonizing the environmental, economic and social objectives of the society and by not exceeding the permissible limits of the environmental impact. Burinskienė and Rudzkienè (2009), Medineckienè et al. (2010), Wedding and Crawford-Brown (2007) and many others agree that the goal of the sustainable development is to harmonize the economic growth, social progress, economically use the natural resources and ensure the favourable living conditions now and in the future. Sustainable development is based not on economic, social or institutional dimension, but on their system, understandable as the integrated society (Ciegis et al. 2009). Juškevičius (2005) states that the conception of the sustainable development is understandable as the process of creating the healthy environment, social welfare and active community, and the sustainable development in construction is understandable as the construction of the buildings which satisfy the needs of the people and environment. However, it must be emphasized that the negative environmental impact had by the human, both when constructing and renovating the buildings, must be as low as possible. According to Andruškevičius (2005), the renovation of the building is an activity, the purpose of which constitutes the rearrangement of the existing construction works, in order to eliminate its physical, architectural and aesthetic, functional, comfort-related, operational, social, economic and other types of depreciation of engineering equipment, etc. However, this purpose must be achieved by following the conception of the sustainable building. ALwaer and Clements-Croome (2010) understand the sustainable building as a complex of three main interrelated parts: namely, people (owners, residents, users, etc.), products (constructional materials, fabrics, constructions, structure, plants, equipment, automation and control, services) and processes (maintenance, control of equipment). These are the key closely interconnected parts. However, another highly relevant question is the following: should the sustainable building not stand in the sustainable environment?

Over the last decade, more and more global organizations are investing significant resources to create sustainably built environments, emphasizing sustainable building renovation processes to reduce energy consumption and carbon dioxide emissions (Juan et al. 2010). Renovation of the buildings constructed in the last decades and their environment is the task of the increasing importance to the private, public, non-profit owners or investors. The well-being of a human and the whole humankind depends from the equilibrium of difficult social, economic and natural processes; therefore, these parts of development must be examined as a whole. Not only the sustainable construction, sustainable renovation of buildings, but also the sustainable world can be created only in this manner.

The term "sustainable construction" is used to describe the application of sustainable development in construction. The basic definition of sustainable 
construction was formulated in the conference organized by CIB, held in USA in 1994: its the creation and management of the healthy environment in the construction works and beyond their limits, following the principles of the efficient consumption of resources and environmental friendliness (Ofori 1998; Pollington 1999; Šaparauskas 2001; Antuchevičienè 2005). This conception also covers the sustainability-ensuring constructional materials, safe construction practice and new technologies. The same definition may be applied also to the sustainable renovation of the multi-apartment houses and their environment. According to the climate change, high energy consumption, it is important in the residential sector to understand and encourage the application of new technologies, the efficient consumption of energy and renewable energy sources.

With the renovation of residential houses, it is sought to reduce the energy and building-maintenance bills, in order to improve the safety, comfort, aesthetics, to increase the market value (Martinaitis et al. 2007; Užšilaitytè, Martinaitis 2010). However, all this must be executed according to the principles of sustainable development. The priority goal of the Master Plan of Vilnius City is to provide the conditions for continuous, socially and economically motivated growth of the quality of life and reduction of territorial differences. Construction sector has an especially close connection in social, economic and environmental views. Despite the different climate, culture and economy, there are many similarities among the developed and developing countries in terms of the impact of construction industry on environment (Melchert 2007). Energy needs grow in the present world especially rapidly, and it is one of the main reasons why the sustainable renovation of buildings must be sought (Kaminski 2008). Report of Implementation of the National Sustainable Development Strategy for 2005-2007 (Juknys 2008) provides for that 70\% of old multi-apartment houses (about 28.000 multi-apartment houses) will be renovated in Lithuania by 2020, and the thermal energy costs in the housing sector will be reduced to about $30 \%$. In order to implement these plans and to obtain the efficient result, it is necessary to fulfill many conditions, including the one - to properly assess the versions of renovation of the buildings and their surrounding environment, by applying the internationally acclaimed sustainable building certification systems.

Strategy is interpreted as use of available resources, skills or competencies to achieve goals in view of environment limitations or risks. A strategy can implement one or several goals. Certain scenarios must be developed for relevant strategies, because strategies stand on scenarios. Scenarios help to show possible outcomes achieved using certain measures.

Strategies for modernisation of areas with apartment houses must have the following key goals:

- to improve living standards and the quality of environment;

- to cut energy consumption and $\mathrm{CO}_{2}$ emissions; 
- to maintain mixed social structure;

- to integrate new buildings in the existing environment in a sustainable manner;

- to develop an urban centre of a residential area as a functioning part of the city;

- democratic planning;

- close cooperation of partners involved in modernisation;

- lasting retrofit and facilities management.

Gorgolewski (1995) and Balaras et al. (2000) state that to achieve optimum energy saving, the most efficient groups of energy saving measures must be set for modernisation of buildings, the best scenario must be selected and the main investment geared towards such scenario. Economic efficiency of building retrofit depends on implementation of energy saving measures (Ginevičius et al. 2008; Zavadskas et al. 2008 a, b, c; Kaklauskas et al. 2004). Johansson et al. (2007) state that a politically reasonable way to do this in Sweden would be to suggest municipalities preparation of "the best strategies" for various types of buildings, and then such strategies could be recommended for certification of energy performance in buildings. Alanne (2004) suggested a method that would facilitate finding a project for lasting retrofit actions geared towards retrofit of residential buildings. However, for retrofit to be lasting and efficient, modernisation of an entire residential area must follow an action plan and strategies.

In view of climate change and big energy consumption, it is important in residential sector to understand and promote new technology and efficient use of energy and renewable energy resources. Buildings must be renovated taking every opportunity to use progressive building materials and processes as ecofriendly as possible, which means using "eco-packages" such as:

- rainwater for gardening and special tanks for toilet flushes;

- solar energy for hot water;

- photovoltaic installations for additional electricity;

- choice of building materials following strict environmental criteria;

- possibilities to reduce waste.

Both physical and economic retrofit of an area is essential to ensure return on investment into energy saving, because, in addition to its quality, a building's value is also determined by surrounding buildings, infrastructure and quality indicators of the area in question (Sunikka 2005). Redesign of residential environment should attempt to include all buildings, to ensure both practical value and the feel of cosiness and modernity. New designs of building façades can be highlighted by colour shading and by bringing out polished pigmentation with bright shades of foundations, parapets and colours of canopies. Blocks of an area can have their individual image: artistic, garden, park or other themes. 
The rainwater collected from roofs and directed through rainwater pipes to underground tanks could be used to irrigate yards and flower beds or for ponds with surrounding green spaces, recreational areas or any other such spaces.

Modernisation of residential blocks is related to improved quality of life and new architectural solutions, which give residents a chance to "live outdoors" (spacious balconies, terraces, etc.). Glazed towers with elevators attached to five-storey buildings would boost the quality of life, the architectural appearance and the value of apartments.

Larger income persons try to move out of outdated city blocks that need retrofit, because such blocks lack suitable apartments. Such areas face the threat of lost social balance. Since many people want high quality dwellings and part of them move to areas of single-family houses, we must construct various dwellings and to create the city atmosphere.

Since the requirements and needs of people towards housing increased and changed, this strategy aims to stabilise mixed social structure and to provide a set of diverse and attractive offers:

- construction of new apartments;

- layout redesign in buildings;

- diversity of the forms of ownership;

- improved equipment and installations;

- social housing;

- foster homes for elderly people and children.

Residential houses should form blocks: the free spaces must be populated with buildings and the perimeter of blocks must be closed from the outside but have open areas inside. Retrofit of an area also demands for other solutions, such as gardens and sculptures on some roofs and construction of additional floors on existing houses. The old large-panel construction usually restricts architectural solutions, as it is difficult to change the layouts of flats due to the internal loadbearing walls. But the opportunities to improve architectural aspects, however scarce, are available: entrances could be replaced by glazed porches, floor area could be increased by connecting the glazed balcony to a room, the kitchen could be joined to the sitting-room by cutting an opening in an internal wall, floor areas of bathrooms could also be increased.

Retrofit of residential blocks must also consider social housing for low-income young and large families, for orphans or disabled people. Possibilities to set up a medical facility, a foster home, a home for overnight accommodation or any other similar facility must also be considered.

Before their modernisation, residential areas usually have inadequate infrastructure: lack of shops and lack of any signs of cultural life. The trends of extensive construction, with large internal unbuilt areas, dominated in Lithuania for quite some time (Turskis et al. 2006); thus cities are sprawled and far 
from compact, while central parts of residential areas also lack concentration. Without viable centres of attraction, such areas cannot be developed as functioning areas. The most important aspect of this strategy is to create an area's central part by determining its best location for each area and then attracting residents with a range of services and leisure activities: for instance, one area has a park, another an old cinema or some abandoned buildings, which after retrofit and population with service companies, playgrounds and other facilities can become an attractive spot not only for recreation and the key needs but also for leisure activities. Parks can be renovated by digging ponds, planting bushes and trees, also by building playgrounds, sites for skaters and artificial rock walls for climbing.

Residential areas with apartment houses lack green spaces, their social infrastructure is inadequate and there are no facilities for recreation. Part of unused spaces in such areas should be planned for recreation, including walkways and play-fields close to homes. The environment could become cosier, should teachers, schoolchildren and their parents plant some flowers, trees and bushes in school and kindergarten territories. Benches, railings and wastebaskets could also be constructed upon request. Involvement of people in the process of modernisation would see them more caring and respecting their renovated environment. The solutions related to retrofit of residential areas make direct impact on residents. Therefore, it is very important to involve society in planning processes. From experience, expenses for public awareness and explanations pay dividends by clearly improved consent to planning solutions, which, in turn, speeds up the planning procedures (Projekt Großsiedlungen 1996). Since most people live in apartments which they own, cooperation between the planners and society is a must. The concept of planning processes involving residents is part of further development of residential blocks. Meetings of architects and planners with people, entrepreneurs and politicians speed up implementation of offered solutions:

- arrangement of yards;

- optimisation of walkway networks;

- moving of waste containers;

- improved situation with parking.

Improvement of the legal basis, which governs setting up of tenants' associations and maintenance of residential buildings, implementation of the Modernisation Programme for Residential Houses, retrofit and modernisation of dwellings and improvement of their energy performance would cut thermal energy consumption and would improve management and maintenance of dwellings (LR Vyriausybè... 2009). Retrofit of all buildings would be an important step towards modernisation of a neighbourhood, while project implementation would have strict deadlines. Residents involved in preparation for modernisation and in each step of construction would have more interest and would actively supervise the work. 
One of the goals set in strategies is to improve the quality of life with involvement of residents. Buildings can be renovated without the need for residents to move out temporary, one stairway after another, following a certain schedule. Those unwilling to wait for their turn specified in the schedule would be allowed to renovate their apartments themselves. Professionals have been invited to form the counselling service "Do It Yourself".

One of the advantages in residential areas with apartment houses is a neighbouring recreational zone. Harmony between housing and nature is a strategic task for further development of multi-storey housing (EXPO... 2000). Retrofit should attempt to maintain the pervious natural environment, while new yards, planted bushes, trees and flower beds should create the "green" quality of life as an inseparable distinction of a residential area.

Cooperation of partners is highly important in any modernisation process, modernisation of residential areas among them. Municipalities, authorities, construction companies, designers, architects and residents must cooperate closely, organise discussions and make joint, possibly halfway, decisions. To achieve good results, all these different people must cooperate (Naaranoja, Uden 2007).

Scenarios based on relevant strategies must define the retrofit measures, their priority and their potential effect.

Four portfolios of retrofit measures-portfolios for small, average and large investment and a portfolio of "basic" measures can be prepared to determine the preliminary investment and its economic efficiency. The small investment portfolio would foresee replacement, reconstruction or retrofit of building elements and systems in critical and worst condition. It is attractive due to rather smaller investment, but means only slight improvement in the thermal properties of the envelope (only windows and doors) and architectural-aesthetical appearance (only due to replaced windows). Another drawback is that, in such case, deficient measuring of heat consumption (by floor area) will be retained and the possibility to control heating in each flat will not be installed.

The average investment portfolio ensures better energy saving and rather high economic efficiency. Individual heating meters and regulation of heating intensity encourage people to save more energy and, depending on their consumption habits, the savings of thermal energy could be higher. Such portfolios also foresee minimal measures for landscaping. Nevertheless, the architecturalaesthetical appearance after implementation will hardly change and walls (except for back façades) will still fail to meet modern norms.

The large investment portfolio helps to achieve the highest quality: the envelopes will meet the requirements of heat preservation and the heating systems will be technologically most advanced (precise heating meters, possibilities to heat premises or to turn off heating irrespective of the heating season, also repairs or emergency in one flat will not demand turning off of the entire system 
of the house). The house will be as economical as new houses. However, the investment is large and people rarely can afford it. This portfolio is more suited for prestigious areas, because a slanting roof and some additional apartments can be constructed, which means new housing for sale, which, in turn, means a possibility to reduce the sum of investment.

The "basic" portfolio ensures that envelopes will meet the requirements of heat preservation, structures will have sufficient mechanical resistance and durability, and a more advanced heating system and individual heating meters will be installed. This portfolio also foresees minor landscaping.

The paramount measures for retrofit of apartment buildings and landscaping must coincide with the strategic goals which define the city's image and the improvement of housing and residential environment. Various areas set different priorities for measures, because the condition of buildings and their environment differs. Therefore, retrofit of buildings must consider the zoning and must be based on territories; it means that blocks/areas must be renovated following a priority order and the retrofit of buildings must be complex and the environment modernized.

\subsection{The selection of effective retrofit scenarios for panel houses}

Most European countries have succeeded in reducing energy consumption of new dwellings by more than $50 \%$ without increasing their building cost, and therefore, energy efficiency has achieved great acceptance among building owners (BRITA in PuBs... 2004). These buildings represent about $20 \%$ of the building stock but consume only $5 \%$ of energy. Concentration on improving the energetically poor building stock has great potential. The lack of interest in housing retrofit can be explained by the fact that economic interest in a building expires after thirty years.

When the problems involved in housing retrofit, especially the solutions aimed at energy conservation, are considered, the increased market value of renovated buildings is not always taken into account. The experience has shown that reconstruction of local heating units as well as the renovation and regulation of heating systems are effective measures of saving energy. However, insulation of walls, replacement of windows, renovation of roofs, etc., which also help save energy, are not so economically effective because of large investments needed (they are usually repaid only in more than twenty years) (Pikutis, Seduikyte 2006). The benefits of retrofit are often considered in terms of reduced thermal energy costs. However, retrofitting also improves the condition of all building elements as well as prolonging the lifetime of a building. It makes possible a considerable reduction in building maintenance costs and investments in the repair and replacement of worn-out elements, which would be inevitable in 
the future. By ignoring these significant factors, the above approach makes it difficult to prove the need for a more extensive renovation intended to improve the condition, energy conservation, and architectural and aesthetic appearance of a building (when trying to get the required loan). The order of priorities in implementing retrofit scenarios of apartment buildings in particular urban neighborhoods is determined by strategic urban development programs and the current condition of the buildings and the environment in a district.

\subsubsection{The criteria used in rating retrofit scenarios}

The critical criterion when examining and proposing any of the alternative management schemes is the sustainable development of society (Liias 1998). Coherent and efficient retrofit scenarios are commonly based on a building's state of degradation and its obsolescence. An advanced method, based on multicriteria analysis, also helps design effective retrofit scenarios (Flourentzou, Roulet 2002). Before a decision is made to proceed with any project of building retrofit, a brief but reliable report is needed describing the current state of the building and estimating the cost of building operations to be performed (Caccavelli, Genre 2000). The developed methodology and software apply to specific refurbishment work and cost assessment of building renovation needs with respect to energy conservation and improvement of the indoor environment.

Several methods were proposed for rating buildings or retrofit scenarios based on criteria including thermal energy consumption for heating, availability of cooling and other appliances, retrofit impact on the environment, indoor climate, and costs (Roulet et al. 2002).

The potential for energy conservation in apartment buildings was investigated following the EPIQR methodology and several scenarios were evaluated for various apartment buildings (Balaras et al. 2000). Energy savings in each building were accounted for in order to identify the most effective scenarios.

According to Zavadskas, Kaklauskas, Gulbinas (2004), design and realization of effective building retrofit scenario requires an exhaustive study of all solutions involving planimetric and volumetric changes, the elimination of the deteriorated and obsolete elements of a building, the improvement of its architectural and aesthetic appearance and indoor amenities, etc. The effectiveness of the building retrofit under consideration depends on many factors, including costs, annual fuel savings, when the retrofit is completed, the tentative payback period, harm to human health caused by the materials used, aesthetics, maintenance, functionality, comfort, sound reduction, longevity of structures, etc.

In general, housing renovation policy aims to:

1. Reduce energy consumption by $50 \%$, and thus to improve the environmental value.

2. Increase the market value of dwellings. 
3. Improve the condition of buildings and prolong their lifetime (for about $30-40$ years) as well as preserve housing resources.

4. Raise the level of comfort in apartment blocks.

5. Avoid maintenance expenses and investments in buildings which would otherwise be needed in the future.

6. Improve the architectural appearance of the façades of apartment houses as well as harmonize them with the environment.

7. Make residential areas more attractive to their residents; improve the residential quality of a building.

8. Attract more middle-class residents to these areas.

When apartment buildings do not meet the residents' needs, the question arises of whether they should be renovated or demolished. A consensus is growing that it is easier and less expensive to slow down building deterioration by investing in proper maintenance and, thereby, prolonging its service life before reconstruction. To compare reconstruction to renovation in mathematical terms, the following formula (Zavadskas et al. 1997) was proposed:

$$
C \geq R+M\left(\frac{1-(1+i)^{-n}}{i}\right)+\frac{C}{(1+i)^{n}},
$$

where $C$ is the cost of new construction, $R$ is the cost of renovation, $M$ denotes the savings in annual maintenance costs in the case of new construction, $n$ is the expected prolonged service life (in years) of the renovated building, and $i$ is the interest rate per year. The right-hand side of this formula is the sum of the renovation costs plus the current value of higher maintenance cost and the discounted current value of the new construction which might be delayed by $n$ years. This basic formula has several logical flaws. Some researchers believe that the value of the existing building should also be added to the renovation cost. Others argue the opposite, namely, that reconstruction should bear as an extra cost the waste of demolishing a valuable (though old and ill-functioning) existing building, while the renovation option utilizes the existing value of the old building and just adds to it.

Deciding between renovation and demolition can be made easier by the use of criteria for assessing the value of preserving a building. Not only technical building requirements but also, above all, the economic and ecological advisability of comprehensive renovation measures as compared to demolition of a building and construction of a new one or to its fundamental redevelopment must be examined more closely (Zavadskas et al. 1994). Once a decision to retrofit has been made, questions must usually be answered about the extent to which retrofitting measures are necessary and the extent to which one must and/ or can retrofit the building structure and its technical systems. The speed and 
security of the return on one's investment is becoming increasingly important for property managers and owners as a criterion for their decision, in particular with respect to the nature and extent of retrofit.

In order to achieve the goals of an optimal retrofit strategy, it is essential that any given capital investment be directed to the most cost-effective group of energy-saving measures. This can be achieved by ranking the measures in order of decreasing savings - to investment ratio (SIR), where (Hatush et al. 1997):

$$
S I R=\frac{\text { Current value of the total lifetime energy saving }}{\text { Investment cost }} .
$$

If a measure has a SIR greater than 1, the predicted savings exceed the investment, and the measure can be regarded as cost-effective. The higher the SIR, the larger the return on the investment. To calculate the SIR, the current value of the total energy saved must be found. Finding this value requires the discounting of all future savings to their equivalent current value, using the following equation:

$$
P V_{c}=C\left[\frac{1-(1+r)^{-n}}{r}\right]
$$

This gives the current value, $P V_{c}$, for an annual saving $C$, occurring for $n$ number of years (lifetime of measure), with a real discount rate of $r$.

The implementation of some energy-saving retrofit measures is associated not only with reduced energy consumption but also with the improved condition of building elements, durability, and the value of the building ( $\mathrm{Ng}$, Skitmore 1999; Parasonis, Ambrasas 1995). However, investments in property should not be assessed only as static costs; instead, long-term security and stability of value as well as re-usability and profitability of the retrofitted building should be considered. It is recommended that comprehensive renovations be carried out in order to increase a building's value and to ensure long-term security of that value (Zavadskas et al. 1994). Renovation aimed to increase building value for users has not only technical, ecological, and economic aspects but also a social dimension that should be considered. Renovation will be made only if there is a demand and acceptance among the users. The cost of a market-oriented retrofit is not simply the market value. There exists some difference between them, known as the acceptance of the market. If economic function of a building is fulfilled, the added value can increase its acceptance among the users and so increase the demand. The increase in price depends on the cost of the retrofit scenario. From the perspective of real estate market value, an effective retrofit may be described by the following market value ratio (MVR): 


$$
M V R=\frac{\left(M_{v a}-M_{v b}\right)}{C_{r}},
$$

where $M_{v a}$ is the market value of the building after retrofit, $M_{v b}$ is the market value of the building before retrofit, $C_{r}$ denotes the retrofit costs of the building (Zavadskas et al. 2004; Zavadskas et al. 2004a). If the package of investments in retrofit has an $M V R$ greater than 1, the package can be regarded as cost-effective from the perspective of real estate market value.

From the perspective of value, it is hardly reasonable to develop retrofit packages which, if implemented, would make apartment values, when their average current price plus the cost of dwelling retrofit are taken into account, equal to or even higher than the prices of newly constructed apartments. The cost of investment packages depends on the difference between the market value of $1 \mathrm{~m}^{2}$ of new dwelling area and the average price of $1 \mathrm{~m}^{2}$ of old dwelling area, plus the cost of retrofit measures per $1 \mathrm{~m}^{2}$ of area. Therefore, the efficiency of retrofit from the market value perspective can be expressed by the market value ratio as follows:

$$
M V R=\frac{a \cdot\left(M_{v n}-M_{v o}\right)}{C_{r}},
$$

where $M_{v n}$ is the market value of $1 \mathrm{~m}^{2}$ of new dwelling area, $M_{v o}$ is the market value of $1 \mathrm{~m}^{2}$ of old dwelling area, $\alpha$ is the average coefficient of correction, depending on a particular district where retrofit is made.

In general, when energy savings and the increase in market value are taken into account, a package $k$ of retrofit measures is effective when:

$$
S I R_{\mathrm{k}}>1 ; M V R_{k}>1 .
$$

The following criteria in particular are relevant in the renovation/reconstruction discussion: costs (taking into account the construction of a new building, the costs of demolition, relocating tenants, renovation costs, operating costs of a new building (as compared to the renovated building), defects and drawbacks of the building (associated with heat insulation, concrete quality, humidity, ground water, soundproofing, the condition of the living environment, ventilation, parking space), architecture of the building (aesthetics, types of layout), urban planning aspects (nature of the development in the area, availability of public transport system, engineering infrastructure) and social infrastructure (building status, tenant satisfaction). When considering renovation, the major factors, such as social infrastructure and some problems, relating to urban development, in particular, should be considered first. Not only technical building requirements, but the economic and ecological purposefulness of comprehensive renovation measures 
as compared to demolition and constructing a new building, must be examined more closely. The assessment of the property with the option to rebuild, as compared to the existing building value, should be made and potential profitability of various renovation possibilities should be analysed. Only then should one begin the analysis of the building itself or work to answer the questions of technical detail. If a building has an insufficiently developed social infrastructure, then, this is an argument for demolition, and vice versa. If a building has an intact social infrastructure, then, this is an argument for renovation.

A decision about renovating or demolishing a building mainly depends on its physical condition, blending in the environment, maintenance quality, the planned service life, the extent of degradation, the expected economic effect of renovation, the cost of demolishing an old building and the construction of a new one, as well as social infrastructure and the priorities of urban development. One of the retrofit effectiveness criteria is $M V R$, therefore it can be used at the first stage of decision-making about the renovation or demolition of a building. The cost-benefit analysis can be made for a short, middle, or long term. Renovation measures are a good investment only if they improve the residential quality of a building. Improved residential quality means more than simply reducing energy consumption; renovation to increase value must do more than achieve thermal renovation. If the building's economic function is fulfilled, the added value due to market-oriented renovation can increase its acceptance by the tenants and so increase the demand. Investment value in the single most likely scenario is equivalent to market value which would be likely to result in a hold decision and thus the scenario approach potentially provides extra insight. However, not all retrofit measures can improve residential quality. If retrofit scenario which can raise residential quality is used, but its calculated $M V R$ is less than one, then the renovation can be effective from the perspective thermal energy saving in the long term. In terms of market value, it is not advisable to develop retrofit investment scenarios which, when implemented, would make apartment values equal to or even greater than those of newly constructed dwellings in the same area, when their average current market value and the cost of retrofit are taken into account. In this case, the renovation utilizes the existing value of the old building and just adds to it, but the value is lower than the renovation scenario cost. Renovation becomes economically inefficient, i.e. market value increment of dwelling due to renovation is lower than the cost of renovation. In this case, it is not comprehensive, substantial, and sustainable renovation. Therefore, we must distinguish between energy-efficient retrofitting and market value-efficient retrofitting of buildings. An effective decision implies energy-efficient retrofitting and market value-efficient retrofitting. When, in renovation scenario $k M V R_{\mathrm{k}}<1$, then, it is the market value-inefficient retrofitting scenario. The problem arises what to do with such buildings. Probably, they should be reconstructed. To 
make a decision, a comprehensive analysis of the state of the building, its deterioration, architecture, costs of construction of a new building, the costs of demolition, relocation of the tenants, renovation costs, operating costs of a new building as compared to the renovated building, the increased rent as well as some aspects of urban planning and social infrastructure should be made. If the amount of comprehensive, substantial, and sustainable renovation investment exceeds the investment limit, it makes more sense for building owners or other investors to demolish the old building and finance the construction of a new one with the required energy efficiency and other characteristics. However, if energy prices are likely to grow, energy-efficient retrofitting would be a more attractive investment opportunity.

Developing renovation packages for apartment houses of particular districts it is possible to determine the effectiveness of these packages (from $i$ to $j$ ) by calculating their values $S I R_{i}$ up to $S I R_{j}$ and $M V R_{i}$ up to $M V R_{j}$ in a single step. If at least one of the indicators $S I R_{\mathrm{k}}$ of the package $k$ is less than one, or $M V R_{k}$ is less than one, or both their values are less than one, then, such a package cannot be considered cost-effective. Only the packages with $S I R>1$ and $M V R>1$ should be further analysed, and the $k_{\max }$ package, ensuring the highest energy saving and market value increase, i.e. $k_{\max }=\left\{\max P V_{c k} ; \max \left(M_{v a k}-M_{v b}\right)\right\}$, should be chosen, taking into account the available financial resources.

When choosing a retrofit package, a number of criteria, such as retrofit cost, thermal energy savings, the extent of building deterioration and obsolescence, indoor and outdoor environmental quality, as well as technical, economic, ecological, and social aspects should be considered. The market value of real estate reflects and is affected by the interaction of four basic forces that influence human activity: social trends, economic development, governmental control and regulations, and environmental conditions. The forces are interactive because they exert pressure on human activities and are, in turn, affected by these activities. The interaction of the social, economic, governmental, and environmental forces that affect real estate value must be studied.

The index SIR refers to energy conservation, while $M V R$ shows the market value for the evaluation of the retrofit packages. After renovation the market value of the building increases because the quality of dwelling as well as indoor and outdoor environmental quality, comfort level and living conditions are greatly improved, while maintenance costs, etc. are decreased. These criteria are reflected to some extent in the two indices SIR and $M V R$. Thus, in this case, a contribution principle can be observed, implying that any dwelling improvement is worth as much as the increase of the property's market value it brought about, regardless of the cost of improvement, i.e. the actual increase of the total property value is more important than the cost of improvement. The above criteria 
are included in the research through the geographical analysis of districts based on SIR and $M V R$.

\subsubsection{The application of geographical analysis in decision-making on the retrofit of panel houses in residential neighborhoods}

The preparatory period for the renovation of residential neighborhoods includes:

1. Carrying out preliminary research.

2. Determining the retrofit areas.

3. Determining the retrofit objectives.

4. City planning.

5. Discussing renovation problems.

6. Preparing a social development plan.

7. Planning specific construction operations.

It would be more rational to renovate apartment houses based on territorial principle, i.e. arranging the districts in the order of priority and renovating them in a complex way, renewing dwelling houses and their environment. Besides, the renovation should be economically beneficial. The limits of the neighbourhood can be determined based on its physical borders as well as taking into account some economic and legislative aspects. From the economic point of view, the neighbourhood is delimited depending on the uses of land, while the limits of urban zones are established by legislation. The renovation of buildings should not be separated from the improvement of environmental conditions. The latter is difficult to analyse in economic terms. It is difficult to accurately predict the cost of the works to be performed in this field. Moreover, design solutions as well as economic effects may vary to a large extent. However, if the environmental conditions are improved, the market value of the land will considerably increase and the area will become much more attractive to investors. Therefore, it is clear that the renovation of a neighbourhood should not be restricted to the renewal of houses, but should be extended to the whole territory. Moreover, the renovation of apartment houses should be followed by the state-financed construction of administrative and public buildings, schools, recreational areas, parks, squares, roads, etc. Only in this case a monotonous residential area can become a functional part of the city, providing its residents with all the conditions of urbanized life. Usually, the renovation of neighbourhoods is effective if it proceeds without any delays and is completed in 10-15 years. During this period the neighbourhoods should become so attractive that they could keep their residents from moving out. At the beginning, some pilot projects must be implemented for getting the experience and demonstrating the results of renovation, and then the whole neighbourhood can be renewed. 
The renovated buildings raise the market value of the neighbouring houses, and the progression principle comes into operation. Renovation should also follow "the sustainable environment" principle which would help the neighbourhood acquire some new quality. A complex analysis of renovation should include cost analysis and the variation of apartment values depending on particular districts of the city. The specific character of the district largely determines the market value of apartments. The plans for district development and the state of the neighbouring districts are also important. Districts with well developed infrastructure (workplaces, transport system, health and consumer services) have many advantages compared to the districts with poor infrastructure. The demand, offer and market value of a particular district are strongly influenced by the changes taking place in other neighbourhoods, and vary to a considerable extent, depending on how attractive they are to residents (Raslanas et al. 2006). Vilnius neighbourhoods can be divided into several groups according to their attractiveness to residents and market value of property (apartment):

- Group 1 - Highly prestigious neighbourhoods

- Group 2 - Prestigious neighbourhoods

- Group 3 - Non-prestigious neighbourhoods

The first steps in renovating the apartment houses should be in line with the strategic aims of urban development stated in the strategic plan. The strategic plan of city development is worked out in several stages: first, a particular vision of a city or town is created, then, the analysis of current social and economic problems is made and, finally, the priorities of long-term urban development are established. The competitiveness of any city or town as a complex social, economic and urban entity can be described by a set of criteria. For a city to be competitive on an international scale, the values of all the criteria describing it need not be the highest. The strategy of urban development defines the main movers or starting points for further activity involving the development of other areas as well.

From the perspective of their location the strategically vital districts are those where the airport, railway and bus stations are located, as well as the central districts of the city. Therefore, they can be considered perspective and the market value of real estate can be expected to grow in these districts. The image of the above districts and their attractiveness play an important part in maintaining the competitiveness of the city. This means that apartment houses on their territory should be renovated in the first place. Some of the areas may have the environment not properly adapted to residents' needs. The strategic plan of city development should include some measures aimed at converting industrial enterprises into commercial or housing facilities. This could increase the property value in the area. Every district (neighbourhood) should be evaluated based on the list of priorities in the long-term development plan of the city. 
The degradation of the apartment houses is a good reason for starting the renovation. To make the final decision, the state of the buildings in various neighbourhoods should be thoroughly analysed. The order of priority for renovating the standard districts which are of the same importance for strategic city development is determined based on the age and condition of their apartment houses. The state of the houses is described in terms of the defects found, deterioration of particular building elements, the state of engineering services, thermal characteristics of enclosures and heating systems, which are usually outdated single-pipe unbalanced systems, not allowing for temperature regulation in the premises and individual metering of the consumed thermal energy. The priority for being renovated should be given to a district the houses and the environment of which are in a worse state compared to the condition of other districts.

To make a particular area more attractive, a complex approach to renovation should be used, implying that both dwelling houses and the environment should be enhanced. The renovation of districts with medium or low values of geographical location indicators can hardly be expected to considerably increase the market value of property. The latter will never reach the market value of property located in highly prestigious districts because the significance of 'geographical location' criterion of these districts is very high.

A district is unattractive to residents if its houses are degraded and the infrastructure, transport system and environmental conditions are poor. Besides, the level of noise, pollution and crime rate are high, etc. The investments in the renovation of neglected districts may be larger than the increase in property value after renovation, i.e. they can even be unprofitable. However, the willingness of the residents of these districts to renew their houses and their financial state as well as the financial support of renovation by municipalities should be taken into account.

The priorities of the districts in the renovation project can be established based on multicriteria analysis of their significance in the strategic plans of city development, the state of their dwelling houses and the environment, renovation costs, the expected reduction of thermal energy consumption, the market value of property in the houses of old and new construction and the expected increment of market value of the renovated houses. Whenever these indicators change, the priorities of districts for renovation also change. Determining the growth of the market value of property due to renovation, some other measures which could also increase its market value should be taken into account. These are the so-called "external" effects. This could be the laying of the tram route, the construction of a supermarket or bridge, etc. on the renewed territory, which would undoubtedly raise the market value of property in the area. 
Geographical analysis of the districts to be renovated is carried out in the following steps:

1. The urban area is divided into three groups depending on its attractiveness to residents and market value of property. They include highly prestigious, prestigious and non-prestigious districts.

2. Depending on the renovation objectives, various retrofit investment packages are formed.

3. The effectiveness indicators $S I R_{i j k}$ and $M V R_{i j k}$ of every retrofit investment package $k$ are calculated in one step for every type of dwelling houses $i$ located in the city district $j$.

4. The retrofit investment packages $k$ with $S I R_{i j k}>1$ ir $M V R_{i j k}>1$ are included in further analysis.

5. Multicriteria analysis based on the principles described above is performed. The significances of the criteria are determined by experts. The analysis yields the retrofit priorities of the districts considered.

The renovation of a particular district may greatly influence the market value and attractiveness of the neighbouring areas and their property. Therefore, before starting the renovation of a district according to the priorities established earlier, any recent changes in market value of property or thermal energy and construction cost should be taken into account, and a new multicriteria analysis aimed at determining retrofit priorities of the districts should be performed if required.

\subsubsection{Condition of apartment houses in residential areas/blocks, quality issues with residential spaces}

Power (2008) claims that modernisation of buildings presents more benefits than demolition. However, in order to renovate an old building efficiently, a thorough analysis is needed (Kaklauskas et al. 2005). About 70\% of residential buildings in Europe are over 30 years old, and about 35\% among them are over 50 years old (Balaras et al. 2005). It leads to huge consumption of thermal energy. The European building sector is responsible for about $40 \%$ of the total primary energy consumption (Tommerup, Svendsen 2006; Uihlein, Eder 2010; Balaras et al. 2007), which means for more than industrial and transport sectors in the EU and the USA (Pérez-Lombard et al. 2008; Juan et al. 2010). Meanwhile, the sector of residential buildings in the EU accounts for some $22 \%$ of all energy consumption (Kavgic et al. 2010; International Energy Agency... 2008). To determine the wear of building elements, Denmark, France, Germany, Greece, Italy, Poland and Switzerland audited about 50 buildings in each of these countries. The research helped to determine the main reasons of wear: type of ownership, quality of structures (elements), age, type of finishing, type of materials, repair/ maintenance, location, etc. The dominating type of housing in Czech Republic, 
Slovenia, Slovakia, Hungary, Latvia and Bulgaria is flats. Flats make up 75\% of the entire housing stock in Estonia; some $10 \mathrm{~m}$ Polish citizens, about 25\% of the population, live in standard flats; while forecasts show that in 20 years $80 \%$ of flats in Romania will be uninhabitable. In most of these countries, the flats are located in large-panel houses (Raslanas et al. 2003). Šeduikytė and Jurelionis (2009) state that European apartment buildings have similar technical, functional and architectural problems, thus a single information system for modernisation of typical apartment houses would save considerable time and funds. Improvement of condition would also cut energy consumption in such buildings. About half of construction expenses in Europe are related to building repair and maintenance; however, early deterioration of concrete structures is becoming a serious problem in many countries (Balaras et al. 2005). In the Swiss residential building stock, accounting for about half of the energy demand of all the buildings, i.e. roughly a quarter of the total national energy demand, there is an enormous energy saving potential which can be best exploited by combining energy efficient measures with the normal retrofit cycle of buildings (Amstalden et al. 2007). Siller et al. (2007) believe that by 2050 the Swiss residential building stock can cut thermal energy consumption (heating and preparation of hot water) by a third and $\mathrm{CO}_{2}$ emissions by a fifth; however, considerable efforts are needed. In eastern and central Europe, thermal energy consumption in residential buildings is often averaging two to three times higher than that of similar buildings in Western Europe (Balaras et al. 2000). Loss of energy in apartment buildings constructed in Moscow between 1953 and 1964 makes up 30-40\%; internal engineering equipment sometimes is far from suitable for use. Part of such apartment buildings was demolished. However, in view of the problem related to settlement of people from demolished houses, a research was performed and revealed that the foundation of such five-storey buildings would be able to support another 5 storeys, while the general deterioration of a house was about $30-50 \%$, meaning that the deterioration of the supporting structures was $10-15 \%$. Thus demolition of such buildings was suspended and modernisation started instead. Estonia inspected about 200 buildings in various locations and determined that the average annual thermal energy consumption in apartment houses connected to local district heating systems is $256-315 \mathrm{kWh}$ per one square meter. Studies show that thermal energy loss in residential buildings is $20-40 \%$ higher than planned (Sasi, Hääl 2002). Sitar et al. (2006) point out that the condition of blocks of apartment buildings in Slovenia is also problematic, and in some cases worrying. Apartment buildings constructed in 1940s, 1950s and 1960s are in the most critical condition. About $20 \%$ of Hungarian families live in apartment houses constructed using industrialised technologies-mostly prefab reinforced concrete structures. Many were built in 1960s. They HVAC systems are outdated, and damage to buildings increases and becomes more serious (Zöld, Csoknyai 
2005). In Denmark, external walls in residential buildings constructed before 1960 account for most thermal energy losses (Tommerup, Svendsen 2006). In the Netherlands, most residential buildings were constructed between 1945 and 1965: they lack quality and comfort. The technical condition of such buildings witnesses limited possibilities of those times, as the houses have single glazed windows, no thermal insulation at all, just a wall of perforated bricks, thermal bridges, tile roofs without insulation and outdated layouts (Ham, Wouters 2006). Bluyssen (2000) states that the main indoor comfort issues in European residential houses are noise, insufficient thermal comfort, humidity, air quality (inadequate ventilation), etc. The research results of Jo and Sohn (2009) show that temperature and humidity make a significant impact on indoor microclimate. Replacement of old windows often means reduced quality of air due to inadequate ventilation (Roberts 2008), but the thermal transmittance of new windows may be lower three times.

Most people in Lithuania (as many as 66\%) live in various types of apartment houses built between 1961 and 1990 (Girčys et al. 2005). The houses were constructed following the Soviet norms, which stipulated particularly low energy efficiency requirements (Burinskienè 2003). There are currently about 30000 apartment houses in our country, and their modernisation is necessary. There are a handful of types: about 7 types of large-panel houses dominate (see Table 3.1), followed by 6 types of brick houses and 4 types of monolith houses. About $59 \%$ of flats in Vilnius are in large-panel apartment houses.

Table 3.1. Features of apartment houses

\begin{tabular}{|l|c|c|c|c|}
\hline \multicolumn{1}{|c|}{ Series No. } & Total heated area, $\mathrm{m}^{2}$ & $\begin{array}{c}\text { Number of } \\
\text { floors }\end{array}$ & $\begin{array}{c}\text { Number of } \\
\text { flats }\end{array}$ & $\begin{array}{c}\text { Number of } \\
\text { stairways }\end{array}$ \\
\hline 1-464LI-18/1 & 1725 & 5 & 30 & 2 \\
\hline $120 \mathrm{~V}-06 / 1$ & 1069 & 5 & 20 & 1 \\
\hline $1605 \mathrm{~A}$ & 2876 & 5 & 60 & 3 \\
\hline $1-464 \mathrm{~A}-14 \mathrm{LT}$ & 5803 & 5 & 120 & 8 \\
\hline $120 \mathrm{~V}-027 / 1$ & 2212 & 9 & 36 & 1 \\
\hline $1-464 \mathrm{LI}-53 / 1$ & 3783 & 9 & 72 & 2 \\
\hline $1 / 3905$ & 2890 & 12 & 60 & 1 \\
\hline
\end{tabular}

The key problems, defects and flaws of the condition of large-panel houses are common across all types, and also similar in case of brick houses and monolith houses. The oldest large-panel houses in Lithuania are about 50 years old, but they still have not had major repairs. Privatisation of flats in Lithuania came without the experience and traditions in facilities management (Martinaitis et al. 
2007). Lack of proper maintenance caused significant wear of apartment houses. Their quality is very poor and demands for urgent modernisation. Although the Civil Code of the Republic of Lithuania (LRS... 2000) sets a legal basis for a flat owner "to take the necessary measures without prior consent of other owners (users) in order to prevent damage or eliminate threats to parts of common use, and demand from the other owners of flats and premises reimbursement of expenses in proportion to the share of these owners in the common partial property", separate owners are not keen to apply these rules. They fail to ensure proper maintenance of such common partial property and timely repair needed by parts of common use. Moreover, separate owners of flats cannot handle issues related to inefficient energy use in their apartment houses either. Housing retrofit and maintenance projects were almost absent until 1996. The data of the Ministry of Environment of the Republic of Lithuania shows that after initiation of the experimental project for energy saving/housing some 700 apartment houses have been partially renovated in Lithuania; however, there are many more to be modernised.

Now, most of the apartment buildings in Vilnius do not meet new specifications for housing construction and the needs of residents. Most dwellings of each type also have flaws that make their maintenance more difficult and shorten the lifetime of the buildings.

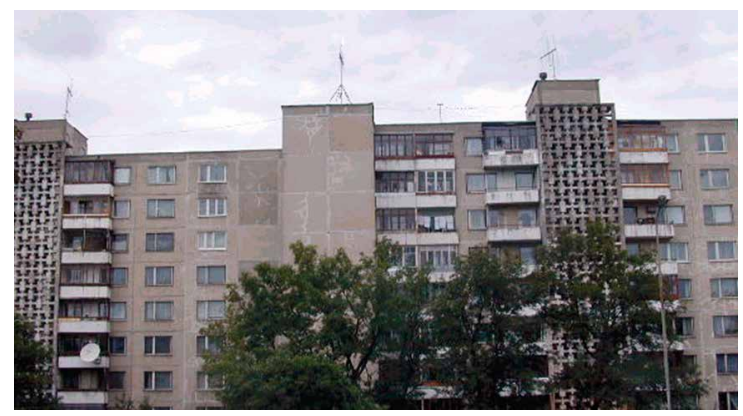

Figure 3.1. Damaged external walls of a panel house

Large-panel houses are of the following series: 1-464LI-18/1 (5/30/2), 120V06/1 (5/20/1), 1605A (5/60/3), 1-464A-14LT (5/120/8), 120V-027/1 (9/36/1), $1-464 \mathrm{LI}-53 / 1$ (9/72/2), and 1/3905 (12/60/1) (in parentheses, the number of floors, apartments, and staircases is given). The external walls of houses belonging to the 1605 series are sandwich walls with mineral wool insulation, while the houses of the 1-464LI series have single-layer walls made of 300-mm-thick expanded-clay lightweight concrete slabs. In five-story houses the expanded-clay lightweight concrete $\mathrm{C} 5 / 8$ is used, while in taller buildings concrete $\mathrm{C} 8 / 10$ is applied. Theoretically, the lifetime of such walls is 125 years. Most of the wall 
slabs on the façades have surface cracks through which moisture and pollutants infiltrate, damaging the walls and thermal insulation (Kulakauskas 2004). Flaws in the walls are also caused by migrating moisture, which contributes to crack formation and façade failure. Water gets into external walls when it is raining or drizzling. This migrating moisture washes away various salts on the wall surface, making the walls look unattractive. Since the finishing materials of such walls have worn out, their water absorption is thirty times higher than specified. Such external walls are often damp and houses experience higher thermal losses. When not properly repaired, panel houses look unattractive, with their façades decorated with "cobwebs" (Figure 3.1). The joints between the external panels of these houses are also cracked. Therefore, water and pollutants pass through them, damaging insulation and increasing thermal losses. Joints are designed to last for eight years. Then, they wear out and should be replaced. In general, the extent of deterioration of the external walls of panel houses constructed before 1970 in Vilnius is about 40\%.

Another problem is associated with high thermal transmittance of the windows and doors of most apartment houses as well as their poor airtightness due to aging, which increases cold air infiltration into dwellings (in cold seasons) and thermal losses due to ventilation. The lifetime specified for the wooden windows and entrance doors of panel houses was fifty years. However, cold air, wind, and pollutants could pass through them from the beginning of their service. Because of poor maintenance, these doors and windows have warped, their paint has peeled off, and the wood has rotted in some places. They look unsightly and need to be replaced. Some residents have replaced the doors and windows in their apartments. However, they have used doors and windows of various types, materials, and colors; therefore, there is a lack of harmony between building façades, and this spoils the view of the city. Moreover, even though many residents have replaced the windows in their apartments, most of the old windows still remain unchanged.

The roofs of panel houses are mostly of the same type. These are flat roofs with an internal water removal system, covered with prepared roofing paper (ruberoid in rolls). The service life specified for this kind of roof covering is twelve years; therefore, theoretically the roofs of the panel houses in Vilnius must be worn out now. The main flaws in these roofs are the leakage of water through the joints connecting them with parapets and vertical structures as well as through the roofing itself. As a result, thermal insulating materials get damp, thermal losses increase, and the wall finish is damaged, making living conditions in such dwellings unhealthy. The joints in the galvanized tin plate covering have also corroded and should be replaced. The roofing is weathered and blistered in many places. This worn-out roofing needs to be replaced, and some new thermal 
insulation materials should be added. The deterioration of cornices and parapets in panel houses reaches $45 \%$.

The foundations and basement walls of panel houses are made of single-layer reinforced concrete elements which are designed for a lifetime of 125 years. Their defects are usually caused by mechanical damage of external basement wall joints and finishes. Many problems also arise in the vertical joints of external basement wall slabs that are cracked and leak water and pollutants. The latter damage external basement walls, and their joints need to be fixed because of these defects.

Many of the problems in panel houses are associated with the current state of their balconies and porches, which were designed to last for 150 years. However, they are now the most heavily worn-out elements (up to 50\%). The deterioration of balconies and porches was caused by the weakening of their horizontal reinforced concrete supporting slabs exposed to rain, snow, changes of temperature, and pollution. The tin-plate covering of these slabs has also corroded. Glazing balconies and porches not only helps to save thermal energy but also protects the reinforced concrete slabs from snow and rainwater, thereby reducing the deterioration of these elements.

The entrance to a panel house usually has a canopy of reinforced concrete slab over it as well as 2-3 reinforced concrete steps and a landing. These elements are often in a critical state. They are hazardous to people as well as being unsightly. When panel houses are retrofitted, all entrances need to be renovated.

The layout of flats in the oldest apartment houses, particularly early largepanel houses, is outdated and fails to meet modern requirements. They lack auxiliary premises, all sanitary fittings are in the same room, kitchens and entryways are small, and there are some communicating rooms (Karvelis et al. 1998). Apartment houses are far from economical, their windows, walls and internal partitions have poor thermal and noise insulation properties, the heating systems are outdated, they lack ventilation and are known for bad indoor microclimate. Apartment houses with the usable area smaller than $500 \mathrm{~m}^{2}$ use most thermal energy, which makes up $243 \mathrm{kWh} / \mathrm{m}^{2}$; while those with usable area over $1500 \mathrm{~m}^{2}$ use the smallest amount of thermal energy, which makes up $147 \mathrm{kWh} / \mathrm{m}^{2}$. However, modernisation efforts help to cut these numbers by half (see Figure 3.2).

Thermal properties of envelopes in large-panel houses, and in most other apartment houses built before 1993-1996, fail to meet the requirements set by construction normative documents (Raslanas et al. 2004). Juozaitienè (2007) states that thermal energy consumption in such houses is twice as large as in Scandinavian countries and 1.75 times as large as in new apartment houses constructed in Lithuania. 


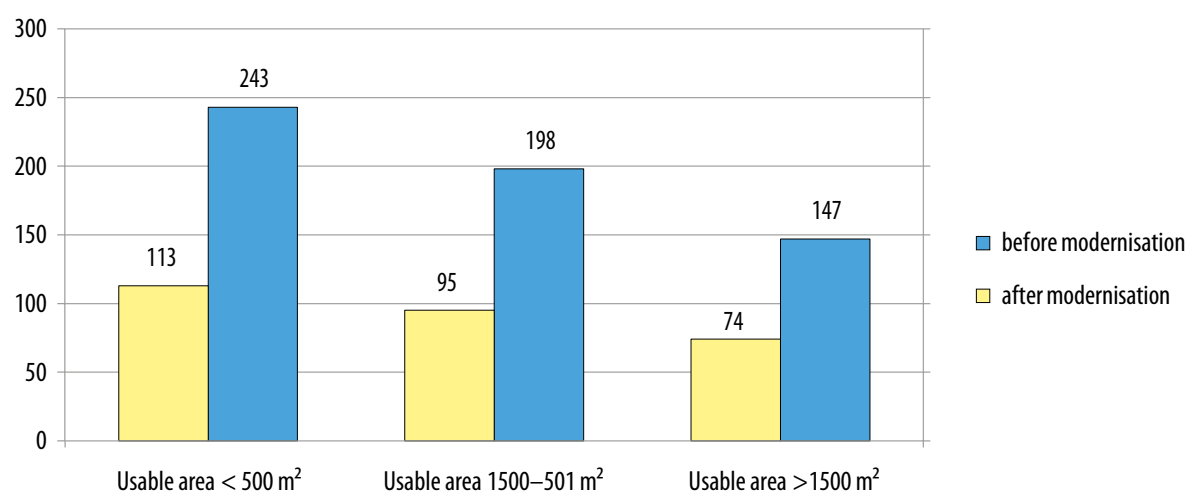

Figure 3.2. Annual thermal energy consumption per $1 \mathrm{~m}^{2}(\mathrm{kWh})$ of usable area

(Būsto ir urbanistinès plètros agentūra... 2009)

Table 3.2. Standard values for thermal transmittance of building's envelopes $U_{N}, \mathrm{~W} /\left(\mathrm{m}^{2} \cdot \mathrm{K}\right)$ and for thermal transmittance $\Psi_{N}, \mathrm{~W} /(\mathrm{m} \cdot \mathrm{K})$ of linear thermal bridges

\begin{tabular}{|c|c|c|c|c|}
\hline \multirow{2}{*}{ Envelope } & \multirow{2}{*}{ Mark } & \multirow{2}{*}{$\begin{array}{l}\text { Residential } \\
\text { buildings }\end{array}$} & \multicolumn{2}{|c|}{ Non-residential buildings } \\
\hline & & & Public & Industrial \\
\hline Roof & $\mathrm{r}$ & \multirow{2}{*}{$U_{N}=0.16 \cdot \kappa$} & \multirow{2}{*}{$U_{N}=0.20 \cdot \kappa$} & \multirow{2}{*}{$U_{N}=0.25 \cdot \kappa$} \\
\hline Floors, bounded with outside & ce & & & \\
\hline $\begin{array}{l}\text { Envelops of heating rooms, } \\
\text { bounded with ground }\end{array}$ & $\mathrm{fg}$ & \multirow{2}{*}{$U_{N}=0.25 \cdot \kappa$} & \multirow{2}{*}{$U_{N}=0.30 \cdot \kappa$} & \multirow{2}{*}{$U_{N}=0.40 \cdot \kappa$} \\
\hline Floors above cool cellars & $\mathrm{cc}$ & & & \\
\hline Walls & $\mathrm{w}$ & $U_{N}=0.20 \cdot \kappa$ & $U_{N}=0.25 \cdot \kappa$ & $U_{N}=0.30 \cdot \kappa$ \\
\hline Windows & wd & $U_{N}=1.6 \cdot \kappa$ & $U_{N}=1.6 \cdot \kappa$ & $U_{N}=1.9 \cdot \kappa$ \\
\hline Doors & d & $U_{N}=1.6 \cdot \kappa$ & $U_{N}=1.6 \cdot \kappa$ & $U_{N}=1.9 \cdot \kappa$ \\
\hline Linear thermal bridges & $\mathrm{t}$ & $\Psi_{\mathrm{N}}=0.18 \cdot \kappa$ & $\Psi_{\mathrm{N}}=0.20 \cdot \kappa$ & $\Psi_{\mathrm{N}}=0.25 \cdot \kappa$ \\
\hline
\end{tabular}

A large portion of large-panel houses (older in particular) is a source of troubles for their inhabitants because of the leaks between panel joints. Lack of tightness at panel joints often causes the walls to become damp, while in winter they may even freeze in. Such events damage finish and decoration in rooms, boost thermal transmittance of walls thus causing ever-increasing loss of heat. Indoor microclimate also deteriorates. The loss of heat through the envelope in most apartment houses exceeds the norms twice, while the properties of separate envelope elements may be as many as 4-4.5 times worse than the established norms (Table 3.2; STR 2.05.01:2005). Analysis of roofs shows that their main 
defects are related to water leaks through joints of roll roofing with parapets and vertical structures, and through the roofing itself. Leaks at parapets often cause the wall structures to become damp, which is particularly obvious in brick buildings. Water penetrates the roofing, makes the thermal insulation damp thus boosting heat loss, damaging finishing in rooms and causing unacceptable sanitary conditions.

According to benchmarking with thermal insulation of public buildings, the thermal transmittance of roof $U_{r}$ is equal (STR 2.05.01:2005):

$$
U_{N}=0.20 \cdot \kappa,
$$

where: $\kappa=20 /\left(\theta_{i}-\theta_{e}\right)$ - correction of temperature, $\theta_{i}$ - indoor temperature, ${ }^{\circ} \mathrm{C} ; \theta_{\mathrm{e}}$ - mean outdoor temperature for heating season.

Studies of large-panel houses in Vilnius by Ignatavičius (2009) revealed the worst situation to be with vertical joints between external panels of basement walls, which are usually cracked in multiple places. The protective plaster is gone in some places; and they are not covered with mastic. Such joints easily accumulate atmospheric humidity and a number of pollutants, which cause damage to external basement walls. We do not have any data sowing any major repair or retrofit of such joints within the lifecycle of such buildings. Heat loss through floors in ground floors needs a particular attention, because the majority of apartment houses have basements, and the basement temperatures are very important for indoor comfort in ground floors and heat loss through the floor (Šimkus et al. 2002).

Panel surfaces of external walls in façades of most large-panel houses are cracked; the cracks accumulate humidity and pollution, which, in turn, negatively affect the aesthetic properties of walls, their physical condition and thermal insulation (Ignatavičius 2004; Ignatavičius et al. 2008; Zavadskas et al. 2008d; Kulakauskas et al. 2004). Internal walls in apartment houses are in good repair. Although sometimes they are cracked, such cracks are mostly due to natural settlement right after construction and do not change. General wear of internal walls is up to $10 \%$, general wear of external walls between $10 \%$ and $30 \%$, while general wear of roof brackets and parapets in large-panel buildings is between $10 \%$ and $45 \%$. The condition of balconies in apartment houses is probably the worst, sometimes even critical. They are the most worn elements - up to 50\%. Due to poor water proofing, poor condition of flooring and corroded metal parts, water penetrates through to the balcony's panel, erodes concrete and causes corrosion in reinforcements. The outlines of reinforced concrete slabs are, however, in better condition when balconies are glazed, because such balconies prevent accumulation of precipitation and pollution, which, in turn, means less precipitation and pollution on reinforced concrete slabs and less damage. 
Metal parts and water proofing of entrance roofs are also worn, water penetrates through to the slab, erodes concrete and corrodes reinforcement. The stairs, platforms and roofs of entrances are often in critical condition, while the wear of flights of stairs and their platforms is $10-25 \%$. Although faults of these elements do not affect the overall strength of a building, they pose danger to people and damage the appearance.

Windows and external doors of most apartment houses are worn and are aesthetically hardly pleasing; such windows and doors cause up to $45-50 \%$ heat loss. People seal old windows or replace them themselves. Thus windows in one house are often of various types and colours, different materials, with different thermal insulation parameters, questionable ventilation, etc. Such practice disfigures façades and the general image of an area and a city. Examples of such apartment houses are ample across Lithuania.

Structures of apartment houses in newer residential areas of Vilnius are in sufficiently good repair, the flats have average or good layouts and their engineering systems are of satisfactory condition. From an architectural perspective, however, residential areas with typical apartment houses look monotonous, lack vitality and are less aesthetically pleasing.

The main problems with residential spaces are as follows: lack of parking lots, playgrounds, pedestrian walkways and bikeways; also insufficient attention to the needs of disabled people. Newer residential areas of Vilnius, such as Pilaitè, Pašilaičiai and Fabijoniškès, lack green spaces. People who chose to live in apartment houses care about their environment, noise levels, air quality, safety, neighbours (Raslanas et al. 2006) and other aspects; however, most of these features in Vilnius lately deteriorated due to insufficient maintenance of apartment houses (Zavadskas et al. 2008d).

General harmony in the appearance of cities and suburbs is missing, as well as public infrastructure and public spaces necessary for the best quality of life. Up to now, the focus has been on particular detailed plans for private parcels (Narvydaite 2008), while such focused planning and development of a parcel rather than a block or an area cause extensive damage to urban and national landscapes (Šulcienè 2008). One of the main reasons behind such situation is lack of territorial planning norms to ensure the quality of life. It causes urban sprawl, which means access problems and more difficulties to ensure engineering infrastructure in line with contemporary principles of sustainable development. Sector approach affects the environment and utility services, also further depletes energy resources and heritage resources, and boosts social exclusion (Darni urbanistinè plètra Lietuvoje... 2008).

The data of Statistics Lithuania shows that, at the end of 2007, Lithuania's housing stock included $82.1 \mathrm{~m}$ square meters of usable area. Since 1995, our national housing stock increased by almost $10 \%$. Soviet residential areas fail to 
meet the today's requirements. Also, social mix of residents in such areas has changed, and some new residential buildings and social infrastructure objects have been built in free spaces. As said, population densities in areas set for planning are not regulated, thus systematic errors occur, because areas become overpopulated or underpopulated. Municipalities find it difficult to change engineering infrastructure, street networks and public transport.

Insufficient maintenance and management leads to deterioration of residential houses and areas; they become uninhabitable. The importance of ongoing maintenance if often underestimated (Reichelt 2006; Reichelt et al. 2008; Zavadskas et al. 2009; Otto, 2008; Maliene et al. 2008). The data of Statistics Lithuania suggests that residential houses in Lithuanian cities and towns are worn in physical, economic and functional terms. With increasing energy prices, many households are struggling with their bills. Dormitory-type apartment houses are considered especially problematic. The data of Statistics Lithuania shows that about 3\% of Lithuanian housing stock show signs of critical condition as stipulated in the Construction Regulation STR 1.12.01:2004. Data of 2008 shows that, among Lithuanian urban municipalities, Kaunas (9.8\%) and Šiauliai (5.4\%) had the largest portions of such dwellings (Statistikos departamentas).

Problems with physical and social infrastructure in residential areas, as well as issues of social housing, eco-friendliness, building modernisation, transport and engineering infrastructure are currently of particular importance.

The cities of Lithuania try to handle the following key issues (LR Aplinkos Ministerija... 2008):

- uncoordinated development of city centres and suburbs;

- the current urban structure in towns and cities has considerable functional zoning, is insufficiently compact, lacks multifunctional and polycentric properties;

- uncoordinated development of cities and outskirts: underdeveloped external streets and roads, underdeveloped suburban centres, shrinking industrial territories in urban periphery and outskirts, still unbalanced numbers of jobs and places for residence;

- insufficient quality and image of physical environment in cities and residential territories (extensiveness of building density, lack of infrastructure, lack of green spaces);

- high mobility of people (more and longer trips due to the features of functional and physical structure);

- insufficient density of street networks;

- worse urban environments: deterioration of buildings, expanding wastelands (uninhabited areas);

- increasing unemployment, unbalanced social structure;

- emerging differences of the quality of life in central and peripheral areas: 
central parts with the best physical quality of residential environment have the highest concentrations of traffic and jobs, suffer from pollution issues, pedestrian and traffic conflicts, and issues of social environment; while peripheral areas with underdeveloped physical and functional structures mostly suffer from issues related to engineering and social infrastructure and lack of public transport.

These differences bring about negative processes: emigration or forced mobility of people, degradation of separate areas, social segregation and hindrance to sustainable development. All these problems affect urban economy, social and eco environment, the quality of life.

The inner climate in dwellings depends not only on the temperature and relative humidity but also on the carbon dioxide $\left(\mathrm{CO}_{2}\right)$ content in the air, volume flow, air velocity, dew point, the temperature of the envelope surface and the ambient air (Seduikyte, Bliudzius 2005). Hygienic standards provide for an adequate level of thermal comfort in public and residential buildings by specifying such parameters as air temperature, appreciable temperature, relative humidity, air velocity, and differences in temperature between the envelope surface and inside the building (Mitkus 2001). The specified values of thermal comfort parameters are given in Table 3.3.

Table 3.3. The values of the parameters determining thermal comfort conditions in public and residential buildings provided in specifications HN 42: 2004

\begin{tabular}{|l|l|l|}
\hline \multicolumn{2}{|c|}{ Parameters of thermal comfort } & \multicolumn{2}{c|}{ Specified values } \\
\cline { 2 - 3 } & for cold season & for warm season \\
\hline 1. Air temperature, C & $20-24$ & $23-25$ \\
\hline 2. Appreciable temperature, C & $19-23$ & $22-24$ \\
\hline $\begin{array}{l}\text { 3. Temperature difference between the air 1.1 m } \\
\text { and 0.1 m above the floor, not exceeding C }\end{array}$ & 3 & 3 \\
\hline $\begin{array}{l}\text { 4. Temperature difference between the envelope } \\
\text { and the rooms, not exceeding C }\end{array}$ & 2 & 2 \\
\hline 5. Floor temperature, C & $19-26$ & Not specified \\
\hline 6. Relative humidity, \% & $40-60$ & $40-60$ \\
\hline 7. Air velocity, not exceeding m/sec & 0.15 & 0.25 \\
\hline
\end{tabular}

The microclimate of a two-bedroom apartment in a panel house on Taika St. in Justiniskes was studied (Indoor climate 2006). The average air temperature in the room was $19.90{ }^{\circ} \mathrm{C}$. The graph was regular and slightly curved (because wind passed through the windows). Therefore, it could be claimed that the air temperature was below the specified value and reflected outside temperature fluctuations (Fig 3.3). The average volume flow in the living room was 
$11.45 \mathrm{~m}^{3} / \mathrm{h}$. The irregularity of the volume flow graph may be explained by draughty windows in the dwelling. The average air velocity in the room was $0.09 \mathrm{~m} / \mathrm{s}$. The graph was irregular, therefore, it could be claimed that the dwelling was draughty. The average relative humidity in this room was $24.65 \%$. The chart was regular and reflected natural relative humidity fluctuations outside the building. The relative humidity registered in the dwelling was lower than the value specified in the hygienic standards for residential houses. Thus, more powerful air conditioning or a source of moisture is needed. The average dew point temperature in this room was $0.85{ }^{\circ} \mathrm{C}$ (while outside air temperature was $9{ }^{\circ} \mathrm{C}$, the temperature in the dwelling was $19.90{ }^{\circ} \mathrm{C}$, and relative humidity $-24.65 \%$ ). The changes in the diagram of dew point temperature reflect the changes in the diagrams of temperature and relative humidity.

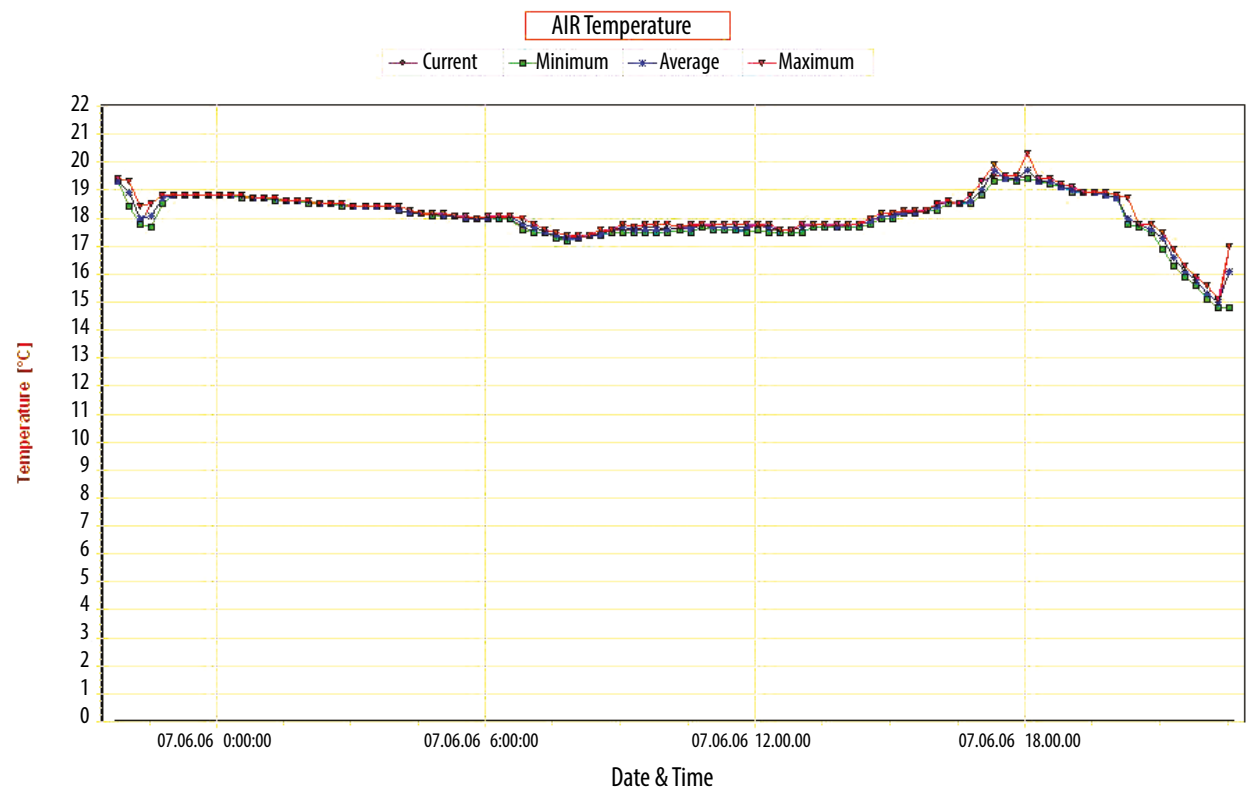

Figure 3.3. Air temperature diagram showing the microclimate in a panel-house two-bedroom apartment in Justiniskes, on Taika St., in Vilnius

It is hard to find detailed data on the microclimate parameters associated with human health and working and leisure conditions in Lithuanian panel houses. However, high $\mathrm{CO}_{2}$ content, moldy walls, and large difference between the temperatures of the envelope and the air in the dwelling, etc. observed in panel houses show that these parameters do not meet the specifications. The Housing and Health Research Project, carried out in 2002 by the World Health Organization (WHO), identified some key problems associated with a negative 
effect of the conditions in panel houses of Vilnius on human health. Dwellings have a high noise level, insufficient heating, and low air quality (Housing and Health 2002).

About $60 \%$ of Vilnius residents were not satisfied with the air temperature in their apartments in winter. More than $80 \%$ of houses do not have their own thermostats. About 75\% (over 129 thousand) of apartments in Vilnius depend on centralized district heating (the municipal heat-supply systems). Houses are provided with elevator-type heating units (with their heating systems not separated from the central city system). Now, autonomous automated heating units are being installed in panel houses. Heating systems in panel houses are mostly represented by single-pipe upfeed heating. The apartments are provided with hot-water heating cast-iron or steel radiators. Heat distribution in heating risers is often not balanced. The consumption of thermal energy is determined for the whole building, and the billing is made by dividing the cost of the consumed energy by the number of apartments according to their floor space. Since residents cannot regulate heating in their dwellings and calculate the amount of thermal energy consumed in their apartments individually, they are not particularly interested in saving energy.

Another serious problem mentioned by $68.1 \%$ of respondents in Vilnius is noise. The main source of noise pollution is car traffic in the streets and in the yards of the houses. Poorly insulated windows, walls, and envelopes of houses also considerably worsen the situation. Leaking windows cause air pollution within the dwellings. About 50\% of residents are not satisfied with the air quality in panel houses. Pollution and very dry air in the dwellings are the main problems. In most cases, the air quality cannot be controlled and is low.

In many panel houses, the slab joints are leaky, causing the walls to grow damp or even freeze in winter. This situation leads to higher thermal transmittance and, consequently, heat loss, as well as making the microclimate in the dwellings even less comfortable and healthy for people.

\subsubsection{A Retrofit concept for panel houses}

Large-panel houses in Vilnius are in a state of disrepair and do not meet current housing needs. If not renovated, these houses may cause social problems because middle-class families can move elsewhere. Therefore, renovation is necessary, and it should be a comprehensive process because retrofitting a single house can reduce maintenance costs for residents but can hardly change the quality of life. By retrofitting the whole neighborhood or a group of houses, better results can be obtained in quality, aesthetics, and in solving social problems.

The residential districts of Vilnius are mostly built up with panel houses of the same type. However, they possess some peculiar features because of their unique environment and due to various city-planning concepts of the architects. 
When neighborhoods are renovated, efforts should be made to preserve and enhance their individual characteristics, environment, and design of their buildings. It is also important to develop two or three typical retrofit alternatives for each series of panel buildings. This would be cost-effective because it would help avoid the development of a new project, allowing the same elements and finishing materials to be used and a uniform architectural appearance and style to be preserved.

Several façade-finishing alternatives for insulating houses from the outside are possible. These are the use of painted stucco, façade plates, structural clay products, and tin-plate façade finishes. The insulation of the roof and new roofing should also be included in a retrofit project. If a mansard roof is built, the renovated house looks better architecturally, and the additional apartments can be sold to partially cover the retrofit expenses of the residents.

Houses, spaces, and neighborhoods may be diversified by using different colors, building extensions, mansard roofs, etc. A comprehensive approach to façade painting, i.e. preparing different painting projects for different groups of houses and neighborhoods, can help preserve the individual character of residential areas built up with panel houses.

Changing the inner layout of panel houses is hardly possible because the spacing between the external and internal bearing walls is small. Retrofit projects should provide for renovation of staircases, entrance doors, the canopies over them and balconies, which can become attractive elements of the renovated apartment houses.

Outdoor amenities, i.e. pedestrian and bicycle paths, parking lots, children's playgrounds, sports grounds, benches, litterbins, street lamps, etc., should also be renovated and rebuilt because the quality of housing largely depends on them.

One of the main objectives of the housing strategy approved by the Government of the Republic of Lithuania is the efficient use of available housing resources, their maintenance, renovation and update, as well as the efficient use of energy resources and substantial improvement of the condition of existing houses and efforts to maintain and increase their value (The Lithuanian Housing Strategy... 2004; Martinaitis 2004). The scope of renovation is determined by its goal and the state of a building assessed from technical and functional perspectives (Sobotka 1998). The problems and drawbacks described above emphasize the need for renovating apartment buildings and outdoor amenities in Vilnius. For this purpose, the following measures should be taken:

- Laying new waterproof roofing.

- Adding more roof insulation.

- Replacing a flat roof with a mansard roof with new apartments in the space obtained.

- Repairing the balconies that are in a critical state. 
- Replacing windows.

- Replacing entrance doors.

- Installing windows on the balconies.

- Fixing wall slab joints.

- Insulating flank walls.

- Insulating all the walls of a building.

- Renovating the heating unit, making it an independent automated system of heating and hot water supply.

- Balancing the heating system by installing balanced valves above the heating system risers.

- Installing gauges and individual thermostats in the apartments.

- Reconstructing the heating system by installing a collector.

- Replacing sewage pipes.

- Renovating the electrical equipment on staircases and in other shared spaces.

- Providing and renovating outdoor amenities.

To assess the preliminary investment packages and their profitability, four retrofit alternatives (based on small, medium, large and basic investment projects) were developed, and calculations were made for various types of panel houses. The main features of the investment packages for renovating apartment buildings of the series 1-464LI-18/1 are presented in Tables 3.4 and 3.5.

A package of small investments is aimed at repairing, reconstructing, or replacing systems and elements which are in critical or poor condition (Table 3.4). This package is attractive because of the relatively small investments, although the thermal characteristics of the building envelope can be only slightly improved (in reference to doors and windows only). The same applies to the architectural and aesthetic characteristics, which are also improved through the replacement of windows. There is also a drawback in the old system of regulation of thermal energy consumption, consisting in determining the energy consumed by the entire building and dividing it by the number of apartments according to their floor space. This system does not allow residents to individually regulate the temperature in their apartments.

Medium-size investment packages are more oriented to saving energy and, therefore, give relatively high returns (Table 3.4). The individual regulation of heating devices and thermal energy consumption encourages residents to save energy, with the savings depending on how much heat is used. The renovation of essential outdoor amenities is also planned. However, the implementation of this investment project does not result in great changes in the architectural appearance and aesthetics of panel houses. Walls (except for flank walls) do not meet current specifications and standards. Providing radiators with thermostats 
Table 3.4. Small and medium retrofit investment packages for a panel house of the series 1-464LI-18/1

\begin{tabular}{|c|c|c|c|c|c|c|}
\hline \multicolumn{2}{|r|}{ Small investment package } & \multicolumn{2}{|c|}{ Investments, USD } & \multicolumn{2}{|c|}{ Savings, USD } & \multirow{2}{*}{$\begin{array}{c}\text { Payback } \\
\text { (in years) }\end{array}$} \\
\hline No. & Retrofit measure & Total & $1 \mathrm{~m}^{2}$ & Total & $1 \mathrm{~m}^{2}$ & \\
\hline 1 & Laying a new roof covering & 8007 & 4.55 & - & - & - \\
\hline 2 & $\begin{array}{l}\text { Repairing balconies in a critical } \\
\text { state }\end{array}$ & 7014 & 4.21 & - & - & - \\
\hline 3 & Replacing windows & 73486 & 42.78 & 2650 & 1.54 & 27.73 \\
\hline 4 & Replacing entrance doors & 3065 & 1.75 & 96 & 0.07 & 31.92 \\
\hline 5 & Fixing slab joints & 3811 & 2.11 & - & - & - \\
\hline 6 & Reconstructing the heating unit & 11924 & 7.01 & 1469 & 0.84 & 8.12 \\
\hline \multirow[t]{2}{*}{7} & Balancing the heating system & 2525 & 1.40 & 1041 & 0.59 & 2.42 \\
\hline & Total for construction work: & 109832 & 63.81 & 5256 & 3.04 & 20.90 \\
\hline 8 & $\begin{array}{l}\text { Design and engineering } \\
\text { services }\end{array}$ & 8787 & 5.26 & - & - & - \\
\hline 9 & Client's reserve & 10652 & 7.01 & - & - & - \\
\hline & TOTAL & 129271 & 76.08 & 5256 & 3.04 & 24.59 \\
\hline \multicolumn{7}{|c|}{ Medium investment package } \\
\hline 1 & $\begin{array}{l}\text { Insulating the roof and laying } \\
\text { new roofing }\end{array}$ & 19572 & 11.75 & 1051 & 0.59 & 18.62 \\
\hline 2 & $\begin{array}{l}\text { Repairing balconies in a critical } \\
\text { state }\end{array}$ & 7014 & 4.20 & - & - & - \\
\hline 3 & $\begin{array}{l}\text { Replacing staircases and apart- } \\
\text { ment windows }\end{array}$ & 73486 & 42.78 & 2650 & 1.54 & 27.73 \\
\hline 4 & Replacing entrance doors & 3065 & 1.75 & 96 & 0.07 & 32.04 \\
\hline 5 & Insulating flank façades & 9941 & 5.61 & 500 & 0.28 & 19.88 \\
\hline 6 & Reconstructing the heating unit & 11924 & 7.01 & 1469 & 0.83 & 8.12 \\
\hline 7 & Balancing the heating system & 2525 & 1.40 & 1041 & 0.59 & 2.42 \\
\hline 8 & Installing individual thermostats & 10609 & 6.31 & 2251 & 1.29 & 4.71 \\
\hline 9 & $\begin{array}{l}\text { Providing and renovating } \\
\text { outdoor amenities }\end{array}$ & 24193 & 14.02 & - & - & - \\
\hline \multicolumn{2}{|r|}{ Total for construction work: } & 162329 & 94.83 & 9058 & 5.19 & 17.92 \\
\hline 10 & Design and engineering services & 12986 & 7.36 & - & - & - \\
\hline 11 & Client's reserve & 17531 & 10.17 & - & - & - \\
\hline \multicolumn{2}{|r|}{ TOTAL } & 192846 & 112.36 & 9058 & 5.19 & 21.29 \\
\hline
\end{tabular}

and devices to measure thermal energy consumption, when a single-pipe heating system is used, has some drawbacks as follows: 
- Regulation of the temperature in the dwelling may lower the heating temperature in the apartments located on the left and right sides of a building.

- Measuring devices in a particular apartment do not record the total amount of thermal energy consumed, with the energy consumed by the house being proportionally divided among the apartments according to the readings on their gauges.

- If the heating system in one apartment fails or is being repaired, the heating of the other apartments is interrupted.

- The residents of individual apartments cannot use their heating systems before the heating season starts.

A package of large investments is aimed at achieving the highest-quality standard for a house in which the envelope meets the requirements of minimum heat losses, and the heating system is most efficient (with the accurate measurement of thermal energy consumed and the freedom to start or finish heating of the dwelling at any time and not to stop heating the entire building in the case of repair or failure of any system in an individual apartment) (Table 3.5). In fact, the overall economic efficiency of such buildings is equal to that of newly constructed houses. However, the investments are large (331.40 USD/ $\mathrm{m}^{2}$ ) and hardly affordable for most tenants. These packages are most suitable for prestigious districts because, when a mansard roof is built and, therefore, additional apartments are created, some of the investments can be returned by selling these new premises.

A basic investment package aims to ensure that the building envelope meets standard specifications for heat losses, mechanical strength and durability of structures as well as the requirements for an efficient heating system and individual control of thermal energy consumption (Table 3.5). This retrofit investment package also provides for minimal outdoor amenities.

These calculations show that the investments in $1 \mathrm{~m}^{2}$ of floor space of various types of panel houses are similar for the same types of investment packages (Figure 3.4). The cost of implementing small investment packages ranges from $62 \mathrm{USD} / \mathrm{m}^{2}$ to $78 \mathrm{USD} / \mathrm{m}^{2}$, with an average of $70 \mathrm{USD} / \mathrm{m}^{2}$, while the cost of a medium-size investment package is about $100 \mathrm{USD} / \mathrm{m}^{2}$ (ranging from 89 to $111 \mathrm{USD} / \mathrm{m}^{2}$ ). The cost of implementing packages of large investments is about $286 \mathrm{USD} / \mathrm{m}^{2}$ (ranging from $240 \mathrm{USD} / \mathrm{m}^{2}$ to $332 \mathrm{USD} / \mathrm{m}^{2}$ ). The cost of a basic investment package is approximately $168 \mathrm{USD} / \mathrm{m}^{2}$ (ranging from $150 \mathrm{USD} / \mathrm{m}^{2}$ to $186 \mathrm{USD} / \mathrm{m}^{2}$ ).

Since one of the retrofit objectives is to increase the economic efficiency of dwellings, a comparative analysis of retrofit scenarios from an energy-saving perspective was made (Figure 3.5). The largest energy savings were obtained by implementing large packages of investments and basic investment packages. 
Table 3.5. Large and basic retrofit investment packages for a panel house of the series 1-464LI-18/1

\begin{tabular}{|c|c|c|c|c|c|c|}
\hline \multicolumn{2}{|r|}{ Large investment package } & \multicolumn{2}{|c|}{ Investments, USD } & \multicolumn{2}{|c|}{ Savings, USD } & \multirow{2}{*}{$\begin{array}{l}\text { Payback } \\
\text { (in years) }\end{array}$} \\
\hline No. & Retrofit measure & Total & $1 \mathrm{~m}^{2}$ & Total & $1 \mathrm{~m}^{2}$ & \\
\hline 1 & $\begin{array}{l}\text { Constructing a mansard roof } \\
\text { with dwellings inside }\end{array}$ & 147675 & 85.57 & 1336 & 0.78 & 110.54 \\
\hline 2 & $\begin{array}{l}\text { Repairing balconies and } \\
\text { installing windows in them }\end{array}$ & 36475 & 21.03 & 869 & 0.50 & 41.92 \\
\hline 3 & $\begin{array}{l}\text { Replacing apartment and } \\
\text { staircase windows }\end{array}$ & 73487 & 42.78 & 2650 & 1.54 & 27.73 \\
\hline 4 & Replacing entrance doors & 3065 & 1.76 & 96 & 0.07 & 31.92 \\
\hline 5 & Insulating façades & 64217 & 37.18 & 3235 & 1.85 & 19.85 \\
\hline 6 & Reconstructing the heating unit & 11925 & 7.01 & 1469 & 0.83 & 8.12 \\
\hline 7 & $\begin{array}{l}\text { Reconstructing the heating } \\
\text { system collector }\end{array}$ & 89435 & 51.90 & 3294 & 1.90 & 27.15 \\
\hline 8 & Replacing the piping & 24798 & 14.37 & - & - & - \\
\hline 9 & $\begin{array}{l}\text { Replacing the electrical } \\
\text { equipment }\end{array}$ & 5236 & 3.16 & - & - & - \\
\hline \multirow[t]{2}{*}{10} & $\begin{array}{l}\text { Providing and renovating } \\
\text { outdoor amenities }\end{array}$ & 24193 & 14.02 & - & - & - \\
\hline & Total for construction work: & 480506 & 278.78 & 12949 & 7.47 & 37.11 \\
\hline 11 & Design and engineering services & 38440 & 22.45 & - & - & - \\
\hline 12 & Client's reserve & 51895 & 30.17 & - & - & - \\
\hline & TOTAL & 570841 & 331.40 & 12949 & 7.47 & 44.10 \\
\hline \multicolumn{7}{|c|}{ Basic investment package } \\
\hline 1 & $\begin{array}{l}\text { Insulating the roof and laying new } \\
\text { roofing }\end{array}$ & 19572 & 11.23 & 1051 & 0.59 & 18.62 \\
\hline 2 & $\begin{array}{l}\text { Repairing balconies and installing } \\
\text { windows in them }\end{array}$ & 36475 & 21.03 & 866 & 0.49 & 42.12 \\
\hline 3 & $\begin{array}{l}\text { Replacing apartment and } \\
\text { staircase windows }\end{array}$ & 73487 & 42.78 & 2650 & 1.53 & 27.73 \\
\hline 4 & Replacing entrance doors & 3065 & 1.76 & 96 & 0.07 & 31.92 \\
\hline 5 & Insulating façades & 64217 & 37.18 & 3235 & 1.85 & 19.85 \\
\hline 6 & Reconstructing the heating unit & 11925 & 7.01 & 1469 & 0.84 & 8.12 \\
\hline 7 & Reconstructing the heating system & 2525 & 1.40 & 1041 & 0.59 & 2.42 \\
\hline 8 & Installing thermostats & 10609 & 6.31 & 2251 & 1.30 & 4.71 \\
\hline \multirow[t]{2}{*}{9} & $\begin{array}{l}\text { Providing and renovating } \\
\text { outdoor amenities }\end{array}$ & 24193 & 14.02 & - & - & - \\
\hline & Total construction work: & 246068 & 142.72 & 12659 & 7.26 & 19.44 \\
\hline 10 & Design and engineering services & 19686 & 11.58 & - & - & - \\
\hline 11 & Client's reserve & 26575 & 15.42 & - & - & - \\
\hline \multicolumn{2}{|r|}{ TOTAL } & 292329 & 169.72 & 12659 & 7.26 & 23.09 \\
\hline
\end{tabular}


Actually, the savings obtained by using medium, large, and basic investment packages can vary considerably because, when residents have individual thermostats in their dwellings, they can choose any temperature which seems comfortable for them and consume as much thermal energy as they can afford.

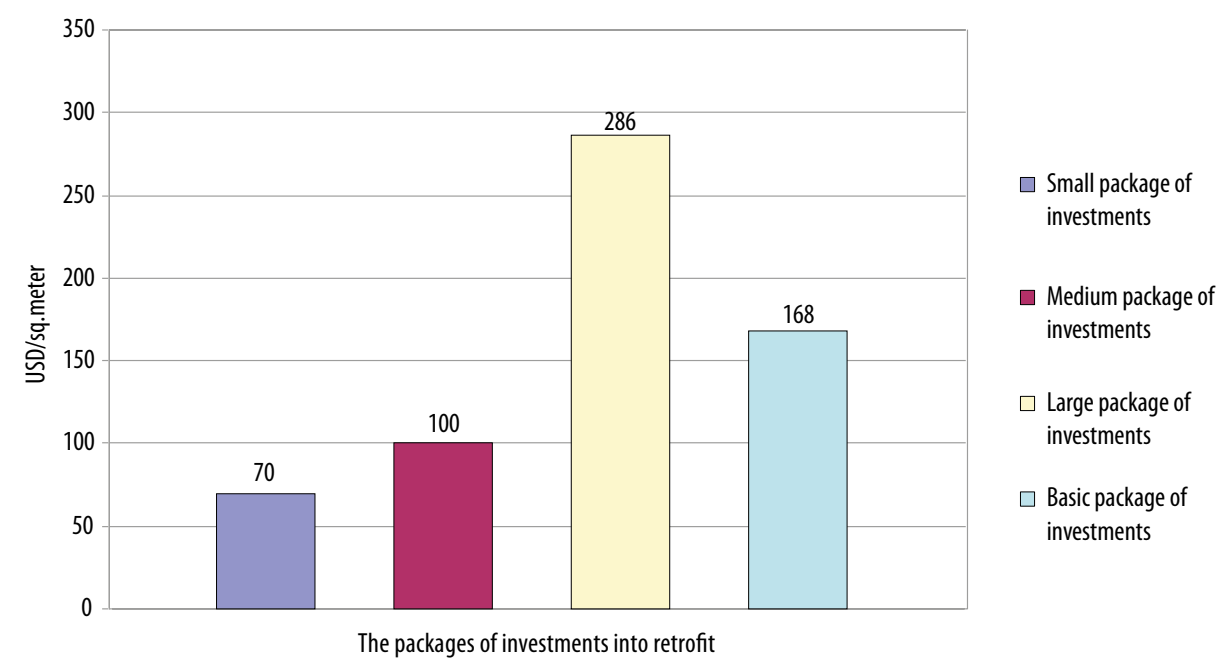

Figure 3.4. Average cost of retrofit investment packages, USD $/ \mathrm{m}^{2}$

The average payback period for small, medium, large, and basic investment packages is $25,22,40$, and 24 years, respectively. As can be seen, the mediumsize investment package seems to be most attractive because its payback period is the shortest. However, the use of this package will hardly improve the aesthetics of panel houses.
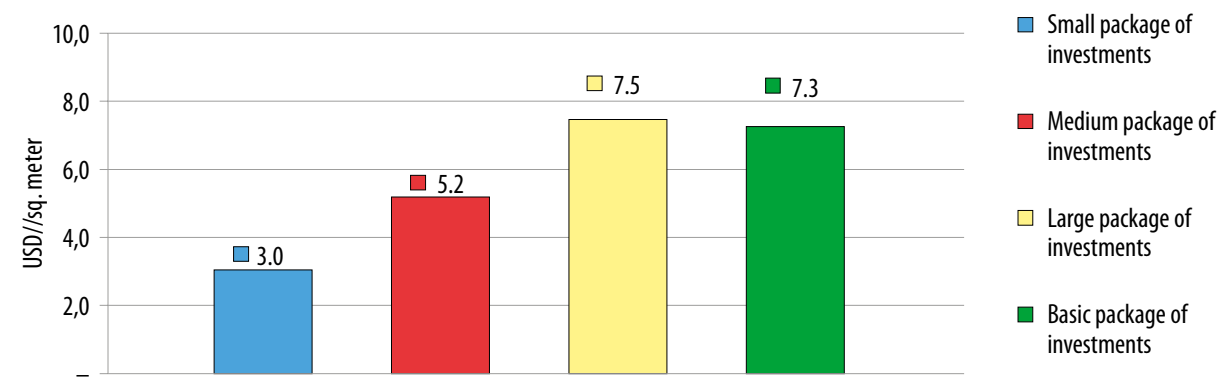

The packages of investments into retrofit

Figure 3.5. Average savings resulting from the implementation of retrofit investment packages, $\mathrm{USD} / \mathrm{m}^{2}$

In the process of decision-making, i.e. selecting effective retrofit packages, designers manually produce two or more alternative scenarios, which then will 
be evaluated for the final choice. To determine the optimal investment in renovation of apartment houses, several factors should be taken into account. It is obvious that the number of measures to be taken depends on a particular case. In general, it depends on the financial resources needed to attain the goals and objectives of renovation of dwelling houses and their environment. The analysis of the above types of retrofit packages has shown that, to increase energy efficiency and the environmental quality of a building, the investment should be from 150 to $332 \mathrm{USD} / \mathrm{m}^{2}$ (of the apartment floor space). The large investment package was elaborated, taking into account the maximum allowable costs of the project. The retrofit scenarios were developed that could be recommended in the case of certain financial constraints, taking into consideration municipalities' subsidies and the financial position of residents.

To assess energy-efficiency and market value-efficiency of retrofitting, the investment analysis was made of four progressively energy-efficient retrofit packages. The packages were made up so that the small investment package was the least energy-efficient. Energy-efficiency of other projects was higher, with the large investment package, providing for creating new apartments by constructing a mansard roof being the most energy-efficient. According to the criterion of energy efficiency, the basic investment package was nearly equal to the large investment package. The packages were combinations of particular retrofit components, intended for gradual upgrading of heating systems and building insulation. They were also progressively applied to different components of the building envelope and renovation of outdoor amenities. In renovating panel houses, energy-saving measures related to the renovation of the building heating system and the envelope (i.e. insulation of external walls, windows, and roof structures) should be given the priority because of their long-term effect. Typical retrofit measures have been selected for packages, aiming to increase energy efficiency and quality of dwelling houses.

The generation of retrofit scenarios as well as their evaluation and selection of optimal scenarios can be automated by applying various decision-making tools and expert systems. This would allow us to automatically evaluate a large amount of retrofit scenarios in order to find the most rational alternative. The calculation of investments based on this method would help to increase the profitability of renovation projects, due to increased energy-efficiency and market value of the renovated apartment buildings.

\subsubsection{The Selection of Effective Retrofit Scenarios for Panel Houses in Residential Neighborhoods}

One of the main objectives of the programme of strategic Vilnius development in 2002-2011 is to support housing construction and renovation of apartment buildings in Vilnius neighborhoods that are becoming less attractive for residents 
by encouraging investments in their renovation and the development of common-type retrofit projects and energy-saving programs (Vilnius City... 2003). The priority order of houses and neighborhoods to be renovated depends on the strategic development plans for Vilnius as well as the degree of deterioration of the existing houses and their environment. The renovation of houses should be accompanied by the renovation or creation of outdoor amenities. The programme of Vilnius development in 2002-2011 emphasizes the importance of developing the center of the city, the area on the right bank of the Neris river and other places often visited by tourists. These areas must be made more attractive to visitors in order to make Vilnius competitive on an international scale. The goals of the strategic plan for Vilnius development impose some restrictions on determining retrofit priorities for neighborhoods. A zoning principle has to be followed, the order of neighbourhood's renovation has to be established, and, finally, a comprehensive program for renovating residential buildings and their surroundings has to be carried out. These measures can greatly increase the attractiveness of these areas as well as their market value. As a result, more private investments can be drawn to these districts.

Based on geographical analysis, the territory of Vilnius was subdivided into three groups of districts according to their attractiveness to residents and the market value of property as follows: highly prestigious, prestigious and nonprestigious areas. Retrofit investment packages were prepared for four apartment houses. Retrofit effectiveness ratios $S I R_{i j k}$ and $M V R_{i j k}$ were calculated in one step for every type of dwelling house $i$ located in district $j$ and every renovation investment package $k$. Then, only the investment packages $k$ having $S I R_{i j k}$ and $M V R_{i j k}>1$ were left for further analysis. Based on such criteria as the significance of districts for strategic development plans of the city, the current state of buildings and the environment, cost of renovation, thermal energy saving, market value of apartments of new and old construction and the expected rise in the market value of property, the MCDM method COPRAS was applied to determine the priority order of Vilnius neighborhoods to be renovated according to particular scenarios (Zavadskas et al. 1994). This method assumes the direct and proportional dependence of the significance and degree of utility of the options studied on a set of criteria adequately describing the alternatives and on the values and weights of these criteria. The significance, priority order, and degree of utility of the alternatives are determined in five stages (Kaklauskas et al. 2005, Kaklauskas et al. 2006):

1. Generating the weighted normalized decision-making matrix $D$.

2. Calculating the sums of the weighted normalized criteria describing the $j$-th alternative.

3. Determining the significances $Q j$ of the alternatives compared and describing the advantages $S_{+j}$ and disadvantages $S_{-j}$ of the alternatives. 
4. Calculating the utility degree $N_{j}$ of the alternatives $a_{j}$.

5. Determining the priority order of the alternatives.

6. The geographical analysis performed yielded the following priority order of renovating Vilnius neighborhoods and their houses:

7. Zirmunai, Antakalnis.

8. Naujininkai, Vilkpede, Naujamiestis.

9. Virsuliskes, Karoliniskes, Lazdynai.

10. Snipiskes.

11. Seskine, Verkiai.

12. Justiniskes, Fabijoniskes, Pasilaiciai.

13. Pilaite.

14. Paneriai.

15. Grigiskes, Naujoji Vilnia.

USD/sq. meter

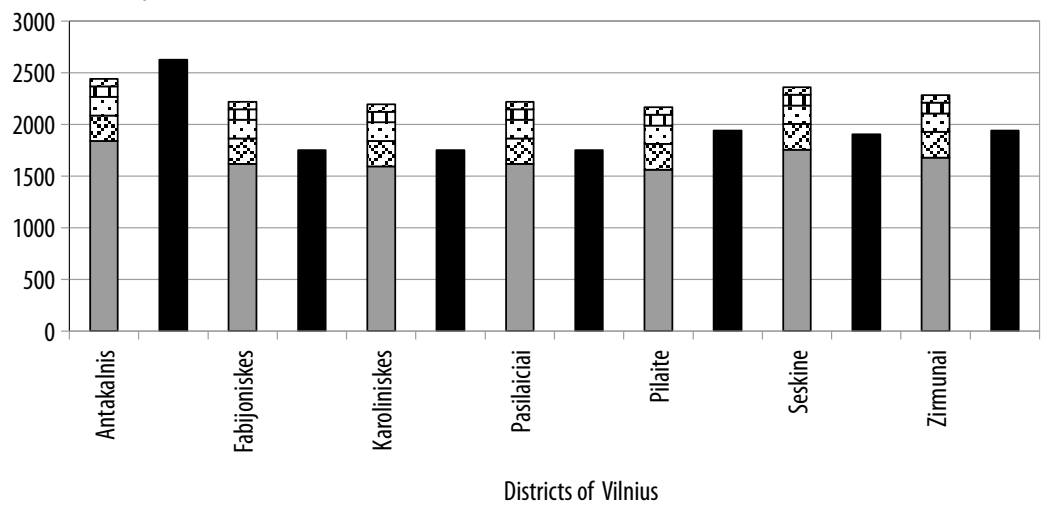

$\square$ Small package of investments

ஐ Medium package of investments

$\square$ Basic package of investments

๑ Large package of investments

- New construction

$\square$ Old construction

Figure 3.6. Average market values of $1 \mathrm{~m}^{2}$ of one-bedroom newly built and old apartment floor space plus the cost of retrofit investment packages in various Vilnius districts

A mathematical-statistical analysis allowed us to determine the average market value of $1 \mathrm{~m}^{2}$ of floor space in apartments of old and new construction. In terms of market value, it is not advisable to develop retrofit investment scenarios which, when implemented, would make apartment values equal to or even higher than those of newly constructed houses in the same area, taking into account their average current market value and the cost of retrofit (Figure 3.6).

The SIR and $M V R$ were calculated in one step for various retrofit packages, various panel houses and districts. When the values of SIR and MVR were calculated for retrofit scenarios of various types of panel houses in Vilnius, three groups of districts to be renovated were determined (Figure 3.7): 
1. Group 1, including highly prestigious districts (Antakalnis, Zirmunai, Virsuliskes), where basic investment retrofit scenarios could be energy and market value-effective.

2. Group 2, including prestigious districts (Fabijoniskes, Karoliniskes, Pasilaiciai, Pilaite, etc). Medium and basic investment retrofit scenarios could be proposed for these districts.

3. Group 3, including non-prestigious districts (Paneriai, Vilkpede, etc.). Small investment retrofit scenarios could be energy-effective in these neighborhoods.

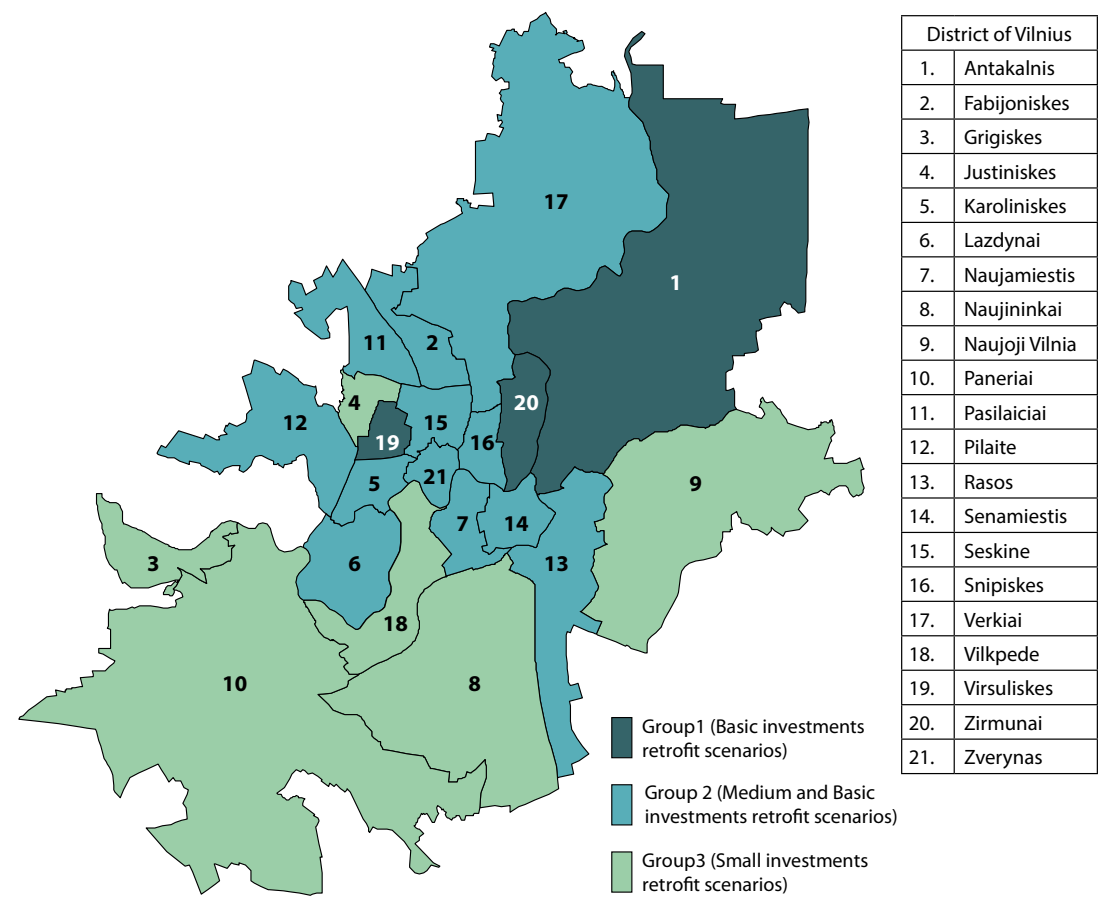

Figure 3.7. Retrofit scenarios for panel houses in various Vilnius districts

The SIR and MVR calculations show that the value of SIR depends on the type of investment package, the type of house and the energy saved, while $M V R$ depends on the type of investment package, the type of house and the neighborhood where the houses are located (Figure 3.8). SIR is the highest for small and medium retrofit investment packages. For basic investment packages, its value ranges from 0.925 to 1.05 . These figures show that, in terms of energy saving, the investments can pay off. However, the value of the ratio SIR is reduced to 0.752 for large investment packages.

The calculations have shown that in renovating the districts of Antakalnis, Zirmunai, and Virsuliskes large investment package can be effective in terms 
of market value of property, i.e. $M V R>1$. However, if thermal energy saving is considered, $\operatorname{SIR}<1$. Finally, basic investment retrofit scenarios, with $S I R>1$ and $M V R>1$, were chosen for these districts.

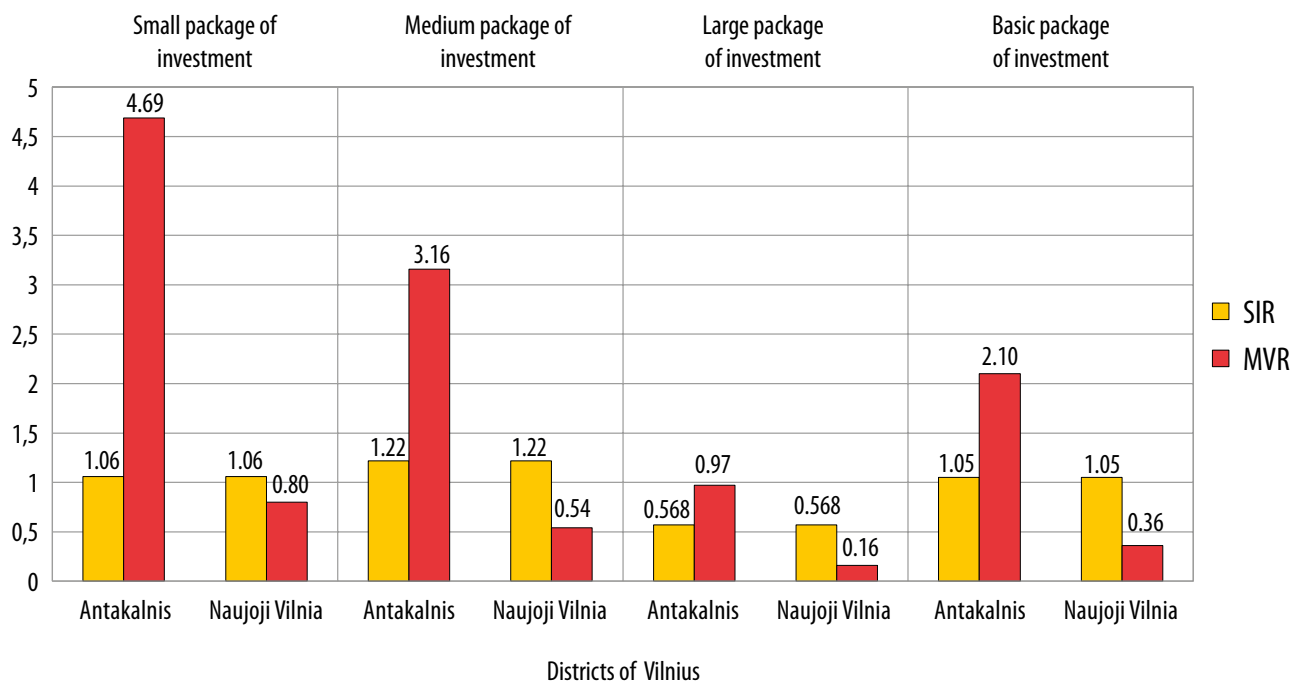

Figure 3.8. Retrofit effectiveness for the panel house 1605A

(5 stories, 60 apartments, 3 staircases) based on SIR and MVR ratios

Assessing the expected benefits of retrofit scenarios, it can be stated that hostel-type buildings of 30 (and more) years of service life, found in various Vilnius districts, are the worst in this respect. Their state is often critical because of poor quality of building work, deterioration and poor maintenance. This primarily applies to balconies and canopies over the entrance doors. The roofs are often leaky, while the windows and entrance doors are completely worn out. The heating, water and electricity supply systems and equipment are also deteriorated. This increases the accident and failure rate. The hazard of fire is also high in such buildings. Thermal characteristics of enclosures in these buildings, like in all houses built before 1993-1996, do not meet the specifications. The lay-out is obsolete and has the following drawbacks: corridor system with the shared kitchen and WC, insufficient living space, not satisfying the needs of the tenants, etc. Large investments $\left(300-380 \mathrm{USD} / \mathrm{m}^{2}\right)$ are needed to improve the aesthetics and physical state of the buildings as well as to reconstruct the deteriorated structures and make the houses energy-efficient and ecological. It is hardly possible to change the lay-out of the apartments in these houses. The calculated retrofit effectiveness indicators $M V R$ are much lower than one, therefore, the increase of the market property value can hardly be expected in this case. The owners or tenants of the apartments are mostly people of low-income group who can hardly 
pay the bills for services. They are usually not willing to join the owners' associations, therefore, their participation in renovation project implementation is rather questionable. Thus, comprehensive renovation of these apartment buildings is not economically effective and, therefore, cannot be recommended. It is more rational to demolish these houses and to construct some new administrative, residential or commercial buildings in this area (especially, taking into account the need for new schools, hospitals, recreation and shopping centres in the city).

In 1996, a pilot project initiated by the Government of Lithuania and the World Bank was launched to save energy in dwellings. This project allows the residents of apartment buildings who have established owners' associations to obtain loans under favourable conditions to make their homes more energyefficient. In 2004, a retrofit project for a panel apartment house (of the series $1605 \mathrm{~A}$ ) was begun in Zirmunai in order to demonstrate the benefits of comprehensive renovation, embracing not only the building itself but also its surroundings (Figure 3.9). In this project, a basic investment package was used.

The choice of a particular retrofit scenario and investment package may change if the renovation program is announced in a district. In this case, the price of apartments will rise in this area, and, consequently, the MVR value will also change. The value of SIR will change because of the rise in construction and energy costs. Therefore, before starting the renovation of a district, the effectiveness of the selected retrofit scenario should be analyzed.
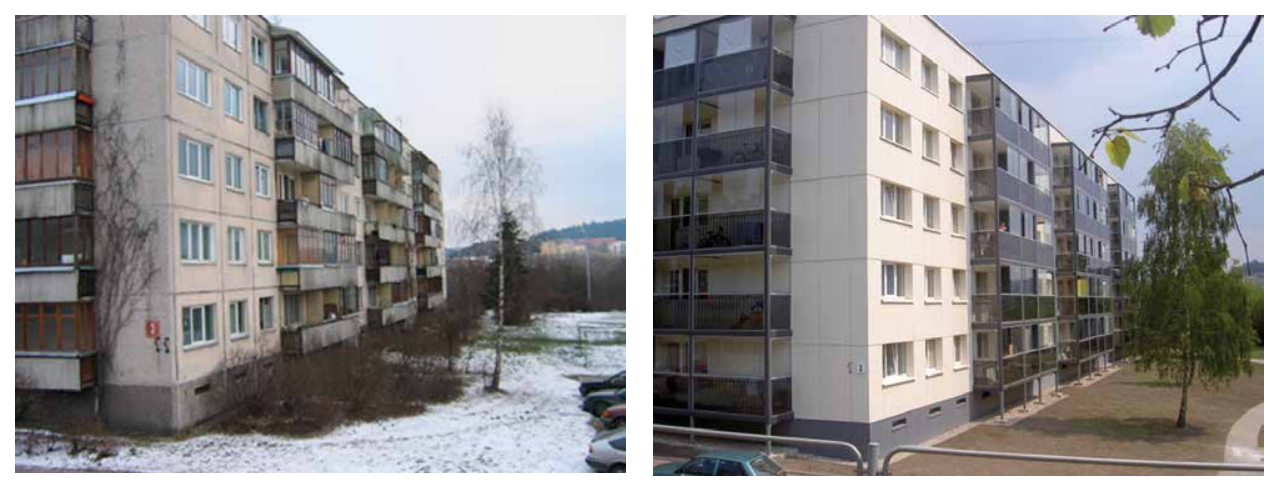

Figure 3.9. A panel house in Vilnius, Zirmunai St. 3, before and after retrofitting based on a package of basic investments

When various retrofit scenarios for apartment buildings are evaluated, the solutions are usually based on the expected reduction in energy consumption. However, it should be mentioned that retrofit considerably improves the state of building structures as well as prolonging the lifetime of a building. The building's market value, which can be determined by applying $M V R$, is also raised. Therefore, the effectiveness of retrofitting an apartment building should 
be evaluated from various perspectives, with both energy conservation and an increase in market value taken into account. In order to make investments in building retrofit profitable, several retrofit scenarios should be developed and assessed from various perspectives. The choice of a particular retrofit scenario depends on strategic urban development programs as well as the condition of panel houses and their environment, renovation costs, saving of heat energy and the expected increment of market value of the renovated apartments. Retrofit scenarios should be based on a comprehensive approach, providing for the renovation of buildings and their surroundings. The SIR and $M V R$ ratios may be applied to evaluating the effectiveness of retrofit scenarios.

The research made has shown that most of the apartment buildings in Vilnius do not meet the needs of their residents as well as current building specifications, and, therefore, they should be renovated. The values of thermal characteristics of panel apartment houses make only about a quarter of their specified values. The geographical analysis suggested in this paper was used to develop retrofit scenarios for large-panel buildings in Vilnius. Three retrofit scenarios based on small, medium, and basic investment packages were proposed for apartment houses in Vilnius neighborhoods and the priority order of their application was determined.

\subsection{Retrofit of public buildings}

In order to design and realize an efficient building refurbishment, it is necessary to carry out an exhaustive investigation of all solutions that form it. The efficiency level of the considered building's refurbishment depends on a great many of factors, including: cost of refurbishment, annual fuel economy after refurbishment, tentative pay-back time, harmfulness to health of the materials used, aesthetics, maintenance properties, functionality, comfort, sound insulation and longevity, etc. Solutions of an alternative character allow for a more rational and realistic assessment of economic, ecological, legislative, climatic, social and political conditions, traditions and for better the satisfaction of customer requirements. They also enable one to cut down on refurbishment costs. In carrying out the multivariant design and multiple criteria analysis of a building refurbishment much data was processed and evaluated. Feasible alternatives could be as many as 100,000 . How to perform a multivariant design and multiple criteria analysis of alternate alternatives based on the enormous amount of information became the problem.

The project Framework 6 "Bringing Retrofit Innovation to the Application of Public Buildings" (BRITA in PuBs) proposal on Eco-buildings aimed at increasing the market penetration of innovative and effective retrofit solutions so as to improve energy efficiency and to implement renewables, with moderate 
additional costs. In the first place, this was realized by the exemplary retrofit of 9 demonstration public buildings (see http://dss.vtu.lt/renovacija/index_educational.asp). One of the project's goals was to develop the method of Multivariant Design and Multiple Criteria Analysis of a Building's Refurbishment and on that basis, developed a Decision Support System for Building Refurbishment.

\subsubsection{Decision-making models and methods}

A thorough building's refurbishment evaluation is quite difficult to undertake, because a building and its environment are complex systems (technical, technological, ecological, social, comfort, esthetical, etc.), where all sub-systems influence the total efficiency performance and where the interdependence between sub-systems play a significant role. Many decision-making models and methods (cost-benefit analysis (Goodacre et al. 2002), multiple criteria analysis (Brandt et al. 2002), the lattice method for global optimization (Saporito et al. 2001), predict a building's habitability index (Kusuda 2001) and energy rating systems for existing houses (Zmeureanu et al. 1999), etc.) have been developed in the world for solving the above-mentioned and other problems.

Goodacre et al. (2002) use a cost-benefit analysis framework to assess the potential scale of some of the benefits from the comprehensive upgrading of heating and hot water energy's efficiency in the English building stock. Goodacre et al. (2002) attempted to evaluate the potential scale for societal costs that are associated with poor levels of domestic space heating and hot water energy's efficiency in the English building sector. The basic premise of this paper has been that an appraisal of these costs should be evaluated against a wider range of potential benefits, not only the direct benefits (micro-economic) and current government monetary appraisals (Goodacre et al. 2002).

The TOBUS method aims at offering a tool for selecting office building's upgrading solutions with respect to multiple criteria. One of the key elements to reach this goal is an assessment of the degree of physical degradation, extent of any degradation, extent of the necessary work to renovate the building and the costs (Brandt et al. 2002).

The energy performance in buildings is a complex function of the building's form and structure, heating system, occupancy pattern, operating schedules, and the external climatic conditions. To carry out a multi-parameter analysis for the optimization of the building's energy performance, the lattice method for global optimization was used (Saporito et al. 2001).

Kusuda (2001) would like to see the extension of the predicted building habitability index (PIHI) as an integrated evaluation criterion for a building's performance in which the simulated hourly energy consumption, comfort index and system's economic factors were weighted (in accordance to specific application requirements) and were algebraically summed up to arrive at an index 
for determining the building's air conditioning needs. This PIHI concept can be extended to include other elements such as lighting, acoustics, moisture condensation, plumbing, etc. (Kusuda 2001).

According to Zmeureanu et al. (1999), different approaches have been developed to evaluate the energy performance of houses, by using a simple index and they are known under the generic term of Home Energy Rating Systems (HERS) which can be classified in the following three main categories: the points system, which evaluates the energy performance of a house by giving points of performance or scores to each sub-system such as exterior walls, roof or heating system; the performance system, which assigns an index of performance in terms of the annual heating energy consumption or cost; and the awareness system, which recommends the total annual and heating site's energy consumption, and the corresponding costs, in terms of the year the house was constructed and its climatic zone and the source of energy.

As one can see, the above-mentioned research has enabled the authors to solve a majority of problems in a complex way as far as a building's renovation is concerned. However, one of the weakest aspects of the above research was the formation and multiple criteria analysis of alternative variants of the whole building. The authors of this paper have developed a method of Multivariant Design and Multiple Criteria Analysis of a Building's Refurbishment to tackle these problems.

\subsubsection{Collection of initial data for multiple criteria analysis}

The determination of the building refurbishment's utility degree and the establishment of the order of priority for its implementation has less difficulty if the criteria values and weights are obtained and when multiple criteria decisionmaking (MCDM) methods are used. All criteria are calculated for the whole project. The decision tree of criteria decomposes the refurbishment problem at hand, into sub-problems (criteria) that are, in their turn, decomposed into subproblems and so on until the problem is represented as a decision tree of criteria. The process for determining the system of criteria, numerical values and initial weights of the qualitative criteria of the project under investigation, are based on the use of various experts' methods.

The results of the comparative analysis of projects are presented as a grouped decision-making matrix where columns contain $n$ alternative projects, while all quantitative and conceptual information pertaining to them is found in Table 3.6 Any alternative that has a criterion value worse than the required level is rejected.

In order to perform a complete study of the project, a complex evaluation of its economic, qualitative, technical, technological, ecological, climatic and social conditions, traditions and for better satisfaction of customer requirements 
is needed. Quantitative and conceptual descriptions provide this information. The diversity of aspects being assessed should include a variety of presented data that are needed for decision-making. Therefore, the necessary conceptual information may be presented in numerical, textual, graphical (schemes, graphs, diagrams, drawings), equation formats and audio or as videotapes. The criteria used for conceptual descriptions, their definitions and reasons for the choice of the criteria's system, their values and weights should all be analyzed. Conceptual information about the possible ways of doing a multivariant design is needed to make a more complete and accurate evaluation.

Table 3.6. Grouped decision-making matrix of refurbishment project's multiple criteria analysis

\begin{tabular}{|c|c|c|c|c|c|c|c|c|c|c|}
\hline \multirow{2}{*}{\multicolumn{2}{|c|}{$\begin{array}{l}\text { Criteria describing } \\
\text { the project }\end{array}$}} & \multirow[t]{2}{*}{$*$} & \multirow[t]{2}{*}{ Weights } & \multirow{2}{*}{$\begin{array}{l}\text { Measuring } \\
\text { units } 1\end{array}$} & \multicolumn{6}{|c|}{ Comparable projects } \\
\hline & & & & & 2 & $\ldots$ & $j$ & $\ldots$ & $n$ & \\
\hline \multirow{6}{*}{$\begin{array}{l}\text { Quan- } \\
\text { titative } \\
\text { criteria }\end{array}$} & $X_{1}$ & $z_{1}$ & $q_{1}$ & $m_{1}$ & $x_{11}$ & $x_{12}$ & $\ldots$ & $x_{1 j}$ & $\ldots$ & $x_{1 n}$ \\
\hline & $X_{2}$ & $z_{2}$ & $q_{2}$ & $m_{2}$ & $x_{21}$ & $x_{22}$ & $\ldots$ & $x_{2 j}$ & $\ldots$ & $x_{2 n}$ \\
\hline & $\ldots$ & $\ldots$ & $\ldots$ & $\ldots$ & $\ldots$ & $\ldots$ & $\ldots$ & $\ldots$ & $\ldots$ & $\ldots$ \\
\hline & $X_{i}$ & $z_{i}$ & $q_{i}$ & $m_{i}$ & $x_{i 1}$ & $x_{i 2}$ & $\ldots$ & $x_{i j}$ & $\ldots$ & $x_{i n}$ \\
\hline & $\ldots$ & $\ldots$ & $\ldots$ & $\ldots$ & $\ldots$ & $\ldots$ & $\ldots$ & $\ldots$ & $\ldots$ & $\ldots$ \\
\hline & $X_{m}$ & $z_{m}$ & $q_{m}$ & $m_{m}$ & $x_{m 1}$ & $x_{m 2}$ & $\ldots$ & $x_{m j}$ & $\ldots$ & $x_{m n}$ \\
\hline \multirow{5}{*}{$\begin{array}{l}\text { Qualitative } \\
\text { criteria }\end{array}$} & $X_{n}$ & $z_{n}$ & $q_{n}$ & $m_{n}$ & $x_{n 1}$ & $x_{n 2}$ & $\ldots$ & $x_{n j}$ & $\ldots$ & $x_{n n}$ \\
\hline & $\ldots$ & $\ldots$ & $\ldots$ & $\ldots$ & $\ldots$ & $\ldots$ & $\ldots$ & $\ldots$ & $\ldots$ & $\ldots$ \\
\hline & $X_{q}$ & $z_{q}$ & $q_{q}$ & $m_{q}$ & $x_{q 1}$ & $x_{q 2}$ & $\ldots$ & $x_{q j}$ & $\ldots$ & $x_{q n}$ \\
\hline & $\ldots$ & $\ldots$ & $\ldots$ & $\ldots$ & $\ldots$ & $\ldots$ & $\ldots$ & $\ldots$ & $\ldots$ & $\ldots$ \\
\hline & $X_{t}$ & $z_{t}$ & $q_{t}$ & $m_{t}$ & $x_{t 1}$ & $x_{t 2}$ & $\ldots$ & $x_{t j}$ & $\ldots$ & $x_{t n}$ \\
\hline \multicolumn{11}{|c|}{ Conceptual information relevant to projects (i.e. text, drawings, graphics, video tapes) } \\
\hline$C_{f}$ & & $C_{z}$ & $C_{q}$ & $C_{m}$ & $C_{1}$ & $C_{2}$ & $\ldots$ & $C_{j}$ & $\ldots$ & $C_{n}$ \\
\hline
\end{tabular}

* The sign $z_{i}(+/-)$ indicates that a greater/lesser criterion value corresponds to a greater weight for a client

Quantitative information is based on criteria systems and subsystems, units of measure, values and initial weights of the projects' alternatives. Conceptual information is a more flexible and less accurate means of expressing estimates than numbers. Quantitative information is more accurate and reliable and allows one to use multiple criteria decision-making methods.

The information's grouping in the matrix should be performed so as to facilitate the calculation process and to express their meaning. The criteria system here is formed from criteria describing the building's refurbishment as expressed 
in a quantitative form (quantitative criteria) and the criteria describing the building's refurbishment that cannot be expressed in a quantitative form (qualitative criteria).

The qualitative criteria values should be put into a numerical and comparable form. They must be comparable because a "medium" value for one qualitative criterion needs to receive approximately the same numerical values as "medium" values of other qualitative criteria.

\subsubsection{A method of multivariant design and multiple criteria analysis of a building's refurbishment}

According to the method developed by authors, the determination of significance, priority and utility degree of alternatives is carried out in the first six stages. Theses stages assumes direct and proportional dependence of significance and the utility degree of investigated versions on a system of criteria that adequately describes the alternatives, and values and weights of the criteria. A decision maker by using the best practices of similar situations and experts' methods determines the system of criteria and calculates the values and initial weights of qualitative criteria. Multivariant design and multiple criteria analysis of the whole building refurbishment are carried out in next 6 stages.

\subsubsection{Determination of the significance, utility degree and priority of all the renovation elements of a building}

While carrying out building renovations it is rational to analyze all its possible combinations. In order to create possible combinations, the efficiency of separate elements (windows, walls, thermal units, roof, etc.) of building renovations should be analyzed. The efficiency of these separate elements of building renovations is estimated during the first five stages.

Stage 1. The weighted normalized decision-making matrix $D$ is formed (see Table 3.7) at this stage. The purpose here is to receive dimensionless weighted values from comparative indexes. When the dimensionless values of the indexes are known, all criteria can be compared. The following equation is used for this purpose:

$$
d_{i j}=\frac{x_{i j} \cdot q_{i}}{\sum_{j=1}^{n} x_{i j}} ; i=\overline{1, m} ; j=\overline{1, n},
$$

where $x_{i j}$ is the value of the $i$ criterion in the $j$ alternative of a solution; $m$ is the number of criteria; $n$ is the number of the alternatives compared; $q_{i}$ is weight of $i$ criterion. 
The sum of dimensionless weighted index values $d_{i j}$ of each criterion $x_{i}$ is always equal to the weight $q_{i}$ :

$$
q_{i}=\sum_{j=1}^{n} d_{i j}, i=\overline{1, m} ; j=\overline{1, n}
$$

In other words, the value of weight $q_{i}$ of the investigated criterion is proportionally distributed among all alternative versions $a_{j}$ according to their value $x_{i j}$.

Stage 2. The sums of weighted normalized indexes describing the $j$-th version are calculated. The versions are described by minimizing indexes $S_{-j}$ and maximizing indexes $S_{+j}$. The lower the value of minimizing indexes, such as the price of a building's refurbishment, the better the attainment of goals. The greater the value of maximizing indexes, such as comfort and aesthetics, the better attainment of goals.

Sums are calculated according to:

$$
S_{+j}=\sum_{i=1}^{m} d_{+i j} ; \quad S_{-j}=\sum_{i=1}^{m} d_{-i j}, i=\overline{1, m} ; j=\overline{1, n} .
$$

The greater the value $S_{+j}$, the more satisfaction of the stakeholders. The lower the value $S_{-j}$ the better the attainment of goals of stakeholders. $S_{+j}$ and $S_{-j}$ express the degree of goals attained by the stakeholders in each project. In any case, the sums of 'pluses' $S_{+j}$ and 'minuses' $S_{-j}$ of alternative projects are always respectively equal to sums of weights of maximizing and minimizing criteria:

$$
S_{+}=\sum_{j=1}^{n} S_{+j}=\sum_{i=1}^{m} \sum_{j=1}^{n} d_{+i j}, \quad S_{-}=\sum_{j=1}^{n} S_{-j}=\sum_{i=1}^{m} \sum_{j=1}^{n} d_{-i j}, i=\overline{1, m} ; j=\overline{1, n} .
$$

In this way, the calculations may be additionally checked.

Stage 3. The significance of comparative alternatives is determined on the basis of describing positive projects' characteristics $S_{+j}$ and negative projects characteristics $S_{-j}$. The relative significance $Q_{j}$ of each project $a_{j}$ is found according to (see Table 3.7):

$$
Q_{j}=S_{+j}+\frac{S_{-\min } \cdot \sum_{j=1}^{n} S_{-j}}{S_{-j} \cdot \sum_{j=1}^{n} \frac{S_{-\min }}{S_{-j}}}, j=\overline{1, n} .
$$


Table 3.7 Building's refurbishment multiple criteria analysis results

\begin{tabular}{|c|c|c|c|c|c|c|c|c|c|}
\hline \multirow{2}{*}{$\begin{array}{l}\text { Criteria under } \\
\text { evaluation }\end{array}$} & \multirow{2}{*}{$\begin{array}{l}\text { Measuring } \\
\text { units }\end{array}$} & \multirow[t]{2}{*}{$*$} & \multirow[t]{2}{*}{ Weights } & \multicolumn{6}{|c|}{ Comparable projects (matrix $D$ ) } \\
\hline & & & & 1 & 2 & $\ldots$ & $j$ & $\ldots$ & $n$ \\
\hline$X_{1}$ & $m_{1}$ & $z_{1}$ & $q_{1}$ & $d_{11}$ & $d_{12}$ & $\cdots$ & $d_{1 j}$ & $\ldots$ & $d_{1 n}$ \\
\hline$X_{2}$ & $m_{2}$ & $z_{2}$ & $q_{2}$ & $d_{21}$ & $d_{22}$ & $\cdots$ & $d_{2 j}$ & $\cdots$ & $d_{2 n}$ \\
\hline$\cdots$ & $\cdots$ & $\cdots$ & $\cdots$ & $\cdots$ & $\cdots$ & $\cdots$ & $\cdots$ & $\cdots$ & $\cdots$ \\
\hline$X_{m}$ & $m_{m}$ & $z_{m}$ & $q_{m}$ & $d_{m 1}$ & $d_{m 2}$ & $\cdots$ & $d_{m j}$ & $\cdots$ & $d_{m n}$ \\
\hline$\cdots$ & $\cdots$ & $\cdots$ & $\cdots$ & $\cdots$ & $\cdots$ & $\cdots$ & $\cdots$ & $\cdots$ & $\cdots$ \\
\hline$X_{t}$ & $m_{t}$ & $z_{t}$ & $q_{t}$ & $d_{t 1}$ & $d_{t 2}$ & $\cdots$ & $d_{t j}$ & $\cdots$ & $d_{t n}$ \\
\hline \multicolumn{4}{|c|}{$\begin{array}{l}\text { The sums of weighted normalized maximizing } \\
\text { indices of the project }\end{array}$} & $S_{+1}$ & $S_{+2}$ & .. & $S_{+j}$ & $\ldots$ & $S_{+n}$ \\
\hline \multicolumn{4}{|c|}{$\begin{array}{l}\text { The sums of weighted normalized minimizing } \\
\text { indices of the project }\end{array}$} & $S_{-1}$ & $S_{-2}$ & $\ldots$ & $S_{-j}$ & $\ldots$ & $S_{-n}$ \\
\hline \multicolumn{4}{|c|}{ Significance of the project } & $Q_{1}$ & $Q_{2}$ & $\ldots$ & $Q_{j}$ & $\ldots$ & $Q_{n}$ \\
\hline \multicolumn{4}{|c|}{ Project's priorities } & $P r_{1}$ & $\mathrm{Pr}_{2}$ & $\cdots$ & $P r_{j}$ & $\cdots$ & $P r_{n}$ \\
\hline \multicolumn{4}{|c|}{ Project's utility degree (\%) } & $N_{1}$ & $N_{2}$ & $\ldots$ & $N_{j}$ & $\ldots$ & $N_{n}$ \\
\hline
\end{tabular}

* The sign $z_{i}(+/-)$ indicates that a greater/lesser criterion value satisfies a client

Stage 4. Determination of building refurbishment's priorities $\left(Q_{j}\right)$. The greater $Q_{j}$ the higher is the priority of the project. The significance $Q_{j}$ of a building's refurbishment $a_{j}$ indicates the satisfaction degree of demands and goals pursued by the stakeholders. In this case, the significance $Q_{\max }$ of the most rational project will always be the highest. The significance of all remaining projects is lower, compared to the most efficient building refurbishment. Total demands and goals of stakeholders will be satisfied to a smaller extent than in the case of the best project.

Stage 5. It is assumed that people can measure values of various projects, in terms of the so-called utility. Each project has its consumer or other stakeholder utility. In the proposed method, the utility of alternatives is measured quantitatively.

The degree of the project's utility is directly associated with the quantitative and conceptual information that is related to the building's refurbishment. If one project is characterized by the highest comfort level, aesthetics, lowest price indices, while other projects show better maintenance characteristics, having 
obtained the same significance values as a result of multiple criteria evaluation, it means that their utility degree is also equal. With the increase/decrease of the significance of a building's refurbishment, its degree of utility also increases/ decreases. The degree of project utility is determined by comparing the analyzed projects with the most efficient project. All the values of the utility degree related to the analyzed projects will range from $0 \%$ to $100 \%$.

Utility degree $N_{j}$ of building refurbishment $a_{j}$ is calculated as follows:

$$
N_{j}=\left(Q_{j}: Q_{\max }\right) \cdot 100 \%,
$$

where $Q_{j}$ and $Q_{\max }$ are the significance of projects obtained from Eqn (3.12).

Stage 6. Determination of the significance, utility degree and priority of all building renovation elements. Further on, one repeats the first five stages till the significance, utility degree and priority of all the renovation elements of a building are estimated (see Table 3.8).

Table 3.8. Most efficient solution alternatives set according to priorities (priority table)

\begin{tabular}{|l|l|l|l|l|l|l|l|l|}
\hline \multirow{2}{*}{$\begin{array}{l}\text { Solutions con- } \\
\text { sidered }\end{array}$} & \multirow{2}{*}{$\begin{array}{c}\text { Significance of } \\
\text { solutions }\end{array}$} & \multicolumn{6}{|c|}{ Priority of the best alternative solutions } \\
\cline { 3 - 10 } $\begin{array}{l}\text { 1. Window } \\
\text { alternatives }\end{array}$ & $\mathrm{Q}_{1}$ & 1 & 2 & 3 & $\ldots$ & $j$ & $\ldots$ & $p$ \\
\hline $\begin{array}{l}\text { 2. Wall } \\
\text { alternatives }\end{array}$ & $\mathrm{Q}_{2}$ & $a_{11}$ & $a_{12}$ & $a_{13}$ & $\ldots$ & $a_{1 j}$ & $\ldots$ & $a_{1 p}$ \\
\hline$\ldots$ & $\ldots$ & $a_{21}$ & $a_{22}$ & $a_{23}$ & $\ldots$ & $a_{2 j}$ & $\ldots$ & $a_{2 p}$ \\
\hline $\begin{array}{l}\text { i. Thermal unit } \\
\text { alternatives }\end{array}$ & $\mathrm{Q}_{i}$ & $\ldots$ & $\ldots$ & $\ldots$ & $\ldots$ & $\ldots$ & $\ldots$ & $\ldots$ \\
\hline$\ldots$ & $\ldots$ & $a_{i 1}$ & $a_{i 2}$ & $a_{i 3}$ & $\ldots$ & $a_{i j}$ & $\ldots$ & $a_{i p}$ \\
\hline $\begin{array}{l}t . \text { Roof } \\
\text { alternatives }\end{array}$ & $\mathrm{Q}_{t}$ & $\ldots$ & $\ldots$ & $\ldots$ & $\ldots$ & $\ldots$ & $\ldots$ & $\ldots$ \\
\hline
\end{tabular}

\subsubsection{Multivariant design and multiple criteria analysis of the whole building's refurbishment}

Much data had to be processed and evaluated in carrying out the multivariant design and multiple criteria analysis of a building refurbishment. Numbers of feasible alternatives can be as large as 100,000. Each of the alternatives may be described from various perspectives, e.g. by conceptual and quantitative information. The problem arises as how to perform design and multiple criteria analysis of the alternatives, based on this enormous amount of information. To solve this problem, multivariant design and multiple criteria analysis of the 
whole building refurbishment are carried out in stages 7-12. These stages are briefly described below.

Stage 7. Rejection of potentially inefficient versions. When determining possible building refurbishment alternative versions, 10 alternatives are considered for any 10 solutions and then until ten billion combinations of building refurbishments can be obtained. It is evident that in this and similar cases it is hardly possible to analyze all the versions from various perspectives. Therefore, it is advisable to reduce their numbers as follows. If a building refurbishment of $c$ solutions having $n_{i}$ alternatives allows $k$ combinations by using multiple criteria analysis methods, $p$ most efficient versions should be chosen from every solution for further consideration (see Table 3.8). This stage involves removing non-rational alternatives before entering further phases. Any alternatives passing this sieve become candidates for further evaluation. In this way, inefficient alternatives are removed. The best alternatives for solutions are obtained then grouped according to priorities. In Table $3.8 a_{i 1}$ is a code of the best variant of $i$ solution, while $a_{i p}$ is a code of its weakest version.

Table 3.9. Codes of building refurbishment alternative solutions with conceptual and quantitative information

\begin{tabular}{|c|c|c|c|c|c|c|c|}
\hline \multirow[t]{2}{*}{ Solutions considered } & \multicolumn{7}{|c|}{ The codes of the alternative solutions considered } \\
\hline & 1 & 2 & 3 & $\ldots$ & $j$ & $\ldots$ & $n_{i}$ \\
\hline 1. Window alternatives & $a_{11}$ & $a_{12}$ & $a_{13}$ & $\cdots$ & $a_{1 j}$ & $\cdots$ & $a_{1 n}$ \\
\hline 2. Wall alternatives & $a_{21}$ & $a_{22}$ & $a_{23}$ & $\cdots$ & $a_{2 j}$ & $\cdots$ & $a_{2 n}$ \\
\hline$\cdots$ & $\cdots$ & $\cdots$ & $\cdots$ & $\cdots$ & $\cdots$ & $\cdots$ & $\cdots$ \\
\hline $\begin{array}{l}i \text {. Thermal unit alterna- } \\
\text { tives }\end{array}$ & $a_{i 1}$ & $a_{i 2}$ & $a_{i 3}$ & $\ldots$ & $a_{i j}$ & $\ldots$ & $a_{\text {in }}$ \\
\hline$\cdots$ & $\cdots$ & $\cdots$ & $\cdots$ & $\cdots$ & $\cdots$ & $\cdots$ & $\cdots$ \\
\hline$t$. Roof alternatives & $a_{t 1}$ & $a_{t 2}$ & $a_{t 3}$ & $\cdots$ & $a_{t j}$ & $\cdots$ & $a_{t n}$ \\
\hline \multicolumn{8}{|c|}{ The information provided by code $a_{i j}$ of $i$ solution $j$ alternative } \\
\hline \multirow[t]{2}{*}{ Conceptual information } & \multicolumn{7}{|c|}{ Information } \\
\hline & $\begin{array}{l}\text { Cost, } \\
X_{1}\end{array}$ & $\begin{array}{l}\text { Aesthetics, } \\
X_{2}\end{array}$ & $\begin{array}{l}\text { Com- } \\
\text { fort, } X_{3}\end{array}$ & $\ldots$ & $X_{j}$ & $\cdots$ & $\begin{array}{l}\text { Quality, } \\
X_{n}\end{array}$ \\
\hline$C_{i j}$ & $x_{i j 1}$ & $x_{i j 2}$ & $x_{i j 3}$ & $\cdots$ & $x_{i j j}$ & $\cdots$ & $x_{i j n}$ \\
\hline Units of measure & USD & Points & Points & $\cdots$ & $u_{i j j}$ & $\cdots$ & Points \\
\hline Weights & $q_{i j 1}$ & $q_{i j 2}$ & $q_{i j 3}$ & $\cdots$ & $q_{i j j}$ & $\cdots$ & $q_{i j n}$ \\
\hline$*$ & $z_{i j 1}$ & $z_{i j 2}$ & $z_{i j 3}$ & $\ldots$ & $z_{i j j}$ & $\ldots$ & $z_{i j n}$ \\
\hline
\end{tabular}

* The sign $z_{i}(+/-)$ indicates that a greater/lesser criterion value satisfies a client 
That is, the alternatives are arranged in descending order of priority in the table. There is also the total weight $\left(Q_{i}\right)$ and refers to their total significance, the given total utility and the price in the context of all the building's renovation.

Stage 8. Development of codes of building refurbishment's alternative solutions with conceptual and quantitative information. In order to reduce the amount of information used in the multivariant design, codes of alternative solutions are used. Any $i$ solution of $j$ alternative is given $a_{i j}$ code providing thorough system of criteria, units of measure, weights and values. As well, conceptual (text, drawings, graphics, videotapes) information about the alternative being considered (see Table 3.9) is presented. The use of codes for alternative solutions in multivariant design reduces the volume of information and provides a better insight into the physical meaning of computations.

Development of the table of building refurbishment alternative solutions' codes includes the formation of the alternative codes and conceptual and quantitative data provided with their help. Codes, providing conceptual and quantitative information, are used for describing all available alternative building refurbishment solutions. The total number of code forms the table of codes of building refurbishment alternatives, allowing one to get the alternative versions in a more simple way. Table 3.9 shows $t$ solutions of a building refurbishment (windows, walls, thermal units, roof, etc.) of the $n_{i}$ alternative versions codes.

Any $i$ line of the code table represents the codes of $A_{i}$ solution and $a_{i j}$ alternatives. If the information relating to the solutions in the code table of building refurbishment alternatives is represented by codes, then the code contains quantitative and conceptual information (see Table 3.9). Here $n_{i}$ alternatives of any $i$ solution are considered when developing the alternative versions of a building refurbishment. The maximum number of projects obtained may be calculated as follows:

$$
k=\prod_{i=1}^{t} n_{i},
$$

where $t$ is the number of solutions considered in determining a building refurbishment; $n_{i}$ is the number of $i$ solution alternatives to be used in developing a building refurbishment.

Stage 9. Development of building refurbishment alternatives based on codes of solution alternatives. Building refurbishment alternatives are developed and based on the efficient $p$ alternatives of chosen $c$ solutions. At the beginning, this process should involve the codes of alternative solutions. The first building refurbishment variant is obtained by analyzing the best solution alternatives according to a priority (see Table 3.10). In the process of forming possible versions the compatibility of separate variants of complex renovation is taken into account. The best alternatives of renovated building elements frequently are not 
compatible, which is encountered in practice. A null variant of building renovation is also being analyzed, when a building is not renovated at all. Maybe the market value of this building is comparatively low, and the building is not worth to be renovated? The last variant is based on solution versions from the end of the priority table (see Table 3.8). Intermediate alternatives are obtained with an account of versions and are also found on this table. The first building refurbishment version is based on $a_{11}$ window, $a_{21}$ wall, $a_{i 1}$ thermal unit, $a_{t 1}$ roof alternatives. The last building refurbishment's version takes into account alternatives $a_{1 p}$ window, $a_{2 p}$ wall, $a_{i p}$ thermal unit and $a_{c p}$ roof alternatives. Combinations are obtained by using $p$ alternatives from any $t$ solutions. Therefore, the maximum number of building refurbishment alternatives obtained may be determined as follows:

$$
K=\prod_{i=1}^{t} p,
$$

where $t$ is the number of solutions used in determining a building refurbishment; $p$ represents the number of best alternatives of every solution used in developing a building refurbishment.

Table 3.10. Development of building refurbishment alternatives based on codes of solution variants

\begin{tabular}{|c|c|c|c|c|c|c|c|c|c|c|c|c|}
\hline \multirow[t]{2}{*}{$\begin{array}{l}\text { Solutions } \\
\text { considered }\end{array}$} & \multicolumn{12}{|c|}{$\begin{array}{c}\text { Development of building refurbishment alternatives based on codes of } \\
\text { solution alternatives }\end{array}$} \\
\hline & 1 & 2 & 3 & $\ldots$ & $p$ & $p+1$ & $p+2$ & $p+3$ & $\ldots$ & $2 p$ & $\ldots$ & $K$ \\
\hline $\begin{array}{l}\text { 1. Window } \\
\text { alternatives }\end{array}$ & $a_{11}$ & $a_{11}$ & $a_{11}$ & $\ldots$ & $a_{11}$ & $a_{11}$ & $a_{11}$ & $a_{11}$ & $\ldots$ & $a_{11}$ & $\ldots$ & $a_{1 p}$ \\
\hline $\begin{array}{l}\text { 2. Wall } \\
\text { alternatives }\end{array}$ & $a_{21}$ & $a_{21}$ & $a_{21}$ & $\ldots$ & $a_{21}$ & $a_{21}$ & $a_{21}$ & $a_{21}$ & $\ldots$ & $a_{21}$ & $\ldots$ & $a_{2 p}$ \\
\hline$\ldots$ & $\ldots$ & $\ldots$ & $\ldots$ & $\ldots$ & $\ldots$ & $\ldots$ & $\ldots$ & $\ldots$ & $\ldots$ & $\ldots$ & $\ldots$ & $\ldots$ \\
\hline $\begin{array}{l}i \text {. Thermal } \\
\text { unit } \\
\text { alternatives }\end{array}$ & $a_{i 1}$ & $a_{i 1}$ & $a_{i 1}$ & $\ldots$ & $a_{i 1}$ & $a_{i 1}$ & $a_{i 1}$ & $a_{i 1}$ & $\ldots$ & $a_{i 1}$ & $\ldots$ & $a_{i p}$ \\
\hline$\ldots$ & $\ldots$ & $\ldots$ & $\ldots$ & $\ldots$ & $\ldots$ & $\ldots$ & $\ldots$ & $\ldots$ & $\ldots$ & $\ldots$ & $\ldots$ & $\ldots$ \\
\hline$t-1$ & $a_{t-11}$ & $a_{t-11}$ & $a_{t-11}$ & $\ldots$ & $\begin{array}{l}a_{t-1} \\
1\end{array}$ & $a_{t-12}$ & $a_{t-12}$ & $a_{t-12}$ & $\ldots$ & $a_{t-12}$ & $\ldots$ & $a_{t-1 p}$ \\
\hline $\begin{array}{l}t . \text { Roof } \\
\text { alternatives }\end{array}$ & $a_{t 1}$ & $a_{t 2}$ & $a_{t 3}$ & $\ldots$ & $a_{t p}$ & $a_{t 1}$ & $a_{t 2}$ & $a_{t 3}$ & $\ldots$ & $a_{t p}$ & $\ldots$ & $a_{t p}$ \\
\hline
\end{tabular}

The variants developed during this stage in which elements are not compatible are not analyzed hereinafter. 
Stage 10. Development of building refurbishment alternatives based on the conceptual and quantitative information. In Table 3.10 the development of building refurbishment alternatives was based on codes of solution alternatives. Table 3.11 presents conceptual and quantitative information about the alternatives, instead of the codes. When a particular building refurbishment is being considered, the values relating to various solutions but based on the same criterion are recalculated into a single reduced value.

Table 3.11. Development of building refurbishment alternatives based on conceptual and quantitative information

\begin{tabular}{|c|c|c|c|c|c|c|c|c|}
\hline \multirow{3}{*}{$\begin{array}{l}\text { Solutions used } \\
\text { in develop- } \\
\text { ing building } \\
\text { refurbishment } \\
\text { alternatives }\end{array}$} & \multicolumn{8}{|c|}{ Information related to building refurbishment versions } \\
\hline & \multirow{2}{*}{$\begin{array}{l}\text { Concep- } \\
\text { tual }\end{array}$} & \multicolumn{7}{|c|}{ Quantitative } \\
\hline & & $\begin{array}{l}\text { Cost, } X_{1} \\
\text { (USD) }\end{array}$ & $\begin{array}{l}\text { Aesthetics, } \\
X_{2} \text { (Points) }\end{array}$ & $\begin{array}{c}\text { Comfort, } \\
X_{3} \text { (Points) }\end{array}$ & $\cdots$ & $X_{j}$ & $\cdots$ & $\begin{array}{l}\text { Quality, } \\
X_{n} \\
\text { (Points) }\end{array}$ \\
\hline \multicolumn{9}{|c|}{ Information related to refurbishment of 1 -st building } \\
\hline $\begin{array}{l}\text { 1. Window, } \\
a_{11}\end{array}$ & $C_{11}$ & $x_{111}$ & $x_{112}$ & $x_{113}$ & $\cdots$ & $x_{11 j}$ & $\cdots$ & $x_{11 n}$ \\
\hline 2. Wall, $a_{21}$ & $C_{21}$ & $x_{211}$ & $x_{212}$ & $x_{213}$ & $\cdots$ & $x_{21 j}$ & $\cdots$ & $x_{21 n}$ \\
\hline$\cdots$ & $\cdots$ & $\cdots$ & $\cdots$ & $\cdots$ & $\ldots$ & $\cdots$ & $\cdots$ & $\cdots$ \\
\hline $\begin{array}{l}i \text {. Thermal } \\
\text { unit alterna- } \\
\text { tives, } a_{i 1}\end{array}$ & $C_{i 1}$ & $x_{i 11}$ & $x_{i 12}$ & $x_{i 13}$ & $\ldots$ & $x_{i 1 j}$ & $\cdots$ & $x_{i 1 n}$ \\
\hline$\ldots$ & $\ldots$ & $\ldots$ & $\ldots$ & $\ldots$ & $\ldots$ & $\ldots$ & $\ldots$ & $\ldots$ \\
\hline$t$. Roof, $a_{t 1}$ & $C_{t 1}$ & $x_{t 11}$ & $x_{\mathrm{t} 12}$ & $x_{t 13}$ & $\cdots$ & $x_{t 1 j}$ & $\cdots$ & $x_{t 1 n}$ \\
\hline$\ldots$ & $\ldots$ & $\ldots$ & $\ldots$ & $\ldots$ & $\ldots$ & $\ldots$ & $\ldots$ & $\ldots$ \\
\hline \multicolumn{9}{|c|}{ Information related to refurbishment of $K$ building } \\
\hline $\begin{array}{l}\text { 1. Window, } \\
a_{1 p}\end{array}$ & $C_{1 p}$ & $x_{1 p 1}$ & $x_{1 p 2}$ & $x_{1 p 3}$ & $\cdots$ & $x_{1 p j}$ & $\cdots$ & $x_{1 p n}$ \\
\hline 2. Wall, $a_{2 p}$ & $C_{2 p}$ & $x_{2 p 1}$ & $x_{2 p 2}$ & $x_{2 p 3}$ & $\ldots$ & $x_{2 p j}$ & $\ldots$ & $x_{2 p n}$ \\
\hline$\cdots$ & $\ldots$ & $\ldots$ & $\cdots$ & $\cdots$ & $\cdots$ & $\ldots$ & $\cdots$ & $\cdots$ \\
\hline $\begin{array}{l}i \text {. Thermal } \\
\text { unit alterna- } \\
\text { tives, } a_{i p}\end{array}$ & $C_{i p}$ & $x_{i p 1}$ & $x_{i p 2}$ & $x_{i p 3}$ & $\ldots$ & $x_{i p j}$ & $\ldots$ & $x_{i p n}$ \\
\hline$\ldots$ & $\ldots$ & $\ldots$ & $\ldots$ & $\ldots$ & $\ldots$ & $\ldots$ & $\ldots$ & $\ldots$ \\
\hline$t$. Roof, $a_{t p}$ & $C_{t p}$ & $x_{t p 1}$ & $x_{t p 2}$ & $x_{t p 3}$ & $\cdots$ & $x_{t p j}$ & $\cdots$ & $x_{t p n}$ \\
\hline
\end{tabular}


Stage 11. Development of a summarized decision making table of all building refurbishment versions obtained and the overall related conceptual and quantitative information. When reducing the same criterion e.g. cost and comforts values of various solutions, to a single one, it is necessary to appraise the weights of these solutions. For example, noise level inside and outside the building is not of equal importance to inhabitants. The same applies to paying money and this depends on whether it should be done now or in the future. Using experts, financial analysis and other methods determine the above weights of the solutions. The weights should be made compatible in two directions: horizontally (among criteria) and vertically (among solutions). In this way, Table 3.11 transforms into a summarized decision making table (Table 3.12) containing all building refurbishment versions and the overall related information.

Table 3.12 Summarized decision making table of all building refurbishment versions obtained and the overall related conceptual and quantitative information

\begin{tabular}{|c|c|c|c|c|c|c|c|c|}
\hline \multirow{3}{*}{$\begin{array}{l}\text { The obtained } \\
\text { versions of } \\
\text { building } \\
\text { refurbishment }\end{array}$} & \multicolumn{8}{|c|}{ Information related to versions of building refurbishment } \\
\hline & \multirow{2}{*}{$\begin{array}{l}\text { Con- } \\
\text { ceptual }\end{array}$} & \multicolumn{7}{|c|}{ Quantitative } \\
\hline & & $\begin{array}{c}\text { Cost, } \\
X_{1}\end{array}$ & $\begin{array}{l}\text { Aesthet- } \\
\text { ics, } X_{2}\end{array}$ & $\begin{array}{c}\text { Com- } \\
\text { fort, } X_{3}\end{array}$ & $\ldots$ & $X_{j}$ & $\ldots$ & $\begin{array}{c}\text { Quality, } \\
X_{n}\end{array}$ \\
\hline $\begin{array}{l}1 \text { building refur- } \\
\text { bishment's version }\end{array}$ & $C_{1}$ & $x_{11}$ & $x_{12}$ & $x_{13}$ & $\cdots$ & $x_{1 j}$ & $\cdots$ & $x_{1 n}$ \\
\hline $\begin{array}{l}2 \text { building refur- } \\
\text { bishment version }\end{array}$ & $C_{2}$ & $x_{21}$ & $x_{22}$ & $x_{23}$ & $\cdots$ & $x_{2 j}$ & $\ldots$ & $x_{2 n}$ \\
\hline$\ldots$ & & $\ldots$ & $\ldots$ & $\ldots$ & $\ldots$ & $\ldots$ & $\ldots$ & $\ldots$ \\
\hline $\begin{array}{l}i \text { building refur- } \\
\text { bishment version }\end{array}$ & $C_{i}$ & $x_{i 1}$ & $x_{i 2}$ & $x_{i 3}$ & $\cdots$ & $x_{i j}$ & $\cdots$ & $x_{\text {in }}$ \\
\hline$\ldots$ & & $\ldots$ & $\ldots$ & $\ldots$ & $\ldots$ & $\ldots$ & $\ldots$ & $\ldots$ \\
\hline $\begin{array}{l}K \text { building refur- } \\
\text { bishment version }\end{array}$ & $C_{K}$ & $x_{K 1}$ & $x_{K 2}$ & $x_{K 3}$ & $\cdots$ & $x_{K j}$ & $\cdots$ & $x_{K n}$ \\
\hline \multicolumn{2}{|l|}{ Weights of criteria } & $q_{1}$ & $q_{2}$ & $q_{3}$ & $\cdots$ & $q_{j}$ & $\cdots$ & $q_{n}$ \\
\hline \multicolumn{2}{|c|}{ Criteria's measuring units } & USD & Points & Points & $\cdots$ & $u_{j}$ & $\cdots$ & Points \\
\hline
\end{tabular}

Stage 12. Determination of building refurbishment significances, priorities and utility degree (see Table 3.7). Further, after the formation of decision-making matrix (see Table 3.12), the possible most rational versions of a whole building's refurbishment are determined and grouped according to their priority (see Stages 1-5). The greater the priority of a version, the higher is the efficiency of the building refurbishment. Significance $Q_{i}$ of a project indicates the satisfaction degree of demands and goals pursued by clients - the greater the $Q_{i}$ the higher is 
the efficiency of the building's refurbishment. In this case, the significance $Q_{\max }$ of the most rational project will always be the greatest. The significances of all remaining projects are lower when compared with the most rational one. This means that demands and goals of the stakeholders will be satisfied to a lesser extent than would be the case of the best building refurbishment.

However, in practice the customers are more concerned not with the priority of the surveyed building refurbishment, but with their utility degree and costs. In other words, a customer is mostly interested in a project that will satisfy its demands and goals to the greatest extent and will be the cheapest and render the least infringement of interests of other parties participating in the project. The results of this assessment are expressed by the project utility degree concept (see Table 3.7).

\subsubsection{Example illustrating the efficiency boost of building refurbishment}

The example considered is the main, public building from Vilnius Gediminas Technical University (VGTU) (see Figure 3.10). The configuration of a rectangular, comprises of the shape of the building with the measurements $74,30 \times 17,22 \mathrm{~m}$. The floor-area totals $8484,20 \mathrm{~m}^{2}$. The main building was built in 1971. It includes several departments and lecture halls and seats from 50 to 100 students. Number of storeys is 7 .

The substructure of the building is made from frame pillar with UK type columns. The walls of the building have ferroconcrete frame and three-layer ferroconcrete panels (60/90/90). A glass area occupies the biggest part of the external sectors partitioned off in the main facades. All window glass is placed by wooden or aluminium profile frameworks. The windows of the main building are very old. Closing windows and lack of tightness are of major inconvenience. Current construction of the windows does not correspond to modern window requirements and does not ensure proper inside comfort conditions. The roof is flat and the covering is made from the roll.
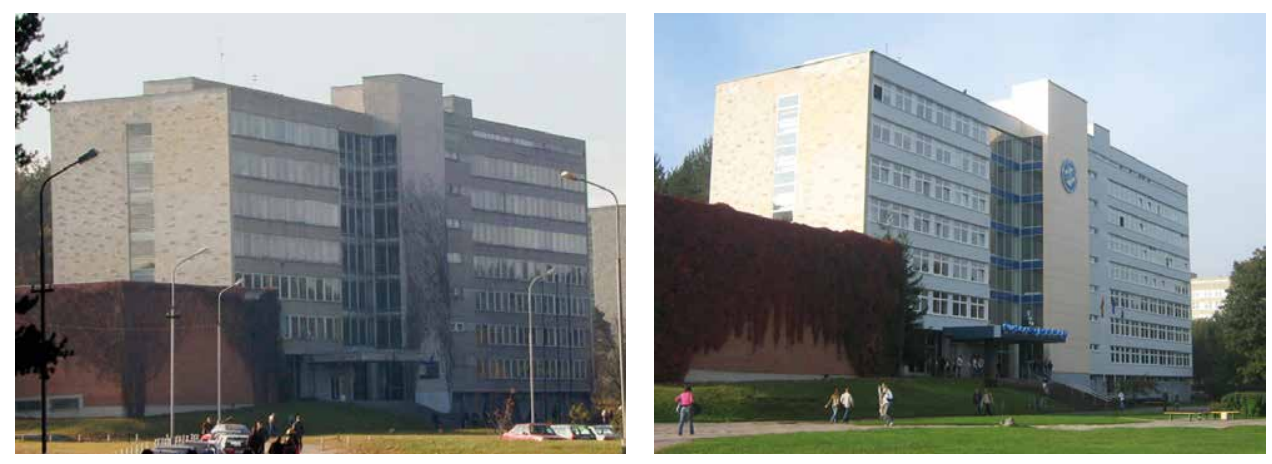

Figure 3.10. The main building of Vilnius Gediminas Technical University before and after retrofitting 
Referring to the task of the Framework 6 project Brita in PuBs the walls, windows, roof, entrance door and thermal unit had to be renovated of the building of VGTU. Further on, the determination of the significance, utility degree and priority of the renovated windows (see Stages 1-6) will be analyzed in brief as an example. Alternative windows of 5 companies according to 16 indicators (see Table 3.13) were analyzed. Values of these criteria are different. For instance, the offered prices of building renovation by 5 companies range from 72116 to 115072 USD.

For a better understanding of the stated facts mentioned above, let us make a comparison of the 1st alternative with the 4th one. The cost of thermal renovation in the 1st version is lower while longevity of 4th version is more favorable. The 1st alternative, however, differs from the 4th one in possessing better quality characteristics (i.e. reliability, thermal transmission coefficient $\lambda$ of profile, parameter $R w$ of air sound isolation, air leakage, when pressure difference $D p=$ $50 \mathrm{~Pa}$, waterproof-ness, guarantee period, light transmission of double glazing unit, pay-back period, etc.).

As can be seen from Table 8, each criterion goes together with its measurement unit and weight. The magnitude of weight indicates how many times one criterion is more significant than the other one in a multiple criteria evaluation of windows refurbishment. For example, in the evaluation of guarantee period significance by computer-aided calculations, it was obtained that $\mathrm{q}_{10}=0.0302$, what is $1.37\left(\mathrm{q}_{10}: \mathrm{g}_{12}=0.0302: 0.022=1.37\right)$ times more significant for client than the light transmission of double glazing unit (significance $\mathrm{q}_{12}=0.022$ ). The calculations revealed that the key factors that have affected the efficiency of windows refurbishment are (see Table 8): cost (weight $\mathrm{q}_{1}=0.60$ ), thermal transmission of double-glazing unit $\left(\mathrm{q}_{5}=0.0322\right)$, longevity $\left(\mathrm{q}_{11}=0.0309\right)$, waterproof-ness $\left(\mathrm{q}_{9}=0.0302\right)$, etc.

The determination of significance, priority and utility degree of alternatives is carried out in five stages.

Stage 1. The weighted normalized decision-making matrix D is formed (see Table 3.14). First formula is used for this purpose:

$$
\begin{aligned}
& d_{11}=0,6 * 72116:(72116+101896+84176+115072+92166)=0,93, \\
& d_{12}=0,1314, d_{13}=0,1085, d_{14}=0,1483, d_{15}=0,1188, \text { etc. }
\end{aligned}
$$

The value of significance $q_{i}$ of the investigated criterion is proportionally distributed among all windows versions $a_{j}$ according to their values $x_{i j}$. For example:

$$
q_{4}=0,0048+0,0057+0,0057+0,0057+0,0066=0,0284 .
$$


Table 3.13. Decision making matrix of windows

\begin{tabular}{|c|c|c|c|c|c|c|c|c|c|}
\hline Nr. & $\begin{array}{l}\text { Criteria under } \\
\text { evaluation }\end{array}$ & $\begin{array}{l}\text { Measuring } \\
\text { units of } \\
\text { criteria }\end{array}$ & $*$ & $\begin{array}{c}\text { Weights of } \\
\text { criteria }\end{array} \mid$ & Ltd 1 & Ltd 2 & Ltd 3 & Ltd 4 & Ltd 5 \\
\hline 1 & Price & USD & - & 0,6 & 72116 & 101896 & 84176 & 115072 & 92166 \\
\hline 2 & $\begin{array}{l}\text { Mechanical strength } \\
\text { and stiffness }\end{array}$ & $* *$ & + & 0,0275 & 1 & 1 & 1 & 1 & 1 \\
\hline 3 & Reliability & Cycles & + & 0,0291 & 10000 & 1000 & 10000 & 1000 & 1000 \\
\hline 4 & $\begin{array}{l}\text { Thermal transmis- } \\
\text { sion coefficient } \lambda \text { of } \\
\text { profile }\end{array}$ & $\mathrm{W} / \mathrm{m}^{2} \mathrm{~K}$ & - & 0,0284 & 1,2 & 1,4 & 1,4 & 1,4 & 1,63 \\
\hline 5 & $\begin{array}{l}\text { Thermal transmis- } \\
\text { sion coefficient } \lambda \text { of } \\
\text { double glazing unit }\end{array}$ & $\mathrm{W} / \mathrm{m}^{2} \mathrm{~K}$ & - & 0,0322 & 1,1 & 1,2 & 1,1 & 1,1 & 1,14 \\
\hline 6 & $\begin{array}{l}\text { Emission ability of } \\
\text { low emissive glass } \\
\text { coating } \varepsilon\end{array}$ & $* * *$ & - & 0,023 & 0,05 & 0,1 & 0,05 & 0,05 & 0,05 \\
\hline 7 & $\begin{array}{l}\text { Parameter } R w \text { of air } \\
\text { sound isolation }\end{array}$ & $d B$ & + & 0,0259 & 34 & 33 & 34 & 33 & 32 \\
\hline 8 & $\begin{array}{l}\text { Air leakage, when } \\
\text { pressure difference } \\
D p=50 \mathrm{~Pa}\end{array}$ & $\left(\mathrm{~m}^{3} / \mathrm{m}^{2} \mathrm{~h}\right)$ & - & 0,0246 & 0,18 & 0,15 & 0,18 & 0,3 & 0,31 \\
\hline 9 & Waterproof-ness & $\mathrm{Pa}$ & + & 0,0302 & 600 & 300 & 600 & 250 & 100 \\
\hline 10 & Guarantee period & Years & + & 0,0302 & 10 & 5 & 5 & 5 & 5 \\
\hline 11 & Longevity & Years & + & 0,0309 & 35 & 30 & 50 & 40 & 30 \\
\hline 12 & $\begin{array}{l}\text { Light transmission of } \\
\text { double glazing unit }\end{array}$ & $\%$ & + & 0,022 & 81 & 78 & 81 & 79 & 78 \\
\hline 13 & Pay-back period & Years & - & 0,0262 & 13,2 & 40 & 30 & 45 & 25,9 \\
\hline 14 & Duration of works & Days & - & 0,0225 & 60 & 50 & 60 & 60 & 60 \\
\hline 15 & $\begin{array}{l}\text { Quantity of windows } \\
\text { with two opening } \\
\text { positions (horizontal } \\
\text { and vertical) (in } \\
\text { percent of the area } \\
\text { of all windows) }\end{array}$ & $\%$ & + & 0,0215 & 78,5 & 100 & 37 & 100 & 27,43 \\
\hline 16 & \begin{tabular}{|l|} 
Quantity of windows \\
with closing infiltra- \\
tion air vent or \\
the third opening \\
position (in percent \\
of the area of all \\
windows)
\end{tabular} & $\%$ & - & 0,0258 & 78,5 & 100 & 37 & 100 & 27,43 \\
\hline
\end{tabular}

** Does it meet the requirements for the norms (if so, t.i. 1)

$\because * *$ There is no unit for criterion measurement. 
Table 3.14. Window refurbishment's multiple criteria analysis results

\begin{tabular}{|c|c|c|c|c|c|c|c|c|}
\hline \multirow{2}{*}{$\begin{array}{l}\text { Criteria under } \\
\text { evaluation }\end{array}$} & \multirow{2}{*}{$\begin{array}{l}\text { Meas- } \\
\text { uring } \\
\text { units of } \\
\text { criteria }\end{array}$} & \multirow[t]{2}{*}{$*$} & \multirow{2}{*}{$\begin{array}{l}\text { Weights } \\
\text { of crite- } \\
\text { ria }\end{array}$} & \multicolumn{5}{|c|}{$\begin{array}{l}\text { Weighted normalized values of criteria of the } \\
\text { comparable alternatives }\end{array}$} \\
\hline & & & & Ltd 1 & Ltd 2 & Ltd 3 & Ltd 4 & Ltd 5 \\
\hline Price & USD & - & 0,6 & 0,093 & 0,1314 & 0,1085 & 0,1483 & 0,1188 \\
\hline $\begin{array}{l}\text { Mechanical strength } \\
\text { and stiffness }\end{array}$ & $* *$ & + & 0,0275 & 0,0055 & 0,0055 & 0,0055 & 0,0055 & 0,0055 \\
\hline Reliability & Cycles & + & 0,0291 & 0,0127 & 0,0013 & 0,0127 & 0,0013 & 0,0013 \\
\hline $\begin{array}{l}\text { Thermal transmission } \\
\text { coefficient } \lambda \text { of profile }\end{array}$ & $\mathrm{W} / \mathrm{m}^{2} \mathrm{~K}$ & - & 0,0284 & 0,0048 & 0,0057 & 0,0057 & 0,0057 & 0,0066 \\
\hline $\begin{array}{l}\text { Thermal transmission } \\
\text { coefficient } \lambda \text { of double } \\
\text { glazing unit }\end{array}$ & $\mathrm{W} / \mathrm{m}^{2} \mathrm{~K}$ & - & 0,0322 & 0,0063 & 0,0069 & 0,0063 & 0,0063 & 0,0065 \\
\hline $\begin{array}{l}\text { Emission ability of low } \\
\text { emissive glass coating } \varepsilon\end{array}$ & $* * *$ & - & 0,023 & 0,0038 & 0,0077 & 0,0038 & 0,0038 & 0,0038 \\
\hline $\begin{array}{l}\text { Parameter } R w \text { of air } \\
\text { sound isolation }\end{array}$ & $\mathrm{dB}$ & + & 0,0259 & 0,0053 & 0,0051 & 0,0053 & 0,0051 & 0,005 \\
\hline $\begin{array}{l}\text { Air leakage, when pres- } \\
\text { sure difference } D p= \\
50 \mathrm{~Pa}\end{array}$ & $\begin{array}{l}\left(\mathrm{m}^{3} /\right. \\
\left.\mathrm{m}^{2} \mathrm{~h}\right)\end{array}$ & - & 0,0246 & 0,004 & 0,0033 & 0,004 & 0,0066 & 0,0068 \\
\hline Waterproof-ness & $\mathrm{Pa}$ & + & 0,0302 & 0,0098 & 0,0049 & 0,0098 & 0,0041 & 0,0016 \\
\hline Guarantee period & Years & + & 0,0302 & 0,0101 & 0,005 & 0,005 & 0,005 & 0,005 \\
\hline Longevity & Years & + & 0,0309 & 0,0058 & 0,005 & 0,0084 & 0,0067 & 0,005 \\
\hline $\begin{array}{l}\text { Light transmission of } \\
\text { double glazing unit }\end{array}$ & $\%$ & + & 0,022 & 0,0045 & 0,0043 & 0,0045 & 0,0044 & 0,0043 \\
\hline Pay-back period & Years & - & 0,0262 & 0,0022 & 0,0068 & 0,0051 & 0,0077 & 0,0044 \\
\hline Duration of works & Days & - & 0,0225 & 0,0047 & 0,0039 & 0,0047 & 0,0047 & 0,0047 \\
\hline $\begin{array}{l}\text { Quantity of windows } \\
\text { with two opening posi- } \\
\text { tions (horizontal and } \\
\text { vertical) (in percent of } \\
\text { the area of all windows) }\end{array}$ & $\%$ & + & 0,0215 & 0,0049 & 0,0063 & 0,0023 & 0,0063 & 0,0017 \\
\hline $\begin{array}{l}\text { Quantity of windows } \\
\text { with closing infiltration } \\
\text { air vent or the third } \\
\text { opening position (in } \\
\text { percent of the area of } \\
\text { all windows) }\end{array}$ & $\%$ & + & 0,0258 & 0,0059 & 0,0075 & 0,0028 & 0,0075 & 0,0021 \\
\hline \multicolumn{4}{|c|}{$\begin{array}{l}\text { The sums of weighted normalized maximizing } \\
\text { indices of the windows } S_{+j}\end{array}$} & 0,0645 & 0,0449 & 0,0563 & 0,0459 & 0,0315 \\
\hline \multicolumn{4}{|c|}{$\begin{array}{l}\text { The sums of weighted normalized minimizing } \\
\text { indices of the windows } S_{-j}\end{array}$} & 0,1188 & 0,1657 & 0,1381 & 0,1831 & 0,1516 \\
\hline
\end{tabular}




\begin{tabular}{|c|c|c|c|c|c|c|c|}
\hline \multirow{2}{*}{$\begin{array}{c}\text { Criteria under } \\
\text { evaluation }\end{array}$} & $\begin{array}{c}\text { Meas- } \\
\text { uring } \\
\text { units of } \\
\text { criteria }\end{array}$ & \multirow{3}{*}{$\begin{array}{c}\text { Weights } \\
\text { of crite- } \\
\text { ria }\end{array}$} & \multicolumn{5}{|c|}{ Weighted normalized values of criteria of the } \\
\cline { 4 - 9 } & & Ltd 1 & Ltd 2 & Ltd 3 & Ltd 4 & Ltd 5 \\
\hline Windows's significance Qj & & 0,2534 & 0,1803 & 0,2188 & 0,1684 & 0,1795 \\
\hline Windows's degree of efficiency Nj & $100 \%$ & $71,15 \%$ & $86,35 \%$ & $66,46 \%$ & $70,84 \%$ \\
\hline Windows's priority & 1 & 3 & 2 & 5 & 4 \\
\hline
\end{tabular}

Stage 2. The sums of weighted normalized indexes describing the $j$-th version are calculated. The sums are calculated according to third formula:

$$
\begin{aligned}
& S_{+1}=0,0055+0,0127+0,0053+0,0098+0,0101+0,0058+ \\
& 0,0045+0,0049+0,0059=0,0645, \\
& S_{-1}=0,093+0,0048+0,0063+0,0038+0,004+0,0022+ \\
& 0,0047=0,1188 \text {, etc. }
\end{aligned}
$$

In any case, the sums of "pluses" $S_{+j}$ and "minuses" $S_{-j}$ of all alternative projects are always respectively equal to all sums of the weights of maximizing and minimizing criteria (see Formula 4):

$$
\begin{aligned}
& S_{+}=0,0645+0,0449+0,0563+0,0459+0,0315=0,243 \\
& S_{-}=0,1188+0,1657+0,1381+0,1831+0,1516=0,757
\end{aligned}
$$

Stage 3. Relative significance $Q_{j}$ of each project $\mathrm{a}_{\mathrm{j}}$ is found according to fifth formula (see Table 3.14):

$$
\mathrm{Q}_{1}=0,0645+\frac{0,1188 \cdot(0,1188+0,1657+0,1381+0,1831+0,1516)}{0,1188 \cdot\left(\frac{0,1188}{0,1188}+\frac{0,1188}{0,1657}+\frac{0,1188}{0,1381}+\frac{0,1188}{0,1831}+\frac{0,1188}{0,1516}\right)}=0,2534 .
$$

Stage 4. The greater the $Q_{j}$ the higher is the efficiency (priority) of the windows alternatives._ $Q_{1}>Q_{3}>Q_{2}>Q_{5}>Q_{4}(0,2534>0,2188>0,1803>0,1795>$ 0,1684 ). Table 3.14 shows that the first version is the best in the utility degree equaling $100 \%$. The third version was second according to priority and its utility degree was equal to $86,35 \%$.

Stage 5. Sixth formula is used for the calculation utility degree $N_{j}$ :

$$
\begin{aligned}
& N_{1}=(0,2534: 0,2534) \cdot 100 \%=100 \%, \\
& N_{2}=71,15 \%, N_{3}=86,35 \%, N_{4}=66,46 \%, N_{5}=70,84 \% .
\end{aligned}
$$

The results of a multiple criteria evaluation of 5 window refurbishment versions are presented in Table 3.14. From the Table 3.14 it is seen that the first version is the best in the utility degree that equals $100 \%$. 
Stage 6. Multiple criteria analysis of solutions dealing with renovation of a thermal unit, roof, walls, entrance door etc. was carried out in a similar way as that of the windows. Further on, we repeated the first five stages till the significance, utility degree and priority of all the renovation elements of a building were estimated.

After the multiple criteria analysis of the refurbishment project's components (walls, windows, roof, thermal unit, etc.) and a selection the most efficient versions, the received compatible and rational components of a refurbishment are joined into the alternatives. Having performed a multivariant design and multiple criteria analysis of the building refurbishment in this way, one can select the most efficient alternatives. Multivariant design and multiple criteria analysis of the whole building refurbishment are carried out in next 6 stages.

Stage 7. Rejection of potentially inefficient versions. Further complex multiple criteria analysis of building refurbishments was based on the four best solution versions (see Table 3.15) that were chosen separately for various components. For example, wall renovation top priority versions are correspondingly 3 , 4, 1 and 2 while those dealing with the renovation of windows are 1, 3, 2 and 5.

Table 3.15. Four best versions of solutions under consideration

\begin{tabular}{|l|l|c|c|c|c|c|}
\hline \multicolumn{2}{|c|}{ The solutions considered } & \multicolumn{1}{|c|}{$\begin{array}{c}\text { Significance of } \\
\text { solutions }\end{array}$} & \multicolumn{4}{c|}{$\begin{array}{c}\text { The numeration of } \\
\text { versions }\end{array}$} \\
\hline \multirow{3}{*}{ Renovation of } & Walls & 0.302 & 3 & 4 & 1 & 2 \\
\cline { 2 - 7 } & Windows & 0.419 & 1 & 3 & 2 & 5 \\
\cline { 2 - 7 } & Roof & 0.145 & 1 & 3 & 2 & 4 \\
\cline { 2 - 7 } & Entrance door & 0.048 & 3 & 4 & 1 & 2 \\
\cline { 2 - 7 } & Thermal unit & 0.086 & 3 & 1 & 4 & 2 \\
\hline
\end{tabular}

Table 3.16. Development of building refurbishment alternatives based on codes of solution alternatives

\begin{tabular}{|c|c|c|c|c|c|c|c|c|c|c|c|c|c|c|c|c|c|c|c|}
\hline \multirow{2}{*}{\multicolumn{2}{|c|}{$\begin{array}{l}\text { The solutions } \\
\text { considered } 1\end{array}$}} & \multicolumn{18}{|c|}{ The formation of versions of building refurbishment } \\
\hline & & 2 & 3 & 4 & 5 & 6 & 7 & 8 & 9 & 10 & $\ldots$ & 123 & $\ldots$ & 528 & 529 & $\ldots$ & 1023 & 1024 & \\
\hline \multirow{5}{*}{ 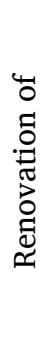 } & 1. Walls & 4 & 4 & 4 & 4 & 4 & 4 & 4 & 4 & 4 & 4 & ... & 4 & $\ldots$ & 2 & 2 & $\ldots$ & 1 & 1 \\
\hline & 2.Windows & 5 & 5 & 5 & 5 & 5 & 5 & 5 & 5 & 5 & 3 & .. & 3 & .. & 5 & 5 & $\ldots$ & 2 & 2 \\
\hline & 3. Roof & 4 & 4 & 4 & 4 & 4 & 4 & 4 & 4 & 4 & 3 & .. & 3 & . & 4 & 1 & .. & 3 & 3 \\
\hline & $\begin{array}{l}\text { 4. Entrance } \\
\text { door }\end{array}$ & 4 & 4 & 4 & 4 & 3 & 3 & 3 & 3 & 2 & 2 & .. & 2 & $\ldots$ & 1 & 4 &.. & 1 & 1 \\
\hline & $\begin{array}{l}\text { 5. Thermal } \\
\text { unit }\end{array}$ & 3 & 1 & 4 & 2 & 3 & 1 & 4 & 2 & 3 & 4 & $\ldots$ & 4 & .. & 2 & 3 & .. & 4 & 2 \\
\hline
\end{tabular}


Stage 8. The codes of building refurbishment alternative solutions with conceptual and quantitative information (see Table 3.16) have been developed.

Stage 9. Development of building refurbishment alternatives based on codes of solution alternatives. An example formation of the variants (according to their codes) making a complex building refurbishment scheme is given in Table 3.16. In the process of forming possible versions the compatibility of separate variants of complex renovation is taken into account.

Stages 10 and 11. Development of a summarized decision making table of all building refurbishment versions are obtained. An example of the formation of complex building refurbishment versions and pertinent characteristics (e.g. the system of criteria, units of measure, values and weights) is shown in Table 3.17. The prepared building refurbishment versions are assessed according to different requirements. A version not corresponding to these requirements is stricken out and no longer considered.

Stage 12. Determination of building refurbishment significances, priorities and utility degree.

The results of the multiple criteria evaluation of the 1024 building refurbishment versions are given in Table 3.18. From the numeric values it can be seen that the 915th version is the best among all the versions that were evaluated. The utility degree of it $N_{915}=100 \%$. The 925 th version according to its priority was recognized as the second best. The utility degree of it $N_{925}=99.94 \%$ (see Table 3.18).

Multiple criteria analysis of the building's refurbishment allows for the evaluation of economic, technical, and qualitative architectural, aesthetic and comfort aspects. In addition, technological, social, legislative, infrastructure, technical and other decisions are made in conformity with needs and opportunities of clients, designers, contractors, users, and other participants. These needs are expressed through the systems, values and weights of quantitative and qualitative criteria.

The presented methodology of Multivariant design and multiple criteria analysis of a building refurbishment enabled one to form up to 100,000 alternative versions. This methodology allows one to determine the strongest and weakest points of each building's refurbishment project and its constituent parts. Calculations are made to find out by what degree one version is better than another and the reasons as to why this is so are disclosed. In order to demonstrate the developed method, a practical example is presented in this paper. 


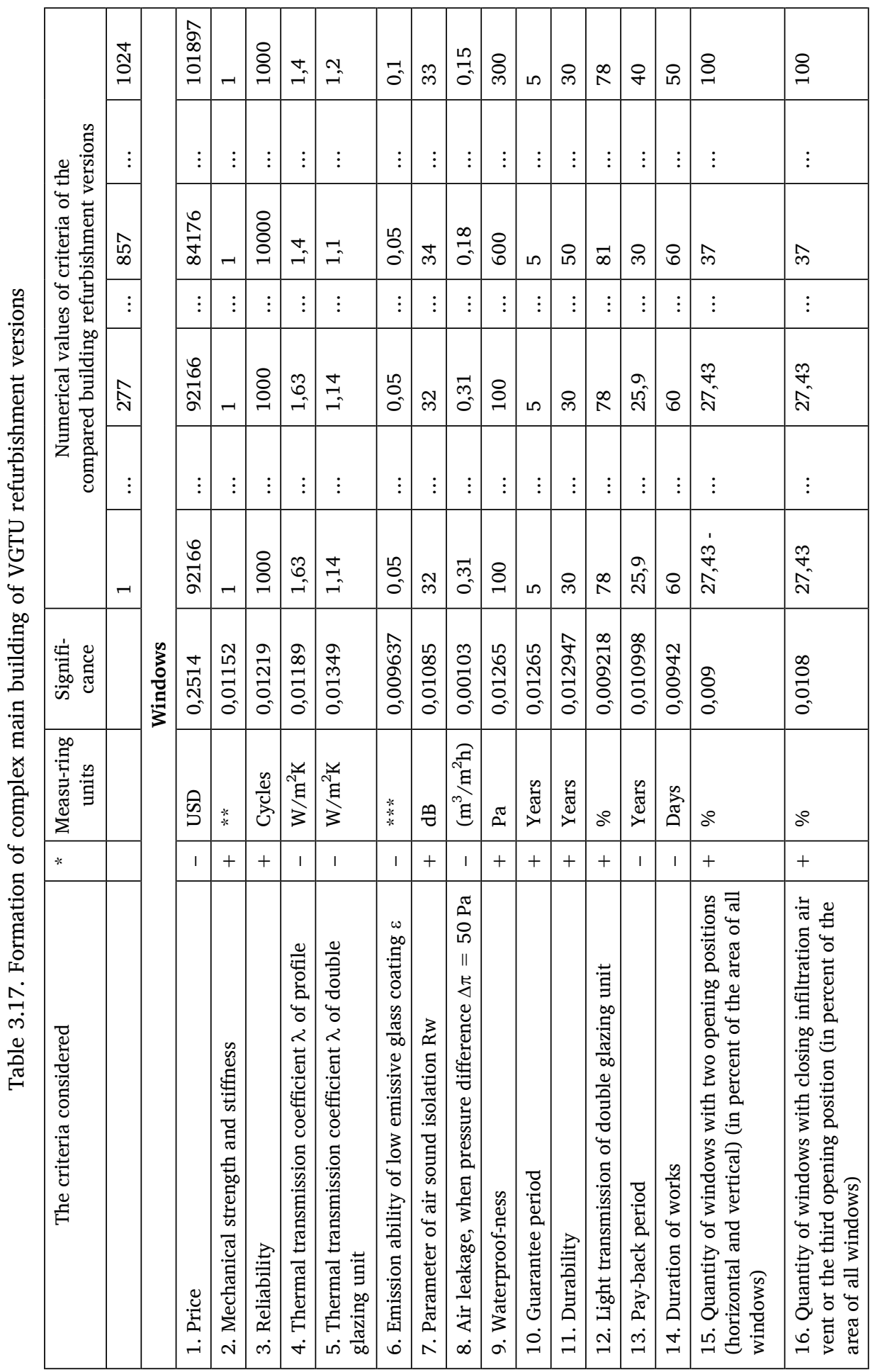




\begin{tabular}{|c|c|c|c|c|c|c|c|c|c|c|c|c|c|c|c|c|c|c|c|c|c|c|c|}
\hline 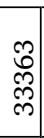 & 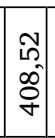 & $\stackrel{m}{\circ}$ & $\wedge$ & $\rightarrow$ & $\stackrel{2}{\sim}$ & $\begin{array}{l}\infty \\
+ \\
+\end{array}$ & 윽 & ద & - & 욱 & - & เ & q & ث. & & ¿ & $m$ & เุ & $\dot{c}^{-1} \stackrel{\Im}{-}$ & -1 & 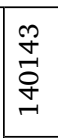 & & 요 \\
\hline & & & & & & & & & & & & & & & & & & & & & $\vdots$ & & \\
\hline 闬 & & ஓे & $\stackrel{2}{\wedge}$ & -1 & $\stackrel{2 \Omega}{\sim}$ & $\stackrel{m}{\sim}$ & $a$ & 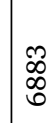 & -1 & \& & $\rightarrow$ & เ & 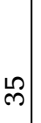 & เิ & & \% & L) & เి & $\hat{~}$ & $-\rightarrow$ & 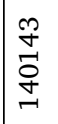 & & mे \\
\hline & & & & & & & & & & : & & $\vdots$ & & & & & & $\vdots$ & & $\vdots$ & $\vdots$ & $\vdots$ & $\vdots$ \\
\hline $\mid$ & & ले & $\stackrel{12}{\wedge}$ & $\rightarrow$ & $\stackrel{2 \Omega}{\sim}$ & $\stackrel{m}{+}$ & $\sigma$ & స్ & -1 & 8 & - & เ & ஓे & సి. & & $\frac{8}{10}$ & เ & เి & 상의 & -7 & 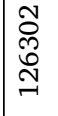 & & 이 \\
\hline & & & & & & & & & & & & : & $:$ & & & & & $\vdots$ & & 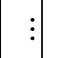 & $\vdots$ & $\vdots$ & \\
\hline 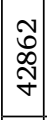 & $\mid \begin{array}{l}m \\
\alpha \\
\alpha \\
\text { மn }\end{array}$ & m & $\infty$ & -1 & $\stackrel{2}{\rightarrow}$ & की & ? & 咅 & -1 & $\stackrel{\leftrightarrow}{\sim}$ & $-i$ & 으 & in & 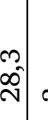 & & 8 & เ & เ & $\hat{~}$ & -7 & 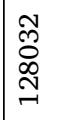 & & q \\
\hline \begin{tabular}{|l|}
0 \\
0 \\
0 \\
0
\end{tabular} & 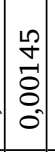 & 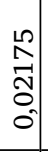 & \begin{tabular}{l}
0 \\
\hdashline \\
0 \\
0 \\
0
\end{tabular} & $\begin{array}{l}\text { ণิे } \\
\text { ठे }\end{array}$ & $\begin{array}{l}\text { Na } \\
\hat{o} \\
0\end{array}$ & $\begin{array}{l}8 \\
0 \\
0\end{array}$ & . & $\begin{array}{l}\underbrace{}_{n} \\
\infty \\
\infty \\
0 \\
0 \\
0\end{array}$ & $\begin{array}{l}\overrightarrow{0} \\
\tilde{m} \\
0 \\
0 \\
0\end{array}$ & $\begin{array}{l}\text { oे } \\
\tilde{o}^{\circ} \\
0 \\
0\end{array}$ & $\begin{array}{l}0 \\
\text { సै } \\
\text { ర్ } \\
0\end{array}$ & $\begin{array}{l}\frac{1}{\Delta} \\
\text { రे } \\
0 \\
0\end{array}$ & $\begin{array}{l}0 \\
0 \\
0 \\
0 \\
0\end{array}$ & \begin{tabular}{|c}
$\tilde{N}$ \\
0 \\
0 \\
0 \\
0 \\
\end{tabular} & \begin{tabular}{l}
0 \\
\multirow{2}{*}{} \\
5 \\
0 \\
0
\end{tabular} & 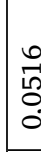 & $\infty$ & 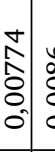 & 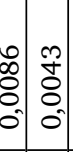 & $\mid \begin{array}{l}\infty \\
0 \\
0 \\
0 \\
0 \\
0 \\
\end{array}$ & $\begin{array}{l}\infty \\
\infty \\
0 \\
0 \\
\end{array}$ & $\mid \begin{array}{l}\hat{n} \\
\tilde{ల} \\
\delta \\
\delta \\
0 \\
0\end{array}$ & 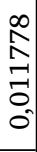 \\
\hline 点 & 空 & $>$ & $a_{1}$ & $\bar{z}$ & $\sqrt{a}$ & 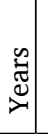 & $\ddot{\Delta}$ & s. & & (3) & & & 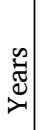 & : & בُ & 5 & & & 就 & $\left|\begin{array}{l}0 \\
0 \\
0 \\
0 \\
\tilde{c}\end{array}\right|$ & की & 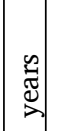 & 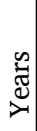 \\
\hline 1 & & + & & & & & & 1 & + & + & & + & + & 1 & & 1 & + & + & 11 & + & 1 & + & + \\
\hline
\end{tabular}

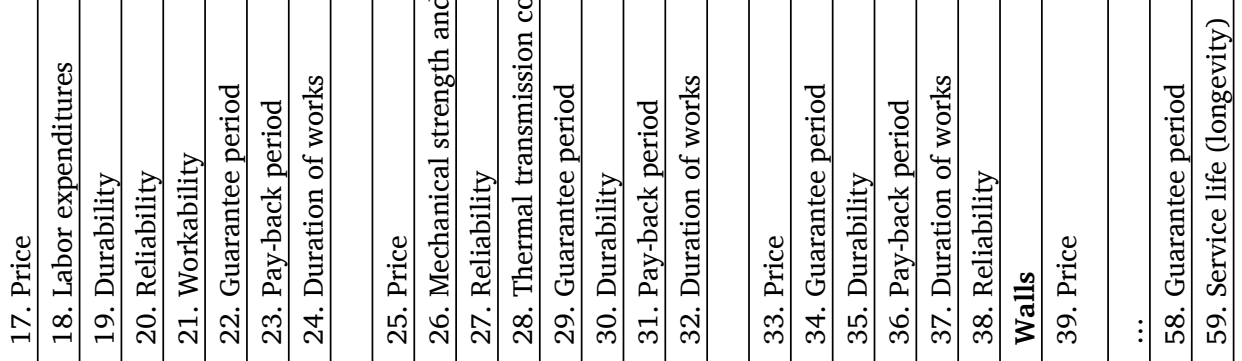


Table 3.18. Determination of building refurbishment significances, priorities and utility degree

\begin{tabular}{|l|c|c|c|}
\hline Priority & $\begin{array}{c}\text { Renovation alternative } \\
\text { number }\end{array}$ & $\begin{array}{c}\text { Total significance, } \\
\mathrm{Q}_{\mathrm{j}}\end{array}$ & $\begin{array}{c}\text { Total utility degree, } \\
\mathrm{N}_{\mathrm{j}}\end{array}$ \\
\hline 1 & 915 & 96,93 & 100,00 \\
\hline 2 & 925 & 97,43 & 99,94 \\
\hline 3 & 948 & 96,44 & 99,76 \\
\hline 4 & 959 & 96,93 & 99,69 \\
\hline 5 & 932 & 95,95 & 99,53 \\
\hline 6 & 943 & 96,44 & 99,46 \\
\hline 7 & 954 & 96,93 & 99,39 \\
\hline 8 & 934 & 96,44 & 99,15 \\
\hline 9 & 900 & 95 & 99,06 \\
\hline 10 & 905 & 95,47 & 98,99 \\
\hline
\end{tabular}

\subsubsection{Selection of low-e windows in retrofit of public buildings by applying multiple criteria method of multiple criteria complex proportional assessment (COPRAS)}

Public buildings may be of different types, such as colleges, cultural centers, nurseries, student halls of residence, and churches, etc. Public buildings are most suitable for achieving the market's penetration of innovative and effective retrofit solutions to improve energy efficiency and implement renewables, with moderate additional costs. With their help it will be easier to reach groups of differing age and social origin. Public buildings can also be used as engines to heighten awareness and sensitize society on energy conservation.

In all European countries it can be observed that general opinion on the realization of energy saving measures differs greatly between residential and non-residential buildings as well as between new and existing buildings. Most European countries have succeeded in reducing their energy consumption in new dwellings by more than $50 \%$ without increasing the building cost and, therefore, energy efficiency concept has reached greater acceptance by the building's owners.

Development is quite different for the non-residential buildings. Energy consumption problems are secondary to the improvement of comfort. Decisions to retrofit a building are often made because of dissatisfaction regarding the comfort level. Therefore, the primary goal is to improve these comfort conditions. Decision makers are often skeptical about measures that aim to reduce energy consumption because they are afraid that these measures could limit the effect of improving the indoor climate and increase costs. The improvement of comfort as the primary aim can be achieved alongside energy saving. 
It is, therefore, particularly important to demonstrate the effective solutions of public building retrofit and to make them visible to the wider public. One such project that represents the renovation of a main building at VGTU is considered in this paper.

Retrofit evaluation of a building is quite difficult to undertake because a building and its environment are complex systems (embracing technical, technological, ecological, social, comfort, aesthetic and other aspects), where all subsystems influence the efficiency of performance and where interdependence between the subsystems plays a significant role. Coherent and effective retrofit scenarios are commonly designed on the basis of knowledge of the degradation state of the building and its obsolescence. A systematic method, based on multicriteria analysis and a constructivist approach are also helpful in designing retrofit scenarios (Flourentzou, Roulet 2002).

A methodology for rating buildings or retrofit scenarios according to criteria such as use of energy for heating, cooling and other appliances, impact on the environment, indoor climate and cost has been suggested (Roulet et al. 2002).

The methodology of a multivariant design and multiple criteria analysis of a building's retrofit enables users to develop thousands of alternatives and to evaluate their economic, technical and architectural, aesthetic and comfort aspects (Kaklauskas et al. 2005).

For the energy saving measures to be profitable, the value of energy saved over the building's life will need to be greater than the capital investment and optimization would involve the selection of all measures with the savings-toinvestment ratio (SIR) being more than one (Gorgolewski 1995), where:

$$
S I R=\frac{\text { Present value of the total lifetime energy saving }}{\text { Investment cost }} .
$$

The retrofit implementation of the benefits of some energy saving measures is associated not only with the reduction of energy consumption, but also with the improvement of the condition of the building elements, as well as with durability and the market value of a building (Martinaitis et al. 2004). Building retrofit also improves the indoor climate in the building, its interior and architectural appearance as well as raising its market value (Zavadskas et al. 2004a). In terms of real estate market value, the effective retrofit may be described by the following market value ratio $(M V R)$ :

$$
M V R=\frac{\left(M_{v a}-M_{v b}\right)}{C_{r}},
$$

where $M_{v a}$ - market value of building after retrofit, $M_{v b}$ - market value of building before retrofit, $C_{r}$ - building retrofit costs. If the implement into retrofit has 
an $M V R$ greater than 1, it can be regarded as being cost effective with respect to real estate market value. When real estate market is active, the replacement of windows is effective in terms of $M V R$ which is greater than 1.

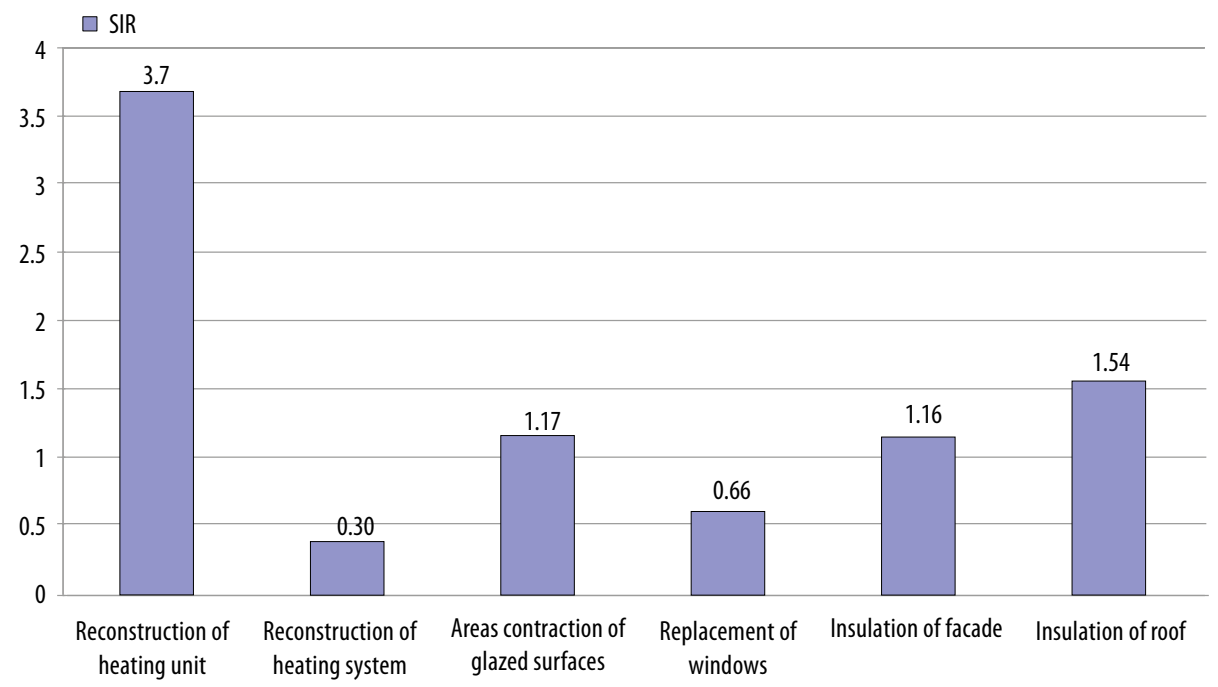

Figure 3.11. Savings-to-investment ratios (SIR) for implements of retrofit in the main building of VGTU

The efficiency of retrofit implements in the main VGTU building is calculated by determining their SIR (see Figure 3.11). As shown in the figure, the most efficient renovation procedures include the upgrading of the heating unit, the reduction of glazed area and the provision of wall and roof insulation. The replacement of windows is not as effective in terms of heat energy saving because it is an expensive and slowly repaid investment (with $S I R=0.66$ ). However, the windows of the VGTU building are old, unsafe, not opening \& shutting and poorly insulated. In cold seasons, great heat losses are experienced due to poor insulation and sometimes there are draughts in the spaces. In general, the existing windows do not satisfy standard requirements, their thermal transmittance being $U_{w}=2.5 \mathrm{~W} / \mathrm{m}^{2} \mathrm{~K}$.

The renovation of old windows is not reasonable from both technical and economical perspectives. Therefore, the most effective retrofit solution would be the replacement of the original windows with new ones. The building considered was designed and constructed 34 years ago, in the soviet times, when energy saving was not an acute problem. Buildings were designed with large glazed surfaces. Thus, the glazed area of the main VGTU building makes up $27 \%$ of the total enclosure surface of the building. Moreover, building renovation is usually done in the following order: first, windows are renovated or replaced and, then, walls are insulated. Therefore, windows should be renovated or replaced prior 
to carrying out insulation work. As shown by infrared thermovision photographs that were used to determine heat losses of a building, the latter are mostly caused by poorly insulated low-quality windows. Their replacement by low-e windows can cut heating expenses up to $30 \%$.

\subsubsection{Various types of windows and the problem of making the proper choice}

Windows, like doors, walls and the roof, make up an essential part of a building. These also play an important role in forming the façade and the interior of a building. A residential or public building can hardly be imagined without windows. However, about $30 \%$ of heat is lost, if windows are poorly insulated.

The main function of windows in a building is to pass light through to the interior and to decorate the building. However, windows are the thinnest elements transmitting cold, heat, noise, harmful ultraviolet rays, etc. into a building. Ordinary glass is mainly responsible for all negative effects because it conducts heat, noise, sunrays (from infrared to ultraviolet spectrum) as well as being fragile and easily broken. Thermal resistance of windows is much lower than that of walls, however, high-quality windows may reduce heat losses to a minimum. Modern technologies can provide windows with very good thermal and noise damping characteristics.

Good performance of windows may be achieved, if they are made of frost resistant glass, with a hermetically sealed frame and if the space in the room is well ventilated and heated. In general, in the process of a building's retrofit the balance between the main three components must be maintained (Figure 3.12)

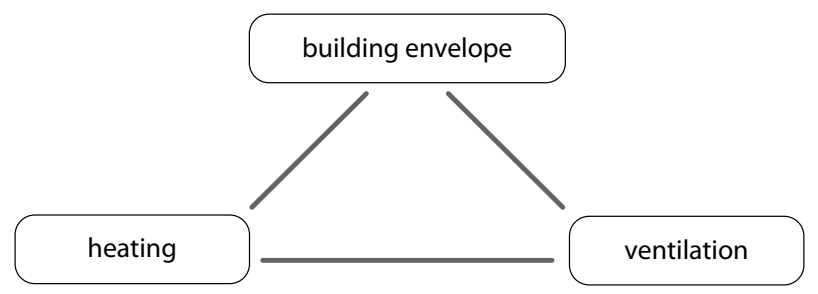

Figure 3.12. The main retrofit components of a building

Windows multiple glazing units reduce heat losses through glass, while the emissive glass reflects from $40 \%$ to $70 \%$ of the heat rays back to room, and further improve the thermal insulation of the units. Multiple glazing units with low-e glass are filled with argon. This also increases their thermal insulation by $20 \%$. Moreover, such windows retain two-thirds of harmful ultraviolet rays and in this way protect walls and furniture from fading. Multiple glazing units of the last generation with a soft emissive glass covering, emit threefold less heat into 
the atmosphere than ordinary units because their thermal transmittance may be very low, with $U_{g}=1.1 \mathrm{~W} / \mathrm{m}^{2} \mathrm{~K}$.

Currently, used plastic windows may have profiles of 3-8 chambers. Their thermal transmittance $U_{p}$ ranges from 1.8 to $0.9 \mathrm{~W} / \mathrm{m}^{2} \mathrm{~K}$. Eight closed air chambers of the frame profile can provide the best heat insulation characteristics. A special structure of plastic and aluminum reinforces the profiles as well as improving their insulation, by not using steel reinforcement as in an ordinary unit and, therefore, avoid cold air crossing.

Noise problems can be solved in various ways: thicker windowpanes or sheets of various thicknesses may be used for this purpose. The spacing between glass sheets can be enlarged or gases heavier than air, of two-chamber glazed units or laminated glass sheets with transparent acrylic rubber, etc may also be used. Windows are divided into six classes according to their acoustic performance, while their weighed sound reduction index $R_{w}$ can range from 25 to $50 \mathrm{~dB}$. Noise may be of high or low frequency or of a wide acoustic spectrum. Noise frequency should be determined prior to using any damping technique otherwise it would not provide the desired effect.

Multiple glazed units provide protection from hot solar rays with an external glass sheet made from reflective glass, which is more effective than dimmed glass. It reflects heat and light rays, and therefore, the illumination intensity in the room is lower. In fact, modern glass used in glazed units looks like ordinary transparent glass, but it can effectively reduce heat in summer and help to preserve heat in winter. To protect room from harmful ultraviolet radiation, reflective as well as laminated glass covered with PVC film or transparent acrylic rubber (from the inside), that allows only a very small percentage of ultraviolet radiation into the premises, is used.

According to resistance to wind load test pressure P1, windows are divided into six classes, i.e. from $400 \mathrm{~Pa}$ to more than $2000 \mathrm{~Pa}$, while, according to frame deflection, they are divided into three classes: A $(\leq 1 / 150)$, B $(\leq 1 / 200)$, C $(\leq 1 / 300)$.

Windows should be watertight (weather resistant). According to the watertightness test method $\mathrm{A}$, windows are divided into 10 classes, i.e. water pressure may range from zero to more than $600 \mathrm{~Pa}$. According to the test method $\mathrm{B}$, windows may be divided into seven classes, with water pressure ranging from zero to more than $300 \mathrm{~Pa}$.

According to air permeability, windows may belong to one of four classes, and under maximum test pressure it may range from 150 to $600 \mathrm{~Pa}$. At $100 \mathrm{~Pa}$, air permeability may range from 50 to $3 \mathrm{~m}^{3} /\left(\mathrm{h} \times \mathrm{m}^{2}\right)$.

According to mechanical strength, windows are divided into four classes, while, according to resistance to repeatedly being opened and closed windows are divided into three classes (from 5000 to 20000 cycles). 
Burglar resistance can be provided by laminated glass consisting of two 4 mm-thick glass sheets and 4 layers of $1.52 \mathrm{~mm}$-thick film between them, by considerably increasing impact resistance of windows. According to this characteristic, windows are divided into 5 classes, with a drop height ranging from $200 \mathrm{~mm}$ to $950 \mathrm{~mm}$ respectively.

According to reaction to fire, windows are grouped into seven classes.

Depending on a particular manufacturer, windows can also differ considerably in such characteristics as resistance to snow, permanent load and dangerous substances as well as radiation properties (i.e. solar factor $g$ and light transmittance $\tau_{v}$ ), ventilation (i.e. air flow exponent $n$ and air flow characteristic $K$ ), explosion and burglar resistance, etc.

To ensure good window performance and to avoid weeping, windows should be properly installed and insulated. Proper installation accounts for $50 \%$ of a window's quality. An efficient ventilation system should also be provided. Special limit stops that adjust a window's position in opening and closing are used for providing microventilation. There are a great number of air vents aimed at allowing fresh air into spaces that can even have noise damping characteristics. Recently, air vents provided with humidity sensors that react to air humidity fluctuation in the premises have emerged on the market. When relative humidity exceeds the admissible level, the air vent is opened automatically to allow in some fresh air. To provide the required ventilation, the inflow and outflow of air should be ensured.

Today, various types of windows including wooden, plastic and aluminum windows are offered in the market. Modern windows should be selected and based on their quality and operational characteristics. The windows characteristics are associated with the type of building (residential or administrative), a particular district - the Old Town or a new district (with modern multistory buildings), etc. Nowadays, more than 200 enterprises produce modern windows in Lithuania, of which about 50 produce plastic windows made from a plastic profile and are manufactured both in Lithuania and abroad. There is a great offering of windows of various shapes made from various kinds of glass, e.g. transparent, dimmed, smoked, plate glass, etc. as well as limit stops, ventilation and hinging systems, etc.

Therefore, given the wide variety of windows, it is not easy, even for a specialist, to make a decision, as to what type of windows to choose, especially, when the quality of the products also differs considerably.

\subsubsection{Contractor selection using COPRAS, a multicriteria decision making method}

Selection of a retrofit contractor is a decision characterized by multiple objectives. Owners want to minimize the likely cost of projects, but they also want 
contractors to maintain schedules as well as to achieve acceptable quality standards (Hatush, Skitmore 1997). Contractor selection is often based on the lowest bid that is made. However, the choice can be ineffective in terms of quality standard and lifetime. Contractors trying to win a contract often reduce the bid price. This may result in many changes, poor quality work, delays or perhaps all of these. From a client's point of view, such contractors are risky. Many countries have defined the criterion to limit the lowest bid price. In the U.S.A. and Canada, in the public sector, the "lowest bidder" is selected, but a bid bond in an amount equal to $10 \%$ of the bid price also has to be provided. In Denmark, the two highest and the two lowest bidders are excluded, while preference is given to a bidder suggesting an average bid price. The public sector system of bid evaluation, concentrating as it does solely on the bid price, is one of the major causes of project delivery problems. Most clients, especially those in the public sector, necessarily have to be accountable for their decisions and this becomes more difficult when selecting bidders other than the lowest.

A single criterion cannot give a full expression of the goals pursued by various clients. In most cases, the alternative versions provide a different degree of satisfaction to the client, i.e. bidders have different utility degrees (Rosenfeld, Shohet 1999). Apparently, for selecting a contractor one such method based on utility theory should be used because award of contract should be made to the responsible contractor whose proposal provides the best overall value to the client. In the determination of the best value, other technical factors and the bid price should be separately ranked. A number of criteria relating to contractors and technical products need to be considered in selecting contractors. For this purpose, multicriteria decision methods can be used.

In Lithuania, the main characteristics of building products are described in technical specifications and provided together with the bidding documents. This helps to ensure fair competition as well as allowing for alternative engineering solutions to be considered. The client can reject a bid if the product does not meet the specification. Bids are assessed and based on the following criteria (The amendment to... 2002):

1) The lowest bid price,

2) Economically effective bid chosen by considering a number of product characteristics, i.e. quality standard, price, aesthetic and operational characteristics, environmental and technical characteristics, maintenance costs, efficiency, warranty period and technical support, project delivery time, etc.

The client asks for determination of a relative weight for the criteria of every economically effective bid and in addition, he/she should evaluate the technical characteristics of the bids and inform the contractors about the evaluation results. Then, basing him/herself on the bid price, the client makes a general assessment of the bids. If the bid price is too low, the client should ask the 
contractor to give reasons for it. If the client is not satisfied with the reasons provided, he/she may reject the bid. The price is considered to be too low, if it is lower by $15 \%$ than the average price that is suggested by all the potential contractors.

For public procurement of construction works the model of bimatrix games may be applied (Mitkus 2001).

Selection of a building renovation contractor can be performed in three stages (Martinaitis, Rogoza 2001):

1. Selecting the criteria relating to a contractor and his/her product.

2. Pre-qualification of contractors, where the bid price is not one of the criteria.

3. The selection of construction and Project Manager of the renovation.

A variety of criteria have been proposed to date for contractor selection: in addition to the bid price, there are such criteria as financial soundness, technical ability, management capabilities, safety performance and reputation of a firm (Gorgolewski 1995). Examples of technical information that Metropolitan Washington Airports Authority may be requested to submit include (Metropolitan Washington 2003):

i) Recent experience with contracts of similar value;

ii) Evidence that they have the required specific technical capability and experience;

iii) A technical proposal that describes how they will satisfy the client's requirements;

iv) Schedule of their current contracts;

v) Breakdown of their available equipment and workforce resources;

vi) The firm's latest financial statement, and

vii) Evidence such as a letter from an acceptable surety showing that the firm will be able to obtain bonds in the required amounts.

Therefore, a contractor's selection should be based not only on past experience and capabilities of the candidate but should also take into consideration quantitative and qualitative characteristics of the product, i.e. thermal transmittance of windows, weighed sound reduction index $R_{w}$, durability, etc. In this case, the problem of price and quality ratio arises. A low price cannot ensure quality standards that are expected by the client because the contractor can reduce costs at the expense of the product's quality.

For this purpose, a pre-qualification of contractors is made and is based on multicriteria analysis of the contractor's bidding for a window replacement's project. The choice of the project is made fully satisfying the client's needs at minimum cost (Ambrasas et al. 1996). Technical evaluation will normally be made without the technical evaluator(s) having access to the pricing data. Further, technical information, and the technical criteria alone can be used to establish 
Table 3.19. PQC and minimal requirements for new windows

\begin{tabular}{|c|c|c|c|}
\hline No. & PQC & Units of measurement & Minimal requirements \\
\hline 1 & $\begin{array}{l}\text { Mechanical strength and stiff- } \\
\text { ness }\end{array}$ & $*$ & $\begin{array}{l}\text { Conformity to standard } \\
\text { GOST } 24033-80\end{array}$ \\
\hline 2 & Reliability & cycles & $\geq 10000$ \\
\hline 3 & $\begin{array}{l}\text { Thermal transmittance } U_{p} \text { of } \\
\text { profile }\end{array}$ & $\mathrm{W} / \mathrm{m}^{2} \mathrm{~K}$ & $\leq 1.4$ \\
\hline 4 & $\begin{array}{l}\text { Thermal transmittance } U_{g} \text { of } \\
\text { double glazing unit }\end{array}$ & $\mathrm{W} / \mathrm{m}^{2} \mathrm{~K}$ & $\leq 1.2$ \\
\hline 5 & $\begin{array}{l}\text { Emission ability of low emissive } \\
\text { glass coating } \varepsilon\end{array}$ & $*$ & $\leq 0.1$ \\
\hline 6 & $\begin{array}{l}\text { Weighed sound reduction index } \\
R_{w}\end{array}$ & $\mathrm{~dB}$ & $\geq 32(-2,-5)$ \\
\hline 7 & $\begin{array}{l}\text { Air permeability, when pressure } \\
\text { difference } \Delta p=50 \mathrm{~Pa}\end{array}$ & $\left(\mathrm{~m}^{3} / \mathrm{m}^{2} \mathrm{~h}\right)$ & $\leq 0.5$ \\
\hline 8 & Water-tightness & $\mathrm{Pa}$ & $\geq 250$ \\
\hline 9 & Warranty period & Years & $\geq 5$ \\
\hline 10 & Durability & Years & $\geq 30$ \\
\hline 11 & $\begin{array}{l}\text { Light transmittance } \tau_{v} \text { of double } \\
\text { glazing unit }\end{array}$ & $\%$ & $\geq 78$ \\
\hline 12 & Duration of work & Days & $\leq 60$ \\
\hline 13 & $\begin{array}{l}\text { The number of windows with } \\
\text { two opening positions (horizon- } \\
\text { tal and vertical) (in percent of } \\
\text { the total area of windows) }\end{array}$ & $\%$ & $\geq 25$ \\
\hline 14 & $\begin{array}{l}\text { The number of windows with } \\
\text { closing infiltration air vent or } \\
\text { the third opening position (in } \\
\text { percent of the total area of } \\
\text { windows). }\end{array}$ & $\%$ & $\geq 25$ \\
\hline
\end{tabular}

* There is no unit for criterion measurement

a competitive range of proposals. A pre-qualification of contractors helps the client to identify contractors with whom the client could enter into a contract. The main goal in contractor pre-qualification is to establish a set of decision Pre-Qualification Criteria (PQC) through which the capabilities of contractors 
are measured and judged. The choice of PQC depends on two factors: clients' objectives and the decision-maker's perceptions (Gorgolewski 1995).

The client should decide on the type of windows he/she needs, especially, as regards to low thermal transmittance or high sound insulation windows. In general, the client should be aware of the available technical solutions of renovation (Parasonis, Ambrasas 1995). He/she may get the necessary information from experts or in contractor pre-qualification. If the client is not sufficiently qualified to make a decision, it affects his/her choice of contractor.

A number of retrofit professionals were asked to elicit the utility functions needed to retrofit the main building of VGTU. Prior to performing a contractor's pre-qualification for the main building of VGTU windows replacement, window specialists, manufacturers, suppliers and researchers were consulted. The evaluation criteria were chosen taking into account the fact that VGTU is a public sector client. The type of client is an important factor that influences a contractor's bidding behavior (Drew et al. 2001). Significant differences exist between the public and private sector's clients. PQC for a public client are more stringent and well defined so as to eliminate any imprudent inclusion of contractors.

Improvement of comfort in public buildings as the primary aim should be combined with measures for energy saving. Therefore, the selection of PQC for window replacement in VGTU was based on these two most important factors. To reduce heat energy losses and to provide comfortable conditions in the main building of VGTU, the sufficiently stringent minimal requirements of PQC were established. For example, they included thermal transmittance of the window profile $U_{p} \leq 1.4 \mathrm{~W} / \mathrm{m}^{2} \mathrm{~K}$, thermal transmittance of double glazing unit $U_{g} \leq 1.2$ $\mathrm{W} / \mathrm{m}^{2} \mathrm{~K}$, emission ability of low emissive glass coating $\varepsilon \leq 0.1$, weighed sound reduction index $R_{w} \geq 32(-2,-5) \mathrm{dB}$, and light transmittance of double glazing unit $\tau_{v} \geq 78 \%$, etc. (see Table 3.19 ). In general, the criteria had to satisfy 14 requirements.

One of the major tasks is to determine the weights of the criteria. To determine the weights of the criteria, the expert's judgment method is applied (Kaklauskas et al. 2005), which has been successfully used in research by the authors since 1987 (Raslanas et al. 2006; Zavadskas et al. 2001). This expert judgment method was implemented in the following stages:

- Calculation of values $t$,

- Calculation of weights $q$;

- Calculation of values $S$;

- Calculation of values $T_{k}$;

- Calculation of values $W$;

- Calculation of values $\chi^{2}$;

- Testing the statement $\chi^{2}>\chi_{t b l}^{2}$. 
The values $t_{j k}$ for statistical processing were obtained by interviewing respondents. A survey of experts, based on questionnaires, was conducted to elicit data on the significance of criteria. The criteria provided for evaluation were actually similar to those used at the pre-qualification step, though they had been given much earlier than when this procedure was performed. All experts (interested parties) were subdivided into six categories: experts over 35 years of age, experts under 35, and students. Then, the experts were divided into two groups consisting of males and females. Teachers that were acquainted with the discussed window's problems, administration staff and students studying in the main building of VGTU represented the experts. About 30 questionnaires were filled and processed with the aim of finding the alternative of the type of windows that would meet the requirements of all interested parties. The evaluation scale ranged from 1 to 10 points: 1,2 - insignificant criterion, $3,4-$ the criterion is of little significance, 5,6 - the criterion is of average significance, 7, 8 - significant criterion, and 9, 10 - very significant criterion. The average criterion value $\bar{t}_{j}$ was calculated by the formula:

$$
\overline{t_{j}}=\frac{\sum_{k=1}^{r} t_{j k}}{r},
$$

where $t_{j k}$ is the ranking of the $j$-th criterion by the $k$-th respondent, $r$ is the number of respondents.

The weights of the criteria were calculated by dividing the sum of the criteria's average values by the average value of each criterion:

$$
q=\frac{\sum_{j=1}^{n} \overline{t_{j}}}{t_{j}} .
$$

The total weight of the criteria must be equal to one:

$$
\sum_{j=1}^{n} \frac{\sum_{j=1}^{n} \overline{t_{j}}}{\overline{t_{j}}}=1.0 .
$$

The reliability of the data can be expressed by the coefficient of concordance (agreement) of the respondents' opinions by describing the extent of proximity of individual views. In the cases with reiterated ranks for the same parameters, as in this case, the coefficient of concordance is:

$$
W=\frac{12 S}{r^{2}\left(n^{3}-n\right)-r \sum_{k=1}^{r} T_{k}}, W \in[0 ; 1],
$$


where $S$ total square deviation of the rankings of each criterion, $T_{k}$ index of reiterated ranks in the $r$ rank; $n$ number of evaluation criteria.

The deviation of the criterion ranking is as follows:

$$
S=\sum_{j=1}^{n}\left[\sum_{k=1}^{r} t_{j k}-\frac{1}{n} \sum_{j=1}^{n} \sum_{k=1}^{r} t_{j k}\right]^{2},
$$

where $t_{j k}$ is the rank conferred by the $k$-th respondent to the $j$-th criterion.

However, the calculated value $W$ is stochastic, meaning that the significance of the concordance coefficient has to be calculated. Kendall (1970) has shown that, when $n>7$, then the value $\chi^{2}=W \cdot r \cdot(n-1)$ has a distribution with degrees of freedom $v=n-1$. It has also been proved that if the calculated value $\chi^{2}$ is larger than the critical tabular value $\chi_{t b l}^{2}$ for the pre-selected level of significance (e.g. $\alpha=0.05$ ), then the hypothesis on the agreement of independent experts' judgments is not rejected. In our case, we have $n=14, v=13$ and the pre-selected level of significance is $\alpha=0.05$, therefore, the above-mentioned conditions are satisfied.

The significance $\chi^{2}$ of the concordance coefficient is calculated as follows:

$$
\chi_{\alpha v}=W \cdot r \cdot(n-1)=\frac{12}{r n(n+1)--\sum T} .
$$

If $\chi_{\alpha, v}^{2}>\chi_{t b l}^{2}$, the significance of the concordance coefficient exists at $\alpha$ level, then the agreement of experts' opinions is satisfactory and a group's opinion is established. Otherwise, when $\chi_{\alpha, v}^{2}<\chi_{t b l}^{2}$ is obtained, the respondents' opinions are not in agreement, implying that they differ substantially and the hypothesis of the rank's correlation cannot be accepted.

The concordance coefficient based on the criteria weights is $W=0.87$. The value of $\chi_{\alpha, v}^{2}$ calculated by formula (3.20) is equal to 26.36. This value should be greater than $\chi_{t b l}^{2}$, which depends on the degrees of freedom $v$ and the preselected level of significance $\alpha$. In this case, the tabular value was taken from Fisher and Yates statistical tables. When the degrees of freedom $v=13$ and preselected level of significance is $\alpha=0.05$ (or error probability $P=5 \%$ ), then we have the value of $\chi_{t b l}^{2}$ equal to 23.685. Since 26.36 $>23.685$, when $\alpha=0.05$, and $v=13$, then, the assumption is made that the coefficient of concordance is significant and expert rankings are in concordance with $95 \%$ probability. The significances of the criteria obtained by this method are presented in Table 3.20.

The best-known Lithuanian firms were invited to take part in the pre-qualification for window replacement. Two of firms could not meet the requirements needed to provide sufficient thermal transmittance of the profile and 
light transmittance of double-glazing unit. Finally, five firms remained which submitted their bids.

The first bidder offered windows that had the best qualities according to the following criteria: thermal transmittance of profile $\mathrm{U}_{\mathrm{p}}=l .2 \mathrm{~W} / \mathrm{m}^{2} \mathrm{~K}$, thermal transmittance of double glazing unit $U_{g}=l .1 \mathrm{~W} / \mathrm{m}^{2} \mathrm{~K}$, emission ability of low emissive glass coating $\varepsilon=0.05$, weighed sound reduction index $R_{w}=34 \mathrm{~dB}$, light transmittance of double glazing unit $\tau_{v}=81 \%$, water-tightness $p=600 \mathrm{~Pa}$, warranty period 10 years. However, these windows were worse according to these criteria: longevity - 35 years, duration of work -60 days, the amount of windows with two opening positions $-78.5 \%$, the number of windows with closing infiltration air vent or the third opening position (in \% of the total area of windows) $78.5 \%$. It is hardly possible to choose the best alternative based only on a visual inspection of products without using any mathematical methods.

The MCDM method COPRAS was first announced in 1994 (Zavadskas et al. 1994). This method assumes direct and proportional dependence of the significance and utility degree of investigated versions on a system of criteria adequately describing the alternatives and on values and weights of the criteria. Determination of significance, the priority order and utility degree of the alternatives is carried out in five stages (Kaklauskas et al. 2005):

1. Forming the weighted normalized decision-making matrix $D$ (see Table 3.21).

2. Calculating the sums of weighted normalized indices describing the $j$-th alternative.

3. Determining the significances $Q j$ of the compared alternatives describing the advantages $S_{+j}$ and disadvantages $S_{-j}$ of the alternatives.

4. Calculating the utility degree $N_{j}$ of alternative $a_{j}$.

5 . Determining the priority order of the alternatives.

The results of multiple criteria evaluation of five window replacement versions for the pre-qualification of bidders shows that the first alternative is the best with respect to the utility degree that equals $100 \%$, the third version is the second best in the utility degree that equals $86.35 \%$, the second version is the third best in the utility degree that equals 71.15 , etc. This shows that the first alternative is more useful than the third alternative by $13.65 \%$, and is more useful than the second alternative by $28.85 \%$.

The next stage in the final choice of a contractor includes the consideration of bids by the candidates who satisfied the pre-qualification requirements. At this stage, an additional criterion, i.e. bid price, is considered alongside the criteria of technical specifications. Once technical evaluation is complete, price proposals of contractors on the final short-list will be combined with the technical score in making the final selection of a contract's award. 


\begin{tabular}{|c|c|c|c|c|c|c|c|c|c|c|c|c|c|c|c|}
\hline 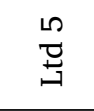 & -1 & \begin{tabular}{l}
8 \\
8 \\
$\searrow$ \\
\hdashline
\end{tabular} & $\stackrel{+}{\sim}$ & $\underset{ت}{\stackrel{\Xi}{\sim}}$ & $\begin{array}{l}0 \\
0 \\
0\end{array}$ & లి & $\ddot{0}$ & $\begin{array}{l}\text { ㅇํ } \\
\text { N }\end{array}$ & 10 & ిે & $\stackrel{\infty}{\wedge}$ & 8 & 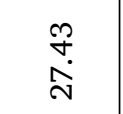 & $\underset{\stackrel{m}{\sim}}{\stackrel{m}{\sim}}$ & \\
\hline $\begin{array}{l}+ \\
\stackrel{D}{ت}\end{array}$ & $r$ & \begin{tabular}{l}
8 \\
8 \\
8 \\
\hdashline
\end{tabular} & $\stackrel{\nabla}{\sim}$ & ت־ & $\begin{array}{l}n \\
0 \\
0\end{array}$ & $m$ & $\stackrel{m}{0}$ & 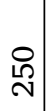 & 10 & P & $\Omega$ & రి & $\stackrel{8}{\circ}$ & $\stackrel{8}{\circ}$ & \\
\hline $\begin{array}{l}m \\
\stackrel{D}{=}\end{array}$ & -1 & $\begin{array}{l}8 \\
8 \\
8 \\
-1\end{array}$ & $\stackrel{\nabla}{r}$ & ت. & $\begin{array}{l}0 \\
0 \\
0\end{array}$ & ఉా & $\stackrel{\infty}{\stackrel{\infty}{*}}$ & ৪ & 10 & 잇 & $\vec{\infty}$ & 8 & $\hat{m}$ & $\hat{m}$ & \\
\hline $\begin{array}{l}N \\
\stackrel{\varpi}{二}\end{array}$ & $r$ & $\begin{array}{l}8 \\
8 \\
8 \\
\end{array}$ & $\stackrel{\nabla}{\sim}$ & ָ̦ & $\overrightarrow{0}$ & $\stackrel{m}{m}$ & 웅 & ষి & 10 & ిొ & $\stackrel{\infty}{\wedge}$ & 오 & ঃ & ঃ & \\
\hline ت્ّ & -1 & \begin{tabular}{l}
8 \\
8 \\
8 \\
\hdashline
\end{tabular} & ণ̦ & 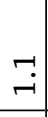 & $\begin{array}{l}10 \\
0 \\
0\end{array}$ & ঙे & $\stackrel{\infty}{\stackrel{\infty}{0}}$ & ৪ి & $\stackrel{0}{\rightarrow}$ & $\stackrel{\llcorner}{m}$ & $\vec{\infty}$ & రి & $\begin{array}{l}\stackrel{1}{\infty} \\
\infty \\
\end{array}$ & $\begin{array}{l}10 \\
\infty \\
\infty\end{array}$ & \\
\hline 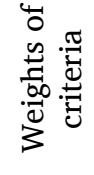 & $\begin{array}{l}10 \\
\infty \\
0 \\
0 \\
0\end{array}$ & $\begin{array}{l}\stackrel{0}{ } \\
\hat{N} \\
\hat{0} \\
0\end{array}$ & $\begin{array}{l}\vec{\sigma} \\
0 \\
0\end{array}$ & $\begin{array}{l}\infty \\
0 \\
\\
0\end{array}$ & $\begin{array}{l}\stackrel{1}{0} \\
\hat{0} \\
0 \\
0\end{array}$ & $\begin{array}{l}\stackrel{0}{0} \\
\hat{N} \\
0 \\
0 \\
0\end{array}$ & $\begin{array}{l}10 \\
50 \\
0 \\
0\end{array}$ & $\begin{array}{l}\llcorner\Omega \\
\stackrel{2}{ } \\
0 \\
0 \\
0\end{array}$ & $\begin{array}{l}\llcorner\Omega \\
\\
0 \\
0 \\
0\end{array}$ & $\begin{array}{l}\stackrel{0}{N} \\
\hat{N} \\
0 \\
0\end{array}$ & $\begin{array}{l}10 \\
\\
0 \\
0\end{array}$ & $\begin{array}{l}\text { ஸे } \\
\text { } \\
\text { மீ} \\
0 \\
0\end{array}$ & $\begin{array}{l}\text { م⿱ } \\
\hat{0} \\
\text { ஜூ } \\
0 \\
0\end{array}$ & 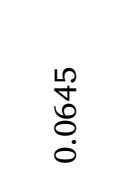 & \\
\hline$*$ & + & + & 1 & 1 & 1 & + & 1 & + & + & + & + & 1 & + & + & 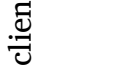 \\
\hline 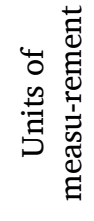 & $*$ & $\begin{array}{l}\frac{\tilde{d}}{0} \\
\vec{v}\end{array}$ & 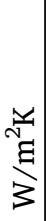 & 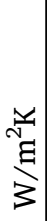 & $\begin{array}{l}* \\
* \\
*\end{array}$ & 甲ै & 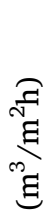 & $\tilde{\Omega_{1}}$ & 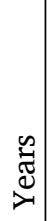 & 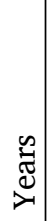 & $\partial^{0}$ & 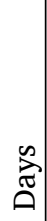 & $\partial^{0}$ & $\partial^{0}$ & 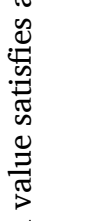 \\
\hline & 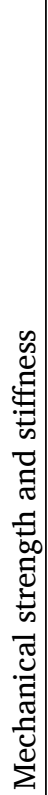 & 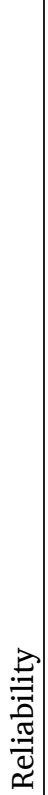 & 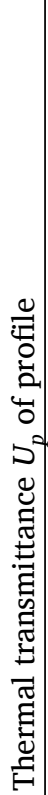 & 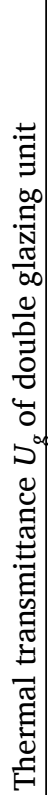 & 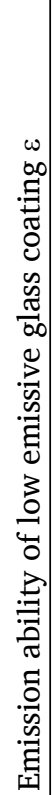 & 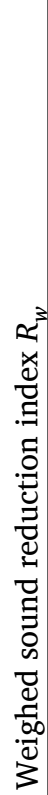 & 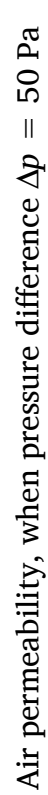 & 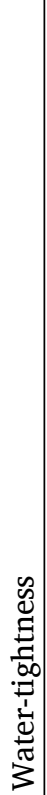 & 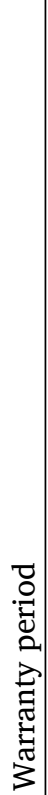 & $\begin{array}{l}2 \\
. \\
0 \\
00 \\
0 \\
0 \\
.9\end{array}$ & 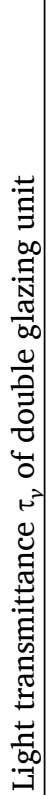 & 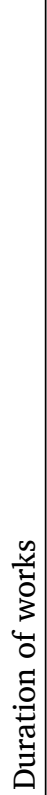 & 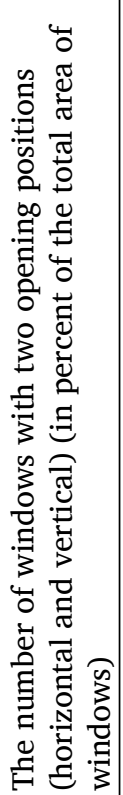 & 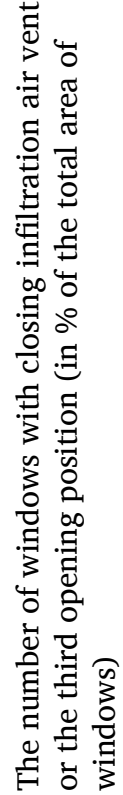 & 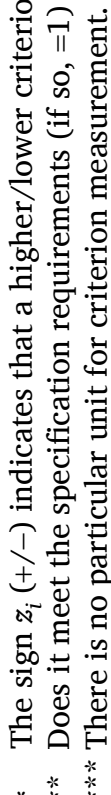 \\
\hline
\end{tabular}




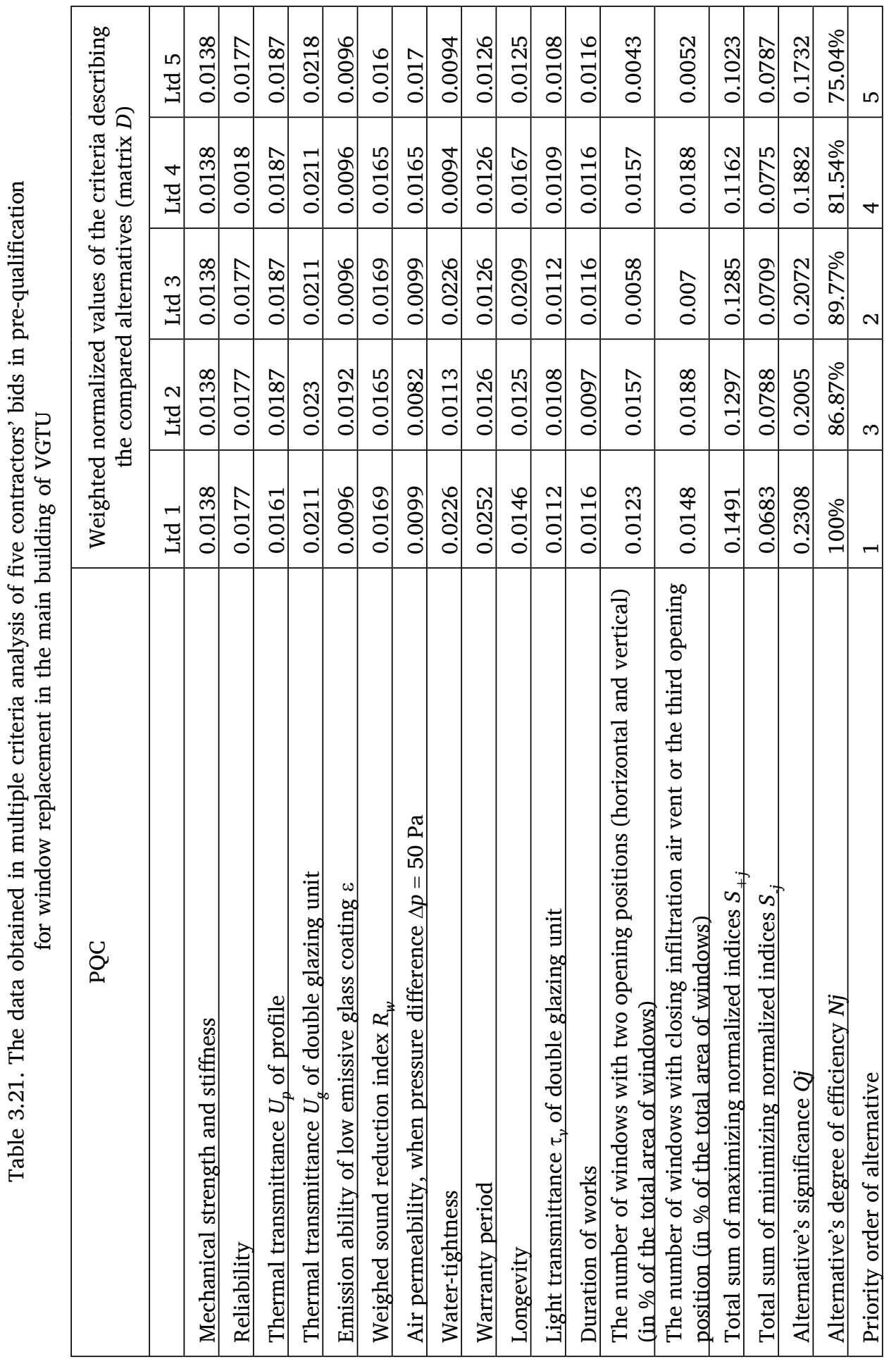


In assessing the economic effect of bids and stating the priorities, bid prices and relative weights of values should be determined. For this purpose, Hotl et al. combine the so-called P2 points (symbolizing the information collected about a bid) with $\mathrm{P} 3$ points (referring to the bid price) to make a single criterion. Hotl et al. set the weight of 0.40 to P2 and 0.60 to P3 (Holt 1993). The Finnish Road Administration applies the price points (with a relative weight of 0.75) and quality points (with a relative weight of 0.25) (Mäkinen 2003) in choosing the contractor. The relative weight of the construction's cost in Lithuania can be 0.60 , while the sum of the relative weights in the evaluation of operational characteristics and maintenance costs may reach 0.40 . The relative weight of 0.60 is specified when the price and three or more other criteria are evaluated. Therefore, the relative weight of the price was taken to be equal to 0.6 , while the relative weight of operational-maintenance characteristics was 0.4 (Kaklauskas et al. 2006). Contractors offered the following prices for window replacement (see Table 3.22).

Table 3.22. Contractors' bid prices for window replacement

\begin{tabular}{|c|c|c|c|c|c|}
\hline \multirow{2}{*}{ Contractor bids (USD) } & Ltd 1 & Ltd 2 & Ltd 3 & Ltd 4 & Ltd 5 \\
\cline { 2 - 6 } & 72,116 & 101,896 & 84,176 & 115,072 & 92,166 \\
\hline
\end{tabular}

We can see that Ltd 1 offered the lowest bid price, while was Ltd 4 offered the highest price. According to pre-qualification results, Ltd 1 was first in the list of priorities, while Ltd 3 was the second and Ltd 2 was the third.

The final choice of a low-e window's contractor was made by using the MCDM method COPRAS. According to the calculation's results, Ltd 1, which was the best in pre-qualification, offered windows that have the highest utility for a client in terms of technical characteristics and a good price for the product. The first alternative is also the best in terms of its utility degree that equals $100 \%$. Low-e windows offered by the first bidder have the following technical characteristics: thermal transmittance of the profile $U_{p}=1.2 \mathrm{~W} / \mathrm{m}^{2} \mathrm{~K}$, thermal transmittance of double glazing unit $U_{g}=1.1 \mathrm{~W} / \mathrm{m}^{2} \mathrm{~K}$, emission ability of low emissive glass coating $\varepsilon=0.05$, weighed sound reduction index $R_{w}=34 \mathrm{~dB}$, light transmittance of double glazing unit $\tau_{v}=81 \%$, water-tightness $p=600 \mathrm{~Pa}$, warranty period 10 years, longevity 35 years, duration of works - 60 days, the number of windows with the third opening position (in \% of the total area of windows) $78.5 \%$.

However, the priority order of other firms (contractors) changed after the final evaluation. Thus, Ltd 1, Ltd 2 and Ltd 3 retained their positions that were obtained in pre-qualification, while Ltd 4 and Ltd 5 changed places in the list of priorities. 
The windows in the main building of VGTU were replaced according to the results obtained by using the MCDM method COPRAS (Figure 3.13).

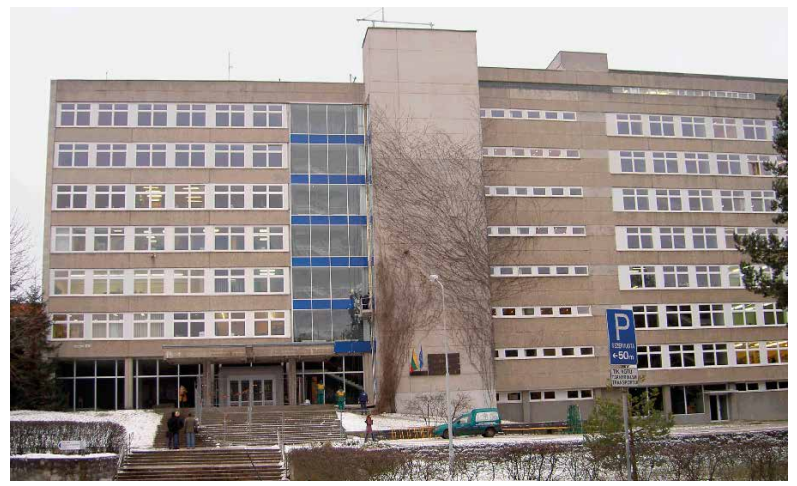

Figure 3.13. A view of the main building of VGTU with replaced windows

$\mathrm{n}$ order to realize an effective selection of low-e windows in a building's retrofit, it is necessary to carry out an exhaustive investigation of all possible solutions. The efficiency level of a particular window's replacement alternative depends on a large number of factors, including cost of the project, energy savings gained after renovation, tentative pay-back time, thermal transmittance of the profile and double glazing unit, emission ability of low emissive glass coating, weighed sound reduction index, light transmittance of double glazing unit, water-tightness, warranty period, longevity, the number of windows with the third opening position, and duration of work, etc.

On the other hand, the evaluation of the retrofit also benefits in respect to heat energy savings as was shown in the main building of VGTU in that the replacement of the original windows with the new ones is not so effective as other improvements $(S I R=0.66)$. However, in addition to energy saving, window replacement improves the indoor climate of the building, its interior and architectural appearance as well as raising its market value. When the financial resources are limited, managers often resort to window replacement as the first step in a building's retrofit.

The MCDM method COPRAS provides an opportunity to select a low-e windows contractor. The selection of a low-e windows contractor by using this method allows for a more precise assessment of a customer's needs as well as cutting down the window replacement's costs.

\section{References}

Alanne, K. 2005. Selection of renovation actions using multi-criteria "knapsack" model, Automation in Construction 13(3): 377-39. 
ALwaer, H.; Clements-Croome, D. J. 2010. Key performance indicators (KPIs) and priority setting in using the multi-attribute approach for assessing sustainable intelligent buildings, Building and Environment 45(4): 799-807.

Ambrasas, G.; Kaklauskas, A.; Zavadskas, E. K. 1996. Demonstration system for development of efficient projects, Statyba, Journal of Civil Engineering and Management 4(8): $84-100$.

Amstalden, R.W.; Kost, M.; Nathani, C.; Imboden, D.M. 2007. Economic potential of energy-efficient retrofitting in the Swiss residential building sector: The effects of policy instruments and energy price expectations, Energy Policy 35(3): 1819-1829.

Andruškevičius, A. 2005. Selection of Prefobricated Construction Renovation Variants: Social and Information Aspects, Business: Theory and Practice 6(3): 187-197.

Antuchevičienè, J. 2005. Apleistų pastatų naudojimo modeliavimas darnaus vystymo (-si) aspektu [Modelling of Derelict Buildings' use from the Perspective of Sustainable Development]. Daktaro disertacija, VGTU, Technologijos mokslai, statybos inžinerija (02T).

Balaras, C. A.; Droutsa, K.; Argiriou, A. A.; Asimakopoulos, D. N. 2000. Potential for energy conservation in apartment buildings, Energy and Buildings 31: 143-154.

Balaras, C. A.; Droutsa, K.; Dascalaki, E.; Kontoyiannidis, S. 2005. Deterioration of European apartment buildings, Energy and Buildings 37(5): 429-442.

Balaras, C. A.; Gaglia, A. G.; Georgopoulou, E.; Mirasgedis, S.; Sarafidis, Y.; Lalas, D. P. 2007. European residential buildings and empirical assessment of the Hellenic building stock, energy consumption, emissions and potential energy savings, Building and Environment 42(3): 1298-1314.

Bardauskienè, D. 2007. The Expert's Estimates application in the preparation of City General Plan, Technological and economic development of economy 13(3): 223-236. (in Lithuanian)

Bell, M.; Lowe, R. 2000. Energy efficient modernisation of housing: a UK case study, Energy and Buildings 32(3): 267-280.

Bluyssen, P. M. 2000. EPIQR and IEQ: indoor environment quality in European apartment buildings, Energy and Buildings 31(2): 103-110.

Brandt, E.; Rasmussen, M. H. 2002. Assessment of building conditions, Energy and Buildings 34(2): $121-125$.

Bringing Retrofit Innovation to Application in Public Buildings (BRITA in PuBs) 2004. EU $6^{\text {th }}$ Framework Program, Integrated Project BRITA in PuBs.

Burinskienè, M. 2003. Subalansuota miestu plètra [Sustainable Urban Development]. Vilnius: Technika, 251 p. (in Lithuanian)

Burinskienė, M.; Rudzkienė, V. 2009. Future insights, scenarios and expert method application in sustainable territorial planning, Technological and economic development of economy 15(1): 10-25.

Būsto ir urbanistinès plètros agentūra [Housing and Urban Development Agency] [interactive] 2009. Pasiūlymai dèl daugiabučių namų suskirstymo ị grupes, kuriuos reikètų atnaujinti pirmumo tvarka [Suggestions on Classification of Apartment Houses 
into Groups which should have the Priority in Retrofit]. Available at: http://www. am.lt/VI/index.php\#a/9879 [viewed on 25 May 2010] (in Lithuanian).

Caccavelli, D.; Genre, J. L. 2000. Diagnosis of the degradation state of building and cost evaluation of induced refurbishment works, Energy and Buildings 31: 159-165.

Ciegis, R.; Ramanauskiene, J.; Martinkus, B. 2009. The Concept of Sustainable Development and its Use for Sustainability Scenarios, Engineering Economics 2: 28-37.

Darni urbanistinè plètra Lietuvoje 2008. Darni urbanistinè plètra Lietuvoje - problemos ir sprendimo būdai [Sustainable Urban Development in Lithuania: Problems and Solutions]. Conference proceedings, 9 April 2008. LRS. 2008. Vilnius: Valstybès žinios. ISBN 978-9986-18-181-1. (in Lithuanian)

EXPO 2000 Hannover. The Hellersdorf project. Hannover, 2000. (in Deutsch)

Filippin, C.; Larsen, F. S. 2009. Analysis of energy consumption patterns in multi-family housing in a moderate cold climate, Energy Policy 37(9): 3489-3501.

Flourentzou, F.; Genre, J. L.; Roulet, C. A. 2002. TOBUS software - an interactive decision aid tool for building retrofit studies, Energy and Buildings 34(2): 193-202.

Flourentzou, F.; Roulet, C. 2002. Elaboration of retrofit scenarios, Energy and Buildings 34: $185-192$.

Galvin, R. 2010 Thermal upgrades of existing homes in Germany: The building code, subsidies, and economic efficiency, Energy and Buildings 42(6): 834-844.

Ginevičius, R.; Podvezko, V. 2008. Housing in the context of economic and social development of Lithuanian regions, International Journal of Environment and Pollution 35(2-4): 309-330.

Ginevičius, R.; Podvezko, V.; Raslanas, S. 2008. Evaluating the Alternative Solutions of Wall Insulation by Multicriteria Method, Journal of Civil Engineering and Management 14(4): 217-226.

Girčys, G.; Gruževskis, B.; Juknys, R.; Miškinis, V.; Pakalnis, R.; Staniškis, J.; Stoškus, L.; Vèbra, E.; Zemeckis, R.; Zurlytė, I.; Žilinskienė, D. 2005. [interactive]. Nacionalinės darnaus vystymosi strategijos igyvendinimo 2003-2004 metais ataskaita [Report on Implementation of the National Strategy for Sustainable Development in 2003-2004] Available at: http://www.sd-network.eu/pdf/resources/NSDS-Eval-Report_Lithuania. pdf [viewed on 12 January 2010]

Goodacre, C.; Sharples, S.; Smith, P. 2002. Integrating energy efficiency with the social agenda in sustainability, Energy and Buildings 34(1): 53-61.

Gorgolewski, M. 1995. Optimizing Renovation Strategies for Energy Conservation in Housing, Building and Environment 30: 583-589.

Ham, M.; Wouters, R. 2006. [interactive]. The Comprehensive Housing Renovation Approach. The 23rd Conference on Passive and Low Energy Architecture, Geneva, Switzerland, 6-8 September 2006. Available at: http://www.unige.ch/cuepe/html/ plea2006/Vol2/PLEA2006_PAPER220.pdf [viewed on 15 October 2008]

Hatush, Z.; Skitmore, M. 1997. Contractor Selection Using Multicriteria Utility Theory: An Additive Model, Building and Environment 33(2-3): 105-1 15. 
Holt, G, D.; Olomolaiye, P. 0.; Harris, F. C. 1993. A conceptual alternative to current tendering practice, Building Research and Information 21(3): 167-172.

Housing and Health 2002. [interactive]. The World Health Organization (WHO) project. [viewed on December 15, 2002]. Available on the Internet: http://www.vilnius.lt/ new $/$ vadovybe.php?open $=41 \& w n=39 \& y=2003$.

Ignatavičius, Č. 2004. Pastatų konstrukcijos. Rekomendacijos būsto ir gyvenamosios aplinkos renovacijai [Building Structures. Guidelines for Renovation of Dwellings and Residential Environment]. The Municipal Company "Vilniaus planas", pp. 135-179. (in Lithuanian)

Ignatavičius, Č. 2009. Stambiaplokščių namų natūriniai tyrimai, išvados ir rekomendacijos namų modernizavimui: Mokslo darbo ataskaita [Large-panel Buildings: Experimental Research, Conclusions and Recommendations for their Modernisation. Research report] 100 p. (in Lithuanian)

Ignatavičius, Č.; Zavadskas, E.K.; Ustinovičius, L. 2008. Modernization of large-panel houses in Vilnius, in The 9th international conference: Modern building materials, structures and techniques, May 16-18, 2007 Vilnius, Lithuania 1: 258-264.

Indoor climate analysis 2006. [interactive]. DSSRE, Vilnius Gediminas Technical University. . [viewed on December 13, 2006]. Available on the Internet: http://dss. vtu.lt/realestate

International Energy Agency (IEA) 2008. [interactive]. Energy consumption by sector. Available at: http://www.eia.doe.gov/emeu/aer/pdf/pages/sec2.pdf [viewed on 21 December 2009]

Jo, W.J.; Sohn, J.Y. 2009. The effect of environmental and structural factors on indoor air quality of apartments in Korea, Building and Environment 44(9): 1794-1802.

Johansson, P.; Nylander, A.; Johnsson, F. 2007. Primary energy use for heating in the Swedish building sector-Current trends and proposed target, Energy Policy 35(2): 1386-1404.

Juan, Y. K.; Gao, P.; Wang, J. 2010. A hybrid decision support system for sustainable office building renovation and energy performance improvement, Energy and Buildings 42(3): 290-29.

Juknys, R. 2008. Nacionalinės darnaus vystymosi strategijos igyvendinimo ataskaita 2005-2007. Vilnius [Report of National Strategy for Sustainable Development 20052007]. [interactive] [viewed on December 3, 2010]. Available on the Internet: http:// www.am.lt/VI/article.php3?article_id $=5502$

Juozaitienè, J. 2007. Daugiabučių gyvenamųjų namų padètis Lietuvoje [Situation of Apartment Houses in Lithuania]. The conference proceedings from the conference "The State and Consumers are in Charge of Heating Expenditures", 7 November 2007. Available at: http://www.lsta.lt/files/events/1_j.juozaitiene.ppt.pdf [viewed on 23 April 2010] (in Lithuanian)

Jurelionis, A.;Isevičius, E. 2008. CFD predictions of indoor air movement induced by cold window surfaces, Journal of Civil Engineering and Management 14(1): 29-38.

Juškevičius, P. 2005. Quality of Life and Sustainable Development in Urban Design, Urbanistika ir architektūra 29(4): 174-181. (in Lithuanian) 
Kaklauskas A.; Zavadskas E. K.; Šaparauskas J. 2009. Conceptual modelling of Sustainable Vilnius Development, Technological and economic development of economy 15(1): 154177.

Kaklauskas, A.; Zavadskas, E. K.; Raslanas, S. 2005. Multivariant design and multiple criteria analysis of building refurbishments, Energy and Buildings 37: 361-372.

Kaklauskas, A.; Zavadskas, E. K.; Raslanas, S.; Ginevicius, R.; Komka, A.; Malinauskas, P. 2006. Selection of low-e windows in retrofit of public buildings by applying multiple criteria method COPRAS: A Lithuanian case, Energy and Buildings 38: 454-462.

Kaklauskas, A.; Zavadskas, E.K.; Raslanas, S.; Gulbinas, A. 2004. Multiple criteria decision support web-based system for building refurbishment. Energy for buildings: proceedings of the 6th International Conference, October 7-8, 2004, Vilnius, Lithuania, pp. 284-291.

Kaminski, A. 2008. Visuomeninių pastatų atnaujinimas pagal darnos principus [Refurbishment of Public Buildings According to Sustainability Principles]. Daktaro disertacija, VGTU, Technologijos mokslai, Statybos inžinerija (02T).

Karvelis, H.; Zubrus, V.; Krūminis, B. 1998. Stambiaplokščių gyvenamųjų namų renovacija. Pirmosios kartos stambiaplokščių gyvenamujų namų atnaujinimo techniniai sprendimai [Renovation of Large-panel Residential Houses. Technical Solutions for Renovation of First Generation Large-panel Residential Buildings]. The Ministry of Environment of the Republic of Lithuania. Vilnius. (in Lithuanian)

Kavgic, M.; Mavrogianni, A.; Mumovic, D.; Summerfield, A.; Stevanovic, Z.; DjurovicPetrovic, M. 2010. A review of bottom-up building stock models for energy consumption in the residential sector, Building and Environment 45(7): 1683-1697.

Kazakevičius, E.; Vitkauskas, A.; Mikkelsen, S.E. 2002. Lithuanian energy efficiency project, Energy Policy 30(7): 621-627.

Kendall, M.G. 1970. Rank Correlation Methods. 4-th ed. Griffin, London.

Kulakauskas, J.; Ruseckas, D.; Grabauskas, M.; Sinkevicius, L. 2004. Recommendations on renovation of dwellings and their environment, Municipal Administration of the City of Vilnius, Department of Urban Development, Vilnius (in Lithuanian)

Kusuda, T. 2001. Building environment simulation before desk top computers in the USA through a personal memory, Energy and Buildings 33(4): $291-302$.

Liias, R. 1998. Housing stock: the facilities for future development, Facilities 16(11): 288-294.

Lithuanian hygienic standard HN 42: 2004: The microclimate in residential and administrative buildings, Ministry of Public Health of Lithuania (in Lithuanian). [interactive]. [viewed on December 15, 2004]. Available on the Internet: http:// www3.lrs.lt/c-bin/getgr?C1 = bin\&c2 $=236900 \& c 3=6828$

Lloyd, C.R.; Callau, M.F.; Bishop, T.; Smith, I.J. 2008. The efficacy of an energy efficient upgrade program in New Zealand, Energy and Buildings 40(7): 1228-1239.

LR Aplinkos Ministerija 2007. LR Aplinkos Ministro 2007 m. gruodžio 21 d. i̇sakymas Nr. D1-694 „Dèl atskirujų rekreacinès paskirties želdynų plotų normų ir priklausomųjų želdynų normų (plotų) nustatymų tvarkos aprašo patvirtinimo" [The order No. D1694 "On Approval of the Procedure for Setting of Norms Defining the Size of Separate 
Recreational Green Spaces and Mandatory Norms (Sizes) of Green Spaces" of the Minister of Environment of the Republic of Lithuania of 21 December 2007]. Valstybes žinios 137-5624. (in Lithuanian)

LR Aplinkos Ministerija 2008. [The Ministry of Environment of the Republic of Lithuania]. Statybos strategija UAB. Atskirų gyvenamujjų rajonų (kvartalų) modernizavimo investicijų programų finansavimo ir privačių investuotojų dalyvavimo jose galimybių studija, pasiūlymai ekonominiam jų skatinimui ir teisiniam reglamentavimui [Feasibility Study on Funding of Investment Programmes for Modernisation of Separate Residential Areas/Blocks and on Possibilities To Involve Private Investors, Suggestions For Economic Promotion and Legal Regulation]. [interactive] Available at: http://www.am.lt/VI/files/0.149606001265185876.pdf [viewed on 12 May 2010] (in Lithuanian)

LR Aplinkos Ministerija 2009. [The Ministry of Environment of the Republic of Lithuania]. „Miestų, miestelių ir kaimų (gyvenamųjų vietovių) planavimo normos“. Projektas Nr. VP 08-83 [Norms for Planning of Cities, Towns and Villages (settlements). Project No. VP 08-83]. Municipal Company "Vilniaus planas". (in Lithuanian)

LR Vyriausybè 2008a. [the Government of the Republic of Lithuania]. Valstybès paramos daugiabučiams namams modernizuoti teikimo ir investicijų projektų energinio efektyvumo nustatymo taisyklès (Regulations on State Support for Modernisation of Apartment Buildings and Determination of Energy Efficiency in Investment Projects). Approved by the Resolution No. 1213 of the Government of the Republic of Lithuania of 23 September 2004 (the new version set in the Resolution No. 243 of the Government of the Republic of Lithuania of 5 March 2008). Valstybès žinios 36-1282. (in Lithuanian)

LR Vyriausybė 2008b. LR Vyriausybės Ministro Pirmininko 2008 m. sausio 8 d. potvarkiu Nr.7 sudarytos darbo grupès pasiūlymai, kiti veiklos rezultatai. II-asis urbanistinis forumas. „Darnioji plètra teritorijų planavime ir urbanistikoje“ [Suggestions of the group formed by the decree No. 7 of the Prime Minister of the Republic of Lithuania of 8 January 2008 and other results of its activities. The Second Urbanisation Forum "Sustainable Development in Planning and Urbanisation"].

LR Vyriausybė 2009. Nacionalinè darnaus vystymosi strategija [National Strategy for Sustainable Development]. Approved by the Resolution No. 1160 of the Government of the Republic of Lithuania of 11 September 2003 (the new version set in the Resolution No. 1247 of the Government of the Republic of Lithuania of 16 September 2009). [interactive]. Available at: http://www.am.lt/VI/index.php\#a/8084 [viewed on 28 May 2010] (in Lithuanian)

LRS 2000. LR Civilinio kodekso patvirtinimo, įsigaliojimo ir igyvendinimo įstatymas [The Law on Approval, Entering into Force and Implementation of the Civil Code of the Republic of Lithuania]. 18 July 2000. No. VIII-1864. Current Edition: 16/12/2008. Valstybės žinios, 06/09/2000, No. 74-2262.

LRS 2010. LR Teritorijų planavimo įstatymas Nr. I-1120 [The Law of the Republic of Lithuania on Territorial Planning No. I-1120], current edition: 01/01/2010.

Mäkinen, S. 2003. Pilot project of lifetime design of asphalt concrete in Finnish road administration, Integrated life-time engineering of buildings and civil infrastructures, pp. $403-408$. 
Maliene, V.; Alexander, K.; Lepkova, N. 2008. Facilities management development in Europe, International Journal of Environment and Pollution 35(2-4): 171-184.

Martinaitis, V.; Kazakevičius, E.; Vitkauskas, A. 2007. A two-factor method for appraising building renovation and energy efficiency improvement projects, Energy Policy 35(1): 192-201.

Martinaitis, V.; Rogoza, A. 2001. Technological model of building life cycle, Statyba, Journal of Civil Engineering and Management 7(1): 73-77.

Martinaitis, V.; Rogoza, A.; Bikmanien, I. 2004. Criterion to evaluate the "twofold benefit" of the renovation of buildings and their elements, Energy and Buildings 36: 3-8.

McDonald, S.; Malys, N.; Malienè, V. 2009. Urban regeneration for sustainable communities: a case study, Technological and economic development of economy 15(1): 49-59.

Medineckienè, M.; Turskis, Z.; Zavadskas, E. K. 2010. Sustainable construction taking into account the building impact on the environment, Journal of Environmental Engineering and Landscape Management 18(2): 118-127.

Melchert, L. 2007. The Dutch sustainable building policy: A model for developing countries? Building and Environment 42(2): 893-901.

Metropolitan Washington Airports Authority 2003. Contracting Manual, Washington.

Mickaitytė, A.; Zavadskas, E. K.; Kaklauskas, A.; Tupėnaitė, A. 2008. The Concept Model of Sustainable Buildings Refurbishment, International journal of strategic property management 12(1): 53-68.

Mitkus, S. 2001. Public procurement of construction work: a bimatrix game model, Statyba, Journal of Civil Engineering and Management 7(4): 334-338.

Mitkus, S.; Šostak, O. R. 2009. Preservation of Healthy and Harmonious Residential and Work Environment during Urban Development, International journal of strategic property management 13(4): 339-357.

Naaranoja, M.; Uden, L. 2007. Major problems in renovation projects in Finland, Building and Environment 42(2): 852-859.

Naimavičienè, J.; Mickaitytè, A. 2007. Analysis, modelling and forecasting of housing in Lithuania: special emphasis on energy efficiency. The 7th international conference "Reliability and statistics in transportation and communication" (RelStat-07), 24-27 October 2007, Riga, Latvia: proceedings. Riga: Transport and Telecommunication Institute, pp. 270-278.

Narvydaitè, M. 2008. Darni plètra: iššūkis ar rožinė svajonė? [Sustainable Development: Challenge or Wishful Thinking?]. [interactive]. Available at: http://www.delfi.lt/ news/economy/realestate/article.php?id = 18686240 [viewed on 19 December 2009]

$\mathrm{Ng}$, S. T.; Skitmore, R. M. 1999. Client and consultant perspectives of pre-qualification criteria, Building and Environment 34: 607-621.

Ofori, G. 1998. Sustainable construction: principles and framework for attainment comment, Construction Management and Economics 16: 141-145.

Otto, J. 2008. Implementation of future service requirements in building management, International Journal of Environment and Pollution 35(2-4): 265-274. 
Parasonis, J.; Ambrasas G. 1995. An analysis of factors for the selection of a solution version in thermal renovation of buildings, Statyba, Journal of Civil Engineering and Management 4(4): $67-74$.

Pérez-Lombard, L.; Ortiz, J.; Pout, Ch. 2008. A review on buildings energy consumption information, Energy and Buildings 40(3): 394-398.

Pikutis, R.; Seduikyte, L. 2006. Estimation of the effectiveness of renovation work in Lithuanian schools, Journal of Civil Engineering and Management 12(2): 163-168.

Pollington, Ch. 1999. Legal and procurement practices for sustainable development, Building Research \& Information 27(6): 409-411.

Power, A. 2008. Does demolition or refurbishment of old and inefficient homes help to increase our environmental, social and economic viability? Energy Policy 36(12): 4487-4501.

Projekt Großsiedlungen 1996. Rucksaldruck, Berlin. 68 p.

Raslanas, S.; Palubinskas, V.; Tupènaitė, L. 2003. Rekomendacijos Vilniaus daugiabučio būsto renovacijai nekilnojamojo turto vertès požiūriu [Recommendations for Retrofit of Apartment Houses in Vilnius from the Perspective of the Real Estate Value]. VGTU. Vilnius. $185 \mathrm{p}$.

Raslanas, S.; Palubinskas, V.; Tupènaitè, L. 2004. Nekilnojamo turto vertè. Rekomendacijos būsto ir gyvenamosios aplinkos renovacijai [Real Estate Value. Guidelines for Renovation of Dwellings and Residential Environment]. Municipal company "Vilniaus planas". pp. 25-50.

Raslanas, S.; Tupenaite, L.; Steinbergas, T. 2006. Research on the prices of flats in the South East London and Vilnius, International Journal of Strategic Property Management 10(1): 51-63.

Reichelt, B. 2006. Maintenance strategy for municipal buildings from the viewpoint of facility management, Technological and economic development of economy 12(3): 236-245.

Reichelt, B.; Melnikas, B.; Vilutiene, T. 2008. The model for selection of a maintenance strategy for municipal buildings, International Journal of Environment and Pollution 35(2-4): 219-236.

Roberts, S. 2008. Altering existing buildings in the UK, Energy Policy 36(12): 4482-4486.

Rosenfeld, Y. Shohet, I. M. 1999. Decision support model for semi-automated selection of renovation alternatives, Automation in Construction 8: 503-510.

Roulet, C. A.; Flourentzou, F.; Santamouris, M.; Koronaki, I.; Dascalaki, E.; Richalet, V. 2002. ORME: A multicriteria rating methodology for buildings, Building and Environment 37: 579-586.

Saidur, R.; Masjuki, H.H.; Jamaluddin, M.Y. 2007. An application of energy and exergy analysis in residential sector of Malaysia, Energy Policy 35(2): 1050-1063.

Šaparauskas, J. 2001. The Idea and Approach of Sustainable Construction and Environment Development in Various Countries, Technological and Economic Development of Economy 7(1): 20-23. 
Saporito, A.; Day, A. R.; Karayiannis, T. G.; Parand, F. 2001. Multi-parameter building thermal analysis using the lattice method for global optimisation, Energy and Buildings 33(3): $267-274$.

Sartori, I.; Wachenfeldt, B. L.; Hestnes, A. G. 2009. Energy demand in the Norwegian building stock: Scenarios on potential reduction, Energy Policy 37(5): 1614-1627.

Sasi, L.; Hääl, K. 2002. [interactive]. Renovation, Indoor Climate and Energy Saving in Multi-Storey Apartment Building in Estonia. Building Physics 2002 - 6th Nordic Symposium. Available at: http://www.ivt.ntnu.no/bat/bm/buildphys/ proceedings/135_Sasi.pdf [viewed on 19 January 2009]

Seduikyte, L.; Bliudzius, R. 2005. Pollutants emission from building materials and their influence on indoor air quality and people performance in offices, Journal of Civil Engineering and Management 11(2): 137-144.

Šeduikytè, L.; Jurelionis, A. 2009. Analysis of the Refurbishment Process in Lithuania in Terms of Sustainable Development. 5th International Vilnius Conference "KnowledgeBased Technologies and OR Methodologies for Strategic Decisions of Sustainable Development" September 30-October 3, 2009, Vilnius, Lithuania. pp. 175-180.

Siller, T.; Kost, M.; Imboden, D. 2007. Long-term energy savings and greenhouse gas emission reductions in the Swiss residential sector, Energy Policy 35(1): 529-539.

Šimkus, R.; Stankevičius, V.; Karbauskaitè, J. 2002. Bendrujų pastato šilumos nuostolių analizè ir ịvertinimas bei jų paskirstymo butams metodikos sudarymas (5 a. gyvenamųų namų pavyzdžiu): Mokslinio tyrimo darbo ataskaita [Analysis and Assessment of General Heat Loss in Buildings and Formulation of the Methodology for Distribution of such Loss among Flats (a case of five-storey buildings). Research report]. Kaunas, 28 p. (in Lithuanian)

Sitar, M.; Korošak, D.; Krajnc, K. 2006. [interactive]. The Existing Housing Stock - New Renovation Possibilities; A Case of Apartment Building Renewal in Maribor. Paper presented at the ENHR conference "Housing in an expanding Europe: theory, policy, participation and implementation" Ljubljana, Slovenia July 2-5. Available at: http:// enhr2006-ljubljana.uirs.si/ [viewed on 19 October 2008]

Sobotka, A. 1998. Sustainable development in the practice of building resources renovation, Facilities 16(11): 319-325.

STR 2.02.01:2004 „Gyvenamieji pastai“ [Residential Buildings. The order No. 705 of the Minister of Environment of the Republic of Lithuania approving the construction technical regulation]. 2004. Valstybès žinios 23-721.

STR 2.02.09:2005 „Vienbučiai gyvenamieji pastatai“ [Single-family Houses. The order No. D1-338 of the Minister of Environment of the Republic of Lithuania approving the construction technical regulation]. 2005, Valstybès žinios 93-3464.

STR 2.05.01:2005 „Pastatų atitvarų šiluminė technika“ [Thermal Techniques of Building Envelopes. The order No. Nr. D1-156 of the Minister of Environment of the Republic of Lithuania approving the construction technical regulation]. 2005, Valstybès žinios Nr. 100-3733.

Šulcienè, I. 2008. Viešasis interesas per aiškias normas [Public Interest through Clear Norms]. [interactive]. Available at: http://www.spec.lt/lt/Viesasis_interesas_per_ aiskias_normas [viewed on 20 January 2010] 
Swan, L. G.; Ugursal, V. I. 2009. Modeling of end-use energy consumption in the residential sector: A review of modeling techniques, Renewable and Sustainable Energy Reviews 13(8): 1819-1835.

The amendment to Public Purchasing law of Lithuanian Republic adopted on December 3, 2002. Vilnius, Valstybes zinios Nr. IX 1217.

The Lithuanian Housing Strategy, Ministry of Environment of the Republic of Lithuania 2004. [interactive]. [viewed on December 15, 2004]. Available on the Internet: www. am.lt/VI/en/VI/article.php3?article_id $=78$

Tommerup, H.; Svendsen, S. 2006. Energy savings in Danish residential building stok, Energy and Buildings 38(6): 618-626.

Tupenaite, L.; Zavadskas, E.K.; Kaklauskas, A.; Turskis, Z.; Seniut, M. 2010. Multiple criteria assessment of Alternatives for Built and Human Environment Renovation, Journal of Civil Engineering and Management 16(2): 257-266.

Turskis, Z.; Zavadskas, E.K.; Zagorskas, J. 2006. Sustainable city compactness evaluation on the basis of gis and bayes rule, International Journal of Strategic Property Management 10(3): 185-207.

Uihlein, A.; Eder, P. 2010. Policy options towards an energy efficient residential building stock in the EU-27, Energy and Buildings 42(6): 791-798.

Užšilaitytė, L.; Martinaitis, V. 2010. Search for optimal solution of public building renovation in terms of life cycle, Journal of Environmental Engineering and Landscape Management 18(2): 102-110.

Vilniaus miesto 2002-2011 metų strateginis planas [The Strategic Plan of the City of Vilnius for 2002-2011]. [interactive]. Patvirtintas Vilniaus miesto savivaldybès tarybos $2002 \mathrm{~m}$. birželio 19 d. sprendimu Nr. 607 [Approved by the Resolution No. 607 of the Board of Vilnius City Municipality on 19 June 2002]. Available at: http:// www.vilnius.lt/vmsp/ [viewed on 06 November 2009]

Vilnius City Strategic Plan 2002-2011, Municipal Administration of the City of Vilnius, Department of Urban Development, 2003. [interactive]. [viewed on December 10, 2003]. Available on the Internet: http:// www.vilnius.lt/vmsp/en

Viteikienè, M.; Zavadskas, E.K. 2007. Evaluating the Sustainability of Vilnius City Residential Areas, Journal of Civil Engineering and Management 13(2): 149-155.

Wedding, G. C.; Crawford-Brown, D. 2007. Measuring site-level success in brownfield redevelopments: A focus on sustainability and green building, Journal of Environmental Management 85(2): 483-495.

Zavadskas, E. K.; Kaklauskas, A.; Gulbinas, A. 2004. Multiple criteria decision support web-based system for building refurbishment, Journal of Civil Engineering and Management 10(1): 77-85.

Zavadskas, E. K.; Kaklauskas, A.; Raslanas, S. 2004a. Evaluation of investments into housing renovation, International Journal of Strategic Property Management 8(3): 177-190.

Zavadskas, E. K.; Kaklauskas, A.; Tupènaitè, L.; Mickaitytè, A. 2008b. Decision-making model for sustainable buildings refurbishment. Energy efficiency aspect, in The 7th International conference Environmental engineering, May 22-23, 2008 Vilnius, Lithuania 2: 894-901. 
Zavadskas, E. K.; Kaklauskas, A.; Turskis, Z. 1997. Multicriteria decision-making system for building refurbishment, Statyba, Journal of Civil Engineering and Management 12(4): $62-68$.

Zavadskas, E. K.; Kaklauskas, A.; Turskis, Z.; Tamošaitienė, J. 2008a. Selection of the effective dwelling house walls by applying attributes values determined at intervals, Journal of Civil Engineering and Management 14(2): 85-93.

Zavadskas, E. K.; Raslanas, S.; Kaklauskas, A. 2008c. The selection of effective retrofit scenarios for panel houses in urban neighborhoods based on expected energy savings and increase in market value: The Vilnius case, Energy \& Buildings 40(4): 573-587.

Zavadskas, E.K.; Kaklauskas, A.; Kvedaryte, N. 2001. Multivariant design and multiple criteria analysis of a building life cycle, Informatica 12(1): 169-188.

Zavadskas, E.K.; Kaklauskas, A.; Sarka, V. 1994. The New Method of Multicriteria Complex Proportional Assessment of Projects, Technological and Economic Development of Economy 1(3): $131-139$.

Zavadskas, E.K.; Kaklauskas, A.; Vilutienè, T. 2009. Multicriteria Evaluation of Apartment Blocks Maintenance Contractors: Lithuanian Case Study, International Journal of Strategic Property Management 13(4): 319-338.

Zavadskas, E.K.; Raslanas, S.; Kaklauskas, A. 2008d. The selection of effective retrofit scenarios for panel houses in urban neighborhoods based on expected energy savings and increase in market value: The Vilnius case, Energy \& Buildings 40(4): 573-587.

Zmeureanu, R.; Fazio, P.; DePani, S.; Calla, R. 1999. Development of an energy rating system for existing houses, Energy and Buildings 29(2): 107-119.

Zöld, A.; Csoknyai, T. 2005. [interactive]. Refurbishment of blocks of flats. Available at: http://web.byv.kth.se/bphys/reykjavik/pdf/art_055.pdf [viewed on 10 February 2010] 


\section{CHAPTER 4}

\section{SUSTAINABLE DEVELOPMENT OF ENERGY SECTOR WITH EMPHASIS ON SOCIAL ASPECTS}

\section{Jūratė ŠLIOGERIENĖ}

Comprehension of the effect of energy generation technologies on the natural environment, human health and safety leads to a new and responsible approach to the choice and development of technologies. Although the issues predominant in the concept of sustainable energy development are economic and environmental ones, the changing environment necessitates a new approach towards the impact of social systems on the industry and demands for a more profound assessment of the role this aspect plays. Social development obeys the laws of sociology, thus energy policies must be established and solutions of technological development that meet societal needs must be found always making sure that the impact on social processes has been considered and public attitudes, values, sentiments towards development decisions, and the right of self-determination have been respected. Values culture, cultural identity, ethics, beliefs, religion, education, weight of social institutes and other can make an important impact on decisions related to the development of energy generation technologies, or even be the determining factor.

\subsection{Sustainable development of the energy sector}

By the late 20th century, efforts of the world's scientific community and activist organisations succeeded in drawing attention to climate change processes caused by unrestrained national economic development, unsustainable natural resource use and growing air pollution emissions. Climate change and the deterioration of the environment damage human health and ecosystems, and are destroying established ethnocultural lifestyle values. In the early 1980s, the United Nations introduced a new approach to national development and the notion of sustainable development emerged, with an aim to reconcile the needs of economic development and environmental protection. Sustainable development is a complex concept that seeks to define all areas of human activity and human actions both globally and locally. Although the concept of sustainability is now essential to various debates and the political life, a yawning gulf still separates goals and realities at the economic and social level (Baumgartner 2011; Lorek, Spangenberg 2014). 
The most common explanation of the concept of sustainability lists three fundamental dimensions: economic, environmental and social. Scientists point out that no desired level of either economic or ecological or social sustainability can be achieved individually if at least minimum sustainability is not simultaneously ensured in each dimension (Vallance et al. 2011; Koh 2011; Goosen 2012; Lorek, Spangenberg 2014).

Academic literature examines and interprets political, economic, social and philosophical components of the concept of sustainability from various angles. A more general interpretation of the concept can be that it means adhering to the following fundamental principles in various areas of public life (Lafferty, Meadowcroft 2000; Robinson 2004; Sneddon et al. 2006; Hugé et al. 2011):

- global responsibility in efforts to address global social and ecological issues;

- integration, which means an interaction between ecological, social and economic factors and their integration to solve development problems;

- equality between generations by also ensuring the needs of future generations;

- the alleviation of existing social differences between and within countries;

- caution, which is understood as an argument that lack of scientific evidence cannot be grounds to refrain from measures that prevent environmental deterioration;

- engagement, which means that all stakeholders are involved in sustainable development decisions.

Although the notion of sustainable development is used in virtually all areas of life, its understanding is a shade different in various sectors. Economics understands sustainable development as an obligation to leave future generations at least not worse off than we are today to meet their needs and seek prosperity. Environmental protection sees it as efforts to conserve natural resources and biodiversity and cut pollution. In social area, the main goal is to preserve social prosperity, education, culture, social connections and ethnic distinctions. The interaction between these dimensions rests on the principle of equity between generations, nations and social groups. The principle of equity is fundamental to the development of democratic processes and to the engagement of the public and public institutions in important decision-making processes that drive national development.

Interestingly, explanations of the concept of sustainability emphasise the social aspect in each component of sustainability. But both in academic literature and in different development studies the social dimension of sustainable development itself is not as much analysed as the economic or environmental ones. Despite economic growth and our progress in environmental protection, social development issues are the most challenging task. Social development does not always respond to simulated solutions or economic development schemes; it 
often relies on such subjective factors as beliefs, cultural specifics, traditions, palatability of information and so on. All industries and their sustainable development must be examined from the social perspective as well; development models should look at indicators that describe the angle of social considerations and values and their role (Rotmans 2006; Hugé et al. 2011; Bečić et al. 2012).

In efforts to achieve sustainable development, the energy sector's development issues play an outstanding role. This, first of all, is a prerequisite for economic viability, energy supply to the public and access to modern technologies. At the same time this means the issues of reckless consumption of natural resources, consequences of pollution, and climate change. This also means our obligation to preserve resources for future generations, alleviation of energy poverty, ethic treatment of consumers, and civic spirit in important decisions on the sector's development. Although the role of the value aspect is plainly understood, academic literature that investigates energy industry environment and sustainable development issues often rather disregards the aspect of social considerations and values. B. K. Sovacool (2014) has analysed 9,597 academic publications on energy from the past 15 years and points out that only 19.6\% of them fall in the field of social sciences and only $1.9 \%$ discuss issues of energy policies. Barely $0.9 \%$ of publications discuss sociology issues of the energy sector and only $0.3 \%$ investigate psychology, communication and gender equality. The importance to expand social studies in the energy sector is emphasised by G. Assefa and B. Frostell (2007), S. Rayner (2009), D. A. Shepherd, V. Kuskova and H. Holger Patzelt (2009), D. Gallego Carrera and A. Mack (2010), E. V. Hobman and P. Ashworth (2013), and other authors.

This chapter discusses the social aspect of the energy sector and analyses its role both in the sector's development and in national economic development. It highlights the place of the social/value aspect and values in the energy sector's value creation.

\subsection{Infrastructure of the energy industry and its economic significance}

The energy industry is a complex field of the economy, having huge impacts on a country's economics, dynamics of growth, rational distribution of investments and payment balance. It covers several interrelated systems: electrical power industry, production and supply of central heating/cooling and supply of primary energy sources - oil and its products, natural gas, etc. These are the areas that consume most of energy resources. The key consumers of primary energy resources are the sectors of electrical energy production and central heating/cooling.

Expenses for building the energy industry infrastructure, export and import of energy resources and their processing products and energy prices for the 
end user have very strong influence on the development of economies, making tendencies of economic indicators for the energy sector the primary index of an economy's future development. The energy industry with its specific technological, economic, social, ecological and other aspects is closely integrated into the key areas of social life: politics, education, science, economic and social spheres, and environmental protection. The economic community of today's countries is undergoing rapid integration and forming a single economic system, where energy industry's infrastructure is becoming a component part and linking element of the economy. Due to its exceptional significance for the economic and social systems, performance of energy systems is the object of state regulation in many countries.

Energy sector enterprises have one common feature: they perform a very specific function within a particular territory, using a complex infrastructure that has been specially built for them. Infrastructures of energy industry enterprises are created during the long-time process of their performance and make up the major part of the structure of the enterprise's capital. Due to big capital investments, it is not so simple to compete with these enterprises, and in most cases, such competition would not be a well-reasoned deal. In most territories or regions, energy industry enterprises operating there serve the needs of the economy and residents of this particular territory. However, significant shifts in the European Union's energy policy, application of market tools within the energy industry, development of renewable resource technologies and investments by private capital into the infrastructure call for fundamental changes to the energy industry. The goals outlined for reforming the energy industry provide measures for establishing competition, ensuring transparency of activities, availability of resources, secure supply and lesser reliance on external suppliers (Sliogeriene 2014).

Due to an insufficiently developed infrastructure, the supply tends to be very limited, systemic failures occur and there are delays in meeting growing industrial and consumer demands. For that reason, the focus of energy enterprises should be on building and developing purpose specific infrastructures and more active application of multiple forms of ownership, thus increasing concentration of capital resources and achieving higher levels of performance efficiency. The Energy Commission of the European Union holds the view that the level of investments into infrastructures of electricity transmission networks in EU Member States is insufficient, which, in its turn, makes return of investments into networks low. EU promotes development of the infrastructure by financing projects for trans-European electricity networks. It is a common consideration that in order to achieve effective management of the energy industry, the main focus should be on management of energy demand and measures promoting investments into the infrastructure, namely trans-border connections, which 
are sole prerequisite for successful operation of the EU's internal energy market (Bacauskas 1999). The total budget of the European Grid Infrastructure for 2014-2020 will be 50 billion EUR, from which 9.1 billion EUR will be allocated for the development of the energy infrastructure.

The most effective means to balance out fluctuations in energy production, i.e. its lack or excess (particularly when renewable resource technologies are applied), is more extensive integration into international energy systems. This makes energy industry systems to associate themselves into systemic alliances - both physically and from the management point of view. Managers of 36 transmission systems operators (TSO) from 31 countries signed a declaration in Prague in 2008 concerning the establishment of ENTSO-E (The European Network of Transmission System Operators for Electricity). ENTSO-E seeks to harmonise efforts of TSOs in creating a single European energy market. As far back as in 2009, ENTSO-E comprised 42 transmission systems operators from 34 countries, covering 5 synchronic zones, including Baltic states. The goal is closer partnership between energy systems in creating a single European energy market. Naturally, physical laws which regulate functioning of energy industry systems remain the same: the final integration will be achieved only after new connections will have joined continental networks and started synchronically functioning within the network of Continental Europe. Today's Europe encounters increase in energy consumption and its potential lack. The more powerful the economic potential of the country, the more energy it produces and consumes. In this framework, in order to achieve economic and social goals targeted at ensuring well-being of the population, our major focus should inevitably be on developing the energy industry. The energy industry is a fundamental part of the whole infrastructure designed for "serving the entire reproduction process and permitting this process" (Webster's 1976). In today's knowledge-based economy, the role of the energy industry is even more increasing: systemic failures in energy systems may damage most of the technologies indispensable for successful functioning of the society. Furthermore, due to the progress of other technology fields, new consumers emerge, e.g. telecommunications and electrical transport means. Almost all the multiple level scenarios for energy industry's development are forecasting increase in electrical energy consumption.

The energy industry is responsible for most of the environmental pollution and carbon dioxide emission into the atmosphere. There are serious environmental protection tasks that the electrical power industry is supposed to face in the future: gradual transition to more efficient and "cleaner" technologies and setting up technical facilities for decreasing carbon dioxide emission within the transport and heating/cooling systems. The need to achieve sustainable development of communities, without negative impacts on the environment, requires conserving energy resources, is a key attitude in finding the most suitable 
solutions to reduce and mitigate climate change. Energy infrastructure and technologies development is significant and absolutely relevant to all regions around the world (Clark, Cooke 2014).

\subsection{Objectives of the sustainable development of the energy industry}

The sustainable development is thus depicted schematically using three circles for the target dimensions of environment, economy and society, to which are added the time (i.e., intergenerational equity) and north-south dimensions (i.e., intragenerational equity), which is illustrated in Figure 4.1. The equal treatment of the three dimensions environment, economy and society is not without controversy. An alternative perspective postulates that human society has to develop within the boundaries set by the environment, and that economy (together with the energy sector) has to satisfy societal needs - not the reverse (NEEDS... 2007).

A large number of studies investigated the relationship between energy consumption, $\mathrm{CO}_{2}$ emission, and economic growth. They confirmed a significant bi-directional causal relationship between energy consumption and growth in the US, African countries, China and other countries. Moreover, there was no evidence of a short long causal relationship from energy consumption per capita and $\mathrm{CO}_{2}$ emission to the GDP per capita (Al-Mulali, Binti Che Sab 2012). Another group of studies found a relationship between energy consumption and economic development. For instance, it were found that the clean and renewable energy consumption significantly increases China's genuine savings, thus, the renewable energy consumption promotes sustainable development ( $\mathrm{Yu}, \mathrm{Qu} 2013$ ).

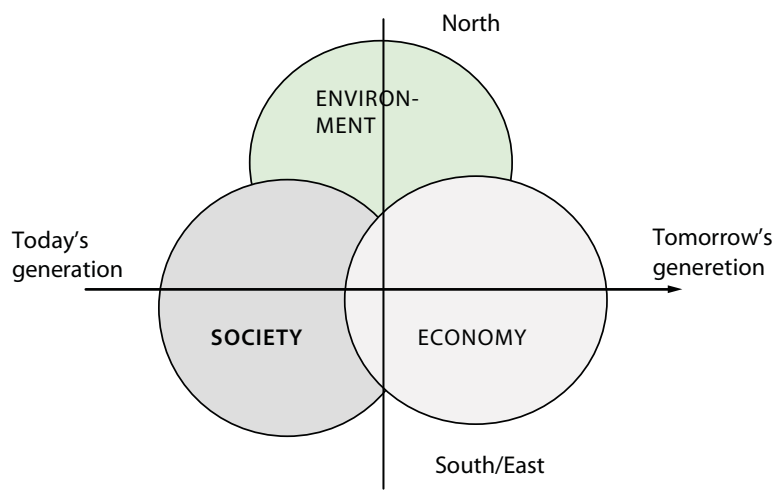

Figure 4.1. Scematic representation of the central aspects of sustainable development (NEEDS... 2007) 
Main environmental, economic and social dimensions are characterized by a number of indicators. Each set of indicators expresses aspects or consequences of the production and use of energy. Taken together, the indicators give a clear picture of the whole system, including interlinkages and trade-offs among various dimensions of sustainable development, as well as the longer-term implications of current decisions and behaviour. The same value for a given energy indicator might not mean the same thing for two different countries. The meaning will depend on the state of development of each country, the nature of its economy, its geography, the availability of indigenous energy resources and so on. The most meaningful Indicators is shown in Figure 4.2.
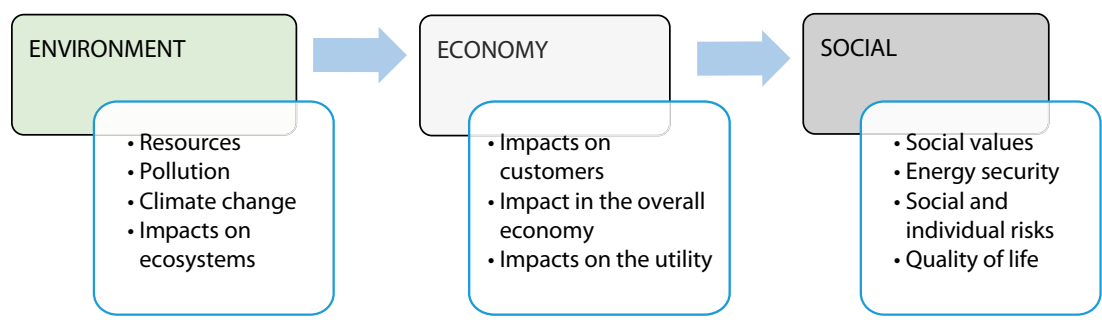

Figure 4.2. Main indicators for sustainability assessment of energy sector

In order to avoid potential catastrophic consequences of global warming the political consensus was established concerning rise of temperature limited to $2^{\circ} \mathrm{C}$ above pre-industrial levels as a global target. The Energy Sector is facing its biggest upheaval. Governments around the globe are discussing the best way to combat climate change. Different mechanisms and policies have been introduced to reach a global carbon dioxide reduction of up to $80 \%$ by 2050 , based on 1990 emission levels.

An energy policy for sustainable development must both meet the growing need for energy, and prevent climate change. The emphasis is centred on:

- the technological development and integration of renewable sources in all aspects of energy supply (storage, distribution, use);

- energy and efficiency savings, including the use of primary renewable energy sources;

- the development of alternative fuels;

- improving transport and storage technology, in particular hydrogen technology;

- reducing $\mathrm{CO}_{2}$ emissions by using cleaner fossil fuel installations.

A large number of technical options have been identified to reduce $\mathrm{CO}_{2}$ emissions worldwide. However due to the significant share of $\mathrm{CO}_{2}$ emissions from the power sector, coupled with the limited number of actors involved in this sector, political pressure has been strongest on the power industry to achieve 
significant emission reductions. Numerous policies are now in place, both at a European and Member State level, designed to achieve the required $\mathrm{CO}_{2}$ emission reductions as agreed in the Kyoto protocol and broken down to country targets within the EU.

In attempts to find the best solutions to satisfy growing energy demands and ensure reliable supply, increasingly prevalent is the idea that technological parameters and economic efficiency are not crucial to guarantee welfare. The most relevant issue in today's energy development is selection of the technologies which are the best for people, rather than the most efficient. Operation and growth of energy systems is very closely related to public needs, security and welfare, hence they cannot be viewed without consideration of relevant important aspects.

Climate change is the dominating environmental concern of the international environmental political discussion of today. Global warming is not only an issue for the environment, but rather for human society as a whole, since rising global temperatures might have serious consequences not only on the environment, but on our economy and social life as well. Among the potential consequences are more frequent extreme weather events like heat waves, storms, floodings and droughts, stress due to higher temperatures for plants and humans, rising sea level, and altering occurrence of pathogenic organisms. The anthropogenic impact on the climate system is due to the emission of $\mathrm{CO}_{2}$ and other greenhouse gases, directly or indirectly caused by human activities. The reduction of $\mathrm{CO}_{2}$ emission is on top of the environmental agenda of the 21st century. Direct $\mathrm{CO}_{2}$ emissions originate e.g. from the combustion of fossil fuels (NEEDS... 2007). At present, district heating alone is responsible for avoiding at least 113 million tons of $\mathrm{CO}_{2}$ emissions per year. This corresponds to $2.6 \%$ of total European $\mathrm{CO}_{2}$ emissions. Special chemical wastes, which have to be stored in underground depositories, pose a potential risk for the environment, even if in case of proper handling these wastes do not cause any environmental burdens. Electricity-only incinerators emit 33 per cent more fossil $\mathrm{CO}_{2}$ than gas power stations, but 40 per cent less than a coal power station. According to the 2009 World Waste Survey, between 3.4 and 4 billion tons of waste are produced each year worldwide. Leading the pack is China, with 300 million tons produced in 2005, followed closely by the United States, with 238 million tons. In Europe, $500 \mathrm{~kg}$ of waste is produced per capita per year for a total of 2 billion tons generated annually, and a growth rate of $10 \%$ in ten years' time. Between two-thirds and three-quarters of these waste materials are sorted, and a portion of them is recycled (Gaillochet 2009). The rest is either carted away to a dumping ground, or incinerated. But this waste is primarily domestic, and still contains energy, energy that can be recovered.

Efforts to implement the provisions of sustainable energy development set forth by a range of EU directives highlight the ties that link the three 
dimensions of sustainable energy. Their implementation requires a combination of different objectives: reliable energy supply, environmental protection, and meeting social needs and overcoming issues caused by fluctuating prices of primary energy resources. But the top imperative of sustainable development is to address the issue of energy supply looming over future generations. The Europe 2020 strategy agreed by the European Commission on 26 March 2010 puts forward five flagship initiatives, which are of primary significance for achieving sustainable development, social cohesion and economic convergence of European nations. One of these initiatives, "20-20-20", is targeted at transforming energy industry systems. The targets to be met by 2020 are the following: reduction of greenhouse gas emissions by $20 \%$, coming of $20 \%$ of the energy consumption from renewable sources and improving energy efficiency by $20 \%$. The Europe 2020 strategy's three climate and energy targets are interrelated and mutually support each other. Energy used for electricity generation, transport and heating and cooling is responsible for the lion's share of the EU's GHG emissions. Therefore, reducing energy use and switching to low-carbon, renewable energy sources are the major levers for cutting emissions (European Commission 2010).The dynamics of the development of renewable energy sources is shown in Figure 4.3.

$25 \%$

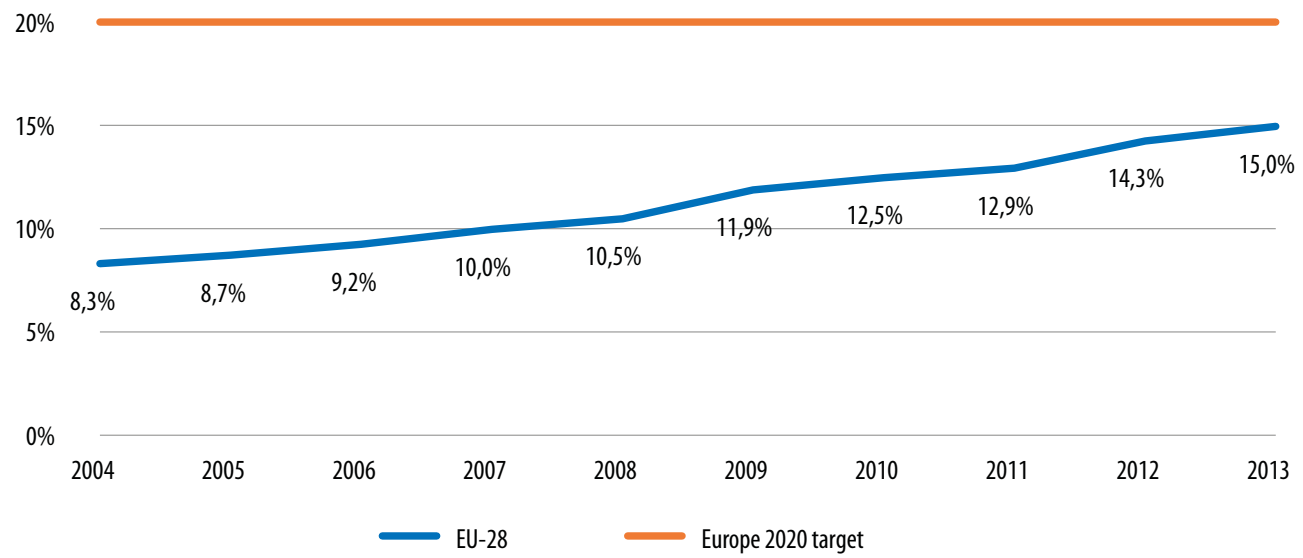

Figure 4.3. Share of renewable energy in gross final energy consumption, EU-28 Source: Eurostat 2014, Renewable energy statistics

Renewable energy sources accounted for more than one third of gross inland consumption of energy in Sweden (37.2\%) and Latvia (36.4\%) in 2012, and their share was over one quarter of the total in Finland (29.2\%) and Austria (30.1\%). The fastest expansion between 1990 and 2012 in the share of renewable energy 
sources in energy consumption was recorded in Latvia, rising by 23.2 percentage points; increases in excess of 10.0 percentage points were also recorded in Denmark, Lithuania, Sweden, Estonia, Romania and Finland 8\%. The latest data shows that electricity generated from renewable energy sources contributed almost one quarter (23.5\%) of the EU-28's gross electricity consumption (Eurostat 2014, Renewable energy statisrics).

Political and regulatory measures are not sufficient for achieving these goals. There should be efforts for modernising the energy sector, accumulating financial resources, attracting and channelling necessary investments, using the scientific potential and entering into a useful dialogue with social partners. The following major activity areas will have to be addressed when transforming and developing energy industry's infrastructure: 1) diversification of energy production sources and ensuring security and technical safety of energy supply; 2) promotion of the use of local resources best corresponding to the natural environment and expansion of the network; 3) implementing means for saving energy and its efficient use; 4) collaboration of the private and public capital, and promotion of private investments into the energy sector; 5) application of new and more effective management models for energy systems.

1. Diversification of energy production technologies. A whole number of countries have been reconsidering their priorities for the energy industry in recent years as a result of their efforts to reduce reliance on ever-pricier imported energy resources and stock, and awareness of negative environmental impacts of fossil fuels. Tangible climate changes, diminishing natural resources, as well as the Chernobyl and Fukushima Daiichi nuclear disasters and their severe outcome, stimulated interest in renewable resource technologies. It has become popular to highlight deficiencies and threats of old fossil fuel-based technologies and emphasise advantages of alternative energy technologies. This tendency is often caused by society's attitude and views, which are not always based on factual information. Such countries as Germany, Japan, Italy and Switzerland, under the pressure of social opinion, no longer use nuclear technologies and have started navigating towards renewable and environmentally friendly power engineering technologies. Still, such solutions do not fit some countries, and for others, they may cause economic burden. There is no reason to entirely deny advantages of nuclear energy technologies, especially for countries which possess limited primary energy resources. Nuclear energy will have its place in the future, as it still serves a as a major source of electrical power with low-carbon emission. In fact, there is no one preferred technology - all of them have certain strengths and weaknesses, and all energy sources are able to compete in the market without any additional support.

Currently, European countries do not possess technologies allowing them to significantly reduce the use of fossil fuels within the energy industry, namely 
the electrical power industry and heating/cooling systems. Fossil fuels account for $77,7 \%$ of the production of primary energy (see Figure.4.4).
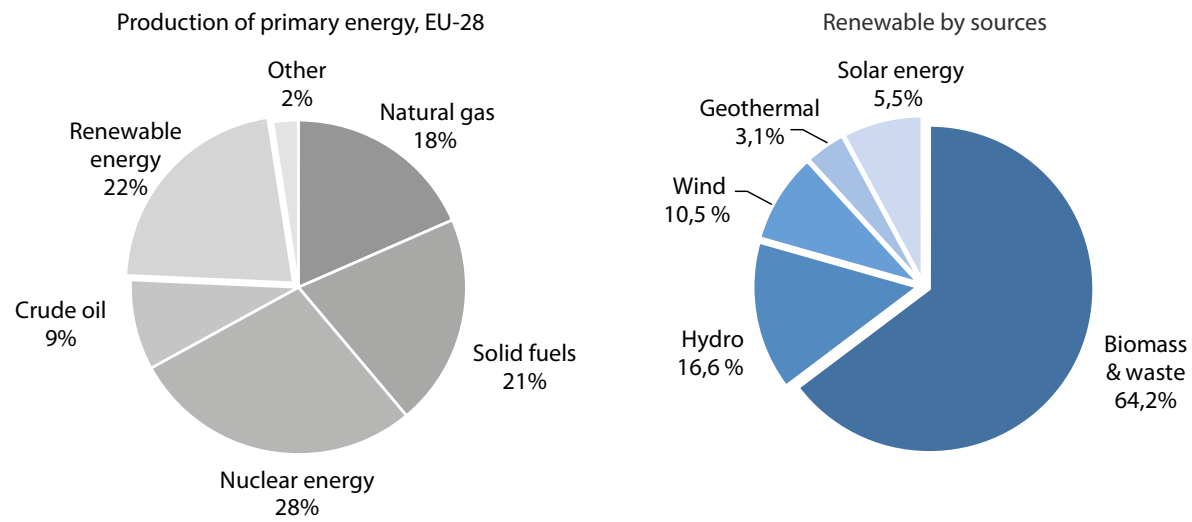

Figure 4.4. Production of primary energy, EU-28, 2013

(\% of total, based on tonnes of oil equivalent)

Source: Eurostat 2014, Energy production and imports

All EU countries have focused their political, economic and technological resources on gradual reduction of the use of fossil fuel technologies and advancement of renewable resource technologies. Governments are devising and implementing various mechanisms motivating designers and manufacturers of new technologies and investors to change their approach to both consumption of energy within production processes and development of power engineering technologies - they are encouraged to create new more energetically efficient and environmentally friendly technologies and enter the market of the changing energy sector. Use of renewables in the electrical power industry does not much exceed 17\%. Figure 4.5 presents the mix of EU's energy sources in 2013.

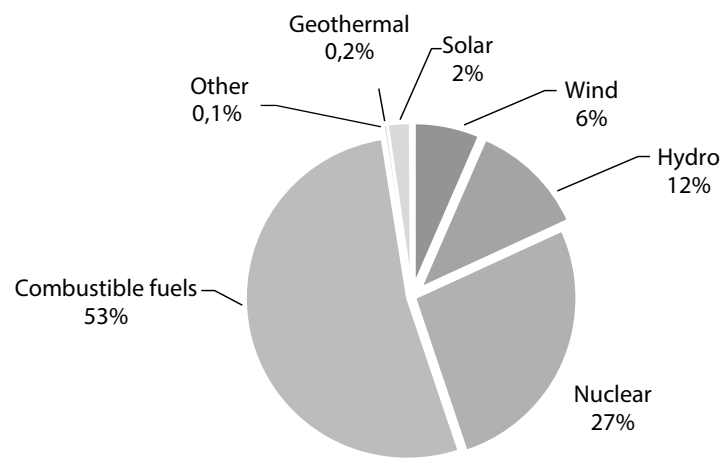

Figure 4.5. The mix of EU's energy sources in 2013 Source: Eurostat 2014, Energy production and imports 
Use of renewable energy resources has a rich potential and may presumably result in supplying comparatively clean and, what is very important, mostly local energy. Despite the fact that technologies for the use of renewables in power engineering are still more expensive than traditional production methods, use of these resources is expanding. Some facilities of wind, small hydro and geothermal energy are starting to compete in wholesale energy markets. Other facilities, such as photodetectors, solar water heaters and biomass, if appropriately subsidised, may provide services in regions with insufficient energy networks. Hydro and wind energy is still predominating within the renewable energy industry.

The highest share of electricity in 2012 was produced in coal fired power plants (27.4\%), followed by nuclear power plants (26.8\%), power plants using renewable sources of energy (24.2\%), gas (18.6\%), oil (2.2\%) and non-renewable waste (0.8\%). Also, nuclear is one of the EU's largest single energy source for power generation, closely of coal at $29 \%$ and ahead of gas at $23 \%$ (Eurostat... 2014).

There have been significant changes in the structure of renewable energy sources used for electricity production. over the last two decades. In 1990, 94\% of renewable electricity was produced from hydro energy, while in 2012 the share of hydro energy was less than half of that. The structure of energy sources used for renewable electricity production shown in Figure 4.6.

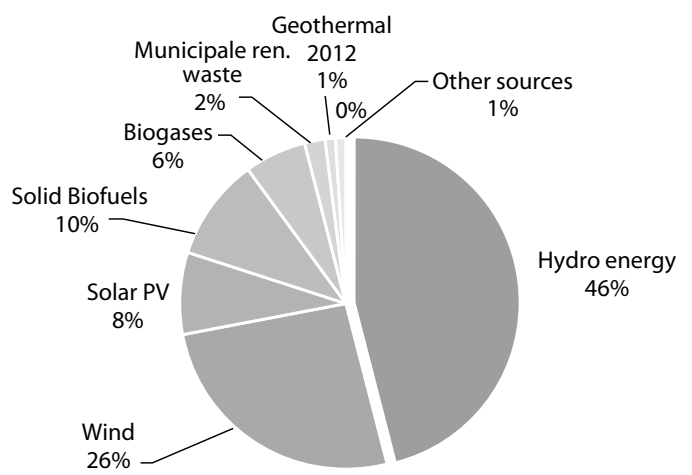

Figure 4.6. The structure of energy sources used for renewable electricity production, in 2012

Source: Eurostat 2014, Energy production and imports

An analysis of the final end use of energy in the EU-28 in 2013 shows three dominant categories: namely, transport (31.6\%), households $(26.8 \%)$ and industry $(25.1 \%)$, see Figure 4.7.

The final consumption of electricity and heat energy by sectors in 2013 is shown in Figure 4.8.

The highest amounts of electricity available for final consumption in industry were used in the chemical and petrochemical industry, iron \& steel industry, 
machinery, paper, pulp and print industry and in food and tobacco (Eurostat... 2014).

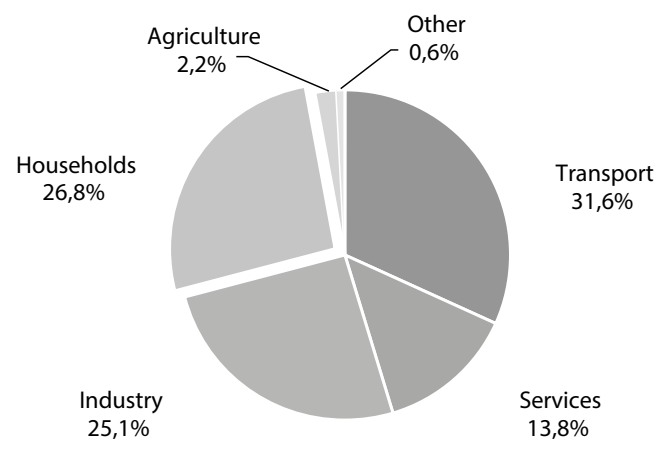

Figure 4.7. Final energy consumption, EU-28, \%

Source: Eurostat 2014, Consumption of energy

An analysis of Eurostat data shows that residential sector is the biggest consumer of energy and also holds the biggest potential to save it. But the implementation of EU directives is gradually giving a tangible result: renewable energy makes an increasingly bigger share in the structure of both primary and secondary energy.
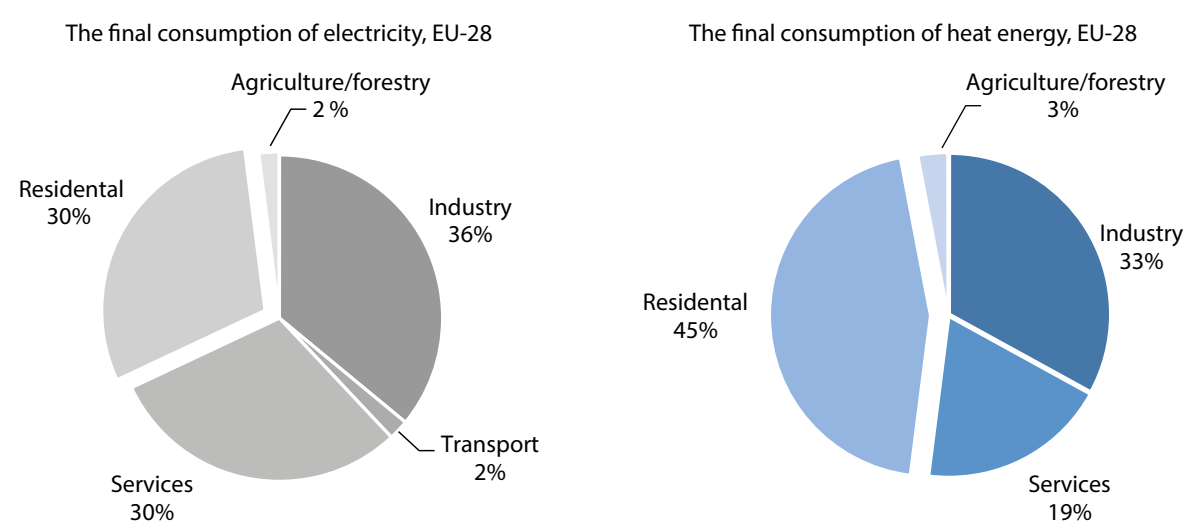

Figure 4.8. The final consumption of electricity and heat energy, EU-28 Source: Eurostat 2014, Electricity and heat statistics

2. Development of local resources, integration and centralised systems. A major precondition for a sustainable and safe energy system is increased consumption of energy from renewable resources. Countries differ not only in their natural resources, but also possibilities for applying renewable resource technologies and production methods. Every country chooses a production method that is most acceptable and economically reasonable. Renewables, however, are not able to 
guarantee the needed amounts of energy. Technologies enabling to accumulate the produced energy are still under development and expensive. In order to be able to use electrical energy produced from renewable resources, it is necessary to modernise the infrastructure of energy distribution so that increased electricity demands arising from multiple dispersed sources (e.g. solar, photovoltaic or wind energy) could be met. Electrical power engineering is becoming more decentralised, and innovative electricity networks are being developed. A more innovative energy transmission and distribution network will be able to balance fluctuations of wind and solar energy production by using renewable resource energy produced at other locations in Europe. This could reduce the necessity for storage of energy, expensive reserve capacities and basic supply .

3. Saving energy and management of demand. It is the major priority for tomorrow's energy industry. More efficient consumption of energy brings about a whole range of benefits - saving natural resources, decrease in the emission of carbon dioxide and other pollutants as well as optimising the use of financial, material and other resources within the energy sector.

There exist numerous tools for increasing efficiency of energy consumption. One of the most powerful is increased energy efficiency of buildings. Buildings with almost zero energy must be a norm. More efficient vehicles should be employed within the transport sector. Products and facilities should conform to the highest energy economy standards, and new smart technologies, such as for household automation, should receive broader application. Motivating people to change their consumption behaviour is, nevertheless, the primary measure. Responsible behaviour, positive environmental attitudes, conscious consumption these are the most effective measures for limiting the scope of energy demands. It is estimated that by applying saving measures, the total energy consumption in 2020 may be $17 \%$ lower than it was in 2009 . Households and the transport sector have the largest propensity to save energy: total savings could amount to 65\% (Kaklauskas et al. 2013).

4. New ways for energy management. Since production of electricity from renewable resources is increasing, which makes steady supply of energy at risk, one of the goals to be achieved is ensuring flexibility of resources for electrical energy production - production, storage, and management of demands should be flexible. Another goal is related to the impact that production of such energy has on wholesale market prices. Under increasing competititon, prices of energy from renewable resources may start falling down and facilities for generating renewable resources may attract fewer investments. Certain measures should be applied for ensuring return of the invested capital, and existing control mechanisms should stimulate investments into the renewable energy industry and contribute to creating new capacities (Sugulov et al. 2002). 
Development of the renewable energy industry requires coordination: it is essential to consider solutions taken by neighbouring countries and their impact on the national electricity production system. Joint effort helps lower costs and ensure reliable supply, whereas closed systems reduce security and efficiency of supply. The electricity market should be organised in such a way that makes it possible to perform all activities concerning flexible supply, management of energy demands as well as storage and production of energy within the market.

5. Participation of the state in the management of energy systems. Many experts on infrastructure are of the opinion that the infrastructure is an important segment of the social life and that the principal subject of its development policy is the state, very often taking the responsibility for its management and owning the infrastructure objects or entire systems. A management model based on centralised planning and state ownership does not always justify itself due to its delayed response to shifts and insufficient economic efficiency. To increase performance efficiency, energy enterprises began applying multiple forms of ownership and management models, and there have been processes of privatisation and segmentation of enterprises as well as separation of activities. Still, new market-based energy industry management models have their own drawbacks. Not all infrastructure systems are able to function within the economic market system without the state's interference and regulation. To achieve economic changes, state-level initiatives for realisation of reforms are needed as well as appropriate mechanisms for market regulation. This makes many countries to intensively discuss issues of infrastructure management and ownership (Moreau 2004; Oss, Zeltina \& Zeltins 2003; Guthey, Clark \& Jackson 2009).

The degree of state regulation within the energy sector is very high due to the impact on the political and economic systems. Succesful functioning and development of the energy industry requires political agreements and great capital resources, and participation of the state in the sector's activities brings certain guarantees and ensures viability of development projects. The scope of application of the model for partnerhip between the public and private sectors has been expanding lately. Though the state's influence within the management of the energy sector is not likely to diminish, private sector investors will retain their significance within the concept for the market-oriented energy policy.

Implementation of sustainable development is becoming a distinct priority for the energy industry. Sustainable energy systems are the reality that is attainable, though requiring a long-time process with plenty of urgent issues that need to be solved. Growing energy costs call for increasing energy efficiency and investments; they also restrict availability of modern energy services for the entire population and impede the state's efforts to ensure development of a competitive economy. The key long-time objective for the energy industry should be gradual transition from today's most popular organic fuel technologies, which 
are wasting natural resources, towards new renewables-based technologies. One of the major priorities within this long-time process is education, promotion of responsible business within the sector, and energy culture.

\subsection{Energy sector and the environment}

Energy is a fundamental aspect of human existence: it is the principal means for providing access to basic needs: food, water, warmness and it facilitates various opportunities for the achievement of a decent quality of life. This led to very rapid development of energy technologies of the 20th century. At the same time determine to enormous changes in the environment. Awareness of the effect of energy generation technologies on the natural environment, human health and safety leads to a new and responsible approach to the choice and development of technologies. When it comes to preparing energy growth scenarios and handling issues related to the choice and assessment of technologies, environmental studies must be in a particular spotlight. One way to make quantitative and qualitative assessment of the effect of technologies on the environment is through a thorough integrated analysis, which, in addition to economic and technical solutions, also considers other aspects of concern to the public. A changed environment demands for systems of criteria which help consider its changes, the attitudes of the general public and public values, sentiments toward the effect of technologies and the need for a healthy environment. The most critical challenge related to energy for sustainable development is how to increase access to affordable, modern energy services, while also ensuring that the energy services provided do not cause further adverse environmental and socio-economic impacts. One of the problem facing the global development community is that there is no clear consensus on what the term "energy access" means. one can consider three incremental levels of access to energy services and the benefits they can provide (see Figure 4.9).

While universal access only to the most "basic human needs" levels of energy services will have a limited impact on greenhouse gas emissions (basic universal electricity access would add around 1.3 per cent of total global emissions in 2030, according to the IEA), 15 increasing the level of energy provision and consumption for productive uses could increase emissions substantially. Access to modern energy services will require a combination of electricity and modern fuels and technologies.

Energy-sector development has a direct link to climate-change reduction measures and the conservation of resources for future generations. Such scientists as L. Garniati, A. Owen, J. Kruijsen, Y. Ishadamy, I. Wibisono (2013), and F. Marechal, D. Favrat and E. Jochem (2005) point out that energy policies and the development of production capacities can be, and often are, responsible 
for society's vulnerability, poverty, and issues with society's cultural and informational development. Sustainable social development is impossible without sustainable energy-sector development.

LEVEL 1

Basic human needs

Electricity for lighting, health, education, communication and community services (50-100 kWh per person per year)

Modern fuels and

technologies for cooking and heating (50-100 kgoe of modern fuel or improved biomass cook stove)
LEVEL 3

Modern society needs

Modern energy services for many more domestic appliances, increased requirements for cooling and heating (space and water), private transportation (electricity usage is around $2000 \mathrm{kWh}$ per person per year)

Figure 4.9. Incremental levels of access to energy services

(Sustainable future... 2010)

International organisations and the scientific community are looking for a way to define the general concept of sustainable energy development. In 2006 the European Union (EU) presented its vision of sustainable energy in the Green Book. The book states three principal goals: energy security, competitiveness and sustainability (Figure 4.10).

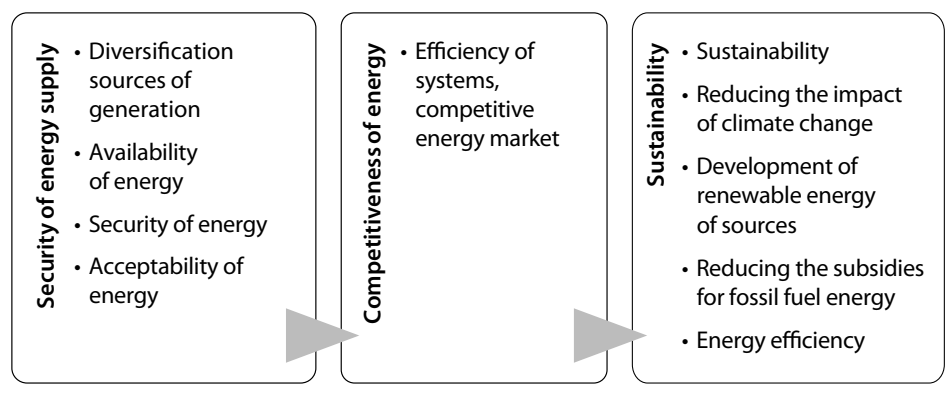

Figure 4.10. Objectives of sustainable development to energy sector

The methodology for the assessment of sustainable energy development published by the International Atomic Energy Agency, the UN Department of Economic and Social Affairs, the International Energy Agency, Eurostat and the European Environment Agency defines sustainable energy development as "a 
balance between energy accessibility, security, economic development and environmental protection" (International Atomic Energy... 2005).

The lack of access to modern energy services most severely affects social prosperity: development of health care and education systems, gender equality and the alleviation of poverty. Currently, more than 1.5 billion people have no access to electricity, and up to a billion more have access in name only because their power supply is highly unreliable. An estimated 2.5 to 3 billion people rely on biomass and transitional fuels, such as coal and kerosene for cooking and heating. At the global level, the energy system - supply, transformation, delivery and use - is the dominant contributor to climate change, representing around 60 per cent of total current greenhouse gas (GHG) emissions. Current patterns of energy production and consumption are unsustainable and threaten the environment on both local and global scales. Emissions from the combustion of fossil fuels are major contributors to the unpredictable effects of climate change, and to urban air pollution and acidification of land and water. Reducing the carbon intensity of energy - that is, the amount of carbon 4 emitted per unit of energy consumed - is a key objective in reaching longterm climate goals. Energy system design, providing stronger incentives for reduced GHG emissions in supply and increased end-use efficiency, will therefore be critical for reducing the risk of irreversible, catastrophic climate change (Sustainable future... 2010).

Access to energy resources alone cannot ensure social prosperity. The energy sector needs to be competitive in order to offer services and resources at nondiscriminating prices affordable to all social strata. A more integrated market, a more diverse supply, higher competition and the development of local energy resources would make the sector more competitive. Meanwhile, support for R\&D and innovations drives not only progress in the energy sector, but social progress as well. The importance of access to affordable forms of modern energy is also emphasised by the International Association for Energy Economics, which points out that "better access to energy resources makes a serious effect on the social environment: it improves health care, security, access to information and knowledge, quality of education and poverty alleviation" (Gaggl, Schellekens \& Gentili 2014). Although it falls within the economic domain, the economic growth indicator, if we consider the full cycle from energy production to its distribution to end-users, makes a significant impact both on economic and social development.

The energy production, supply and consumption models prevailing today are not sustainable and pose a threat to the environment. The sector's environment is changing; markets are becoming ever more complex as they are affected by policy changes, development of innovative technologies, and public pressure. The current models fail to cope with challenges in the environment: introduction of new technologies to the market, the decentralisation of systems, abundance 
of information, and a confrontation between politicians and the public. Efforts to achieve the sustainable energy development goals mean a need to combine conflicting demands: to meet energy needs and reliable supply, at the same time taking care of environmental improvement; to meet social needs and address issues caused by growing prices of energy resources; to build an efficient energy market and reduce energy consumption; and to attract private capital to the energy industry at the same time regulating profit margins.

\subsection{Social considerations and values in sustainable energy development}

The European social model rests on the preservation of a common set of values (peace, social justice, equality and solidarity) and emphasises the necessity to enhance the values associated with the European social model: equality, individual rights and responsibilities, non-discrimination and redistribution with access for all citizens to high-quality public services. Economic development and enhanced market opportunities is the best way to achieve material prosperity of the public and, simultaneously, to develop socially. But the market itself never enhances values. On the contrary, the market depends on the values, culture and morals the public holds. It has been observed that economic and ecological factors alone cannot explain the existing and growing differences between the level of development in various countries/regions, inequalities within societies, or demographic problems. Programmes being devised often fail to deliver and important development projects come to nothing due to public adversity, underestimation of the public's sway, and lack of knowledge or information. Many important factors contribute to sustainable social development; they span society's political and organisational structures, social and legal norms, the institutions of democracy, culture, education, upholding of national identities, the sense of community, and so on. Different societies (or countries) develop their social sector differently; factors defining the social aspect in different societies can differ both by their specificity and the role they play. If ecological sustainability is difficult to assess due to enormous amounts of components and functions and due to its links with various forms of public life, social sustainability is even less defined, although people are becoming more aware of its significance, which is growing.

The role social values play in public life and their links with cultural, communal, political values and economic developments are becoming ever more significant in investigations of various aspects of sustainable development. Although the public focuses on the importance of economic and technological changes, social aspects and values are changing too and they affect all areas of public life. 
The issue of values was taken up by philosophy. The concept was first used by Herman Lotze (1817-1881) in the 19th century. Later, investigations of values split away into an individual branch of science. Values can be understood as beliefs born from conscious activities; their assessment criteria or standards are used in considerations which alternative goals, priorities or principles of operation to choose, which means they help to give sense to human experiences and actions. B. L. Katcher (2006) argues that values span beliefs, activities, opinions, moral norms, traditions, self-regulation, imagination and public opinion as well as other more objective and material things. Williams (1994), who investigated what constitutes social values, proposed the following definitions of social values: "the perception of the desirable state of a social system" or "community as a value that enhances general prosperity or is necessary to maintain it". B. Morkevičius (2005) proposed the following definition of social values: "social values are abstract beliefs created or adopted by the specific subject in question that state what is desirable or not in connection with the society of a broad scope and profile one lives in." Braithwaite (1998) analysed specific values important to the public and singled out the following ones:

1) international collaboration;

2) social progress and social reforms;

3) absence of wars and conflicts;

4) arts (music, literature, fine arts);

5) personal dignity and guaranteed self-esteem;

6) equal opportunities (for social groups, sexes and ethnicities);

7) economic equality;

8) conservation of the environment.

Social values that are important in social development include the entire set of economic, political, sociocultural and national ethical values that take a certain place in the society's framework and are an important dimension in the analysis of various aspects of development. The diagram in Figure 4.11 illustrates what constitutes social values.

Social values are being designed in the domain where states and their internal relatively autonomous formations or cross-border bodies operate (Hitlin and Piliavin 2004). The UN General Assembly recognized the importance of people's values in efforts driving towards sustainable development and declared that "certain fundamental values [are] essential to international relations in the 21st Century" (UN 2000). Its declaration lists such values as solidarity, tolerance, equality, respect for nature and shared responsibility. Despite their importance, little is known about the nature of sustainability values and much work needs to be done in developing acceptable scales that will affect people's quality of life around the world and the preservation of the social and natural environment (Shepherd et al. 2009). 


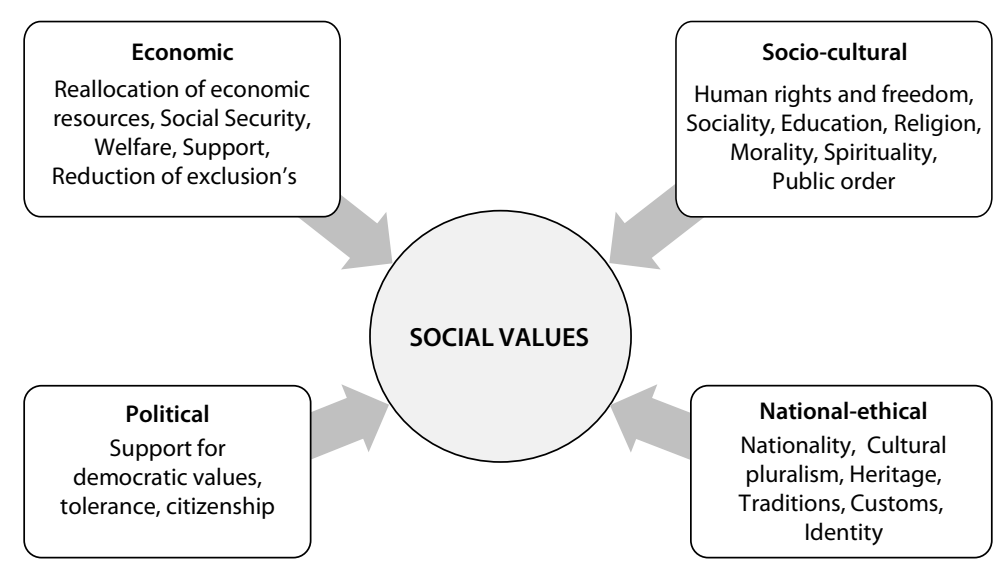

Figure 4.11. Content of social values

Different regions have been observed to have different perception of the role of values. In one country, citizens, for instance, give the priority to freedom and equality, while in others they favour shared responsibility. This may be one reason why countries develop and understand sustainability pursuits differently. A deeper understanding why different parts of the world implement sustainable development differently and why sustainable development takes different forms in different countries is important. If we want to achieve the goals of sustainable development, people should also change their values; the change, in turn, would help set individual goals, state views and attitudes, and make due judgement of the efforts persons, organisations and the public make (Leiserowitz et al. 2006; Shepherd et al. 2009).

A search for solutions that can help with meeting energy demands and ensuring its reliable supply is reinforcing a stance that it is not technological solutions or their economic efficiency that can secure social prosperity. The main goals of sustainable energy development are, in essence, connected to the development of the entire society; the assessment of the social aspect is, therefore, no less important than that of the political or economic one. So far the issues of energy production, transmission and distribution have been in the spotlight. This has to change, because the goal of energy development is not to develop individual technologies, but to build a sustainable energy system that promotes efficient use and social prosperity. Energy systems and their efficiency should be assessed more from the social standpoint, rather than the technological one. The running and development of energy systems are closely related to public security, prosperity, ethics and culture, and cannot be analysed without considering the aspects that are important to it and ensure social prosperity, with only geopolitical or economic benefits in mind (Rayner 2010). 
Many systems of criteria have been devised and are employed in assessments of the sustainability of national energy sectors; they are designed to rate national progress, changes, price policies, social impact, the state of environmental protection, and accessibility taking into account country-relevant development aspects (Sovacool, Mukherjee 2011; Steimikienė, Ciegis, Grundey 2007; Vera, Langlois 2007; Angelis-Dimakisa et al. 2011). The majority of proposed indicators or their sets suggest the assessment of variables that describe economic, political, environmental, social and technological dimensions of the energy sector. In most sets of indicators that analyse the sector's situation and its development trends, the social dimension is never analysed using value-related criteria. Moreover, some countries do not assess the value aspect in their energy sector at all, or the assessment is very nominal. But in the social context such values as ethics, education and knowledge, traditions, public opinion, trust, mutual agreements and their observance, and the clout of public institutions can make a significant impact, or even be the deciding factor, in decisions on energy sector development.

In attempts to find the best solutions to satisfy growing energy demands and ensure reliable supply, increasingly prevalent is the idea that technological parameters and economic efficiency are not crucial to guarantee welfare. Life cycle of energy system is much longer than period of reliable economical prognosis. The most relevant issue in today's energy development is selection of the technologies which are the best for people, rather than the most efficient. Operation and growth of energy systems is very closely related to public needs, security and welfare, hence they cannot be viewed without consideration of relevant important aspects.

Planning the course of energy-sector growth or handling issues related to the choice of energy generation technologies means assessment of loads of technical, economic, social and other information - contradictory at times. It is important to use relevant sets of criteria, which describe in detail the environment being analysed; one must also be aware of the effect of criteria and obtain helpful information for preparation of solutions. The indicators for sustainable energy development formulated by the International Atomic Energy Agency, EUROSTAT and the United Nations help evaluate the sustainability of national energy sector, compare it between countries by separate indicators, assess the trends of sustainable energy development and take appropriate actions which shift or promote these trends (International Atomic Energy... 2005). A number of systems of criteria have been developed and are used to assess sustainability and growth of energy sector in individual countries, with a view to national priorities and aspects relevant to the growth. Such sets of criteria define economic, environmental protection and social dimensions of energy generation technologies. In the said systems of criteria, the social dimension usually omits the criteria of 
values. But values - culture, cultural identity, ethics, beliefs, religion, education, weight of social institutes and other - can make an important impact on decisions related to the development of energy generation technologies, or even be the determining factor. Growing significance of public attitudes demands consideration of the dimension of values in environmental studies; when problems concern technologies they must also consider the values which are important and significant to the public or its separate groups.

The role of values came into focus not by accident. The dimension of values and analysis of cultural, ethical and psychological specifics and differences is increasingly dominant when it comes to relationship-building at various levels (Vallance et al. 2011). In general, values may be perceived as desirable principles of action, goals and wealth-generating factors present in society or a certain societal group. At the same time, values determine the limits observed in the pursuit of goals. The substance of the concept of values may be construed as the perception about the desirable state of some system and deliberately chosen rules of coexistence (Williams 1979; Schwartz 1996). Acknowledging the fact that values are a fundamental concept in any system, it should be noted that economic and technological factors dominate in any decision on development or choice of technologies. A. Kemmler and D. Spreng noticed that "the use of energy indicators is not restricted to environmental and economic issue but is also relevant for social issues" (Kemmler, Spreng 2007, p. 2466).

The United Nations General Assembly has recognised the importance of human values to achieve sustainable development and declared certain fundamental values to be essential to international relations in the twenty-first century. The declaration lists values such as solidarity, tolerance, equality, respect for nature, and shared responsibility (UN 2000). Despite their importance, little is known about the nature of sustainability values and much work needs to be done in developing such scales (Shepherd et al. 2009).

Although the importance of the dimension of values is fully comprehended, academic literature examining the environment of energy sector and issues of sustainable development has never presented a through analysis of relationships between "values" and energy. The authors reviewed the academic literature from the past five years containing such keywords as energy technologies and value, energy and ethics, energy and psychology, energy culture, energy security, value criterion, cultural aspects in energy sector, value and sustainable energy development, etc. Another goal was to review papers analysing aspects of values in the context of sustainable energy development. It can be noted that measurable criteria, which describe economic, environmental-protection or social environment, have been thoroughly described in a range of publications. Assessment of the social aspect is usually suggested through measurable economic and demographic criteria without any consideration of the criteria of values. Criteria 
of values have not been systematically analysed, nor have been described any integrated studies examining the role of values in the development of energy projects. Academic publications accentuate and analyse individual values significant to solutions concerning energy growth, but new and original academic research, resting on the value-based approach to the aspects of public importance, must be performed in the future (Becker 2001; Leiserowitz et al. 2006; Loomis, Rosenberger 2006). Though the dimension of values is relevant at all levels, this article analyses the criteria of values attributed to the social factor. Such analysis of social environment, supplemented with the criteria of values, looks into the social aspect in an integrated way, considers important public attitudes and gives them prominence in environmental studies.

Having summarised the studies examining the dimension of social issues and values in energy sector and considering the opinion of experts who took part in the study, the following criteria, which are important to the industry's environment and should be investigated when various solutions of energy growth are being prepared, can be distinguished:

1) energy security;

2) assessment of public opinion on energy growth;

3) knowledge (understanding of technologies);

4) energy culture and ethics;

5) creating equal opportunities to be employed and be responsible for decision-making;

6) the principles of corporate social responsibility in energy companies.

1. Energy security

In their discussions of sustainable energy development, both policymakers and academic circles often use the concept of energy security, although this concept has never been precisely explained. The concept of security of energy is usually dealing with the supply side of the energy systems. Energy security can be expressed by long-term independence from foreign energy source. This indicator was applied for evaluation of autonomy of electricity generation in NEEDS project (NEEDS... 2007). Energy security is chiefly understood as capacity to secure stable, accessible and economically non-discriminating supply of energy sources for industrial, production and transportation needs (Löschel et al. 2010).

Today the concept of security of energy supply is much more expanded and includes more aspects than prior definitions. Environmental issues have become a very important element limiting the reliability of energy. Literature examines the concept of energy security from a number of aspects, including risks related to sufficient supply of imported primary energy sources, diversification and variety of energy generation technologies, and the ratio of exports/imports and demand/supply. Energy security has also been assessed 
considering the social impact of the development of energy generation technologies (Löschel et al. 2010; Jansen and Seebregts 2010; Gallego Carrera \& Mack 2010). In their studies of the concept of energy security, B. Kruyt, D. P. Vuuren, H. J. M. Vries and H. Groenenberg, distinguished four defining dimensions: the availability, accessibility, affordability and acceptability of energy (Kruyt et al. 2009). These dimensions, which define the gist of this concept, are also related to the dimension of social issues and values. Depending on national politicaleconomic and cultural specifics, the role of energy security may vary. Having surveyed expert opinions in different countries and analysed sets of criteria, which include "security and reliability of energy provision", "political stability and legitimacy", "social and individual risks" and "quality of life", D. Gallego Carrera and A. Mack have noticed some differences between expert opinions in various countries (Gallego Carrera, Mack 2010). The differences probably rest on the difference of culture and values in these countries. In an integrated assessment, when the scale of social factors has been supplemented with the criterion "energy security", the environment of energy generation technologies or the effect of their development can be examined and assessed considering national and cultural specifics.

Security of energy supply is a complex field of scientific research based on modelling of economical processes, analysis of geopolitical situations, network reliability and resistance to disturbance energy analysis, statistical expertise in emergency situations and violations in energy systems, risk analysis, energy supply problems, technical, social, political and other consequences (Augutis et al. 2011).

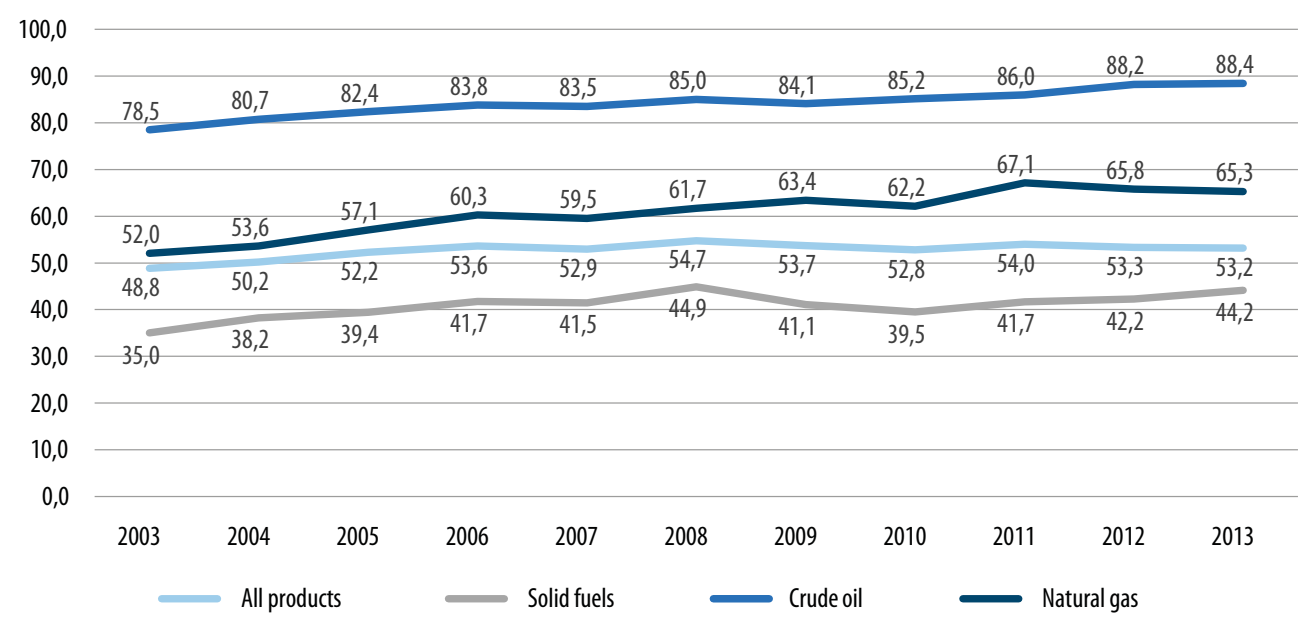

Figure 4.12. Energy dependency rate, EU-28, 2003-2013 Source: Eurostat 2014, Energy production and import 
EU-28 dependency on energy imports increased from less than $40 \%$ of gross energy consumption in the 1980 s to reach $53.2 \%$ by 2013 . This latest figure marked a slight decrease in the dependency rate, which had stood as high as $54.7 \%$ in 2008. The highest energy dependency rates in 2013 were recorded for crude oil $-88.4 \%$, and for natural gas $-65.3 \%$ (see Figure 4.12). In the last decade the EU's dependency on non-member countries for supplies of natural gas grew 13.3\%, crude oil 9.9\% and solid fuels 9.2\% (Eurostat 2014, http:// ec.europa.eu/eurostat/statistics-explained/index.php/Energy_production_and_ imports).

The European Union (EU) is one of the most active developers of energy security assessment methods and assurance measures. Its initiatives expressed in the directives up to 2020 would lead to a significant reduction of EU energy dependence on import.

\section{Public opinion}

Research shows that the dimension of values, construed as expressed public opinions, affects the implementation success of various development projects. Energy policymakers and people who prepare development strategies must consider public opinions, because energy technologies are related to the safety of the public and its environment. Academic papers explicitly assert that the public must take part in debates and discussions on the choice of future energy scenarios, because the public wants "reliable" energy in the future, the choice of energy technologies is relevant to the public, and projects must be broadly discussed (Grunwald 2011; Smith 2004; Rayner 2010). "What the public thinks about energy is important because public opinion is a major force influencing public policy on energy production and consumption" (Smith 2004, p.169). Unfortunately, the usual practice in political and public life is often to introduce to the public the solutions which have already been chosen for implementation.

Worries about climate change and energy security, rather than public determination, were the main arguments that decided the development of nuclear energy technologies as the key source of electricity in such countries as Finland, France and the UK. Having analysed the discussions which took part in the public domain of these countries and involved market participants, the state and the civil society, T. Teravainen, M. Lehtonen and M. Martiskainen have distinguished three key reasoning strategies that dominated these discussions: 'technology-and-industry-know-best' in Finland, 'government-knows-best' in France, and 'markets-know-best' in the UK. They reflect the attempts of stakeholder groups to find ways to reconcile the positions of the market, politics and civil society (Teravainen et al. 2011). But the wording of these strategies suggests that the public is not they key participant in the decision-making process. The importance of dialogue with the public has been proved by E. R. N. Smith with the help of this US example: "public opposition to nuclear power, especially after the 
1979 Three Mile Island accident, helped block the construction of new nuclear power plants. In the aftermath of the accident, public support for nuclear power dropped sharply, and every proposal for a new nuclear facility was met with mass protests. Public opposition, coupled with soaring construction costs, ended the growth of the nuclear power industry. No more nuclear power plants were ever ordered" (Smith 2004, p. 169). The decision by Germany's government on the national energy growth may be another example. In 2010 energy growth in Germany was still associated with nuclear energy. Despite the differences of natural environment, the disaster in Fukushima power plant made the German society take a U-turn in their opinion about the development of nuclear energy technologies. After extensive public and academic discussions, in which the public unambiguously said "no" to the development of nuclear technologies, the German government made a decision to associate the future with the development of renewable energy generation technologies (Grunwald 2011). Japanese, Swiss and Italian governments considered public opinions and made equivalent decisions (at a referendum in June 2011, as many as 94\% of Italian voters that went to the polls voted against plans to expand nuclear energy). Obviously, the debates with the public, or organisations representing the public position, made a significant impact on the choice of new development strategies.

Interestingly, despite growing popularity of renewable energy technologies, the development of these technologies is also subjected to debates. For instance, emerging wind power sparked worries in the public domain about the negative aspects of wind farms: changes of the natural environment (new bird migration patterns), noise and deteriorated landscape. Studies are necessary to support or reject these arguments, with the results announced to the public. In Britain, for instance, the effect of wind farms on the value of real property was examined after the communities, in which wind farms were being developed, had expressed their concern. A thorough analysis, based on the hedonistic price model, of data from real property deals did not show any causal relationship linking the drop of property's market value with wind farms in the vicinity. Announcement of the research findings helps to ground discussions and change public attitudes (Sims, Dent, Oskroch 2008).

Analysis of the effect of public opinion on the decision-making process highlights the role of informing the general public and transfer of scientific data. Mutually equal discussion and the best outcome are only possible when the public has sufficient knowledge. Growth of interdisciplinary scientific fields in energy sector would let the science play a more important role in strengthening the relationships linking the public, politics and business (Palm, Thollander 2010). Motivated debates are a basis to integrate new energy generation technologies. Scientists and science policymakers must hear the public opinion, try to understand it and respond to issues raised by the public (Rayner 2010). „What the 
public thinks about energy is important because public opinion is a major force influencing public policy on energy production and consumption" (Smith 2004).

\section{Knowledge: the understanding of technology}

Even in the 21st century, the issue of effective communication between science, government, industry and the public remains acute. The question of the understanding and acceptability of knowledge and technology has to be analysed from two perspectives:

1) necessary appropriate-level knowledge to understand energy sector development solutions proposed by the government or other authorities, to consider the arguments put forward by scientists, and to take part in effective debates;

2) necessary knowledge that would help change behaviours at home and in the environment towards habits that save and conserve energy and other resources through a broader adoption and use of innovative energy-saving technologies.

A decline of public trust in science and scientific solutions has been observed (Rayner 2010). Lack of knowledge about benefits, risks and issues technologies bring or ways to address the issues, together with insufficient information dissemination, often leads to spontaneous protests against the development of new technologies or innovative solutions. The majority of new technologies and innovations are, in principle, more energy- or resource-efficient. But the development of energy infrastructure (e.g. high-voltage transmission lines) or renewable energy technologies is met with opposition from local communities, most often due to insufficient or incompetent delivery of information (Batel, Devine-Wright \& Tangeland 2013). An opinion survey "Public attitudes to energy security" carried out by scientists from the Energy Security Research Centre at Vytautas Magnus University, for instance, shows that as many as $36 \%$ of respondents could not answer the question what they thought about the safety of the planned nuclear power plant (Lietuvos energetinis saugumas... 2014). Not only is it a sign of "energy illiteracy", but low interest in energy and its security usually hampers rational debates. On the other hand, high-quality research of the sector's environment and examinations of the acceptability of technologies and attitudes are only possible with respondents who are sufficiently informed and have a certain level of knowledge.

G. Assefa and B. Frostell (2007) assessed the aspects of public acceptance of social sustainability and technological systems by analysing them against three indicators: cognition, perception and fear. Their survey results revealed that respondents have so little information and knowledge about new energy technologies that they cannot even prioritise them. "This hampers discussions on where and how to channel and distribute public funds for the implementation of solutions," argue the authors (Assefa, Frostell 2007). Dissemination of information 
and proper promotion of scientific knowledge is, therefore, a prerequisite for an effective, rational dialogue.

Most studies show a positive relation between the level of society's education and energy use. Education also promotes household behaviour changes, as people start to save energy and other resources and choose technologies that save energy at home. Energy saving is the cheapest and universally accessible alternative. Estimations show that even the technologies available now can help us save about $20 \%$ of the growing energy needs. The most efficient measure to promote energy saving is disseminating information, educating, and providing the public with clear knowledge about energy resources, climate change, and the impact and efficiency of energy generation technologies. B. Mills and J. Schleich (2012) point out that the reaction of a well-informed society to various proposals, solutions and innovations is adequate. Educational efforts need more efficiency; they must encourage real changes in behaviour, rather that just offer deeper knowledge about ways to save energy.

If we admit that knowledge and its contribution to the understanding of technologies and to changes in behaviour are a value, we must also admit that the contribution of the scientific community has been so far insufficient. The communication from the Commission to the European Parliament, the Council, the European Economic and Social Committee and the Committee of the Regions "Results of the public consultation on the Europe 2020 strategy for smart, sustainable and inclusive growth" states that "a significant information gap between science and society still exists. Citizens need to be engaged in an open and informed dialogue throughout the research and innovation process. They need to be provided with reliable insight into the benefits and risks of innovative technologies and existing practices, and more ample opportunities to debate new findings and their implications" (Europian Commision... 2012)

If before the end of the past decade communication with the public was practically one-way information and knowledge simply delivered to the public today communication is believed to be a two-way process, an efficacious mutual dialogue and debates between those who build knowledge and make research and the public looking for answers to its concerns. A well-informed society armed with knowledge is keen to debate and accept arguments (Rayner 2010). Scientists and science policymakers must, therefore, listen to the questions and concerns expressed by the public, must understand them and respond (Rayner 2010). The task that falls on science is multimodal. It is not only a search for and use of technological solutions and innovations. A very important role of science is educating the public. Equal debates and the best outcome are only possible when the public is knowledgeable enough. Development of interdisciplinary sciences in energy would improve the role of science by reinforcing links between the public, politics and business (Palm, Thollander 2010; Gallego Carrera, Mack 2010). To forge stronger ties between 
science, the public and energy policymakers, a dialogue is necessary with consumers engaged in it.

\section{Energy culture and ethics}

Energy culture is construed as a relation between energy technologies and the public, as a way of communication. Energy culture is a new concept, but it encompasses a great deal of aspects of public life, including educating public to conserve energy resources, environmental protection issues and confidence in decisions concerning energy sector. Search for more effective means of understanding, and attempts to encourage energy-conserving behaviour, requires a focus on the shaping of a specific energy culture. The concept of energy culture has been partly formulated to achieve higher energy-efficiency, improve understanding of the effect on the environment and change the habits of consumption. Energy culture is also an attempt to help energy generation and supply companies understand different consumer-behaviour models and better accommodate their tariff plans and products. Energy culture affects consumer perceptions of technologies and shapes their convictions and attitudes (Stephenson et al. 2010).

Analysis of the role of energy culture cannot ignore ethical issues related to the public behaviour, the public's relationship with the nature and technologies, and responsibility. C. Moeller, who analyses ethical issues and the evolution of ethical relationships in the society, asserted that the attention to ethics is not a passing whim but is the answer to the changes in our society: the technological revolution brought forward new issues of air and environment pollution; changed laws mandate equal opportunities. Handling of sensitive public issues is only possible when ethical norms are respected (Moeller 1998). The dimension of ethics is important in all areas. Science and technology cannot be above ethics (Matson, Carasso 1999). Lack of attention to ethical issues decreases the chance to achieve the goals of sustainable development in energy sector-accessibility and reliability of energy generation technologies. The importance of the dimension of ethics is particularly highlighted in wake of disasters. The case of Chernobyl, for instance, revealed that disregard of ethical and moral norms (failure to provide timely information about the accident, the possible effect on health, the protection measures, the necessity to evacuate and the places of evacuation; using victims for biomedical studies; etc.) raised not only public distrust but also more painful outcomes (Melnov, Sarana 2010).

\section{Creating equal opportunities to be employed and be responsible for decision-making}

The equality between men and women is a fundamental EU value. Unfortunately, even in the 21st century gender differences persist and are especially prominent in the labour market. In 2012 as many as $83 \%$ of EU women had at least secondary education (the figure is $77 \%$ for men) and the proportion of women among college and university graduates is as high as $60 \%$. Nevertheless, 
the average wages of EU women are by $16 \%$ lower than those of men. According to Statistics Lithuania, in 2013 the wage gap between women and men in Lithuania's economy was $12.5 \%$ and grew by 0.5 percentage points in one year. One reason why women earn less is that they occupy lower job positions. This is especially prominent in management, because management salaries are the highest. But the prime reason is fields in which women are employed. Such industries as construction and energy are traditionally dominated by men. The figures of Statistics Lithuania, for example, show that energy companies belong to the group of businesses that pay their specialists salaries higher than the national average. But women are poorly represented in this industry's managerial bodies and rarely take top positions in energy sector management.

Academic literature has also examined ways to ensure the principles of equal opportunities for men and women in energy companies. A. Carlsson-Kanyama, I. R. Julia \& U. Rohr have performed a study and analysed the situation of gender quality in management of energy companies and the role of women as members of managerial bodies in preparing and making strategic decisions (Carlsson-Kanyamaa, Juliáb, Röhrc 2010; Huse, Tacheva Nielsen, Hagen 2009). The scientists noticed different work styles and decision-making methods of both sexes and a slightly different perception of risks. Having surveyed 464 large energy companies in Germany, Spain and Sweden, they stated that among the companies surveyed as many as $295(64 \%)$ had no women in their managerial bodies and only $5 \%$ of companies could be considered examples of gender equality ( $40 \%$ or more women in managerial bodies). Interviews with energy companies confirmed current trends that gender equality efforts within decision-making in business are weak or non-existent. The research findings suggest that male consumption and emissions of greenhouse gases. Women have been noticed to be keener to take risks than men, which in boards, at a certain degree, may affect the decision-making process. More active involvement, and more say, of women in management of energy companies and in investment decision-making may encourage more radical handling of climate change and environmental issues, more determination with innovative solutions and choice of renewable technologies (Carlsson-Kanyamaa, Juliáb, Röhrc 2010). Analysis of membership in boards and supervisory bodies of Lithuanian energy companies, including academic institutions, performed in 2011, confirms the trends noticed by the aforementioned scientists, because women account for less than $10 \%$ of members in managerial bodies of Lithuanian energy companies, and none of the companies could be considered ensuring gender equality. "The main argument promoting women as board members from a business case is usually that diversity is important for corporate value creation and that women can add unique perspectives, experiences and work style compared with their male counterparts" (Carlsson-Kanyamaa, Juliáb \& Röhrc 2010, p. 4738). 


\section{The principles of corporate social responsibility}

Economic development can be considered sustainable only if the investments not only have economic efficiency but also do not violate the ecological and social foundation of economics. But economic entities must also move away from the system which has profit maximisation as its main goal toward a system which achieves this goal within the limits of sustainability. In order to achieve responsible consumption and rational attitude towards development strategies, the dimensions of profits and social benefits must be combined (Husted, Salazar 2006).

Although awareness of the influence of social factors is growing, economic factors generally play the key role in decision-making related to development. The issues related to the choice and development of technologies are usually "reduced" to the level of economically most rational decisions. Business often exerts pressure to stick to more conservative decisions-particularly if they have greater economic efficiency (Cappers, Goldman 2010). Even the model of sustainable development sets economic tasks as the main goal (Sychev 2010). Some authors believe that economic goals are stressed and given prominence not only because of the traditional interpretation of market behaviour but also by institutions of business education, which, in their teaching process, over-stress the economic matters and profits as the main goal of business and the purpose of corporate activities. It determines corresponding behaviour of future executives and managers, which later is transferred on to organisations and respectively shapes operational strategies of such organisations, corporate culture and the relationship with the consumer (Ferraro, Pfeffer, Sutton 2009; Ghoshal 2005). Corporate culture and appropriate management systems can reinforce the connection between the dimension of social capital and the economic and cultural dimension (Chenhall et al. 2010). In order to achieve sustainable energy development, energy companies should apply the principles of social responsibility in their activities. This voluntary measure implemented by energy enterprises can ensure efficient public-private partnership in achieving sustainable development targets. The main sustainable energy development goals and indicators to monitor achievements of these goals are: 1) increase in energy efficiency and 2) use of renewable energy sources (Streimikiene, Simanaviciene, Kovaliov 2009).

Management strategies and policies directed towards economic efficiency of expenditures in research and development with human capital knowledge and investments into technologically intensive export- oriented products are significant for long-term sustainable economic development. Hence, despite the importance of economic goals and technological advances (Bojnec, Papler 2011), increasing attention is paid to the dimension of values: ensured opportunities to discuss and express opinions, respected culture, ethics and the principles of trust and equality. Social evolution follows the laws of sociology, thus social issues and the issues of values must be centre-stage when questions concern 
development and the assessment of technologies. Social aspects and acceptability of new technologies is a new alternative of energy policy (Schweizer-Ries 2008; Musango, Brent 2011).

\subsection{The role of the Social/value aspect in energy sector value creation}

If we take the value the sector creates, it must be noted that the posing of various social/value-related questions and aspects, research, and active public debates initiated by public organisations and activists opened up a new take on the sector's objectives and the value its business creates. The energy sector is inherently a multi-aspect entity. The external and internal pressure to choose a certain course of development, strategy or new technology and to consider global issues is transforming the approach to what constitutes a success in the business. The sector's response to the issues raised is also multifaceted: value creation demands for a rethinking and understanding of the sector's role in the community, the state and the world.

The value chain of the modern energy system has become much more complex. A new approach to the course of social development, more intense public involvement in political and economic life, and the tasks imposed on the sector make energy companies change their business strategies and rethink their position in the creation of the energy value chain and their commercial possibilities. Companies operating in the sector need well-timed response to changes in order to make the right decisions at the right time. In their decision-making processes, energy companies must find the right balance between:

1) the technical capacity of their systems, innovations, reliable energy supply and public pressure (e.g. to reconcile the development of new technologies, large investments and affordable energy prices);

2) environmental protection, rising resource prices, economic fluctuations and social prosperity (rising resource prices, plus investments into environmental protection and pollution-cutting measures, add to energy prices and cause public discontent);

3) goals set for their systems and business tasks of individual companies. Companies should collaborate not only in such branches as generation, transmission and distribution, but also with renewable energy producers, and service and supply companies. This also includes understanding user issues and participation in efforts to address such issues as energy in buildings, household energy saving and transport energy;

4) various stakeholder groups actively involved in the industry and social systems. An active dialog must be maintained by communicating with the public and by providing it with information and knowledge; 
5) owners, shareholders, politicians and users. Such matters as profits, the reliability of technologies and social efficacy need to be reconciled.

By reconciling these conflicting goals, the sector's companies would become competitive, responsible and innovative members of the energy market, reduce their impact on the environment, improve energy security, and contribute towards the goals of sustainable development. Figure 4.13 shows the value diagram of the energy sector.

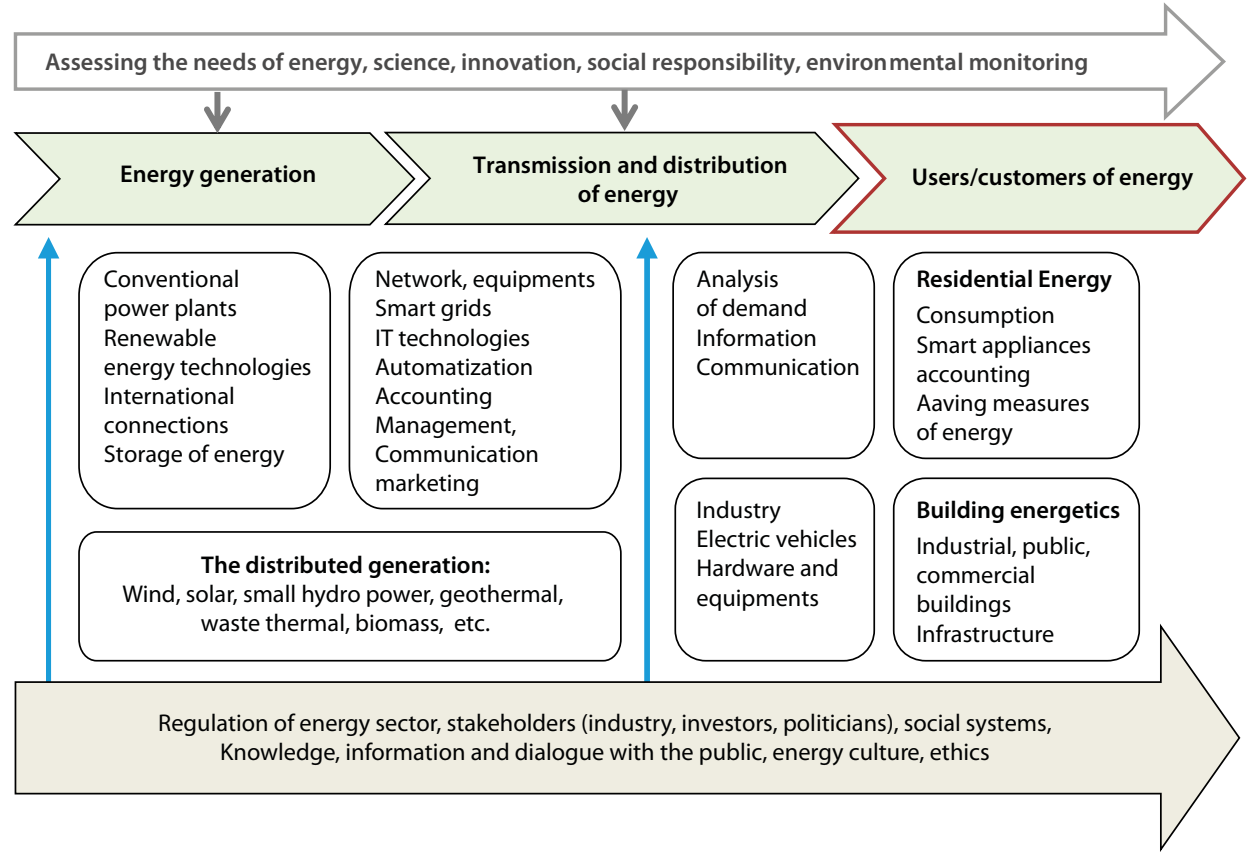

Figure 4.13. Energy industry value chain

Energy generation, transmission and distribution form the connecting backbone in the value chain. They are the core of an energy system. As part of the requirements set forth by the European Commission in its third energy package, energy companies have been decentralised by splitting their business and assets. Between individual branches of the energy sector, companies must find a strategy and ways to create the biggest value by combining improvements of the reliability of their systems, development of renewable technologies, use of other advanced technological measures, and common public goals.

Users take a very important place in the chain. It is this group that is responsible for sparing and efficient energy use. Although economic indicators of energy producers and suppliers depend on growing sales, they still need to support all initiatives that encourage users to save resources and contribute to the creation of a healthier environment. This covers a range of areas of public 
life: from more innovative and efficient industrial technologies to the construction of passive or zero-energy houses, new transport fuels and energy-saving household appliances.

Another important aspect in the value chain is public relations and communication with users and stakeholder groups. This means not only relay of information. This also means dissemination of relevant knowledge and maintaining a dialogue. By informing users properly, their attitudes can be changed, awareness raised and dialogue held. At the same time, it means taking part in processes that are important to the public, listening to public opinions and becoming aware of your responsibility.

Awareness of the energy sector's role in national economic development and social development processes and its impact on the natural environment, human health and safety leads to a new and responsible approach to the energy sector's tasks, business and development. The fact must be considered that the value of the energy sector is inseparable from the value created by other sectors, such as industry, construction, transport, communication and the development of social systems. The value of the energy sector is created by activities oriented not only to economic and technical solutions, but at the same time to environmental and social aspects that are important to the public from the ethical and cultural perspective.

The focus of research still too seldom falls on the analysis of the energy sector's social aspect. In its operation and development, the energy sector is here to serve public needs. Hence, in the run-up to decision-making, especially when it concerns the development and market replication of new technology, a contact with the public must be ensured, which means that such aspects as environmental protection and the social/value dimension must be considered.

The review of scientific literature suggests that a firm notion which social values are crucial and make the biggest impact on the processes of sustainable development and individual systems has not been established yet. No sets of such values are available. Nor their assessment approaches have been discussed. Nonetheless, the growing body of research publications only proves that this issue is vital. The progress in separate areas has, apparently, been too slow, even though sufficient funds and efforts have been put to drive it. This suggests that sometimes outcomes are not determined by technological or economic leverage. If the standpoint on social aspects and values is ignored, this may lead to a public backlash against development projects, upcoming innovations, and ongoing research.

Efforts to educate, duly inform and keep in touch with the public are critical in the values scale. A well-informed knowledgeable public is quicker to change its established attitudes, behaviours and approaches to environmental conservation. Such public makes well-motivated decisions and is also ready for reasoned 
debates or can even get into motion civic initiatives, especially when they concern environmental conservation, the choice of technologies, and development.

In a broader perspective, an important fact is that energy business is "business without borders". In attempts to seek integration, the choice of energy policies and technologies is not unimportant. Regard for the public attitudes and cultural levels present in neighbouring countries is of equal importance. This creates a foundation for future collaboration and partnership. The aspect of values must be analysed in any decision model concerning technology development. It is a norm for the future.

But the role of values cannot be seen as a system that is an end in itself. Values affect all areas of life, all systems created by human activities. The more crucial and global such systems are, the deeper, more complex and more diverse is the aspect of values. On the other hand, the systems, in they turn, also shape values; they are important to lifestyles and affect them. The task of sustainable development is not only to develop economic, environmental and social aspects; it also should forge their interrelations, keep the existing systems running, and take heed of the role of values. The great variety of social/value aspects and technological systems can only be reconciled after extensive sociological studies, when the main dimensions and priorities of public values are known.

In summary, one may stress that the assessment of outcomes that economic, technological, environmental and social/value-related interventions into markets bring about is a way to decide on the benefits and acceptability of the technologies one chooses and on their compatibility with the public. In this context, it may mean a choice of technologies that are more efficient, more appealing to the public and of higher quality in terms of environmental protection.

\subsection{Use of multiple criteria decision support tools to validate energy sector development decisions}

As the principles of sustainable development were introduced, they made a strong impact on energy policies around the globe and imposed a number of political commitments on countries. In this context, the problem of climate change gets much attention, as well as investigations of adverse effects that air pollution emissions have on human health and ecosystems. "Energy systems are formed not only of the ecological and technological aspects of energy sources but also, and equally importantly, 'of the social structures for the appropriation and management of these sources and converters'. An energy system is the original combination of diverse converter chains which draw on determined sources of energy and depend on each other, initiated or controlled by classes or social groups which develop and consolidate on the basis of this control" (Barca 2010). Evidently, the public, even if the significance of energy supply is realised, still 
cares which energy production technologies will be at the core of the supply. All dimensions economic, environmental and social are important in the concept of sustainable development. The choice of the best energy production technologies, decisions which energy projects to implement or possible future development scenarios of the energy sector, therefore, must all take into account all criteria, often contradictory, and consider political commitments and interests that various groups have, which means a multiple criteria decision must be made. In the decision-making process, which implies an analysis of diverse data, sometimes hard to compare, it is important to employ appropriate measures fit to assess a changing environment, determine the weight of its defining criteria, and combine economic, environmental, technological, social and other aspects.

\subsubsection{Preparation of the decisions making process}

A decision support system is treated as a chance, in view of the priorities, to select the best alternative from a set of alternatives framed or offered by the system. A typical decision-making procedure includes four main phases (see Figure 4.14). Each decision has a different context, thus we must consider:

- the goals;

- the object in question and its environment;

- the criteria defining the efficiency of our choice;

- the variables of the solution;

- the restrictions and risks.

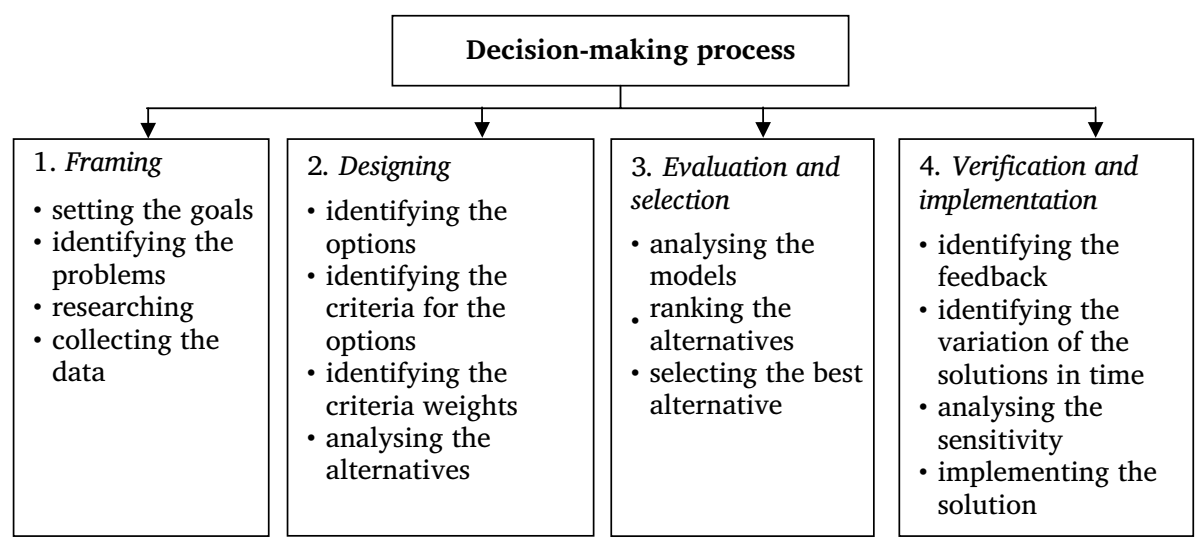

Figure 4.14. Phases in decision-making

The decision-making process starts from goal setting and problem identification. When our decision-making concerns the energy sector, the first and foremost step is defining the development priorities or the strategic goals of the development in the energy sector. The goal setting is of vital importance to make 
right decisions. The strategic goals must be clear and have explicit wording, they must be specific, measurable, matched, realistic, and time-dependent. Sometimes it is best to classify goals by their level. For instance, the Green Paper separates primary, interim and direct goals (Commission of the European... 2006), but in real life primary and direct goals are more frequent.

Primary goals are usually defined by variables at the strategic or higher level (degree of economic growth, social cohesion or sustainable development). These goals may be set forth in the White Paper, national strategies of economic development, and in other national strategic documents of importance. Direct goals are directly related to political instruments, programmes, or projects. Considering the suggested goals one must focus and select the criteria which contribute to direct urgent goals. These goals are seen in national energy strategies or development programmes for national energy sectors.

The next phase designing includes setting of the options, which may be handy while seeking the set goals. The options may include ranking of energy development scenarios or selection of the principal key political instruments, such as new environmental taxes for the energy sector, or individual projects to improve the reliability of energy supply. The most promising options are to be developed further. They may include the key political plans, such as changes in the tax policy, or more detailed options related to preparation of individual investment projects and development scenarios for electricity with the lowest costs. Here, feedback is important. The designing stage also must choose the way to compare the impact of different options or alternatives on implementation of the goals of the first priority. The selected criteria must reflect the performance related to the goals. Each criterion must be measurable for the sake of assessment it must be possible to pick specific indicators that will help to assess the impact of choices on achievement of the set goals. This assessment may be also qualitative; it may express the relation between a certain criterion and the selected option. Identification of weights is an important aspect; a range of methods (described above) may be used for that purpose and the process also includes the assessment of the preferences of social groups.

The evaluation and selection phase includes the analysis of the alternatives. Practical solutions most often require financial analysis, price efficiency analysis, and, in some fields, the cost-benefit analysis. These types of analysis fully, or partially, depend on the expression in money. Conversely, multiple criteria analysis is directly related to some uncertainties and includes qualitative assessment; it allows to make the aspects considered sensitive by the public part of the decision-making process. The most solemn part of this phase is ranking of the alternatives to identify the best solutions. The reliability of the end result depends directly on the identified issues, analysed data, selected system of indicators, thoroughness in the assessment of environmental factors, etc. 
The implementation and verification phase is for implementation of the selected solution and, if possible, verification of the result. It includes identification of the feedback and the variability of solutions in time, as well as the sensitivity analysis.

\subsubsection{Multiple criteria analysis methods and their application}

The core issues of the energy sector may be classified into macroeconomic ones and microeconomic ones. The macro-level issues are addressed by an analysis of energy policies and environmental policies (Diakoulaki et al. 1999; Georgopoulou et al. 1997; Wang et al. 2002) and by planning energy sector investments (Linares 2002; Voropai, Ianiva 2002). Macro-level studies are related to analyses with an aim to choose energy production technologies (Goumas et al. 1999; Haralambopoulos, Polatidis 2003), studies of ways to develop and run energy companies (Dunning et al. 2001; Pan, Rahman 2000), and ways to address environment control and management issues in the energy sector (Hokkanen, Salminen 1997; Ramanathan 2001). Recently, a need for integrated analyses of energy, economy, environmental protection and the social aspect has grown.

Multiple criteria decision support (MCDS) methods were first used in energy planning in the 1970s. Later, as research in the field of multiple criteria modelling was developing fast, the number of practical studies designed to solve multiple criteria decision problems increased greatly. Due to changing economic, social and environmental protection environment, interest in MCDS instruments was growing and became especially prominent in the 1980s. The main reasons behind the fast development of MCDS instruments and their use in energy sector's decision making were the liberalisation of energy markets, implementation of the principles of sustainable development, and engagement of stakeholders in energy decision making to ensure a broad public representation in policymaking. Multiple criteria methods are an attempt to choose an optimal solution by simultaneously assessing alternative solutions against several contradictory criteria. Here is a list of the main energy problems that are solved by using multiple criteria analysis instruments:

- a choice of the most appropriate energy production technologies;

- a choice between competing energy projects to improve energy production efficiency and address environmental issues;

- a choice of the best pricing practice and its criteria in the electrical power market;

- a choice of the best location for energy facilities;

- a choice of the best energy policy measures;

- decisions on the development of new energy resources and prudence of their use; 
- performance assessment in energy companies taking into account such concepts as sustainable development, social responsibility and so on.

When it comes to handling of diverse practical tasks - otably to building of development scenarios, strategic scenarios and investment projects - one must consider economic, environmental, technological, social and other aspects, assess possible alternatives and rank them in the selected order of priority. It may be selection of the best investment or technological project, analysis of alternative scenarios, environmental assessment of different regions in a quest for investment opportunities, etc. More and more books offer decision-making based on multiple criteria analysis methods. Effective decisions are of particular importance in investment projects aiming to ensure provision to the public, in projects financed by national authorities, and in cases that warrant objectivity, transparency and minimised influence of stakeholders.

A number of multiple criteria analysis and evaluation methods have been developed, and are used, worldwide. The newest multiple criteria evaluation methods, above all, facilitate assessment and comparison of objects described by both quantitative and qualitative criteria, by indicators expressed in different units of measurement. The scientists Gutsche, Zimmermann built and described typical systems of indicators, which can be used in multiple criteria analysis methods to measure the differences of quantity, quality and market conjuncture between a comparable object and a valuated object (Zimmermann, Gutsche 1991). Ming$\mathrm{Te} \mathrm{Lu}$ developed an expert system, which uses a system of criteria and helps to select the most profitable or adequate real estate projects (Lu, So 2005). Hwang and Quigley suggest a price assessment model based on the analysis of hedonic and sales comparison approaches; the model helps to estimate an efficient price indicator (Hwang, Quigley 2004). Multiple criteria decision-making methods were used for evaluation of external services available to companies (Almeida 2005), for evaluation of risk management and management of water supply systems (Morais \& Almeida 2007), for project risk assessment (Zeng, Min \& Smith 2007), for risk evaluation in natural gas supply systems (Brito, Almeida 2008), and to reconcile infrastructure investments with environmental problems (Higgins et al. 2008). Multiple criteria methods are an attempt to choose an optimal decision when the alternative decisions must be concurrently assessed based on several contradictory criteria. Multiple criteria analysis methods view alternatives in an integrated manner: they deal with quantitative (operational territory, number of objects, cost, expenses, production capacity, etc.) and qualitative (legal acts, regulations, restrictions, stakeholder influence, technological novelty, compliance with environmental requirements, level of innovation, etc.) criteria of the current market conjuncture that describe the value of the item in question. Many current tasks related to energy strategy, development and technology selection are multiple criteria tasks. 
Sources of literature, which discuss multiple criteria evaluation methods, also suggest conditional classifications: methods are classified according to the sets of alternatives, the units of measurement, the decision-making rules, and the standardisation of evaluation results. For instance, by the type of data, decision-making methods may be classified into three groups: 1) deterministic, 2) stochastic, and 3) fuzzy sets. There may be cases, however, when different types of data are combined. Many authors suggest classifications which generally differ only by the comprehensiveness and number of methods. The key difference between classifications suggested by various authors is that some classify methods only by the type of information about indicators, while others introduce categories of information about alternatives (Chen, Hwang 1991; Hwang, Yoon 1981; Triantaphyllou 2000).

Multiple criteria decision-making methods are most often classified into two distinct groups with different methodology for identification of preferences and for aggregation of information about criteria (Zavadskas, Peldschus \& Kaklauskas 1994). The first group includes multiple criteria methods from the value (utility) theory based on the premise of compensation - comparison of criteria: a possibility to fully balance the negative aspects of one criterion with positive aspects of another. The other group includes the outranking methods based on the concept of value without compensation and denies that criteria may offset one another. This methods may be further classified into three subgroups: 1) selection of the most beneficial variant using the utility function, 2) compromise models for selection of the variant closest to ideal, 3) concordance models to determine the priority relations of the highest compatibility (Hwang, Yoon, 1981; Zavadskas, Peldschus \& Kaklauskas 1994; Guitouni, Martel 1998; Jeroen, 1999).

Multiple criteria analysis methods are abundant; their choice is based on the available data, goals, desired result and participation of decision-makers in the evaluation process. We shall proceed with a brief review of several multiple criteria methods, which are most adequate worldwide and are best suited for environmental analysis, for evaluation of project alternatives and technologies in the energy sector, and for integrated handling of environmental issues.

1. Multiple criteria methods of the value (utility) theory. This group of methods uses qualitative input and produces quantitative output. The group has two main subgroups: analytic hierarchy process methods and fuzzy set methods. The Analytic Hierarchy Process (AHP) was developed by the American scientist Thomas A. Saaty; lately, it is gaining popularity worldwide and is the most frequently used method for paired comparison of indicators (criteria, objects, features). It helps to find the weights of indicators located on the same level of a hierarchy with respect to a higher level or weights of hierarchically unstructured indicators. This method is based on a paired comparison matrix. Experts compare pairs of all indicators (technologies) in question $R_{i}$ and $R_{j}(i, j=1, \ldots m$ ); here $m$ is the number of compared indicators (features). 
It is a convenient method, because paired comparison of indicators is simpler than comparison of all at once. The comparison of indicators is simple and rather reliable: it reveals the degree to which one indicator is more important than the other. This method enables transformation of a qualitative expert assessment of indicators into quantitative assessment. Such comparison produces a quantum matrix $P=\left\|p_{i j}\right\|(i, j=1, \ldots m)$. Mr Saaty suggests evaluations using a 5-point scale (1-3-5-7-9), which is frequently used in real-life applications (Saaty 2000; Tam, Tong \& Chiu 2006).

Multipurpose problems need to be separated into several components, because it helps to simplify the problem and to structure it better. A hierarchy with different goals and/or layers of instruments must be compiled for each problem. This method is handy when one has to deal with problems hard to define and to assess expert opinions to be later used in problem solving. Moreover, the method is better at rendering the processes of human thinking than the method of logical strings. Besides being handy in finding the best solution, the Analytic Hierarchy Process also facilitates qualitative expression of priorities with the help of outranking tools.

The Graphical Evaluation Method is handy for visual representations of information related to facts identified after assessment of alternatives. Graphical visualisation of information also helps to determine the interrelations in and the structure of a phenomenon, and is useful in comparison of alternatives with several criteria, because it helps to visualise the interrelations between the respective criteria (Bertin 1981; Khuri 2002).

Sensitivity Analysis. Whereas the comparative scores and priorities of criteria are undefined in many comparisons of alternatives, evaluations and the selected valuation techniques are based on different premises. Since any evaluation aims to provide a decision-maker with the best alternative or a ranking of alternatives, such uncertainties are important only in assessment of their effect on the ranking. The decision-maker should find to what extent (percentage) the actual values could deviate from the values in the tables for effect evaluation or in the set of weights. The method offers the probability ranking of alternatives, which may be used in the analysis of ranking sensitivity of alternatives considering the overall uncertainty of the effects and priorities (Tam, Tong \& Chiu 2006).

2. Outranking methods. Both input and output of these methods is quantitative. This group includes multiple criteria methods of the utility theory and a number of other types: TOPSIS (Technique for Order Preference by Similarity to Ideal Solution), SAW (Simple additive Weighting), LINMAP (Linear Programming Techniques for Multidimensional Analysis of Preference), ELECTRE (Elimination Et Choix Traduisant la Realite), PROMETHEE I, II, MELCHIOR, ORESTE, COPRAS, etc. The methods in this group have a strict mathematical foundation on axioms. They are convenient because each alternative has its utility expressed in 
a quantitative form, and the comparison of values is simple. But these methods have a drawback: quantitative measurements are prone to inaccuracies due to slips by respondents or to other types of errors. When this group of methods is used, the results produced by various criteria are ranked and then the rankings are analysed. The outranking method is based on paired comparison of alternatives. All pairs for a criterion in question must be compared. The better alternative of each pair is determined by summing the results according to all criteria. This simple technique is used for quantitative data. Qualitative data, if any, are interpreted as unknown quantitative weights. The set $S$ must be defined to include all strings of quantitative weights matching the qualitative priority information. Sometimes one alternative will be preferred from the entire set $S$, and in other cases one alternative may be preferred only from a certain part of the set $S$, with preference given to other alternatives in other parts of the said set. The distribution of weights in the set $S$ is deemed unchangeable; the relative values of subsets in the set $S$ may, therefore, be interpreted as a probability that one alternative in each pair is always preferable over the other. Probabilities are then summed to rank general alternatives (Von Winterfeldt, Edwards 1986; Šliogerienè, Štreimikienė \& Kaklauskas 2011).

The PROMETHEE method differs from other multiple criteria methods with its deeper logics. The method is based on the so-called priority functions. Decision-makers may select these functions and set their parameters themselves. The PROMETHEE method offers a wide selection of functions to enable better reflection of the evaluator's opinions. At the basis of the method, there is the matrix $R=\left\|r_{i j}\right\|$ compiled from the defining indicators of compared objects and statistical data (or expert assessment), and weights of the indicators $\omega_{i} ;(i=1$, $2, \ldots, m ; j=1,2, \ldots, n$, here $m$ is the number of indicators and $n$ is the number of compared objects, i.e. alternatives).

Quantitative multiple criteria evaluation methods determine whether an indicator is maximising or minimising. The best values of maximising indicators are the highest, while the best values of minimising indicators are the lowest. The criteria in quantitative multiple criteria methods often combine normalised values and weights of indicators. The logics employed in the PROMETHEE method differs from other quantitative multiple criteria methods. The decision-maker is an active participant in the phase of problem shaping and problem solving. The decision-maker adds the priorities in the method's assessment procedure: determines the permissible extremes of differences $q$ and $s$ (highest and lowest) for each indicator (criterion) $R_{i}$. In the PROMETHEE method, alternatives $A_{j}$ and $A_{k}$ are considered indifferent with respect to the indicator $R_{i}$, if the difference $\mathrm{d}_{i}$ $\left(A_{j}, A_{k}\right)=r_{i j}-r_{i k}$ between the indicator's values $r_{i j}$ and $r_{i k}$ is below the lowest extreme value $q$. Also, the alternative $A_{j}$ is preferred over the alternative $A_{k}$ if the difference is above the highest extreme value $s$. Moreover, Decision maker sets 
a specific priority function $p(d)$ (with the parameters $q$ and $s$ ) for each indicator. The function's values vary between 0 and 1 , and show the extent to which the alternative $A_{j}$ is more important than the alternative $A_{k}$ (with respect to the indicator $R_{i}$ ). In practical applications, six variants of typical priority functions $p(d)$ suffice (Podvezko \& Podvezko 2009). The PROMETHEE method bases its final evaluation on all positive priorities of each alternative. The PROMETHEE I method defines the relation of priority and indifference for all alternatives $A_{j}$ and $A_{k}$ with either plus or minus: $P^{+}, P^{-}, I^{+}, I^{-}$. The PROMETHEE II method ranks the alternatives by the differences $\mathrm{F}_{j}=\mathrm{F}^{+}{ }_{j}-\mathrm{F}^{-}{ }_{j}$. The PROMETHEE I method determines the best of compared alternatives (Brans, Mareschal 2005).

COmplex Proportional ASsessment method (COPRAS). This method was developed by E. K. Zavadskas and A. Kaklauskas, scientists from Vilnius Gediminas Technical University. In multiple criteria analysis, it is expedient to combine the quantitative and qualitative assessment. It is the COPRAS method that helps to analyse more aspects of one object by combining quantitative and qualitative criteria. This method has a huge advantage it helps not only to compare any alternatives but also to measure their market value. In this method, the selected alternatives are subjected to integrated analysis, considering quantitative (e.g., operational territory, number of objects, cost of products or services, production capacity, the replacement cost) and qualitative (e.g., restrictions imposed by legislation and regulations, technological novelty, compliance with environmental requirements, level of innovation, stakeholder influence, etc.) criteria of the market conjuncture, which describe the object (Zavadskas, Peldschus \& Kaklauskas 1994).

It is easy to express quantitative criteria by the quantitative measures of your choice (amount of money, technical parameters, etc.), but in case of qualitative criteria expressed by conditional measures (scores, percentages) it is a more complex procedure to measure their values and weights. Weights for qualitative criteria must be identified through analysis, scientific studies and databases, by comparing equivalents, and by analysing macro-, meso- and microenvironment in regions with similar development degrees or development trends.

Additive methods deserve a separate mention, in particular the widely applied simple additive weighting method and its later improved versions (MacCrimmon 1968; Ginevičius 2004; Zavadskas, Turskis \& Vilutiene 2010).

The methods in this group have a strict mathematical foundation on axioms. They are convenient, because each alternative has its utility expressed in a quantitative form and the comparison of such values is easy. But these methods have a weakness: it is hard to avoid inaccuracies in quantitative measurements due to mistakes made by respondents or other types of errors (Štreimikienè, Mikalauskienè 2009). When this group of methods is applied, the results produced by various criteria are ranked and then the rankings analysed. The ranking method is based 
on pairwise comparison of alternatives. All pairs of alternatives are compared for each criterion. Summing of the results according to all criteria determines which of two alternatives is better. This simple method is applied for quantitative data. Qualitative data are interpreted as unknown quantitative weights. The set $S$ is defined comprising all strings of quantitative weights that match the qualitative priority information. Sometimes one alternative will be preferred from the entire set $S$; in other cases one alternative will be preferred only from a certain part of the set $S$, but another alternative will be favoured in other parts of the set. The distribution of weights in the set $S$ is deemed unchangeable, thus the relative values of the subsets in the set $S$ can be interpreted as a probability that in each pair one alternative is preferred over the other. The probabilities are then summed to rank general alternatives (Von Winterfeldt, Edwards 1986).

Around the world various methods are employed to solve energy sector problems, but every time we need to make a comprehensive analysis to assess the energy sector's environment and its development scenarios with an aim to choose technologies, a decision must be made which methods are the most appropriate. A method's validity and handiness are important in the choice. A possibility to interpret intermediate results and other factors are important, too.

Scientific literature usually applies such methods as AHP, PROMETHEE and ELECTRE to analyse energy sector decisions. Recently, COPRAS (Complex Proportional Assessment method) and MOORA, multipurpose methods developed by Lithuanian scientists, have also been used as tools to chose energy generation technologies.

\subsubsection{How criteria sets are assembled}

Activities of the energy sector, or separate companies operating within it, are commonly analyzed using methods based on the analysis of quantitative (mostly economic) indicators. However, only those measures that enable evaluation of the entire set of factors which affect operation in the short term and in the long term can be effective. For this task, a system of criteria must be compiled enabling evaluation of qualitative and quantitative factors.

The environmental analysis and decision making in the energy sector are complex matters that imply multiple contradictory goals. Inherent to the matters is also a great deal of uncertainties, long time periods, capital-intensive investments, and a mass of stakeholders with different attitudes and preferences. The key tasks in solving energy sector problems are to come up with a set of criteria that fits the problem's description and to choose the right multiple criteria decision method. Some comprehensive studies have focused on ways to assemble systems of criteria for analyses of energy economics and environmental protection. The studies examined scientific publications dealing with the application of MCDS instruments in the energy sector and proposed sets of criteria for the 
sector's analysis. The criteria are classified into four main groups: technical, economic, environmental and social (Wang et al. 2009). Although some problems may need specific criteria, is appears that depending on the problem's nature the same or very similar sets of criteria are usually used, with economic, social, technological and environmental aspects considered.

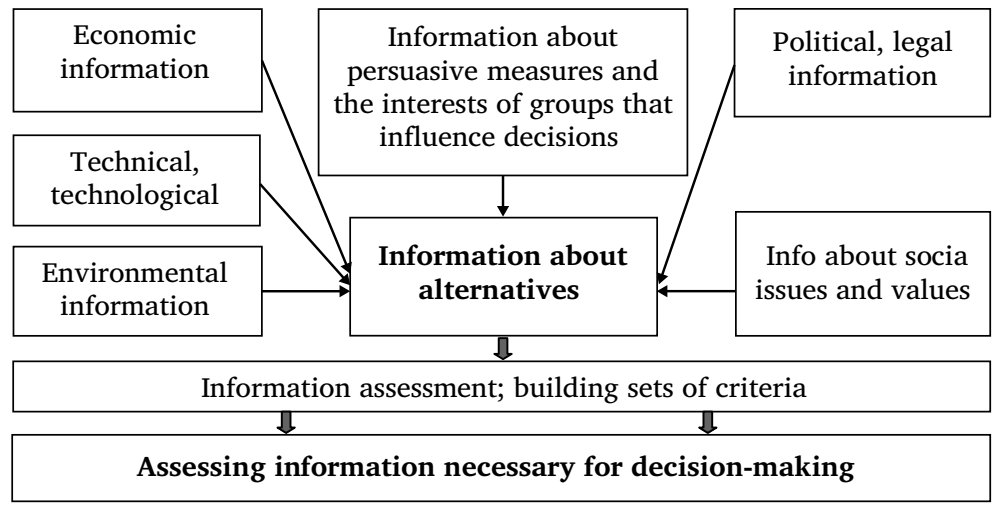

Figure 4.15. The information model for preparation of decisions

Handling of issues related to the choice and assessment of alternatyves includes analysis of highly diverse information - from economic and technological to social and value-related to the needs and impact of stakeholder groups. In order to select the most relevant information that describes alternatives, the research scope must be determined: 1) the environmental factors most relevant to the analysis distinguished; 2) quantitative and qualitative criteria that best describe the alternatives in question determined; 3) the set of criteria for the decision support system built; 4) select the most appropriate multicriteria method. Because a set of measurable criteria is insufficient to make a thorough analysis of the effect of environment considering the principles of sustainable development and public expectations, properly adapted sets of criteria are needed for the assessment of technologies. Any alternatives may be described using the information model in Figure 4.15, which combines technical, technological, economic and political information related to the environment and the dimension of social issues and values, but also allows describing the effect of the environment on the value of technologies.

The information needed for decision-making consists of quantitative and qualitative criteria. When the sets include qualitative criteria, the system can be more flexible in the integrated analysis of changing environment and can assess the role of the dimension of social issues and values. Some criteria, such as the profit margin and the risk of accidents, may be expressed both by quantitative and qualitative criteria. The number of criteria in the sets depends on the research scope. 
Table 4.1. Assessment criteria of energy generation technologies

\begin{tabular}{|c|c|c|c|}
\hline Criteria & Aspect & Criteria & $\begin{array}{c}\text { Units of } \\
\text { measurement }\end{array}$ \\
\hline \multirow{3}{*}{ 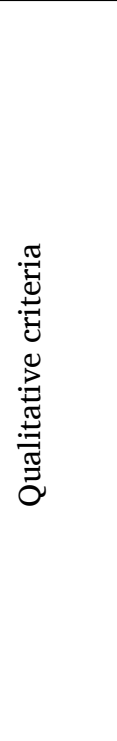 } & Political, legal & $\begin{array}{l}\text { Legal regulation of activities } \\
\text { Impact on energy security }\end{array}$ & $\begin{array}{l}\text { points } \\
\text { points }\end{array}$ \\
\hline & $\begin{array}{l}\text { Social issues } \\
\text { and values }\end{array}$ & $\begin{array}{l}\text { Accessibility of energy sources } \\
\text { Competitiveness of technologies } \\
\text { Dependence on resource provision } \\
\text { Profit margin } \\
\text { Energy culture and ethics } \\
\text { Equal employment opportunities } \\
\text { Collaboration with academic and research } \\
\text { institutions } \\
\text { Influence on social environment } \\
\text { Innovativeness of the technology } \\
\text { Public attitude toward the technology } \\
\text { Application of social responsibility principles }\end{array}$ & $\begin{array}{l}\text { points } \\
\text { points } \\
\text { points } \\
\text { points } \\
\text { points } \\
\text { points } \\
\text { points } \\
\text { points } \\
\text { points } \\
\text { points } \\
\text { points }\end{array}$ \\
\hline & $\begin{array}{l}\text { Environmental } \\
\text { protection }\end{array}$ & $\begin{array}{l}\text { Reliability of the technology (risk of accidents) } \\
\text { Contribution to the share of renewable energy } \\
\text { resources (RER) in the total balance } \\
\text { Effect on climate change and pollution cuts }\end{array}$ & $\begin{array}{l}\text { points } \\
\text { points } \\
\text { points }\end{array}$ \\
\hline \multirow{3}{*}{ 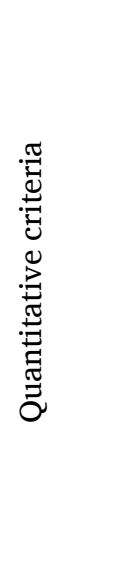 } & Economic & $\begin{array}{l}\text { Energy intensity in GDP terms } \\
\text { Energy generation technologies, the plant } \\
\text { value (creation costs) } \\
\text { Energy generation technologies, value of inte- } \\
\text { grated exploitation } \\
\text { Product cost (production price of energy) }\end{array}$ & $\begin{array}{l}\text { the } / € \mathrm{~m} \\
€ \\
€ \text { cents }\end{array}$ \\
\hline & $\begin{array}{l}\text { Environmental } \\
\text { protection }\end{array}$ & $\begin{array}{l}\text { Share of RER in final energy output } \\
\text { Greenhouse gas emissions } \\
\text { Traditional emissions: SO2, NOx, CO } \\
\text { Energy consumption intensity by GDP }\end{array}$ & $\begin{array}{l}\% \\
\text { '000 tonnes } \\
\text { '000 tonnes } \\
\text { (TNE) / €m } \\
\text { of GDP }\end{array}$ \\
\hline & Technical & $\begin{array}{l}\text { Pollution taxes } \\
\text { Rated capacity } \\
\text { Risk of accidents }\end{array}$ & $\begin{array}{l}€ \mathrm{~m} \\
\mathrm{MW} \\
\%\end{array}$ \\
\hline
\end{tabular}

In the decision support system, the selected quantitative criteria are expressed by relevant measuring units; qualitative criteria are scored by points determined through expert methods. An example of a set of criteria, supplemented with the criteria characterizing the aspect of values, is shown in Table 4.1.

Such large amounts of often contradictory information are best processed using multiple criteria evaluation methods and integrated software applications. Multiple criteria decision-making methods help compare and assess technologies, development scenarios, political measures and their efficiency. An advantage is the possibility to combine both quantitative and qualitative criteria in 
an integrated manner and to assess the relevant aspect from the entire pool of information. It can be meaningful to apply more than one method or combination of methods in order to reach a broader decision basis. Application of more than one method can provide decision makers different perspectives and an opportunity to compare results so that a more appropriate final decision can be made (Atici, Ulucan 2011).

Analysis of the environment of energy sector using multiple criteria analysis facilitates thorough examination of trends and the effect of environment, while comparison and ranking of alternatyves helps choose the most appropriate solution and incorporate them into energy models.

\subsubsection{Case study: assessment of energy generation technologies considering the dimension of values}

Issues related to the choice or development of energy generation technologies are usually handled using economic evaluation and decision justification methods which are typical in the market. These methods lack measures to make an integrated assessment of environmental factors. Energy sector is typically multidimensional and indeterminate, while the energy generation technologies in question have different quantitative and qualitative parameters. An decision support system, which is based on multiple criteria analysis methods and integrates economic, technological and environmental criteria, as well as the criteria of social issues and values, facilitates analysis of the environmental effect on the value of technologies, selection of the best technologies and analysis of the impact of criteria that determine such decisions.

A variety of multicriteria methods can be used for various purposes. The decision maker usually decides which method to be used by taking the nature of the problem into consideration. In method selection, the suitability, validity and user-friendliness of the methods are the important factors to be considered (Atici, Ulucan 2011; Loken 2007). A number of the recent studies deal with application of multiple criteria decision making methods in energy range. Also, multiple criteria decision making methods are suitable to tackle energy source selection problem (Wang et al. 2009; Yue, Yang 2007).

The decision support system EGTAV-SPS for assessment of energy generation technologies has been developed based on the multiple criteria complex analysis method COPRAS (suggested by Lithuanian scientists E. K. Zavadskas and A. Kaklauskas) and the results of an expert survey (Zavadskas, Kaklauskas 1991; Kaklauskas, Zavadskas, 2009; Šliogerienè et al. 2009) The main goal of the research is to compare, using quantitative and qualitative description, the utility of each technology in relation to each other, to rank them, to find the criteria with the biggest impact on the value of technologies and, above all, to assess the impact of the criteria of social issues and values. 
Kaunas Hydroelectic power Plant

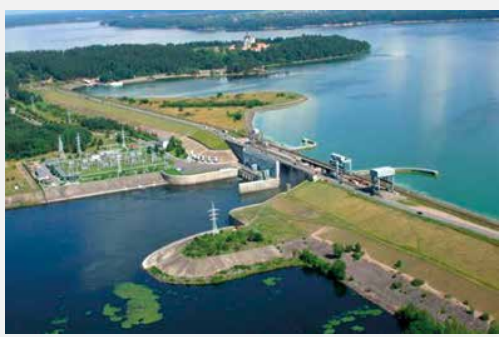

Wind mill park „Benaičiai-1“

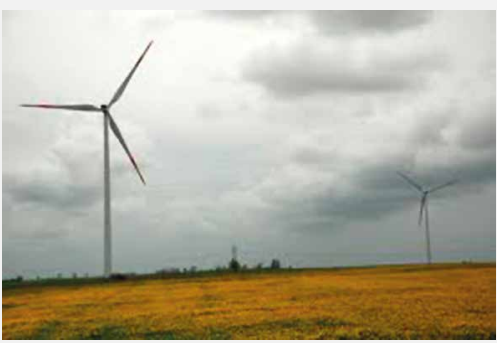

Geothermal Power Plant

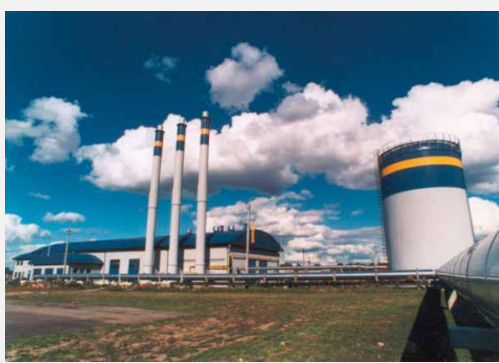

Kaunas HPP, which was constructed and launched in 1960, is the biggest power plant that uses renewable resources in Lithuania. The facilities of the hydroelectric power plant include auxiliary structures of the power plant and hydrotechnical buildings: dam, embankments and dikes. The machinery plant located in the dam contains hydrotechnical equipment, turbines and generators. This object is especially attractive in economic and environmental terms. The power plant produces over $80 \%$ of our national energy based on renewable resources. The amount of produced electricity depends on the seasonal amounts of water resources.

On 29 December 2010, the company's largest object, 34 MW capacity wind energy park "Benaičiai-1" was put in operation. Over the years, the new park will produce approximately 86 million $\mathrm{kWh}$ of electricity and reduce $\mathrm{CO} 2$ emissions by nearly 67 thousand. The wind energy park in Benaičiai has seventeen Enercon E-82 type wind power stations. The hight of one WEP Benaičiai-1 wind power station is about 97 meters. The wind energy equipment was acquired from the leader in this field equipment manufacturing, the German company ENERCON. The wind power stations manufactured by this company are among the most modern and most powerful in Europe.

The geothermal power plant was constructed in 2004 seeking to continue industrial geothermal research, as well as to develop technologies for tapping of underground resources and make integrated use of them in economic activities. Facilities of the company include: the building of Klaipeda geothermal power plant used for activities and the first geothermal bores made in Lithuania, in 1989. Geothermal bores reach geothermal water of a temperature of $40^{\circ} \mathrm{C}$, which is then heated up to $70^{\circ} \mathrm{C}$ and supplied to centralised urban networks. Operating efficiency of the power plant depends on the price of natural gas and on fixed prices for procurement of the produced heat. Despite complicated operating conditions, activities of the geothermal power plant are considered very promising and its development is actively promoted.

Figure 4.16. Description of analyzed objects

To formulate a real-life multiple criteria analysis problem and the algorithm for the automated decision support system, energy generation technologies 
employing different primary energy sources ( hydro, wind and geothermal energy) have been selected: Kaunas Hudroelectric Power Plant, Wind park Benaičiai-1 and Geothermal Power Plant (see Figure 4.16). These types of renewable energy generation technologies are the most suitable for Lithuania's energy industry.

The database is the basis for multi-variant designing and multiple criteria analysis of the objects. The information model presented in Figure 4.15 and the criteria defined in Table 4.1 were used to compile a set of criteria for analysis. The set of criteria has been compiled to describe each dimension of the environment. The set of quantitative criteria includes three quantitative criteria that describe economic and technical parameters of the objects. The qualitative criteria have been selected considering the research goals; they define political and environmental priorities, the preferred values and public attitudes. The dimension of social issues and values has been supplemented with the criteria which express public attitudes and public opinion about the technologies. The criteria which define the preferred values are as follows: influence on social environment (social responsibility), influence on energy culture, equal employment opportunity, public attitude toward technologies. The final set of criteria was built considering expert opinions (of experts involved in the study) on the importance of criteria in assessment of energy generation technologies. The set was used as a basis to compile an expert questionnaire with the key quantitative and qualitative criteria characterising the selected technologies. The weights of the qualitative criteria were established with the help of expert methods.

The study is based on a survey of six experts; they are persons knowledgeable in the field, have technical degrees and are energy-sector executives. The experts were interviewed. They scored the criteria and ranked the criteria respectively. The criteria weights were determined in conditional units: points between 0 and 5. The higher the weight, the more important the criterion to relevant expert and the bigger its impact on the end result of the assessment. Average values of the criteria were estimated using the expert evaluation results and determined for each expert individually. The weights of importance of the criteria groups (institutional-political, technological, economic, social and environment protection) were determined during the first stage. Experts believe that economic factors dominate in the choice and assessment of energy generation technologies. But their second priority was the group of environmental factors - another evidence that environmental issues are important. Furthermore, social factors outranked institutional/political factors. Experts ranked 17 criteria by their importance and then the value of each criterion was determined. Based on the evaluation results the economical and environment protection criteria of the energy sector are assigned with the maximum weight of importance. The results are provided in Figure 4.17. 


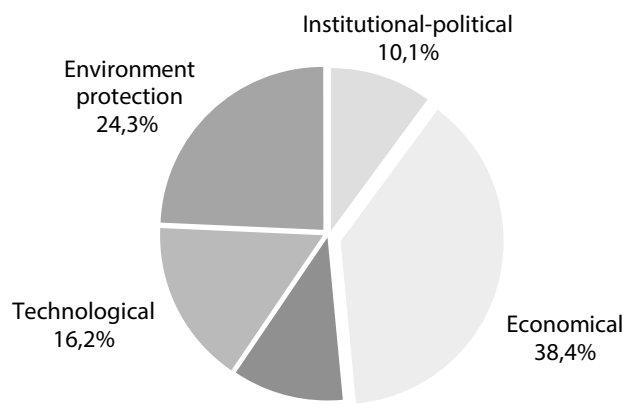

Social-ethics $11 \%$

Figure 4.17. Weights of energy-sector environment factors determined by expert judgement

The research results show that the most significant criteria are production cost, technological complex value, company's (technology's) rated capacity, the technology's dependability and competitiveness, while the technology's innovativeness and dependence on resource provision (political criterion) were specified as the least important. Table 4.2 lists the criteria weights as they were ranked during the expert judgement.

Table 4.2. Criteria rankings

\begin{tabular}{|l|l|c|c|}
\hline No. & \multicolumn{1}{|c|}{ Criterion } & $\begin{array}{c}\text { Criterion } \\
\text { weights }\end{array}$ & Criterion ranks \\
\hline 1. & Production cost (energy price) & 0,0618 & $\mathbf{1}$ \\
\hline 2. & Legal regulation of activities & 0,0617 & $\mathbf{2}$ \\
\hline 3. & Technological complex value & 0,0610 & $\mathbf{3}$ \\
\hline 4. & Company's (technology's) rated capacity & 0,0605 & $\mathbf{4}$ \\
\hline 5. & Technology's dependability (risk of accidents) & 0,0600 & $\mathbf{5}$ \\
\hline$\ldots$ & $\ldots .$. & $\ldots$. & $\ldots$ \\
\hline 14. & Dependence on resource provision & 0,0583 & $\mathbf{1 1}$ \\
\hline 15. & Technology's innovativeness & 0,0566 & $\mathbf{1 5}$ \\
\hline 16. & Dependence on resource provision & 0,0583 & $\mathbf{1 1}$ \\
\hline 17. & Equal employment opportunities & 0,0556 & $\mathbf{1 7}$ \\
\hline
\end{tabular}

Expert evaluations are of stochastic nature: a new set of experts would change the criteria values, which also determine the compatibility of expert opinions (concordance coefficient) and the research reliability. This research is experimental 
and a more general result would require a survey of as broad circle of experts as possible. In future it would be wise to take into account the opinions of at least three expert groups when modeling decisions or selection scenarios. The first expert group would represent analyzed sector, the second - independent national experts, while the third would represent analogous foreign experts.

The multiple criteria analysis method COPRA and the research results were used to develop the experimental decision support system for the analysis of environmental factors of energy generation technologies EGTAV-SPS, which is intended as a tool to determine the utility degree and priority of energy generation technologies employing different energy sources, as well as the effect of environmental factors on their value (Zavadskas, Kaklauskas 1991; Šliogeriene et al. 2012)

The decision support system includes a database and a database management system, a model base and a model base management system, and a user interface (Figure 4.18). The model base includes a multiple criteria analysis model, a model of utility degree and priority, and a recommender model.

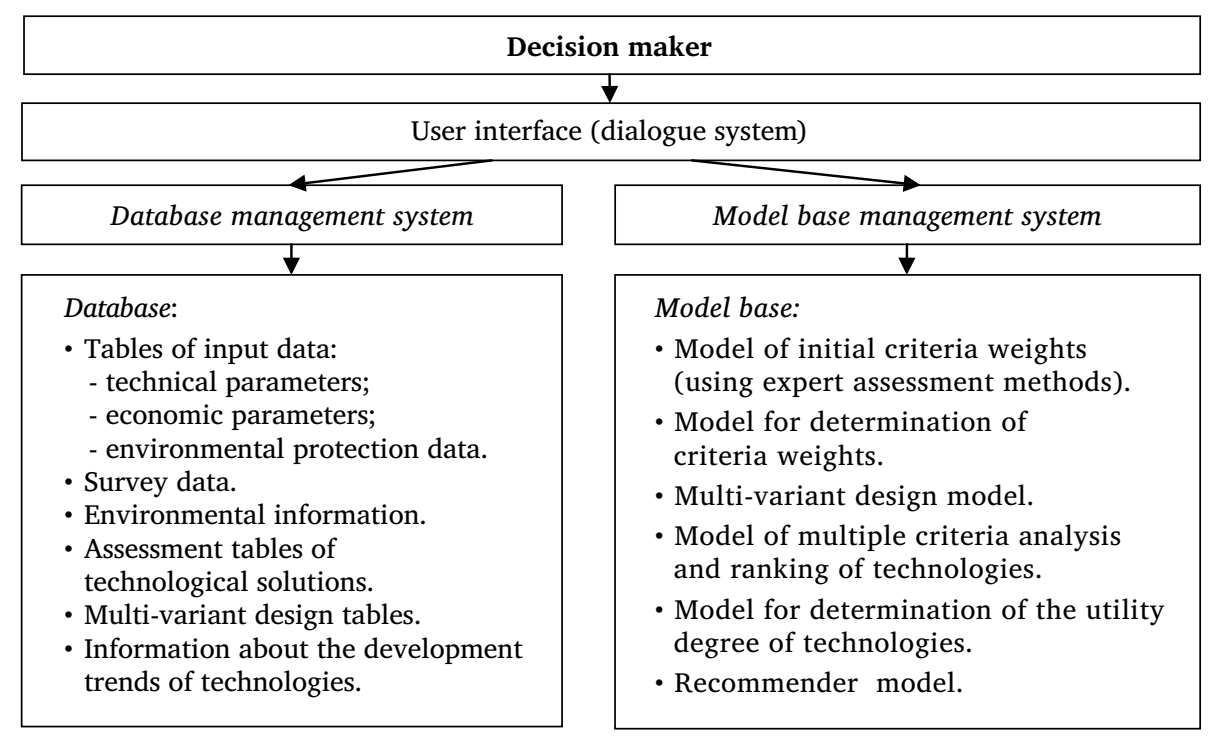

Figure 4.18. Components of the EGTAV-SPS (Zavadskas, Kaklauskas 1991)

The model base management system lets the user choose any required model. The system is designed in such way that the results of calculations in one model are used as the input data in other models, which, in turn, return results which become the input data for yet other models. The decision support system EGTAVSPS enables processing of large amounts of data and monitoring of changes of all criteria in question. The system may be supplemented with new objects and data 
about them. A significant advantage is that the system displays the intermediate results, which reflect the impact of each criterion on the utility and value. This research was the first time the decision support system EGTAV-SPS was used to determine the effect of environmental factors on the value of energy generation technologies with different technical and economic properties (Šliogerienè, Kaklauskas, Štreimikienė \& Bianchi 2012).

The user enters the expert evaluation results and the determined criteria weights in the module's table in the screen "Description of the alternatives" (see Figure 4.19). Then the system automatically solves the multiple criteria problem and presents the results in model bases: determines the utility and priority of objects in question and the effect of criteria on the value of alternatives.

\section{Decision Support System for Measurement of Effect of Environment Factors on Value of Energy Companies}

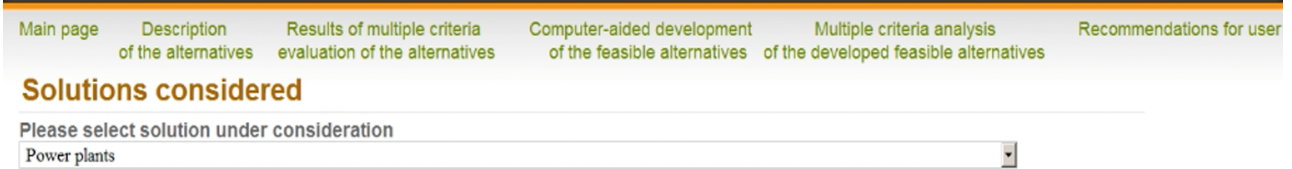

Qualitative and quantitative description of the alternatives

\begin{tabular}{|c|c|c|c|c|c|}
\hline \multicolumn{6}{|c|}{ Quantitative and qualitative information pertinent to alternatives } \\
\hline \multirow[t]{2}{*}{ Criteria describing the alternatives } & \multirow{2}{*}{ ^ $\begin{array}{l}\text { Measuring } \\
\text { units }\end{array}$} & \multirow[t]{2}{*}{ Weight } & \multicolumn{3}{|c|}{ Compared alternatives } \\
\hline & & & \begin{tabular}{|l|} 
Kauno \\
HPP \\
\end{tabular} & $\begin{array}{l}\text { Geothermal } \\
\text { PP }\end{array}$ & $\begin{array}{l}\text { Wind PP } \\
\text { park }\end{array}$ \\
\hline Legal regulation of activities & + points & 0,062 & 25 & 18 & 15 \\
\hline Influence on energy security & + points & 0,06 & 30 & 28 & 30 \\
\hline Technology dependability (accidents risk) & + points & 0,06 & 28 & 20 & 28 \\
\hline Technological competitiveness & + points & 0,06 & 29 & 19 & 21 \\
\hline Dependence on resource provision & - points & 0,058 & 6 & 21 & 9 \\
\hline Profitability degree & + points & 0,059 & 30 & 18 & 26 \\
\hline Influence on social enviroment & + points & 0,057 & 24 & 24 & 27 \\
\hline Technology innovation & + points & 0,057 & 22 & 24 & 26 \\
\hline Influence on enegertic culture & + points & 0,057 & 27 & 25 & 26 \\
\hline Equal employment opportunity & + points & 0,056 & 17 & 15 & 21 \\
\hline Influence on climate changes, pollution decrease & points & 0,058 & 6 & 8 & 6 \\
\hline Cooperation with science establishments & + points & 0,057 & 20 & 26 & 28 \\
\hline $\begin{array}{l}\text { Influence of RER (renewable energy resources) in total energy } \\
\text { balanse }\end{array}$ & points & 0,058 & 30 & 29 & 30 \\
\hline Public attitude towards technologies & - points & 0,06 & 6 & 9 & 8 \\
\hline Company's rated capacity & $+M W$ & 0,061 & 100 & 35 & 35 \\
\hline Production cost price (energy price) & + Ecnt/kwh & 0,062 & 3,2 & 5,5 & 6,9 \\
\hline Technological complex value & + EUR & 0,061 & 52000000 & 24030000 & 31250000 \\
\hline
\end{tabular}

"- The sign "n" indicates that a greater (less) criterion value corresponds to a greater significance for a user (stakeholders)

Figure 4.19. Display of the results of expert evaluation properties (Šliogerienè, Kaklauskas, Štreimikienė \& Bianchi 2012)

Use of the EGTAV-SPS is simple, but the system performs a thorough analysis and presents a lot of useful information. The system's advantage is the analysis 
of the weights of all criteria used in research. The weights of criteria are analysed in the module's window "Results of multiple criteria evaluation of the alternatives". A click on the value of any selected criterion in a matrix cell on the links AVG, MN displays the value of each selected criterion in percent compared to the same criterion of other objects (see Figure 4.20). The result also shows the increase of the percentage that would raise the value of the object in question.

\section{Results of multiple criteria evaluation of the alternatives}

Please select solution under consideration

\begin{tabular}{|c|c|c|c|c|c|}
\hline \multicolumn{6}{|c|}{ Quantitative and qualitative information pertinent to alternatives } \\
\hline \multirow[t]{2}{*}{ Criteria describing the alternatives } & \multirow[t]{2}{*}{ Measuring units } & \multirow[t]{2}{*}{ Weight } & \multicolumn{3}{|c|}{ Compared alternatives } \\
\hline & & & Kauno HPP & Geothermal PP & Wind PP park \\
\hline Legal regulation of activities + + & + points & 0,062 & $\begin{array}{c}0,0267 \\
\text { AVG MIN }\end{array}$ & $\begin{array}{c}0,0192 \\
\text { AVG MIN }\end{array}$ & $\begin{array}{c}0,016 \\
\text { AVG MIN }\end{array}$ \\
\hline Influence on energy security + & + points & 0,06 & $\begin{array}{c}0,0205 \\
\text { AVG MIN }\end{array}$ & $\begin{array}{c}0,0191 \\
\text { AVG MIN }\end{array}$ & $\begin{array}{c}0,0205 \\
\text { AVG MIN }\end{array}$ \\
\hline Technology dependability (accidents risk) + & + points & 0,06 & $\begin{array}{c}0,0221 \\
\text { AVG MIN }\end{array}$ & $\begin{array}{r}0,0158 \\
\text { AVG MIN } \\
\end{array}$ & $\begin{array}{c}0,0221 \\
\text { AVG MIN }\end{array}$ \\
\hline Technological competitiveness + & + points & 0,06 & $\begin{array}{c}0,0252 \\
\text { AVG MIN } \\
\end{array}$ & $\begin{array}{r}0,0165 \\
\text { AVG MIN } \\
\end{array}$ & $\begin{array}{c}0,0183 \\
\text { AVG MIN } \\
\end{array}$ \\
\hline Dependence on resource provision & - points & 0,058 & $\begin{array}{c}0,0097 \\
\text { AVG MIN } \\
\end{array}$ & $\begin{array}{r}0,0338 \\
\text { AVG MIN } \\
\end{array}$ & $\begin{array}{r}0,0145 \\
\text { AVG MIN } \\
\end{array}$ \\
\hline Profitability degree + & + points & 0,059 & $\begin{array}{c}0,0239 \\
\text { AVG MIN } \\
\end{array}$ & $\begin{array}{r}0,0144 \\
\text { AVG MIN } \\
\end{array}$ & $\begin{array}{c}0,0207 \\
\text { AVG MIN } \\
\end{array}$ \\
\hline Influence on social enviroment + & + points & 0,057 & $\begin{array}{c}0,0182 \\
\text { AVG MIN } \\
\end{array}$ & $\begin{array}{r}0,0182 \\
\text { AVG MIN } \\
\end{array}$ & $\begin{array}{c}0,0205 \\
\text { AVG MIN } \\
\end{array}$ \\
\hline Technology innovation + & + points & 0,057 & $\begin{array}{c}0,0174 \\
\text { AVG MIN }\end{array}$ & $\begin{array}{c}0,019 \\
\text { AVG MIN }\end{array}$ & $\begin{array}{c}0,0206 \\
\text { AVG MIN }\end{array}$ \\
\hline Influence on enegertic culture + & + points & 0,057 & $\begin{array}{c}0,0197 \\
\text { AVG MIN }\end{array}$ & $\begin{array}{c}0,0183 \\
\text { AVG MIN }\end{array}$ & $\begin{array}{c}0,019 \\
\text { AVG MIN }\end{array}$ \\
\hline Equal employment opportunity + & + points & 0,056 & $\begin{array}{c}0,018 \\
\text { AVG MIN } \\
\end{array}$ & $\begin{array}{c}0,0158 \\
\text { AVG MIN } \\
\end{array}$ & $\begin{array}{c}0,0222 \\
\text { AVG MIN } \\
\end{array}$ \\
\hline Influence on climate changes, pollution decrease & points & 0,058 & $\begin{array}{c}0,0174 \\
\text { AVG MIN } \\
\end{array}$ & $\begin{array}{r}0,0232 \\
\text { AVG MIN } \\
\end{array}$ & $\begin{array}{c}0,0174 \\
\text { AVG MIN } \\
\end{array}$ \\
\hline Cooperation with science establishments + & + points & 0,057 & $\begin{array}{c}0,0154 \\
\text { AVG MIN } \\
\end{array}$ & $\begin{array}{c}0,02 \\
\text { AVG MIN } \\
\end{array}$ & $\begin{array}{c}0,0216 \\
\text { AVG MIN }\end{array}$ \\
\hline Influence of RER (renewable energy resources) in total energy balanse + & + points & 0,058 & $\begin{array}{c}0,0196 \\
\text { AVG MIN }\end{array}$ & $\begin{array}{c}0,0189 \\
\text { AVG MIN }\end{array}$ & $\begin{array}{c}0,0196 \\
\text { AVG MIN }\end{array}$ \\
\hline Public attitude towards technologies & - points & 0,06 & $\begin{array}{c}0,0157 \\
\text { AVG MIN }\end{array}$ & $\begin{array}{c}0,0235 \\
\text { AVG MIN }\end{array}$ & $\begin{array}{c}0,0209 \\
\text { AVG MIN }\end{array}$ \\
\hline Company's rated capacity + & $+M W$ & 0,061 & $\begin{array}{c}0,0359 \\
\text { AVG MIN }\end{array}$ & $\begin{array}{c}0,0126 \\
\text { AVG MIN }\end{array}$ & $\begin{array}{c}0,0126 \\
\text { AVG MIN }\end{array}$ \\
\hline$\overline{\text { Production cost price (energy price) }}+$ & $+€ \mathrm{cnt} / \mathrm{kwh}$ & $\overline{0,062}$ & $\begin{array}{c}0,0127 \\
\text { AVG MIN }\end{array}$ & $\begin{array}{c}0,0219 \\
\text { AVG MIN }\end{array}$ & $\begin{array}{c}0,0274 \\
\text { AVG MIN }\end{array}$ \\
\hline Technological complex value + & + EUR & $\overline{0,061}$ & $\begin{array}{c}0,0296 \\
\text { AVG MIN }\end{array}$ & $\begin{array}{c}0,0137 \\
\text { AVG MIN }\end{array}$ & $\begin{array}{c}0,0178 \\
\text { AVG MIN }\end{array}$ \\
\hline The sums of weighted normalized maximizing (projects 'pluses' & $\left.s^{\prime}\right)$ indices of the alt & ernative & 0,3049 & 0,2434 & 0,2789 \\
\hline The sums of weighted normalized minimizing (projects 'minuses' & $\left.s^{\prime}\right)$ indices of the alt & ernative & 0,0428 & 0,0805 & 0,0528 \\
\hline & gnificance of the alt & ernative & 0,3597 & 0,2854 & 0,3398 \\
\hline & Priority of the alt & ernative & 1 & 3 & 2 \\
\hline Utility de & legree of the alterna & ative (\%) & $99,99 \%$ & $79,34 \%$ & $94,46 \%$ \\
\hline
\end{tabular}

*- The sign "*" indicates that a greater (less) criterion value corresponds to a greater significance for a user (stakeholders)

Figure 4.20. Determining the utility and priority of energy generation technologies, as well as the weights of criteria, in the EGTAV-SPS properties (Šliogerienè, Kaklauskas, Štreimikienè, Bianchi 2012) 
The same screen of the model can display the effect of environmental factors determined considering quantitative and qualitative criteria, the priority of the object in question and the utility degree.

Having processed the expert evaluation data, the system returned the following results:

1) the highest utility was attributed to Kaunas HHP, which employs hydrotechnologies;

2) the second priority was attributed to the wind farm;

3) the third priority, in terms of utility, was attributed to the power plant which employs geothermal technologies.

\section{Recommendations for user}

Please select solution under consideration

Power plants

Qualitative and quantitative description of the alternatives

\begin{tabular}{|c|c|c|c|c|c|c|}
\hline \multicolumn{7}{|c|}{ Quantitative and qualitative information pertinent to alternatives } \\
\hline \multirow[t]{2}{*}{ Criteria describing the alternatives } & \multirow[t]{2}{*}{$\pi$} & \multirow[t]{2}{*}{$\begin{array}{l}\text { Measuring } \\
\text { units }\end{array}$} & \multirow[t]{2}{*}{ Weight } & \multicolumn{3}{|c|}{$\begin{array}{l}\text { - Compared alternatives } \\
\text { - Possible improvement of the analysed criterion in \% } \\
\text { - Possible increase of the value of the alternative in \% through increased } \\
\text { value of the aforementioned criterion }\end{array}$} \\
\hline & & & & Kauno HPP & Geothermal PP & Wind PP park \\
\hline Legal regulation of activities & + & points & 0,062 & \begin{tabular}{|l}
25 \\
$(0 \%)(0 \%)$
\end{tabular} & $\begin{array}{l}18 \\
(38,89 \%)(2,404 \%)\end{array}$ & $\begin{array}{l}15 \\
(66,67 \%)(4,121 \%)\end{array}$ \\
\hline Influence on energy security & + & points & 0,06 & $\begin{array}{l}30 \\
(0 \%)(0 \%)\end{array}$ & $\begin{array}{l}28 \\
(7,14 \%)(0,427 \%)\end{array}$ & $\begin{array}{l}30 \\
(0 \%)(0 \%)\end{array}$ \\
\hline Technology dependability (accidents risk) & + & points & 0,06 & $\begin{array}{l}28 \\
(0 \%)(0 \%)\end{array}$ & $\begin{array}{l}20 \\
(40 \%)(2,393 \%)\end{array}$ & $\begin{array}{l}28 \\
(0 \%)(0 \%)\end{array}$ \\
\hline Technological competitiveness & + & points & 0,06 & $\begin{array}{l}29 \\
(0 \%)(0 \%)\end{array}$ & $\begin{array}{l}19 \\
(52,63 \%)(3,148 \%)\end{array}$ & $\begin{array}{l}21 \\
(38,1 \%)(2,279 \%)\end{array}$ \\
\hline Dependence on resource provision & - & points & 0,058 & $\begin{array}{l}6 \\
(0 \%)(0 \%)\end{array}$ & $\begin{array}{l}21 \\
(71,43 \%)(4,13 \%)\end{array}$ & $\begin{array}{l}9 \\
(33,33 \%)(1,928 \%)\end{array}$ \\
\hline Profitability degree & + & points & 0,059 & $\begin{array}{l}30 \\
(0 \%)(0 \%)\end{array}$ & $\begin{array}{l}18 \\
(66,67 \%)(3,922 \%)\end{array}$ & $\begin{array}{l}26 \\
(15,38 \%)(0,905 \%)\end{array}$ \\
\hline Influence on social enviroment & + & points & 0,057 & $\begin{array}{l}24 \\
(12,5 \%)(0,71 \%)\end{array}$ & $\begin{array}{l}24 \\
(12,5 \%)(0,71 \%)\end{array}$ & $\begin{array}{l}27 \\
(0 \%)(0 \%)\end{array}$ \\
\hline Technology innovation & + & points & 0,057 & $\begin{array}{l}22 \\
(18,18 \%)(1,033 \%)\end{array}$ & $\begin{array}{l}24 \\
(8,33 \%)(0,474 \%)\end{array}$ & $\begin{array}{l}26 \\
(0 \%)(0 \%)\end{array}$ \\
\hline Influence on enegertic culture & + & points & 0,057 & $\begin{array}{l}27 \\
(0 \%)(0 \%)\end{array}$ & $\begin{array}{l}25 \\
(8 \%)(0,455 \%)\end{array}$ & $\begin{array}{l}26 \\
(3,85 \%)(0,219 \%)\end{array}$ \\
\hline Equal employment opportunity & + & points & 0,056 & $\begin{array}{l}17 \\
(23,53 \%)(1,314 \%)\end{array}$ & $\begin{array}{l}15 \\
(40 \%)(2,233 \%)\end{array}$ & $\begin{array}{l}21 \\
(0 \%)(0 \%) \\
\end{array}$ \\
\hline $\begin{array}{l}\text { Influence on climate changes, pollution } \\
\text { decrease }\end{array}$ & F & points & 0,058 & $\begin{array}{l}6 \\
(0 \%)(0 \%)\end{array}$ & $\begin{array}{l}8 \\
(25 \%)(1,446 \%)\end{array}$ & $\begin{array}{l}6 \\
(0 \%)(0 \%)\end{array}$ \\
\hline Cooperation with science establishments & + & points & 0,057 & $\begin{array}{l}20 \\
(40 \%)(2,273 \%)\end{array}$ & $\begin{array}{l}26 \\
(7,69 \%)(0,437 \%)\end{array}$ & $\begin{array}{l}28 \\
(0 \%)(0 \%)\end{array}$ \\
\hline $\begin{array}{l}\text { Influence of RER (renewable energy } \\
\text { resources) in total energy balanse }\end{array}$ & + & points & 0,058 & $\begin{array}{l}30 \\
(0 \%)(0 \%)\end{array}$ & $\begin{array}{l}29 \\
(3,45 \%)(0,199 \%)\end{array}$ & $\begin{array}{l}30 \\
(0 \%)(0 \%)\end{array}$ \\
\hline Public attitude towards technologies & F & points & 0,06 & $\begin{array}{l}6 \\
(0 \%)(0 \%)\end{array}$ & $\begin{array}{l}9 \\
(33,33 \%)(1,994 \%)\end{array}$ & $\begin{array}{l}8 \\
(25 \%)(1,496 \%)\end{array}$ \\
\hline Company's rated capacity & + & MW & 0,061 & $\begin{array}{l}100 \\
(0 \%)(0 \%)\end{array}$ & $\begin{array}{l}35 \\
(185,71 \%)(11,295 \%)\end{array}$ & $\begin{array}{l}35 \\
(185,71 \%)(11,295 \%)\end{array}$ \\
\hline Production cost price (energy price) & + & $€ \mathrm{cnt} / \mathrm{kwh}$ & 0,062 & $\begin{array}{l}3,2 \\
(115,62 \%)(7,147 \%)\end{array}$ & $\begin{array}{l}5,5 \\
(25,45 \%)(1,573 \%)\end{array}$ & $\begin{array}{l}6,9 \\
(0 \%)(0 \%) \\
\end{array}$ \\
\hline Technological complex value & + & EUR & 0,061 & $\begin{array}{l}52000000 \\
(0 \%)(0 \%)\end{array}$ & $\begin{array}{l}24030000 \\
(116,4 \%)(7,079 \%)\end{array}$ & $\begin{array}{l}31250000 \\
(66,4 \%)(4,038 \%)\end{array}$ \\
\hline
\end{tabular}

*- The sign "x" indicates that a greater (less) criterion value corresponds to a greater significance for a user (stakeholders)

Figure 4.21. The recommender module properties (Šliogerienè, Kaklauskas, Štreimikienè, Bianchi 2012) 
Such results have been determined by the technology creation costs, the production cost of energy and favourable assessment of the environment. Kaunas HHP, for instance, has low production costs, received favourable assessment of the environmental aspect and is favourably received by the public. The geothermal power plan, ranked third by its utility, partly uses traditional technologies based on organic fuels (to heat the extracted geothermal water up to the required temperature). The geothermal power plant was ranked lowest because of the high production cost of energy, partial dependence on resources and less favourable public opinion of this technology.

The main advantage of the EGTAV-SPS, which distinguishes it among other decision support systems, is recommendations to user. The model analyses all alternatives using the entire set of criteria. The system automatically analyses each criterion, determines its effect, compares it among alternatives and assesses its potential to change the end result in the assessment of alternatives (see Figure 4.21).

The system calculates the level of influence each criterion can have on the priority and utility of an object and provides visual recommendations. For instance, the recommendations show that a $40 \%$ increase (compared to the best technology in this respect) of the reliability of technology in the geothermal power plant could improve its utility by about $2.4 \%$, while a $25 \%$ improvement of public opinion about the power plant employing wind power would raise its utility by $1.5 \%$.

The analysis of such results may be an efficient and helpful tool for comparison of energy generation technologies, for preparation of development and management decisions, and for assessment of efficiency. While changes in the effect of some criteria are hardly possible or even impossible, some of them such as reliability, effect on the social environment and public opinion - can be changed by efforts of parties concerned.

The recommender model selects and displays three most significant criteria, which determine the utility of each alternative in question (see Figure 4.22). Although quantitative criteria - the rated capacity, the value of the technology and the production cost of energy - have been determined as the most significant for all three technologies in question, qualitative criteria were also listed among the most important ones. For instance, based on the most significant utility-determining criteria picked by the system, the utility of the power plant employing hydro-energy depends on poor scores given to the collaboration with academic institutions and the influence on social environment (social responsibility). Higher values of these criteria would improve the object's utility of by $2.2 \%$ and $0.7 \%$ respectively. The values of the criteria can be changed without any significant investments-efforts of the staff operating the technologies would suffice (Zavadskas, Kaklauskas 1991; Šliogerienè, Kaklauskas, Štreimikienè \& Bianchi 2012). 
The cost of technologies and the rated capacity are the most important criteria to the geothermal power plant and the wind farm. But the criteria "Dependence on resource provision" and "Legal regulation of activities" are also specified among the most important. While independence of resources, the prices of which are ever increasing, requires substantial investment into new technologies (the case of geothermal power plant), the settlement of legal issues is possible through efforts of executives, professional associations or public organisations (the case of wind farm).

TOP 3 object criterions that have greatest influence on ranking

\begin{tabular}{|c|c|c|c|}
\hline \multicolumn{4}{|c|}{ Kauno HPP } \\
\hline Position & $\begin{array}{l}\text { Criteria describing the } \\
\text { alternative }\end{array}$ & $\begin{array}{l}\text { Possible improvement of the } \\
\text { analysed criterion in \% }\end{array}$ & $\begin{array}{l}\text { Possible increase of the value of the alternative in \% through } \\
\text { increased value of the aforementioned criterion }\end{array}$ \\
\hline 1 & $\begin{array}{l}\text { Production cost price } \\
\text { (energy price) }\end{array}$ & $116 \%$ & $7 \%$ \\
\hline 2 & $\begin{array}{l}\text { Cooperation with science } \\
\text { establishments }\end{array}$ & $40 \%$ & $2 \%$ \\
\hline 3 & $\begin{array}{l}\text { Influence on social } \\
\text { enviroment }\end{array}$ & $12 \%$ & $1 \%$ \\
\hline
\end{tabular}

\begin{tabular}{|c|c|c|c|}
\hline \multicolumn{4}{|c|}{ Geothermal PP } \\
\hline Position & $\begin{array}{l}\text { Criteria describing the } \\
\text { alternative }\end{array}$ & $\begin{array}{l}\text { Possible improvement of the } \\
\text { analysed criterion in \% }\end{array}$ & $\begin{array}{l}\text { Possible increase of the value of the alternative in \% through } \\
\text { increased value of the aforementioned criterion }\end{array}$ \\
\hline 1 & $\begin{array}{l}\text { Company's rated } \\
\text { capacity }\end{array}$ & $186 \%$ & $11 \%$ \\
\hline 2 & $\begin{array}{l}\text { Technological complex } \\
\text { value }\end{array}$ & $116 \%$ & $7 \%$ \\
\hline 3 & $\begin{array}{l}\text { Dependence on } \\
\text { resource provision }\end{array}$ & $71 \%$ & $4 \%$ \\
\hline
\end{tabular}

\begin{tabular}{|c|c|c|c|}
\hline \multicolumn{4}{|c|}{ Wind PP park } \\
\hline Position & $\begin{array}{l}\text { Criteria describing the } \\
\text { alternative }\end{array}$ & $\begin{array}{l}\text { Possible improvement of the } \\
\text { analysed criterion in } \%\end{array}$ & $\begin{array}{l}\text { Possible increase of the value of the alternative in \% through } \\
\text { increased value of the aforementioned criterion }\end{array}$ \\
\hline 1 & $\begin{array}{l}\text { Company's rated } \\
\text { capacity }\end{array}$ & $186 \%$ & $11 \%$ \\
\hline 2 & $\begin{array}{l}\text { Legal regulation of } \\
\text { activities }\end{array}$ & $67 \%$ & $4 \%$ \\
\hline 3 & $\begin{array}{l}\text { Technological complex } \\
\text { value }\end{array}$ & $66 \%$ & $4 \%$ \\
\hline
\end{tabular}

Figure 4.22. The most significant criteria specified by the recommender module properties (Šliogerienė, Kaklauskas, Štreimikienė \& Bianchi 2012)

The decision support system for assessment of energy generation technologies EGTAV-SPS facilitates the decision-maker to extract from its database versatile and thorough quantitative and qualitative information about the effect of environment and to use the model base for flexible analysis of these factors and for decision-making. The EGTAV-SPS provides logical and informative results about the utility of the technologies in question and the effect of environmental factors on their value; it also gives recommendations for each criterion and helps avoid errors and partiality. In summary, the developed decision support system 
EGTAV-SPS enables unbiased results, which can be used in assessment of a range of energy generation technologies, their utility and the efficiency of their environment; in other analyses as well (Šliogerienè, Kaklauskas, Štreimikienė \& Bianchi 2012).

The EGTAV-SPS is an experimental system, but at this stage it can already be used as an additional tool in a range of studies or as a controlling tool to verify the results of other investigations. Improvements of the system could make it useful for the analysis of performance, identification of crucial values of environmental factors and as an auxiliary tool to plan the course of actions, choose development scenarios and compare technologies. The system may also include the model of market value determination, but assessment of energy generation technologies from the market perspective would require market data and other types of studies.

When it comes to the analysis of the development trends of energy generation technologies, selection of technological alternatives or measurement of the utility and efficiency of individual energy generation technologies, the main course of research is selection of criteria and building their system which can be universally applied across the technologies. It is important to determine the relationship among criteria describing various aspects, to choose proper criteria important to the analysis and perform rather broad studies, which enable proper assessment of the weights. Such actions would help to develop more universal decision support systems for the analysis of this industry and to make their use increasingly popular. Integrated assessment of technical, economic and environmental aspects, as well as the dimension of social issues and values is possible by choosing and using appropriate multiple analysis methods, such as COPRAS (the multiple criteria complex utility degree and market value determination method) used in this research (Zavadskas, Kaklauskas 1991; Šliogerienè, Kaklauskas, Štreimikienè \& Bianchi 2012). The method was used to process the values of the environmental factors of energy objects chosen for this analysis, to determine criteria weights and to compile the set of criteria, which can be used in analysis of other equivalent objects.

The expert assessment of the effect of environmental factors on the value of energy generation technologies has shown that such technologies must be analysed from a much broader perspective than just their technical or economic properties. Because the goal of creation and implementation of energy generation technologies is satisfaction of public needs, their assessment must also consider the feedback, which is expressed through the environmental protection aspect and the dimension of social issues and values. The research suggests that criteria of social issues and values play a role in the utility of objects, as well as in their value. The criteria of values may force modification of plans of action and set new guidelines of communication with the public. Assessment of the 
dimension of social issues and values enables finding the relationship linking technological solutions, economic benefits and the general public.

On a broader scale, the fact that energy generation and supply is "business without borders" should also be considered. In integration attempts, the choice of technologies is not an insignificant factor. Regard for public attitudes and the cultural level of neighbouring countries is the foundation of future collaboration and partnership. The models dealing with preparation of decisions on technological development must analyse the dimension of values - it is the future norm.

To sum up, assessment of the outcomes related to the role played in markets by economic, technological and environmental dimensions, as well as the dimension of social issues and values, helps make a decision on the utility and acceptability of selected technologies and on their suitability to the public; in this context, it also determines the choice of technologies which are more efficient, more appealing to the public, and have better quality in terms of environmental protection.

In conclusion, it could be emphasized that evaluation of economic, technological, environment protection and social consequences of intervention into markets enables to take a decision regarding the efficiency, acceptability, compatibility with the society's opinion of the selected technologies and, to this matter, may lead to selection of more efficient technologies, more attractive ones for the society, including of better quality from the environment protection point of view. Application of multiple criteria methods provides support in solving problems of different ranking arising in the energy sector. Such decision making support method may be a vital component in substantiating the energy development scenarios and especially in seeking to facilitate the process of selection of different technologies.

\section{References}

Almeida, A.T. 2005. Multicriteria modelling of repair contract based on utility and ELECTRE I method with dependability and service quality criteria, Annals of Operations Research 138: 113-126.

Al-muladi, U.; Binti Che Sab, C. N. 2012. The impact of energy consumption and $\mathrm{CO}_{2}$ emission on the economic growth and financial development in the Sub Saharan African countries, Energy 39(1): 180-186.

Angelis-Dimakis, A.; Biberacher, M.; Dominguez, J.; Fiorese, G.; Gadocha, S.; Gnansounou, E.; Guariso, G.; Kartalidis, A.; Panichelli, L.; Pinedo, I.; Robba, M. 2011. Methods and tools to evaluate the availability of renewable energy sources, Renewable and Sustainable Energy Reviews 15(2): 1182-1200.

Assefa, G.; Frostell, B. 2007. Social sustainability and social acceptance in technology assessment: A case study of energy technologies, Technology in Society 29(1): 63-78. 
Atici, K. B.; Ulucan, A. 2011. A multicriteria energy decision support system, Technological and Economic Development of Economy 17(2): 219-245.

Augutis, J.; Krikštolaitis, R.; Pečiulytè, S.; Konstantinavičiūtė, I. 2011 Sustainable dvelopment and energy security level after Ignalina NPP shutdown, Technological and Economic Development of Economy 17(1): 5-21.

Bacauskas, A. 1999. Investments in the Lithuanian power sector to secure adequate and reliable supplies of energy, in International Conference Investment in Energy in the Baltic Sea Region. Conference Proceedings. Riga, pp. 122-125.

Barca, S. 2011. Energy, property, and the industrial revolution narrative, Ecological Economics 70(15): 1309-1315.

Batel, S.; Devine-Wright, P.; Tangeland, T. 2013. Social acceptance of low carbon energy and associated infrastructures: A critical discussion, Energy Policy 58:1-5.

Baumgartner, R. J. 2011. Critical perspectives of sustainable development research and practice, Journal of Cleaner Production 19(8): 783-786.

Bečić, E.; Mulej, E. M.; Švarc, J. 2012. Measuring Social Progress by Sustainable Development indicators: Cases of Croatia and Slovenia, in Procedia - Social and Behavioral Sciences, 37: 458-465.

Becker, H. A. 2001. Social impact assessment, European Journal of Operational Research 128: $311-321$.

Bertin, J. 1983. Semiology of Graphics. Madison, WI: University of Wisconsin Press, ISBN 0299090604.

Bojnec, S.; Papler, D. 2011. Economic efficiency, energy consumption and sustainable development, Journal of Business Economics and Management 12(2): 353-374.

Braithwaite,V. A. 1998. The Value Balance Model of Political Evaluations. British Journal of Psychology, 89(2), 223-247. Access on internet (13 Apr 2012): http://dx.doi. org/10.1111/j.2044-8295.1998.tb02682.x

Brito, A. J.; Almeida, A. T. 2008. Multi-attribute risk assessment for risk ranking of natural gas pipelines, Reliability Engineering \& System Safety 14: 69-82.

Cappers, P.; Goldman, Ch. 2010. Financial impact of energy efficiency under a federal combined efficiency and renewable electricity standard: Case study of a Kansas "super-utility", Energy Policy 38(8): 3998-401.

Carlsson-Kanyamaa, A.; Juliáb, I. R.; Röhrc, U. 2010. Unequal representation of women and men in energy company boards and management groups: Are there implications for mitigation? Energy Policy 38(8): 4737-4740.

Chen, S. J.; Hwang, C. L.1992. Fuzzy Multiple Attribute Decision Making Methods and Applications. Lecture Notes in Economics and Mathematical Systems, 375. SpringerVerlag, Berlin, Germany.

Chenhall, R. H.; Hall, M.; Smith, D. 2010. Social capital and management control systems: A study of a non-government organization, Accounting, Organizations and Society 35(8): 737-756.

Clark, W. W.; Cooke, G. 2014. The Green Industrial Revolution: Energy, Engineering and Economics, Elsevier 2014. ISBN 978-0-12-802314-3. 
Commission of the European Communities. 2006. Green Paper. A European Strategy for Sustainable, Competitive and Secure Energy. Brussels, 2006. Access on internet: http://europa.eu/documents/comm/green_papers/pdf/com2006_105_en.pdf .

Diakoulaki, D.; Zopounidis, C.; Mavrotas, G.; Doumpos, M. 1999. The use of a preference disaggregation method in energy analysis and policy making, Energy 24: 157-166.

Dunning, D. J.; Lockfort, S.; Ross, Q. E.; Beccue, P. C.; Stonebraker, J. S. 2001. New York power authority uses decision analysis to schedule refueling of its Indian point 3 nuclear power plant, Interfaces 315: 121-135.

European Commission. Communication From the Commission Europe 2020, A strategy for smart, sustainable and inclusive growth. Brussels, 2010. Available online: http:// ec.europa.eu/eu2020/pdf

European Commission. Communication from the Commission to the European Parliament, the Council, the European Economic and Social Committee and the Committee of the Regions, Innovating for Sustainable Growth: a Bioeconomy for Europe. Brussels, 2012. Access on internet: http://ec.europa.eu/research/bioeconomy/pdf/201202_ innovating_sustainable_growth_en.pdf .

Eurostat 2014. Renewable energy statistics. Access on internet: http://ec.europa.eu/ eurostat/statistics-explained/index.php/Renewable_energy_statistics.

Eurostat 2014. Energy production and imports. Access on internet: http://ec.europa.eu/ eurostat/statistics-explained/index.php/Energy_production_and_imports.

Eurostat 2014. Consumption of energy. Access on internet: http://ec.europa.eu/eurostat/ statistics-explained/index.php/Consumption_of_energy.

Eurostat 2014. Electricity and heat statistics. Access on internet: http://ec.europa.eu/ eurostat/statistics-explained/index.php/Electricity_and_heat_statistics.

Ferraro, F.; Pfeffer, J.; Sutton, R. I. 2009. How and why theories matter: A comment of Felin and Foss, Organization Science 20(3): 669-675.

Gaggl, P.; Schellekens, G.; Gentili, P. 2014. De-central Energy Access Through Crosssector Partnerships. International Atomic Energy Agency (IAEA). Access on internet: www.iaee.org/en/publications/newsletterdl.aspx?id $=222$

Gaillochet, Ch. 2009. From waste to resource, World waste survey 2009. Economica. France. ISBN 2717857680.

Gallego Carrera, D.; Mack, A. 2010. Sustainability assessment of energy technologies via social indicators: Results of a survey among European energy experts, Energy Policy 38(2): 1030-1039.

Garniati, L.; Owen, A.; Kruijsen, J.; Ishadamy, Y.; Wibisono, I. 2014. Interface between appropriate technology and sustainable energy policy in vulnerable societies, Sustainable Cities and Society 12: 9-15.

Georgopoulou, E.; Lalas, D.; Papayannakis, L. 1997. A multicriteria decision aid approach for energy planning problems: The case of renewable energy option. European Journalof Operational Research 103: 38-54.

Ghoshal, S. 2005. Bad management theories are destroying good management practices, Academy of Management Learning and Education 4(1): 75-91. 
Ginevičius, R.; Podvezko, V. 2005. Daugiakriterinio vertinimo rodiklių sistemos formavimas, Verslas: teorija ir praktika 6(4): 199-207.

Goosen, M.F.A. 2012. Environmental management and sustainable development. Procedia Engineering 33: 6-13.

Goumas, M. G.; Lygerou, V. A.; Papayannakis, L. E. 1999. Computational methods for planning and evaluating geothermal energy projects, Energy Policy 27: 147-154.

Grunwald, A. 2011. Energy futures: Diversity and the need for assessment. Futures of Evolutionary Psychology 43(8): 820-830.

Guitouni, A.; Martel, J. M. 1998. Tentative guidelines to help choosing an appropriate MCDA method. European Journal of Operational Research 109(2): 501-521.

Guthey, E.; Clark, T.; Jackson, B. 2009. Demystifying business celebrity. New York: Routledge. ISBN-13:000-0415327822.

Haralambopoulos, D.A.; Polatidis, H. 2003. Renewable energy projects: structuring a multicriteria group decision-making framework, Renewable Energy 28: 961-973.

Higgins, A. J.; Hajkowicz, S.; Bui, E. 2008. A multi-objective model for environmental investment decision making. Computers and Operations Research 35(1): 253-266.

Hitlin, S.; Piliavin, J. A. 2004. Values: Reviving a Dormant Concept. Annual Review of Sociology 30: 359-393.

Hobman, E.V.; Ashworth, P. 2013. Public support for energy sources and related technologies: The impact of simple information provision. Energy Policy 63: 862-869.

Hokkanen, J.; Salminen, P. 1997. ELECTRE III and IV decision aids in an environmental problem, Journal of Multi-Criteria Decision Analysis 6: 215-226.

Hugé, J., Waas, T., Eggermont, G., Verbruggen, A. 2011. Impact assessment for a sustainable energy future-Reflections and practical experiences, Energy Policy 39: 6243-6253.

Huse, M.; Tacheva Nielsen, S.; Hagen, I.M. 2009. Women and employee-elected board members, and their contributions to board control tasks, Journal of Business Ethics 89: 581-597.

Husted, B. W.; Salazar, J. J. 2006. Taking Friedman seriously: maximizing profits and social performance. Journal of Management Studies 43(1): 75-91.

Hwang, C.L.; Yoon, K. 1981. Multiple attribute decision making - methods and applications. Springer Verlag, Berlin.

Hwang, M.; Quigley, J. M. 2004. Selectivity, quality adjustment and mean reversion in the measurement of huse values, The Journal of Real Estate Finance and Economics 28(2-3): 161-178. Springer.

International Energy Agency (IEA). 2010. Energy Technology Perspectives 2010 Scenarios and Strategies to 2050. OECD/International Energy Agency, Paris. Access on internet: https://www.iea.org/publications/freepublications/publication/etp2010.pdf .

International Atomic Energy Agency, United Nations Department of Economic and Social Affairs, International Energy Agency, Eurostat and European Environment Agency. 2005. 
Energy Indicators for Sustainable Development: Guidelines and Methodologies. Access on internet: http://www-pub.iaea.org/MTCD/publications/PDF/Pub1222_web.pdf

Jansen, J. C.; Seebregts, A. J. 2010. Long-term energy services security: What is it and how can it be measured and valued? Energy Policy 38(4): 1654-1664.

Jeroen, C. J .M. van den Bergh. 1999. Handbook of Environmental and Resource Economics. Cheltenham, UK. Northampton, Mass: Edward Elgar Pub.

Kaklauskas, A.; Zavadskas, E. K. 2007. Decision support system for innovation with a special emphasis on pollution, International Journal of Environment and Pollution 30(34): 518-528.

Kaklauskas, A.; Zavadskas, E. K.; Lapinskienė, V.; Šliogerienė, J.; Gudauskas, R.; Raistenskis, J.; Čerkauskienè, R.; Jackutè, I.; Kumžaitè, S. 2013. Multiple-criteria analysis of life cycle of energy-efficient built environment, Nearly Zero Energy Building Refurbishment: A Multidisciplinary Approach 299-324. London: Springer. ISBN 9781447155225,

Katcher, B.L. 2006. Does Your Organization Live Up To Its Values? American Management Association. Access on internet (12 May 2014): www.amanet.org

Kemmler, A.; Spreng, D. 2007. Energy indicators for tracking sustainability in developing countries, Energy Policy 35(4):2466-2482.

Khuri, A. I. 2002. Graphical evaluation of the adequacy of the method of unweighted means, Journal of Applied Statistics 29(8): 1107-1119.

Koh, L. P. 2011. Balancing societies' priorities: An ecologist's perspective on sustainable development, Basic and Applied Ecology 12: 389-393.

Kruyt, B.; Vuuren, D. P.; Vries, H. J. M.; Groenenberg, H. 2009. Indicators for energy security, Energy Policy, 37(6): 2166-2181.

Lafferty, W. M., Meadowcroft, J. 2000. Implementing Sustainable Development. Strategies and Initiatives in High Consumption Societies. Oxford University Press, United Kingdom.

Leiserowitz, A.; Kates, R.; Parris, T. 2006. Sustainability values, attitudes and behaviors: A review of multi-national and global trends. Annual Review of Environment and Resources 413-444.

Lietuvos energetinis saugumas. Metinè apžvalga 2012-2013. Kaunas: Vytauto Didžiojo universitetas, 2014. Energy security of Lithuania. Annual Review 2012-2013. Kaunas: Vytautas Magnus University. ISSN 2335-7037. Access on internet: http://estc.lt/wpcontent/uploads/2014/01/Lietuvos-energetinis-saugumas-2012\%E2\%80\%932013_ el.leidinys.pdf

Linares, P. 2002. Multiple criteria decision making and risk analysis as risk management tools for power systems planning, IEEE Trans Power Syst 17, 895-900.

Loken, E. 2007. Use of multicriteria decision analysis methods for energy planning problems, Renewable and Sustainable Energy Reviews 11(7): 1584-1595.

Loomis, J. B.; Rosenberger, R. S. 2006. Reducing barriers in future benefit transfers: Needed improvements in primary study design and reporting, Ecological Economics 60: 343-350.

Lorek, S.; Spangenberg, J. H. 2014. Sustainable consumption within a sustainable economy - beyond green growth and green economies, Journal of Cleaner Production 63(15): 33-44. 
Löschel, A.; Moslener, U.; Rübbelke, D. T. G. 2010. Indicators of energy security in industrialised countries, Energy Policy 38(4): 1665-1671.

Lu, M.; So, R. W. 2005. Return relationships between listed banks and real estate firms: evidence from seven asian economies, The Journal of Real Estate Finance and Economics 31(2):189-206.

MacCrimmon K. R. 1968. Decision making among multiple - attribute alternatives: a survey and consolidated approach, RAND Memorandum, RM-4823-ARPA.

Marechal, F.; Favrat, D.; Jochem, E. 2005. Energy in the perspective of the sustainable development: The 2000 W society challenge, in Resources, Conservation and Recycling, Sustainability and Renewable Resources - A Special Issue PRES'03 - 6th Conference on Process Integration, Modelling and Optimisation for Energy Saving and Pollution Reduction 44(3): 245-262.

Matson, R. J.; M. Carasso, M. 1999. Sustainability, Energy Technologies and Ethics. Renewable Energy 16: 1200-1203.

Melnov, S. B.; Sarana, J. V. 2010. Ethical Aspects of Chernobyl Disaster Consequences. Environmental Ethics: The Power of Ethics for Sustainable Development: collective monograph. Vilnius: Mykolas Romeris University.

Mills, B.; Schleich, J. 2012. Residential energy-efficient technology adoption, energy conservation, knowledge, and attitudes: Ananalysis of European countries, Energy Policy 49: 616-628.

Moeller, C. 1988. Ethics training. In Kellar, (Ed.). Ethical Insight, Ethical Action: Perspectives for the Local Government Manager, International City/County Management Association, pp. 116-130.

Morais, D.; C, Almeida, A. T. 2007. Group decision-making for leakage management strategy of water distribution network, Resources, Conservation and Recycling 52(2): 441-459.

Moreau, F. 2004. The role of state in evoliutionary economics, Cambridge Journal of Economics (28): 847-874.

Morkevičius, V. 2006. Socialinių vertybių raiška politiniame diskurse: Lietuvos seimo debatų turinio analize (1992-2004). Social values in political discourse: content analysis of the debates in the Seimas of Lithuania: doctoral thesis. Kaunas University of Technology.

Musango, J. K.; Brent, A. C. 2011. A conceptual framework for energy technology sustainability assessment. Energy for Sustainable Development 15(1): 84-91.

NEEDS (New energy externalities Development for Sustainability), 2007. Access on internet: http://www.needs- project.org/RS2b/RS2b_D3.1.pdf .

Oss, A.; Zeltina, L.; Zeltins, N. V. 2003. Cooperation between developed countries and the Republic of Latvia in the field of energy globalization, International Journal of Global Energy 19(2/3): 212-224.

Palm, J.; Thollander, P. 2010. An interdisciplinary perspective on industrial energy efficiency. Applied Energy 87(10): 3255-3261.

Pan, J.; Rahman, S. 1998. Multiattribute utility analysis with imprecise information: an enhanced decision support technique for the evaluation of electric generation expansion strategies, Electric Power Systems Research 46:101-109. 
Podvezko, V.; Podviezko, A. 2010. Dependece of Multi-Criteria Evaluatio Result on Choice of Preference Functions and Their Parameters. Technological and Economic Development of Economy 16(1): 143-158.

Ramanathan, R. 2001. A note on the use of the analytical hierarchy process for environmental impact assessment, Journal of Environmental Management 63: 27-35.

Rayner, S. 2010. Trust and the transformation of energy systems, Energy Policy 38(6): 2617-2623.

Robinson, J., 2004. Squaring the circle? Some thoughts on the idea of sustainable development. Ecological Economics 48: 369-384.

Rotmans, J. 2006. Tools for integrated sustainability assessment: a two-track approach, The Integrated Assessment Journal 6(4): 35-57.

Saaty, T. L. 2000. Fundamentals of the Analytic Hierarchy Process. RWS Publications, 4922 Ellsworth Avenue, Pittsburgh, PA 15413.

Schweizer-Ries, P. 2008. Energy sustainable communities: Environmental psychological investigations. Energy Policy 36(11): 4126-4135.

Shepherd, D. A.; Kuskova, V.; Holger Patzelt, H. 2009. Measuring the values that underlie sustainable development: The development of a valid scale, Journal of Economic Psychology 30(2): 246-256.

Sims, S.; Dent, P.; Oskrochi, R. 2008. Moddeling the impact of winds farms on house prices in the UK, International Journal of Strategic property Management 12(4): 251-269.

Sliogeriene, J. 2014. Global sustainablecommunities handbook: green design technologies and economics/ Woodrow W. Clark II (ed.). Chapter 13 - Energy system of the Baltic states and its development. Elsevier. ISSN 9780123979148.

Šliogerienė, J.; Kaklauskas, A.; Štreimikienè, D.; Bianchi, M. 2012. Multiple Criteria Decision Support System for the Assessment of Energy Generation Technologies Considering the Dimension of Values, International Journal of Strategic Property Management 16(4): 370-391.

Šliogerienė, J.; Kaklauskas, A.; Zavadskas, E. K.; Bivainis, J.; Seniut, M. 2009. Environment factors of energy companies and their effect on value: analysis model and applied methods, Technological and Economic Development of Economy 15(3): 490-521.

Šliogerienè, J.; Štreimikienè, D.; Kaklauskas, A. 2011. Decision Support System for Sustainability Assessment of Power Generation Technologies. Efficient Decision Support Systems - Practice and Challenges From Current to Future, Edited by Chiang S. Jao. Published by InTech. ISBN 978-953-307-326-2, pp. 509-542.

Smith, E. R. N. 2004. Public Reaction to Energy, Overview, Encyclopedia of energy 1(6): 169-179.

Sneddon, CH.; Howarth, R. B.; Norgaard, R. B. 2006. Sustainable development in a post Brundtland world, Ecological Economics 57(2): 253-268.

Sovacool, B. K. 2014. What are we doing here? Analyzing fifteen years of energy scholarship and proposing a social science research agenda, Energy Research and Social Sciences 1: 1-29. 
Sovacool, B. K.; Mukherjee, I. 2011. Conceptualizing and measuring energy security: A synthesized approach, Energy 36(8): 5343-5355.

Stephenson, J.; Barton, B.; Carrington, G.; Gnoth, D.; Lawson, R.; Thorsnes, P. 2010. Energy cultures: A framework for understanding energy behaviours. Energy Policy 38(10): 6120-6129.

Štreimikiene, D.; Čiegis, R.; Grundey, D. 2007. Energy indicators for sustainable development in Baltic States, Renewable and Sustainable Energy Reviews 11(5): 877-893.

Štreimikienè, D.; Mikalauskienè, A. 2009. Integruotų rodiklių taikymas Nacionalinès energetikos strategijos monitoringui/Application of integrated indicators for monitoring the National energy strategy, Energetika T55, 3:158-167.

Streimikiene, D.; Simanaviciene, Z.; Kovaliov, R. 2009. Corporate social responsibility for implementation of sustainable energy development in Baltic States, Renewable and Sustainable Energy Reviews 13: 813-824.

Sugulov, P.; B. Dodonov, B.; Hirshhausen, C. 2002. Infrastructure Policies and Economic Development, in East Europiean Transition Countries//International Society for New Institutional Economics, pp. 31-38.

Sustainable Future. Summary report and recomendations. The secretary-general's advisory group on on Energy and ClimateChange (AGECC), Kandeh K. Yumkella, chair. 2010. New York. Access on internet: http://www.un.org/wcm/webdav/site/climatechange

Sychev, A. 2010. Ethical Dimensions of Sustainability. Environmental Ethics: The Power of Ethics for Sustainable Development: collective monograph. Vilnius: Mykolas Romeris University.

Tam, C. M.; Tong, T. K. L.; Chiu, G. W. C. 2006. Comparing non-structural fuzzy decision support system and analytical hierarchy process in decision-making for construction problems, European Journal of Operational Research 174(2): 1317-1324.

Teravainen, T., Lehtonen, M., Martiskainen, M. 2011. Climate change, energy security, and risk - debating nuclear new build in Finland, France and the UK, Energy Policy 39: 3434-3442.

Triantaphyllou, E. 2000. Multi-criteria Decision Making Methods: a Comparative Study. Dordrecht. The Netherlands: Kluwer Academic Publishers (Springer).

UN (2000). The United Nations Millennium Declaration. New York: United Nations. Internet access: http://www.un.org/millennium/declaration/ares552e.htm

Vallance, S., Perkins, H. C., Jennifer E. Dixon, J. E. 2011. What is social sustainability? A clarification of concepts, Geoforum 42: 342-348.

Vera, I.; Langlois, L. 2007. Energy indicators for sustainable development. (Third Dubrovnik Conference on Sustainable Development of Energy, Water and Environment Systems), Energy 32(6): 875-882.

Von Winterfeldt, D.; Edwards, W. 1986. Decision Analysis and Behavioural Research. Cambridge University Press.

Voropai, N. I.; Ivanova, E. Yu. 2002. Multi-criteria decision analysis techniques in electric power system expansion planning, International Journal of Electrical Power Energy Systems 24: 71-78. 
Wang, J. J.; Jing, Y. Y.; Zhang, C. F.; Zhao, J. H. 2009. Review on multi-criteria decision analysis aid in sustainable energy decision-making, Renewable and Sustainable Energy Review 13(9): 2263-2278.

Webster's Third New International Dictionary 1: 1161. 1976. Springfield, Massachusetts (USA).

Williams, Jr. R .M. 1960. American Society: A Sociological Interpretation. (2nd ed.) Alfred A. Knopf. New York.

Zavadskas, E. K.; A. Kaklauskas, A. 1991. Automated multivariant design of buildings, multi-purpose comprehensive evaluation and selection of the most efficient versions. Aalborg University. Aalborg, Denmark: Aalborg Universitetscenter, 66 p.

Zavadskas, E. K.; Peldschus, F.; Kaklauskas, A. 1994. Multiple criteria evaluation of projects in construction. Vilnius: Technika.

Zavadskas, E. K.; Kaklauskas, A. 2008. Model for Lithuanian construction industry development. Transformations in Business \& Economics 1(13):152-168.

Zeng, J.; Min, A.; Smith, N. J. 2007. Application of a fuzzy based decision making methodology to construction project risk assessment, International Journal of Project Management 25(6): 589-600.

Zimmermann, H. J.; Gutsche, L. 1991. Multi-Criteria Analyse. Berlin: Heidelberg.

Yue, C-D.; Yang, G. G-L. 2007. Decision support system for exploiting local renewable energy sources: A case study of the Chigu area of southwestern Taiwan, Energy Policy 35(1): 383-394. 


\title{
CHAPTER 5
}

\section{KNOWLEDGE MANAGEMENT IN THE BUILT ENVIRONMENT}

\author{
Artūras KAKLAUSKAS, Lina BARTKIENE்
}

\subsection{Knowledge management}

Knowledge management can be defined in several ways:

- Knowledge management (KM) is an umbrella term encompassing the many unique but related facets of creating, organizing, sharing, and using information and experiences. While there is no universally accepted definition of KM, most available definitions have common elements. KM is often described as a "process" rather than one activity or event, and many definitions discuss $\mathrm{KM}$ as the practice of delivering the right content to the right people at the right time. Other definitions discuss the specific activities included within KM. For example, one definition of knowledge management is " $\ldots$ the systematic process by which knowledge needed for an organization to succeed is created, captured, shared and leveraged" (Rumizen 2002).

- Knowledge management is employed within a variety of disciplines and fields, including business, information systems, and library and information science. Public health and development organizations have also been discussing the importance of undertaking $\mathrm{KM}$ activities. While raw data are important, it is often more important to focus on "information products that support directly the transfer of useful knowledge to those making decisions" (Goddard et al. 2004).

- Knowledge management is explicit and systematic management of processes enabling vital individual and collective knowledge resources to be identified, created, stored, shared, and used for benefit. Its practical expression is the fusion of information management and organizational learning (Serrat 2009).

- Knowledge management is generally defined as a set of new organizational practices with wide relevance in the knowledge economy. Knowledge management deals with any intentional set of practices and processes designed to optimize the use of knowledge, in other words, to increase allocative efficiency in the area of knowledge production, distribution and use (Young 2013). 
- Knowledge Management: The creation and subsequent management of an environment which encourages knowledge to be created, shared, learnt, enhanced, organised and utilised for the benefit of the organisation and its customers. This definition assumes that knowledge cannot be managed in the traditional sense but that an organisation can optimise the value of its knowledge through an appropriate blend of leadership, values, culture, processes, tools and skills to support knowledge access and use. Managing this stock of Intellectual capital (q.v.) in an organisation as it flows and grows is the domain of knowledge management. The way that stocks of intellectual capital change and evolve over time is then dependent on knowledge management strategies in knowledge creation, access and use (Young 2003).

- Knowledge management is the systematic management of an organization's knowledge assets for the purpose of creating value and meeting tactical \& strategic requirements; it consists of the initiatives, processes, strategies, and systems that sustain and enhance the storage, assessment, sharing, refinement, and creation of knowledge (Frost 2010).

- Knowledge management is achieving organizational goals through the strategy-driven motivation and facilitation of (knowledge-) workers to develop, enhance and use their capability to interpret data and information (by using available sources of information, experience, skills, culture, character, personality, feelings, etc.) through a process of giving meaning to these data and information (Beijerse 1999).

- Knowledge management involves activities related to the capture, use and sharing of knowledge by the organisation. It involves the management both of external linkages and of knowledge flows within the enterprise, including methods and procedures for seeking external knowledge and for establishing closer relationships with other enterprises (suppliers, competitors), customers or research institutions. In addition to practices for gaining new knowledge, knowledge management involves methods for sharing and using knowledge, including establishing value systems for sharing knowledge and practices for codifying routines (OECD Glosary of Statistical Terms 2005).

- Knowledge management is an integrated systematic approach which, when applied to an organization, enables the optimal use of timely, accurate and relevant information; it also facilitates knowledge discovery and innovation, fosters the development of a learning organization and enhances understanding by integrating all sources of information, as well as individual and collective knowledge and experience (Blodgett, Crowell \& Lahaise 2005).

In recent years, many knowledge theories, methods, models and systems for the analysis of the life cycle of the built environment and relates areas (Tennøy 
et al. 2015, Kamsu-Foguem et al. 2015, Chen et al. 2015, Liu et al. 2015, Kalafatis et al. 2015, Baud et al. 2015, Calvo-Mora et al. 2015, Reed et al. 2014, Hussain et al. 2015, Bosch-Sijtsema et al. 2014, Yigitcanlar 2014, von Wirth et al. 2014, Baud et al. 2014, Carvalho et al. 2014, Hong et al. 2014, Petri et al. 2014, Lin et al. 2014) have been developed worldwide.

Site layout planning is a significant but relatively ignored work on construction site, which has been treated improperly as somewhat routine. It is known that the complex interrelationship of material, equipment, laborers, space, environment, assess road, surrounding buildings, and building types affect the productivity and efficiency of a construction process. This complexity was inhibiting the smooth flow of resources especially when many trade contractors were working simultaneously on site (Hamzah et al. 2011). Hamzah et al. (2011) extract a set of core factors in site planning focusing on the tacit knowledge acquisition process to develop a Tacit-based Decision Support System (TDSS). These types of knowledge are often implicit, hidden and lie inside the experts' minds. Most of them are lost when the expert retires or changes his job to another field. To be a competitive construction company, the first stage to stay competitive is to find a knowledge acquisition tool to extract the tacit knowledge from the company's experts and any other sources (Hamzah et al. 2011).

Knowledge acquisition is a process of collecting the valued and useful information from both kinds: tacit and explicit. In this new information era, knowledge acquisition would be one of the first missions for a construction company to determine where their precious knowledge is. Construction site layout planning is a highly dynamic process. The tacit knowledge acquisition in this research was to structure and formalize the concepts and rules that lie inside the minds of site planning experts. The repertory grid technique was used for the acquisition of tacit knowledge. Repertory grid is a special technique based on the personal construct theory. Originally it had been used in psycho-therapeutic treatment. After four decades of evolution, the repertory grid has been widely applied to various fields such as business, computer science, social science, and engineering. In this section, the reviews on repertory grid, personal construct theory, and construction site layout planning are conducted. The repertory grid technique was used in this research to retrieve the tacit knowledge of site planning experts (Hamzah et al. 2011).

The main question concerns the ways in which knowledge management configurations (KM) within urban governance are being transformed through digitization and spatializing information (GIS). This question fits into broader discussions on how knowledge construction, circulation and utilization can improve competences in local government (efficiency and effectiveness), make urban planning more knowledge-based, and provide greater recognition of citizens' knowledge (accountability). Local governments need such instruments in 
dealing with increasing complexity and uncertainty in urban development (Baud et al. 2015). Baud et al. (2015) examine how uneven patterns of technological change in using ICT and GIS are transforming current local government work processes in terms of efficiency and effectiveness in their outcomes, utilizing empirical data from extended case studies in six medium-sized cities in India, South Africa, Brazil, and Peru, participating in the Chance2Sustain research network. Knowledge management in cities is configured through several dimensions: 1) discourses for digitizing $\mathrm{KM}$ in local urban development; 2) actor networks producing socio-spatial knowledge; 3) embedding KM in decision-making processes (power struggles, exclusion); and 4) influences of KM on work practices and interfaces with citizens. The case study results show that 1) KM discourses concerned four issues: strategic urban planning and integrated land use planning; determining geographic boundaries in urban development discourses; streamlining work processes of local governments, and mapping poverty and needs assessments; 2) initiatives mainly link government with the private sector at various scale levels; 3 ) codified and technical knowledge remains dominant in discussions on urban development; and 4) effects of KM are uneven, but improve work process efficiency, although the interface with citizens remains limited, focusing on middle-class relations to the exclusion of the poor (Baud et al. 2015).

The way things appear depends on our physiological and psychological states. Therefore one thing or another may appear differently even to the same individual, not to mention, to different people. Democritus even asserted that what we perceive is not what is actually true; more-over he argued that the same things are not what we believe them to be. He said that the external semblance of things "changes as the state of our body changes". The statement, "People know more than they can say" demonstrates the importance and value of tacit knowledge value. A summary must stress that the latest trends knowledge management actually evolve from explicit knowledge to tacit knowledge management (Bieliūnas 2000).

The benefits of Knowledge management systems (KMSes) to businesses are the following:

- KMSes ease the accumulation, registration and organization of explicit knowledge along with its filtration, analysis, retrieval and dissemination. Explicit knowledge consists of documents and data that are stored in computer memory. This information must be easily accessible in order for an organization to be able to receive unhindered all the knowledge it needs. A system is valuable to business to the extent it is able to use all the existing possibilities of a system in practice.

- KMSes ease the accumulation, registration and organization of implicit knowledge along with its filtration, analysis, retrieval and dissemination. Implicit knowledge consists of informal and unregimented procedures, 
practices and capabilities. Such knowledge is vitally important because it defines the abilities and experiences of the employees. A KMS is valuable to a business enterprise to the extent that it quantitatively and qualitatively describes meaningful examples of "best practices" for an organization and then stores and disseminates them within the organization according to need. This way a company becomes less dependent on staff turnovers; i.e., the knowledge accumulated by the employees remains within the organization even after they leave. Employees express such knowledge in some certain form.

- KMSes are also able to perform a strategic function. Many people believe that only one advantage exists in the rapidly changing environment of business and that it is strategic and actually stable. The organization that creates such is so flexible it can deal with any sort of changes in the micro, meso and macro environment, no matter how unpredictable they might be. Those sorts of opportunities are only possible by making use of a system that is as flexible as a KMS, which forms beneficial conditions to receive all needed information and worthwhile pointers upon shifts in the external and internal environments and which help in overcoming complicated situations successfully.

- Use of knowledge portals that are based on the three aforementioned benefits of knowledge can be applied throughout the entire supply chain.

The problems relevant to the creation and installation of KMSes are provided next:

- There is a certain unwillingness on the part of experts to submit their own knowledge into a KMS, because employees believe that they have power by controlling special knowledge. The singular people in an organization who know how to perform the tasks in some certain field qualitatively and effectively have assurance that their employment termination is not probable; furthermore it is more probable that they will receive raises in their compensations. Even if they are not well acquainted with the course of economic demand and supply, they know that a shortage of necessary experience and knowledge will raise their price (or salary), because the market is competitive, and the need of companies for the required, most advanced experience and knowledge continues to increase. The perspective of an individual is that there is no reason to share his/her unique knowledge and skills with other people in a competitive market.

- There is a shortage of opportunities to integrate KMSes with other management information systems, especially with those of an older generation.

- Problems can also arise regarding a shortage of suitable experts on qualifications. There are not many experts on qualifications and those same 
experts learned on-the-job. Therefore it is quite complicated to form a base of knowledge of the needed quality level.

- The expenses relevant to a KMS can be quite expensive.

- People are usually inclined to think first about the means for creating a KMS but not about the strategy for its formation. There is always confusion due to this. Where you are and what you want to achieve must be clearly defined first, before selecting the means for creating KMSes.

Further there are several recommendations provided for rationally installing a KMS in a specific organization:

- Try to achieve all-around support from the organization's governing body regarding this project.

- Convince the organization's employees that a KMS is a component essential to the operations of the organization and that the employees will be coming face-to-face with it constantly.

- Attempt to increase the level of approval for implementing a KMS by forming an essentially needed, multi-functional team encompassing all the organization's branches in all regions. It is essential to train these experts and to execute their supervision during the transitory period of the system's implementation.

- Utilize different means of promotion. A certain part of the senior managerial personnel can be designated to install and use a KMS and they can be offered bonuses to their compensations for such. Bonuses can be allocated for the mid-level administration under conditions such as, for example, when they promote additional sales by utilizing the KMS. Employees can be allocated various bonuses for encouraging them to supplement the knowledge base with their own experiences.

- Promote a friendly atmosphere for working together. The experts in some certain field could have reason to withhold dissemination of their acquired knowledge under conditions of high competitiveness. The final decision of an employee - whether or not to supplement the knowledge base with his/her own experience - will depend on the comparison between financial incentives for disseminating one's available knowledge (bonuses for the use of his/her experience by other employees) and the incentives for competing (safeguarding the job and the importance of the employee to the organization). The company should not accent how to increase one's compensation but how to expand on new opportunities that would increase the organization's effectiveness and thereby, the compensations for employees. Correcting the incentives system can accomplish this by orienting it towards teamwork, not at an individual. It will become clear to employees that cooperating with others at work will best serve their own personal interests. This will lessen any incentive to compete with other 
employees for no reason and increase interest in transmitting one's own experiences to others. The accent needs to be on the competition of the company with other companies, not between the employees of one's own organization.

- The sales and senior management personnel will be best off by accenting the possibilities a KMS offers for bettering sales results. Employees should be materially and morally encouraged to utilize the KMS for gaining supplemental income from sales as well as to use their own knowledge to supplement and information base, thereby allowing the other employees to make use of it. Incentives for increasing income are applied throughout the company, not limited to merely those employees in management and sales.

- Initially it is useful to arrange a contest for installing a KMS or using it more actively to raise employee interest. A fully paid, two-week vacation could interest most employees in an organization. The winners of such a contest should be those who best defined how the KMS could be used more effectively in the different operations of the organization. Employees would become more interested in the KMS and use it more broadly, which would mean the beginning of launching and using a practical knowledge base.

- Expand the system. A KMS operates on a network principle: as more people use it, it becomes even more valuable to each user. It should be installed in all the branches of the organization.

- Integrate the knowledge portal into the system. A KMS can be used for extranet. A Knowledge portal can be used in the effort to gain important information from suppliers, major clients and other interest groups, so it can become useful to everyone. Some of this information can be disseminated to suppliers and major clients.

- Use a decision-making support or an expertise system. A KMS could become even more useful upon integration with a decision-making support or expertise system in some specific field. An analysis of information contained in the knowledge base can use the application of mathematical and analytical models in an effort to provide greater hands-on support to decision-makers. Use of capabilities for generating conclusions that, in turn, provide recommendations is for an effort to analyze the knowledge base more effectively. Use of systems of both types is suitable for an effort to gain as many benefits as possible from the information accumulated in a knowledge base, because certain kinds of knowledge management problems are better decided with a decision support system, while others - with an expertise system.

Lately the understanding that it is necessary to pay much more attention to generating knowledge and disseminating the best practices in the form of knowledge and databases has taken hold in the most advanced areas of public 
activities. The governments of the most developed countries encourage educational, health care and social services systems along with different branches of industry to accumulate and disseminate knowledge on best practices. The endeavor is to discover them as fast as possible, describe them in quantitative and qualitative forms, classify them and disseminate them. Companies from the United States frequently indicate in their advertising that they apply the best practices in their area. One of the main and justifiable priorities of American companies is the accumulation, management and improvement of their best practices along with development of best practices knowledge and databases.

Comparative analyses of best practices are becoming more and more popular in the world. Their substantiation is an analysis of examples reflecting best client services. Specific recommendations drawn upon study conclusions indicate needed improvements in order to provide higher-quality services better and achieve better satisfaction of client needs. These provide opportunities to adapt and apply methods quickly and effectively to achieve quality in client services at a global level. Best practice recommendations that frequently come up regarding in such comparative analyses appear next in brief:

- Generate an atmosphere favorable for a company's employees to take interest in best practices constantly.

- Pay constant attention on discovering best practices and making practical use of them.

- Link best practices to implementing the company's strategy.

- Develop systems for establishing and recognizing best practices.

- Develop systems for transferring and disseminating informational best practices.

The following advantages are possible by organizing the applications of the information stored in the best practices databases:

- Safeguard the vitally important experiences of employees leaving the organization.

- Introduce an improved mechanism for making decisions.

- Develop an ability to adapt to the changing internal and outer environments more flexibly.

- Perceptively establish client needs and how to satisfy them more aptly.

- Increase the effectiveness of company operations.

- Reduce expenses.

Best practices databases are means for acquiring knowledge that saves considerable time by providing information about best business practices in various forms (indicator systems, slide presentations and structural diagrams along with textual, video and audio materials and the like).

Interest groups usually pursue various economic, technical, technological, social and other kinds of goals. Various means can achieve these. Some goals 
may not be so easy to achieve, whereas others might require greater expenses. Best practices permit unlimited implementation of goals other than economic and provide a condition for rising to a higher level and grasping who views the particular practice as best and from which perspective. The main problem with best practices is their means of presentation - they do not consider the specific situation when offered. Let us say automobile engineers will be determining the best injection system, best transmission mechanism, best motor cooling system, best suspension system and so forth. Let us say that, upon completing the evaluation, it becomes clear (which is what would happen most likely) that the systems (fuel injection and such) of various manufacturers (like Audi, Mercedes and the like) have recognized such systems. All best systems of the best automobile makes will fail to operate when interconnected, and the automobile will not drive. The design of every subsystem of a best automobile involves coordinating it better with all the other specifically designed parts of a specific automobile model. The concept of the entire automobile is as a singular, highly integrated mechanism. Often parts cannot be substituted for others either physically or because they are not worth it from the perspective of economy and effectiveness. However, the presentation of a best practice often appears as if it was applicable despite the specific situation involved.

Application of various means is possible to obtain best practices:

- by fundamental and applied studies;

- by the wisdom and experience accumulated by the practices;

- by the experiences of clients and other interest groups;

- by expert opinion;

- by repetitive models in various areas and such.

The knowledge contained by many organizations can be found in business documents and software, such as, for example, spreadsheets, presentations and e-mails, which are the types of information that are not shared.

The submission of all the results from a search of best practices contains a summary of each document, an assessment of the suitability of the search criteria and the source of the document.

Knowledge is very easily lost, whenever an employee leaves a company or the company assigns different duties to an employee. Companies can gain a competitive edge in different areas of their operations by taking advantage of a chance to effectively disseminate and repeatedly use the collective knowledge of the organization as a foundation.

Systems for the comparative analyses of best practices help companies to prioritize steering towards increases in the effectiveness of operations and towards finding means for accomplishing improvements permitting a comparison of the manufacturing processes under execution with those found at other organizations, determining the areas that are lagging behind the most and offering means 
for eliminating such shortcomings. Modern companies know how to exploit the possibilities inherent in comparative analyses thus they lower their expenses and increase productivity and competitiveness.

The effort to allocate existing resources efficiently prompts performing a comparative analysis in the areas, where achievement of the best results is possible with minimal analyses. The principle of price to benefits is generally applied. A successful comparative analysis assists in allocating available resources appropriately, and then the company can implement its strategic goals. The high priorities must be in line with the main goals of the company for allocating funds, planning time, attempting to apply experiences relevant to projects and modernizing operations. Reports usually present best practices along with detailed information about the justified strategies and tactics at the organizations. The most advanced companies use such reports for making decisions about assignments essential to their operations.

Knowledge management helps decide issues regarding the adaptation, survival and competency of an organization, which become vitally significant due to the lack of continuity and consistency of the constantly increasing environmental changes. This trend encourages a synergetic coordination of capabilities for receiving and processing information at organizations and increasing the creative and innovative skills of the employees.

Managers who are endeavoring to introduce best practices into their organizations effectively should heed the following recommendations:

- Comprehend the organization as a community of people, which is able to provide multifaceted meaning to acquired information by utilizing technological systems. A traditional standpoint cannot be a guide when most of the attention is on directives and regulations.

- Avoid the standpoint of "that has to be done because it was always done that way." Thereby an assessment of the best practice experience and its consistent application to a dynamically changing external environment by various aspects are possible.

- Encourage formation of various outlooks and do not come to a consensus too quickly, when a more thorough analysis of assumptions and reasons is essential. Frequently the views among differently qualified people with varying life experiences can differ, which opens up an opportunity to take a broader look at issues under consideration. This is vitally important for grasping the essence of the major issues, especially when the micro, meso and macro environment are changing rapidly. Then it is necessary to take a fresh look at the consideration of a standard or a best practice in the past.

- Encourage employees to take a more active initiative at employing their own fantasies and creativity. This helps to achieve inner satisfaction in congruence with the variety in the environment. 
Major principles and methods basing development of a knowledge base

Interest groups. Information and knowledge on potential employee duties (bricklayers, plastering and the like), project designers, construction materials manufacturers, suppliers, salespersons, contractors, building exploitation organizations, financial institutions, municipalities and such. Their goals are economic, social, moral, legal, qualitative and others.

Macro-environment. Information and knowledge: governmental policies under execution (structural funds, regional support programs, regulations on competition, preferential credits, tax preferences, governmental orders), legal and normative documents regulating construction industry operations, tax system, credit procedures, environmental pollution, interest rates, customs and traditions, insurance systems, social policies, inflation, the market, unemployment rate, labor force qualifications, work compensation level, labor laws, environmental protection, availability of local resources and such.
Explicit knowledge (for example, estimates, price lists, constructional selections [walls, windows, floors and so on) and technical, economic and qualitative indicators) and implicit knowledge (abilities, competencies, experience, organizational culture, informal and unrecorded procedures, skills, informal networks of organizational contacts, organization's

intelligent capital, ideals, values and emotions).
Life process of the built environment. Information and knowledge: brief; design; raw material extraction, transport and processing; construction materials production and distribution; construction; use, repair and maintenance; demolition; disposal, reuse, or recycling.

Micro and meso-environment. Information and knowledge: prices of land lots and buildings, construction sites social physical infrastructure, available informational systems on construction, organizational merger activities in the construction industry and such.

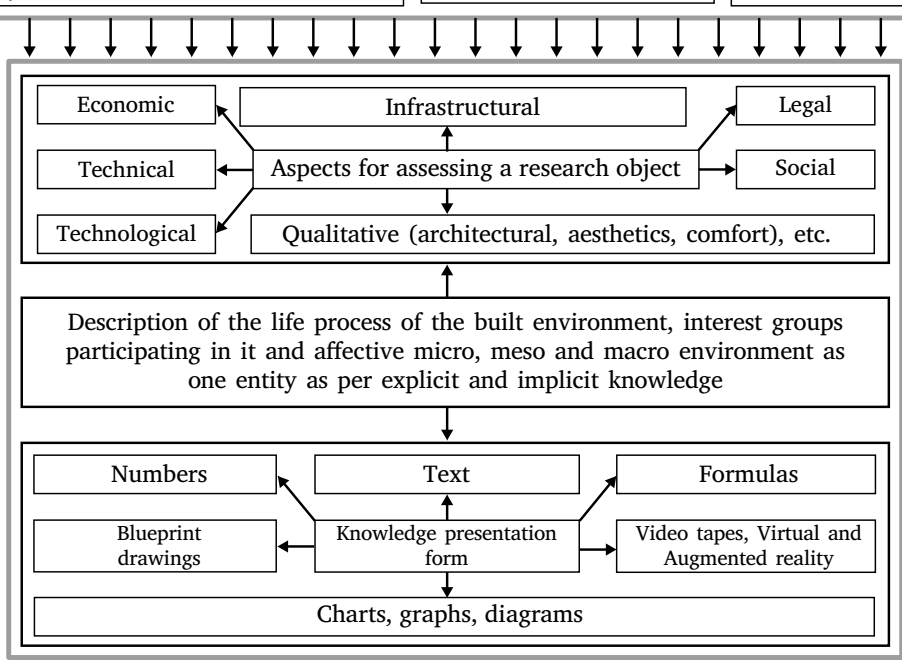

Figure 5.1. Various aspects of explicit and implicit knowledge regarding the life process of the built environment

- Be more emphatic of your approval for implicit knowledge and the humane aspects associated with it, such as ideals, values or emotions, in order to formulate a more comprehensive concept of knowledge management more effectively.

- Implement new, flexible forms of organization at the company, which would generate conditions for companies to form to handle local operations. Companies involving such operations are unofficial and semi-official 
action groups consisting of employees and others, who do not work at the organization bound by common concerns and interests.

- Generate good conditions, according to abilities, for employees of the organization to use informational and knowledge systems; however, at the same time, assure that these employees have skills and the necessary empowerments to make needed decisions quickly under changed environmental conditions.

The description of the life process of the built environment, the interest groups acting within it and the micro, meso and macro environment acting on project effectiveness regards them as one entity. This description contains various aspects of explicit and implicit knowledge regarding the life process of the built environment (Figure 5.1).

A description of the life process of the built environment by implicit knowledge is presented in a textual or graphic form (slide presentations, structural charts, graphs, diagrams), by blueprint drawings and with audio materials and video tapes, augmented and virtual reality.

Explicit knowledge includes a system of criteria, units of measurement, values and initial significances and information on forming alternative projects.

A major portion of knowledge on the built environment is implicit (Figure 5.2): abilities, competence, experience, an organization's culture, informal and unrecorded procedures, skills, informal networks of organizational contacts, an intelligent organization's capital, ideals, values, customs, traditions and emotions.

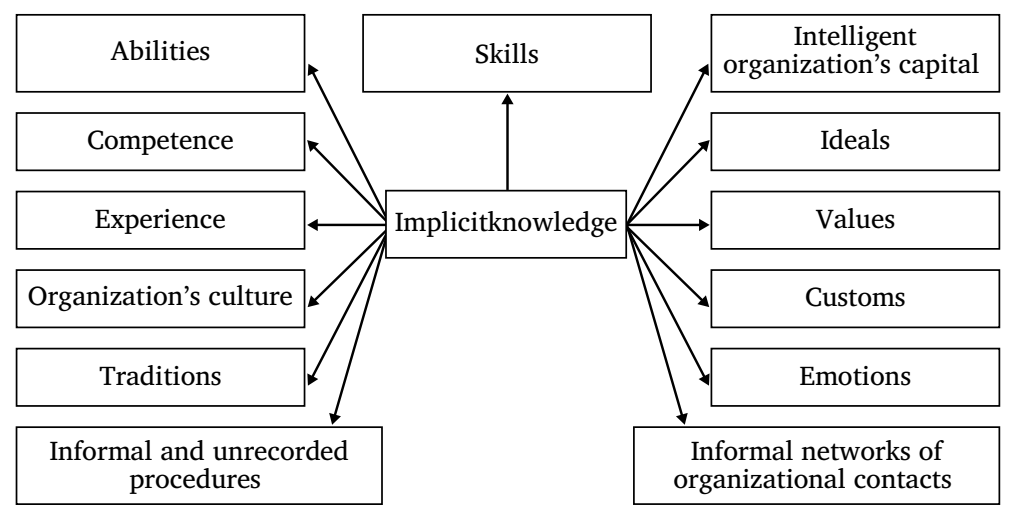

Figure 5.2. Implicit knowledge

For example, customs (traditions) regulate various informal relationships between people at the point where laws regulating construction and the limits of validity of other legal documents end. For example, formed traditions regulate the boundaries between different professions and positions in the effort to guarantee quality during renovations. Analogical, informal procedures are used to 
assure quality while designing projects and engaging in construction as well as at other organizations.

Implicit knowledge is vitally important, because it describes the abilities and experiences of the employees and the examples of best practices. An organization that uses implicit knowledge becomes less dependent on staff changes; i.e., the knowledge employees accumulate remains in the organization after they leave. Knowledge management systems (KMSes) ease the accumulation of implicit knowledge as well as its registration, organization, filtration, analysis, retrieval and dissemination.

The base of implicit knowledge regarding best practices in the built environment area encompasses unofficial and unrecorded procedures, practical experience and skills. This knowledge is fundamental because it delineates the abilities and competence of the employees. KMSes are valuable because they can systematize and store such "best practices" and, if necessary, disseminate them within the organization. Thereby a company is less vulnerable to the destructive factor of employee turnover. Implicit knowledge changes into the explicit. Implicit knowledge has an especially personal nature, its contents are specific and therefore, it is difficult to summarize, express quantitatively and transmit. Implicit knowledge is the knowledge inside a person's head, such as experience, comprehension or professional insight that forms due to experience. Implementation of very individualized projects is usual; therefore the basis of most knowledge in the built environment is experience and it remains unexpressed. The needs for knowledge are dynamic, depending on the assignment to be completed or the issue to be resolved, the time available for implementation and the relationship between demand and supply. Despite this, the typical strategy for knowledge management is converting such knowledge into the explicit and storing it in the form of computer software and databases. Organizations are successful at gathering and storing explicit information in company databases but weak in the area of searching and exchanging knowledge. Professionals realize how difficult it is to make use of essential expert knowledge repeatedly in the areas of built environment, which demand a great deal of knowledge. Such a situation demands greater dispersion of the implicit knowledge existing in the minds of experts wanting to achieve a higher level of quality in built environment projects. The generation of a huge flow of innovative knowledge in built environment occurs at the time of brief; design; raw material extraction, transport and processing; construction materials production and distribution; construction; use, repair and maintenance; demolition; disposal, reuse, or recycling. Organizations depend on their experience, professional intuition and other forms of implicit knowledge over the entire life cycle of a project to perform a job successfully. An effort to develop a knowledge base of unexpressed best practices requires an analysis of economic, technical, quantitative, technological, social, legal, infrastructural and 
other aspects. The variety of assessed aspects must uphold the variety means for presenting the data necessary for making decisions. Thus presentation of the necessary data is possible in numerical, textual, graphic (blueprint sketches, diagrams or tables) forms, formulas, video tapes and other forms.

An implicit knowledge base of built environment expertise is gaining greater and greater popularity around the world. Organizations expect their employees to be working with similar types of projects over the long terms, even when there is no clear connection between such projects at first glance. An organization's management usually believes that experts already have the implicit knowledge and experience needed to accomplish certain jobs. This allows experienced employees share their knowledge and experiences about best practices with beginners during talks and lectures. Experienced professionals, who have completed good educations, successfully apply effective and innovative technological processes and the latest organizational and managerial methods in built environment. Such knowledge is especially meaningful to small and medium-sized companies, because specialists tend to forget a number of details once they have completed some run-of-the-mill and started to execute new projects. Therefore the multiple use of knowledge is the essential factor that increases the effectiveness of built environment projects. One of many successful initiatives for sharing implicit knowledge involves best practices associations. These associations endeavor to develop a network of high-level experts who would work as one for resolving complicated problems and sharing experiences while looking for a better paid, more perspective or more interesting work. Such associations are informal unions working unofficially during meetings, video conferences or by exchanging e-mails on topics of interest to members, thereby exchanging knowledge and work practices. The use of Internet technologies, knowledge bases of expertise and knowledge systems makes it possible to search for experts and then eases the interactions with them. A professional can look for an expert with relevant knowledge by connecting to expertise knowledge bases and knowledge systems and contact the appropriate person in real time by employing instant message exchanges, an e-mail and/or a telephone or web conference. Thereby an SME professional is able to receive direct, implicit help from an expert with experience on a similar problem. The implicit knowledge that an expert transmits while interacting will appear in the most appropriate forms applicable to the business process. The company's database systems will hear the dialogue between them and store it, making it available for other searches. This way the SME obtains valuable implicit knowledge from the minds of its employees and applies this asset to the ongoing work process. Achievement of better performance levels is theoretically possible by speeding up the processes for transmitting knowledge.

Construction also contains quite a good deal of explicit knowledge. Explicit knowledge consists of documents and data (for example, estimates, price lists, 
constructional decisions - walls, windows, floors and so forth - as well as technical, economic and qualitative indicators) that are stored in computer memory. This information has to be easy to access, so the employees can get all the required knowledge and put it to practical use without hindrance. What is required for this is a special system for the storage, registration, organization, filtration, analysis, retrieval and dissemination of explicit knowledge.

There are different ways to gain knowledge. One of the most easily accessible resources for receiving knowledge involves specialists who have explicit or implicit knowledge interacting with one another. The same can be said about knowledge gained by questioning different interest groups (clients, project designers, contractors and the like). Knowledge also appears in business documents and software, such as calculators, presentations and e-mail messages. There is an unwillingness to share such information. A summary that presents a brief writeup of every document, an assessment of the relevancy of the search criteria and the source of the document describes best practices.

Generally this sort of knowledge is easily lost, if an employee leaves for another job or transferred to another position. Therefore the chance to use the organization's collective knowledge repeatedly is the foundation for companies to gain competitive advantage in various areas of the built environment.

The varying knowledge coming from different specialists on the same object comprises a single entity comprehensively describing the effectiveness of the built environment's life process:

- Databases on the best practices for servicing customers have been formed around the world. Their foundation is an analysis of best customer servicing examples. Generation of specific recommendations occurs upon performance of this analysis, and these recommendations indicate how it can be possible to supply better quality services and better serve customer needs.

- Project designers provide examples of best practices about the built environment's architectural, aesthetic and content-planning decisions, its assurance of developing structural strength and stability that ensure comfortable usage conditions for the facilities (air temperature and relative humidity, natural lighting and noise protection) as well as rational engineering systems (heating, ventilation, water supply, sewerage, communications and automation).

- Hygiene experts can provide experiences on environmental pollution and determine the health hazards of various constructional decisions.

- Economists can provide knowledge on the prices for land lots and the building, exploitation expenses, taxes, insurances, interest rates on loans, the price fluctuation trends for buildings and the building quality levels (social, technical and economic indicators). 
- Contractors can comprise a subsystem on the knowledge involving effective applications of technologies as well as organizational and managerial methods.

- The experts on facilities management can provide knowledge on the effective exploitation of buildings, their maintenance and their renewals.

The main principles and methods applied for compiling this knowledge base are the following:

- Adequate reaction to the rapidly changing environment principle - this means that knowledge systems must be flexible enough to facilitate an adequate reaction on the ongoing changes in the built environment. Such knowledge systems would provide all the necessary information and useful recommendations for overcoming a complicated situation that had formed.

- Multiple practical uses principle - one example involves a construction organization that may need knowledge about the acquisition process for a construction permit. Meanwhile there is only one expert in this field. Under such circumstances, it is possible to develop a subsystem on the knowledge regarding how to acquire a construction permit. Many people can use it, and it will cost less than hiring another expert.

- Integration of various systems principle - this involves a KMS that could be even more beneficial when integrated with a decision-making support system in a specific area or an expertise system and different devices. For example, applying models for a decision-making support system is possible to analyze the information contained in a knowledge base, facilitating decision-making and providing recommendations.

- Consideration of a specific situation principle - this is described by the following example: different companies could offer something specific for implementing some project, like their own best technologies, organizational and managerial methods, employee brigades of varying effectiveness, mechanisms and such. Nevertheless, there is no way to merge the best resources and experiences into a specific project, because they belong to different organizations. Meanwhile the deliberation of a project always treats it, as if this involved a singular, integrated process. Despite this, presentations of best practices are quite often applied as though the specific situation does not need consideration.

- The complex analysis method involves an application for conducting a project's economic, legal, technical, technological, organizational, managerial, architectural, comfort, environmental protection and other optimizations over the entire life process of the built environment.

- Betterment of the benefit to price ratio principle - here the effort is to implement maximally the architectural, aesthetic, comforts, environmental protection, social, legal, moral and other goals with minimal expenses over 
the life process of the built environment, i.e., to better the benefit to price ratio.

- Functional analysis method can serve as a basis for establishing forecast expenses usually by considering their functional effectiveness, price for implementation and the benefits provided.

- Degree of project effectiveness dependency on interest groups and their goals is another principle.

- Interrelatedness of different study disciplines principle - The issue of the benefit to price ratio for the renovation of the built environment can only be resolved successfully by interconnecting various fields of scholarly study, such as management, economics, architecture, law, engineering studies, technology, organizational studies, ethics, aesthetics, psychology and so on.

- Multicriteria project design and analysis variants methods - An application of these methods permits a rational and realistic assessment of the infrastructure, climate, risk conditions, project price reductions and greater satisfaction of customer demands on architecture, comfort, content-planning, exploitation, manufacturing and others along with the goals of all interest groups participating in the same renovation project.

Developed, complex data and knowledge bases on the life process of the built environment would provide the following advantages:

- Safeguarding the experiences of qualified employees who leave the organization

- Making it possible to make more effective decisions

- Permitting more flexible adaptation to a changing environment in the built environment

- Establishing various customer needs more thoroughly and rationally and satisfying them more accurately

- Increasing the effectiveness of the organization's operations

- Reducing expenses

Figure 5.3 presents an example of a potential data and knowledge base on organizing competitive bidding in construction.

Innovative construction knowledge: instilled lessons, training, analogical models (best practices, laws and directives, reports, industrial practices, studies on facts, timely teaching, market analysis), rules/policies/guidelines (starting point for a sense of history, communications, policies and guidelines, new initiatives, assessment tools and techniques and the like. Many SMEs operate in an informational vacuum, because they are unable to reach valuable information found in divisions of other companies, in corporation databases, with their business partners or in publically accessible documents. Information of potential value to numerous SMEs exists in composite areas of files with numerous formats, as much within the company, as beyond its boundaries. An SME faces an 
overwhelming task of developing knowledge and constantly renewing it when it is unable to reach such information in its pursuit of resolving a customer's problems quickly, effectively and accurately.

Quantitative data (price, construction duration and the like) usually constitute the basis for arrangements of competitive bidding sessions in construction. Nevertheless, qualitative information is also important to a customer along with knowledge on the final quality of the construction production, the construction organization's reputation and its financial capabilities, reliability and other factors. The probability that the contractor will not bankrupt during the construction and that all the conditions will be upheld depend on these factors. The provided example shows that arrangements of competitive bidding sessions for obtaining specific orders must have a criteria subsystem, which reflects the pursued goals completely, as their basis. In this case, construction organizations, the same as other interest groups participating in execution of a contract, also have numerous economic and other goals under pursuit. Thus it is necessary for criteria subsystems to describe the needs and purposes of all interest groups explicitly. An appropriate assessment of these criteria subsystems will come later when selecting a rational life process of the built environment.

\begin{tabular}{|c|c|}
\hline$\downarrow$ & $\checkmark$ \\
\hline $\begin{array}{l}\text { Information and knowledge describing the most } \\
\text { effective selection of a contractor: } \\
\text { - renovation price } \\
\text { - final renovation quality } \\
\text { - renovation duration } \\
\text { - financial capability of the construction firm } \\
\text { - construction firm's reliability } \\
\text { - organizational and managerial capabilities } \\
\text { - ability to draw factual plans } \\
\text { - ability to make use of plans appropriately } \\
\text { - level of mastery } \\
\text { - organization of the renovation site } \\
\text { - labor relations regulations } \\
\text { - relations with the subcontractors and } \\
\text { established empowerments } \\
\text { - care for the handling and safety of } \\
\text { the renovation site } \\
\text { - cooperation level } \\
\text { - organizational structure compliance } \\
\text { - effectiveness of communications contacts } \\
\text { - managerial flexibility } \\
\text { - employee encouragements } \\
\text { - employee experiences } \\
\text { - completely reliable subcontractor } \\
\text { - problems regarding subcontractor and } \\
\text { - supplier compensations } \\
\text { - adeed at compensating losses }\end{array}$ & $\begin{array}{l}\text { Information and knowledge describing selection of } \\
\text { a contract type: } \\
\text { - owner's general policy on contracts } \\
\text { - qualification level of the local construction } \\
\text { personnel } \\
\text { - time needed for project design and construction } \\
\text { - owner's request to control certain parts of } \\
\text { the project } \\
\text { - price importance to the owner } \\
\text { - degree of risk for the transaction } \\
\text { - number of available contractors and } \\
\text { their suitability } \\
\text { - climate at the construction site } \\
\text { - level of confidence in the contractor } \\
\text { - contractor's experience } \\
\text { - consultants (contractor or employer selection) } \\
\text { - subcontractors (local, assigned) } \\
\text { - assessment of changes (expensive, cheap or } \\
\text { the same price) }\end{array}$ \\
\hline$\downarrow$ & $\checkmark$ \\
\hline \multicolumn{2}{|c|}{ Construction contracts data and knowledge base } \\
\hline \multicolumn{2}{|c|}{7} \\
\hline
\end{tabular}

Figure 5.3. Organizing competitive bidding sessions for construction data and knowledge base

The basis for composing a complex explicit and implicit knowledge base is the description of the life process of the built environment and its composite parts. This knowledge base describes the object under deliberation comprehensively and forms the conditions for performing its project design for variants and 
a multicriteria analysis. Use of a complex data and knowledge base facilitates effectively coordinating the goals of all interest groups participating in the project, making decisions and increasing project effectiveness in a complex manner.

\subsection{Air pollution \& noise, illnesses they cause and real estate prices}

\subsubsection{Analysis of pollution \& noise, their impact on human health and real estate prices}

Pollution and noise measurements were taken in the Žirmūnai and Antakalnis neighborhoods of Vilnius City, and their impact on human health was analyzed. This involved the effort to establish how this affects real estate prices. This study was performed by Kaklauskas (Kaklauskas et al. 2006a, 2006b, 2007a), Zavadskas (Zavadskas et al. 2007a, 2007b, 2007c), Bartkienè (former Povilaitytė) (Povilaitytė 2006, 2008) and Kalibatas \& Sankovskaja (Sankovskaja 2007). Further there is a brief description on how the performance of this study and a presentation of its conclusions.

Noise and air pollution negatively affect the value of real estate to a greater or lesser degree, depending on its designation. For example, these factors greatly reduce the value of residential property. This was established during research on the real estate markets in developed countries, where the issues on an ecological environment for a dwelling are especially relevant. Also noticeable is that the payments are higher for residential dwellings in those markets where noise and air pollution have a lesser impact, where households enjoy greater incomes and where the overall noise level are comparatively high.

Transportation vehicles are among the greatest polluters in the city environments of Lithuania. The exhaust from motor vehicles pollutes city territories. Exhaust is very dynamic - it penetrates all city areas - residential and industrial regions, the city centers, hospital and sanatorium zones and rest and recreation sites. The exhaust from transportation vehicles contains some 200 different chemical compounds.

Residents in polluted areas suffer from chronic bronchitis $72 \%$ more often than do the people who live in clean neighborhoods. Other respiratory diseases had a noticeably similar increase in morbidity rates as well. There is another important consistency - chronic myocardium infarctions obviously correlate with atmospheric pollution. Researches on environmental pollution show that greater incidences of respiratory diseases and other illnesses are due to greater concentrations of $\mathrm{CO}, \mathrm{NO}_{2}$ and $\mathrm{SO}_{2}$.

The European Union pays very much attention to environmental protection. It is a recognized truism that environmental pollution causes harm to human health and work productivity, and the negative consequences of environmental pollution cost billions of Euros. 
Table 5.1. Noise Depreciation Index (NDI) defining the price change per $1 \mathrm{~dB}$ rise in noise level

\begin{tabular}{|c|c|c|c|c|}
\hline $\begin{array}{c}\text { Study } \\
\text { authors }\end{array}$ & $\begin{array}{l}\text { Time of } \\
\text { conducting } \\
\text { the study }\end{array}$ & Study site & Noise index & $N D I$ \\
\hline \multirow[t]{2}{*}{ Grue et al. } & \multirow[t]{2}{*}{1997} & Oslo, Norway - apartments & Constant noise level $\left(L_{e q}\right)$ & 0.21 \\
\hline & & Oslo, Norway- houses & Constant noise level $\left(L_{e q}\right)$ & 0.52 \\
\hline $\begin{array}{l}\text { Hidano } \\
\text { et al. }\end{array}$ & 1992 & Tokyo, Japan & Constant noise level $\left(L_{e q}\right)$ & 0.7 \\
\hline \multirow{3}{*}{$\begin{array}{l}\text { Hall } \\
\text { et al. }\end{array}$} & \multirow[t]{3}{*}{ 1975-1977 } & Toronto, Canada & Constant noise level $\left(L_{e q}\right)$ & 1.05 \\
\hline & & Toronto, Canada - highway & Constant noise level $\left(L_{e q}\right)$ & 0.42 \\
\hline & & Toronto, Canada - freeway & Constant noise level $\left(L_{e q}\right)$ & 0.52 \\
\hline Hammar & 1974 & Stockholm, Sweden & Constant noise level $\left(L_{e q}\right)$ & $0.8-1.7$ \\
\hline $\begin{array}{l}\text { Iten \& } \\
\text { Maggi }\end{array}$ & 1990 & Zurich, Switzerland & Constant noise level $\left(L_{e q}\right)$ & 0.9 \\
\hline $\begin{array}{l}\text { Pommer- } \\
\text { herne }\end{array}$ & 1986 & Basel, Switzerland & Constant noise level $\left(L_{e q}\right)$ & 1.26 \\
\hline Renew & 1996 & Brisbane, Australia & Constant noise level $\left(L_{e q}\right)$ & 1.0 \\
\hline Soguel & 1990 & Neuchâtel, Switzerland & Constant noise level $\left(L_{e q}\right)$ & 0.91 \\
\hline Vainio & 1995 & Helsinki, Finland & Constant noise level $\left(L_{e q}\right)$ & 0.36 \\
\hline $\begin{array}{l}\text { Vaughan } \\
\text { \& Huck- } \\
\text { ins, } 1975\end{array}$ & 1971-1972 & Chicago, U.S.A. & Constant noise level $\left(L_{e q}\right)$ & 0.65 \\
\hline
\end{tabular}

Source: Nelson (1982) ir Bertrand (1997)

The scientists from foreign countries who discussed the impact of noise on real estate values established Noise Depreciation Index (NDI), defined as the price change when the level of noise rises by $1 \mathrm{~dB}$. Table 5.2 presents a review of the studies on the impact of traffic noise on real estate prices.

Table 5.1 shows the Noise Depreciation Index as ranging from 0.21 to $1.7 \%$, but that result depends more on the conditions of the market at the study site. N. F. Bertrad applied meta-analysis to compare 16 studies performed in the USA, Canada, Switzerland and Finland in his 1997 work entitled "Meta-analysis of studies of willingness to pay to reduce traffic noise". He calculated the average Noise Depreciation Index by extrapolating the results at 0.64 . He thought this index would differ in each market depending on household incomes, i.e., by what price would people be willing to pay for property where noise is not a factor of affect.

Numerous studies discuss the impact of noise on real estate values comprehensively. The Environmental Agency of Denmark ordered a study to analyze 
the dependency of privately owned residential houses on noise exceeding 55 dB (Danish Environmental... 2010). Application of statistical analysis methods established a decrease in real estate property prices due to noise as follows:

- $1.64 \%$ drop when noise increases by $1 \mathrm{~dB}$ for buildings by highways;

- $1.18 \%$ drop when noise increases by $1 \mathrm{~dB}$ for buildings by other roadways;

- $1.20 \%$ drop when noise increases by $1 \mathrm{~dB}$ on average by roads.

This means that, under Danish conditions, the mean price of a home dropped by an average of 13,000 Danish kroner $(1,750 €)$ when noise increased by $1 \mathrm{~dB}$, based on average prices for real estate property in the year 2000. This price, applying a $6 \%$ discount rate, is equal to an annual drop in rental fees by 780 DKK (105 €) when noise increases by $1 \mathrm{~dB}$. Another study, also performed in Denmark, came up with similar results. Notable is that it is unclear, whether potential buyers of real estate evaluate the true level of noise by the facade of the house or whether they evaluate the distance of the residence from the roadside. Actually, the impact of noise on the price of real estate remains unexamined to a large part, despite the number of studies conducted. The research results highly differ. This study analyzes the results from 24 previously performed studies and establishes the greatest impact from noise to reach $1.2 \%$ or the price when noise rises by $1 \mathrm{~dB}$; meanwhile its average impact was at $0.5 \%$ (Danish Institute... 2010).

The suggestion, prior to the performance of research containing comprehensive and reliable data, to the fifteen senior members of the Europe Union is to count a real estate property (rental) rate reduction of $25 € / \mathrm{dB}$ per year when the noise level fluctuates from $50-55 \mathrm{~dB}$ up to $70-75 \mathrm{~dB}$. Additionally the suggestion to the new member countries is to perform research and suggest appraisals to the other members. Lithuania's GDP presently comprises only some $50 \%$ of the level enjoyed by the senior EU members. Thereby application of the central scenario can lead to the following assumptions (Vičkačka 2007):

- The price of real estate property (rental price) in Lithuania in 2003 dropped by $12.5 € / \mathrm{dB}$ per year.

- The 2006 appraisement calculated in consideration of the value of inflation during 2003-2005 and the increase in GDP comprise $17.4 € / \mathrm{dB}$ per year (60 LTL/dB per year).

The impact of air pollution on the built environment is manifold; however, its damage to health causes the most worries. Air pollution also harms buildings, lessens visibility, odors badly and causes other related problems. Nonetheless, one possible speculation is that residents might evaluate the potential discomforts caused by air pollution and therefore value a cleaner environment, which the prices of real estate property would reflect. First, it is necessary to establish the kind of pollution that residents understand best and the kind they do not to get a better explanation of the effect of air pollution on real estate property prices. 
Ridker and Henning conducted the first study on the impact of air pollution on real estate property in 1967 by in the United States (Ridker, Henning 1967). Later, in 1989, Pearce and Marjanday indicated the percentage of air pollution that would cause the value of real estate to drop by one unit (Pearce, Marjanday 1989). Overall this number is about $0.1 \%$; however, it can range from $0.01 \%$ to $0.5 \%$. American scientists Smith and Huang performed very detailed overview of the research done on the effect of air pollution on real estate prices in 1995. They analyzed the data from 37 studies and established the exact monetary expression indicating the depreciation of real estate due to air pollution in the USA by the percentage of air pollution that causes a drop of one unit in the value of real estate (Table 5.2).

Table 5.2. Real estate depreciation due to air pollution in the USA indicating the percentage of air pollution that causes value to drop by one unit

\begin{tabular}{|l|l|l|c|}
\hline \multicolumn{1}{|c|}{ Study authors } & \multicolumn{1}{|c|}{ Study site } & $\begin{array}{c}\text { Year of } \\
\text { study }\end{array}$ & $\begin{array}{c}\text { Monetary value } \\
\text { (1982-1984 } \\
\text { USA \$) }\end{array}$ \\
\hline Anderson \& Crocker 1971 & Kansas, USA & 1960 & $16-32$ \\
\cline { 2 - 4 } & St. Louis, USA & 1960 & $17-33$ \\
\hline Appel 1980 & New York, USA & 1970 & $159-191$ \\
\hline Atkinson \& Crocker 1982 & Chicago, USA & 1964 & 366 \\
\hline $\begin{array}{l}\text { Bender, Gronberg \& } \\
\text { Hwang 1980 }\end{array}$ & Chicago, USA & 1970 & $159-34$ \\
\hline Brookshire et al. 1979 & Southern California Air Basin & 1977 & 577 \\
\hline Brookshire et al. 1982 & Los Angeles, USA & 1977 & 149 \\
\hline Brucato et al. 1990 & Los Angeles, USA & 1972 & $141-191$ \\
\cline { 2 - 5 } & San Francisco, USA & 1978 & 500 \\
\hline Jackson 1979 & Milwaukee, USA & 1970 & 551 \\
\hline Krumm 1980 & Chicago, USA & 1971 & 29 \\
\hline Li \& Brown 1980 & Boston, USA & 1971 & $3-11$ \\
\hline Palmquist 1984 & Several cities, USA & 1977 & $4-174$ \\
\hline $\begin{array}{l}\text { Polinsky \& Rubinfeld } \\
1977\end{array}$ & St. Louis, USA & 1960 & $36-38$ \\
\hline Smith 1978 & & 1970 & 74 \\
\hline Soskin 1979 & Chicago, USA & & $116-138$ \\
\hline
\end{tabular}

Source: Smith \& Huang (1995)

Deliberations of the aforementioned works established that a price would increase by $\$ 109.90$ USD on average, whenever the number of dangerous particles decreases by one unit. This average value differs greatly from the median value 
( $\$ 24.40$ USD). This indicates that the very high assessment of a low number determined an overly high average; therefore the median value is more acceptable.

It is noticeable from the overview of the research that the values of these criteria vary by national and by local markets. Nonetheless, this should come as no surprise, because price changes in different residential areas would differ depending on the level of noise, air pollution and household income. There has not been much discussion on the issue in Lithuania for now; thus the experiences of other countries can guide in establishing the significances of these criteria in the real estate markets of cities and towns in Lithuania.

\subsubsection{Subjective expectations of residents survey}

A part of Vilnius City's Antakalnis and Žirmūnai neighborhoods running along the river was the site selected for analyzing the impact of pollution and noise on real estate prices (Figure 5.4). The boundaries of this zone are Antakalnio, Žirmūnų, Kareivių and Šilo Streets. The selection of this site was due to the similar 1960-1970 construction times of its residential units in multi-unit buildings. Figure 5.4 shows the objects, i.e., two-room residential units in the buildings, where the data gathered constituted the performed analysis. The location of the two-room units under discussion is nearly equally on both sides of the Neris River.

Performance of the survey was to measure the subjective expectations of residents on the effect of the traffic on the busy Žirmūnu and Antakalnio Streets, which are in proximity to their home units.

This survey considered the residents over three blocks from Žirmūnų Street to the Neris River in the Žirmūnai neighborhood regarding the impact of air and noise pollution. The physical distance from Žirmūnų Street to the Neris River varies from 60 to 300 meters. For the survey, the area was subdivided into three categories by proximity to noise and air pollution - closest (0-60 meters) to Žirmūnų Street or most affected, mid-area (60-180 meters) and closest (0-120 meters) to Neris River or least affected.

First, the effort was to measure the effect of noise and air pollution coming from Antakalnio Street on the residential units. The people living two blocks away from Antakalnio Street to the Neris River considered this impact. The physical distance from Antakalnio Street to Neris River varies from 135 to 150 meters. Therefore this area encompassed residents from two categories of proximity - the closest (0-75 meters) to Antakalnio Street with the most noise and air pollution and closest to Neris River (0-75 meters) with the least noise and air pollution.

The subjective impressions people have are very important for evaluating their dwelling conditions. Such conditions not only influence their physical health but also their mental health. Usually the influence on mental health is 

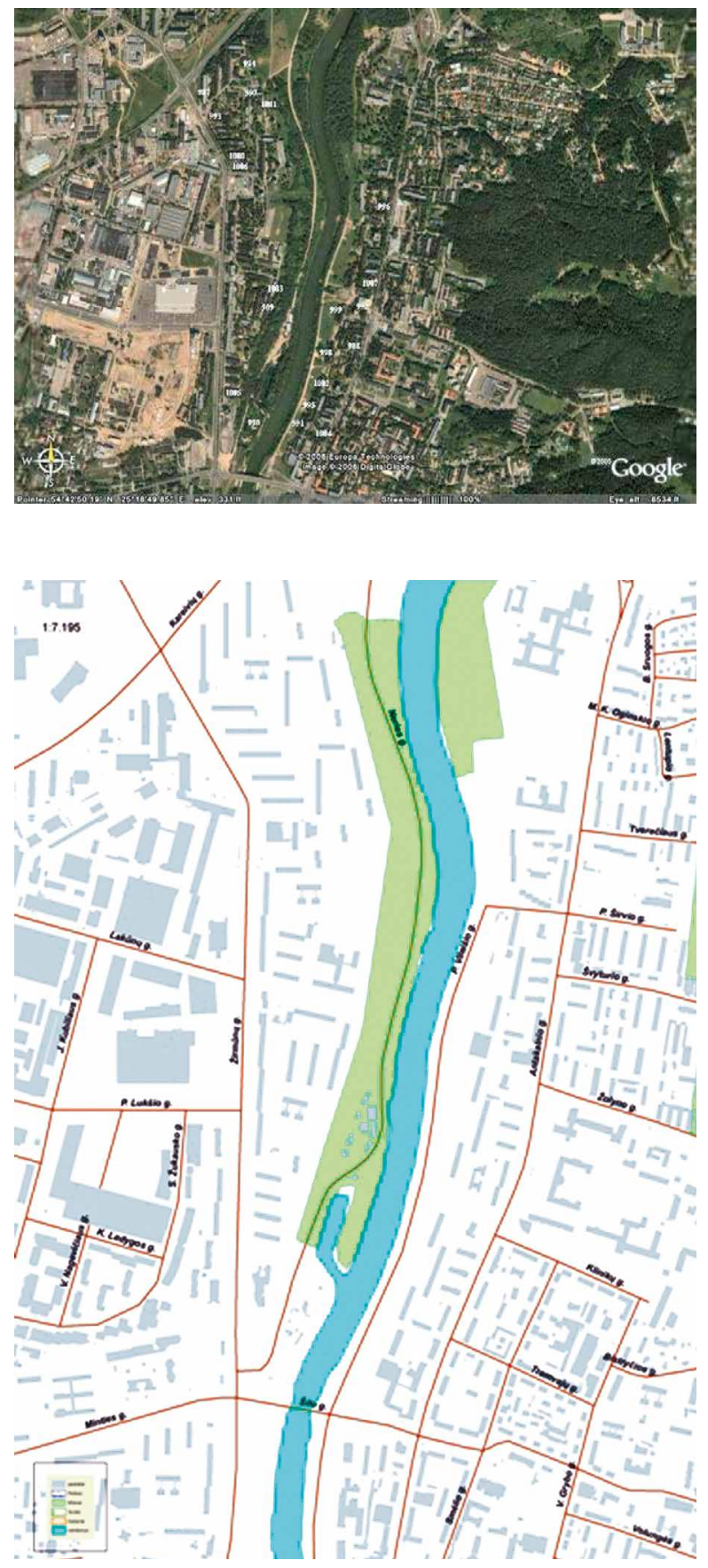

Figure 5.4. Distribution of objects under analysis on the map even greater; however, it is not as frequent and more difficult to determine. Subjective evaluations of satisfaction and comfort are important indicators in the process of improving psychological conditions, which go hand in hand with improvements in life quality and in home value.

Next there is a presentation of some survey data derived in 2005-2006 from three studies that are relevant to this research Citizens of Vilnius City and District Who Live and Work in a Risk Environment, 2000; Vilnius City Housing Survey, 2002 and an Integrated Survey on Health, Surroundings and the Quality of Life of Vilnius Citizens.

The data of the survey performed during 20052006 in Vilnius indicate that $35.0 \%$ and $31.3 \%$ of men and $28.6 \%$ and $32.5 \%$ of women respectively stated as having no problems at all or having few problems regarding air quality in their residential units (dryness, dust, odors and smoke). Meanwhile $26.8 \%$ of men and $28.9 \%$ of women stated that they face problems related to air quality in the surroundings 
of their homes; of them 5.0\% of men and $6.9 \%$ of women indicated "great problems" and $1.9 \%$ of men and $3.1 \%$ of women indicated "very great problems".

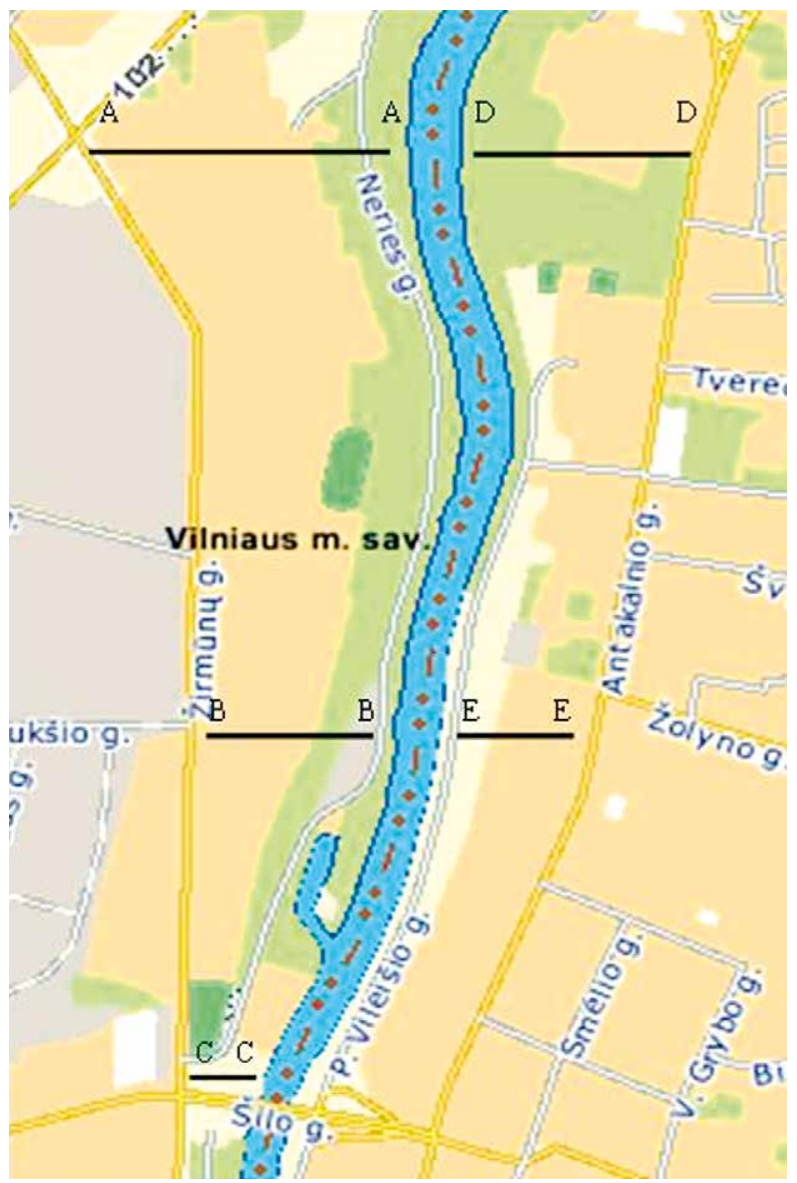

Figure 5.5. Areas investigated for air pollution and noise level

The survey performed in Vilnius resulted in $55.6 \%$ of the respondents who had evaluated their health as "good" and "very good" stating that dusty air influences their health "very much" and "extremely much". Meanwhile $38.7 \%$ of the respondents who evaluated their health as "good" and "very good" said that dusty air does not influence their health "at all".

Apparently the respondents who stated that dusty air influences their health "a little bit" to "extremely much" evaluate their health as better than did the respondents who stated that dusty air influences their health "not at all".

There were $15.9 \%$ of the respondents stated that air polluted with harmful particles influences their health "not at all"; however, these same people evaluated their health as "bad". Meanwhile only $3.5 \%$ of the respondents who stated 
that air polluted with harmful particles influences their health "very much" and "extremely much" evaluated their health as "very bad" $\mathrm{p}<0.001$. More respondents who had evaluated their health as "bad" stated that air polluted with harmful chemical substances influences their health "a little bit" and an "average" amount (12.4\%) than did those who stated they live in surroundings "very much" and "extremely much" polluted with harmful chemical substances $(3.5 \%$ at $\mathrm{p}<0.05)$.

Obviously the real air pollution level depends on the distance between the streets and the Neris River. Figures $5.5-5.7$ provide more information about noise level with decreasing noise level in areas A-A, B-B, C-C, D-D and E-E, which differ by their proximity to the Neris River.

Measurements taken of pollution and noise were within the zone of the Antakalnis and Žirmūnai neighborhoods bounded by Šilo, Žirmūnų, Antakalnio and Kareivių Streets. The main purposes of these measurements were to explain changes in the levels of pollution and noise as the proximity from streets with major traffic increases and the impact of such a change on the rates of certain illnesses among people residing in the zone along with the influence on their respective real estate prices.

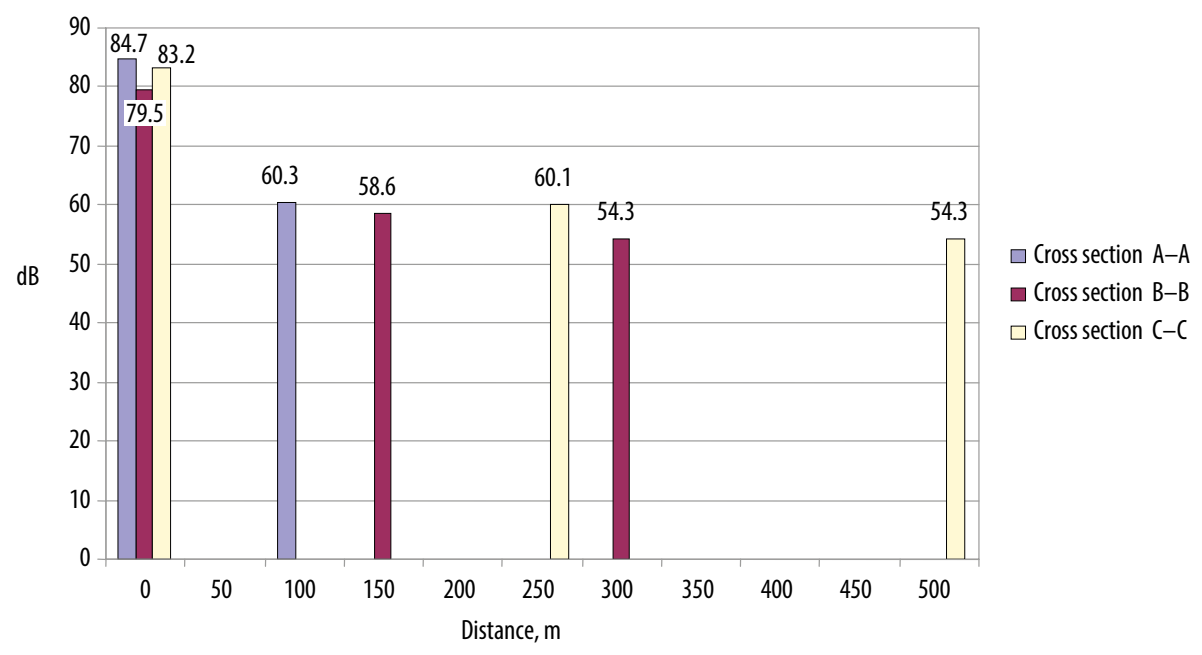

Figure 5.6. Noise level changes in Žirmūnai by Cross sections A-A, B-B and C-C as the distance from the street increases

Measurements were taken throughout the entire zone. However, the special attention was on three characteristic cross sections labeled A-A, B-B and C-C in Žirmūnai and D-D and E-E in Antakalnis (Figure 5.5).

The concentrations of pollutants that were established are:

- carbon monoxide; 
- volatile organic compounds;

- particulates;

- nitrogen oxide;

The noise level was also established throughout the entire zone.

While taking measurements, it became noticeable that noise as well as air pollution lessened greatly as the distance from the street increased. For example, the air pollution in Žirmūnai fell by as much $40 \%$ the nearer the approach to the river and in Antakalnis - by about 30\%.

There was an analogical reduction in air pollution (depending on the pollutants). For example, the amount of particulates rapidly approach a zero value as they distance from the street, i.e., from a maximal value of $0.073 \mathrm{mg} / \mathrm{m}^{3}$ down to a minimal value of $0.001 \mathrm{mg} / \mathrm{m}^{3}$. Naturally the distance between a street and the river also has an influence. Table 5.3 provides more information on air pollution and noise in the A-A, B-B ir C-C cross sections by the street and by the river in the Žirmūnai neighborhood and D-D, E-E cross sections in the Antakalnis neighborhood.

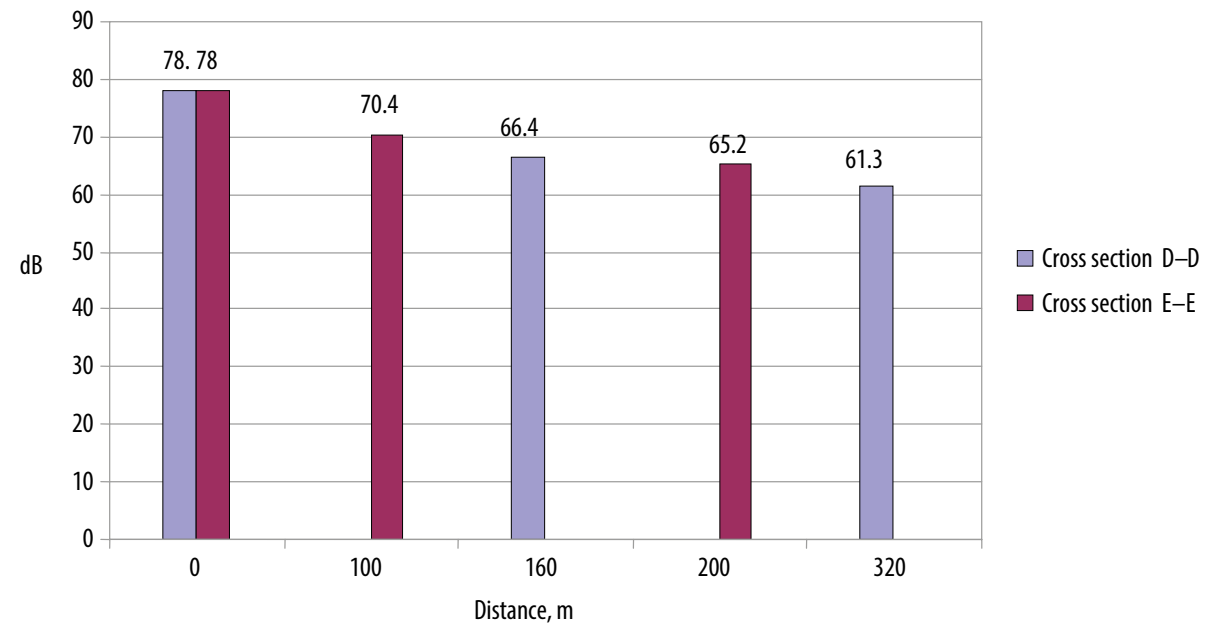

Figure 5.7. Noise level changes in Antakalnis by Cross sections D-D and E-E, as the distance from the street increases

The main factors determining the change in the amount of pollution per $\mathrm{m}^{3}$ are the distance from the street to the river and the number of buildings and their arrangement within the cross section. The greater the distance from the street to the river, the less pollution there is. The number of buildings and their layout also have an analogical influence on the outcome. Both these factors determine the dispersal of pollution over the territory, i.e., the more densely the buildings are standing, the faster the amount of pollution lessens as the distance 
from the street increases. However, in this instance, the speed of wind and air circulation between the buildings is very important. When the spacing between buildings is greater, the air between them moves much more rapidly, which means the pollution will spread farther away from the street. The layout of the buildings is also decisively significant: if the buildings stand parallel with the street and if there is little distance between them, there is a higher probability that the structures will act as a barrier, blocking the way for the pollution to disperse further. Structures standing perpendicularly along the street will be less likely to hold back the pollution. Table 5.3 was composed based on the factors determining the dissipation of these pollutants. It was noticeable that the amount of carbon dioxide in Cross section A-A was highly changeable, i.e., its value fluctuated from $7.13 \mu \mathrm{g} / \mathrm{m}^{3}$ to $0.66 \mu \mathrm{g} / \mathrm{m}^{3}$, while distancing from the street towards the river. An evaluation of these factors included a calculation indicating that the concentration of $\mathrm{CO}$ was decreasing by $0.129 \mu \mathrm{g} / \mathrm{m}^{3}$ every $10 \mathrm{~m}$. Analogically the amount of $\mathrm{CO}$ in Cross sections $\mathrm{B}-\mathrm{B}$ and $\mathrm{C}-\mathrm{C}$ changes by $0.091 \mu \mathrm{g} / \mathrm{m}^{3}$ and $0.469 \mu \mathrm{g} / \mathrm{m}^{3}$, respectively. Nevertheless, it is noticeable that the amount of pollutants changes more slowly in Cross section B-B, although the distance and number of buildings are greater than they are in Cross section $\mathrm{C}-\mathrm{C}$. These happened, because the measurements of the maximal values in Cross sections A-A as well as in C-C were towards the Kareivių-Žirmūnų Street and Žirmūnų-Šilo Street intersections. Here the traffic is much more intense, and therefore, the concentration per $\mathrm{m}^{3}$ is greater. The amount of pollution in Cross sections D-D and E-E change each $10 \mathrm{~m}$ similarly, i.e., from $0.1 \mu \mathrm{g} / \mathrm{m}^{3}$ to $0.1305 \mu \mathrm{g} / \mathrm{m}^{3}$. The same aforementioned factors that determined the change in $\mathrm{CO}$ influenced the change in particulates. The maximal values that were measured by the street in this instance depend more or less on the intensity of traffic during the time of measurement as well as by the direction of the wind. Meanwhile the minimal values depended on distance and the density of buildings. It was noticeable that the amount of particulates changed greatly as the distance from the street increased in all the cross sections. A somewhat smaller change occurred in Cross section A-A. The direction of the wind could have determined this, the same as it determined the movement of particulates from Kareiviu Street in parallel with the riverbed.

The same factors affect the dispersion of noise that affect the dispersion of air pollution:

- The distance from the source of the noise to the river is one.

- The density of buildings on the territory (buildings act as a wall holding back noise) and orientation of the buildings towards the street are others.

- The buildings on both sides of the street is yet another factor that can determine an increase in noise, i.e., sound strikes a building and returns, now stronger, towards the building standing on the opposite side of the street. 


\begin{tabular}{|c|c|c|c|c|c|c|c|}
\hline \multirow{4}{*}{$\begin{array}{l}\mathscr{y} \\
\stackrel{0}{0} \\
Z\end{array}$} & \multicolumn{2}{|c|}{$\begin{array}{c}\text { ш 0 I } \\
\text { Кләнә ә8иечว }\end{array}$} & $\stackrel{1}{0}$ & $\stackrel{+}{\infty}$ & $\begin{array}{l}\infty \\
\infty \\
\text { ஸे }\end{array}$ & กี & $\stackrel{+}{0}$ \\
\hline & \multicolumn{2}{|c|}{ 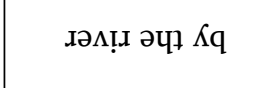 } & $\ddot{n}$ & $\stackrel{m}{\dot{m}}$ & ஜே. & ma. & $\stackrel{\sim}{ம 0}$ \\
\hline & \multicolumn{2}{|c|}{ дәә.џ ә૫ӊ Кq } & $\stackrel{+}{\infty}$ & กุ & $\stackrel{N}{\infty}$ & $\stackrel{\infty}{\wedge}$ & $\stackrel{\infty}{n}$ \\
\hline & \multicolumn{2}{|c|}{ 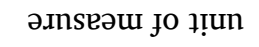 } & 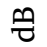 & 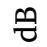 & 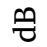 & $\theta$ & $\vartheta$ \\
\hline \multirow{7}{*}{ 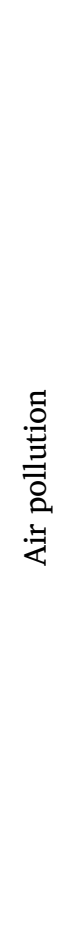 } & \multirow{3}{*}{ 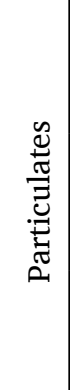 } & 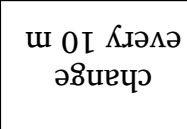 & $\begin{array}{l}8 \\
8 \\
8 \\
0\end{array}$ & $\begin{array}{l}\stackrel{1}{0} \\
\stackrel{8}{8} \\
\stackrel{0}{0}\end{array}$ & $\begin{array}{l}\text { ஜ̊ } \\
\text { ஜ̊ } \\
\dot{0}\end{array}$ & $\begin{array}{l}+ \\
\dot{\delta} \\
\\
0\end{array}$ & $\begin{array}{l}\text { ̦ } \\
\text { Oे } \\
\dot{0}\end{array}$ \\
\hline & & 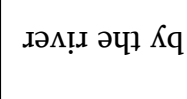 & $\begin{array}{l}\text { ฟิ } \\
\text { ல }\end{array}$ & $\begin{array}{l}5 \\
\text { ᄋ } \\
0\end{array}$ & $\begin{array}{l}5 \\
\text { ᄋ } \\
0\end{array}$ & $\begin{array}{l}5 \\
\\
\end{array}$ & 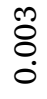 \\
\hline & & 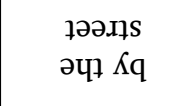 & $\begin{array}{l}\hat{\theta} \\
\text { ○े } \\
0\end{array}$ & $\begin{array}{l}0 \\
\hat{0} \\
0\end{array}$ & $\begin{array}{l}\hat{0} \\
0 \\
0\end{array}$ & $\underset{0}{\stackrel{5}{0}}$ & $\underset{0}{0}$ \\
\hline & \multirow{3}{*}{ ○ } & 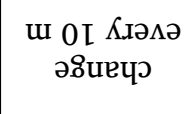 & $\begin{array}{l}\stackrel{\overbrace{}}{\sim} \\
\stackrel{0}{0}\end{array}$ & $\begin{array}{l}\bar{\delta} \\
0 \\
0\end{array}$ & $\begin{array}{l}\hat{o} \\
\text { fo } \\
\dot{0}\end{array}$ & $\ddot{0}$ & $\begin{array}{l}\text { ?0 } \\
\text { m. } \\
\text { ?. }\end{array}$ \\
\hline & & 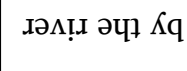 & $\begin{array}{l}\qquad \\
\ddot{0}\end{array}$ & ஸे & $\stackrel{\substack{n \\
o}}{n}$ & ๙ু & ம் \\
\hline & & 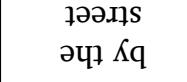 & $\stackrel{m}{\pi}$ & 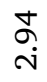 & مે & $\stackrel{\overbrace{}}{\underset{\leftarrow}{+}}$ & $\stackrel{\sim}{\underset{\sim}{*}}$ \\
\hline & \multicolumn{2}{|c|}{ 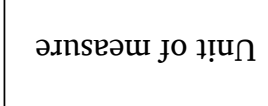 } & 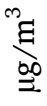 & 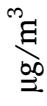 & $\stackrel{m_{0}^{\prime}}{\xi}$ & $\stackrel{m_{00}^{\infty}}{{ }_{0}^{\prime}}$ & $\stackrel{\infty}{E}_{=0}^{m}$ \\
\hline \multicolumn{3}{|c|}{ 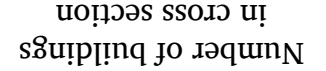 } & $\stackrel{-}{\rightarrow}$ & 0 & N & $\nabla$ & $a$ \\
\hline \multicolumn{3}{|c|}{ 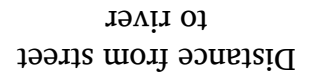 } & ○ & ஓ & $\stackrel{\bigcirc}{\circ}$ & ஸి & 유 \\
\hline \multicolumn{3}{|c|}{ Uо!ฺगวS SSOIכ } & $\underset{1}{1}$ & $\stackrel{\oplus}{n}$ & ú & $\frac{1}{a}$ & $\begin{array}{l}\text { 되 } \\
\text { 도 }\end{array}$ \\
\hline
\end{tabular}


As the data in Table 5.3 was deliberated, it became noticeable that the maximal values are somewhat greater in Cross sections A-A and C-C. The factor here, as mentioned previously, pertains to the values being measured by the intersections of the streets. Figures 5.8-5.10 provide more information about pollution with decreasing solid particles in areas A-A, B-B, C-C, D-D and E-E, which differ by their proximity to the Neris River.

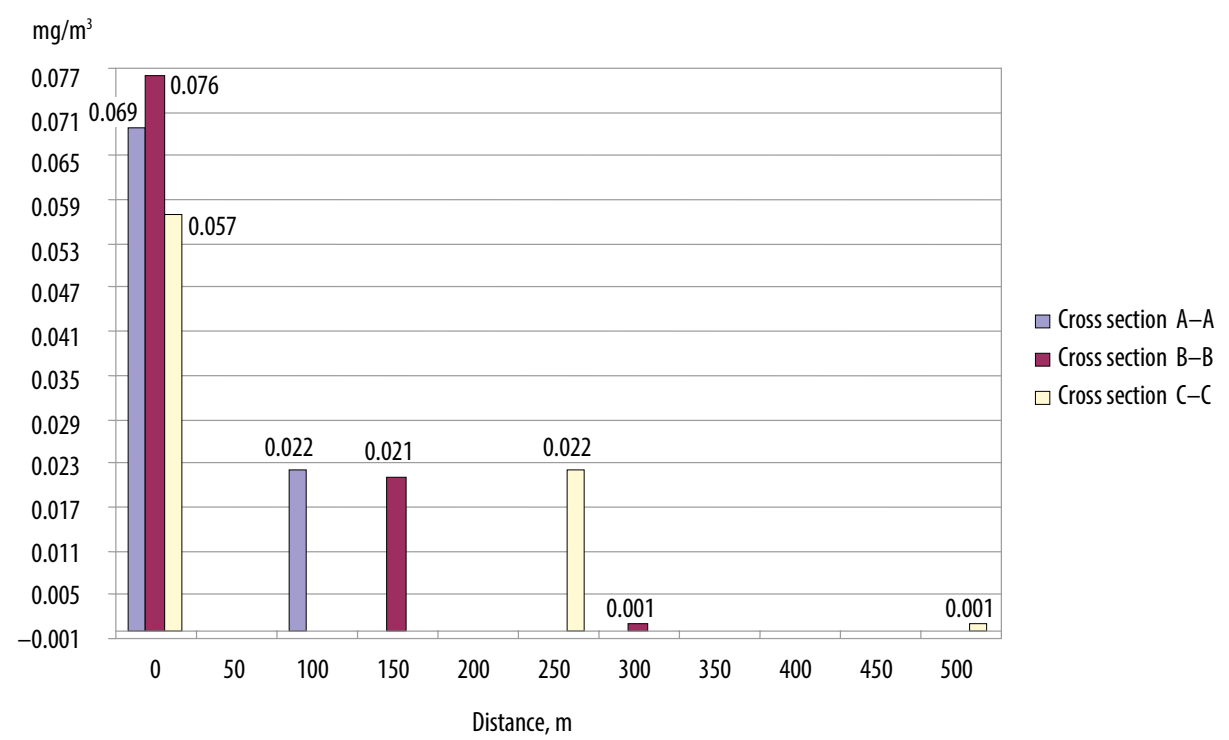

Figure 5.8. Decreasing level of particulate concentration as distance increases from the street in Cross-sections A-A, B-B and C-C in the Žirmūnai neighborhood

Data on the measurements served as the basis for compiling digital maps of different pollutants (carbon monoxide, volatile organic compounds, particulates and nitrogen oxide) and noise.

The survey established that noise is one of the most obvious and most important problems in the multi-unit residential buildings. A full $87.3 \%$ of the residents reported that noise from outdoor or from neighboring housing units disturbs them, even when the windows are closed. Of them as many as $15.7 \%$ said, the noise constantly disturbs them. The most common source of noise is the neighbors from their own homes, i.e., talking, music, TV, work, pets and such, from outdoors, i.e., from bars, playgrounds and other sources) and traffic noise. Therefore $66.7 \%$ of resident participants evaluated the sound insulation in their residential units as the worst. Most think that bad sound insulation is due to the indoor walls, windows and ceilings of these housing units. Of those interviewed, $54.2 \%$ said, they would agree to pay some additional sum every month for the ability to live in a quiet environment. 


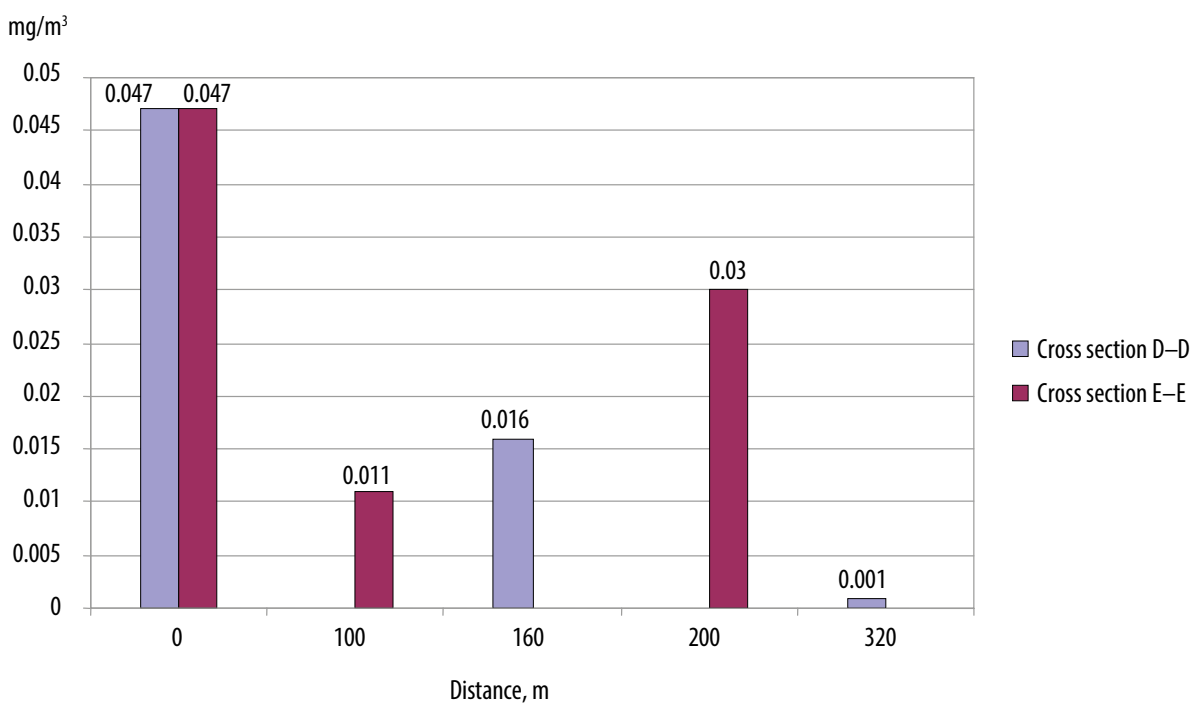

Figure 5.9. Decreasing level of particulate concentration as distance increases from the street in Cross-sections D-D and E-E in the Antakalnis neighborhood

Quite many residents (38.8\%) mentioned noise as the reason for people's sleep disorders or disturbances in regular sleeping. Furthermore $43.3 \%$ of the people cited noise as the reason for being irritated or angry. As many as two thirds of the resident respondents think that noise disturbs them due to insufficient sound insulation. Noise coming from neighboring dwellings (talking, music, TV, repair works, pets, etc.), traffic and parking areas especially anger people.

Three fourth of the residents $(74.4 \%)$ said, they have problems related to sound insulation. Generally they think that bad sound insulation is in the windows (42.5\%), ceilings (41\%), indoor unit walls (34.3\%), walls between their unit and other units or staircases (33.2\%), outdoor walls (31.6\%) and the floor (30.9\%).

The respondents were of a general opinion that their problems usually stem from noise coming from neighboring flats, traffic and car parking areas.

The survey data included $12.5 \%$ respondents who stated that street noise in their residential surroundings affect their health "not at all". The same number indicated that the street noise in their residential surroundings affect their health "very much" and "extremely much" and they evaluated their own health as "very bad".

Street noise, according to $34.4 \%$ of the respondents, prevails in their residential surroundings. The respondents who evaluated the noise prevailing in their residential surroundings as "a little bit" and "on average" evaluated their own health worse than the respondents did who stated that street noise does not influence their surroundings "at all". However, the respondents who stated that street noise affects their residential surroundings "very much" and "extremely much" evaluated their own health better than those did who stated that street noise does not influence their surroundings "at all". 


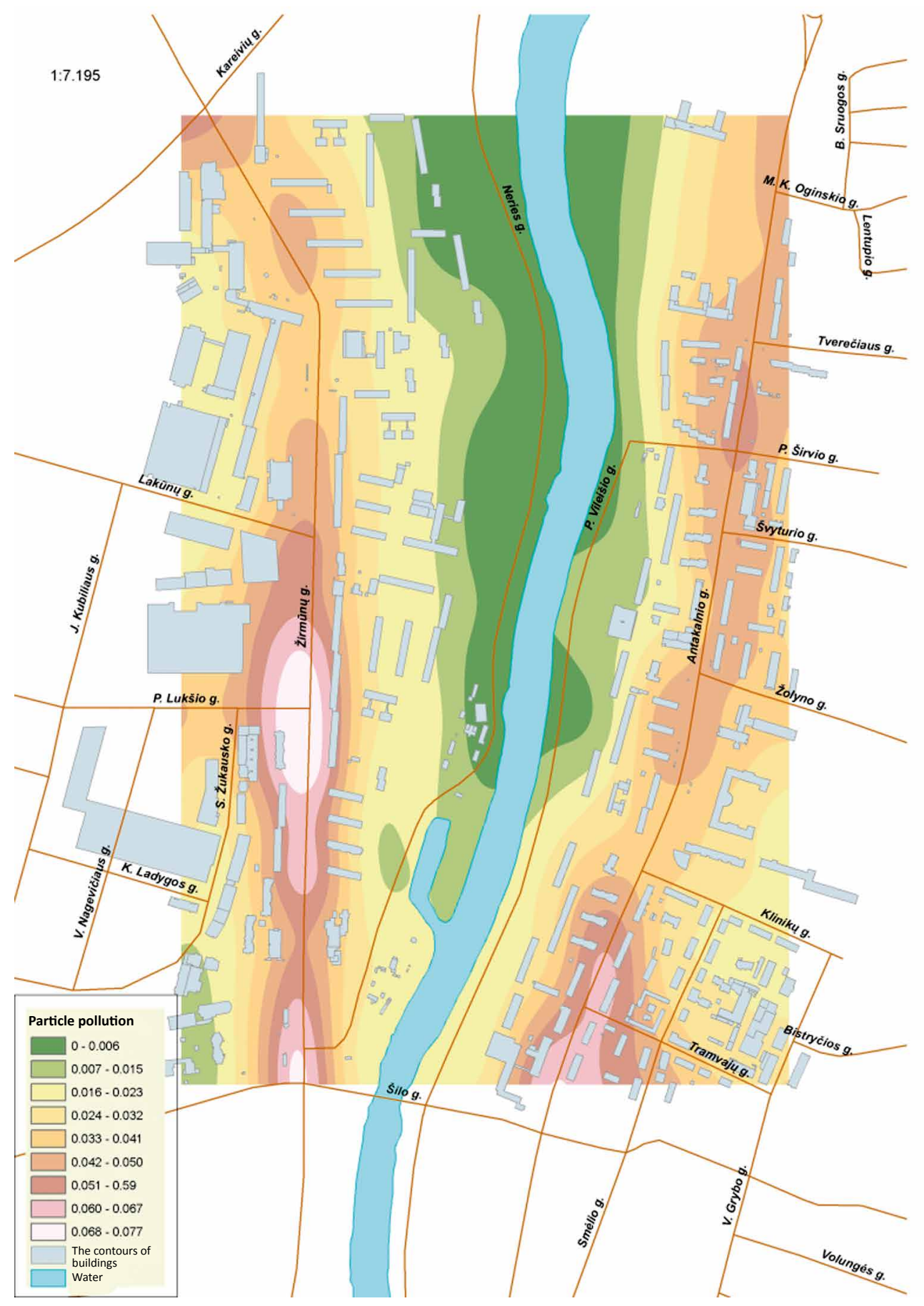

Figure 5.10. Changes in particulate concentration level on a digital map of the Antakalnis and Žirmūnai neighborhoods 
The survey data shows that $43.7 \%$ of the respondents stated that noise does not affect their surroundings. However, those respondents who indicated that traffic noise in their yards affects their surroundings "a little bit" and "on average" evaluated their own health worse than those did who stated that traffic noise in the yards does not affect their surroundings "at all". The respondents who stated that traffic noise in the yard affects their surroundings "very much" and "extremely much" evaluated their own health better than those did who stated that street noise does not influence their residential surroundings.

Of those interviewed, only $5.3 \%$ of the men and $5.1 \%$ of the women reported having very great problems related to noise (from neighbors or motor vehicles). Another $10.9 \%$ of men and $10.3 \%$ of women reported having great problems related to noise; $22.5 \%$ of men and $26.7 \%$ of women indicated that noise causes them average problems and $31.6 \%$ and $29.7 \%$ of men and $30.1 \%$ and $27.8 \%$ of women respectively indicated few problems or no problems at all.

One possible conclusion is that resolving the noise problem should be a major priority.

The data of the survey performed in Vilnius City showed that $13 \%$ of the respondents who complained about their bad health stated that the noise caused by their neighbors affects their health "very much" and "extremely much". The respondents who evaluated the noise caused by their neighbors as "a little bit" and "on average" evaluated their own health worse than did those who evaluated the noise caused by their neighbors as affecting their health status "very much" or "extremely much".

The real noise level depends on the distance between the streets and the Neris River. Figures 5.6 and 5.7 provide more information on the noise level decreasing from the Neris River in the different Cross sections A-A, B-B, C-C, D-D and E-E.

Lithuanian hygiene standard HN 35:2002, "Marginal Values of Air Pollutant Concentrations in Residential Areas", sets the following allowable norms of pollutants:

- Carbon monoxide (CO) is permissible up to $5 \mathrm{mg} / \mathrm{m}^{3}$. CO concentration exceeds the normative requirements at the intersection of Šilo Street with Antakalnio and Žirmūnų Streets by up to $7.15 \mathrm{mg} / \mathrm{m}^{3}$.

- Volatile organic compounds that oil products emit as gases of any compound have a maximum allowable concentration of $5 \mathrm{mg} / \mathrm{m}^{3}$ in a residential neighborhood. Studies have shown that the concentration exceeds this norm at the intersection of Žirmūnų Street with Kareivių Street and in some parts of Antakalnio Street where traffic is more intense.

- Airborne particulate concentrations cannot exceed $0.5 \mathrm{mg} / \mathrm{m}^{3}$. Measurements show that the concentrations are within this norm. Pollutant concentrations are particularly high at intersections, where pollution from particulates reaches up to $0.077 \mathrm{mg} / \mathrm{m}^{3}$. 
- Nitrogen oxide $\left(\mathrm{NO}_{2}\right)$ in the air is allowable up to a concentration of $0.040 \mathrm{mg} / \mathrm{m}^{3}$. Concentration of nitrogen dioxide exceeds the allowable norm considerably at the intersection of Antakalnio with Žolyno Streets, where it reaches up to $0.071 \mathrm{mg} / \mathrm{m}^{3}$. The concentrations of $\mathrm{NO}_{2}$ at intersections ranged from 0.041 to $0.063 \mathrm{mg} / \mathrm{m}^{3}$.

Experiments have shown that humans perceive a reduction of sound by $10 \mathrm{~dB}$ as if the noise level had doubly decreased. Thus it can be said that noise level decreases up to eight times at sites farthest from the street.

Of the respondents, $31.1 \%$ held the opinion that their own residences were relevant to their health disorders and illnesses. Generally these people indicated respiratory disorders and coughing (12.3\%), headaches $(10.0 \%)$, coryza $(5.5 \%)$ and problems of falling asleep (4.6\%). Most believed their health disorders or illnesses related to the conditions of their home facilities with $15.1 \%$ naming the influence as the air quality within their dwelling, 9.1\% - noise level, 8.7\% - temperature and $7.8 \%$ - air humidity. The survey results lead to conclude that the greatest influence on resident respondent's health, in their own opinion, is noise emanating from outdoors or, when their windows are closed, from the neighboring units. Of them $15.7 \%$ of the respondents complained that noise disturbs them constantly. Of those reporting health difficulties due to their premises, $87.3 \%$ reported that the surrounding air pollution, noise, dust and microclimate of their premises disturb them (Ekologinio klubo... 2003; Žvirždinaitè 2007).

Home facilities and their surroundings are factors considerably influencing people's health in a complex way. Even a slight impact on health may turn into a great problem when it influences large groups of people. People's senses are subjective and highly important in evaluating the conditions in which they live. The influence of housing facilities not only affects the physical health of the residents but also usually affects mental health even more. The influence on mental health is a more seldom occurrence; however, it is more difficult to establish. The important indicators about improvements in the psychological conditions of housing involve subjective evaluation, satisfaction and comfort. The quality of life and an understanding of value of the home also play a role in such a process (Ekologinio klubo... 2003; Žvirždinaitė 2007).

The air quality of one's home was a source of complaint with $64.4 \%$ of the resident respondents. Many mentioned dry air, humidity, dust, odors and insufficient air circulation as the factors of air quality. The resident respondents who reported the air quality of their housing unit as bad, quite bad or medium were less satisfied with their unit more often and were inclined to relate people's health disorders with their housing conditions more often than did those residents who evaluated air quality in their unit as quite good or good. A ventilation system greatly influences air quality. The survey data showed that only $20.6 \%$ of the housing units had a mechanical ventilation system installed and that only 
half of these people thought it was sufficiently functioning. The air quality inside the housing unit did not satisfy almost half of the residents. Most residents believe the main reasons for the air quality problems in their premises are dust and other particles (41.9\%), outdoor pollution (38.2\%), dryness (34.9\%), odors (30.2\%), humidity $(22.6 \%)$, smoke $(22.3 \%)$ and insufficient air circulation or "heavy" air (18.6\%).

Smoking in the premises also constitutes one of the reasons regarding poor air quality. It was determined that every fourth person sleeps in a smoke-filled room. People who sleep in smoky rooms complained more often about chronic diseases or long-term health disorders like blood pressure and heart problems and they had colds more often in the winter) than did those who sleep in nonsmoky rooms. The assessments of researches on air quality in housing premises are secondary, and this fact sometimes results in fatal outcomes. People pay insufficient attention to the microclimate of housing premises, and an insufficient amount of money to obtain ventilation systems of good quality. Health suffers due to this. Allergies were not so prevalent fifty years ago. Today it is difficult to find a person who does not suffer from an allergy and is not involved with a close person who suffers from this cunning disease. Nonetheless, many examples are available for finding on how much the air in our premises, where people breathe an average of 21 of 24 hours per day, influences us (Ekologinio klubo... 2003; Žvirždinaitė 2007).

Ventilation is the main measure for reducing pollutants in the air indoors, when there was a lack of control at their site of discharge. Nonetheless, a home ventilation system is insufficient in many cases and it is often non-regulated. Residents tend to evaluate their system as worse than better; i.e., $54.6 \%$ of the respondents assigned theirs an evaluation ranging from 1 to 3 on the evaluation scale of 5 , where 1 is totally dissatisfactory and 5 - totally satisfactory. Meanwhile $38.2 \%$ of the male and $35.7 \%$ of the female respondents indicated that their home ventilation system works very well in the home surroundings and does not cause any problems, none in winter and none in summer. However, $27.6 \%$ of men and $32.5 \%$ of women reported having merely a few problems with their ventilation system. Another $26.3 \%$ of the men and $23.8 \%$ of the women indicated average problems, and $7.2 \%$ and $6.1 \%$ respectfully - great problems. A mere $0.8 \%$ of the men and $1.9 \%$ of the women indicated their ventilation systems cause very great problems, in winter as well as in summer (Ekologinio klubo... 2003; Žvirždinaitė 2007).

One of the main complaints from residents of multi-unit building blocks was dissatisfaction with temperature comfort. More than a half of all interviewed such residents complained about insufficient temperature in their dwelling unit in all seasons, and as many as 73\% complained about a lack of sufficient heat, in autumn and in spring. Most indicated the temperature was too hot for them 
in summer and too cold in winter and in intermediary period. Therefore people must use additional heating appliances for warmth. As per available knowledge, a low temperature in residential premises increases humidity along with the consequent risk of respiratory illnesses. The survey found that those people who complained about the temperature in their home unit during the summer and winter seasons evaluated their own health twice as poorly as those who are satisfied with their home temperature and reported no problems. One of the main complaints of the people living in blocks of multi-unit residential buildings was dissatisfaction with temperature comfort. Almost a third of the residents (30.4\%) were dissatisfied with the air temperature in their housing during summer. Of them $92.1 \%$ complained that it is too hot. Over half of the residents (54.1\%) complain about the temperature during the intermediary period, between summer and winter, and $90.8 \%$ of them complain that it is too cold. As many as $60 \%$ of the residents are dissatisfied with the air temperature in their homes during winter. The most common reason of dissatisfaction with air temperature is that it is too cold (92.0\%), and $15.4 \%$ of these respondents constantly suffer from temperature discomfort in winter. This causes $19.8 \%$ of the respondents to use additional heating appliances in intermediary and in winter (Ekologinio klubo... 2003; Žvirždinaitė 2007).

There was an integrated survey performed in Vilnius City in the autumn of 2005 and spring of 2006 on "Health, Surroundings and the Quality of Life of Vilnius City Citizens". This survey included application of the random selection method. The interviews of the respondents involved using a 274-question questionnaire while maintaining the respondent's anonymity. This questionnaire included questions about factors involving a dwelling environment. It appeared upon analyzing the data that $35.8 \%$ of the men indicated they had no problems in their unit related to air temperature (neither in winter, in summer, in autumn nor in spring), and $27.7 \%$ of the women had no complaints about air temperature either. However, $24.5 \%$ of the men and $35.5 \%$ of the women indicated a few problems, and $24.7 \%$ of the men and $27.2 \%$ of the women reported average problems related to air temperature in the premises. Not many respondents reported great and very great problems - respectively, $3.2 \%$ and $1.9 \%$ of the men and $8.5 \%$ and $1.1 \%$ of the women.

Available knowledge claims that a low temperature in housing premises increases humidity and thereby respiratory illnesses. The people who complained about the temperature in their housing unit during summer and winter, as this survey shows, evaluated their own health twice as poorly as those who reported no problems related to temperature. Draft and insufficient heating insulation are obvious problems of the people living in multi-unit residential buildings. Of the analyzed households, $74.5 \%$ complained about air circulation problems, especially in winter, with wind blowing in through the windows, because the 
windows/door do not close hermetically. Over half of the respondents indicated that draft troubles them often and constantly. Quite many people who complained about air circulation or draft in their housing unit gave worse evaluations about their health and satisfaction with the housing. Non-hermetic windows are the main reason for drafts. This analysis has shown that windows do not close hermetically in $73.5 \%$ of the analyzed households (Ekologinio klubo... 2003; Žvirždinaitè 2007).

The 2002 survey established that two thirds of the residents lived in units with non-hermetic windows (sometimes even with visible cracks) in at least one room where the wind was blowing in. One fifth of the residents had windows consisting of a single glass packet. Over half of the residents complained about problems regarding air shift or a draft in their home, especially in winter, caused by non-hermetic windows or doors and/or their unsuitable quality. Only a fourth of the residents reported no problems related to the temperature in their home. People evaluated the quality of their heating system as poor more often than as good. On a scale of 5 , where 1 means "totally dissatisfactory" and 5 means "totally satisfactory", $54.9 \%$ evaluate their home from 1 to 3 . Many residents cannot regulate heating systems themselves - in more than $80 \%$ of the cases. Some, $27.3 \%$ of the residents must use additional heating appliances 0 , and $28.0 \%$ of them constantly use additional heating appliances, which causes greater expenses related to their home economy (Ekologinio klubo... 2003; Žvirždinaitè 2007).

Two thirds of the residents evaluated the heating insulation in their home from 1 to 3 on a scale of 5 where 1 means "totally dissatisfactory" and 5 means "totally satisfactory". Only $1.1 \%$ of the women complained about great problems relevant to the lighting in their units due to other buildings and trees blocking their windows, and this did not cause the men any particular inconveniences. Nevertheless, $4.8 \%$ of the men and $5.3 \%$ of the women stated there were problems related to lighting. Insufficient lighting in a home caused average discomfort, as $16.7 \%$ of the men and $17.5 \%$ of the women reported. Most respondents indicated there are no problems related to the lighting in their residences at all or only few few problems (respectively, $54.6 \%$ and $23.9 \%$ of the men so reported and $50.6 \%$ and $25.4 \%$ of the women). The data of the 2002 survey showed that almost one third of the residents indicated they sometimes needed to turn on the light during the day on a sunny day, because natural lighting is insufficient in the facility. As many as $51.7 \%$ of the male respondents and $46.1 \%$ of the female respondents indicated no problems related to the humidity of their housing unit at all. Meanwhile $22.5 \%$ of the men and $28.9 \%$ of the women stated there are few problems, and $19.6 \%$ of the men and $17.5 \%$ of the women indicated average problems related to humidity. Great or very great problems relevant to humidity were reported by respectively $4.0 \%$ and $2.1 \%$ of the men and by $5.6 \%$ and $1.8 \%$ of the women (Ekologinio klubo... 2003; Žvirždinaitė 2007). 
Figure 5.11 displays the zones that have a dangerous concentration of $\mathrm{CO}$ and $\mathrm{NO}_{2}$ pollutants (in red). Such a concentration of pollutants can cause respiratory disorders and asthma.
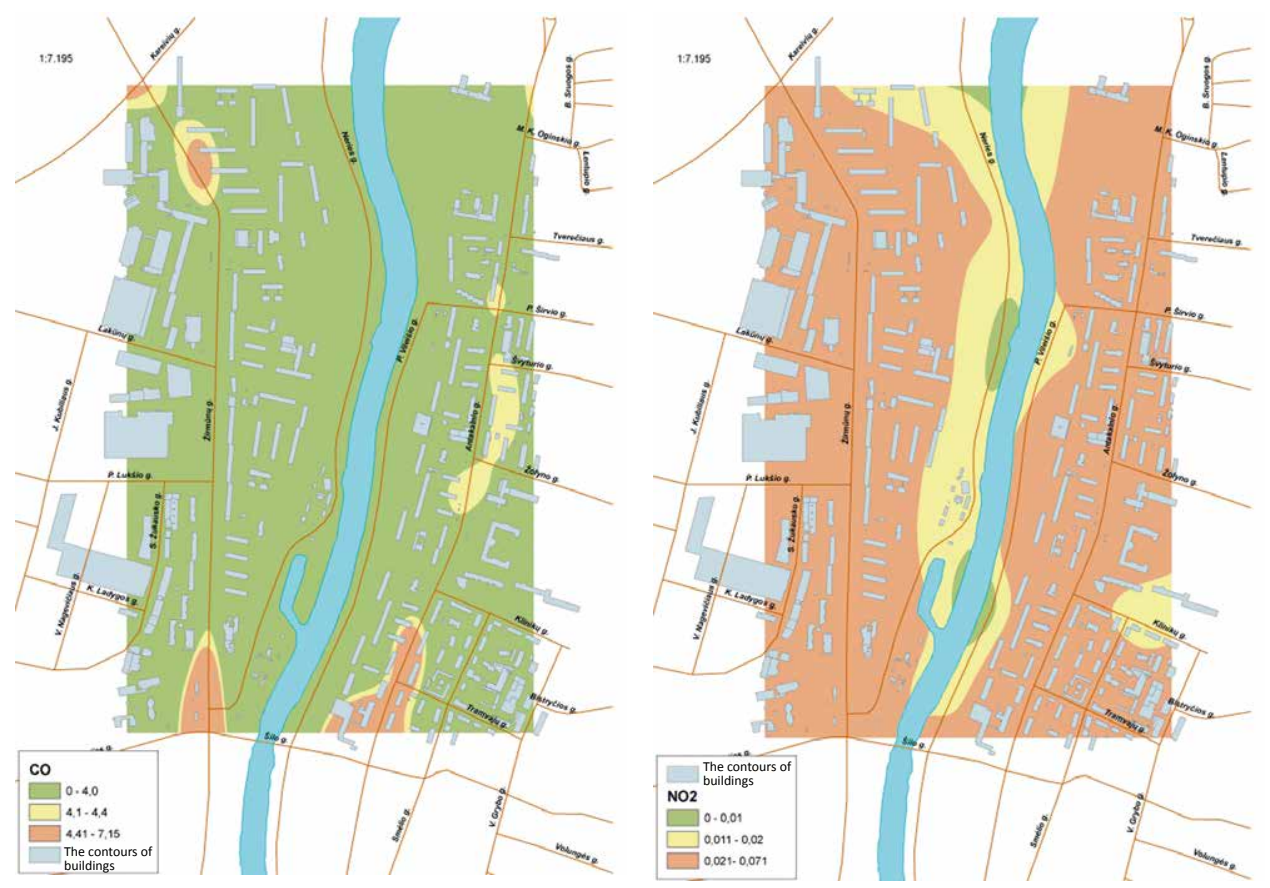

Figure 5.11. Zones with concentrations of $\mathrm{CO}$ and $\mathrm{NO}_{2}$ pollutants dangerous to people with respiratory disorders (in red)

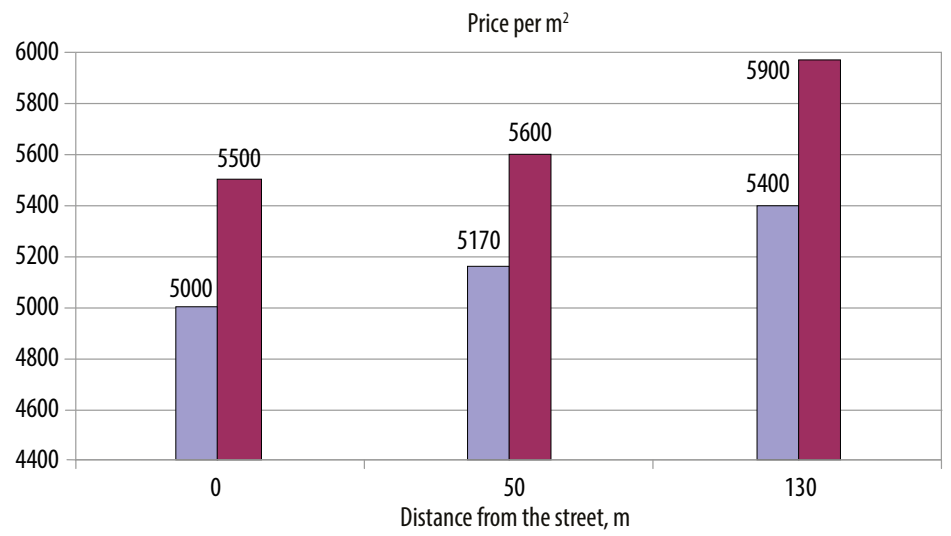

Figure 5.12. Price (thousands LTL. 1 LTL $=3.4528$ Euro) per $\mathrm{m}^{2}$ of a residential unit 1 room apartment; 2 rooms apartment) for sale increases, as the distance from the street increases, in Antakalnis in 2006 


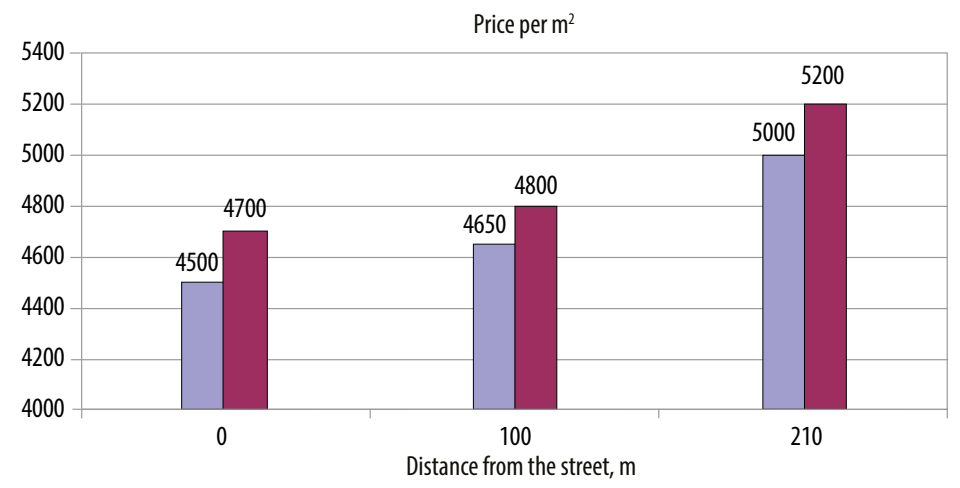

Figure 5.13. Price (thousands LTL. 1 LTL $=3.4528$ Euro) per $\mathrm{m}^{2}$ of a residential unit (1 room apartment; 2 rooms apartment) for sale increases, as the distance from the street increases, in Žirmūnai in 2006

Evidence is available that individuals are knowledgeable about air and noise pollution levels; however, subjective expectations and measured air and noise pollution levels, as found, have different effects on housing values. As expected, a more subjective knowledge about air and noise pollution reduces the values of housing units. For example, residents believe that pollution is greater near Žirmūnų and Antakalnio Streets, and the values of housing units apparently reflect this belief. The correlation between measured pollution and dwelling values also suggests that residents have partial information about the influence of air and noise pollution on their health. Residents appear to be knowledgeable about the relationships between the relative levels of pollution in different neighborhoods and under different weather conditions. The busy traffic on Žirmūnu and Antakalnio Streets and connected intersections probably form the opinion that dwellings near Žirmūnų and Antakalnio Streets will suffer more from pollution.

That air pollution and sound can have a certain effect on dwelling prices, i.e., the prices of housing units close to the street should be slightly lower than prices are for units closer to the river was the assumption made while analyzing changes in pollution and noise and their effects on human health. Substantiation of this assumption began with collecting offer prices for residential dwellings on sale in the analyzed zone from Lithuanian web-based real estate databases and periodicals in the summer of 2006. Then diagrams of average values were drawn for the Žirmūnai and Antakalnis neighborhoods separately (Figures 5.12 and 5.13).

The figures shown above display the changes in the price per $\mathrm{m}^{2}$ for a residential dwelling with respect to the distance from the street, both in the Žirmūnai and the Antakalnis neighborhoods. As seen, the most expensive units are closest to the river, since there is a lower penetration of air pollution and noise from the street, and the environment is more picturesque. In comparison, the figures display the offer prices of units close to the street with the offer prices of those 


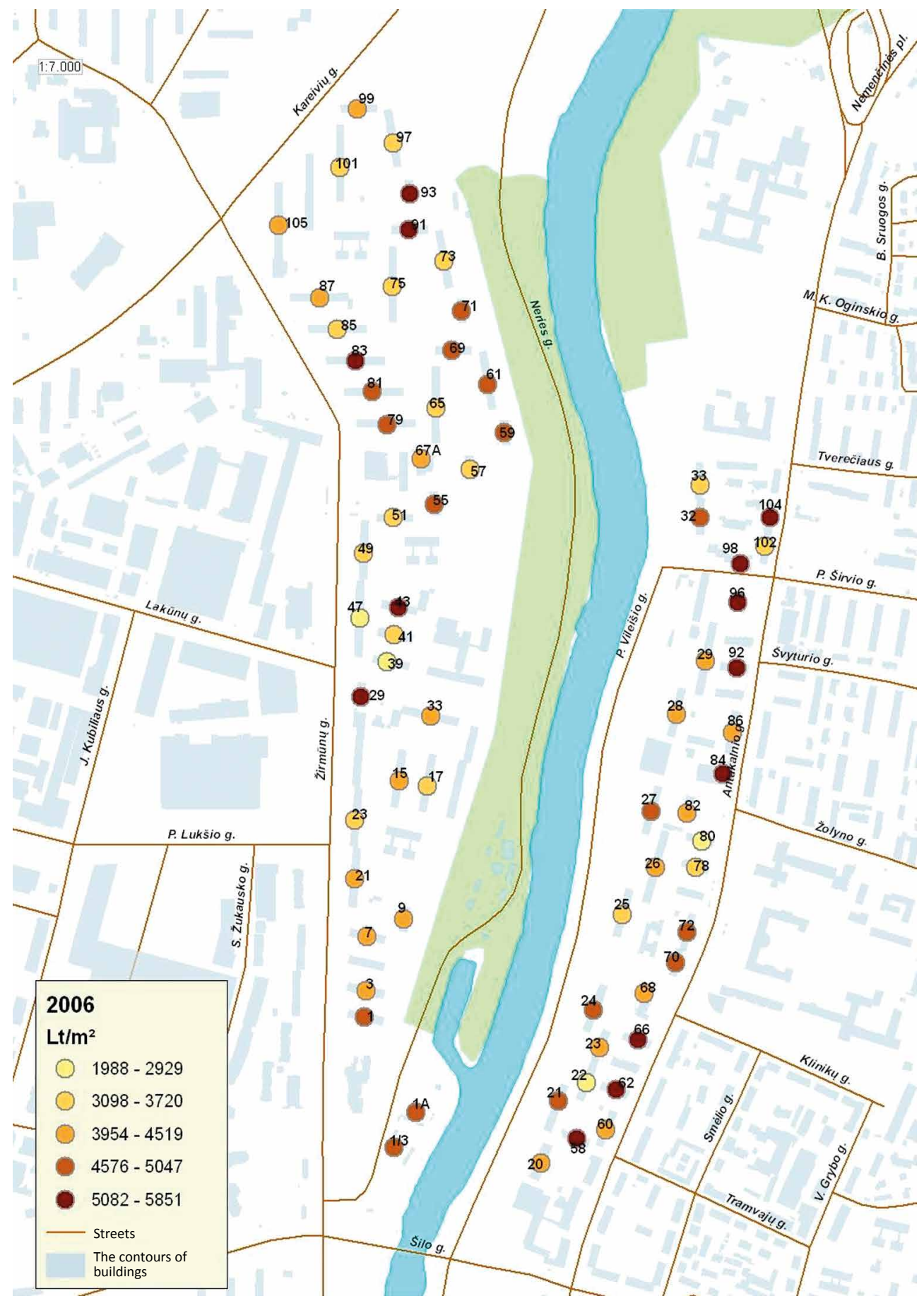

Figure 5.14. Digital map of purchase/sale prices for housing units in the Žirmūnai and Antakalnis neighborhoods under analysis in 2006 
close to the river. There was an analysis performed about people's awareness of the effects of pollution and noise and the adequacy of their assessments of such effects when selling or purchasing dwellings. A noticeable price of about 400-500 per $\mathrm{m}^{2}$ LTL ranged with respect to the dwelling's location, by the river or by the street.

However, the results of this analysis were insufficient for drawing valid conclusions. Use of the data on transactions made in the period from 1998 to 2006 and accumulated in the database of the Lithuanian State Enterprise Centre of Registers was for the further analysis on the effects of pollution and noise on residential unit prices. These data served as the basis for digital maps of purchase/sale transactions made separately from 1998 to 2006 showing the average purchase/ sales price per $\mathrm{m}^{2}$ of a housing unit, ignoring the extreme values.

The digital map of purchase/sales prices for housing units in 2006 (Figure 5.14) shows certain discrepancies between the real situation and the assumption made here that units close to the street should cost less with the price increasing, as the distance from the street increases and decreasing, as the distance to the river increases. For example, expert opinion indicates that housing close to the Neris River should cost $20 \%$ more than similar housing close to Žirmūnų or Antakalnio Streets. However, prices for some homes close to the street are especially high, as the digital map shows. This fact denies the assumption - housing unit prices for some close to the river are considerably lower analogically. The inspection of the area under analysis was to explain this discrepancy and to make a detailed analysis of the available data (Table 5.6). Table 5.6 analyses the transactions made in 2006 and the possible influences of on the transactions by various quantitative and qualitative environment criteria:

- Quantitative criteria:

- year of construction (based on data from the Lithuanian State Enterprise Centre of Registers);

- number of floors (based on the data from the Lithuanian State Enterprise Centre of Registers);

- noise and its digital map;

- CO and its digital map;

- solid particles and their digital map;

- $\mathrm{NO}_{2}$ (nitrogen dioxide) and its digital map.

- Qualitative criteria (determined by a detailed inspection of the analyzed area):

- aesthetic environment: this criterion assesses aesthetics of the environment, quality. of landscaping and green areas - scored by a 5-point system;

- street: this criterion shows whether a building is close to the street; 
- car parking lot: this assesses whether there is a small parking lot or it is missing altogether;

- recreation area: this assesses whether a developed recreation area is near to the analyzed building, such as playgrounds, basketball fields, benches, etc.;

- renovation: this determines whether the building has been renovated a 3-point system scores the access;

- lighting: this is the assessment of whether remote streets (away from the main street) have proper lighting;

- construction works: this criterion assesses whether new construction works are underway near the building;

- retail park: this assesses whether there are retail parks and shops near the building;

- kindergarten, school: this assesses whether a school or kindergarten is near the building.

Table 5.4. Assessment of an aesthetic environment by points

\begin{tabular}{|l|l|}
\hline Points & \multicolumn{1}{c|}{ Description } \\
\hline 5 & $\begin{array}{l}\text { Landscape is especially beautiful. Recreation area complies with modern require- } \\
\text { ments. Trees surround the multi-unit buildings. Lawns or flowerbeds are newly } \\
\text { planted and especially well maintained near the residential building. }\end{array}$ \\
\hline 4 & $\begin{array}{l}\text { Surroundings are beautiful. Trees and flowerbeds grow near the building. } \\
\text { Benches near the building are in good condition. The lawn is trimmed. }\end{array}$ \\
\hline 3 & $\begin{array}{l}\text { The environment is maintained. Trees and bushes grow around the building. } \\
\text { Nearby benches are not in good condition and need painting. The flowerbeds } \\
\text { are chaotic. }\end{array}$ \\
\hline 2 & $\begin{array}{l}\text { The environment is quite messy. Flowerbeds are not maintained, and the lawn is } \\
\text { not cut. Some benches are almost broken or missing. Trees and bushes grow wild. }\end{array}$ \\
\hline 1 & The environment is especially messy. \\
\hline
\end{tabular}

Table 5.5. Assessment of access by points

\begin{tabular}{|l|l|}
\hline Points & \multicolumn{1}{c|}{ Description } \\
\hline 3 & $\begin{array}{l}\text { The access to the house is very convenient. Entry is direct to one's own residential } \\
\text { building without the need to through parking lots of other buildings. }\end{array}$ \\
\hline 2 & $\begin{array}{l}\text { The convenience is reasonable - a driveway is available from two sides; however, } \\
\text { it is necessary to drive through parking lots of several buildings. }\end{array}$ \\
\hline 1 & $\begin{array}{l}\text { Very bad - the access is very complicated. One must pass through parking lots } \\
\text { of several buildings, and the area for a car to turn around by the building is very } \\
\text { small. }\end{array}$ \\
\hline
\end{tabular}




\begin{tabular}{|c|c|c|c|c|c|c|c|c|c|c|c|c|c|}
\hline \multirow{7}{*}{ 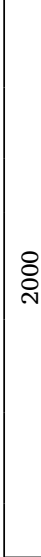 } & 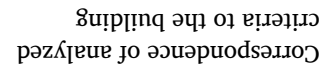 & $\stackrel{\mathscr{\nu}}{\nearrow}$ & & & & & & $\stackrel{\mathscr{\iota}}{\nearrow}$ & & & 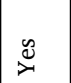 & & \\
\hline & 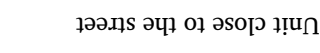 & $\overbrace{\nearrow}^{\infty}$ & & & & & & \& & & & z & & \\
\hline & 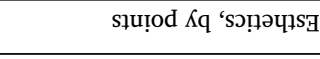 & Ln & & & & & & N & & & in & & \\
\hline & $\mathrm{OJ}$ & $\begin{array}{ll}\dot{0} & \\
\vdots & m \\
0 & 0 \\
0 & 0 \\
0 & 0\end{array}$ & & & & & & 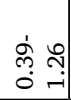 & & & $\begin{array}{l}\infty \\
m \\
0 \\
0 \\
0\end{array}$ & & \\
\hline & (s[әq!юәр) әs!़N & 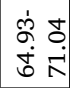 & & & & & & $\begin{array}{l}\text { ळે } \\
\dot{0} \\
\dot{\nabla}\end{array}$ & & & 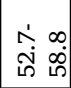 & & \\
\hline & 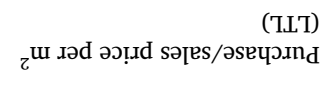 & 哭 & & & & & & 只 & & & 足 & & \\
\hline & dno.8 әэ!̣. & $m$ & & & & & & $N$ & & & N & & \\
\hline \multirow{7}{*}{ gे } & 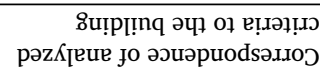 & & & & $\stackrel{\infty}{\varnothing}$ & $\stackrel{\infty}{\varnothing}$ & $\stackrel{\circlearrowright}{\circlearrowright}$ & & 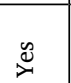 & $\overbrace{\nu}^{\infty}$ & 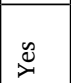 & 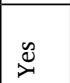 & \\
\hline & 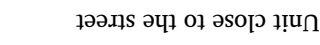 & & & & 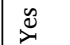 & z & z & & 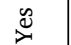 & 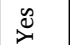 & 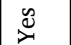 & $\stackrel{0}{0}$ & \\
\hline & 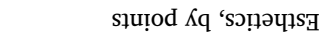 & & & & L 10 & -1 & - & & n & L & L & Ln & \\
\hline & OJ & & & & 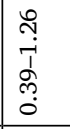 & $\begin{array}{l}0 \\
\dot{P} \\
\dot{f} \\
\vec{i} \\
\end{array}$ & $\begin{array}{l}\stackrel{0}{\dot{p}} \\
\stackrel{+}{+} \\
\vec{i}\end{array}$ & & $\begin{array}{l}\infty \\
m \\
0 \\
0 \\
0 \\
0\end{array}$ & $\begin{array}{l}\infty \\
m \\
0 \\
0 \\
0\end{array}$ & $\begin{array}{l}\infty \\
m \\
0 \\
0 \\
0 \\
0\end{array}$ & $\begin{array}{l}\infty \\
m \\
0 \\
0 \\
0 \\
0\end{array}$ & \\
\hline & (s[əq!̣วр) әs!̣oN & & & & $\mid \begin{array}{ll}1 & \infty \\
& \infty \\
i & \infty \\
i\end{array}$ & 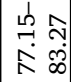 & 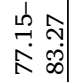 & & 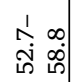 & $\mid \begin{array}{ll}1 & \infty \\
\hat{i} & \infty \\
i & \infty\end{array}$ & $\left|\begin{array}{ll}1 & \infty \\
\hat{i} & \infty \\
& \infty \\
\hdashline\end{array}\right|$ & $\begin{array}{ll}1 & \infty \\
\text { ลิ } & \infty \\
\text { กิ } & \infty\end{array}$ & \\
\hline & 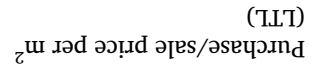 & & & & ล̊ำ & $\underset{⿱ 亠 \infty}{\stackrel{\infty}{\sim}}$ & 롱 & & $\underset{\substack{0 \\
\infty}}{\stackrel{-1}{1}}$ & 定 & ูํำ & gి & \\
\hline & dnox əว!̣d & & & & $m$ & $m$ & $N$ & & $m$ & $m$ & $\theta$ & $\theta$ & \\
\hline \multirow{7}{*}{$\mid \begin{array}{l}\infty \\
\vdots \\
\sigma \\
\sigma\end{array}$} & 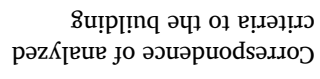 & & & $\stackrel{\circlearrowright}{\succ}$ & 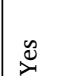 & $\stackrel{0}{0}$ & 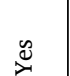 & z & & & $\stackrel{0}{0}$ & & \\
\hline & 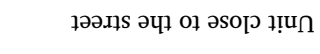 & & & z & 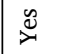 & z & z & z & & & 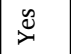 & & \\
\hline & 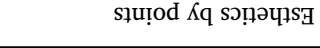 & & & - & in & - & - & N & & & L & & \\
\hline & OJ & & & 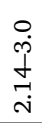 & 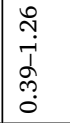 & 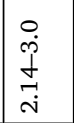 & $\underset{\stackrel{O}{\dot{y}}}{\stackrel{i}{i}}$ & 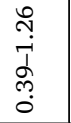 & & & $\begin{array}{l}\infty \\
m \\
0 \\
0 \\
0\end{array}$ & & \\
\hline & (s[әq!̣วр) әs!̣oN & & & $\begin{array}{l}0 \\
\stackrel{1}{R} \\
\hat{i} \\
\vdots \\
0 \\
\dot{R}\end{array}$ & \begin{tabular}{|c}
$\infty$ \\
$\infty$ \\
$\infty$ \\
$\Lambda$ \\
$\hat{1}$ \\
$\hat{i}$ \\
î \\
\end{tabular} & 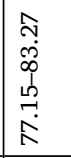 & $\begin{array}{l}\hat{N} \\
\infty \\
\infty \\
1 \\
\omega \\
\stackrel{1}{N} \\
\end{array}$ & $\begin{array}{l}\tilde{J} \\
\dot{T} \\
\hat{1} \\
\tilde{\sigma} \\
\sigma \\
\dot{j} \\
\end{array}$ & & & 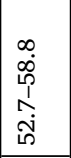 & & \\
\hline & 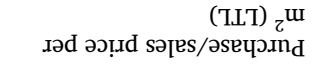 & & & $\stackrel{m}{m}$ & 음 & $\underset{7}{\stackrel{9}{7}}$ & $\underset{\text { స్ }}{\stackrel{\text { I }}{ }}$ & $\stackrel{8}{\infty}$ & & & $\underset{m}{\infty}$ & & \\
\hline & dno.s әృ!̣d & & & $m$ & $\theta$ & $m$ & $N$ & $\theta$ & & & $\theta$ & & \\
\hline & 兽 & $\overbrace{-1}^{m}$ & 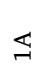 & $m$ & $a$ & N & f & 5 & คิ & 5 & . & $\stackrel{m}{\wedge}$ & ร \\
\hline
\end{tabular}


Table 5.7. Summary analysis of congruity between a housing unit's purchase/sales price per $\mathrm{m}^{2}$ and definitive quantitative and qualitative indicators of the outdoor environment

\begin{tabular}{|c|c|c|c|c|c|c|c|c|c|}
\hline \multirow[t]{2}{*}{$\begin{array}{l}\text { Housing unit } \\
\text { No. }\end{array}$} & \multicolumn{9}{|c|}{$\begin{array}{l}\text { Analysis on adequacy }(+) \text { /inadequacy }(-) \text { of a housing unit's purchase/ } \\
\text { sales price per } \mathrm{m}^{2} \text { to the definitive quantitative and qualitative indicators } \\
\text { of the outdoor environment }\end{array}$} \\
\hline & 1998 & 1999 & 2000 & 2001 & 2002 & 2003 & 2004 & 2005 & 2006 \\
\hline $1 / 3$ & & & + & + & + & + & & + & + \\
\hline $1 \mathrm{~A}$ & & & & + & & + & & + & + \\
\hline 3 & + & & & & - & & & - & + \\
\hline 9 & + & + & & - & & & + & & - \\
\hline 23 & + & + & & & & - & & + & - \\
\hline 47 & + & + & & + & & & + & & + \\
\hline 51 & + & & + & & & + & & - & + \\
\hline 59 & & + & & + & + & + & & + & + \\
\hline 61 & & + & & + & & + & + & & + \\
\hline 71 & + & + & + & & + & & & + & + \\
\hline 73 & & + & & + & & + & & & + \\
\hline 99 & & & & & + & + & & & + \\
\hline$*, \%$ & 100 & 100 & 100 & 86 & 86 & 86 & 100 & 86 & 82 \\
\hline $\begin{array}{l}* * \text {, percent, } \\
\text { price } \\
\text { difference }\end{array}$ & 18.5 & 25.1 & 15.2 & 5.5 & 15.6 & 18.3 & 26.2 & 17.4 & 28.83 \\
\hline
\end{tabular}

* Shows the percentage of analysed purchase/sales prices of housing units corresponding to definitive quantitative and qualitative indicators of the outdoor environment (noise, pollution, aesthetics [river, pond, green areas], closeness to the street, etc.)

** Shows the percentage of housing units closer to Žirmūnų or Antakalnio Streets with a lower average purchase/sales price per $\mathrm{m}^{2}$ compared to those closer to the Neris River

The analysis of prices per $\mathrm{m}^{2}$ of sold units with the comparison of quantitative and qualitative criteria describing both the residential building itself and its environment leads to conclude that the farther the housing is from the river, the less it costs. The comparison of purchase/sales prices of units close to the street and units close to the river confirmed that people are aware of air pollution and noise and respectively assess the price when selling or purchasing a dwelling unit. The summary in Table 5.5 clearly illustrates this fact. It shows that 
the difference in prices per $\mathrm{m}^{2}$ almost reaches $27 \%$. This substantiates the loss a resident could suffer assuming construction of a new road, bypass or similar object near his/her home.

A thorough analysis of dwelling prices with references to pollution maps can serve as a basis to offer rational measures for urban construction and planning. This can involve designing a street network, developing highway bypasses or highways for incessant traffic, determining priority development plans for public transport, rationally arranging buildings in territories under construction and foreseeing the best measures for reducing environment pollution and noise and, most importantly, safeguarding the health of many people.

\subsubsection{Air quality index}

The method provided by the United States Environmental Protection Agency was the means to calculate the air quality index (AQI). It served as the basis for drawing a map on the effect of pollution on human health (Figure 5.15). It is compiled for a certain, defined zone only, i.e., in this case, for the part of the Antakalnio and Žirmūnų neighborhoods with boundaries of Antakalnio, Žirmūnų, Šilo and Kareivių Streets. The subdivisions of this index are six intervals.

It is possible to determine the level of effect the concentration of pollutants in the environment can have on human health and the illnesses it can cause by applying the Pollution effects on human health map and the aforementioned method. Most of the attention is on heart, blood vessel and respiratory ailments by use of this method. The effect of the named pollutants is established for four groups of certain people: sensitive residents group - people who are already ill with heart, blood vessel and respiratory ailments, children, adults and elderly persons.

The presentation here of the digital map on the air quality index shows that, for the time being, air quality is in a good or satisfactory state. It is noticeable that there is more air pollution alongside the street; therefore air quality changes from good to satisfactory. That means people living alongside the street come into frequent contact with the effects of pollution. This can manifest as discomfort and/or symptoms of respiratory difficulties (especially relevant for the group of sensitive residents). Additionally the work of the heart becomes more difficult for people suffering from heart failure and for elderly people. It needs mentioning that the calculated values of the air quality index alongside the road in many places were near the third interval, defined as within the limits of being harmful to the sensitive residents group. A growth in the number of sources of mobile pollutants is the forecast for Lithuania's cities. Therefore, a possible conclusion is that the values of the index can increase along with an increase in the number of target groups. 


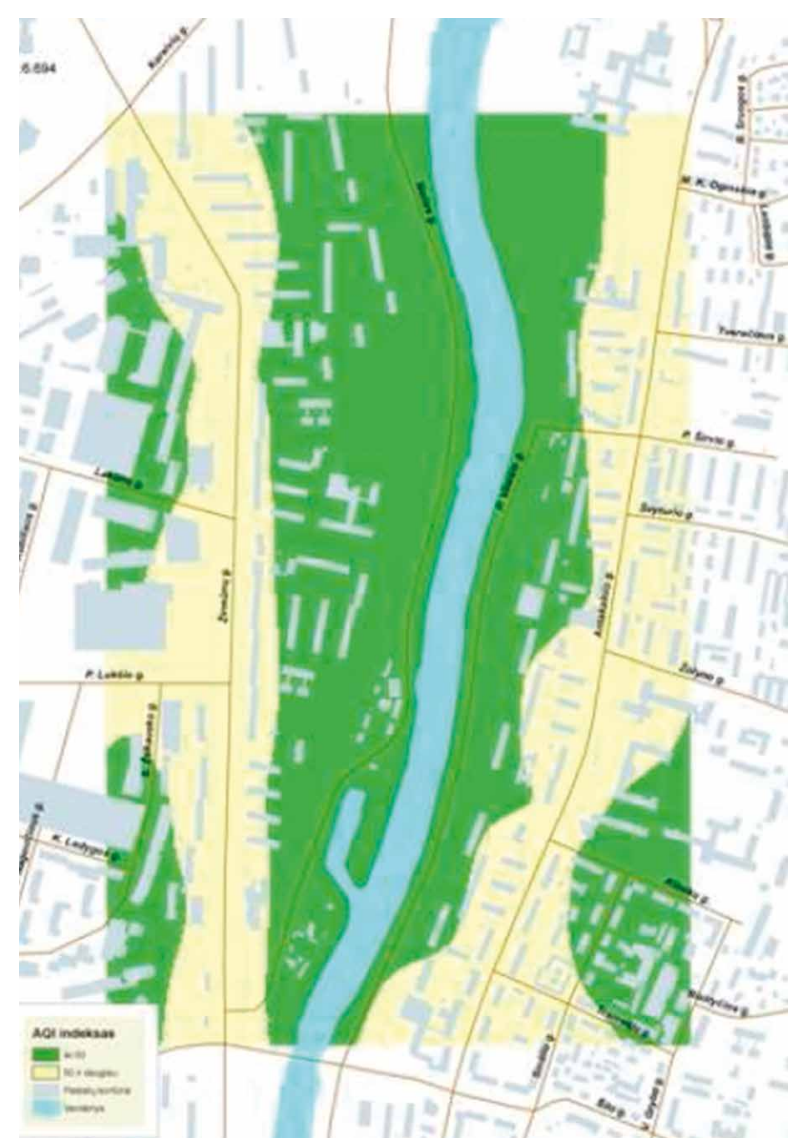

Figure 5.15. Pollution effects on human health map drawn by applying the air quality index $(A Q I)$

\section{References}

Abdul-Rahman, H.; Wang, C.; Eng, K. S. 2011. Repertory grid technique in the development of Tacit-based Decision Support System (TDSS) for sustainable site layout planning, Automation in Construction 20(7): 818-829.

Baud, I.; Scott, D.; Pfeffer, K.; Sydenstricker-Neto, J.; Denis, E. 2015. Reprint of: Digital and spatial knowledge management in urban governance: Emerging issues in India, Brazil, South Africa, and Peru, Habitat International 46: 225-233.

Baud, I.; Scott, D.; Pfeffer, K.; Sydenstricker-Neto, J.; Denis, E. 2014. Digital and spatial knowledge management in urban governance: Emerging issues in India, Brazil, South Africa, and Peru, Habitat International 44: 501-509.

Beijerse, R. P. 1999. Questions in knowledge management: defining and conceptualising a phenomenon, Journal of Knowledge Management 3(2): 94-110.

Bertrand, N. F. 1997. Meta-analysis of studies of willingness to pay to reduce traffic noise, MSc dissertation, University College London. 
Bieliūnas, M. 2000. Žinių vadybos praktinis taikymas: pokyčiai, kuriuos lemia ekonomikos tendencijos, Informacijos mokslai/Information sciences 14: 46-56.

Blodgett, C.; Crowell, M.; Lahaise, K. 2005. Mobilizing knowledge: status of KM in defence, Bravo Defence 5: 5-7.

Bosch-Sijtsema, P. M.; Henriksson, L.-H. 2014. Managing projects with distributed and embedded knowledge through interactions, International Journal of Project Management 32(8): 1432-1444.

Calvo-Mora, A.; Navarro-García, A.; Periañez-Cristobal, R. 2015. Project to improve knowledge management and key business results through the EFQM excellence model. International Journal of Project Management, In Press, Corrected Proof, Available online 7 February 2015.

Carvalho, L.; Santos, I. P.; van Winden, W. 2014. Knowledge spaces and places: From the perspective of a "born-global" start-up in the field of urban technology, Expert Systems with Applications 41(12): 5647-5655.

Chen, L.; Fong, P. S.W. 2015. Evaluation of knowledge management performance: An organic approach, Information \& Management 52(4): 431-453.

Danish Environmental Protection Agency [Online]. Available at: http://www.mst.dk/ [accessed 6 October 2010].

Danish Institute of Governmental Research [Online]. Available at: http://www.akf.dk/ [accessed 6 October 2010].

Frost, A. 2010. Knowledge management definition. Retrieved May 11, 2015 from Knowledge Management Tools website: http://www.knowledge-management-tools. net/knowledge-managementdefinition.html

Goddard, M.; Mowat, D.; Corbett, C.; Neudorf, C.; Raina, P.; Sahai, V. 2004. The impacts of knowledge management and information technology advances on public health decision-making in 2010, Health Informatics Journal 10(2): 111-112.

Hong, H.-Y.; Scardamalia, M. 2014. Community knowledge assessment in a knowledge building environment, Computers \& Education 71: 279-288.

Hussain, S. Y. S.; Said, I. 2015. Knowledge integration between planning and landscape architecture in contributing to a better open space, in Procedia - Social and Behavioral Sciences 170: 545-556.

Kaklauskas, A.; Bagdonavicius, A.; Sliogeriene, J.; Kalibatas, D.; Povilaityte, L.; Gulbinas, A. 2006a. Development of market-based land mass appraisal online system for land taxation, in Conference Proceedings, The First Symposium of the World's "Best Practices in Mass Appraisal for Asia", August 25-26, Bangkok, Thailand, pp. 297-307.

Kaklauskas, A.; Krutinis, M.; Tupenaite, L.; Naimaviciene, J. 2006b. Automated valuation models and knowledge-based decision support in real estate valuation, in Proceedings of the 6th International Conference "Reliability and Statistics in Transportation and Communication”, October 25-28, Riga, Latvia. pp 349-361.

Kaklauskas, A.; Zavadskas, E. K. 2007a. Decision support system for innovation with a special emphasis on pollution. International Journal of Environment and Pollution 30 (3-4): 518-528. 
Kaklauskas, A.; Zavadskas, E. K.; Vainiūnas, P.; Jonaitis, V. 2007a. Gyvenimo kokybè. Lietuvos respublikos statybos technologinè platforma. $109 \mathrm{p}$.

Kalafatis, S. E.; Lemos, M. C.; Lo, Y.-J.; Frank, K. A. 2015. Increasing information usability for climate adaptation: The role of knowledge networks and communities of practice, Global Environmental Change 32: 30-39.

Kamsu-Foguem,B.; Abanda, F. H. 2015. Experience modeling with graphs encoded knowledge for construction industry, Computers in Industry 70: 79-88.

Lin, K. Y.; Hong, H.-Y.; Chai, Ch. S. 2014. Development and validation of the knowledgebuilding environment scale, Learning and Individual Differences 30: 124-132.

Liu, Z.; Chen, D.; Wurm, K. M.; von Wichert, G. 2015. Table-top scene analysis using knowledge-supervised MCMC, Robotics and Computer-Integrated Manufacturing 33: 110-123.

Nelson, J.P. 1982. Highway noise and property values: A survey of recent evidence, Journal of transport Economic and Policy 16(2): 117-38.

OECD, 2005. "The Measurement of Scientific and Technological Activities: Guidelines for Collecting and Interpreting Innovation Data: Oslo Manual, Third Edition" prepared by the Working Party of National Experts on Scientific and Technology Indicators, OECD, Paris, para. 303. Retrieved May 11, 2015, from http://stats.oecd.org/glossary/ detail.asp? $\mathrm{ID}=6878$

Pearce D. W.; Markandya A. 1989. The benefits of environmental policy. Organisation of Economic Cooperation and Development, Paris.

Petri, I.; Beach, T.; Rezgui, Y.; Wilson, I. E.; Li, H. 2014. Engaging construction stakeholders with sustainability through a knowledge harvesting platform, Computers in Industry 65(3): 449-469.

Povilaitytė, L. 2006. Aplinkelių alternatyvų analizė nagrinėjant įvairių suinteresuotų grupių požiūrius. Baigiamasis bakalauro darbas, vadovas A. Kaklauskas. Statybos ekonomikos ir nekilnojamojo turto vadybos katedra, VGTU, 79 p.

Povilaitytė, L. 2008. Skaitmeninių žemėlapių sudarymas taršos poveikio žmogaus sveikatai ir nekilnojamojo turto vertei tirti. Baigiamasis magistro darbas, vadovas A. Kaklauskas. Statybos ekonomikos ir nekilnojamojo turto vadybos katedra, VGTU. $83 \mathrm{p}$.

Reed, M. S.; Stringer, L. C.; Fazey, I.; Evely, A. C.; Kruijsen, J. H. J.2014. Five principles for the practice of knowledge exchange in environmental management, Journal of Environmental Management 146: 337-345.

Ridker, R. A.; Henning, J. A. 1967. The determinants of residential property values with special reference to air pollution, Review of Economic Studies 49: 246-57.

Rumizen, M. C. 2002. The complete idiot's guide to knowledge management. Indianapolis, IN: Alpha Books.

Sankovskaja, I. 2007. Taršos ir jos poveikio sveikatai analizė, renkantis būstą. Baigiamasis bakalauro darbas, vadovas A. Kaklauskas. Statybos ekonomikos ir nekilnojamojo turto vadybos katedra, VGTU, $79 \mathrm{p}$.

Serrat, O. 2009. Glossary of Knowledge Management. Knowledge Solutions: Asian Develeopment Back. 
Smith, V. K.; Huang, J.-C. 1995. Can markets value air quality? A mate-abalysis of hedonic property value. Journal of Political Economy 103(1): 209-27.

Tennøy, A.; Hansson, L.; Lissandrello, E.; Næss, P. 2015. How planners' use and nonuse of expert knowledge affect the goal achievement potential of plans: Experiences from strategic land-use and transport planning processes in three Scandinavian cities. Progress in Planning, In Press, Corrected Proof, Available online 20 June 2015

Vičkačka, A. 2007. Automobilių keliai ir transporto triukšmo poveikio gyvenimo kokybei ekonominis įvertinimas. Baigiamasis magistro darbas, vadovas A. Kaklauskas. Statybos ekonomikos ir nekilnojamo turto vadybos katedra, VGTU, 87 p.

Wirth, von T.; Hayek, U. W.; Kunze, A.; Neuenschwander, N.; Stauffacher, M.; Scholz, R. W. 2014. Identifying urban transformation dynamics: Functional use of scenario techniques to integrate knowledge from science and practice, Technological Forecasting and Social Change 89: 115-130.

Yigitcanlar, T. 2014. Position paper: Benchmarking the performance of global and emerging knowledge cities. Expert Systems with Applications 41(12): 5549-5559.

Young, R. 2003. Knowledge Management Vocabulary, PD 7500: B S I Standards. Knowledge Management for the Public Sector. Tokyo, Japan: Asian Productivity Organziation.

Zavadskas, E. K.; Kaklauskas, A.; Šaparauskas, J.; Kalibatas, D. 2007c. Evaluation of Vilnius urban sustainability with special emphasis on pollution, Ekologija 53(Suppl.): 64-72.

Zavadskas, E.; Kaklauskas, A.; Kaklauskienė, J. 2007b. Modelling and forecasting of a rational and sustainable development of Vilnius: emphasis on pollution, International Journal of Environment and Pollution 30(3-4): 485-500.

Zavadskas, E.; Kaklauskas, A.; Maciunas, E.; Vainiunas, P.; Marsalka, A. 2007a. Real estate's market value, pollution and health effects analysis decision support system, in 4th International Conference on Cooperative Design, Visualization, and Engineering, September 16-20, 2007, Shanghai, Peoples R. China. Berlin: Springer-Verlag, pp. 191200. 


\title{
CHAPTER 6
}

\section{BUILT ENVIRONMENT LIFE CYCLE PROCESS AND CLIMATE CHANGE}

\author{
Artūras KAKLAUSKAS, Lina PEČIŪRĖ
}

\subsection{Introduction}

Climate change mitigation is action to decrease the intensity of radiative forcing in order to reduce the potential effects of global warming. In contrast, adaptation to global warming involves acting to tolerate the actual or expected effects of global warming (IPCC 2010). Most often, climate change mitigation scenarios involve reductions in the concentrations of greenhouse gases, either by reducing their sources or by increasing their sinks (Molina et al. 2009).

Using data from 73 sites around the world, scientists have been able to reconstruct Earth's temperature history back to the end of the last Ice Age, revealing that the planet today is warmer than it has been during 70 to 80 percent of the time over the last 11,300 years (Marcott et al. 2013).

Surface temperature reconstructions of the past 1500 years suggest that recent warming is unprecedented in that time. Here we provide a broader perspective by reconstructing regional and global temperature anomalies for the past 11,300 years from 73 globally distributed records. Early Holocene $(10,000$ to 5000 years ago) warmth is followed by $\sim 0.7^{\circ} \mathrm{C}$ cooling through the middle to late Holocene ( $<5000$ years ago), culminating in the coolest temperatures of the Holocene during the Little Ice Age, about 200 years ago. This cooling is largely associated with $\sim 2{ }^{\circ} \mathrm{C}$ change in the North Atlantic. Current global temperatures of the past decade have not yet exceeded peak interglacial values but are warmer than during $\sim 75 \%$ of the Holocene temperature history. Intergovernmental Panel on Climate Change model projections for 2100 exceed the full distribution of Holocene temperature under all plausible greenhouse gas emission scenarios (Marcott 2013).

The UN defines mitigation in the context of climate change, as a human intervention to reduce the sources or enhance the sinks of greenhouse gases. Examples include using fossil fuels more efficiently for industrial processes or electricity generation, switching to renewable energy (solar energy or wind power), improving the insulation of buildings, and expanding forests and other "sinks" to remove greater amounts of carbon dioxide from the atmosphere (GCCA 2012). The IAEA, an international organization using the UN flag and reporting to the 
$\mathrm{UN}$, asserts that nuclear power belongs to the set of options available to reduce greenhouse gas emissions in the power sector (IAEA 2008).

Scientific consensus on global warming, together with the precautionary principle and the fear of abrupt climate change (Schneider 2004) is leading to increased effort to develop new technologies and sciences and carefully manage others in an attempt to mitigate global warming. Most means of mitigation appear effective only for preventing further warming, not at reversing existing warming. The Stern Review identifies several ways of mitigating climate change. These include reducing demand for emissions-intensive goods and services, increasing efficiency gains, increasing use and development of low-carbon technologies, and reducing fossil fuel emissions (Stern 2007).

Residential sector carbon dioxide emissions originate primarily from: direct fuel consumption (principally, natural gas) for heating and cooking, electricity for cooling (and heating), appliances, lighting, and increasingly for televisions, computers, and other household electronic devices. Energy consumed for heating in homes and businesses has a large influence on the annual fluctuations in energy-related carbon dioxide emissions. In the longer run, residential emissions are affected by population growth, income, and other factors. From 1990 to 2008: residential sector carbon dioxide emissions grew by an average of 1.3 percent per year, U.S. population grew by an average of 1.1 percent per year, per-capita income (measured in constant dollars) grew by an average of 1.7 percent per year, energy efficiency improvements for homes and appliances have offset much of the growth in the number and size of housing units. As a result, direct fuel emissions from petroleum, coal, and natural gas consumed in the residential sector in 2008 were only 1.5 percent higher than in 1990. Energy-related carbon dioxide emissions account for more than 80 percent of U.S. greenhouse gas emissions (EIA report 2009). Other countries have similar proportions of energy-related carbon dioxide emissions.

Global Carbon Cycle buildings in North America contribute $37 \%$ of total $\mathrm{CO}_{2}$ emissions, while US buildings correspond to $10 \%$ of all global emissions. The buildings sector of North America was responsible for annual carbon dioxide emissions of 671 million tons of carbon in 2003, which is $37 \%$ of total North American carbon dioxide emissions and $10 \%$ of global emissions. Options for reducing the carbon dioxide emissions of new and existing buildings include increasing the efficiency of equipment and implementing insulation and passive design measures to provide thermal comfort and lighting with reduced energy. Current best practices can reduce emissions from buildings by at least $60 \%$ for offices and $70 \%$ for homes. Technology options could be supported by a portfolio of policy options that take advantage of cooperative activities, avoid unduly burdening certain sectors, and are cost effective (SOCCR 2008). Therefore, best practices utilisation is a key factor in productively executing a climate change 
mitigation and adaptation in built environment project. The main purpose of this paper is to present the Model and Intelligent System of Built Environment Life Cycle Process for Climate Change Mitigation and Adaptation which the authors of this paper have developed.

Sustainable material selection represents an important strategy in building design. Current building materials selection methods fail to provide adequate solutions for two major issues: assessment based on sustainability principles, and the process of prioritizing and assigning weights to relevant assessment criteria. Akadiri et al. (2006) proposes a building material selection model based on the fuzzy extended analytical hierarchy process (FEAHP) techniques, with a view to providing solutions for these two issues. Assessment criteria are identified based on sustainable triple bottom line (TBL) approach and the need of building stakeholders. A questionnaire survey of building experts is conducted to assess the relative importance of the criteria and aggregate them into six independent assessment factors. The FEAHP is used to prioritize and assign important weightings for the identified criteria. A numerical example, illustrating the implementation of the model is given. The proposed model provides guidance to building designers in selecting sustainable building materials (Akadiri 2006).

\subsection{Climate change mitigation and adaptation in built environment quantitative and qualitative analyses aspects}

By modelling and forecasting future perspectives and trends of climate change mitigation and adaptation in built environment, it is possible to get ready to respond to the variation of micro, meso and macrolevel variables. Model of Built Environment Life Cycle Process for Climate Change Mitigation and Adaptation suggested by Kaklauskas et al. (2013) is based on presumption that the efficiency of climate change mitigation and adaptation depends on many micro, meso and macrolevel variables. The presence of specific micro, meso and macrolevel variable factors right away imposes objective limitations for efficient climate change mitigation and adaptation in built environment.

In order to assure the efficiency of a project, it should be executed within certain bounds which are determined by micro, meso and macrolevel factors.

Model of Built Environment Life Cycle Process for Climate Change Mitigation and Adaptation was developed with the goal of integrating the environmental, energetic, political, economical, legal/regulatory, infrastructural, technical, technological, pollution, health, quality of life, social, cultural, ethical, psychological, emotional, religious, ethnic and other aspects of the process over the life of the climate change mitigation (see Figure 6.1). Description of some above micro, meso and macro factors are follow. 


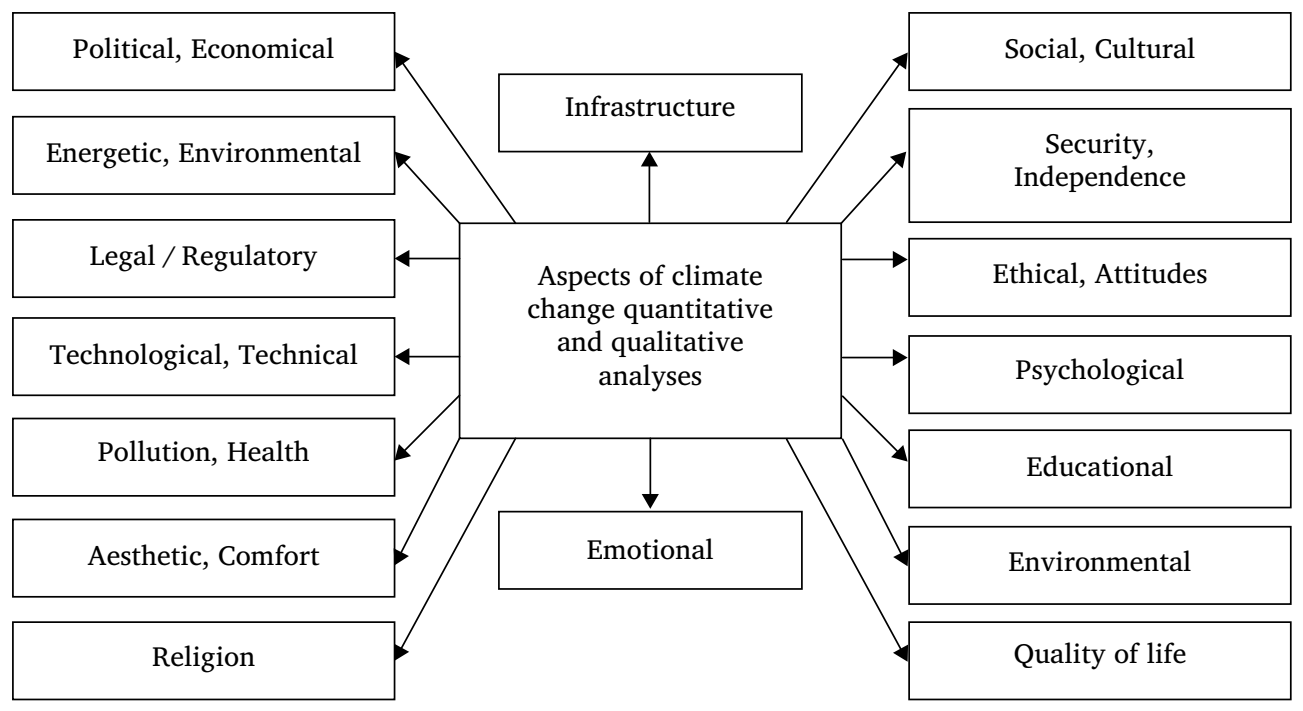

Figure 6.1. Climate change mitigation and adaptation in built environment quantitative and qualitative

\subsubsection{Macro level factors}

The highest level at which factors may be considered is the macro level factors. The level of efficiency and the scope of activities of the built environment depend on the next macrolevel variable factors:

- a key economic indicators for the country as a whole,

- the global warming price,

- stakeholders,

- civil conflicts,

- human culture,

- religion,

- ethics,

- Easterlin paradox and happiness economics,

- intervention of government,

- physical infrastructure,

- financial sector,

- interest rate,

- environment issues,

- unemployment,

- labour skill level,

- wages level,

- insurance,

- inflation, 
- innovations,

- exchange rate,

- unofficial economy, etc.

A few examples regarding relations of climate change and macro level factors (the global warming price, stakeholders, climate mobility social and civil conflicts, climate change and human culture, religion, ethics, easterlin paradox and happiness economics) are follows.

\subsubsection{The Global warming price}

The heated argument about economic costs, however, barely touched one vitally important issue: the costs of NOT taking action on climate. What if last summer's Russian heat wave and drought, which destroyed one third of the country's wheat crop, or the catastrophic floods in Pakistan and China, or category 5 hurricanes like Katrina are just glimpses of future havoc from warming left unchecked? Certain events would have been extremely unlikely to have occurred without global warming, and that includes the Russian heat wave and wild fires, and the Pakistan, Chinese, and Indian floods (Carey 2011).

Droughts, floods, wildfires, and hurricanes have already caused multibilliondollar losses, and these extreme weather events will likely become more frequent and more devastating as the climate continues to change. Tourism, agriculture, and other weather-dependent industries will be hit especially hard, but no one will be exempt. Household budgets, as well as business balance sheets, will feel the impact of higher energy and water costs. Ruth et al. (2007) estimates what the United States will pay as a result of four of the most serious impacts of global warming in a business-as-usual scenario that is, if we do not take steps to push back against climate change (Ruth et al. 2007):

- Hurricane damages: $\$ 422$ billion in economic losses caused by the increasing intensity of Atlantic and Gulf Coast storms. In the business-asusual climate future, higher sea-surface temperatures result in stronger and more damaging hurricanes along the Atlantic and Gulf coasts. Even with storms of the same intensity, future hurricanes will cause more damage as higher sea levels exacerbate storm surges, flooding, and erosion. In recent years, hurricane damages have averaged $\$ 12$ billion and more than 120 deaths per year. With business-as-usual emissions, average annual hurricane damages in 2100 will have grown by $\$ 422$ billion and an astounding 760 deaths just from climate change impacts.

- Real estate losses: $\$ 360$ billion in damaged or destroyed residential real estate as a result of rising sea levels. Our business-as-usual scenario forecasts 23 inches of sea-level rise by 2050 and 45 inches by 2100 . If nothing is done to hold back the waves, rising sea levels will inundate lowlying coastal properties. Even those properties that remain above water 
will be more likely to sustain storm damage, as encroachment of the sea allows storm surges to reach inland areas that were not previously affected. By 2100 , U.S. residential real estate losses will be $\$ 360$ billion per year.

- Energy costs: $\$ 141$ billion in increasing energy costs as a result of the rising demand for energy. As temperatures rise, higher demand for airconditioning and refrigeration across the country will increase energy costs, and many households and businesses, especially in the North, that currently don't have air conditioners will purchase them. Only a fraction of these increased costs will be offset by reduced demand for heat in Northern states. The highest net energy costs -after taking into consideration savings from lower heating bills -will fall on Southeast and Southwest states. Total costs will add up to more than $\$ 200$ billion for extra electricity and new air conditioners, compared with almost $\$ 60$ billion in reduced heating costs. The net result is that energy sector costs will be $\$ 141$ billion higher in 2100 due to global warming.

- Water costs: $\$ 950$ billion to provide water to the driest and most waterstressed parts of the United States as climate change exacerbates drought conditions and disrupts existing patterns of water supply. The businessas-usual case forecasts less rainfall in much of the United States or, in some states, less rain at the times of year when it is needed most. By 2100 , providing the water we need throughout the country will cost an estimated $\$ 950$ billion more per year as a result of climate change. Drought conditions, already a problem in Western states and in the Southeast, will become more frequent and more severe.

\subsubsection{Stakeholders}

The Citizens' support for policies that aim to curb carbon emissions and energy use is often seen as informed by their values, attitudes and perceptions of the environmental problem in question. Fischer et al. (2011) argue that we also need to understand how people conceptualise policies and the governance approaches underpinning them to be able to judge the likely acceptance of policy change. Fischer et al. (2011) draw on qualitative interviews $(n=202)$ from five European countries to explore citizens' views on governance approaches to stimulate behavioural change in the field of resource use, including regulations, price changes, collective action, technological change and education. Fischer et al. (2011) found that many of our interviewees referred to generalised characteristics of humankind and contemporary society to back up their arguments for or against specific governance approaches. In particular, many interviewees concurred that people in general were so self-centred, driven by habit and money- and consumption-oriented that only strict regulations, drastic price changes and technological innovation could possibly achieve widespread behavioural 
change. As a consequence, such 'folk psychologies' can have substantial impact not only on public acceptance, but also on the success of policy measures that aim to reduce citizens' resource use (Fischer et al. 2011).

Climate change has been identified as potentially the biggest health threat of the 21st century. Canada in general has a well developed public health system and low burden of health which will moderate vulnerability. However, there is significant heterogeneity in health outcomes, and health inequality is particularly pronounced among Aboriginal Canadians. Intervention is needed to prevent, prepare for, and manage climate change effects on Aboriginal health but is constrained by a limited understanding of vulnerability and its determinants. Despite limited research on climate change and Aboriginal health, however, there is a well established literature on Aboriginal health outcomes, determinants, and trends in Canada; characteristics that will determine vulnerability to climate change. In this paper Ford et al. (2010) systematically review this literature, using a vulnerability framework to identify the broad level factors constraining adaptive capacity and increasing sensitivity to climate change. Determinants identified include: poverty, technological capacity constraints, socio-political values and inequality, institutional capacity challenges, and information deficit. The magnitude and nature of these determinants will be distributed unevenly within and between Aboriginal populations necessitating place-based and regional level studies to examine how these broad factors will affect vulnerability at lower levels. The study also supports the need for collaboration across all sectors and levels of government, open and meaningful dialogue between policy makers, scientists, health professionals, and Aboriginal communities, and capacity building at a local level, to plan for climate change. Ultimately, however, efforts to reduce the vulnerability of Aboriginal Canadians to climate change and intervene to prevent, reduce, and manage climate-sensitive health outcomes, will fail unless the broader determinants of socio-economic and health inequality are addressed (Ford et al. 2010).

In the U.S., public support for federal, state and local efforts to reduce greenhouse gases (GHGs) continues to be a crucial element of the political viability of these proposals. Shwom et al. (2010) present a detailed analysis of the reasons given by the general public of Michigan and Virginia for supporting or rejecting a number of policies that could be implemented to meet GHG reductions. The data allow us to analyze the relationships between reasons provided by respondents, social psychological and demographic characteristics, and policy support. This analysis can provide policymakers pragmatic guidance in (1) developing tactics to engage the public that build on current concerns about climate change policies and (2) crafting and communicating policies that garner support from various segments of the public. This analysis also raises theoretical questions regarding the relationship between public discourse on environmental issues 
and the formation of public policy support. Shwom et al. (2010) suggest that future efforts to understand the U.S. dynamics of public support for climate change policies could benefit from understanding the public discursive and the reasoning processes that underlie public opinion formation (Shwom et al. 2010).

Anti-coal and some investment policies are widely justified with reference to global warming. Political analysis suggests that these policies are supported by the reinforcing interests of three powerful lobbies: scientific institutions engaged in atmospheric research and earth observation, energy corporations harmed by low fossil fuel prices or supplying 'clean' technologies, and numerous interlocking bureaucracies. Together they have succeeded in maintaining momentum in current climate negotiations (Boehmer-Christiansen 1997).

\subsubsection{Climate mobility social and civil conflicts}

The Climate change can increase societies' propensity to conflict by changes in socio-structural conditions (e.g., resource scarcity, migration). Climate change is expected to bring about major change in freshwater availability, the productive capacity of soils, and in patterns of human settlement. The direst predictions about the impacts of global warming warn about greatly increased risks of violent conflict over increasingly scarce resources such as freshwater and arable land (Raleigh, Urdal 2007). Raleigh and Urdal (2007) argue that our best guess about the future has to be based on our knowledge about the relationship between demography, environment and violent conflict in the past. Previous rigorous studies in the field have mostly focused on national-level aggregates. Raleigh and Urdal (2007) represents a new approach to assess the impact of environment on internal armed conflict by using georeferenced (GIS) data and small geographical, rather than political, units of analysis. It addresses some of the most important factors assumed to be strongly influenced by global warming: land degradation, freshwater availability, and population density and change. While population growth and density are associated with increased risks, the effects of land degradation and water scarcity are weak, negligible or insignificant (Raleigh, Urdal 2007).

Allouche (2011) looks at the interrelationship between water and food security. More specifically, Allouche (2011) examines the resilience and sustainability of water and food systems to shocks and stresses linked to different levels and intensity of conflict, global trade and climate change. Allouche (2011) makes four points: (1) that resource scarcity as a driver of conflict is inconclusive especially at regional and national levels (2) most insecurities surrounding water and food are explained by political power, social and gender relations; (3) global trade has enabled national food and water security, but that is now threatened by increasing food prices, food sovereignty movements and land 'grabbing' (4) 
and that water and food security will face major challenges under conditions of climate change (Allouche 2011).

Climates more suitable for Eurasian agriculture are associated with a decreased likelihood of conflict, while freshwater resources per capita are positively associated with the likelihood of conflict. Moreover, positive changes in rainfall are associated with a decreased likelihood of conflict in the following year (Hendrix, Glaser 2007).

In climate change discourse, climate mobility is often characterised as the production of 'refugees', with a tendency to discount long histories of ordinary mobility among affected populations. The case of Tuvalu in the Pacific juxtaposes migration as everyday practice with climate refugee narratives (Farbotko, Lazrus 2012).

\subsubsection{Climate change and human culture}

If solar variability affects human culture it most likely does so by changing the climate in which the culture operates (Feynman 2007).

Geel et al. (2004) described hypothesis regarding climate change and the expansion of the Scythian culture after 850 BC. In south-central Siberia archaeological evidence suggests an acceleration of cultural development and an increase in the density of nomadic populations around 850 BC. Geel et al. (2004) hypothesize a relationship with an abrupt climatic shift towards increased humidity caused by a decline of solar activity. Areas that initially may have been hostile semi-deserts changed into attractive steppe landscapes with a high biomass production and high carrying capacity. Newly available steppe areas could be invaded by herbivores, making them attractive for nomadic tribes. The central Asian horse-riding Scythian culture expanded, and an increased population density was a stimulus for westward migration towards southeastern Europe (Geel et al. 2004).

Tibetan culture and livelihoods depend on native plants for medicine, food, grazing, wood, as well as cash from market sales. The Medicine Mountains (part of the Hengduan Mountains) of the eastern Himalayas, with tremendous plant diversity derived from steep gradients of both elevation and precipitation, have traditionally been an important source of Tibetan medicinal plants (Salick et al. 2009). Salick et al. (2009) examine climate change in this area and vegetation patterns influenced by biogeography, precipitation and elevation. The Alpine environment has the highest plant diversity and most useful plants and is the most susceptible to climate change with impacts on traditional Tibetan culture and livelihoods-particularly Tibetan medicine and herding (Salick et al. 2009). 


\subsubsection{Religion}

Different religion leaders call on all people and nations to recognise the serious and potentially irreversible impacts of global warming caused by the anthropogenic emissions of greenhouse gases and other pollutants, and by changes in forests, wetlands, grasslands, and other land uses. According to the New Scientist (2007), also religious leaders pray for cold weather to combat climate change. Leaders from world religions gather in Greenland to show unity on the problem of global warming and to pray for the planet (the New Scientist 2007). As example, we will present Vatican and Buddhism point of view regarding climate change.

A Vatican-appointed panel of scientists has reported what climate change experts have been warning for years: the Earth is getting warmer, glaciers are melting, and urgent measures are necessary to stem the damage. The scientists called for urgent reduction of carbon dioxide emissions and reductions in methane and other pollutants that warm the air, and for improved observation of mountain glaciers to better track their changes. The Pontifical Academy of Sciences, a Vatican advisory panel appeal to all nations to develop and implement, without delay, effective and fair policies to reduce the causes and impacts of climate change on communities and ecosystems, including mountain glaciers and their watersheds, aware that we all live in the same home (Vatican-appointed... 2011).

Buddhism is not a religion; it is a way of life. It teaches the moral and ethical conduct... for the happiness of oneself and the welfare of the community. The Buddhist doctrines... [analyze] human life and the intrinsic nature of things... based on reasoning and rational thinking... not based on an initial act of faith (Mendis 1993).

Firstly, Buddhism proposed that beliefs, values and ethics have a strong influence upon the behavioral outcomes that are manifest as the driving forces behind environmental pressures. Although this perspective underplays the role of structural forces that constrain human behavior, the influence of beliefs and values can be seen to operate via their configuration of goals, wants, needs, intent and choices. Secondly, a more complete nexus with Buddhism requires an explicit shift in focus to human welfare as the key objective of both mainstream economic and policy prescriptions, and the Buddhist way of life (Daniels 2010a).

The Second Noble Truth reveals the source of this persistent dissatisfaction or disappointment. It comes from clinging or attachment to external, worldly phenomena in the belief that they will bring sustained and consummate satisfaction or happiness (French 2003). These objects of our desire include not just material goods or assets and the services they provide but people and other animate beings as well as ideas, social and economic roles, success and status (Webster 2005). 
Desire for maximum consumption via material good accumulation, derived services, and control over people for self-satisfaction, drives economic and lifestyle choices and is the natural economic (if not the social) outcome of a belief system based on the principle that the external world is the ultimate source of happiness (Tideman 2001).

Buddhism makes to explain the "double whammy" of the past 60 years of spectacular fossil fuel-based economic growth where happiness levels within nations do not seem to be increasing (the "Easterlin Paradox"), and yet resource use and degradation have reached unsustainable and possibly ecosphere catastrophe levels (Baucells, Sarin 2007, Daniels 2007). The relentless drive for the economic extraction and transformation of nature for economic wealth has not had the anticipated positive impact on subjective well-being. Indeed, craving for material wealth has not only failed to significantly reduce "suffering" (increase well-being) but has increased environmental destruction and instability (Mendis 1993).

Daniels (2010a) examines how central Buddhist world views and themes can contribute to effectively addressing climate change by looking deep within the ethical, economic and ecological nature of consumer market economies. A persistent theme of Daniels (2010a) approach is the structured analysis of climate change in terms of the drivers, pressures, and responses that stem from societal beliefs and world views about human actions and choices, and their links to human goals and well-being. Buddhist notions of interconnectedness, dependent origination, and mindful consumption and production can help explain and reshape human motives and actions for climate and other forms of environmental sustainability. The mode of analysis of Buddhism has had much in common with ecological economics - with primary conceptual and methodological roles ascribed to ethics, the ecologization of society, social capital and sustainability, and ultimate means and ends via an extensive consideration of well-being and the goals of human endeavor (Daniels 2010a).

Environmental, economic, ethical and cosmological dimensions of Buddhism are presented as a logical and practical basis for reducing the climate change pressures deriving from prevailing global modes of production and consumption (Daniels 2010b). Daniels (2010b) presents an analytical framework and philosophical base for understanding the causes and refining the goals behind human and societal endeavor. Buddhist notions of interconnectedness, dependent origination, and mindful consumption and production can help explain and reshape human motives and actions for climate and other forms of environmental sustainability (Daniels 2010b).

\subsubsection{Ethics}

Climate change raises many questions with strong moral and ethical dimensions that are important to address in climate-policy formation and international negotiations (Wardekker et al. 2009). 
The emotional and embodied practice of narrative ethics is offered as one possible response to the overemphasis on technical rationality within our society and its institutions (Willis 2012). Willis (2012) argues that the development of practical wisdom (phronesis) is essential to addressing issues such as climate change, which are not simply technical problems but are fundamentally rooted in the human condition.

Ecoethics is an emerging discipline that trains moral attention and critical reflection on the vastly expanded range of human productive and consumptive powers that are causing increasing and perhaps irreparable damage to many of Earth's ecosystems and the human communities and nonhuman species who depend on those ecosystems' well-being. Ecoethics ponders the significance of how the rapidly rising human population is so widely transforming natural ecosystems that increasing numbers of animal and plant species are being pushed via habitat destruction into endangerment or extinction. Likewise, ecoethics ponders the fate of both humanity and that of all other species as it confronts rising worries about anthropogenic or human-caused global warming or climate-change trends (French 2008).

\subsubsection{Easterlin Paradox and happiness economics}

The Easterlin Paradox is a key concept in happiness economics. It is named for economist and USC Professor Richard Easterlin who discussed the factors contributing to happiness in the 1974 paper "Does Economic Growth Improve the Human Lot? Some Empirical Evidence". Easterlin found that within a given country people with higher incomes are more likely to report being happy. However, in international comparisons, the average reported level of happiness does not vary much with national income per person, at least for countries with income sufficient to meet basic needs. Similarly, although income per person rose steadily in the United States between 1946 and 1970, average reported happiness showed no long-term trend and declined between 1960 and 1970. The implication for government policy is that once basic needs are met, policy should focus not on economic growth or GDP, but rather on increasing life satisfaction or Gross national happiness (Wiki). There is no evidence of a marked increase in life satisfaction in China of the magnitude that might have been expected based on the fourfold increase in the level of per capita consumption during that period. In its transition, China has shifted from one of the most egalitarian countries in terms of distribution of life satisfaction to one of the least egalitarian. Life satisfaction has declined markedly in the lowest-income and least-educated segments of the population, while rising somewhat in the upper SES stratum (Easterlin et al. 2012).

Moreover, the life satisfaction pattern in China fits with the historical context. The factors shaping life satisfaction in China appear to be essentially the same as 
those in the European transition countries - the emergence and rise of substantial unemployment, dissolution of the social safety net, and growing income inequality. The failure of China's life satisfaction to increase despite its differing output experience a rapid increase versus the collapse and recovery of output in the European countries suggests that employment and the social safety net are critically important factors in determining life satisfaction. One may reasonably ask how it is possible for life satisfaction not to improve in the face of such a marked advance in per capita GDP from a very low initial level? In answer, it is pertinent to note the growing evidence of the importance of relative income comparisons and rising material aspirations in China, which tend to negate the effect of rising income. These findings are consistent with the view common in the happiness literature that the growth in aspirations induced by rising income undercuts the increase in life satisfaction related to rising income itself (Easterlin et al. 2012).

Moreover, there is more to life satisfaction than material goods. Other factors include home life and the need for a secure job to support it, health, friends and relatives, and the like. It is possible that the lack of a marked uptrend in overall life satisfaction in China might reflect an adverse impact on life satisfaction of changes in such factors as these, as has been true of the transition experience of East Germany, for which data on such circumstances are available (Easterlin 2010).

The GDP measure registers the spectacular average improvement in material living conditions, whereas the measure of life satisfaction demonstrates that among ordinary people, especially the less-educated and lower income segments of the population, life satisfaction has declined noticeably as material aspirations have soared and concerns have arisen about such critical matters as finding and holding a job, securing reliable and affordable health care, and providing for children and the elderly. Clearly, life satisfaction is the more comprehensive and meaningful indicator of people's life circumstances and well-being (Stiglitz et al. 2008).

It would be a mistake to conclude from the life satisfaction experience of China, and the transition countries more generally, that a return to socialism and the gross inefficiencies of central planning would be beneficial. However, our data suggest an important policy lesson, that jobs and job and income security, together with a social safety net, are of critical importance to life satisfaction. In the last few years, the government of China has begun serious efforts to repair the social safety net. These efforts are an encouraging portent for the future life satisfaction of the Chinese population, particularly for the least advantaged segments (Vodopivec, Tong 2008).

\subsubsection{Micro and Meso Level factors}

The second level factors may be considered as the micro level and these depend upon those at the macro level. 
It is obvious, that in order to design and realize a high-quality passive house project, it is necessary to take care of its efficiency from the initial brief to the end of maintenance. The entire process must be planned and executed taking into account the specific goals of the participating parties. The designing and planning procedure must include multiple criteria optimization, not only of the separate processes and decisions, but also of the whole life cost of the passive house. This must take into account the needs expressed by the parties involved in the project.

In order to efficiently design and implement projects in the built environment, it is necessary to investigate as many of the possible alternative solutions for each variable and to select the most rational one. The selected variables are then combined into one efficient project. Hence, the efficiency of a project will depend to a very great extent not only on the selected variables, but also on micro, meso and macro factors affecting them.

The level of efficiency and the scope of activities of the built environment depend on the next micro variable factors:

- information system of built environment,

- building's life cycle energy analysis,

- energy use in the built environment,

- pollution and health in cities,

- real estate losses as a result of sea level rise,

- education and training,

- types of contracts,

- briefing process,

- design process,

- manufacture process,

- construction process,

- maintenance process,

- facilities management,

- holiday travels,

- festivals.

- etc.

As an example, further on we shall briefly discuss some above mentioned micro level factors (building's life cycle energy analysis, energy use in the built environment, pollution and health in cities, real estate losses as a result of sea level rise, holiday travels, Cherry blossom festivals).

\subsubsection{Building's life cycle energy analysis}

Buildings demand energy in their life cycle right from its construction to demolition. Studies on the total energy use during the life cycle are desirable to identify phases of largest energy use and to develop strategies for its reduction. 
Ramesha et al. (2010) presented a critical review of the life cycle energy analyses of buildings resulting from 73 cases across 13 countries. The study includes both residential and office buildings. Results show that operating (80-90\%) and embodied (10-20\%) phases of energy use are significant contributors to building's life cycle energy demand. Life cycle energy (primary) requirement of conventional residential buildings falls in the range of $150-400 \mathrm{kWh} / \mathrm{m}^{2}$ per year and that of office buildings in the range of $250-550 \mathrm{kWh} / \mathrm{m}^{2}$ per year. Building's life cycle energy demand can be reduced by reducing its operating energy significantly through use of passive and active technologies even if it leads to a slight increase in embodied energy. However, an excessive use of passive and active features in a building may be counterproductive. It is observed that low energy buildings perform better than self-sufficient (zero operating energy) buildings in the life cycle context. Worldwide, $30-40 \%$ of all primary energy is used for buildings and they are held responsible for $40-50 \%$ of green house gas emissions. It is therefore essential for the building built environment to achieve sustainable development in the society. Sustainable development is viewed as development with low environmental impact, and high economical and social gains. To achieve the goals of sustainability it is required to adopt a multi-disciplinary approach covering a number of features such as energy saving, improved use of materials including water, reuse and recycling of materials and emissions control. Life cycle energy analysis of buildings assumes greater significance for formulating strategies to achieve reduction in primary energy use of the buildings and control emissions (Ramesha et al. 2010).

Life cycle energy analysis is an approach that accounts for all energy inputs to a building in its life cycle. The system boundaries of this analysis) include the energy use of the following phases: manufacture, use, and demolition. Manufacture phase includes manufacturing and transportation of building materials and technical installations used in erection and renovation of the buildings. Operation phase encompasses all activities related to the use of the buildings, over its life span. These activities include maintaining comfort condition inside the buildings, water use and powering appliances. Finally, demolition phase includes destruction of the building and transportation of dismantled materials to landfill sites and/or recycling plants (Ramesha et al. 2010).

A large variety of materials are being used in building construction. Some of them may have a life span less than that of the building. As a result, they are replaced to rehabilitate the building. In addition to this, buildings require some regular annual maintenance. The energy incurred for such repair and replacement (rehabilitation) needs to be accounted during the entire life of the buildings. It is the energy required for maintaining comfort conditions and day-to-day maintenance of the buildings. It is the energy for HVAC (heating, ventilation and air conditioning), domestic hot water, lighting, and for running appliances. 
Operational energy largely varies on the level of comfort required, climatic conditions and operating schedules. At the end of buildings' service life, energy is required to demolish the building and transporting the waste material to landfill sites and/or recycling plants (Ramesha et al. 2010).

\subsubsection{Impact of climate change on energy use in the built environment}

Work on the subtropical climates had revealed an increasing trend of temperature and summer discomfort over the past decades and it was found that the anticipated temperature rise could result in more cooling demand. More electricity use for air conditioning would lead to larger emissions, which in turn would exacerbate climate change and global warming. Even in regions with severe cold climates where the decrease in heating energy use could, in terms of final or delivered energy, outweigh the increase in cooling, the impact of climate change on the overall primary energy requirement and the environment would remain uncertain. This is because heating is usually provided by oil- or gas-fired boiler plants whereas cooling relies on electricity-driven chillers (except gas-fired absorption systems). In terms of carbon footprint, electricity tends to have a much lower overall efficiency and higher $\mathrm{CO}_{2}$ emissions per unit energy consumption. From a nationwide energy and environmental perspective, it is important to be able to estimate the magnitude of the likely changes in heating and cooling energy requirements due to climate change in different climate zones. Broadly speaking, there are two main approaches (Li et al. 2012):

- Degree-days method. The degree-days concept is widely used for measuring the influence of climate on heating and cooling requirements. Hekkenberg et al. (2009) argues that socio-economic changes may alter the temperature dependence pattern of energy demand in future years. However, to a good approximation heating and cooling energy requirements can be assumed to be proportional to the HDDs and CDDs, respectively. In recent years, this method has been used to assess the impact of climate change on regional energy demand as well as energy consumption in the built environment in different parts of the world. Pilli-Sihvola et al. (2010) chose five countries along the north-south gradient: Finland, Germany, Netherland, France and Spain. Their main findings were: in central and north Europe the decrease in heating due to climate warming would dominate, and in southern Europe climate warming and the consequential increase in cooling and electricity demand would outweigh the decreasing need for space heating.

- Building energy simulation technique. There had been a number of studies on the impact of climate change on the built environment using sophisticated building energy simulation tools to perform hour-by-hour computation of the heating/cooling loads and corresponding energy use. Building energy simulation is an acceptable technique for assessing the 
dynamic interactions between the external climates, the building envelope and the HVAC system and the corresponding energy consumption. It has played an important role in the development of simple design tools and building energy efficiency codes. This technique has also been used by a number of researchers to assess the impact of climate change on energy use in buildings. Gaterell and McEvoy (2005) assessed the impact of projected climate changes on the thermal performance of the built environment and the measures implemented to improve such performance. The air temperatures were raised by $2{ }^{\circ} \mathrm{C}$ and $2.9{ }^{\circ} \mathrm{C}$ to reflect the climate in 2050 , and by $2.3^{\circ} \mathrm{C}$ and $5.9{ }^{\circ} \mathrm{C}$ in 2100 in a study by Radhi (2009) to investigate the potential impact of global warming on residential buildings in United Arab Emirates. It was concluded that global warming was likely to increase the energy used for cooling by $23.5 \%$ with a $5.9{ }^{\circ} \mathrm{C}$ increase in the ambient temperature. It was also found that energy design measures such as thermal insulation and building thermal mass were important to cope with global warming.

\subsubsection{Climate change, pollution and health in cities}

Excess morbidity and mortality related to extremely hot weather and poor air quality are found in cities worldwide. This is a major public health concern for cities now and looking toward the future because the interactions of global climate change, urban heat islands, and air pollution are predicted to place increasing health burdens on cities. The proposed mitigation and adaptation strategies in cities' climate risk management plans may produce health co-benefits by reducing emissions and cooling temperatures through changes in the built environment. There are challenges, however, to implementing the plans and the most widely documented beneficial policy to date is the adoption of heat warning and air quality alert systems to trigger emergency responses (Harlan, Ruddell 2011).

As the largest developing country, China has been changing rapidly over the last three decades and its economic expansion is largely driven by the use of fossil fuels, which leads to a dramatic increase in emissions of both ambient air pollutants and greenhouse gases (GHGs). China is now facing the worst air pollution problem in the world, and is also the largest emitter of carbon dioxide. A number of epidemiological studies on air pollution and population health have been conducted in China, using time-series, case-crossover, cross-sectional, cohort, panel or intervention designs. The increased health risks observed among Chinese population are somewhat lower in magnitude, per amount of pollution, than the risks found in developed countries. However, the importance of these increased health risks is greater than that in North America or Europe, because the levels of air pollution in China are very high in general and Chinese population 
accounts for more than one fourth of the world's totals. Meanwhile, evidence is mounting that climate change has already affected human health directly and indirectly in China, including mortality from extreme weather events; changes in air and water quality; and changes in the ecology of infectious diseases. If China acts to reduce the combustion of fossil fuels and the resultant air pollution, it will reap not only the health benefits associated with improvement of air quality but also the reduced GHG emissions. Consideration of the health impact of air pollution and climate change can help the Chinese government move forward towards sustainable development with appropriate urgency (Kan et al. 2012).

Urban centers in Latin American often face high levels of air pollution as a result of economic and industrial growth. Decisions with regard to industry, transportation, and development will affect air pollution and health both in the short term and in the far future through climate change. Bell et al. (2006) investigated the pollution health consequences of modest changes in fossil fuel use for three case study cities in Latin American: Mexico City, Mexico; Santiago, Chile; and São Paulo, Brazil. Annual levels of ozone and particulate matter were estimated from 2000 to 2020 for two emissions scenarios: (1) business-as-usual based on current emissions patterns and regulatory trends and (2) a control policy aimed at lowering air pollution emissions. The resulting air pollution levels were linked to health endpoints through concentration-response functions derived from epidemiological studies, using local studies where available. Results indicate that the air pollution control policy would have vast health benefits for each of the three cities, averting numerous adverse health outcomes including over 156,000 deaths, 4 million asthma attacks, 300,000 children's medical visits, and almost 48,000 cases of chronic bronchitis in the three cities over the 20-year period. The economic value of the avoided health impacts is roughly $\$ 21$ to $\$ 165$ billion (US). Sensitivity analysis shows that the control policy yields significant health and economic benefits even with relaxed assumptions with regard to population growth, pollutant concentrations for the control policy, concentration-response functions, and economic value of health outcomes. Bell et al. (2006) research demonstrates the health and economic burden from air pollution in Latin American urban centers and the magnitude of health benefits from control policies (Bell et al. 2006).

The contribution of the road transportation sector to emissions of air pollutants and greenhouse gases is a growing concern in developing countries. Emission control measures implemented within this sector can have varying counteracting influences. In the city of Durban, South Africa, the growing dependence on privately-owned motor vehicles and increasing usage of roads for freight transport have all resulted in significant air pollution and greenhouse gas emissions. In this study, an emissions inventory was developed for the road transport sector and was used as a basis to explore intervention opportunities 
that are likely to reduce simultaneously, air pollution and greenhouse gas emissions in this sector. It was found that reducing the vehicle kilometres travelled by privately-owned motor vehicles and improving the efficiency of road freight transport offered the greatest potential for achieving co-benefits (Thambiran, Diab 2011).

Bollen et al. (2009) present the findings of a combined cost-benefit analysis of local air pollution and global climate change, two subjects that are usually studied separately. Yet these distinct environmental problems are closely related, since they are both driven by the nature of present energy production and consumption patterns. Bollen et al. (2009) also demonstrate that the discounted benefits of local air pollution reduction significantly outweigh those of global climate change mitigation, at least by a factor of 2 , but in most cases of our sensitivity analysis much more. Still, Bollen et al. (2009) do not argue to only restrict energy policy today to what should be our first priority, local air pollution control, and wait with the reduction of greenhouse gas emissions. Instead, Bollen et al. (2009) propose to design policies that simultaneously address these issues, as their combination creates an additional climate change bonus. As such, climate change mitigation proves an ancillary benefit of air pollution reduction, rather than the other way around (Bollen et al. 2009).

\subsubsection{Real estate losses as a result of sea level rise}

The effects of climate change will have severe consequences for low-lying U.S. coastal real estate. If nothing is done to hold back rising waters, sea-level rise will simply cause many properties in low-lying coastal areas to be inundated. Even those properties that remain above water will be more likely to sustain storm damage, as encroachment of the sea allows storm surges to reach inland areas that were not previously affected. More intense hurricanes, in addition to sea-level rise, will increase the likelihood of both flood and wind damage to properties throughout the Atlantic and Gulf coasts. To estimate the value of real estate losses from sea-level rise, we have updated a detailed forecast of coastal real estate losses in the 48 states developed by the Environmental Protection Agency (EPA). In projecting these costs into the future Ackerman and Stanton (2008) assume that annual costs will be proportional to sea-level rise and to projected GDP. Ackerman and Stanton (2008) calculate the annual loss of real estate from inundation due to the projected sea-level rise, which reaches 45 inches by 2100 in the business-as-usual case. These losses amount to $\$ 360$ billion by 2100 , or 0.35 percent of GDP (Ackerman, Stanton 2008).

No one expects coastal property owners to wait passively for these damages to occur; those who can afford to protect their properties will undoubtedly do so. But all the available methods for protection against sea-level rise are problematic and expensive. It is difficult to imagine any of them being used on a large 
enough scale to shelter all low-lying U.S. coastal lands that are at risk under the business-as-usual case. Elevating homes and other structures is one way to reduce the risk of flooding, if not hurricane-induced wind damage. A Federal Emergency Management Agency (FEMA) (1998) estimate of the cost of elevating a frame construction house on a slab-on-grade foundation by two feet is $\$ 58$ per square foot, with an added cost of $\$ 0.93$ per square foot for each additional foot of elevation (FEMA 1998). This means that it would cost $\$ 58,000$ to elevate a house with a 1,000-square-foot footprint by two feet. It is not clear whether building elevation is applicable to multistory structures; at the least, it is sure to be more expensive and difficult (Ackerman, Stanton 2008).

\subsubsection{Holiday travels and Cherry blossom festivals}

Whilst much effort has been made to communicate to the public the importance of reducing carbon footprints in the home, one area where emissions are growing rapidly and little attempt has been made to increase consumer understanding of the impacts is holidays, particularly those involving air travel. Using focus group research, this paper explores tourists' awareness of the impacts of travel on climate change, examines the extent to which climate change features in holiday travel decisions and identifies some of the barriers to the adoption of less carbon-intensive tourism practices. The findings suggest that many tourists do not consider climate change when planning their holidays. The failure of tourists to engage with the climate change impact of holidays, combined with significant barriers to behavioural change, presents a considerable challenge in moving the tourism industry onto a sustainable emissions path. The findings are discussed in relation to theoretical perspectives from psychology and sociology (Hares et al. 2010).

Most global climate change models predict serious ecological and social problems. In Japan, biologists have found climate change is affecting species and ecosystems, including the earlier flowering time of cherry trees which are an important cultural symbol in Japan. Cherry blossom festivals are also important to local economies. This study explored the perceptions of Japanese residents regarding climate change impacts on culturally significant events such as flower timing of cherry trees. Sakurai et al. (2011) conducted interviews of stakeholders of three cherry blossom festivals, including sixteen organizers of festivals and 26 managers of festival-dependent businesses, to understand their awareness, attitudes and behaviors toward global climate change and impacts on cherry blossom festivals. Most organizers of the festival in Kakunodate were concerned about global warming and its impact on cherry blossom times while organizers of festivals in Nakano and Komoro felt it was unimportant if flower timing affected the festival schedule. Most (92\%) managers of festival-dependent businesses mentioned that global warming is occurring and affecting the flower 
timing of cherry trees, but there were diverse perceptions of global warming impacts on their business. Managers more dependent on income from cherry blossom festivals indicated greater concern for the effects of climate change (Sakurai et al. 2011).

\section{References}

Ackerman F.; Stanton E. A. 2008. What We'll Pay if Global Warming Continues Unchecked. Natural Resources Defense Council, $42 \mathrm{p}$.

Akadiri P. O.; Olomolaiye P. O.; Chinyio E. A. 2013. Multi-criteria evaluation model for the selection of sustainable materials for building projects, Automation in Construction 30: $113-125$

Allouche J. 2011 . The sustainability and resilience of global water and food systems: Political analysis of the interplay between security, resource scarcity, political systems and global trade, Food Policy 36(1): 3-8.

Baucells, M.; Sarin, R. K. 2007. Does More Money Buy You More Happiness? 2012. Available from: http://repositories.cdlib.org/anderson/dotm/RS16 [accessed 12 April 2012].

Bell M. L.; Davis D. L.; Gouveia N.; Borja-Aburto V.H.; Cifuentes L. A. 2006. The avoidable health effects of air pollution in three Latin American cities: Santiago, São Paulo, and Mexico City, Environmental Research 100(3): 431-440.

Boehmer-Christiansen, S. 1997. A winning coalition of advocacy: climate research, bureaucracy and 'alternative' fuels: Who is driving climate change policy? Energy Policy 25(4): 439-444.

Bollen, J.; Zwaan, B. V. D.; Brink, C.; Eerens, H. 2009. Local air pollution and global climate change: A combined cost-benefit analysis, Resource and Energy Economics 31(3): $161-181$.

Carey, J. Calculating the True Cost of Global Climate Change. 2011. Available from: http://e360.yale.edu/feature/calculating_the_true_cost_of_global_climate_change/2357/ [accessed 10 July 2012].

Daniels, P. L. 2007. Buddhism and the transformation to sustainable economies, Society and Economy 29(2): 155-180.

Daniels, P. L. 2010b. Climate change, economics and Buddhism - Part I: An integrated environmental analysis framework, Ecological Economics 69(5): 952-961.

Daniels, P. L. 2010b. Climate change, economics and Buddhism - Part 2: New views and practices for sustainable world economies, Ecological Economics 69(5): pp. 962-972.

Da Silva, P. C.; Leal, V.; Andersen, M. 2012. Influence of shading control patterns on the energy assessment of office spaces, Energy and Buildings 50: 35-48. doi:10.1016/j. enbuild.2012.03.019

Day, A. R.; Jones P. G.; Maidment G. G. 2009. Forecasting future cooling demand in London, Energy and Building 41(9): 942-948.

Easterlin, R. A. 2010. Happiness, Growth, and the Life Cycle. New York: Oxford Univ Press. 
Easterlin, R. A.; Morgan, R.; Switek, M.; Wang, F. 2012. China's life satisfaction, 19902010. Available from: http://www.pnas.org/content/early/2012/05/09/1205672109. full.pdf [accessed 17 May 2012].

EIA report, Emissions of Greenhouse Gases in the United States. 2009.

Farbotko, C.; Lazrus, H. 2012. The first climate refugees? Contesting global narratives of climate change in Tuvalu, Global Environmental Change 22(2): 382-390.

Federal Emergency Management Agency (FEMA). 1998. Homeowner's Guide to Retrofitting: Six Ways to Protect Your House From Flooding. Washington, DC, Federal Emergency Management Agency, 173 p.

Feynman J. 2007. Has solar variability caused climate change that affected human culture? Advances in Space Research 40(7); 1173-1180.

Fischer, A.; Peters, V.; Vávra, J.; Neebe, M.; Megyesi, B. 2011. Energy use, climate change and folk psychology: Does sustainability have a chance? Results from a qualitative study in five European countries, Global Environmental Change 21(3): 1025-1034.

Ford, J. D.; Berrang-Ford, L.; King, M.; Furgal, C. 2010. Vulnerability of Aboriginal health systems in Canada to climate change, Global Environmental Change 20(4): 668-680.

French, S. 2003. The Code of the Warrior: Exploring Warrior Values Past and Present. Rowman \& Littlefield, Lanham, MD.

23. French, W. C. 2008. Ecoethics. Encyclopedia of Violence, Peace, \& Conflict (2nd ed.), pp. 607-662.

Gaterell, M. R.; McEvoy, M. E. 2005. The impact of climate change uncertainties on the performance of energy efficiency measures applied to dwellings, Energy and Building 37(9): 982-995.

GCCA. Glossary of climate change acronyms. 2012. Available from: http://unfccc.int/ essential_background/glossary/items/3666.php [accessed 12 April 2012].

Geel, B. V.; Bokovenko, N. A.; Burova, N. D.; Chugunov, K. V.; Dergachev, V. A.; Dirksen, V. G.; Kulkova, M.; Nagler, A.; Parzinger, H.; Plicht, J. V. D.; Vasiliev, S. S.; Zaitseva, G. I. 2004. Climate change and the expansion of the Scythian culture after 850 BC: a hypothesis, Journal of Archaeological Science 31(12): 1735-1742.

Georgiadou, M. C.; Hacking, T.; Guthrie, P. 2012. A conceptual framework for future-proofing the energy performance of buildings, Energy Policy 47: 145-155. doi:10.1016/j.enpol.2012.04.039

Hares, A.; Dickinson, J.; Wilkes, K. 2010. Climate change and the air travel decisions of UK tourists, Journal of Transport Geography 18(3); 466-473.

Harlan, S. L.; Ruddell, D. M. 2011. Climate change and health in cities: impacts of heat and air pollution and potential co-benefits from mitigation and adaptation, Current Opinion in Environmental Sustainability 3(3): 126-134.

Hekkenberg, M.; Moll, H. C.; Schoot Uiterkamp, A. J. M. 2009. Dynamic temperature dependence patterns in future energy demand model in the context of climate change, Energy 34(11): 1797-1806.

Hendrix, C. S.; Glaser, S. M. 2007. Trends and triggers: Climate, climate change and civil conflict in Sub-Saharan Africa, Political Geography 26(6): 695-715. 
IAEA. Climate Change and Nuclear Power. 2008. Available from: http://www.iaea.org/ OurWork/ST/NE/Pess/assets/08-33461-CCNP-Brochure.pdf [accessed 22 May 2012].

IPCC. Glossary Working Group III. Glossary. 2010. Available from: http://www.commondreams.org/archive/2007/08/18/3255 [accessed 10 July 2012].

Marcott, S. M. Science 8 March 2013. 339(6124): 1198-1201 .

Marcott, S. M.; Shakun, J. D.; Clark, P. U.; Mix, A. C. 2013. A Reconstruction of Regional and Global Temperature for the Past 11, 300 Years, Science 339(6124): 1198.

Mendis, P. 1993. Buddhist equilibrium: The theory of middle path for sustainable development. St. Paul. Staff Paper Department of Agricultural and Applied Economics, University of Minnesota, pp. 93-102.

Molina, M.; Zaelke, D.; Sarmac, K. M.; Andersen, S. O.; Ramanathane, V.; Kaniaruf, D. 2009. Reducing abrupt climate change risk using the Montreal Protocol and other regulatory actions to complement cuts in $\mathrm{CO} 2$ emissions, Proceedings of the National Academy of Sciences 106(49): 20616-20621.

Mora, R.; Bitsuamlak, G.; Horvat, M. 2011. Integrated life-cycle design of building enclosures, Building and Environment 46(7); 1469-1479. doi:10.1016/j.buildenv.2011.01.018

Ouedraogo, B. I.; Levermore, G. J.; Parkinson, J. B. 2012. Future energy demand for public buildings in the context of climate change for Burkina Faso, Building and Environment 49: 270-282. doi:10.1016/j.buildenv.2011.10.003

Pacheco, R.; Ordóñez, J.; Martínez, G. 2012. Energy efficient design of building: A review, Renewable and Sustainable Energy Reviews 16(6): 3559-3573. doi:10.1016/j. rser.2012.03.045

Pilli-Sihvola, K.; Aatola, P.; Ollikainen, M.; Tuomenvirta, H. 2010. Climate and electricity consumption - witnessing increasing or decreasing use and costs? Energy Policy 38(5): 2409-2419.

Radhi, H. 2009. Evaluating the potential impact of global warming on the UAE residential buildings - a contribution to reduce the $\mathrm{CO}_{2}$ emission, Building and Environment 44(12): 2451-2462.

Raleigh, C.; Urdal, H. 2007. Climate change, environmental degradation and armed conflict, Political Geography 26(6): 674-694.

Ramesh, T.; Prakash, R.; Shukla, K. K. 2010. Life cycle energy analysis of buildings: An overview, Energy and Buildings 42(10): 1592-1600.

Ruth, M.; Coelho, D.; Karetnikov, D. 2007. The U.S. Economic Impacts of Climate Change and the Costs of Inaction. University of Maryland , $52 \mathrm{p}$.

Sakurai, R.; Jacobson, S. K.; Kobori, H.; Primack, R.; Oka, K.; Komatsu, N.; Machida, R. 2011. Culture and climate change: Japanese cherry blossom festivals and stakeholders' knowledge and attitudes about global climate change, Biological Conservation 144(1): 654-658.

Salick, J.; Fang, Z.; Byg, A. 2009. Eastern Himalayan alpine plant ecology, Tibetan ethnobotany, and climate change, Global Environmental Change 19(2): 147-155.

Shwom, R.; Bidwell, D.; Dan, A.; Dietz, T. 2010. Understanding U.S. public support for domestic climate change policies, Global Environmental Change 20(3): 472-482. 
Schneider, S. H. 2004. Abrupt non-linear climate change, irreversibility and surprise, Global Environmental Change 14(3): 245-258.

SOCCR. The First State of the Carbon Cycle Report: The North American Carbon Budget and Implications National Oceanic and Atmospheric Administration, National Climatic Data Center, Asheville, NC, USA. 2008. 242 p. Available from: http://www. climatescience.gov/Library/sap/sap2-2/final-report/default.htm

Stern, N. Stern Review on the Economics of Climate Change: Part III: The Economics of Stabilisation. HM Treasury, London. 2007. Available from: http://hm-treasury.gov. uk/sternreview_index.htm [accessed 12 April 2012].

Stiglitz, J. E.; Sen. A.; Fitoussi, J. P. 2008. Report of the Commission on the Measurement of Economic Performance and Social Progress. Available from: www.stiglitz-sen-fitoussi.fr [accessed 17 May 2012].

Thambiran, T.; Diab R. D. 2011. Air pollution and climate change co-benefit opportunities in the road transportation sector in Durban, South Africa. Atmospheric Environment 45(16): 2683-2689.

Tideman, S. 2001. Gross national happiness: towards Buddhist economics. Adapted from paper presented to a forum with leaders and scholars from Bhutan, in the Netherlands.

The New Scientist. 2007. Religious leaders pray for cold weather to combat climate change, The New Scientist 195(2621), p. 4.

Tzempelikos, A.; Athienitis, A. K.; Karava, P. 2007. Simulation of façade and envelope design options for a new institutional building, Solar Energy 81(9): 1088-1103. doi:10.1016/j.solener.2007.02.006

Vatican-appointed panel warns of climate change. 2011. Available from: http://www. mb.com.ph/node/317748/vaticanappointed-panel-warn [accessed 10 July 2012].

Vodopivec, M.; Tong, M. H. 2008. China: Improving Unemployment Insurance. World Bank, Washington, DC. 61 p.

Wardekker, J. A.; Petersen, A. C.; Sluijs, J. P. 2009. Ethics and public perception of climate change: Exploring the Christian voices in the US public debate, Global Environmental Change 19(4): 512-521.

Webster, D. 2005. The Philosophy of Desire in the Buddhist Pali Canon. London: Routledge Curzon.

Willis, A. 2012. Constructing a story to live by: Ethics, emotions and academic practice in the context of climate change, Emotion, Space and Society 5(1): 52-59.

Kan, H.; Chen, R.; Tong, S. 2012. Ambient air pollution, climate change, and population health in China, Environment International 42(1); 10-19.

Li, D. H. W.; Yang, L.; Lam, J. C. 2012. Impact of climate change on energy use in the built environment in different climate zones - A review, Energy 42(1): 103-112.

Zabalza Bribián, I.; Valero Capilla, A.; Aranda Usón, A. 2011. Life cycle assessment of building materials: Comparative analysis of energy and environmental impacts and evaluation of the eco-efficiency improvement potential, Building and Environment 46(5): 1133-1140. doi:10.1016/j.buildenv.2010.12.002 



\title{
CHAPTER 7
}

\section{DISTANCE LEARNING EXPERIENCE IN CONSTRUCTION AND REAL ESTATE AT VGTU}

\author{
Natalija LEPKOVA, Silva RIMKUVIENE
}

\subsection{Development of distance learning}

Modern world cannot be imagined without new information technologies, which provide an opportunity to transfer necessary information quickly and independently, contact necessary people, transmit not only static, but dynamic information, not only text, but sound; search for information not only in local, but in global data bases, as well.

Development of information society is transforming not only business, but all other areas of human activities as well, including science and studies (Kliukas et al. 2014).

Distance learning has evolved over the past two centuries from correspondence courses to educational radio, one- and two-way teleconferencing, educational television, video conferencing to computer assisted/Web-based interactive learning opportunities. Yet, with all the technological changes that have evolved in distance learning, there have been few changes in the reason why distance learning exists. Distance learning is intended to offer useful learning opportunities to people at a time and location that is convenient to them (Kaufman et al. 2001).

Distance learning is a process of teaching-learning in which the learner is physically separated from the teacher. The geographical distances involved may be relatively small, or very large. Most definitions accept that there may be a degree of physical interaction between teacher and learner, but in comparison with the normal classroom experience the actual amount of face-to-face contact is usually much reduced or even nonexistent. Because of this, the teacher develops a range of learning materials to impact knowledge, skills and attitudes to the learner. The presence of such technical media (print, audio, video, computerbased) is a distinguishing feature of distance education. Students study these materials, generally alone, at times and in places of their own choosing. There are arrangements to test their knowledge, skills and attitudes through assignments that are sent to a tutor for marking, or marked by computer (Rumble 1997; Rimkuvienė, Lepkova 2004).

The motivation to learn in virtual learning environments is based on successful communication between teachers and students, as well as professional implementation of methodical/didactic methods. This can be achieved through 
a good atmosphere, interest and esteem, along with communication and a good relationship-both of which are essential factors to succeeding in virtual learning (Stokar Von Neuforn, Thomaschewski 2006).

Another way of looking at the interrelationships among the components in a distance education system is to use a common technique in system modeling: viewing the system in terms of inputs and outputs. Inputs are following: Student Characteristics, Instructor/Tutor Experience, Competence of Administrative Staff, Efficiency of Course Development, Student Access to Resources, Response Time, Local Site Coordination, Institutional Cooperation/Support, Reliability of Evaluation. Outputs are following: Student Satisfaction Ratings, Student Achievement Scores, Student Completion Rates, Total Enrollments, Quality Assessments, Accreditation, Costs and Revenue, Staff Turnover. In some cases the relationship is quite direct, such as the case with instructor/tutor experience and students satisfaction ratings. Other relationship are less direct, such as the link between student access to resources and student achievement scores. Most relationships are multiple in nature; for example, student characteristics affect many of the output variables, whereas student completion rates are a function of many of the input factors (Moore, Kearsley 1996; Rimkuvien et al. 2007).

From 1991 year new technologies were developing at an enormous rate. As a result of introduction of such new modern technologies, distance learning has also undergone some rapid improvements, various distance learning media (Web CT, Learning Space, Moodle, etc.) have come into existence, computing capabilities have risen up a thousandfold and students are now given an unprecedented opportunity of completing their studies without travelling to their universities (Targamadze et al. 1999; Rimkuvienè, Lepkova 2004).

\subsubsection{Distance education in Lithuania}

In 1993, Lithuania joined the PHARE Multi-country Program for Distance Education. The Minister for Education and Science issued an order to establish the Lithuanian Centre for Extramural Education (LNSC), which is responsible for implementation of the program in Lithuania. EU funds for pilot activities within the PHARE Multi-country Program for Distance Education were first granted in 1995, when LNSC and EC signed an agreement for the first (pilot) year in Lithuania.

The expansion of the distance education network is also funded by the Lithuanian national budget. The investment program of the Government of the Republic of Lithuania "Development of Distance Education in Lithuania" was launched as early as in 1998; the program covered creation of the infrastructure for distance education video conferencing: it was planned to expand the network of modern distance education classrooms in Lithuania, as well as to prepare laboratories and studios with versatile equipment (Targamadze et al. 1999). 
The Lithuanian Distance Education Network (LieDM) is the main distance education infrastructure in Lithuania open to public at large; it enables universities, colleges, vocational schools and other education and training organisations to render distance education services (see Figure 7.1).

The video conferencing network developed in Lithuania during the LieDM project facilitates development of a joint system for education support throughout Lithuania (Rutkauskiene et al. 2003).

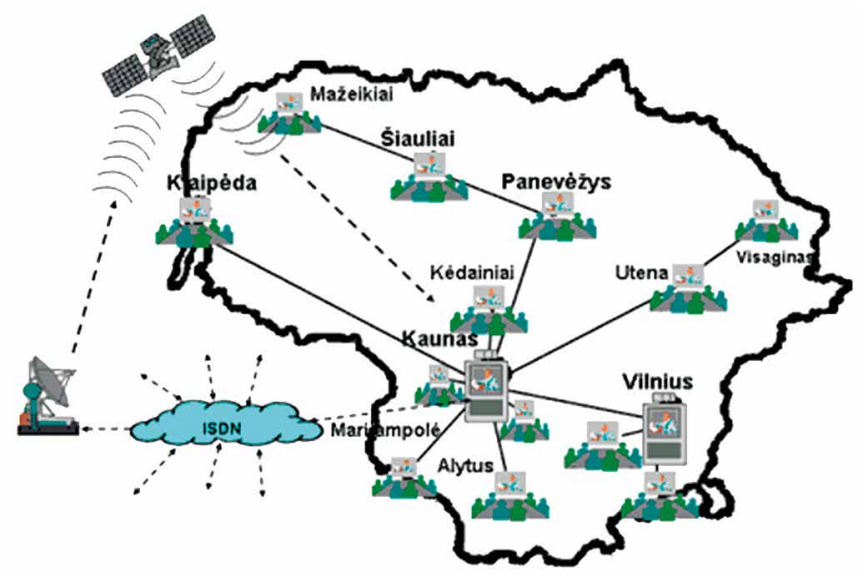

Figure 7.1. Lithuanian Distance Education Network (LieDM)(Rutkauskiene et al. 2003)

A distance classroom can communicate with any other institution, in Lithuania or abroad, with the help of either Internet or ISDN (Integrated Services Digital Network).

Events streamed via the LieDM network can be used as sources of both information and education across Lithuania. They can be, for instance, various recorded workshops, conferences and meetings, or presentations, examinations and lectures.

Geographically, the LieDM network covers the entire territory of Lithuania (see Figure 7.1), though it is more developed in our cities, which boast more universities, institutes and colleges and are home to more students and teachers (Trinkunas et al. 2008).

In certain cases, VGTU students can also use the network to communicate with their teachers and take their examinations.

If the weather is bad, students have important personal or other reasons, for instance, they can use the network with a special permission by the university's administration. Distance students enrolled in such programmes as Real Estate Management and Construction Economics and Business get access to it by default. 
The aim is to further develop the Lithuanian Distance Learning Network, or LieDM, support its operation, and create an IT-based and integrated e-learning space as a platform open to every Lithuanian citizen to learn as well as maintain and develop competences all their life, no matter where they live.

The creation and development of the portal Lithuanian Virtual University, or LVU (http://www.lvu.lt/app), is part of Lithuanian Virtual University 20072012, a programme launched by the Ministry of Education and Science of the Republic of Lithuania which carries on and expands activities of the previous programmes and encourages new institutions to join such activities (Lithuanian Virtual University... 2015).

\subsubsection{Development of distance learning at Vilnius Gediminas Technical University}

As the idea of distance learning emerged in the world and in Lithuania, in 1999 Vilnius Gediminas Technical University became the first university in Lithuania to introduce a full Master's study programme Real Estate Valuation at the Department of Construction Economics and Property Management.

Later, in 2001, Vilnius Gediminas Technical University founded the Distance Learning Centre.

And in 2004 the Faculty of Business Management and the Faculty of Fundamental Sciences introduced their own distance learning programmes.

The infrastructure of the Distance Learning Centre was established with the support of the EU Structural Funds (see Figure 7.2).

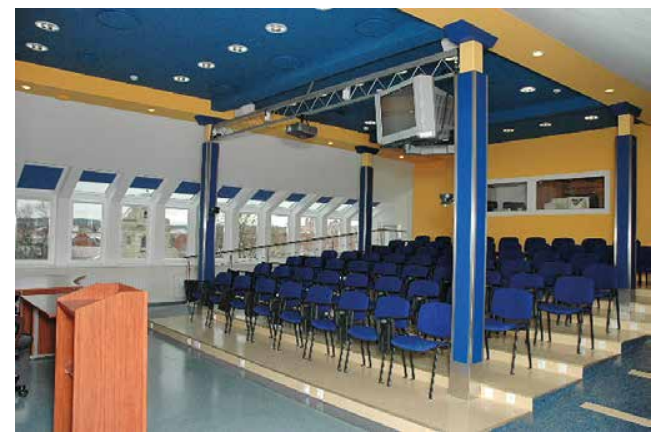

A videoconference hall in the Distance Learning Centre

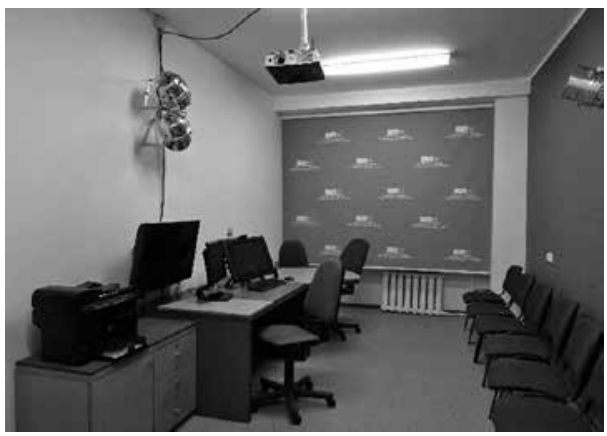

A video studio for distance learning

Figure 7.2. A conference hall and a video studio in the Distance Learning Centre

VGTU Distance Learning Centre pursues the following main aims:

- to be a promoter and supporter of distance learning at the University;

- to manage the University's Learning Management System. 
The centre organises distance learning studies, assigns time slots for communication and work in the virtual environment, and organizes lectures in synchronous or asynchronous way.

At least $50 \%$ of the communication time slots available for each subject must include some time for face-to-face communication.

Face-to-face meetings are the time when students can attend lectures and seminars, do their laboratory assignments and exercises, visit consultation sessions or do other activities with a direct involvement of the teacher.

Face-to-face timeslots are realized by organizing synchronous activities.

All distance learning materials must be approved by the University according to its current approval procedure for distance learning materials.

Distance examinations may also be organised by electronic means.

Only authenticated and authorized users of our virtual learning environment can study, teach or use the virtual learning environment in other ways.

All users are authorised according to with the University's procedures.

All study materials available in the virtual learning environment are owned by the University and their authors; without their consent they cannot be published, reproduced or otherwise transferred to third parties (Organization of distance learning studies at VGTU... 2015).

VGTU is a member of the Lithuanian Distance Learning (LieDM) Consortium (established in 2010).

The consortium unites universities and colleges. Its member universities are Kaunas University of Technology, the Lithuanian University of Health Sciences, Klaipeda University, the Lithuanian Academy of Music and Theatre, the Lithuanian Sports University, Šiauliai University, Vilnius Gediminas Technical University, and Vilnius University. Its member colleges are Alytaus kolegija/ University of Applied Sciences, Kauno Kolegija/University of Applied Sciences, Kaunas Technical College, Marijampolè College, and Vilniaus kolegija/University of Applied Sciences (the Lithuanian Virtual University, LieDM consortium members... 2015).

The consortium members communicate by means of a Desktop video conferencing solution.

The following Learning Management Systems are used at VGTU:

1. Moodle (Modular Object Oriented Dynamic Learning Environment)

Moodle is an Open Source Course Management System (CMS), also known as a Learning Management System (LMS) or a Virtual Learning Environment (VLE).

The focus of Moodle is always on giving educators the best tools to manage and promote learning.

The main features of Moodle system are following (Moodle features 2015):

- Modern, easy to use interface (Designed to be responsive and accessible, the Moodle interface is easy to navigate on both desktop and mobile devices). 
- Personalised Dashboard (Organise and display courses the way you want, and view at a glance current tasks and messages).

- Collaborative tools and activities (Work and learn together in forums, wikis, glossaries, database activities, and much more).

- All-in-one calendar (Moodle's calendar tool helps you keep track of your academic or company calendar, course deadlines, group meetings, and other personal events).

- Convenient file management (Drop and drop files from cloud storage services including MS Skydrive, Dropbox and Google Drive).

- Simple and intuitive text editor (Format text and conveniently add media and images with an editor that works across all web browsers and devices).

- Notifications (When enabled, users can receive automatic alerts on new assignments and deadlines, forum posts and also send private messages to one another).

- Track progress (Educators and learners can track progress and completion with an array of options for tracking individual activities or resources and at course level).

- Customisable site design and layout (Easily customise a Moodle theme with your logo, colour schemes and much more or simply design your own theme).

- Secure authentication and mass enrolment (Over 50 authentication and enrolment options to add and enrol users to your Moodle site and courses).

- Multilingual capability (Allow users to view course content and learn in their own language, or set it up for multilingual users and organisations).

- Bulk course creation and easy backup (Add courses in bulk, back up and restore large courses with ease).

- Manage user roles and permissions (Address security concerns by defining roles to specify and manage user access).

- High interoperability (Freely integrate external applications and content or create your own plugin for custom integrations).

- Simple plugin management (Install and disable plugins within a single admin interface).

- Regular security updates (Moodle is regularly updated with the latest security patches to help ensure your Moodle site is secure).

- Detailed reporting and logs (View and generate reports on activity and participation at course and site level).

Course Development and Management Features:

- Direct learning paths (Design and manage courses to meet various requirements. Classes can be instructor-led, self-paced, blended or entirely online).

- Encourage collaboration (Built-in collaborative publishing features foster engagement and encourage content-driven collaboration). 
- Embed external resources (Teach materials and include assignments from other sites and connect to the gradebook in Moodle).

- Multimedia Integration (Moodle's built-in media support enables you to easily search for and insert video and audio files in your courses).

- Group management (Group learners to share courses, differentiate activities and facilitate team work).

- Marking workflow (Conveniently assign different markers to assignments, manage grade moderation and control when marks are released to individual learners).

- In-line marking (Easily review and provide in-line feedback by annotating on PDF files directly within browser).

- Peer and self assessment (Built-in activities such as workshops and surveys encourages learners to view, grade and assess their own and other course members' work as a group).

- Integrated Badges (Fully compatible with Mozilla Open Badges, motivate learners and reward participation and achievement with customised Badges).

- Outcomes and rubrics (Select from advanced grading methods to tailor the gradebook to your course and examination criteria).

- Security and privacy (Teach and share in a private space only you and your class can access) (Moodle features 2015).

Moodle users are classified into five categories:

- System Administrators,

- Course developers,

- Teachers,

- Students, and

- Guests (Moodle vadovas... 2015).

\section{Desktop video conferencing solution}

The Vidyo solution (commercial across the consortium; see Figure 7.3) offers:

- 75 parallel connections;

- 5,000 licenses, including 1,000 for schools;
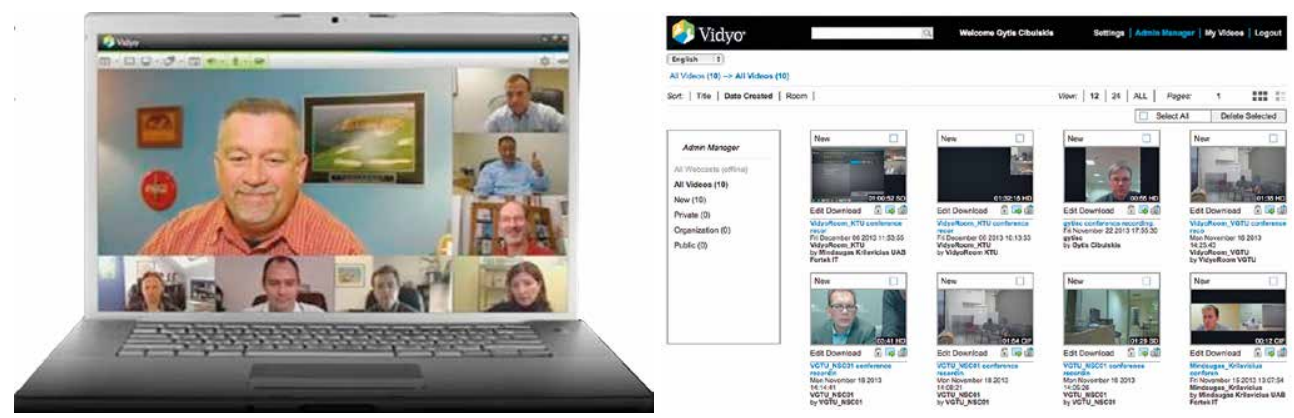

Figure 7.3. The print screens of the Vidyo solution 
- support for Windows, Mac OSX, iOS, Android and other devices; and

- video conferencing recordings.

\subsubsection{Development of idea and distance learning courses at the Faculty of Civil Engineering of VGTU}

The idea to create distance learning programs at the Faculty of Civil Engineering of VGTU originated in 1993-1995 while working on the international PHARE project between VGTU and the Department of Surveying of Salford University. This department is considered one of the frontrunners among 60 other similar departments in Great Britain. While implementing the project Professor Artüras Kaklauskas, with the help of Professor Brian Sloan, familiarized himself with computer learning systems, methods for their creation and the principles of distance learning programs.

As a result of the abovementioned project came up the idea to present this new and modern form of learning at the VGTU. Two international projects were initiated:

1. "Computer learning systems" under TEMPUS program;

2. "Creation of distance learning master degree programs" (jointly between the VGTU and Napier University in Great Britain) under PHARE program.

The project under Tempus program was successfully implemented in 19961997. Professor Artūras Kaklauskas worked at Napier University (Great Britain) in which distance learning programs are advanced. Professor Artūras Kaklauskas worked together with the head of distance learning studies Professor Brian Sloan and gained extensive experience relating to distance learning programs and computer learning systems.

The project proposal did not obtain financing under PHARE program, therefore was decided to create distance learning programs ourselves, using the resources of VGTU. Professors Artūras Kaklauskas and Edmundas Kazimieras Zavadskas took the initiative of implementing this project. The first distance learning courses were created without any financial support, only thanks to the efforts of Professors Edmundas Kazimieras Zavadskas, Romualdas Ginevičius, Artūras Kaklauskas, Povilas Vainiūnas, Aleksandras Vytautas Rutkauskas, Gediminas Marčiukaitis and Associate Professor Saulius Raslanas. Mindaugas Gikys started preparing multimedia materials.

The first distance learning program at the Department of Construction Economics and Property Management of the Faculty of Civil Engineering of VGTU was introduced in September of 1999. It was one of the first masters degree program in Central and Easten Europe. 27 students from all over Lithuania were accepted onto the Real Estate Valuation program. Most of them were people working in the real estate sector. Over the period of four years this study program has been renamed once (in 2001 its name was changed to "Real Estate 
Valuation and Management") and its content and scope have also been subjected to changes. Since 2003 the Real Estate Valuation and Management program contains two major subjects: Real Estate Management and Internet Technologies and Real Estate Business. Since 2000 students can enrol in Construction Management distance learning course selecting Construction Economics and Management as a major subject (Rimkuvienè, Lepkova 2004).

Graduates of the Master's study programme Real Estate Management receive a Master's degree in Management.

Graduates of the Master's study programme Construction Economics and Management receive a Master's Degree in Construction Technologies.

All program materials were available as printed program notes which are enhanced, where appropriate, to take advantage of modern teaching techniques and delivery mechanisms. In particular, the following media are used in specific modules: electronic format of the textbooks, video, computer software, computer learning systems, computer conferencing, computer networks, 'face-to-face' contact. The choice of media is often relatively easy to make because for much of the time, local constraints, questions of accessibility and of cost virtually dictate the media through which learners will have to work. Accessibility is vitally important to any learners who have to use self-instructional materials.

The module writers utilised electronic technologies in the preparation of their module material. This assisted the programming team to prepare the material in a variety of suitable formats for dissemination. Once in electronic format the material can be made available in paper format, on CD, over the Internet and by file transfer (FTP). This ensures that the learners can have the material available in the way which best suits their learning needs. Equipment, such as video-recorders and computers are utilised wherever possible. In addition, faceto-face contact, telephone, fax, surface mail, e-mail also used.

Study materials are prepared with reference to Great Britain, Germany, the USA and other countries' experience (Rimkuvienè, Lepkova 2004).

The analysis of the development of distance learning at the Department of Construction Economics and Property management, outlined below, shows a visible trend of the growing number of students in the pre-crisis period between 2007 and 2008. During this period the focus was on marketing, learning materials and curriculum development. However, the key factor was Lithuania's pre-crisis economic boom.

Table 7.1 shows the main economic and social indicators for this period in Lithuania. Table 7.1 shows that the average population and unemployment rate have decreased in recent years. High emigration is the main reason, especially after the EU accession. 


\begin{tabular}{|c|c|c|c|c|c|}
\hline 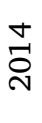 & 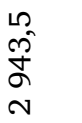 & $\begin{array}{l}\hat{\sigma} \\
\hat{\sigma}\end{array}$ & $\underset{0}{N}$ & 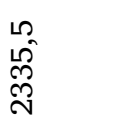 & 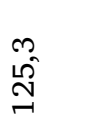 \\
\hline 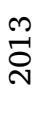 & م્ત & $\stackrel{\infty}{ન}$ & $\stackrel{\sigma_{0}}{0}$ & $\begin{array}{l}\widehat{\hat{N}} \\
\vec{N}\end{array}$ & $\stackrel{\widehat{\overbrace{}}}{\stackrel{\overbrace{}}{r}}$ \\
\hline 공 & $\begin{array}{l}0 \\
\text { m. } \\
\text { Oे } \\
\text { }\end{array}$ & $\begin{array}{l}\dot{\nabla} \\
\stackrel{\sim}{\sigma}\end{array}$ & \begin{tabular}{l}
$\infty$ \\
\multirow{i}{*}{}
\end{tabular} & $\begin{array}{l}\stackrel{\infty}{N} \\
\stackrel{N}{N}\end{array}$ & $\begin{array}{l}0 \\
\text { 10 } \\
\text { ㄱ }\end{array}$ \\
\hline 겅 & $\begin{array}{l}\text { o } \\
\text { ஸ̂ } \\
\text { గ̂ } \\
\text { }\end{array}$ & $\begin{array}{l}\stackrel{+}{0} \\
\stackrel{0}{-}\end{array}$ & $\stackrel{\vec{m}}{\dot{m}}$ & 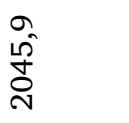 & 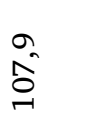 \\
\hline 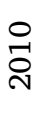 & 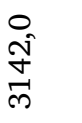 & $\stackrel{\infty}{\stackrel{\infty}{\sim}}$ & $\stackrel{\infty}{\infty}$ & $\begin{array}{l}\overrightarrow{1} \\
\infty \\
\infty \\
\stackrel{-}{न}\end{array}$ & $\hat{\sigma}$ \\
\hline 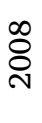 & $\begin{array}{l}\stackrel{0}{0} \\
\text { î } \\
\text { సै }\end{array}$ & $\begin{array}{l}\infty \\
\omega^{\infty}\end{array}$ & $\begin{array}{l}20 \\
\infty \\
\infty\end{array}$ & $\begin{array}{l}\widehat{\vec{N}} \\
\overrightarrow{\mathrm{N}}\end{array}$ & $\begin{array}{l}\stackrel{a}{0} \\
\stackrel{\oplus}{\sigma}\end{array}$ \\
\hline ஜ̊ & 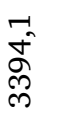 & $\begin{array}{l}\hat{\sigma} \\
\text { ஸे }\end{array}$ & \begin{tabular}{l}
10 \\
\multirow{\sigma}{*}{}
\end{tabular} & $\begin{array}{l}\stackrel{N}{8} \\
\stackrel{8}{\circ} \\
\stackrel{1}{-}\end{array}$ & $\begin{array}{l}\text { ○े } \\
\text { ஸे }\end{array}$ \\
\hline 농 & \begin{tabular}{l}
$m$ \\
\multirow{J}{+}{} \\
$\vec{\sim}$
\end{tabular} & $\begin{array}{l}m \\
\infty\end{array}$ & $\stackrel{0}{m}$ & 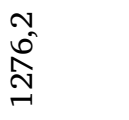 & $\stackrel{N}{\curvearrowright}$ \\
\hline ঠ্ণ & $\begin{array}{l}0 \\
\hat{\rho} \\
\tilde{m} \\
\stackrel{m}{m}\end{array}$ & $\stackrel{\nabla}{\stackrel{\nabla}{\sigma}}$ & ڤิ & 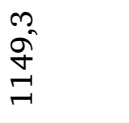 & $\begin{array}{l}0 \\
\text { ชิ }\end{array}$ \\
\hline ஜ & $\begin{array}{l}N \\
\text { ஸे } \\
\stackrel{\text { Dे }}{\text { mे }}\end{array}$ & 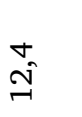 & $\stackrel{m}{r}$ & $\begin{array}{l}\stackrel{0}{0} \\
\text { N} \\
\text { 今ิ }\end{array}$ & $\begin{array}{l}\infty \\
\hat{L}^{0}\end{array}$ \\
\hline 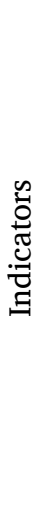 & 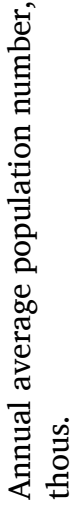 & 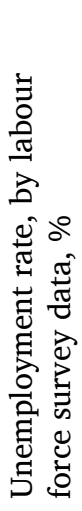 & 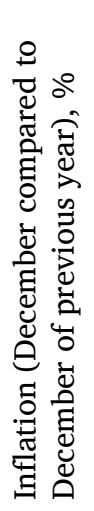 & 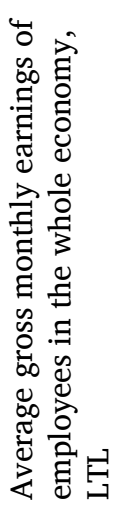 & 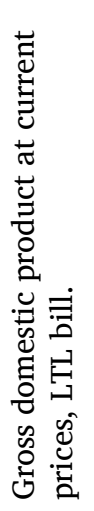 \\
\hline
\end{tabular}


GDP increased and influenced the average monthly gross wages. This contributed to the growth in the number of students. Figure 7.4 shows the variation in the number of students in our e-learning programmes (Real Estate Management (REM) and Construction Economics and Business (CEB)).

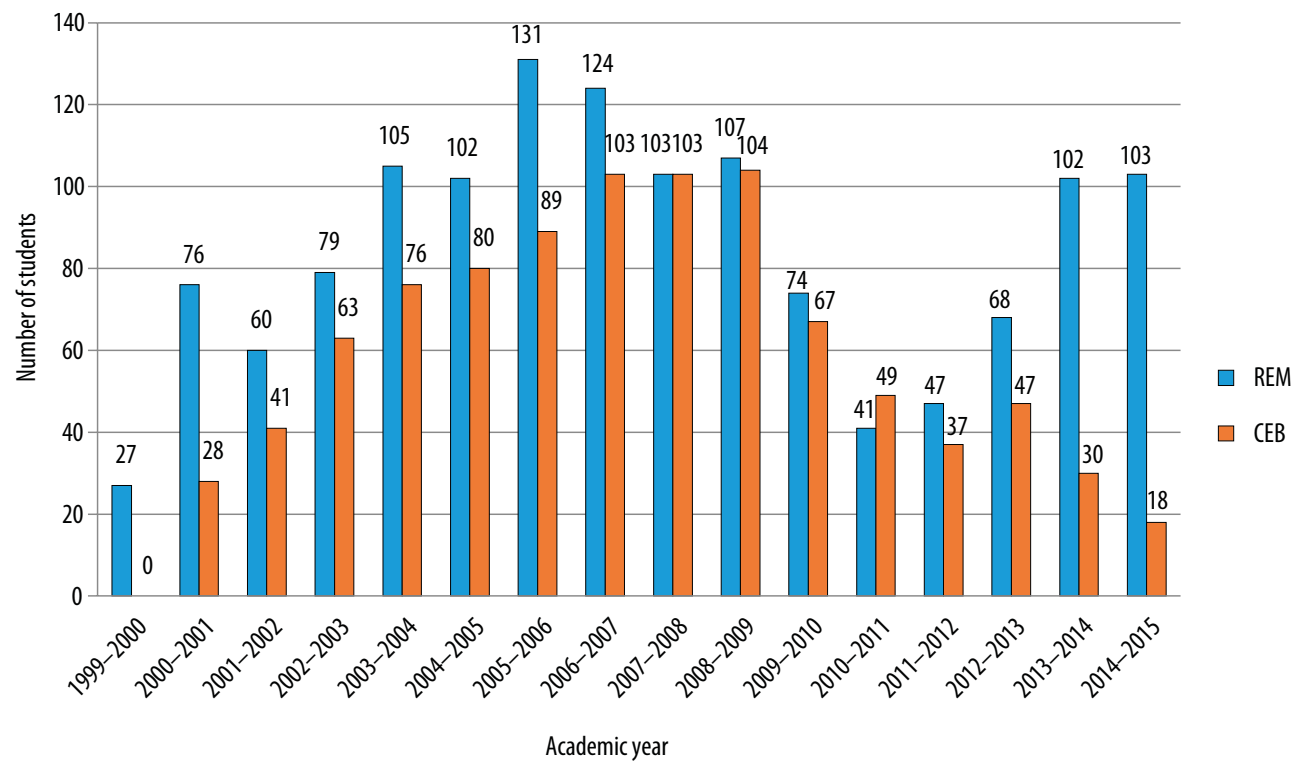

Figure 7.4. The variation in the number of students in distance learning programmes

The economic crisis hit Lithuania in 2008. The department tried to maintain the same number of students by improving its advertising practices (see Figure 7.5).

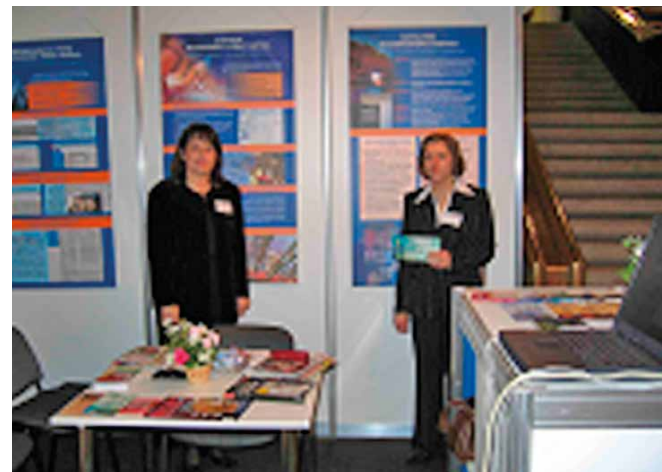

Tutors of distance learning in one of exibitions at Vilnius exibition center (LITEXPO)

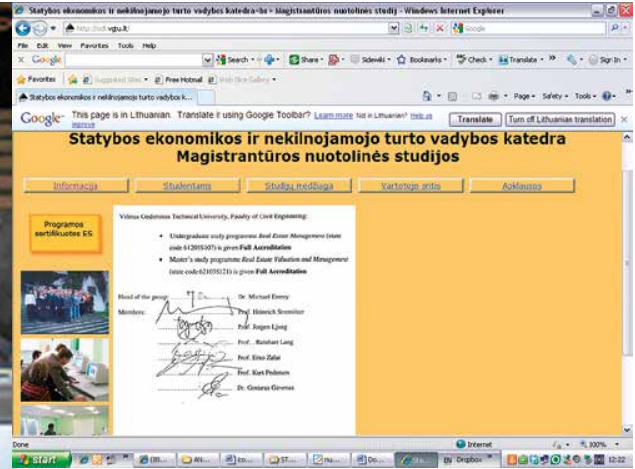

The website of distance learning 


\section{VILNIAUS GEDIMINO TECHNIKOS UNIVERSITETO STATYBOS FAKULTETAS \\ skelbia priemimą i nuotolines magistrantûros studijas \\ Studiju programos ir specializacijos: \\ Nekilnojamojo turto vertinimas ir valdymas: \\ - nckilnojamojo turto valdymas. \\ - internetinés technologijos ir nekilnojamojo turto verslas. Statybos valdymas: \\ - statybos ekonomika ir verslas.}

Dokumentai priimami Statybos fakulteto dekanate (Saul etekio al. 11, Vilnius) bendra tvarka nuo $2007 \mathrm{~m}$, kovo 26 d iki balandzio 27 d Studijos mokamos Informacija tel. (8-5) $2745098,(8-5) 2745244$, mob. tel. (8-688) 84493 Dekanas

A printed advertisement for distance learning at VGTU in the newspaper

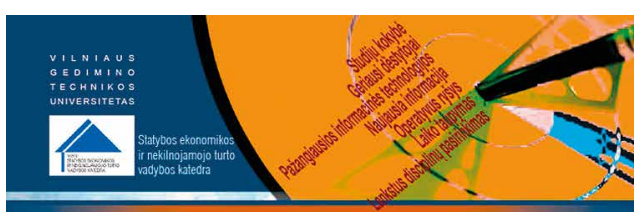

NUOTOLINÉS MAGISTRANTŨROS STUDIJOS

STATYBOS EKONOMIKA IR VERSLAS

Sprendimy paramos sistemos statyboje | Statybos verslo ekonomika | Elektroninis verslas ir statyba | Pastato gyvavimo procesas ir jo daugiakriteriné analizé | Pastaty ukio valdymas ir investicijos | Internetinè ir biometriné verslo valdymo sprendimy parama I Projektu
valdymas | Moksliniutyrimy ir inovaciju pagrindai | Kokybes valdymo sisternos | Nekilnojamojo turto investicjos i plètra | Gyvenamosios aplinkos atnaujinimas | Energetiškai efektyviy pastaty ir atsinaujinanciy energetini y̦ saltiniu plètra | Gyvenamosios paskirties NT vertinimas ir tarpininkavimas | Ivadas i intelektinus statnius ir ju aplinka |

NEKILNOJAMOJO TURTO VALDYMAS

ekilnojamojo turto valdymas | Nekilnojamojo turto tarpininkavimas ir elektroninis verslas | Pastaty

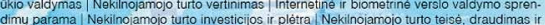
apmokestinimas | Energetiskai efektyviu pastafu ir atsinaujnanciụ energetiniụ saltiniu plêtra| D. Damios użstatytos aplinkos vystymas ir valdymas |

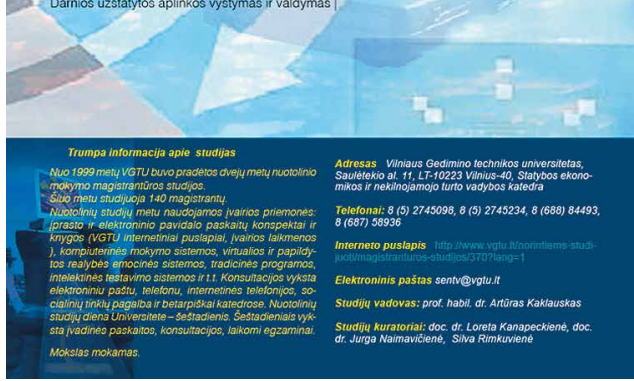

A promotional flyer for distance learning

Figure 7.5. Some examples of the promotion of distance learning

A great deal of attention was also paid to the quality of study materials and to the improvement of material delivery (see Figure 7.6).

The Department of Construction Economics and Property Management, in collaboration with the Research Institute of Smart Building Technologies (VGTU Civil Engineering Faculty), developed the Intelligent Testing System (see Figure 7.7).

The system offers a list of recommendations to:

- students (on ways to improve knowledge);

- teachers (on ways to improve the quality of lecture notes and books) (Kaklauskas et al. 2013).

Despite the efforts the number of students began to drop, as shown in Figure 7.4.

The idea of new forms of distance learning emerged. As a result, new joint study programmes were developed.

Now, in 2015, the e-learning division of the Department of Construction Economics and Property Management has 121 students from Lithuania, Russia and Belarus (see Figure 7.4). 


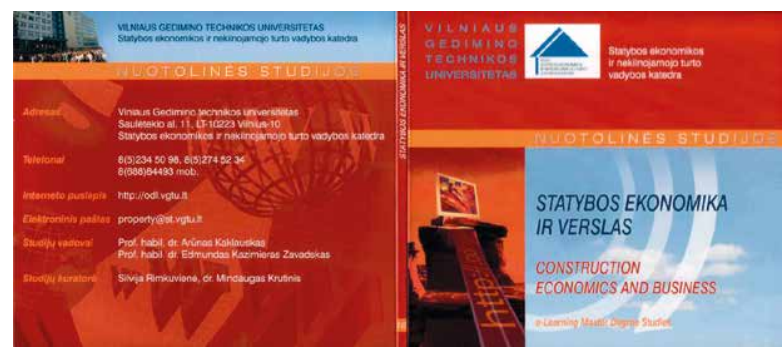

CD for students enrolled in Construction Economics and Business programme (1 specialisation)

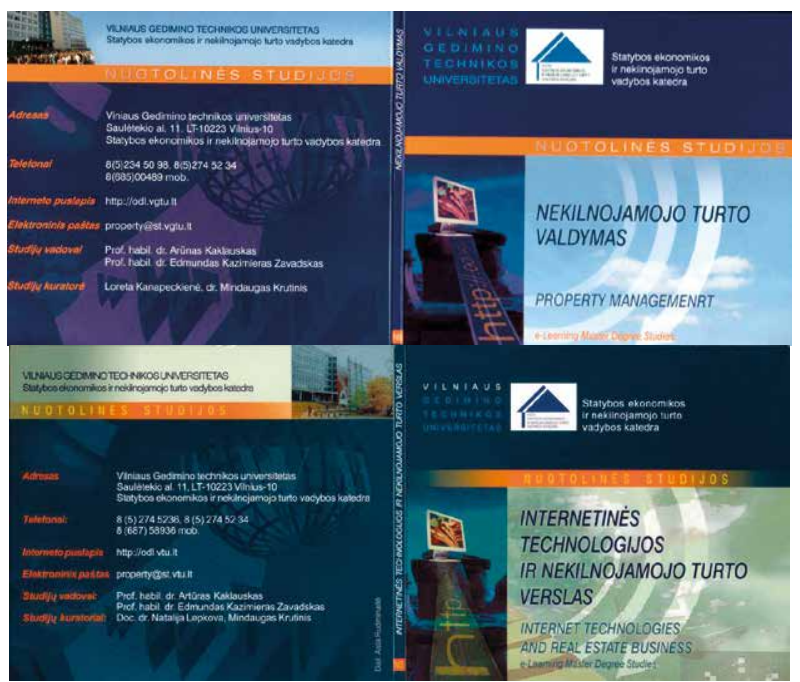

CDs for students enrolled in Real Estate Management programme (2 specialisations)

Figure 7.6. A few examples of CDs with digital materials

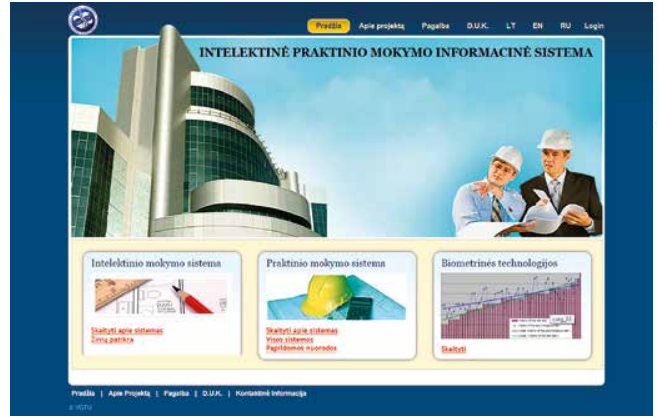

The main website of the Intelligent Testing System

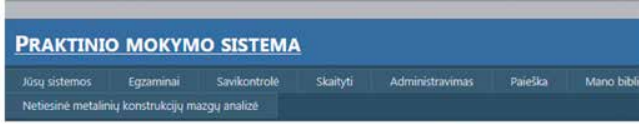

Darnios užstatytos aplinkos vystymas ir valdymas

Kas atsitinka padidejus palûkanụ normai?

Opadideja statybos kaing

Osumateja utakismy

ONera teisingo atsakymo

O Teisingi 1 ir 2

Poreiti prie kito klausimo

Klausimas: 1 is 20

Liko laiko: 14min. 47s,

An example of a test in the Intelligent Testing System

Figure 7.7. A few print screens from the Intelligent Testing System

(Intelektinè praktinio mokymo informacinè sistema... 2015) 


\subsubsection{Joint second-cycle distance-learning programmes at the department of Construction Economics and Property management}

The main purpose of the proposed joint Master's study programmes is to prepare, in collaboration with foreign universities, high quality real estate management specialists with interdisciplinary knowledge awarding them a Master's degree in Management. Such graduates will be competitive both in Lithuanian and global labour markets. Holders of this degree will be able to assess real estate management transactions, developments and information; to plan and carry out research in management, assess research results and apply them in practice; make independent decisions, work in executive positions and continue their studies for a PhD.

Advantages of joint studies:

- leading edge information technologies;

- time-saving process;

- no delays in communication;

- top university teachers;

- up-to-date information;

- high-quality studies;

- a chance to earn diplomas from two higher education institutions;

- student-oriented studies.

The programmes were developed as part of projects funded by the EU Structural Funds.

The three joint study programmes were developed between 2007 and 2013 (see Figure 7.8, the promotion of joint programmes):

1. Sustainable Development of the Built Environment is a joint study programme offered by Lomonosov Moscow State University and Vilnius Gediminas Technical University.

The programme includes the following courses: Applied Economics; Research Methods in Management; Organisational Behaviour; Corporate Finance; Strategic Management; Real Property Risk Management; Sustainable Development and Management of Built Environment; Management of Commercial Real Estate; Management of Real Estate Investment; Commercial Real Estate Valuation and Investment; Biometric Intelligent Decision Support; Management of Built Environment; Economics of Built Environment; Multiple Criteria Analysis of the Built Environment Life-Cycle and Project Management; Real Estate Brokerage and E-Business; Development and Management of Sustainable Built Environment; and Construction and Real Estate Management under the Conditions of Market Instability.

2. Real Estate Management is a joint study programme offered by the Belarusian State Technological University and Vilnius Gediminas Technical University. 
The programme includes the following courses: Management of Social and Economic Systems; Construction and Real Estate Management under the Conditions of Market Instability; Business Language (a foreign language); Internet Decision Support in Business Management; History of Science and Technology; Methodology and Philosophy of Management Science; Climate Change: Social and Political Perspectives; Property and Business Valuation; Real Estate Management; Real Estate Brokerage and E-Business; Applied Econometrics in Business; Real Estate Economics; Intelligent Structures; Real Estate Market Analysis and Forecasting; Organisation and Management of Sectoral Markets; Real Estate Business Investment and Development; Multiple Criteria Analysis of the Life-Cycle of the Building Process and Project Management.

3. Sustainable Real Estate Management is a joint study programme offered by Kaliningrad State Technical University and Vilnius Gediminas Technical University.
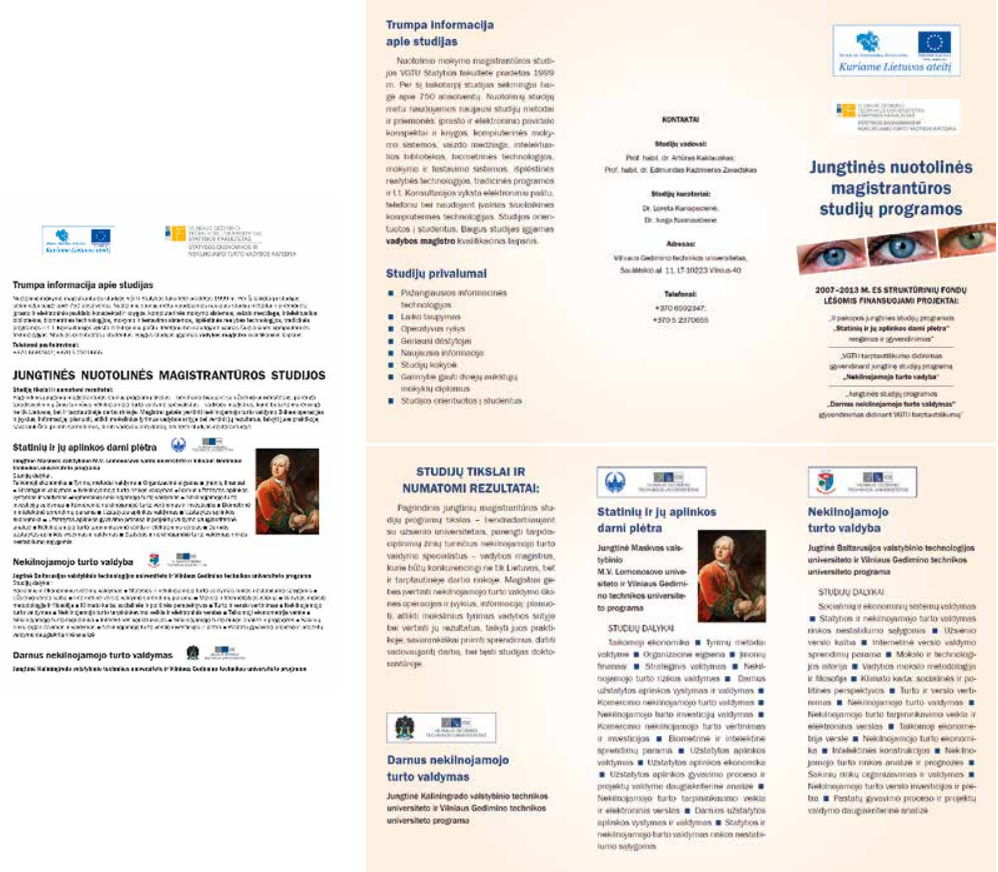

Figure 7.8. The promotion of joint programmes

The programme includes the following courses: Fundamentals of Scientific Research; Individual Manager's Career Planning and Development; Decision Support in Business Management; Strategic Analysis and Management; Computer (Internet and intelligent) Technologies in Management; E-Business and Biometric Technology; Strategic Management of Real Estate Enterprises; Managerial Economics and Corporate Finance; Real Estate Project Management and 
Sustainability Development; Documents Regulating the Construction and Real Estate Business; Modernization, Maintenance and Management of Built Environment; Real Estate Management; Real Estate Lending; Taxation and Insurance; Real Estate Valuation; and Sustainable Real Estate Development.

Table 7.2 shows the variation of student numbers in joint programmes.

Table 7.2. The variation of student numbers in joint programmes

\begin{tabular}{|l|c|c|c|c|}
\hline \multirow{2}{*}{\multicolumn{1}{|c|}{ Programme title }} & \multicolumn{4}{c|}{ Year of studies } \\
\cline { 2 - 5 } & $2011-2012$ & $2012-2013$ & $2013-2014$ & $2014-2015$ \\
\hline "Real Estate Management" & 13 & 52 & 70 & 57 \\
\hline $\begin{array}{l}\text { "Sustainable Real Estate } \\
\text { Managements" }\end{array}$ & 0 & 0 & 19 & 19 \\
\hline $\begin{array}{l}\text { "Sustainable Development of the } \\
\text { Built Environment" }\end{array}$ & 0 & 0 & 0 & 14 \\
\hline
\end{tabular}

The first four years, starting in 2007, were intended for the preparation of learning materials and getting ready for the launch of the programme.

Table 7.2 shows that the first 13 students enrolled in Real Estate Management, a joint study programme offered by the Belarusian State Technological University and Vilnius Gediminas Technical University, in 2011. The studies successfully took off and in four years the number of students increased by 4.4 times.

Sustainable Real Estate Management, a joint study programme offered by Kaliningrad State Technical University and Vilnius Gediminas Technical University, was introduced in 2013.

The third joint study programme, Sustainable Development of the Built Environment, offered by Lomonosov Moscow State University and Vilnius Gediminas Technical University was launched in 2014. Eleven students from Lithuania and three students from Russia are enrolled in the programme.

\subsection{Analysis of questionnaire-based survey results}

In order to clarify a number of issues related to the study process (first and foremost the student motivation, efficiency of advertising, issues related to the quality of study materials, reaction of social environment, etc.) the 4 survey researches were conducted during the period of 2003-2013 years.

The first research was carried out in 2003, before the EU accession; it surveyed 125 respondents. The results of this first research were published in scientific journals and conference proceedings (Rimkuvienè, Lepkova 2004; Lepkova, Rimkuviene 2004; Rimkuvienè, Lepkova 2005; Lepkova, Rimkuvienė 2006). 
The next research was carried out in 2006, after the EU accession in 2004; it surveyed 86 respondents. Its results were published in conference proceedings (Rimkuviene et al. 2007; Lepkova, Rimkuvienè 2008).

There were two main differences between the two researches, a new surveying technique and changed economic conditions in case of the latter, which influenced the responses.

In 2006, the department introduced MOODLE, a virtual learning space, for student surveys. All survey results are gathered by using MOODLE and several additional scripts programmed and installed in the MOODLE learning space. The survey results are available in the VGTU's distance learning website (see Figure 7.9).

\section{Nuotolinio mokymo ivertinimas ir poreikio nustatymas Jūs prisjungęs Mindaugas K. vardu (Atsjiungti)}

NUOTOLINES STUDIJOS $>$ CF101 $>$ Questionnaires $>$ Survey Reports

1 dalis. Informacija apie studijas.

1. Kodèl pasirinkote būtent šią studiju formą ? (Pažymèkite visus tinkamus variantus).

\begin{tabular}{|c|c|c|}
\hline Response & Average & Total \\
\hline Galimybè isigyti gretutinę specialybę. & $39.1 \%$ & 34 \\
\hline Geras profesinis parengimas. & $10.3 \%$ & 9 \\
\hline Gero darbo gavimo galimybès ateityje & $27.6 \%$ & 24 \\
\hline Naujas studiju metodas. & $40.2 \%$ & 35 \\
\hline Patogi studiju forma neatitrūkstant nuo darbo. & $86.2 \%$ & 75 \\
\hline Rekomendavo kiti. & $10.3 \%$ & 9 \\
\hline Other: galimybé suderinti žinias su praktika & - $1.1 \%$ & 1 \\
\hline Other: idomu & - $1.1 \%$ & 1 \\
\hline Other: norejau studijuoti NT & $1.1 \%$ & 1 \\
\hline Other: panašus darbo pobūdis & $1.1 \%$ & 1 \\
\hline Other: tiesiog patinka ši sritis & e $1.1 \%$ & 1 \\
\hline
\end{tabular}

2. Kuo, Jūsų nuomone, nuotolinès studijos yra geresnès už kitas studijų formas ?

\begin{tabular}{l|l} 
Response & Average
\end{tabular}

Figure 7.9. The survey results in the distance learning website (Web-site of distance learning of VGTU... 2013)

The third research was carried out in 2011 with 73 respondents surveyed. This survey was conducted after the 2008-2011 crisis period. The results were published in conference proceedings after a conference at Istanbul University (Lepkova et al. 2012).

The fourth research was carried out in 2013 with 42 respondents surveyed. The main difference from the others surveys was that it also surveyed students from joint Master's degree programmes in other universities.

The respondents were asked to fill in a questionnaire comprising the following four main parts (see Appendix 7.1): 
1) information about the respondent;

2) information about the studies;

3) analysis of the study materials;

4) social aspects of the studies.

Below is an analysis of the data from this questionnaire-based survey.

\subsubsection{Analysis of the information about the respondents}

First, we analysed the information about the respondents (their sex, age, occupation). Figure 7.10 compares the distribution of the respondents from all four studies by sex.

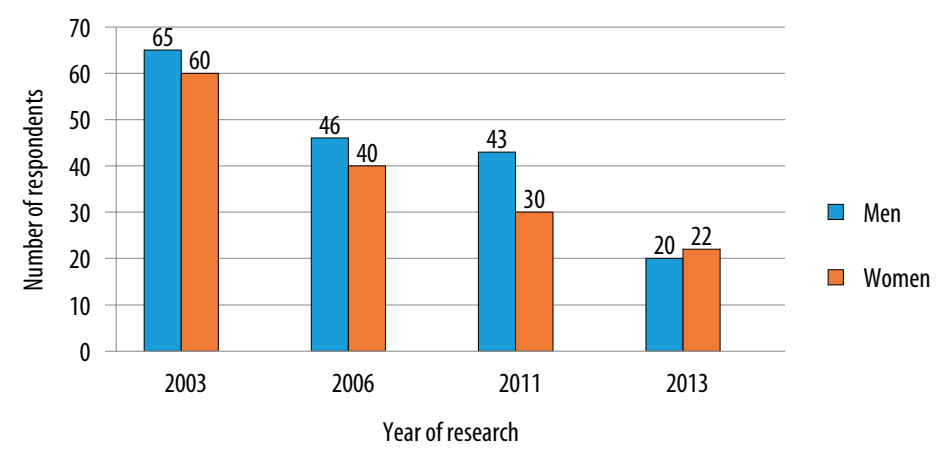

Figure 7.10. The distribution of the respondents by sex

Figure 7.10 shows that the number of students in different studies varies, but their distribution by sex is more or less the same. The age of the respondents is in a range between 21 and 60 years.

Figure 7.11 shows that students enrolled in distance learning courses are people from different age groups (six groups in total).

Figure 7.11 shows that even though students enrolled in distance learning courses are people from different age groups, the majority of them are young men and women under the age of 30 . Sometimes people aged 37 or older also decide to enrol in a study programme. Such news is very welcome. The most recent research carried out in 2013 shows that young people (aged 25 or younger) dominate in the study programmes.

Figure 7.12 shows the distribution of the respondents by the type of their employment. 


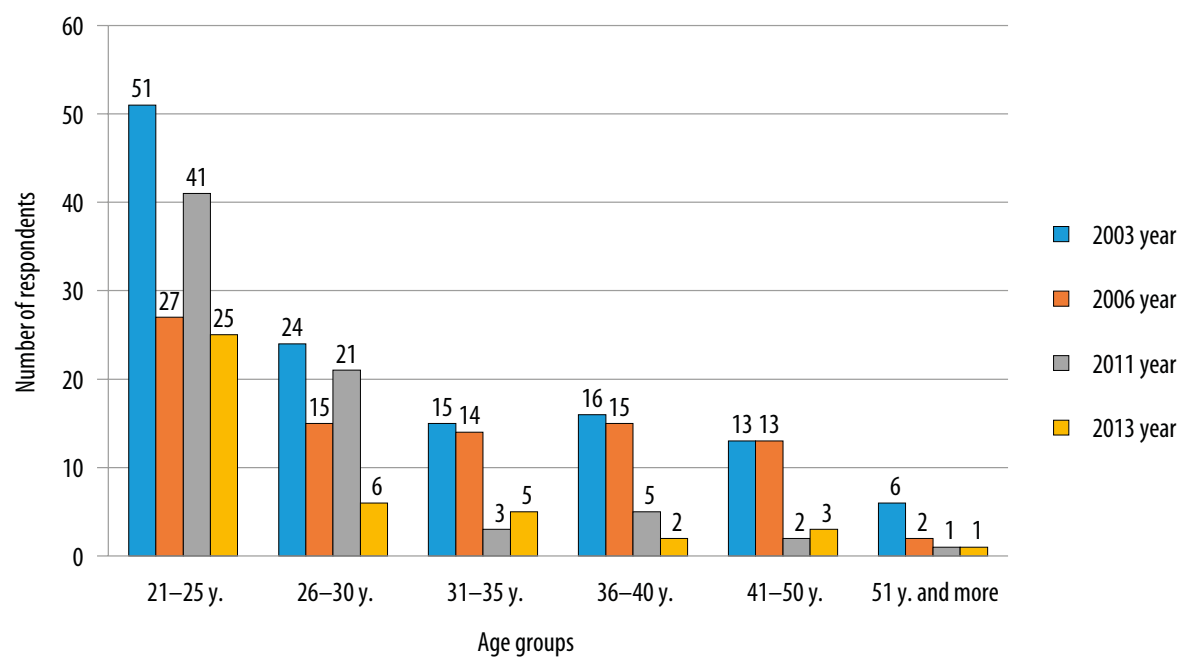

Figure 7.11. The distribution of the respondents by age groups

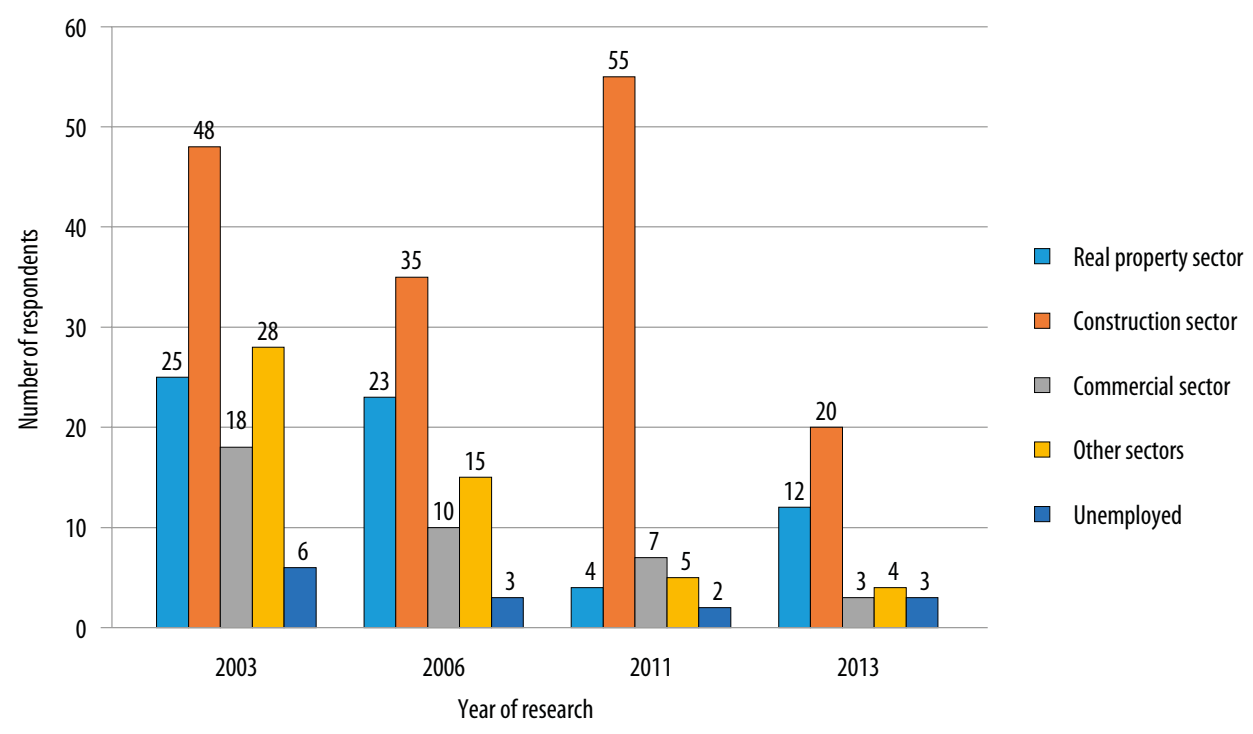

Figure 7.12. The distribution of the respondents by the type of their employment

Figure 7.12 shows that the majority of the respondents were employed in the construction and real property sectors. The reason for this was the growth of the construction and real property sectors and the necessity to have workforce with qualifications in the fields. The 2011 survey is an exception. Its results show a significant decrease of employment in the real property sector. The main reason was the consequences of the 2008-2010 economic crisis in Lithuania. 


\subsubsection{Analysis of the information about the studies}

Next, we continue with an analysis of the results from Part 2 of the questionnaire (the information about the studies).

Student motivation and the purpose of studies make a significant part of the questionnaire. In their answers to these questions, the respondents were allowed to indicate all motives they considered important (see Figure 7.13).

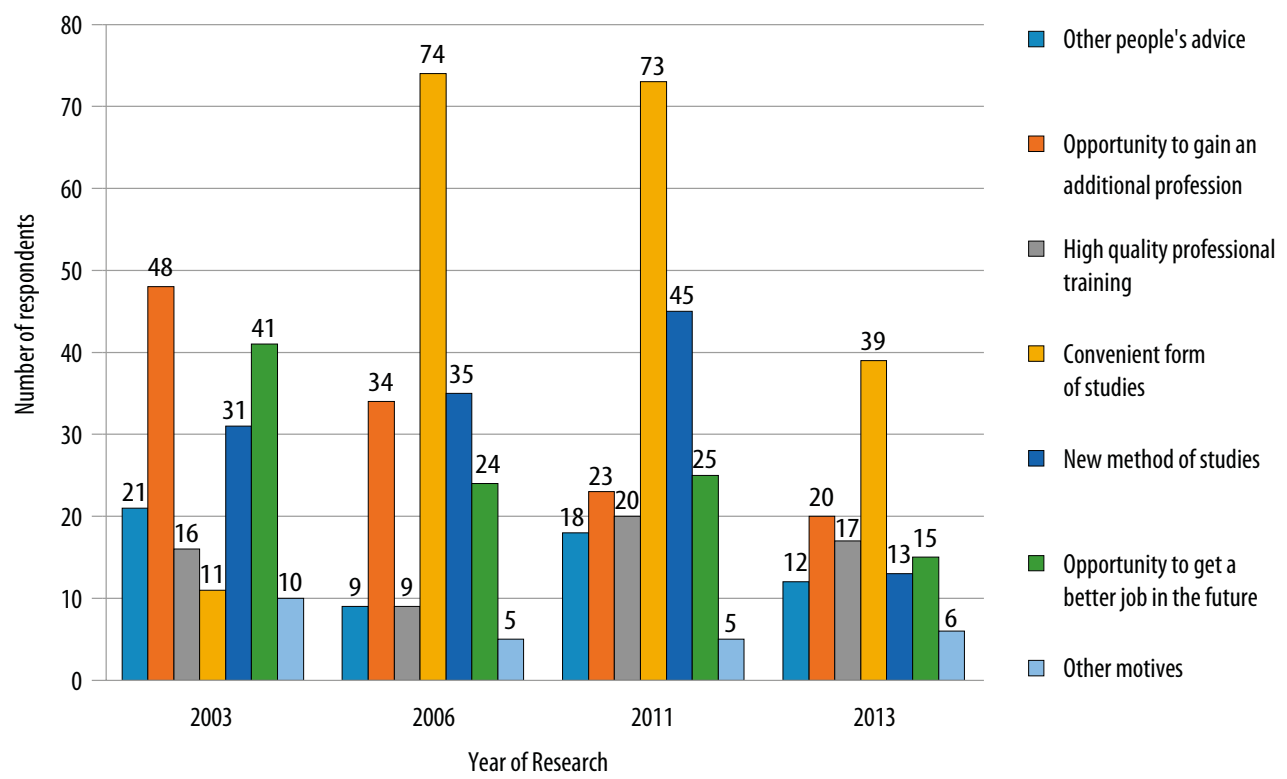

Figure 7.13. The distribution of the respondents by their motives to study

As illustrated by Figure 7.13, the number of the respondents who selected the option "convenient form of studies" made a major group. Students could choose more than one motive that had induced them to study. The overwhelming majority of those polled indicated that the most important advantage of distance studies was the opportunity to study and continue working at the same time, since for them this was the only way to pursue studies. About half of the respondents said they wanted to acquire an additional profession, improve their skills and get a better job in the future.

The reliability and efficiency of information about distance studies is an important research object. It should be noted that in their answers to this question the respondents were allowed to specify several options and score them in points.

The analysis shows that the Internet is considered the most efficient source of information. The second most popular source is other people's advice (Figure 7.14). In 2011 the information about studies was not advertised in press. 


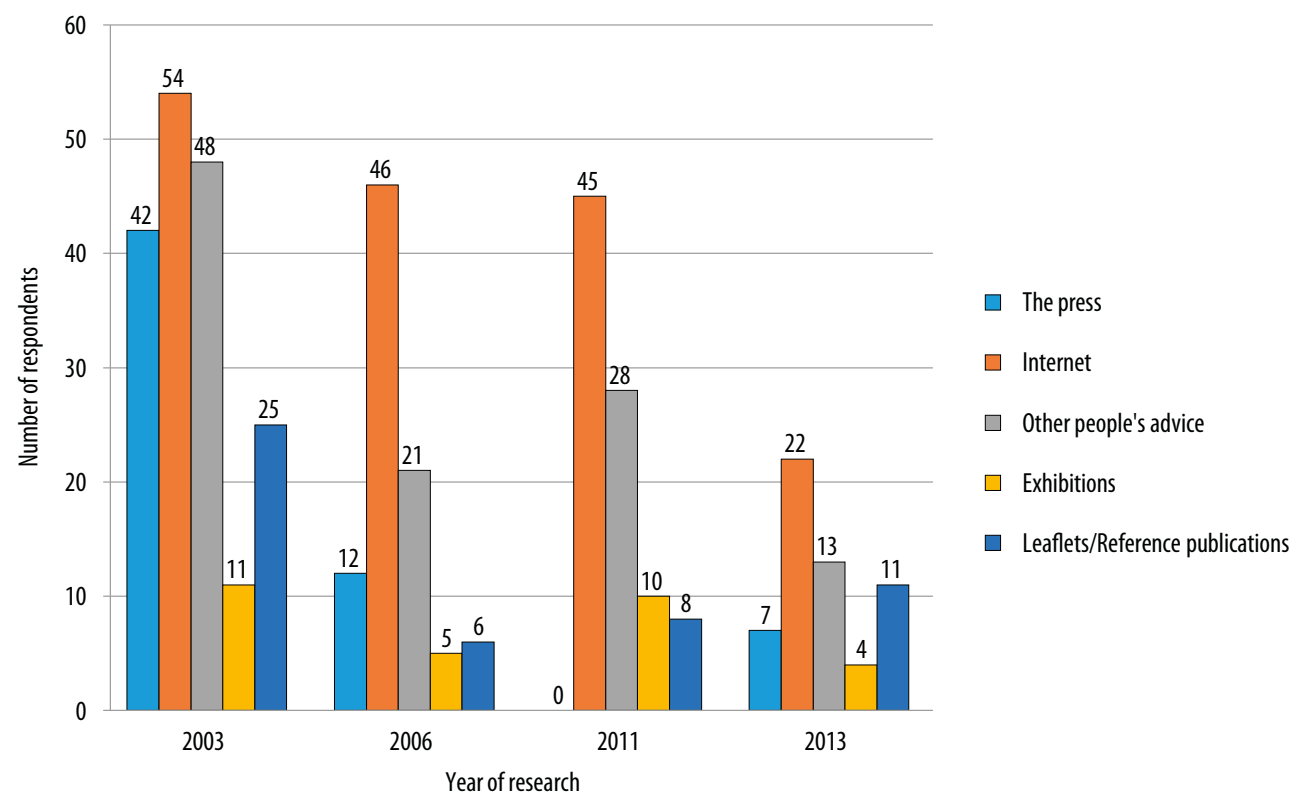

Figure 7.14. The respondents' opinions about the reliability of the sources of information

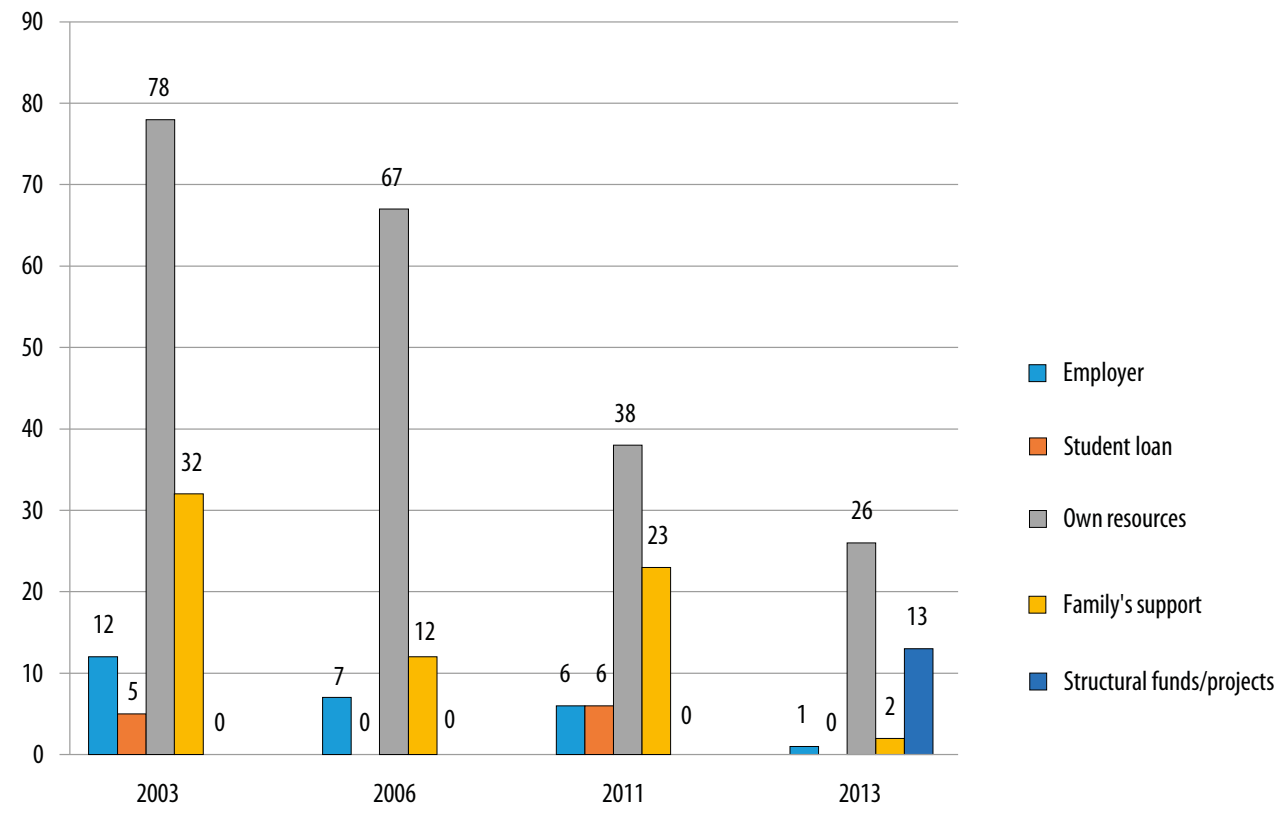

Figure 7.15. The distribution of the respondents by the source of financing 
The majority of those polled indicated that their decision to choose this form of studies was determined mostly by their desire to get acquainted with modern information technologies, save time, get regular access to most up-to-date information and fast communication. There are also other important reasons: flexible choice of academic subjects, good teachers and good level of professional training. Distance learning is also attractive to the respondents because it is a new and progressive form of studies.

All respondents agreed that Saturday was the best day to hold contact meetings. They wanted to continue corresponding with their teachers and tutors by email and contact them by phone. Some of them wanted to communicate via video conferences and social networks (Facebook and others).

The distance learning studies are paid; students were, therefore, asked to specify their source of financing. Figure 7.15 shows the distribution of the respondents by the source of financing.

Figure 7.15 shows that the majority of students had jobs and were mostly paying for their studies themselves. The next group were those supported by their families. A minority of students had their studies financed by their employers. As the first study shows, some of students took student loans, but this form of financing is not popular today, because it is a very small sum.

In the most recent study (2013), 13 students answered that their studies were financed by the Structural Funds (projects). This was a new option available for the new joint programmes. The first cycle of the joint programmes was supported by the Structural Funds.

\subsubsection{Analysis of the study materials}

Students' backgrounds are very diverse, so they have different experiences and expertise in different fields, also in numeracy and IT, and varying communication skills. It is not uncommon for complaints to come from those who do not understand the need for IT on their courses (Williams 2002).

The questionnaire also included a few questions about the quality of study materials. Figure 7.16 shows the distribution of the respondents' opinions about the quality of the study materials. The respondents had to indicate the advantages and disadvantages of study materials.

Figure 7.16 shows that some respondents think that electronic textbooks lack interactivity. Some other shortcomings were also mentioned by the respondents, one of them being the lack of links and graphic information. Recently, the intelligent learning system was introduced in the programmes and students saw this as a big advantage.

When students were asked to share their comments and wishes, they said that the study materials should be better adjusted to the present situation and to the practices adopted in Lithuania. 


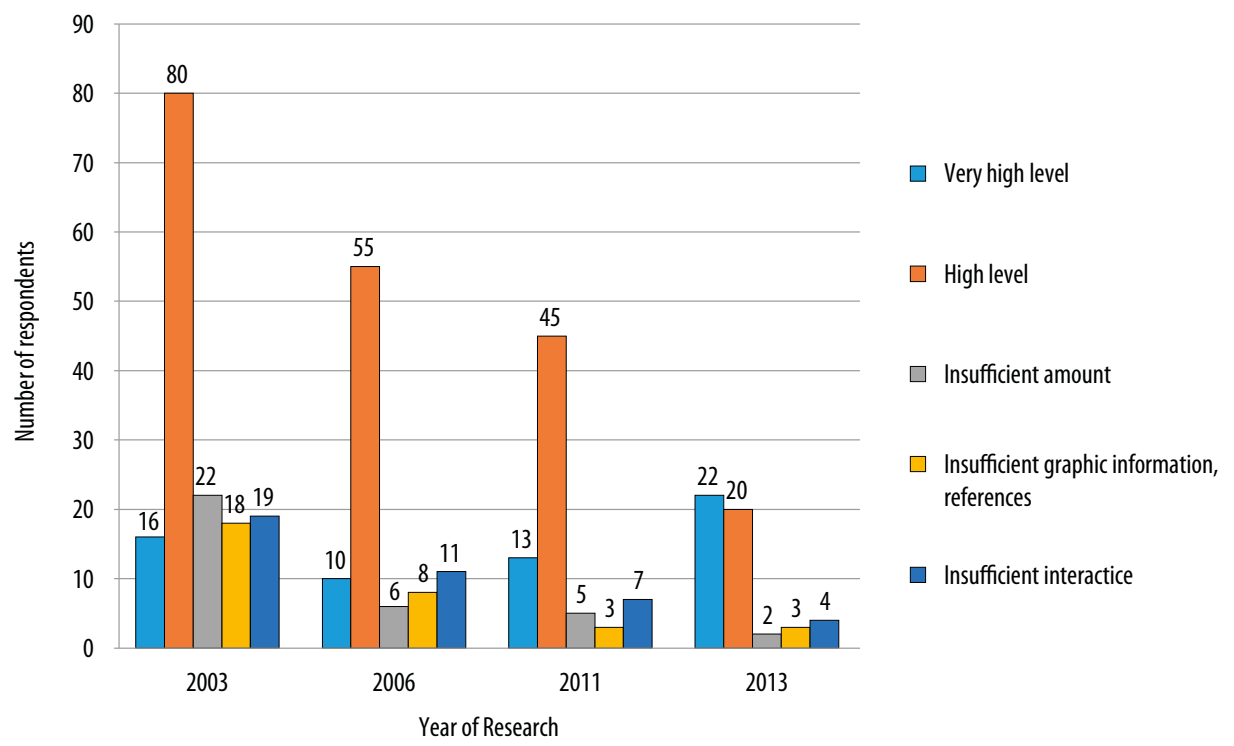

Figure 7.16. The respondents' opinions about the quality of study materials

\section{Reference}

Intelektinè praktinio mokymo informacinè sistema [Intelligent Testing System]. 2015. Viewed 201505 18, Internet access: http://iti.vgtu.lt/imitacijosmain/

Kaklauskas, A.; Vlasenko, A.; Raudonis, V.; Zavadskas, E.K.; Gudauskas, R.; Seniut, M.; Juozapaitis, A.; Ubartè, I.; Kanapeckienè, L.; Rimkuvienè, S. (2013). Student progress assessment with the help of an intelligent pupil analysis system, Engineering applications of artificial intelligence 26(1): 35-50. London: Elsevier Ltd.

Kaufman, R.; Watkins, R.; Guerra, I. 2001. The future of distance learning: defining and sustaining useful results, Educational technology - the magazine for managers of change in education 41(3): 19-26.

Kliukas, R.; Vinogradova, I.; Ulinskaitè, D.; Trinkūnas, V. 2014. Student Oriented Bachelor Degree Engineering Studies, in 5th International Future-Learning Conference on Innovations in Learning for the Future 2014: e-Learning May 5-7, 2014, Istanbul, Turkey.

Lepkova, N.; Rimkuviene, S. 2004. The analysis of distance learning studies in real estate management at Vilnius Gediminas Technical University, in Proc. of International Scientific and Practical Conference: Economy, Valuation and Management of Real Estate 1-3 December, Minsk, pp. 214-221.

Lepkova, N.; Rimkuvienè, S. 2006. E-learning experience at the department of Construction Economics and Property Management of Vilnius Gediminas Technical University, Lithuania, in Proc. of EDEN 2006 Annual Conference E-Competences for Life, Employment and Innovation: " $E$ " is more! E-learning Enabling Education in Evolving Europe, 14-17 June, 2006, Vienna University of Technology Vienna, Austria. European Distance and E-Learning Network (EDEN). Vienna: EDEN, 2006. Ed. by A. Srucs and I. Bo. pp. 650-655. 
Lepkova, N.; Rimkuvienè, S. 2008. Comparison of the results of two research works on e-learning with a special emphasis on the change of economic conditions after Lihuania's accession to the EU. // AoM / IAoM 2008 conference proceedings. Amsterdam, The Netherlands. October 2-4, 2008 / Association of Management, International Association of Management. Virginia : Maximilian Press Publishers, pp. 42-49.

Lepkova, N.; Arslan, V.; Rimkuvienè, S.; Erol, Ç.; Gülseçen, S. 2012. Distance learning in Lithuania and Turkey: a comparative study, in Proceedings FuturE-Learning 2012: 4th International Future-Learning Conference on Innovations in Learning for the Future 2012: e-Learning (Istanbul, Turkey, November 14-16, 2012). Istanbul: Istanbul University. ISBN 9789754049237, pp. 259-279.

Lithuanian Virtual University. 2015. About LVU programe. Viewed 2015 04.17, Internet access: http://www.lvu.lt/cms/liedm/app?service $=$ direct/1/index/border.border.LoginLvu.testLocale

Lithuanian Virtual University. 2015. LieDM consortium members. Viewed 2015 04 17, Internet access: http://www.liedm.lt/cms/liedm/app?service = external/ index $\& \mathrm{sp}=4783 \& \mathrm{sp}=4800$

Moodle features. 2015. Viewed 201505 18, Internet access: https://docs.moodle. org/28/en/Features

Moodle vadovas [Moodle guide]. 2015. Viewed 201505 18, Internet access: http:// kompetencijos.vkk.lt/file.php/1/MOODLE/Moodle_vadovas.pdf

Moore, G. M.; Kearsley, G. 1996. Distance education. A Systems View. USA: Wardsworth Publishing Company, p. 290.

Organization of distance learning studies at VGTU [Studijų organizavimas nuotoliniu būdu]. 2015. Viewed 201504 20, Internet access: http://www.vgtu.lt/studijos/nuotolines-studijos/72970?lang $=1$

Rimkuvienè, S.; Lepkova, N. 2004. Analysis of experience and efficiency of distance learning master's degree programme in construction economics and property management, Journal of civil engineering and management 10(1): 51-60.

Rimkuvienè, S.; Lepkova, N. 2005. The Social Aspects of Using Information Technologies in Distance Learning at VGTU, in Proc. of 6th International Scientific Conference: PUBLIC RELATIONS: Quality, Benefits and Risks, 3 June, Riga, pp. 75-81.

Rimkuvienė, S.; Lepkova, N.; Krutinis, M.; Keraminiyage, K. 2007. The analysis of e-learning master's degree studies outputs at Civil Engineering Faculty with special emphasis on economical conditions, in The 9th international conference "Modern building materials, structures and techniques": selected papers, May 16-18, 2007 Vilnius, Lithuania 1: 354-359. Vilnius: Technika. ISBN 9789955281986.

Rumble, G. 1997. The costs and economics of open and distance learning. London: Kogan Page, p. 224.

Rutkauskiene, D.; Targamadze, A.; Kovertaite V. R. 2003. Distance learning [Nuotolinis mokymasis]. Kaunas: Technologija, p. 255 (in Lithuanian).

Statistics Lithuania. 2014. General information. Statistical year book of Lithuania. p. 686.

Statistics Lithuania. 2007. Economic and Social Development in Lithuania. Vilnius, p.179. 
Stokar Von Neuforn, D.; Thomaschewski, J. 2006. Enhancing the motivation to learn through decoding text based communication reception in virtual learning environments case study for the online course of media informatics, in Proc. of EDEN annual conference: E-competences for life, employment and innovation. 14-17 June, 2006, pp. 381-386.

Targamadze, A.; Normantas E.; Rutkauskiene, D.; Vidziunas, A. 1999. The new possibilities of distance learning (Naujos distancinio svietimo galimybes). Kaunas: Technologija. 246 p. (in Lithuanian).

Trinkunas ,V.; Bigelis, Z.; Vinogradova, I.; Slekiene, I. 2008. Training for tearcers to provide studies in distance learning way (Dėstytojų mokymas teikti studijas nuotoliniu būdu). Vilnius: Technika. p. 290 (in Lithuanian).

Web-site of distance learning of VGTU, Civil Engineering Faculty. 2013. Viewed 201311 15, Internet access: http://odl.vtu.lt/index.php?lang $=1$ t\&menuitem $=$ tr_apie

Williams, P. 2002. The learning Web. The development, implementation and evaluation of Internet-based undegraduate materials for the teching of key skills, Active learning in higher education 3(1): 40-52.

\section{APPENDIX 7.1. QUESTIONNAIRE}

\section{Analysis of experience and efficiency of distance learning}

The following questionnaire should be filled in by the people who have started or have already been doing distance learning for master's degree in the Department of Construction Economics and Property Management of Construction Faculty of VGTU. This questionnaire is aimed at the determination of the advantages and disadvantages of distance learning as well as wishes of students. The tutors and the lecturers are going to take these remarks into their consideration.

Please, specify:

- Name, surname

- Age

- Your education

- Name of place of work

- Position (scope of work)

- Home address (town is compulsory)

- Contact information (telephone/fax, e-mail, mobile phone)

The specialization of distance learning studies:

\section{INFORMATION ON STUDIES}

\subsection{Why have you chosen this particular form of studies?}

(Please, indicate all suitable variants)

other people recommended

convenient form of studies with no distraction from work 
good work opportunity in the future

$\square$ possibility to acquire a parallel

$\square$ new method of studies occupation

good professional training

$\square$ other (indicate)

1.2. In what respect, in your opinion, is distance learning better than other forms of studies?

(Please, evaluate every study advantage in points form 1 to 10)
better study quality
flexible option of subjects time saving
advanced IT
$\square$ better lecturers
$\square$ latest information
fast connection
$\square$ other (indicate)

1.3. From what sources of information did you find out about distance learning master's studies in Construction Department of VGTU?

(Please, mark all suitable variants)

advertisement in a newspaper

$\square$ during an exhibition in Litexpo

$\square$ during conferences

information on VGTU

$\square$ promotional leaflets internet page

other people recommended

other (indicate)

\subsection{Evaluate the efficiency of information sources on distance learning master studies in Construction department of VGTU in points:}
1 point
$\square 3$ points
5 points
$\square$ points
9 points
2 points
4 points
6 points
$\square 8$ points
10 points

1.5. What are your study goals? (Please, mark all suitable variants)

to improve knowledge

to obtain a diploma of new speciality

$\square$ to improve current working skills

to acquire new knowledge

$\square$ opportunities to get good job

$\square$ other (indicate).............. 
1.6. What way of distance communication with lecturers is more acceptable and convenient for You? (Please, mark all suitable variants)

$\square$ e-mail

$\square$ intended contact meetings

$\square$ video conference

$\square$ telephone

$\square$ fax

$\square$ other (indicate)..............

1.7. What way of distance communication with tutors is more acceptable and convenient for You?

$\square$ e-mail $\square$ fax $\square$ video conference

$\square$ telephone $\square$ intended contact meetings $\square$ other (indicate)..............

1.8. How would you evaluate the fact that the meetings with lecturers take place on Saturdays?

$\square$ very convenient $\quad \square$ I want to rest on Saturday

$\square$ convenient $\quad \square$ other (indicate)..............

1.9. Would like to use the services of regional centres of distance learning (to consult, to take exams)?
yes
no, at VGTU would be best

1.9.1. If yes, specify where:

$\begin{array}{lll}\square \text { in Kaunas } & \square \text { in Panevėžys } & \square \text { in Visaginas } \\ \square \text { in Vilnius, VGTU } & \square \text { in Klaipèda } & \square \text { in Kèdainiai } \\ \square \text { in Šiauliai } & \square \text { in Mažeikiai } & \square \text { in Utena }\end{array}$

1.10. Are you satisfied with the study fee?

$\square$ high $\quad \square$ low

$\square$ satisfactory $\quad \square$ other (indicate)..............

1.11. Who covers Your distance studies?

$\square$ place of work $\square$ family support $\square$ other (indicate).............

$\square$ own funds $\quad \square$ study loan

1.12. Is the study fee a hard financial burden for You?

$\square$ very hard $\quad \square$ normal $\quad \square$ not substantial

$\square$ hard $\square$ not noticeable $\square$ other (indicate) 
1.13. Should the duration of Your studies be changed while leaving the same price?

to leave 4 semesters

$\square$ longer than 5 semesters

to study 5 semesters

other (indicate)

\section{ANALYSIS OF STUDY MATERIAL}

2.1. How do you evaluate the quality of distance learning material?

\subsubsection{Electronic notes:}

(Please, mark all suitable variants)

very high level $\quad \square$ insufficient amount

high level $\quad \square$ insufficient graphic information, references

insufficiently interactive

other (indicate)

2.1.2. Evaluate the quality of electronic notes in points:
1 point
$\square 3$ points
5 points
$\square 7$ points
9 points
2 points
4 points
6 points
$\square 8$ points
10 points

2.1.3. Video and audio material (Please, mark all suitable variants)

very high level $\quad \square$ insufficient amount

high level

$\square$ other (please, indicate).

2.1.4. Evaluate the quality of video and audio material in points:
1 point
$\square 3$ points
5 points
$\square 7$ points
9 points
2 points
4 points
6 points
$\square 8$ points
10 points

\subsubsection{Tests:}

very high level

$\square$ insufficient amount

high level

$\square$ other (please, indicate).

2.1.6. Evaluate the quality of tests in points:
1 point
3 points
5 points
$\square$ points
9 points
2 points
4 points
6 points
$\square$ points
10 points

2.2. Do you use internet electronic training systems created by SENTV Department?

$\square$ yes $\square$ no

$\square$ partially $\quad \square$ other (please, indicate).............. 
2.3. Evaluate the quality of use internet electronic training systems created by SENTV Department in points:
$\square 1$ point
$\square 3$ points
$\square 5$ points
7 points
$\square$ points
2 points
4 points
$\square 6$ points
8 points
10 points

\section{NEEDS AND REQUESTS}

3.1. What is the reaction of your environment to Your studies?

a) place of work (Please, explain and evaluate in points from 1 to 10).

b) family and close relatives (Please, explain and evaluate in points from 1 to 10).

c) friends and acquaintances (Please, explain and evaluate in points from 1 to 10).

d) other (Please, explain and evaluate in points from 1 to 10).

3.2. What additional services would be necessary for you?

Please, list:

3.3. Would you like more contact meetings?

Yes

$\square$ No

3.4. Would you like to change anything?

I would not like $\square$ I would like

Please, explain:

3.5. Your other requests and proposals.

\section{THANK YOU FOR YOUR ANSWERS!}

The data of this questionnaire is going to be used only for the purposes of research and, with regard to the answers of respondents, to be used for the improvement of study conditions. 


\section{MULTIPLE CRITERIA ANALYSIS OF THE LIFE CYCLE OF}

\section{THE BUILT ENVIRONMENT}

\section{Monograph}

Apimtis 26,25 aut. 1. Tiražas pagal poreikị.

Leidinio el. versija http://doi.org/doi:10.3846/2335-M

Vilniaus Gedimino technikos universiteto

leidykla „Technika“, Saulètekio al. 11, 10223 Vilnius

http://leidykla.vgtu.lt

Spausdino Bİ UAB „Baltijos kopija“

Kareivių g. 13B, 09109 Vilnius

http://kopija.lt 